WSRC-STI-2007-00537, REVISION 0

SRNL-RPP-2007-00023, REVISION 0

EFFECTS OF ALTERNATE ANTIFOAM AGENTS, NOBLE METALS, MIXING SYSTEMS AND MASS TRANSFER ON GAS HOLDUP AND RELEASE FROM NON-NEWTONIAN SLURRIES

DECEMBER 2007

PROCESS ENGINEERING DEVELOPMENT ADVANCED PROCESS DEVELOPMENT

Savannah River National Laboratory

Savannah River Site

Aiken, SC 29808

Prepared for the U.S. Department of Energy Under

Contract Number DE-AC09-96SR18500 


\section{DISCLAIMER}

This report was prepared for the United States Department of Energy under Contract No. DE-AC09-96SR18500 and is an account of work performed under that contract. Neither the United States Department of Energy, nor WSRC, nor any of their employees makes any warranty, expressed or implied, or assumes any legal liability or responsibility for accuracy, completeness, or usefulness, of any information, apparatus, or product or process disclosed herein or represents that its use will not infringe privately owned rights. Reference herein to any specific commercial product, process, or service by trade name, trademark, name, manufacturer or otherwise does not necessarily constitute or imply endorsement, recommendation, or favoring of same by Washington Savannah River Company or by the United States Government or any agency thereof. The views and opinions of the authors expressed herein do not necessarily state or reflect those of the United States Government or any agency thereof.

Printed in the United States of America

Prepared For

U.S. Department of Energy 
Key Words:

Antifoam agent

AZ-101 simulant

Gas holdup and release

Mixing

Retention:

Permanent

Key WTP R\&T References:

Test Specification:

24590-WTP-TSP-RT-06-022, Rev. 0

Task Technical and QA Plan:

WSRC-TR-2007-00038 Rev. 0

Test Exception 24590-WTP-TEF-RT-07-00010

R\&T Focus Area

\title{
EFFECTS OF ALTERNATE ANTIFOAM AGENTS, NOBLE METALS, MIXING SYSTEMS AND MASS TRANSFER ON GAS HOLDUP AND RELEASE FROM NON-NEWTONIAN SLURRIES
}

\author{
H. N. Guerrero \\ C. L. Crawford \\ M. D. Fowley \\ R. A. Leishear \\ M. L. Restivo
}

DECEMBER 2007

Savannah River National Laboratory

Savannah River Site

Aiken, SC 29808

Prepared for the U.S. Department of Energy Under

Contract Number DE-AC09-96SR18500 


\section{TABLE OF CONTENTS}

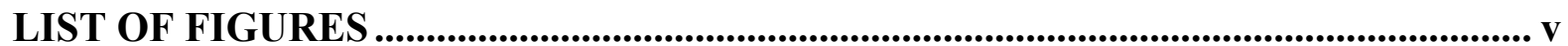

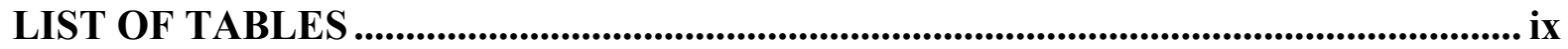

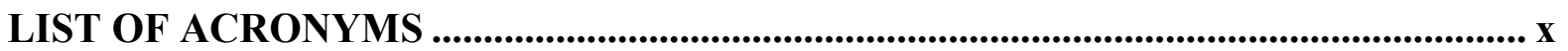

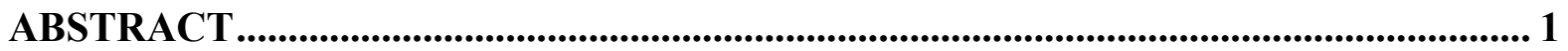

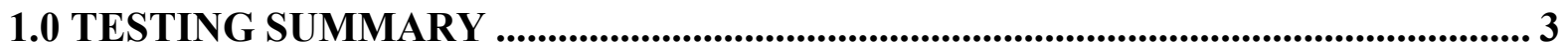

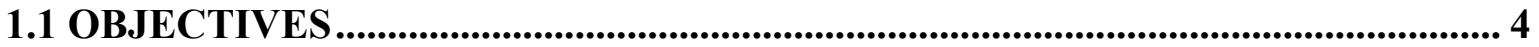

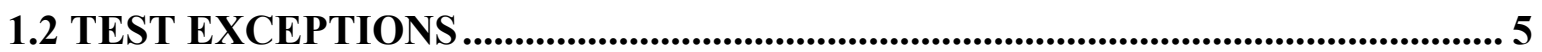

1.3 RESULTS AND PERFORMANCE AGAINST SUCCESS CRITERIA ................. 5

1.4 QUALITY REQUIREMENTS...................................................................... 8

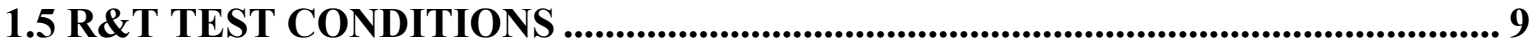

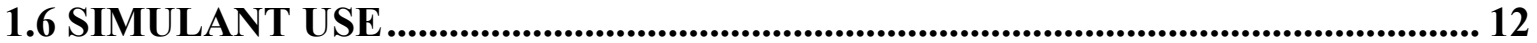

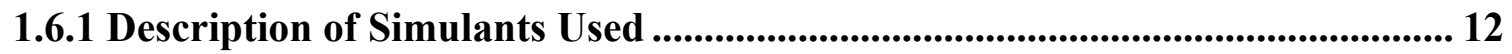

1.6.2 Dilution Curves......................................................................................................... 16

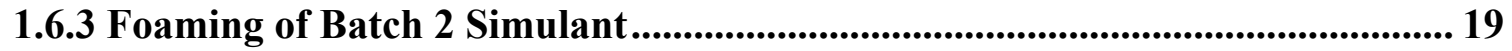

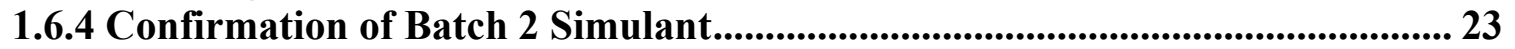

1.7 DISCREPANCIES AND FOLLOW-ON TESTS ................................................... 25

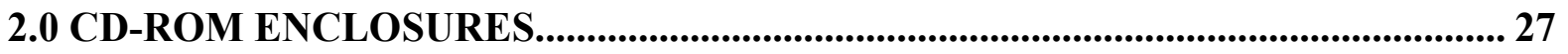

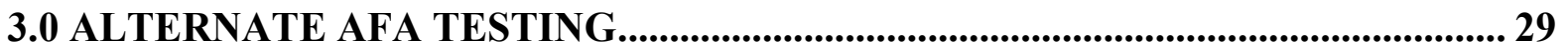

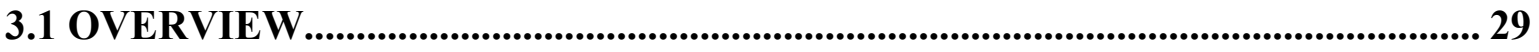

3.1.1 Background .............................................................................................................. 29

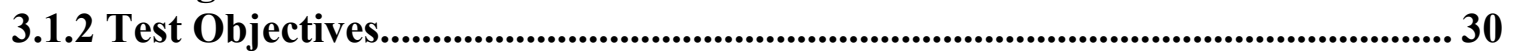

3.2 EXPERIMENTAL METHODS ............................................................................ 31

3.2.1 Bench Scale Test Methods ................................................................................... 31

3.2.2 SRNL Mixing Test Stand Test Methods ............................................................... 33

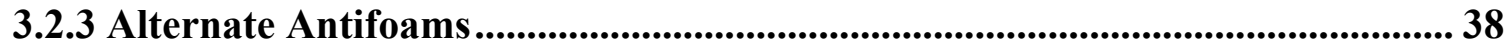

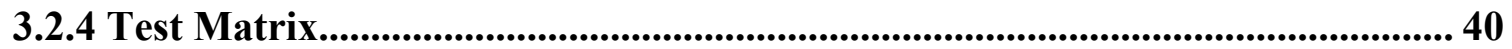

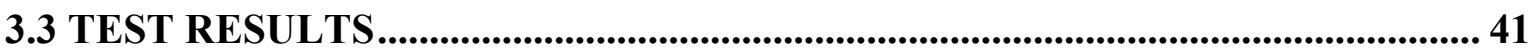

3.3.1 Surface Tension Measurements .......................................................................... 41

3.3.2 Test Results ..................................................................................................................... 42

3.3.3 SRNL Mixing Test Stand Results .................................................................. 51

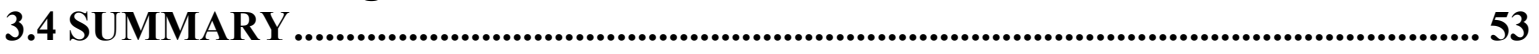

4.0 NOBLE METALS EFFECT TESTING .......................................................... 57

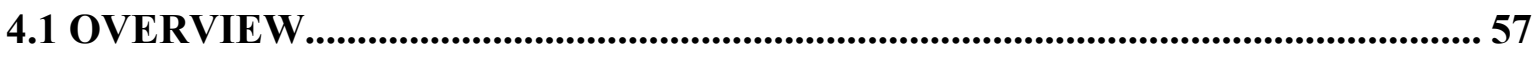

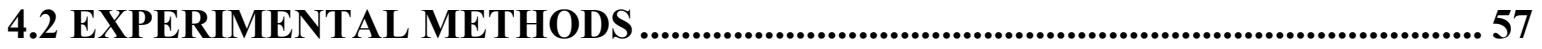

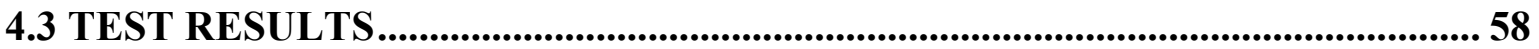

4.3.1 Effect of Adding Noble Metals to AZ-101 Simulant ...................................... 58

4.3.2 Effect of Adding Antifoam to AZ-101 Simulant with Noble Metals................. 58

4.3.3 Effect of Time on Gas Holdup for Simulant with Noble Metals (3 Pa Retest) 61

4.3.4 Higher Yield Stresses ............................................................................................... 62

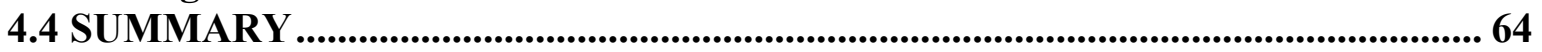

5.0 PJM TESTING vs. MECHANICAL AGITATOR TESTING ............................... 65

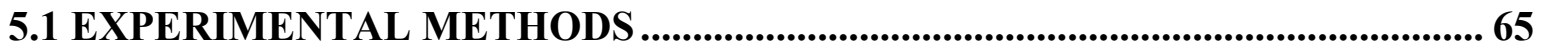

5.1.1 Test Apparatus Description..............................................................................6 65

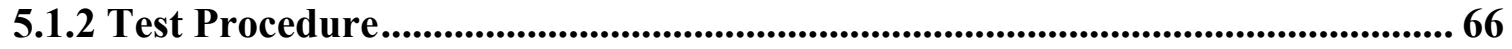


WSRC-STI-2007-00537, REVISION 0

SRNL-RPP-2007-00023, REVISION 0

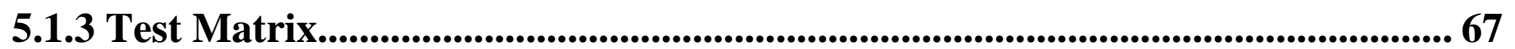

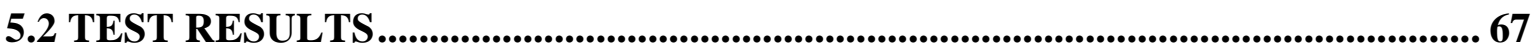

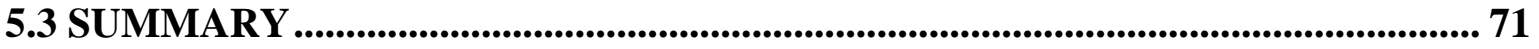

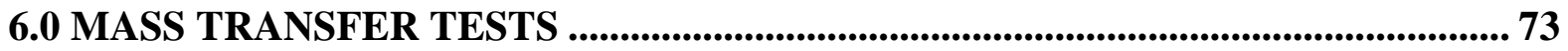

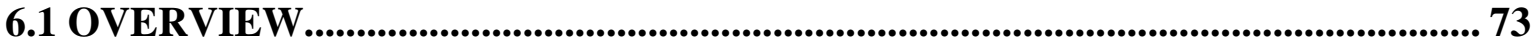

6.1.1 Mass Transfer Coefficient ..................................................................................... 75

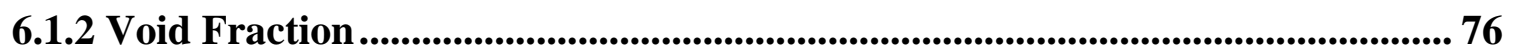

6.2 EXPERIMENTAL METHODS ........................................................................ 77

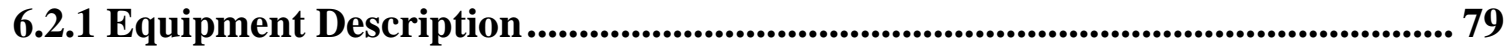

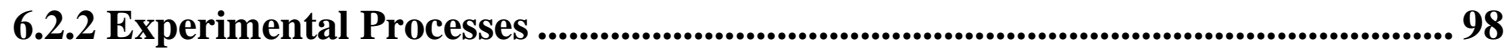

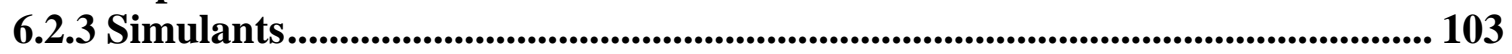

6.3 TEST RESULTS............................................................................................... 106

6.3.1 DO Concentrations During Oxygen Mixing and Air Sparging ..................... 106

6.3.2 Bubble Formation During Tests ..................................................................... 112

6.3.3 Mass Transfer Coefficients.................................................................................. 120

6.3.4 Void Fractions and Gas Holdups ...................................................................... 130

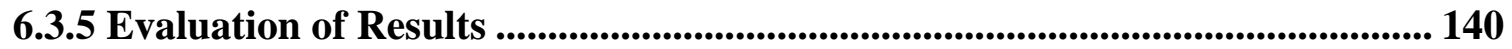

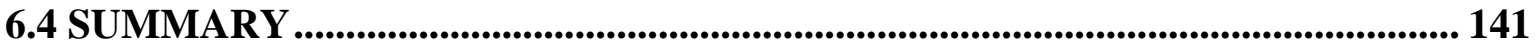

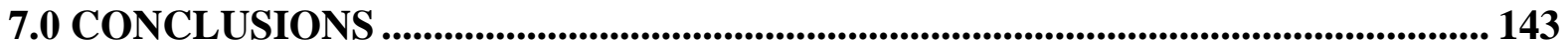

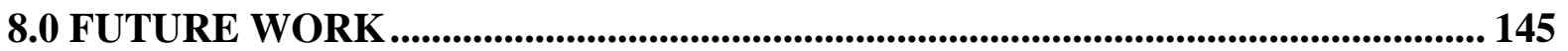

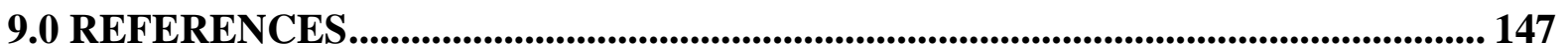

APPENDIX A. BENCH SCALE TEST RESULTS .............................................. 149

APPENDIX B. SRNL MIXING TEST STAND TEST RESULTS.............................. 153

APPENDIX C. MASS TRANSFER TEST RAW DATA ......................................... 157

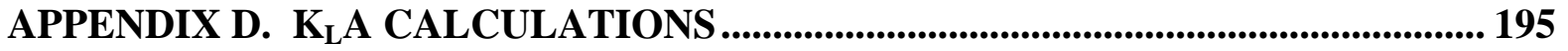

APPENDIX E. MASS TRANSFER CALCULATIONS ........................................... 221 


\section{LIST OF FIGURES}

Figure 1-1. Dilution Curves for Optima Batch 2 and Batch 3 AZ-101 Simulant Compared to

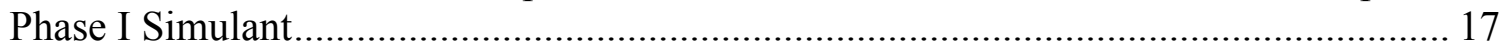

Figure 1-2. Yield Stress vs. Wt.\% Total Solids During Testing Compared to Initial Dilution

Curves ............................................................................................................ 18

Figure 1-3. Dilution Curve for Optima Batch 2 with Noble Metals ..................................... 18

Figure 1-4. Effect of Foaming on Gas Holdup in Batch 2 Simulant at $30 \mathrm{~Pa}$...................... 19

Figure 1-5. Effect of Foaming on Gas Holdup in Batch 2 Simulant at $13 \mathrm{~Pa}$..................... 20

Figure 1-6. Effect of Foaming on Gas Holdup in Batch 2 Simulant at $3 \mathrm{~Pa}$........................ 20

Figure 1-7. Particle Size Distribution for Batch 2 without AFA ………........................... 21

Figure 1-8. Particle Size Distribution for Batch 2 with AFA ............................................... 21

Figure 1-9. Particle Size Distribution for Batch 3 without AFA ……………………........... 22

Figure 1-10. Particle Size Distribution for Batch 2 without AFA ..................................... 22

Figure 1-11. Comparison of Batch 2 and Phase I Simulants with AFA at $30 \mathrm{~Pa}$................. 24

Figure 1-12. Comparison of Batch 2 and Phase I Simulants with AFA at $13 \mathrm{~Pa}$................. 24

Figure 1-13. Comparison of Batch 2 and Phase I Simulants with AFA at $3 \mathrm{~Pa}$.................. 25

Figure 3-1. Schematic of Bench Scale Test Apparatus....................................................... 31

Figure 3-2. Photograph of Bench Scale Test Apparatus......................................................... 32

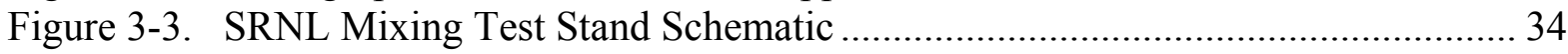

Figure 3-4. Photograph of the SRNL Mixing Test Stand ................................................... 35

Figure 3-5. Mechanical Agitator System .......................................................................... 36

Figure 3-6. Typical Time History Plot of Laser Level Displacement Data with a Number of

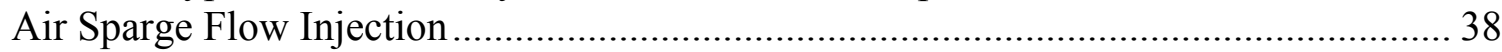

Figure 3-7. Surface Tension Reduction by Addition of Q2-3183A in Water, AZ-101

Simulant, and AZ-101 Simulant Supernate ……………............................................. 41

Figure 3-8. Gas Holdup in Water with and without PDMS or PPG ..................................... 42

Figure 3-9. Gas Holdup in AZ-101 Simulant with PDMS at $30 \mathrm{~Pa}$....................................... 43

Figure 3-10. Gas Holdup in AZ-101 Simulant with PDMS at $13 \mathrm{~Pa}$................................... 43

Figure 3-11. Gas Holdup in AZ-101 Simulant with PDMS at $3 \mathrm{~Pa}$..................................... 44

Figure 3-12. Gas Holdup in AZ-101 Simulant with PPG at $30 \mathrm{~Pa}$...................................... 45

Figure 3-13. Gas Holdup in AZ-101 Simulant with PPG at $13 \mathrm{~Pa}$....................................... 45

Figure 3-14. Holdup in AZ-101 Simulant with PPG at $3 \mathrm{~Pa}$................................................ 46

Figure 3-15. Gas Holdup History at $1 \mathrm{~mm} / \mathrm{s}$ Superficial Velocity During Incremental

Addition of 1520-US Antifoam to 30, 13, and 3 Pa AZ-101 Simulants ......................... 47

Figure 3-16. Gas Holdup History at $1 \mathrm{~mm} / \mathrm{s}$ Superficial Velocity during Incremental

Addition of AF-7500 Antifoam to 30, 13, and 3 Pa AZ-101 Simulant .......................... 48

Figure 3-17. Gas Holdup in AZ-101 Simulant with 1520-US and AF-7500 at $30 \mathrm{~Pa}$........... 48

Figure 3-18. Gas Holdup in AZ-101 Simulant with 1520-US and AF-7500 at 13 Pa.......... 49

Figure 3-19. Gas Holdup in AZ-101 Simulant with 1520-US and AF-7500 at 3 Pa............ 49

Figure 3-20. Gas Holdup Behavior of 1520-US and Q2-3183A in SRNL Mixing Stand

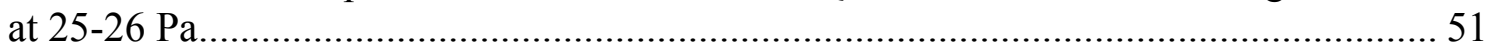

Figure 3-21. Gas Holdup Behavior of 1520-US and Q2-3183A in SRNL Mixing Stand

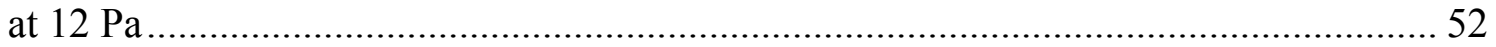


Figure 3-22. Gas Holdup Behavior of 1520-US and Q2-3183A in SRNL Mixing Stand

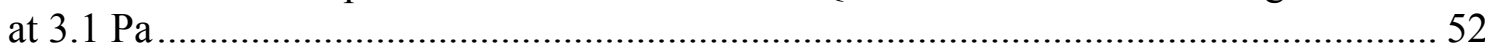

Figure 4-1. Effect of Adding Noble Metals to Batch 2 AZ-101 Simulant without AFA ..... 58

Figure 4-2. Effect of Adding Noble Metals to 22.3 Pa AZ-101 Simulant with AFA........... 59

Figure 4-3. Effect of Adding Noble Metals with and without AFA at 22.4 Pa Compared to

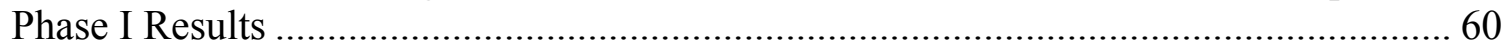

Figure 4-4. Effect of Adding Noble Metals with and without AFA at $13 \mathrm{~Pa}$..........................6 60

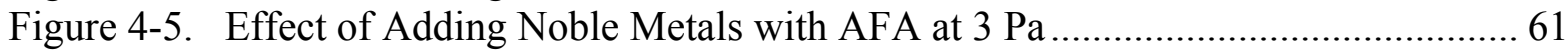

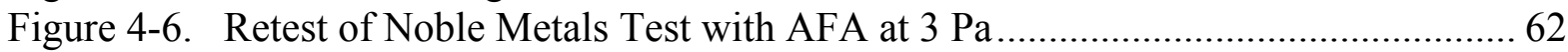

Figure 4-7. Retest of Noble Metals Test with AFA at Nominal 13 Pa.................................. 63

Figure 5-1. Schematic of the SRNL Mixing Test Stand with PJM Agitators..........................66 66

Figure 5-2. Tank Level Rise History after H2O2 Injection in $20 \mathrm{~Pa}$ AZ-101 Simulant....... 68

Figure 5-3. Gas Holdup in 20-25 Pa AZ-101 Simulant under PJM Mixing Conditions ...... 68

Figure 5-4. Tank Level Rise History after H2O2 Injection in 11 Pa AZ-101 Simulant....... 69

Figure 5-5. Gas Holdup in 11 Pa AZ-101 Simulant under PJM Mixing Conditions............. 69

Figure 5-6. Tank Level Rise History after H2O2 Injection in 3 Pa AZ-101 Simulant.......... 70

Figure 5-7. Gas Holdup in 3 Pa AZ-101 Simulant under PJM Mixing Conditions .............. 71

Figure 6-1. Column and Equipment Installation for Large Scale Mass Transfer Testing.... 74

Figure 6-2. Close-up View of Column Installation ............................................................. 74

Figure 6-3. Simplified Mass Transfer System Schematic ......................................................... 78

Figure 6-4. System Schematic for Large Scale Mass Transfer Testing............................... 79

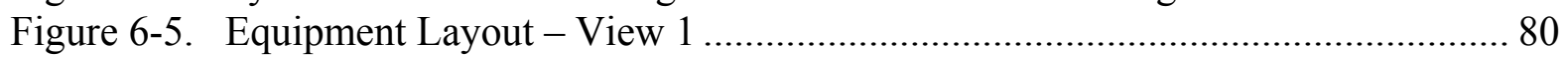

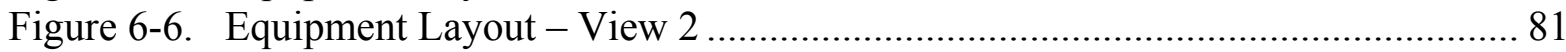

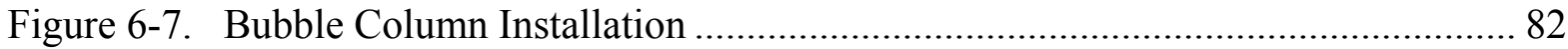

Figure 6-8. Typical View Port ……………………................................................. 82

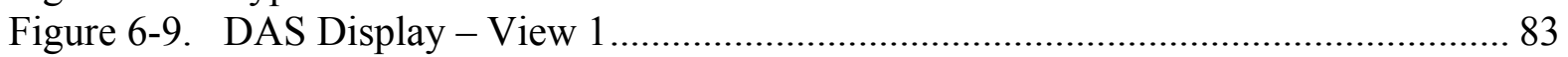

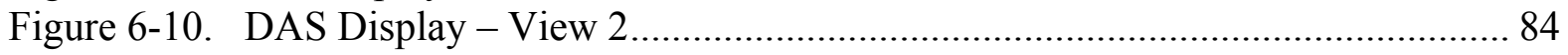

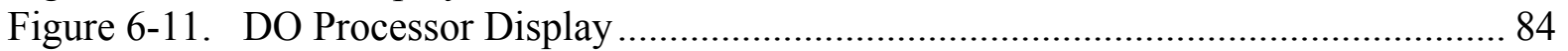

Figure 6-12. Theoretical Oxygen Concentration in Water ................................................... 87

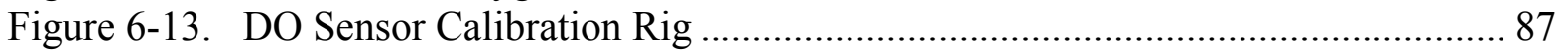

Figure 6-14. Initial Calibration of DO Sensors................................................................ 89

Figure 6-15. DO Post Calibration Where the Expected DO Concentration was 63 ppm..... 89

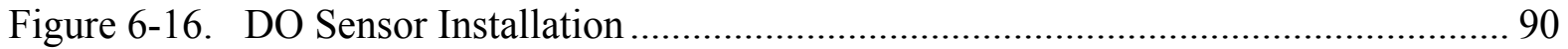

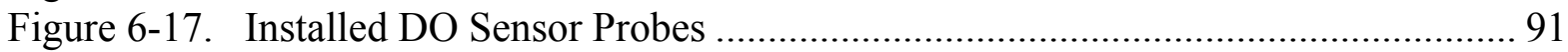

Figure 6-18. Uninstalled DO Sensor Probe …………........................................................ 91

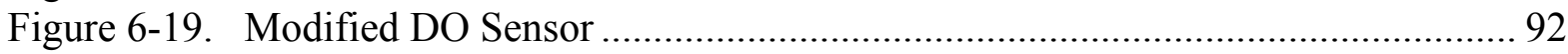

Figure 6-20. Laser Measurements of Water Level ............................................................. 93

Figure 6-21. Typical Plot for Laser Level Indication ........................................................ 94

Figure 6-22. Typical Variance in Measured Flow Rate through an Installed Needle Valve

Due to Facility Pressure Fluctuations …………………………………...................... 96

Figure 6-23. Typical Environmental Conditions above the Column................................... 97

Figure 6-24. Typical Environmental Conditions inside the Column near the Top................ 97

Figure 6-25. Typical Temperature Monitoring of the Column Contents............................. 98

Figure 6-26. Oxygen Sparger and the Oxygen Bubbles Before Entering the Static Mixer.. 99

Figure 6-27. Air Swirling in the Static Mixer................................................................. 100

Figure 6-28. Static Mixer Design, Koflo …………….................................................. 100 
Figure 6-29. Nearly Uniform Bubble Distribution in the Piping after the Static Mixer..... 101

Figure 6-30. Bubbles near the Bottom of the Column after Entering the Column .............. 101

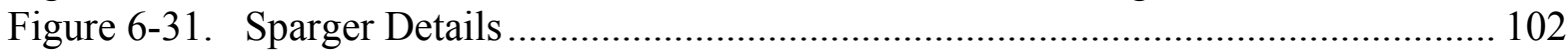

Figure 6-32. Air Discharge from the Sparger for a $10 \mathrm{~mm} / \mathrm{second}$ Superficial Velocity ... 103

Figure 6-33. Oxygen Addition and Air Sparging Effects on DO Concentration When the

Column is Filled to 24.3 Feet $(7.41 \mathrm{~m})$ During Water Testing ...................................... 107

Figure 6-34. Typical Level Changes Indicated by Lasers During Water Testing .............. 108

Figure 6-35. Typical Changes in Pressure at Different Column Depths During Water

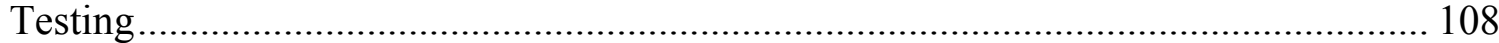

Figure 6-36. Test Results for Water when the Column was Filled to the 3.63 Meter Level

Figure 6-37. Test Results for Water when the Column was Filled to the 1.31 Meter Level

Figure 6-38. Test Results for Water with AFA when the Column was Filled to the

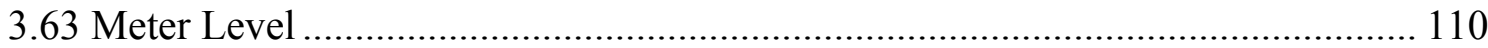

Figure 6-39. DO Concentration when the Simulant is at the Higher Test Level................ 111

Figure 6-40. DO Concentration when the Simulant is at the Lower Test Level ................ 112

Figure 6-41. Files for Photos of Water Testing …………............................................. 114

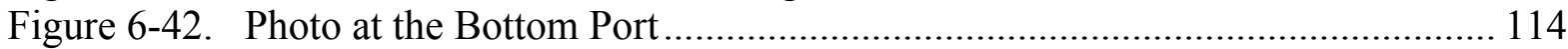

Figure 6-43. Photo at the Second Port from the Bottom................................................... 115

Figure 6-44. Photo at the Third Port from the Bottom ................................................. 115

Figure 6-45. Photo at the Fourth Port from the Bottom................................................ 116

Figure 6-46. Photo from the Top of the Column .......................................................... 116

Figure 6-47. Formation of a Cone of Bubbles Above the Sparger, 3 Feet Above the Column

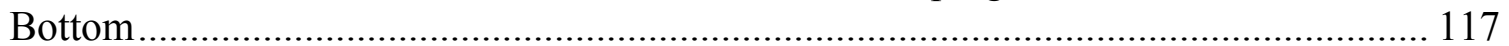

Figure 6-48. $10 \mathrm{~mm} / \mathrm{second}$ Superficial Velocity, 7.41 Feet Level, 13 Pascal AZ-101

Simulant with AFA ………………………………...................................... 118

Figure 6-49. 2 mm/second Superficial Velocity, 7.41 Feet Level, 13 Pascal AZ-101

Simulant with AFA ………………………………....................................... 119

Figure 6-50. $10 \mathrm{~mm} / \mathrm{second}$ Superficial Velocity, 7.41 Feet Level, 33 Pascal AZ-101

Simulant without AFA .......................................................................................... 119

Figure 6-51. $10 \mathrm{~mm} / \mathrm{second}$ Superficial Velocity, 7.41 Feet Level, 33 Pascal AZ-101

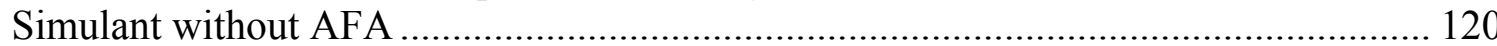

Figure 6-52. Mass Transfer Coefficients for Tests in Water for $1.31 \mathrm{~m}$ High Column....... 122

Figure 6-53. Mass Transfer Coefficients for Tests in Water in 3.63m High Column ........ 123

Figure 6-54. Mass Transfer Coefficients for Tests in Water for 7.41m High Column....... 123

Figure 6-55. Mass Transfer Coefficients for Tests in Water, No AFA, for Different

Column Heights ................................................................................................... 124

Figure 6-56. Mass Transfer Coefficients for Tests in Water with AFA for Different

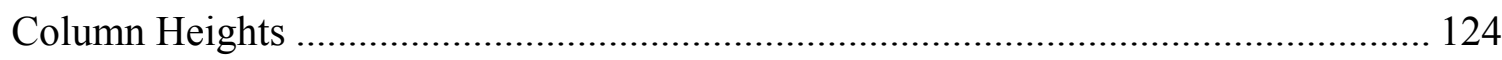

Figure 6-57. Comparison of Mass Transfer Coefficients in Water and AZ-101 Simulant with AFA for 7.41m High Column ..................................................................... 125

Figure 6-58. Comparison of Mass Transfer Coefficients in Water and AZ-101 Simulant with AFA for 1.31m High Column ........................................................................ 125

Figure 6-59. Comparison of Mass Transfer Coefficients in AZ-101 for $7.41 \mathrm{~m}$ and $1.31 \mathrm{~m}$ column levels with the Godhole Correlation ............................................................. 126 
Figure 6-60. Determination of the Mass Transfer Coefficient from the Slope of the Curve

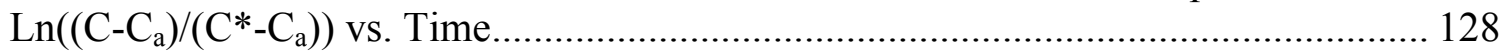

Figure 6-61. Typical Uncertainty for Mass Transfer Tests................................................. 129

Figure 6-62. Large Data Scatter in Test 27 .............................................................. 130

Figure 6-63. Typical Void Fraction Calculation.............................................................. 133

Figure 6-64. Average Void Fractions for Tests in Water with and without AFA in $1.31 \mathrm{~m}$

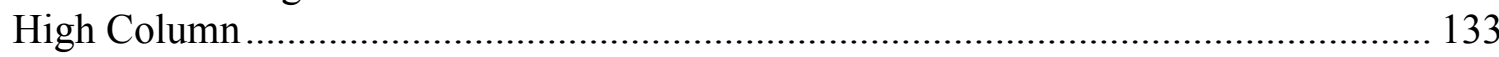

Figure 6-65. Average Void Fractions for Water with and without AFA for 3.63m High Column

Figure 6-66. Comparison of Average Void Fractions in Water in 7.41m High Column Obtained from Laser and Differential Pressure Measurements .................................... 134

Figure 6-67. Local Void Fraction for Tests in Water with and without AFA at Different

Superficial Velocities in 7.41m High Column ............................................................ 135

Figure 6-68. Comparison of Average Void Fractions for Tests in Water with AFA in $1.31 \mathrm{~m}$ and $7.41 \mathrm{~m}$ High Columns

Figure 6-69. Local Void Fractions for Tests in Water in 7.41m High Column................. 136

Figure 6-70. Comparison of Void Fractions for Water and AZ-101 Tests in 7.41m High

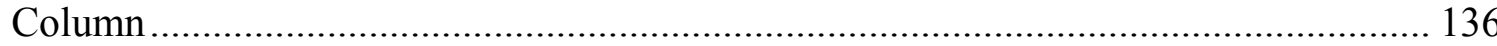

Figure 6-71. Local Void Fractions for AZ-101 Tests in 1.31m High Column ................... 137 


\section{LIST OF TABLES}

Table 1-1. Original R\&T Test Conditions per Test Specification 24590-WTP-TSP-RT-06-

022, Rev. 0 and listed in the Task Technical and QA Plan [6] ...................................... 9

Table 1-2. Metal Oxides/Hydroxides Used in Simulant...................................................... 12

Table 1-3. Chemicals for Producing the HLW Precipitated Hydroxide Feed Simulant....... 13

Table 1-4. Chemicals for Producing the Cesium Ion Exchange Concentrate Simulant ....... 14

Table 1-5. Fe-Scaled Simulant Data for Analyzed Batches \#1, \#2, and \#3 ${ }^{(\mathrm{a}, \mathrm{b}, \mathrm{c})}$.................... 15

Table 1-6. Concentration of Noble Metals Added to 1/9 $9^{\text {th }}$ scale Test Vessel ....................... 16

Table 3-1. Test Conditions for Bench Scale Alternate AFA Testing ..................................... 40

Table 3-2. Test Conditions for SRNL Mixing Test Stand Alternate AFA Testing ............... 40

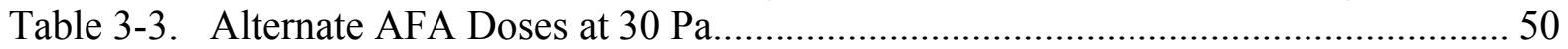

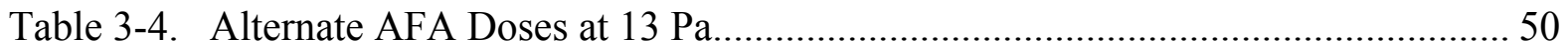

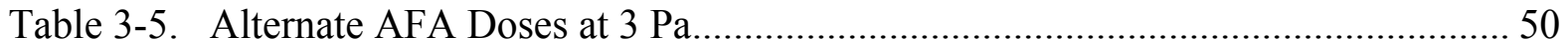

Table 4-1. Noble Metals Testing Test Matrix........................................................................ 57

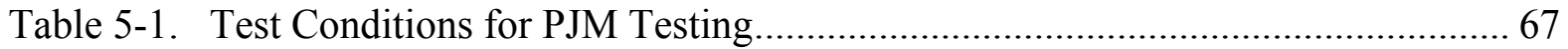

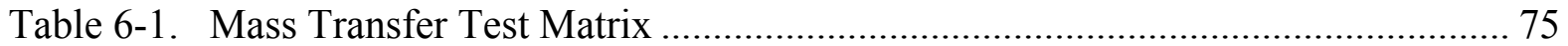

Table 6-2. Uncertainty of Superficial Velocities .................................................................... 95

Table 6-3. Uncertainties in Yield Stress Measurement …………………......................... 104

Table 6-4. AZ-101 Rheology During Mass Transfer Testing........................................... 106

Table 6-5. Mass Transfer Coefficients and Uncertainties for $\mathrm{k}_{\mathrm{L}} \mathrm{a}$..................................... 121

Table 6-6. Void Fraction Results ...................................................................................... 132

Table 6-7. Void Fraction Uncertainties from $\Delta \mathrm{P}$ Measurements........................................ 138

Table 6-8. Uncertainties in Gas Holdup Measured with Laser Meters during Water Testing ........................................................................................................... 139

Table 6-9. Uncertainties in Gas Holdup Measured with Laser Meters during AZ-101

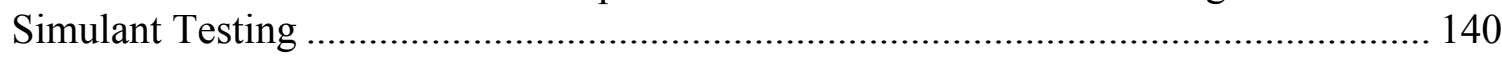


WSRC-STI-2007-00537, REVISION 0

SRNL-RPP-2007-00023, REVISION 0

\section{LIST OF ACRONYMS}

AFA

DBE

DO

HLW

ITS

PJM

scfm

SRNL

WTP

\author{
Antifoam Agent \\ design basis event \\ dissolved oxygen \\ high-level waste \\ important to safety \\ pulse jet mixer \\ standard cubic feet per minute \\ Savannah River National Laboratory \\ Waste Treatment \& Immobilization Plant
}




\title{
WSRC-STI-2007-00537, REVISION 0 \\ SRNL-RPP-2007-00023, REVISION 0
}

\begin{abstract}
Gas holdup tests performed in a small-scale mechanically-agitated mixing system at the Savannah River National Laboratory (SRNL) were reported in 2006. The tests were for a simulant of waste from the Hanford Tank 241-AZ-101 and featured additions of DOW Corning Q2-3183A Antifoam agent. Results indicated that this antifoam agent (AFA) increased gas holdup in the waste simulant by about a factor of four and, counter intuitively, that the holdup increased as the simulant shear strength decreased (apparent viscosity decreased). These results raised questions about how the AFA might affect gas holdup in Hanford Waste Treatment and Immobilization Plant (WTP) vessels mixed by air sparging and pulse-jet mixers (PJMs). And whether the WTP air supply system being designed would have the capacity to handle a demand for increased airflow to operate the sparger-PJM mixing systems should the AFA increase retention of the radiochemically generated flammable gases in the waste by making the gas bubbles smaller and less mobile, or decrease the size of sparger bubbles making them mix less effectively for a given airflow rate.
\end{abstract}

A new testing program was developed to assess the potential effects of adding the DOW Corning Q2-3183A AFA to WTP waste streams by first confirming the results of the work reported in 2006 by Stewart et al. and then determining if the AFA in fact causes such increased gas holdup in a prototypic sparger-PJM mixing system, or if the increased holdup is just a feature of the small-scale agitation system. Other elements of the new program include evaluating effects other variables could have on gas holdup in systems with AFA additions such as catalysis from trace noble metals in the waste, determining mass transfer coefficients for the AZ-101 waste simulant, and determining whether other AFA compositions such as Dow Corning 1520-US could also increase gas holdup in Hanford waste.

This new testing program was split into two investigations, prototypic sparger-PJM tests and modeling being conducted at the Pacific Northwest National Laboratory (PNNL), and smallscale agitation tests and evaluations of effects waste and AFA ingredients have on gas retention and mass transfer being conducted at SRNL. Only work conducted at SRNL is reported here. Key results are:

- The unexpected gas holdup behavior reported in 2006 for a small-scale agitation system is confirmed. The gas holdup data from small-scale and bench-scale impeller-type mixing systems reported herein show very different trends than the behavior exhibited by the prototypic sparger-PJM mixing system tested in the PNNL APEL facility. Results obtained from testing this 1/4-scale prototypic mixing system will be reported by PNNL. The reason for this difference in holdup behavior between the two different mixing systems is not known at this time. Consequently, data from the small mechanical agitation systems should not be extrapolated to prototypic plant conditions.

- Bench-scale and small-scale tests conducted with Dow Corning 1520-US AFA show it to be a viable replacement to Dow Corning Q2-3183A AFA. This alternative AFA will, however, require significantly higher dosage (concentration) to perform the same antifoam function. 
- Addition of noble metals to the AZ-101 waste simulant does not produce a catalytic gas retention effect with the AFA. The Gas holdup is similar whether or not noble metals are present in the AZ-101 simulant.

- Mass transfer tests were performed in a large ( $0.76 \mathrm{~m}$ diameter) bubble column filled to $1.3,3.4$, and $7.4 \mathrm{~m}$ elevations with water and the AZ-101 waste simulant. Mass transfer coefficients for air bubbles emanating from a prototypic $0.051 \mathrm{~m}$ diameter sparger were obtained from the transient decay of dissolved oxygen concentration in the initially saturated fluids. Adding AFA to water reduces the mass transfer coefficient slightly. AFA addition reduces the mass transfer coefficient for AZ-101 simulant more than it does for water because the shear strength of the simulant allows for larger bubble sizes, and larger bubbles have smaller surface area for mass transfer than small bubbles for the same void volume. 


\subsection{TESTING SUMMARY}

The Hanford Tank Waste Treatment and Immobilization Plant (WTP) will utilize a hybrid pulse jet mixer (PJM) sparger mixing system. The antifoam agent (AFA) DOW Corning Q2-3183A was recommended, in the study (WSRC-TR-2003-00216 Rev. 0, [1]), to be added to waste streams in the WTP to prevent foaming, especially in the evaporators. The Dow Corning Q23183A AFA was evaluated together with 3 other antifoams, with contributions from Dow Corning and Illinois Institute of Technology experts. Q2-3183A was found to:

- have good chemical stability in caustic media

- be the best antifoam in treated low-activity waste evaporation

- have good chemical and radiation stability while being the best antifoam for both solids "stabilized foaming" and "surfactant based" foaming

- require lower antifoam concentration than comparable AFAs

Recently completed tests at SRNL [2], PDC \# 24590-101-TSA-W000-0004-150-00005 Rev 0) with the DOW Corning Q2-3183A in a mixing test stand using 60 liters of simulant and a mechanical agitator indicate that additions of this AFA to AZ-101 waste simulant increases gas retention by as much as a factor of four. And this unexpected effect increased as the shear strength of the simulant decreased. These results raise two issues for WTP operations that relate to the maximum puff release of flammable gas to the WTP vessel head space: 1) What effects might additions of different antifoams have on the holdup of prototypic sparge air bubbles and the retention of flammable gas bubbles during conditions of no mixing? and 2) Will the WTP air supply system have enough capacity to release potentially higher levels of retained flammable gas with potentially smaller sparge bubbles, especially during a design basis event (DBE)?

A testing program was developed to:

1) SRNL: a) confirm results of the prior work reported in Ref. [2]; b) assess the effects different variables, such as noble metals, which could have on gas retention in waste systems with AFA additions, characterize the simulant used in PNNL 1/4-scale prototypic tests, and assess use of mechanical agitation vs. PJM mixing, ; c) evaluate alternate AFAs to use in the WTP in the event that the Dow Corning Q2-3183A presents gas retention issues too difficult to resolve; and d) measure mass transfer coefficients in the AZ-101 simulant.

2) PNNL: a) measure gas holdup (increase in surface level of a fluid when a gas phase is introduced into it) in a 1/4-scale sparger-PJM mixing system filled with kaolin-bentonite and AZ-101 waste simulants; and b) determine the chemical makeup of the waste simulant which bounds gas retention 


\subsection{OBJECTIVES}

The following are the specific test objectives from Test Specification 24590-WTP-TSP-RT-06002, Rev. 0 [3]:

\begin{tabular}{|c|c|c|}
\hline Test Objective & $\begin{array}{l}\text { Objective } \\
\text { Met } \\
(\mathbf{Y} / \mathbf{N})\end{array}$ & Discussion \\
\hline $\begin{array}{l}\text { 1. Develop an alternative AFA } \\
\text { which reduces surface foaming } \\
\text { to acceptable levels in WTP } \\
\text { systems without increasing bulk } \\
\text { gas retention }\end{array}$ & $\mathrm{Y}$ & $\begin{array}{l}\text { Components of Q2-3183A were tested } \\
\text { separately in a bench scale apparatus in } \\
\text { water and AZ-101 simulant. Alternate } \\
\text { AFAs, Dow Corning } 1520-\text { US and AF- } \\
7500 \text { were also tested in bench scale and } \\
\text { larger scale mixing test stand. }\end{array}$ \\
\hline $\begin{array}{l}\text { 2. Determine the effect of noble } \\
\text { metals on the gas retention and } \\
\text { release in AZ-101 simulant. }\end{array}$ & $\mathrm{Y}$ & $\begin{array}{l}\text { Noble metals were added to Optima Batch } \\
2 \text { simulant with AFA and tested in SRNL } \\
\text { Mixing Test Stand using mechanical } \\
\text { agitator. }\end{array}$ \\
\hline $\begin{array}{l}\text { 3. Determine the difference in } \\
\text { gas holdups in mechanical } \\
\text { agitator system and PJM mixing } \\
\text { system. }\end{array}$ & $\mathrm{Y}$ & $\begin{array}{l}\text { Mechanical agitators in SRNL Mixing Test } \\
\text { Stand were replaced by PJMs. Testing with } \\
30 \text { Pa simulant exhibited poor mixing, } \\
\text { resulting in inconsistent data. Testing with } \\
13 \text { Pa simulant had good mixing and } \\
\text { slightly lower gas holdup than for } \\
\text { mechanical agitation. Testing with } 3 \mathrm{~Pa} \\
\text { simulant had a foaming problem, resulting } \\
\text { in apparently very high gas holdups. In } \\
\text { general, results confirm gas holdup is } \\
\text { similar to mechanical agitator results. }\end{array}$ \\
\hline $\begin{array}{l}\text { Perform mass transfer tests in } \\
\text { water and AZ- } 101 \text { to measure } \\
\text { mass transfer coefficients }\end{array}$ & $\mathrm{Y}$ & \\
\hline
\end{tabular}




\subsection{TEST EXCEPTIONS}

\begin{tabular}{|l|l|}
\hline List Test Exceptions & Describe Test Exceptions \\
\hline 1.24590 -WTP-TEF-RT-07-00010 [4] & 1. Use Optima Batch 2 because Batch 1 \\
& was out of specification. \\
& 2. Eliminate tests without AFA due to \\
& foaming of Optima Batch 2. \\
& 3. Use hydrogen peroxide instead of air \\
& bubbles in PJM mixing tests due to \\
& difficulty of obtaining small bubbles. \\
& 4. Use oxygen gas instead of hydrogen \\
& peroxide in mass transfer tests due to \\
& dilution effect of hydrogen peroxide. \\
& 5. Cancel bounding waste simulant tests \\
& because PNNL showed that the AZ-101 \\
& simulant produces bounding gas retention \\
\hline 2.24590-WTP-TEF-RT-07-00014 Rev. 0 0 & $\begin{array}{l}\text { Delete clay mass transfer tests, Tests 8-3 } \\
\text { through 8-8 from Table 1 of Task Plan }\end{array}$ \\
& because results from PNNL 1/4-scale \\
t5] & testing show they are not necessary. \\
\hline
\end{tabular}

\subsection{RESULTS AND PERFORMANCE AGAINST SUCCESS CRITERIA}

1. Alternate AFA testing results (Sec. 3.0) are as follows:

- The surface tension of water, AZ-101 simulant and AZ-101 simulant supernate were measured at various additions of Dow Corning Q2-3183A AFA. This AFA decreased the surface tensions by as much as $40 \%$ (relative to zero concentration) to $43 \mathrm{mN} / \mathrm{m}$ at $10 \mathrm{mg} / 1$ and remained at $30 \mathrm{mN} / \mathrm{m}$ for higher concentrations from $500 \mathrm{mg} / 1$ to 2100 $\mathrm{mg} / \mathrm{l}$. This reduced surface tension may be responsible for the increased gas holdup observed in AZ-101 simulants because it leads to reduced bubble sizes. The opposing effect of lower viscosity (reduced yield stress) to increase bubble rise velocity was insufficient to overcome the decreased bubble rise velocity effect of reduced surface tension. 
- Alternate AFA testing was performed in a bench scale vessel filled with 10.3 liters of simulant and mixed with two mechanical agitators The two major components of Q23183A, polydimethylsiloxane (PDMS) and polypropylene glycol (PPG) were tested separately, first in water and then in AZ-101 simulant to determine which of the two has the major effect on increased gas holdup observed with Q2-3183A. Adding PPG to water produced a high gas holdup increase relative to no AFA addition, while PDMS had a much smaller increase. In AZ-101 simulant, the effects of adding PDMS and PPG in the same concentrations as in Q2-3183A were more complicated. At 30 $\mathrm{Pa}, \mathrm{PDMS}$ and PPG had similar effects, which were slight reductions in gas holdup compared to that with Q2-3183A. At 13 Pa, PPG had a higher holdup than PDMS. At $3 \mathrm{~Pa}$ however, PPG had a lower holdup than PDMS. Increasing the PDMS concentration also reduced holdup. These results may be due to different transitions from frother to antifoam characteristics of both AFAs as a function of solids $w t \%$.

- The alternative AFAs Dow Corning 1520-US and AF-7500 were both demonstrated to have lower gas holdups than the Q2-3183A AFA..

- Dow Corning 1520-US was selected over the AF-7500 as the alternate AFA for confirmation testing in the larger scale SRNL Mixing Test Stand since it more consistently reduced the gas holdup at all waste rheologies and is already in use for the Hanford Tank Farm. The SRNL Mixing Test Stand uses mechanical agitators for mixing 60 liters of simulant. Note that larger volumes of 1520-US AFA (on the order of $2000 \mathrm{mg} / \mathrm{l}$ ) are required to prevent foaming compared to the baseline Q2-3183A AFA $(350 \mathrm{mg} / \mathrm{l})$. This is due to the high water content $(60 \%)$ and lower effectiveness $(20 \%$ vs. $100 \%)$ of the ingredients in the 1520 -US AFA.

2. Noble Metals Effect testing results (Sec. 4.0) are as follows:

- Addition of noble metals to the AZ-101 waste simulant does not catalyze AFA to increase gas holdup. Waste simulants with nominal 30, 13, and $3 \mathrm{~Pa}$ shear strengths behaved about the same whether or not they had noble metals. Similarly, no effect of noble metals in larger scale systems would be expected. 
3. The results of tests to determine the effect of mixing using PJMs vs. mechanical agitators (Sec. 5.0) are as follows:

- Operation of PJMs in the SRNL Mixing Test Stand resulted in similar to slightly lower gas holdup than mechanical agitation with an impeller.

- This study also confirms that gas holdup data for small-scale or bench-scale impeller type mixing systems show qualitatively similar trends but not equal values compared to the prototypic1/4-scale sparger-PJM hybrid mixing system at PNNL.

- While there are benefits for using small-scale systems for studying potential effects of temperature, radiation, noble metals, and AFA ingredients on mixing operations, the results from such studies can not be extrapolated directly to full-scale operations in the WTP because the shear rate profiles and time scales are too different. Future work to study the effect of test scale could be performed by varying mechanical agitator rpm, axial vs. radial turbine, sparger size, etc. to make results similar to those from the $1 / 4$ scale tests.

4. Mass Transfer Tests (Sec. 6.0)

Mass transfer tests were performed in a large $0.76 \mathrm{~m}$ dia. bubble column, filled to $1.3 \mathrm{~m}, 3.4$ $\mathrm{m}$, or $7.4 \mathrm{~m}$ elevations with water or AZ-101 simulant. The objective was to measure mass transfer coefficients for air bubbles emanating from a prototypic $0.051 \mathrm{~m}$ dia. sparger, typically used in WTP vessels. The simulant was saturated with pure oxygen before air sparging began. The mass transfer coefficients were derived from the measured transient concentrations of dissolved oxygen in the fluids.

Mass transfer coefficients $\left(k_{L} a\right)$ measured in water varied from: $0.070-0.556 \mathrm{~min}^{-1}$ for the $1.31 \mathrm{~m}$ deep column, $0.089-0.698 \mathrm{~min}^{-1}$ for the $3.63 \mathrm{~m}$ deep column, and $0.111-0.406 \mathrm{~min}^{-1}$ for the $7.41 \mathrm{~m}$ high column, for superficial gas velocities in the range $2-10 \mathrm{~mm} / \mathrm{s}$. Adding Q2-3183A to the water decreased $k_{L} a$ by an average of $36 \%$. $k_{L} a$ was mostly a function of superficial velocity and not gas holdup.

In the case of AZ-101 simulant and $1.31 \mathrm{~m}$ high column, $\mathbf{k}_{\mathbf{L}} \mathbf{a}$ values were very close to the values measured for water. The void fractions were not too different in the two cases. However, for the $7.41 \mathrm{~m}$ column, the $k_{L} a$ values were $0.022-0.16 \mathrm{~min}^{-1}$, a reduction of an average of $62 \%$ from the water values. This may be due to the fact that bubbles observed at the surface during the AZ-101 tests were very large, typically $0.2 \mathrm{~m}$ in diameter. Thus the bubble surface area in AZ-101 simulant would be very small compared to that in water. The void fraction in the AZ-101 case was $30 \%$ that of the water case.

Adding AFA to water reduces the mass transfer coefficient slightly. The data for AZ-101 simulant with AFA shows the mass transfer coefficient to be reduced relative to water values for the high bubble column. This is probably the result of increased bubble sizes in the AZ-101 simulant resulting from its high shear strength and high apparent viscosity. 
WSRC-STI-2007-00537, REVISION 0

SRNL-RPP-2007-00023, REVISION 0

\begin{tabular}{|l|l|}
\hline List Success Criteria & $\begin{array}{l}\text { Explain How the Tests Did or Did Not } \\
\text { Meet the Success Criteria }\end{array}$ \\
\hline $\begin{array}{l}\text { 1. Provide sufficient data to select suitable } \\
\text { form of AZ-101 simulant for 1/4-scale tests. }\end{array}$ & $\begin{array}{l}\text { Results of testing Optima Batch 2 with } \\
\text { Dow Corning Q2-3183A AFA gave the } \\
\text { same results as the AZ-101 simulant-AFA } \\
\text { system tested in the prior program } \\
\text { (Stewart } \text { et al. 2006) } \\
\text { Noble metals testing showed no effect on } \\
\text { gas holdup so 1/4-scale test at PNNL can } \\
\text { use AZ-101 waste simulants without noble } \\
\text { metals. }\end{array}$ \\
\hline $\begin{array}{l}\text { 2. a) Identify specific components of DC } \\
\text { Q2-3183A that affect bulk gas retention. } \\
\text { b) Identify commercial AFA that has less } \\
\text { effect on bulk gas retention. Confirm } \\
\text { alternate AFA in small scale mixing stand } \\
\text { has less effect on gas retention. }\end{array}$ & $\begin{array}{l}\text { PPG and PDMS components of Q2- } \\
\text { simulant. PPG showed higher gas } \\
\text { retention than PDMS in both simulants. } \\
\text { Dow Corning 1520-US and AF-7500 were } \\
\text { found to have lower gas holdup than Q2- } \\
\text { 3183A AFA. Dow Corning 1520-US AFA } \\
\text { was recommended as an alternative AFA } \\
\text { for the WTP Project. }\end{array}$ \\
\hline $\begin{array}{l}\text { Bench tests (PNNL) showed AZ-101 } \\
\text { 3imulant to be bounding, so there was no } \\
\text { simulant in small scale vessel to that with } \\
\text { AZ-101 simulant. }\end{array}$ & $\begin{array}{l}\text { Mass transfer coefficient data were } \\
\text { need to do these tests. }\end{array}$ \\
\hline $\begin{array}{l}\text { 4. Provide sufficient data to determine } \\
\text { mass transfer coefficients for stripping } \\
\text { dissolved gases in AZ-101 simulant. }\end{array}$ & Clay tests were not necessary. \\
\hline
\end{tabular}

\subsection{QUALITY REQUIREMENTS}

This work was conducted in accordance with the RPP-WTP QA requirements specified for work conducted by SRNL as identified in DOE IWO MOSRLE60. SRNL has provided matrices to WTP demonstrating compliance of the SRNL QA program with the requirements specified by WTP. Specific information regarding the compliance of the SRNL QA program with RW0333P, Revision 13, NQA-1 1989, Part 1, Basic and Supplementary Requirements and NQA-2a 1990, Subpart 2.7 is contained in these matrices. 


\subsection{R\&T TEST CONDITIONS}

The original R\&T Test Conditions given in Test Specification 24590-WTP-TSP-RT-06-022, Rev. 0 and tests removed by Test Exceptions are summarized in the Task Plan [6] and also in the test matrix given in Table 1-1.

Table 1-1. Original R\&T Test Conditions per Test Specification 24590-WTP-TSP-RT-06022, Rev. 0 and listed in the Task Technical and QA Plan [6]

\begin{tabular}{|c|c|c|c|c|c|c|}
\hline $\begin{array}{l}\text { Test } \\
\text { No. }\end{array}$ & $\begin{array}{c}\text { Test } \\
\text { removed } \\
\text { from scope?* }\end{array}$ & Simulant & AFA & Test Model & $\begin{array}{l}\text { Rheology, } \\
\text { yield } \\
\text { stress }\end{array}$ & $\begin{array}{l}\text { Air } \\
\text { superficial } \\
\text { Vel. } \mathbf{m m} / \mathbf{s}^{3}\end{array}$ \\
\hline $1 \mathrm{a}-1$ & Yes $^{1}$ & \multirow{3}{*}{$\begin{array}{l}\text { AZ-101 Ppt, } \\
\text { No Noble } \\
\text { metals }\end{array}$} & No & \multirow{9}{*}{$\begin{array}{l}\text { 1/9th scale, } \\
\text { mech. agit. }\end{array}$} & $30 \mathrm{~Pa}$ & \multirow{3}{*}{$\begin{array}{l}0.01,0.031, \\
0.1,0.31,1.0\end{array}$} \\
\hline $1 \mathrm{a}-2$ & Yes $^{1}$ & & No & & $13 \mathrm{~Pa}$ & \\
\hline $1 a-3$ & $\mathrm{Yes}^{1}$ & & No & & $3 \mathrm{~Pa}$ & \\
\hline $1 a-4$ & & \multirow{3}{*}{$\begin{array}{l}\text { AZ-101 Ppt, } \\
\text { With Noble } \\
\text { metals }\end{array}$} & No & & $30 \mathrm{~Pa}$ & \multirow{3}{*}{$\begin{array}{l}0.01,0.031, \\
0.1,0.31,1.0\end{array}$} \\
\hline $1 a-5$ & Yes $^{1}$ & & No & & $13 \mathrm{~Pa}$ & \\
\hline $1 a-6$ & Yes $^{1}$ & & No & & $3 \mathrm{~Pa}$ & \\
\hline $1 \mathrm{a}-7$ & & \multirow{3}{*}{$\begin{array}{l}\text { AZ-101 Ppt, } \\
\text { With Noble } \\
\text { metals }\end{array}$} & Q2-3183A & & $30 \mathrm{~Pa}$ & \multirow{3}{*}{$\begin{array}{l}0.01,0.031, \\
0.1,0.31,1.0 \\
\end{array}$} \\
\hline $1 a-8$ & & & Q2-3183A & & $13 \mathrm{~Pa}$ & \\
\hline $1 \mathrm{a}-9$ & & & Q2-3183A & & $3 \mathrm{~Pa}$ & \\
\hline $1 b-1$ & Yes $^{1}$ & \multirow{3}{*}{$\begin{array}{l}\text { AZ-101 } \\
\text { Chemical } \\
\text { Hydroxide }\end{array}$} & No & \multirow{6}{*}{$\begin{array}{l}\text { 1/9th scale, } \\
\text { mech. agit. }\end{array}$} & $30 \mathrm{~Pa}$ & \multirow{3}{*}{$\begin{array}{l}0.01,0.031, \\
0.1,0.31,1.0\end{array}$} \\
\hline $1 b-2$ & Yes $^{1}$ & & No & & $13 \mathrm{~Pa}$ & \\
\hline $1 b-3$ & Yes $^{1}$ & & No & & $3 \mathrm{~Pa}$ & \\
\hline $1 b-4$ & Yes $^{1}$ & \multirow{3}{*}{$\begin{array}{l}\text { AZ-101 } \\
\text { Chemical } \\
\text { Hydroxide }\end{array}$} & Q2-3183A & & $30 \mathrm{~Pa}$ & \multirow{3}{*}{$\begin{array}{l}0.01,0.031, \\
0.1,0.31,1.0\end{array}$} \\
\hline $1 b-5$ & Yes $^{1}$ & & Q2-3183A & & $13 \mathrm{~Pa}$ & \\
\hline $1 b-6$ & Yes $^{1}$ & & Q2-3183A & & $3 \mathrm{~Pa}$ & \\
\hline $1 \mathrm{c}-1$ & $\mathrm{Yes}^{1}$ & \multirow{3}{*}{$\begin{array}{l}\text { New AZ- } \\
101 \\
\text { Simulant }\end{array}$} & No & \multirow{6}{*}{$\begin{array}{l}\text { 1/9th scale, } 4 \\
\text { PJMs }\end{array}$} & $30 \mathrm{~Pa}$ & \multirow{3}{*}{$\begin{array}{l}0.01,0.031, \\
0.1,0.31,1.0 \\
\end{array}$} \\
\hline $1 \mathrm{c}-2$ & Yes $^{1}$ & & No & & $13 \mathrm{~Pa}$ & \\
\hline $1 c-3$ & Yes $^{1}$ & & No & & $3 \mathrm{~Pa}$ & \\
\hline $1 c-4$ & & \multirow{3}{*}{$\begin{array}{l}\text { New AZ- } \\
101 \\
\text { Simulant }\end{array}$} & Q2-3183A & & $30 \mathrm{~Pa}$ & \multirow{3}{*}{$\begin{array}{l}0.01,0.031, \\
0.1,0.31,1.0\end{array}$} \\
\hline $1 c-5$ & & & Q2-3183A & & $13 \mathrm{~Pa}$ & \\
\hline $1 c-6$ & & & Q2-3183A & & $3 \mathrm{~Pa}$ & \\
\hline $5 a-1$ & & \multirow[b]{3}{*}{ Water } & No & \multirow[b]{3}{*}{ Bench Scale } & NA & \multirow{3}{*}{$\begin{array}{l}0.01,0.031, \\
0.1,0.31,1.0\end{array}$} \\
\hline $5 a-2$ & & & PDMS & & & \\
\hline $5 a-3$ & & & PPG & & NA & \\
\hline $5 a-4$ & & \multirow{3}{*}{$\begin{array}{l}\text { Ph. } 1 \text { AZ- } \\
101 \text { Ppt, No } \\
\text { Noble } \\
\text { metals }\end{array}$} & No & \multirow[b]{3}{*}{ Bench Scale } & $30 \mathrm{~Pa}$ & \multirow{3}{*}{$\begin{array}{l}0.01,0.031, \\
0.1,0.31,1.0\end{array}$} \\
\hline $5 a-5$ & & & No & & $13 \mathrm{~Pa}$ & \\
\hline $5 a-6$ & & & No & & $3 \mathrm{~Pa}$ & \\
\hline
\end{tabular}


WSRC-STI-2007-00537, REVISION 0

SRNL-RPP-2007-00023, REVISION 0

Table 1-1. Original R\&T Test Conditions per Test Specification 24590-WTP-TSP-RT-06022, Rev. 0 and listed in the Task Technical and QA Plan [6] - continued

\begin{tabular}{|c|c|c|c|c|c|c|}
\hline $\begin{array}{l}\text { Test } \\
\text { No. }\end{array}$ & $\begin{array}{c}\text { Test } \\
\text { removed } \\
\text { from scope?* }\end{array}$ & Simulant & AFA & Test Model & $\begin{array}{l}\text { Rheology, } \\
\text { yield } \\
\text { stress }\end{array}$ & \begin{tabular}{|l|} 
Air \\
superficial \\
Vel. $\mathbf{m m} / \mathbf{s}$ \\
\end{tabular} \\
\hline $5 a-7$ & & \multirow{3}{*}{$\begin{array}{l}\text { Ph. } 1 \text { AZ- } \\
101 \text { Ppt, No } \\
\text { Noble metals }\end{array}$} & PDMS & \multirow[b]{6}{*}{ Bench Scale } & $30 \mathrm{~Pa}$ & \multirow{3}{*}{$\begin{array}{l}0.01,0.031 \\
0.1,0.31,1.0 \\
\end{array}$} \\
\hline $5 a-8$ & & & PDMS & & $13 \mathrm{~Pa}$ & \\
\hline $5 a-9$ & & & PDMS & & $3 \mathrm{~Pa}$ & \\
\hline $5 a-10$ & & \multirow{3}{*}{$\begin{array}{l}\text { Ph. } 1 \text { AZ- } \\
101 \text { Ppt, No } \\
\text { Noble metals }\end{array}$} & PPG & & $30 \mathrm{~Pa}$ & \multirow{3}{*}{$\begin{array}{l}0.01,0.031, \\
0.1,0.31,1.0 \\
\end{array}$} \\
\hline $5 a-11$ & & & PPG & & $13 \mathrm{~Pa}$ & \\
\hline $5 a-12$ & & & PPG & & $3 \mathrm{~Pa}$ & \\
\hline $5 b-1$ & & \multirow{3}{*}{$\begin{array}{l}\text { Ph. } 1 \text { AZ- } \\
\text { 101 Ppt, No } \\
\text { Noble metals }\end{array}$} & Alt. AFA 1 & \multirow[b]{3}{*}{ Bench Scale } & $30 \mathrm{~Pa}$ & \multirow{3}{*}{$\begin{array}{l}0.01,0.031, \\
0.1,0.31,1.0\end{array}$} \\
\hline $5 b-2$ & & & Alt. AFA 1 & & $13 \mathrm{~Pa}$ & \\
\hline $5 b-3$ & & & Alt. AFA 1 & & $3 \mathrm{~Pa}$ & \\
\hline $5 b-4$ & & \multirow{3}{*}{$\begin{array}{l}\text { Ph. } 1 \text { AZ- } \\
101 \text { Ppt, No } \\
\text { Noble metals }\end{array}$} & Alt. AFA 2 & \multirow[b]{3}{*}{ Bench Scale } & $30 \mathrm{~Pa}$ & \multirow{3}{*}{$\begin{array}{l}0.01,0.031, \\
0.1,0.31,1.0\end{array}$} \\
\hline $5 b-5$ & & & Alt. AFA 2 & & $13 \mathrm{~Pa}$ & \\
\hline $5 b-6$ & & & Alt. AFA 2 & & $3 \mathrm{~Pa}$ & \\
\hline $5 b-7$ & & \multirow{3}{*}{$\begin{array}{l}\text { Ph. } 1 \text { AZ- } \\
101 \text { Ppt, No } \\
\text { Noble metals }\end{array}$} & PNL AFA & \multirow[b]{3}{*}{ Bench Scale } & $30 \mathrm{~Pa}$ & \multirow{3}{*}{$\begin{array}{l}0.01,0.031 \\
0.1,0.31,1.0 \\
\end{array}$} \\
\hline $5 b-8$ & & & PNL AFA & & $13 \mathrm{~Pa}$ & \\
\hline $5 b-9$ & & & PNL AFA & & $3 \mathrm{~Pa}$ & \\
\hline $5 c-1$ & & \multirow{4}{*}{$\begin{array}{l}\text { New AZ-101 } \\
\text { Confirmatory } \\
\text { test }\end{array}$} & No & \multirow{8}{*}{$\begin{array}{l}1 / 9 \text { th scale, } \\
\text { mech. agit. }\end{array}$} & $30 \mathrm{~Pa}$ & \multirow{4}{*}{$\begin{array}{l}0.01,0.031, \\
0.1,0.31,1.0\end{array}$} \\
\hline $5 c-2$ & & & No & & $13 \mathrm{~Pa}$ & \\
\hline $5 c-3$ & & & No & & $3 \mathrm{~Pa}$ DI w & \\
\hline $5 c-4$ & $\mathrm{Yes}^{1}$ & & No & & 3 Pa Sup. & \\
\hline $5 c-5$ & & \multirow{4}{*}{$\begin{array}{l}\text { New AZ-101 } \\
\text { Confirmatory } \\
\text { test }\end{array}$} & Q2-3183A & & $30 \mathrm{~Pa}$ & \multirow{4}{*}{$\begin{array}{l}0.01,0.031, \\
0.1,0.31,1.0 \\
\end{array}$} \\
\hline $5 c-6$ & & & Q2-3183A & & $13 \mathrm{~Pa}$ & \\
\hline $5 c-7$ & & & Q2-3183A & & $3 \mathrm{~Pa}$ DI w & \\
\hline $5 c-8$ & Yes $^{1}$ & & Q2-3183A & & 3 Pa Sup. & \\
\hline $5 c-9$ & $\mathrm{Yes}^{1}$ & \multirow{3}{*}{$\begin{array}{l}\text { New AZ-101 } \\
\text { Confirmatory } \\
\text { test }\end{array}$} & No & \multirow{6}{*}{$\begin{array}{l}1 / 9 \text { th scale, } \\
\text { mech. agitator }\end{array}$} & $30 \mathrm{~Pa}$ & \multirow{3}{*}{$\begin{array}{l}0.01,0.031, \\
0.1,0.31,1.0\end{array}$} \\
\hline $5 c-10$ & $\mathrm{Yes}^{1}$ & & No & & $13 \mathrm{~Pa}$ & \\
\hline $5 c-11$ & $\mathrm{Yes}^{1}$ & & No & & $3 \mathrm{~Pa}$ & \\
\hline $5 c-12$ & & \multirow{3}{*}{$\begin{array}{l}\text { New AZ-101 } \\
\text { Confirmatory } \\
\text { test }\end{array}$} & Alt. AFA & & $30 \mathrm{~Pa}$ & \multirow{3}{*}{$\begin{array}{l}0.01,0.031 \\
0.1,0.31,1.0 \\
\end{array}$} \\
\hline $5 c-13$ & & & Alt. AFA & & $13 \mathrm{~Pa}$ & \\
\hline $5 c-14$ & & & Alt. AFA & & $3 \mathrm{~Pa}$ & \\
\hline
\end{tabular}


WSRC-STI-2007-00537, REVISION 0

SRNL-RPP-2007-00023, REVISION 0

Table 1-1. Original R\&T Test Conditions per Test Specification 24590-WTP-TSP-RT-06022, Rev. 0 and listed in the Task Technical and QA Plan [6] - continued

\begin{tabular}{|c|c|c|c|c|c|c|}
\hline $\begin{array}{l}\text { Test } \\
\text { No. }\end{array}$ & $\begin{array}{c}\text { Test } \\
\text { removed } \\
\text { from scope?* }\end{array}$ & Simulant & AFA & Test Model & $\begin{array}{l}\text { Rheology } \\
\text { yield } \\
\text { stress }\end{array}$ & $\begin{array}{l}\text { Air } \\
\text { superficial } \\
\text { Vel. } \mathbf{m m} / \mathbf{s}^{3} \\
\end{array}$ \\
\hline $7 b-1$ & Yes $^{1}$ & \multirow{3}{*}{$\begin{array}{l}\text { Bounding } \\
\text { Simulant } 1 \\
\end{array}$} & No & \multirow{6}{*}{$\begin{array}{l}\text { 1/9th scale, } 4 \\
\text { PJMs }\end{array}$} & $30 \mathrm{~Pa}$ & \multirow{3}{*}{$\begin{array}{l}0.01,0.031, \\
0.1,0.31,1.0\end{array}$} \\
\hline $7 b-2$ & $\mathrm{Yes}^{1}$ & & No & & $13 \mathrm{~Pa}$ & \\
\hline $7 b-3$ & Yes $^{1}$ & & No & & $3 \mathrm{~Pa}$ & \\
\hline $7 b-4$ & $\mathrm{Yes}^{1}$ & \multirow{3}{*}{$\begin{array}{l}\text { Bounding } \\
\text { Simulant } 1 \\
\end{array}$} & Alt. AFA & & $30 \mathrm{~Pa}$ & \multirow{3}{*}{$\begin{array}{l}0.01,0.031, \\
0.1,0.31,1.0\end{array}$} \\
\hline $7 b-5$ & $\mathrm{Yes}^{1}$ & & Alt. AFA & & $13 \mathrm{~Pa}$ & \\
\hline $7 b-6$ & Yes $^{1}$ & & Alt. AFA & & $3 \mathrm{~Pa}$ & \\
\hline $7 b-7$ & Yes $^{1}$ & \multirow{3}{*}{$\begin{array}{l}\text { Bounding } \\
\text { Simulant } 2 \\
\end{array}$} & No & \multirow{6}{*}{$\begin{array}{l}\text { 1/9th scale, } 4 \\
\text { PJMs }\end{array}$} & $30 \mathrm{~Pa}$ & \multirow{3}{*}{$\begin{array}{l}0.01,0.031, \\
0.1,0.31,1.0\end{array}$} \\
\hline $7 b-8$ & $\mathrm{Yes}^{1}$ & & No & & $13 \mathrm{~Pa}$ & \\
\hline $7 b-9$ & Yes $^{1}$ & & No & & $3 \mathrm{~Pa}$ & \\
\hline $7 b-10$ & Yes $^{1}$ & \multirow{3}{*}{$\begin{array}{l}\text { Bounding } \\
\text { Simulant } 2 \\
\end{array}$} & Alt. AFA & & $30 \mathrm{~Pa}$ & \multirow{3}{*}{$\begin{array}{l}0.01,0.031, \\
0.1,0.31,1.0\end{array}$} \\
\hline $7 b-11$ & Yes $^{1}$ & & Alt. AFA & & $13 \mathrm{~Pa}$ & \\
\hline $7 b-12$ & $\mathrm{Yes}^{1}$ & & Alt. AFA & & $3 \mathrm{~Pa}$ & \\
\hline $8-1$ & & \multirow[b]{2}{*}{ Water } & No & \multirow{2}{*}{$\begin{array}{l}\text { Large Bub. Col. } \\
3 \text { fill depths }\end{array}$} & $\mathrm{NA}$ & \multirow[b]{2}{*}{$2,5,10$} \\
\hline $8-2$ & & & Q2-3183A & & NA & \\
\hline $8-3$ & $\mathrm{Yes}^{2}$ & \multirow[b]{3}{*}{ Clay } & No & \multirow{6}{*}{$\begin{array}{l}\text { Large Bubble } \\
\text { Column, } 3 \text { fill } \\
\text { depths }\end{array}$} & $30 \mathrm{~Pa}$ & \multirow[b]{3}{*}{$2,5,10$} \\
\hline $8-4$ & $\mathrm{Yes}^{2}$ & & No & & $13 \mathrm{~Pa}$ & \\
\hline $8-5$ & $\mathrm{Yes}^{2}$ & & No & & $3 \mathrm{~Pa}$ & \\
\hline $8-6$ & $\mathrm{Yes}^{2}$ & \multirow[b]{3}{*}{ Clay } & Q2-3183A & & $30 \mathrm{~Pa}$ & \multirow[b]{3}{*}{$2,5,10$} \\
\hline $8-7$ & $\mathrm{Yes}^{2}$ & & Q2-3183A & & $13 \mathrm{~Pa}$ & \\
\hline $8-8$ & $\mathrm{Yes}^{2}$ & & Q2-3183A & & $3 \mathrm{~Pa}$ & \\
\hline $8-9$ & $\mathrm{Yes}^{1}$ & \multirow[b]{3}{*}{ New AZ-101 } & No & \multirow{6}{*}{$\begin{array}{l}\text { Large Bubble } \\
\text { Column, } 3 \text { fill } \\
\text { depths }\end{array}$} & $30 \mathrm{~Pa}$ & \multirow[b]{3}{*}{$2,5,10$} \\
\hline $8-10$ & $\mathrm{Yes}^{1}$ & & No & & $13 \mathrm{~Pa}$ & \\
\hline $8-11$ & $\mathrm{Yes}^{1}$ & & No & & $3 \mathrm{~Pa}$ & \\
\hline $8-12$ & $\mathrm{Yes}^{1}$ & \multirow[b]{3}{*}{ New AZ-101 } & Q2-3183A & & $30 \mathrm{~Pa}$ & \multirow[b]{3}{*}{$2,5,10$} \\
\hline $8-13$ & & & Q2-3183A & & $13 \mathrm{~Pa}$ & \\
\hline $8-14$ & Yes $^{1}$ & & Q2-3183A & & $3 \mathrm{~Pa}$ & \\
\hline
\end{tabular}

1. Deleted by Test Exception Number 24590-WTP-TEF-RT-07-00010 Rev. 0 [4].

2. Deleted by Test Exception Number 24590-WTP-TEF-RT-07-00014 Rev. 0 [5].

3. Air flow was broken up into small bubbles to model the in-situ formation of hydrogen gas by nucleation and growth of small bubbles. 


\subsection{SIMULANT USE}

\subsubsection{Description of Simulants Used}

All AZ-101 simulants used in this testing and in previous testing [2] were prepared following the SRNL recipe [7]. However, there were differences in the final simulants because of differences in processing temperature and method for removing precipitates. The simulant used in these tests was produced by Optima Chemical Group, according to PNNL's Work Statement [8] and described in a forthcoming PNNL report about part of this test program. The simulant used in 2006, here labeled as Phase I simulant, was produced in-house at SRNL. The composition of the AZ-101 simulant was derived from a combination of AZ-101 waste, based on the characterization of a sample of actual AZ-101 sludge, with a portion of cesium ion exchange concentrate, which comes from the return of radioactive cesium from the sludge supernatant to the HLW. The simulant includes all the measured species that are not radioactive or substitutes a nonradioactive surrogate for a radioactive one where appropriate.

Table 1-2 lists specific size-constrained metal oxides that were part of the part of the simulant representing AZ-101 tank waste. Table 1-3 lists the remaining chemicals included in the AZ-101 portion of the simulant to produce 1 liter of AZ-101 feed. The chemicals used for preparing the simulated cesium ion exchange concentrate are given in Table 1-4.

The production of the AZ-101 simulant as originally carried out at SRNL used reagent-grade chemicals and specific oxides/hydroxides of known particle sizes. After hydrous $\mathrm{MnO}_{2} \mathrm{was}$ generated by reacting manganous nitrate $\mathrm{Mn}(\mathrm{NO} 3)_{2}$ with potassium permanganate $\mathrm{KMnO}_{4}$ alkaline-earth and transition-metal nitrates were added to the solution. Sodium hydroxide (not shown in the tables) was added to increase the $\mathrm{pH}$ to 10 , precipitating metal oxides and hydroxides in the same manner as in the original tank waste. Sodium carbonate solution (400 $\mathrm{mL}$ of $0.6 \mathrm{M} \mathrm{Na} 2 \mathrm{CO} 3$ ) was then mixed in to convert slightly soluble hydroxides to more insoluble carbonates. The resulting slurry was washed to remove excess sodium, nitrate, and carbonate ions, the size-constrained reagents in Table 1-2 were added.

Table 1-2. Metal Oxides/Hydroxides Used in Simulant

\begin{tabular}{|l|l|}
\hline \multicolumn{1}{|c|}{ Material } & \multicolumn{1}{c|}{ Product Name } \\
\hline Aluminum Oxide, $99.5 \%$ & Fine powder $(98$ vol $\%<27 \mu \mathrm{m})$ \\
\hline Silica, $\mathrm{SiO}_{2}$ & Silicon(IV) oxide, $99.5 \%-400 \mathrm{mesh}$ \\
\hline Tin (IV) Oxide & Tin (IV) oxide, 325 mesh $99.9 \%$ \\
\hline Titanium Dioxide & Titanium(IV) oxide, powder, $<5$ micron, $99.9+\%$ \\
\hline
\end{tabular}


Table 1-3. Chemicals for Producing the HLW Precipitated Hydroxide Feed Simulant

\begin{tabular}{|c|c|c|}
\hline \multicolumn{3}{|c|}{ HLW Precipitated Hydroxide Feed Simulant } \\
\hline Compounds & \begin{tabular}{|c|} 
Formula \\
\end{tabular} & Mass (g) \\
\hline Potassium Permanganate & $\mathrm{KMnO}_{4}$ & 1.913 \\
\hline Manganese Nitrate Solution, $50 \mathrm{wt} \%$ & $\mathrm{Mn}\left(\mathrm{NO}_{3}\right)_{2}$ & 6.50 \\
\hline Ferric Nitrate & $\mathrm{Fe}\left(\mathrm{NO}_{3}\right)_{3} \cdot 9 \mathrm{H}_{2} \mathrm{O}$ & 453.86 \\
\hline Nickel Nitrate & $\mathrm{Ni}\left(\mathrm{NO}_{3}\right)_{2} \cdot 6 \mathrm{H}_{2} \mathrm{O}$ & 15.348 \\
\hline Zirconyl Nitrate & $\mathrm{ZrO}\left(\mathrm{NO}_{3}\right)_{2} \bullet \mathrm{xH}_{2} \mathrm{O}, \mathrm{X} \sim 6$ & 75.012 \\
\hline Cerium Nitrate & $\mathrm{Ce}\left(\mathrm{NO}_{3}\right)_{3} \cdot 6 \mathrm{H}_{2} \mathrm{O}$ & 5.034 \\
\hline Lanthanum nitrate & $\mathrm{La}\left(\mathrm{NO}_{3}\right)_{3} \cdot 6 \mathrm{H}_{2} \mathrm{O}$ & 5.612 \\
\hline Neodymium Nitrate & $\mathrm{Nd}\left(\mathrm{NO}^{3}\right)_{3} \cdot 6 \mathrm{H}_{2} \mathrm{O}$ & 4.042 \\
\hline Barium Nitrate & $\mathrm{Ba}\left(\mathrm{NO}_{3}\right)_{2}$ & 0.891 \\
\hline Calcium Nitrate & $\mathrm{Ca}\left(\mathrm{NO}_{3}\right)_{2} \bullet 4 \mathrm{H}_{2} \mathrm{O}$ & 13.708 \\
\hline Cadmium Nitrate & $\mathrm{Cd}\left(\mathrm{NO}_{3}\right)_{2} \bullet 4 \mathrm{H}_{2} \mathrm{O}$ & 12.335 \\
\hline Chromium Nitrate & $\mathrm{Cr}\left(\mathrm{NO}_{3}\right)_{3} \bullet 9 \mathrm{H}_{2} \mathrm{O}$ & 5.450 \\
\hline Cobalt Nitrate & $\mathrm{Co}\left(\mathrm{NO}_{3}\right)_{2} \cdot 6 \mathrm{H}_{2} \mathrm{O}$ & 0.195 \\
\hline Cupric Nitrate & $\mathrm{Cu}\left(\mathrm{NO}_{3}\right)_{2} \cdot 2.5 \mathrm{H}_{2} \mathrm{O}$ & 0.662 \\
\hline Magnesium Nitrate & $\mathrm{Mg}\left(\mathrm{NO}_{3}\right)_{2} \bullet 6 \mathrm{H}_{2} \mathrm{O}$ & 5.036 \\
\hline Lead Nitrate & $\mathrm{Pb}\left(\mathrm{NO}_{3}\right)_{2}$ & 0.856 \\
\hline Strontium Nitrate & $\mathrm{Sr}\left(\mathrm{NO}_{3}\right)_{2}$ & 2.554 \\
\hline Zinc Nitrate & $\mathrm{Zn}\left(\mathrm{NO}_{3}\right)_{2} \bullet 6 \mathrm{H}_{2} \mathrm{O}$ & 0.391 \\
\hline Silver Nitrate & $\mathrm{AgNO}_{3}$ & 0.004 \\
\hline Potassium Nitrate & $\mathrm{KNO}_{3}$ & 1.560 \\
\hline Potassium Molybdate & $\mathrm{K}_{2} \mathrm{MoO}_{4}$ & 0.051 \\
\hline Boric Acid & $\mathrm{H}_{3} \mathrm{BO}_{3}$ & 0.088 \\
\hline Sodium Chloride & $\mathrm{NaCl}$ & 0.196 \\
\hline Sodium Fluoride & $\mathrm{NaF}$ & 0.146 \\
\hline Sodium Sulfate & $\mathrm{Na}_{2} \mathrm{SO}_{4}$ & 0.604 \\
\hline Sodium Phosphate & $\mathrm{Na}_{3} \mathrm{PO}_{4} \bullet 12 \mathrm{H}_{2} \mathrm{O}$ & 9.37 \\
\hline Sodium Hydroxide & $\mathrm{NaOH}$ & 6.43 \\
\hline Sodium Carbonate & $\mathrm{Na}_{2} \mathrm{CO}_{3}$ & 6.68 \\
\hline Sodium Nitrite & $\mathrm{NaNO}_{2}$ & 1.17 \\
\hline
\end{tabular}


WSRC-STI-2007-00537, REVISION 0

SRNL-RPP-2007-00023, REVISION 0

Table 1-4. Chemicals for Producing the Cesium Ion Exchange Concentrate Simulant

\begin{tabular}{|l|l|l|}
\hline \multicolumn{3}{|c|}{ Cesium Ion Exchange Concentrate Simulant } \\
\hline \multicolumn{1}{|c|}{ Compounds } & \multicolumn{1}{c|}{ Formula } & Mass (grams) \\
\hline Water & $\mathrm{H}_{2} \mathrm{O}$ & 200 \\
\hline Aluminum Nitrate & $\mathrm{Al}\left(\mathrm{NO}_{3}\right)_{3} \bullet 9 \mathrm{H}_{2} \mathrm{O}$ & 8.19 \\
\hline Sodium Borate & $\mathrm{Na}_{2} \mathrm{~B}_{4} \mathrm{O}_{7} \bullet 10 \mathrm{H}_{2} \mathrm{O}$ & 23.39 \\
\hline Cadmium Nitrate & $\mathrm{Cd}\left(\mathrm{NO}_{3}\right)_{2} \bullet 4 \mathrm{H}_{2} \mathrm{O}$ & 0.404 \\
\hline Calcium Nitrate & $\mathrm{Ca}\left(\mathrm{NO}_{3}\right)_{2} \bullet 4 \mathrm{H}_{2} \mathrm{O}$ & 13.72 \\
\hline Cesium Nitrate & $\mathrm{CsNO}$ & 1.60 \\
\hline Copper Nitrate & $\mathrm{Cu}\left(\mathrm{NO}_{3}\right)_{2} \bullet 2.5 \mathrm{H}_{2} \mathrm{O}$ & 0.54 \\
\hline Ferric Nitrate & $\mathrm{Fe}\left(\mathrm{NO}_{3}\right)_{3} \bullet 9 \mathrm{H}_{2} \mathrm{O}$ & 3.41 \\
\hline
\end{tabular}

The chemical composition requirements for AZ-101 simulants produced for testing are given in Table 1-5 (column labeled Eibling, et al. simulant scaled taken from [7], Table 44) together with the compositions of Optima Batches 1, 2 and 3 measured by PNNL [9]. The SRNL Phase I simulant composition was not measured.

For the comparisons made in Table 1-5, iron, which is present in the greatest amount, is used to scale all of the analytical data to the same slurry solids weight percent. The $\mu \mathrm{g} / \mathrm{g}$ values reported in the table have been iron-scaled to the same slurry solids content. The first batch (identified as Batch 1) was found by PNNL not to meet chemical analytical requirements. The cause of the discrepancy was traced to too high a nitrate concentration (under washing due to incorrect sampling) and insufficient boiling time, which meant that reactions did not go to completion. After consultations with SRNL, Optima adjusted their procedure. A second and third batches (identified as Batch 2 and Batch 3, respectively) were in reasonable agreement with the analytical requirements. Batch 2 was used in tests performed with the SRNL Mixing Stand and the Bench scale test rigs for the Alternate AFA testing, Noble Metals Effect testing, and PJM Mixing tests. Two 208 liter (55 gal) drums of Batch 2 were received. A third batch, Batch 3, consisting of 3600 liters, was used in the Mass Transfer Tests. One difference between Phase I simulant and Optima's Batch 1,2, and 3 simulants is that the process of producing the Phase I simulant used settling to concentrate the simulant, while the Optima process used commercial centrifuges. This could have led to different particle size distributions among the various simulants, which will be discussed in Sec.1.6.3. 
Table 1-5. Fe-Scaled Simulant Data for Analyzed Batches \#1, \#2, and \#3 ${ }^{(a, b, c)}$

\begin{tabular}{|c|c|c|c|c|}
\hline Chemical & $\begin{array}{c}\text { Eibling et al. } \\
\text { simulant } \\
\text { scaled }(\mu \mathrm{g} / \mathrm{g})\end{array}$ & $\begin{array}{c}\text { Batch } 3 \\
\text { scaled } \\
(\mu \mathrm{g} / \mathrm{g})\end{array}$ & $\begin{array}{c}\text { Batch } 2 \\
\text { scaled } \\
(\mu \mathrm{g} / \mathrm{g})\end{array}$ & $\begin{array}{c}\text { Batch 1 } \\
\text { scaled } \\
(\mu \mathrm{g} / \mathrm{g})\end{array}$ \\
\hline $\mathrm{Al}$ & 86659 & 117693 & 113000 & 81749 \\
\hline $\mathrm{Ba}$ & 1657 & 1638 & 1612 & 1484 \\
\hline $\mathrm{B}$ & 3573 & & & 314 \\
\hline $\mathrm{Cd}$ & 11265 & 14540 & 13943 & 13161 \\
\hline $\mathrm{C}_{2} \mathrm{O}_{4}$ & 186 & 310 & 325 & 633 \\
\hline $\mathrm{Ca}$ & 8158 & 7765 & 7102 & 9018 \\
\hline $\mathrm{Ce}$ & 3444 & & & 2453 \\
\hline $\mathrm{Cl}$ & 443 & 880 & 848 & 1267 \\
\hline Co & 150 & & & 82 \\
\hline $\mathrm{CO}_{3}$ & NR & NM & 42375 & 25201 \\
\hline $\mathrm{Cr}$ & 2344 & 2131 & 2334 & 2750 \\
\hline $\mathrm{Cu}$ & 609 & 756 & 508 & 494 \\
\hline $\mathrm{F}$ & 172 & 216 & 310 & 284 \\
\hline $\mathrm{Fe}$ & 202384 & \multicolumn{3}{|c|}{ same value - was the scaling basis } \\
\hline $\mathrm{K}$ & 3172 & & & 4038 \\
\hline $\mathrm{La}$ & 3755 & 4611 & 4996 & 4816 \\
\hline $\mathrm{Mg}$ & 1554 & 1658 & 1278 & 2543 \\
\hline $\mathrm{Mn}$ & 5438 & 5723 & 5810 & 5474 \\
\hline Mo & NR & 146 & 218 & 138 \\
\hline $\mathrm{Na}$ & 42212 & & & 61020 \\
\hline $\mathrm{Nd}$ & 3108 & 3579 & & 2737 \\
\hline $\mathrm{Ni}$ & 9970 & 10030 & 9470 & 9497 \\
\hline $\mathrm{NO}_{2}$ & 4623 & 4554 & 3971 & 6745 \\
\hline $\mathrm{NO}_{3}$ & 48686 & 57817 & 58643 & 90723 \\
\hline $\mathrm{Pb}$ & NR & 1840 & 1496 & 1690 \\
\hline $\mathrm{P}$ & 2564 & 3215 & 2716 & 3141 \\
\hline $\mathrm{PO}_{4}$ & 627 & 694 & 425 & 311 \\
\hline S & NR & & & 7478 \\
\hline $\mathrm{Si}$ & 15794 & 15571 & 15541 & 18246 \\
\hline $\mathrm{Sn}$ & 1554 & 3883 & 4648 & 3619 \\
\hline $\mathrm{SO}_{4}$ & 1997 & 2884 & 2699 & 6491 \\
\hline $\mathrm{Sr}$ & NR & 3130 & 3371 & 3084 \\
\hline $\mathrm{Ti}$ & 341 & 224 & 257 & 248 \\
\hline TOC & NR & NM & 327 & 239 \\
\hline $\mathrm{Zn}$ & 337 & 506 & 523 & 292 \\
\hline $\mathrm{Zr}$ & 61505 & 9221 & 10661 & 27863 \\
\hline
\end{tabular}

(a) Concentrations in italics were below the quantitation limit; error can be $>15 \%$.

(b) Blank cells indicate concentrations below the lower detection limit for the analyte.

(c) NM indicates analyte was not measured; NR indicates not reported. 
Noble Metals Addition

For the tests to determine the effect of Noble Metals, the compounds in Table 1-6 were added to 60 liters of Batch 2 simulant. The Noble Metals concentrations in metal gms/L conform to the required concentration in [7], which were in $\mathrm{gms} / \mathrm{L}$ of the solution procured. The compounds were added slowly to the already prepared Batch 2 simulant while stirring with the mechanical agitator. The cost effectiveness of adding noble metals to the small scale test $(60 \mathrm{~L})$ vs. adding noble metals directly to the larger $1 / 4$ scale test $(3400 \mathrm{~L})$ is evident from the cost multiplier of 57 to the cost of $\$ 7 \mathrm{~K}$ for the small scale test.

Table 1-6. Concentration of Noble Metals Added to $1 / 9^{\text {th }}$ scale Test Vessel

\begin{tabular}{|l|l|c|c|c|}
\hline $\begin{array}{l}\text { Noble Metal } \\
\text { Compound }\end{array}$ & $\begin{array}{l}\text { Concentration } \\
\text { as procured, }\end{array}$ & $\begin{array}{c}\text { Compound } \\
\text { weight, } \\
\text { gms }\end{array}$ & $\begin{array}{c}\text { Noble } \\
\text { Metal } \\
\text { weight, } \\
\text { gms }\end{array}$ & $\begin{array}{c}\text { Noble } \\
\text { Metal } \\
\text { Conc. in } \\
\text { simulant, } \\
\text { g/L }\end{array}$ \\
\hline Palladium nitrate & $10 \mathrm{wt} \%$ soln & 427.8 & 42.78 & 0.713 \\
\hline Rhodium nitrate & $10 \mathrm{wt} \%$ soln & 95.33 & 9.533 & 0.159 \\
\hline Ruthenium chloride & $35 \mathrm{wt} \%$ soln & 85.03 & 29.76 & 0.496 \\
\hline Silver nitrate & $100 \mathrm{wt} \%$ & 0.245 & 0.155 & 0.003 \\
\hline
\end{tabular}

\subsubsection{Dilution Curves}

The dilution curves of several simulants are shown in Figure 1-1. The dilution curve gives the variation of yield stress as a function of weight percent total solids. The yield stress is based on the down curve or decreasing rheometer cup speed and the weight $\%$ total solids was measured by maintaining oven temperature at $102^{\circ} \mathrm{C}$. Figure 1-1 shows that freshly made Batch 2 and Phase 1 simulants are basically similar. The two 55-gal drums of Batch 2 had the same dilution curves, to within measurement uncertainty. 


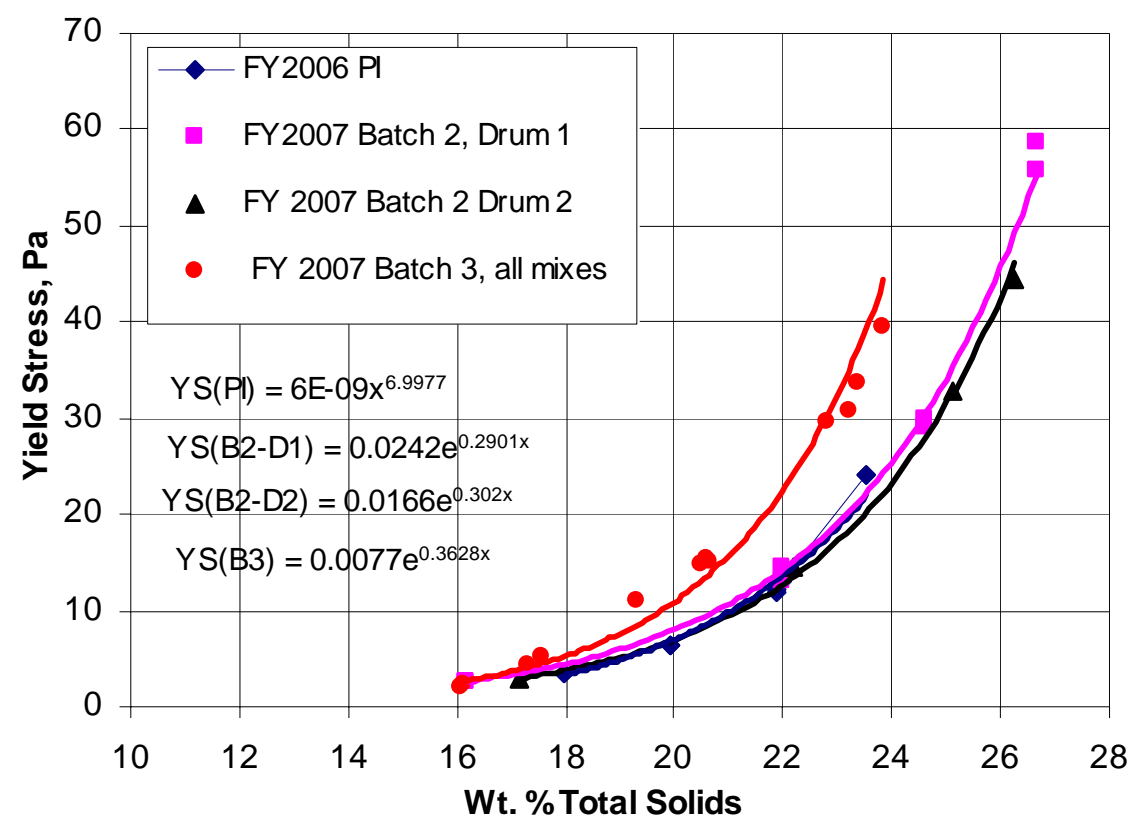

Figure 1-1. Dilution Curves for Optima Batch 2 and Batch 3 AZ-101 Simulant Compared to Phase I Simulant

The dilution curve for Batch 3, which includes samples from three different totes, is significantly higher than that for Batch 2. For the Mass Transfer Tests, for which this batch was used, the required yield stress was $13 \mathrm{~Pa}$. The total $\mathrm{wt} \%$ solids differ from Batch 2 only by $2 \mathrm{wt} \%$ solids. The effect on the mass transfer data would not appear to be significant.

Yield stresses of the samples taken during the testing for three one-month periods are plotted against the original dilution curves for Batch 2, Drums 1 and 2 in Figure 1-2. The data points are clustered slightly below the original dilution curves, indicating little aging effects.

Figure 1-3 gives the dilution curve for Batch 2 with noble metals, in comparison with the dilution curves for Batch 2, Drums 1 and 2, without noble metals. A noticeable effect is shown at $24.8 \mathrm{wt} \%$ total solids, where a 10 Pa reduction is observed by addition of noble metals. 


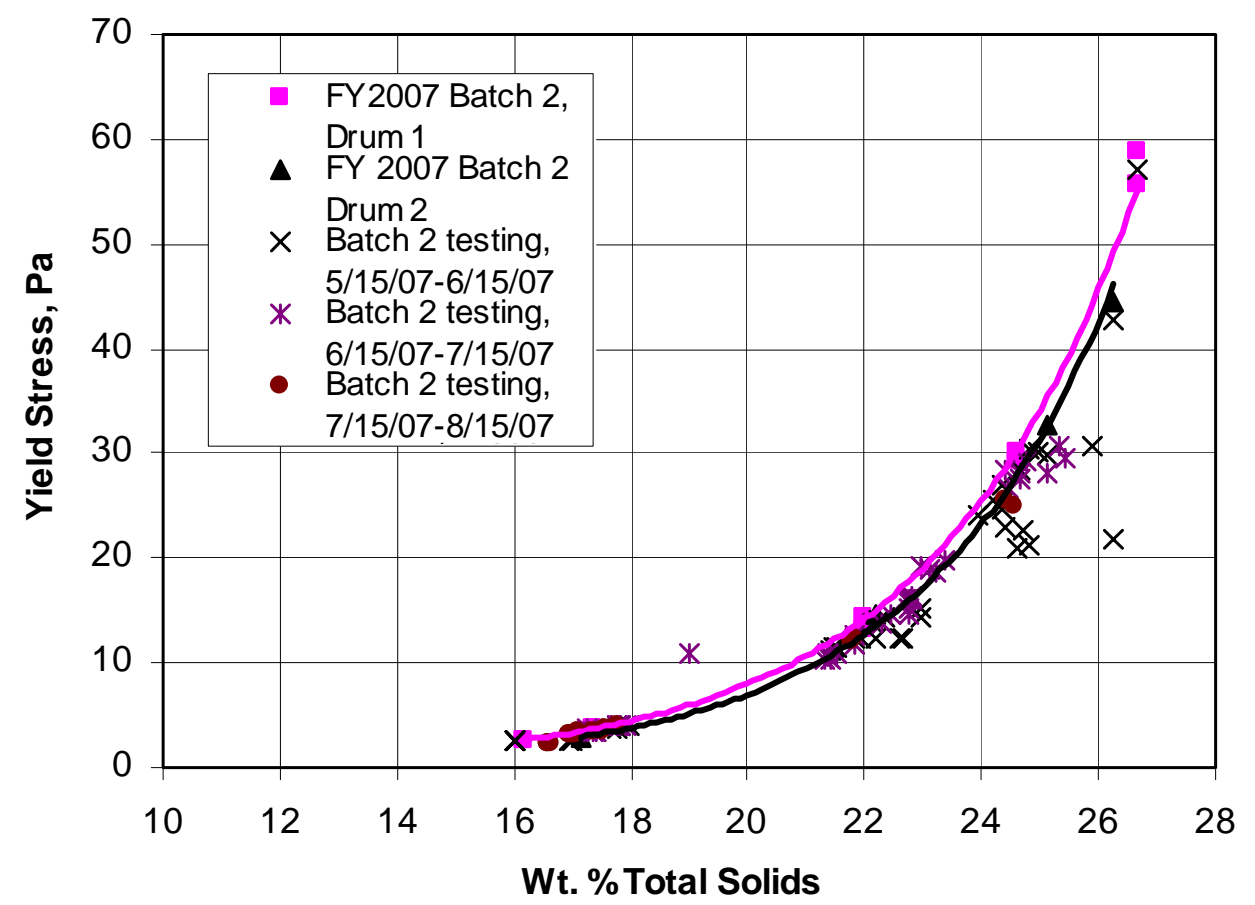

Figure 1-2. Yield Stress vs. Wt.\% Total Solids During Testing Compared to Initial Dilution Curves

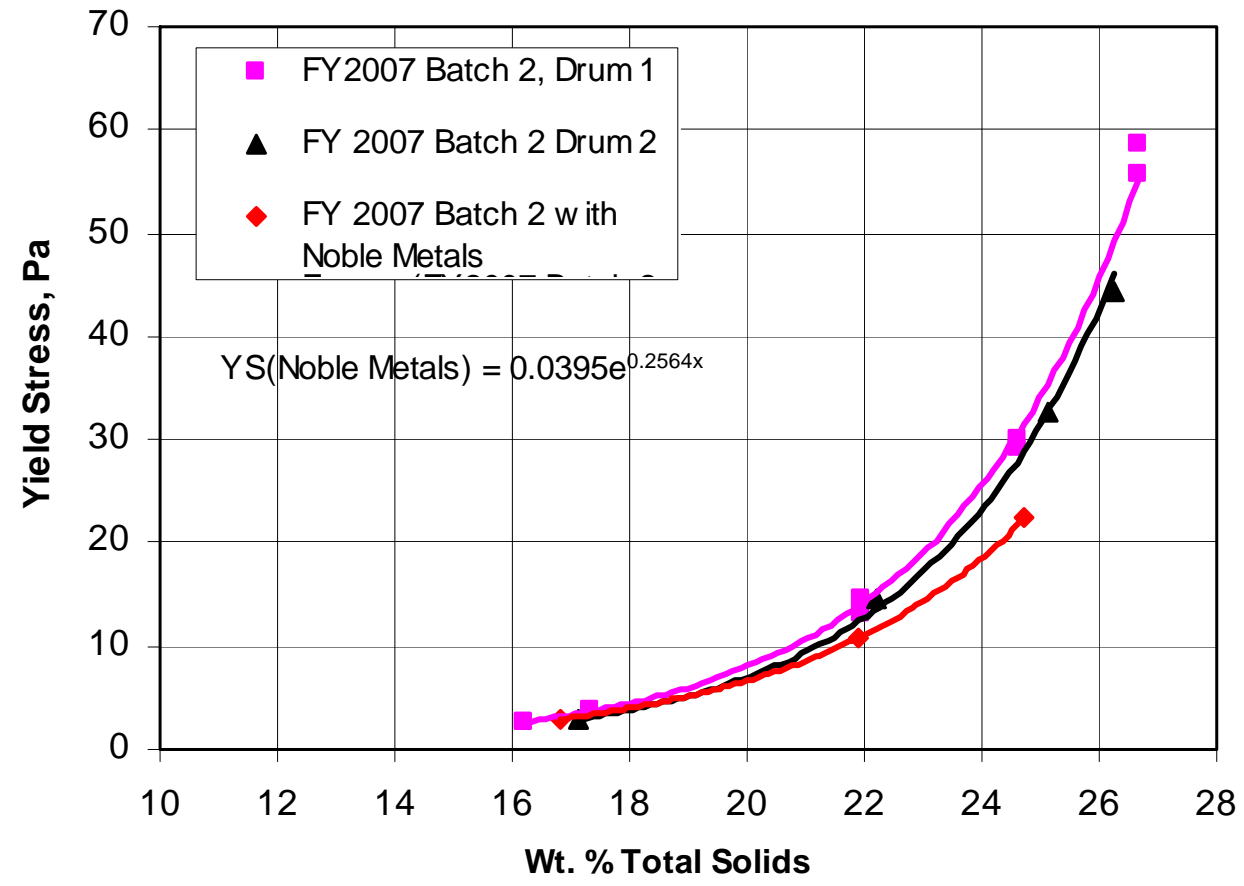

Figure 1-3. Dilution Curve for Optima Batch 2 with Noble Metals 


\subsubsection{Foaming of Batch 2 Simulant}

In contrast to Phase I simulant where no foaming was observed, Batch 2 simulant was observed to foam significantly, especially at the lower yield stresses. Figure 1-4 shows a factor of three increase in the gas holdup vs. superficial gas velocity at $30 \mathrm{~Pa}$, compared to data from Phase I for similar yield stress. Figure 1-5 shows a similar increase at a yield stress of $13 \mathrm{~Pa}$ at a high superficial velocity of $1 \mathrm{~mm} / \mathrm{s}$, decreasing at lower velocities. While there were no data from Phase I at a yield stress of $3 \mathrm{~Pa}$, Figure 1-6 shows a high degree of foaming, up to $50 \%$ void, with this slurry at gas superficial velocity of $1 \mathrm{~mm} / \mathrm{s}$. No definite cause of Batch 2 foamability is known, but the phenomenon of particle-based foaming phenomenon has been advanced as an explanation. In this phenomenon, small solid particles allow more coverage of the bubble surface, and if these are also hydrophobic, foaming is stabilized.

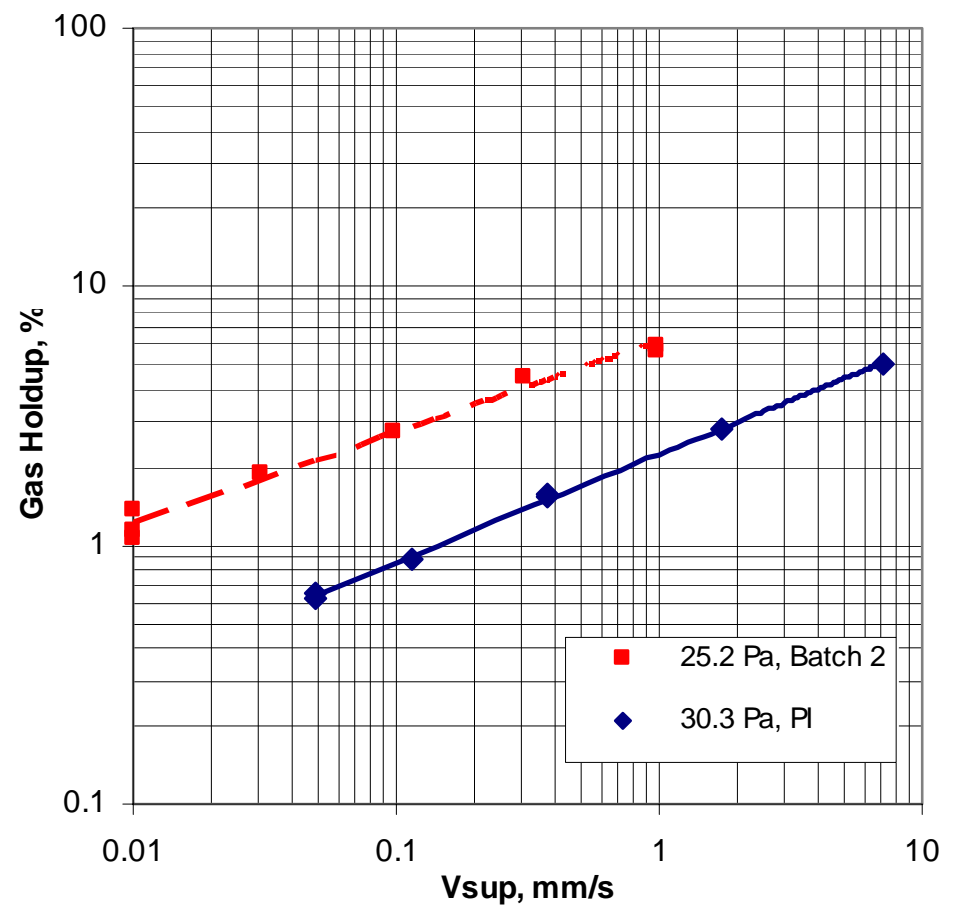

Figure 1-4. Effect of Foaming on Gas Holdup in Batch 2 Simulant at $30 \mathrm{~Pa}$

It is to be noted that in producing the Phase I simulant, the washing process was done using settling to remove the washing solution and concentrate the slurry. This could have resulted in large particle sizes due to long settling times, allowing agglomeration of particles to occur. The production of the large Optima batch used an industrial centrifuge to quickly filter out the washing solution and this could have produced smaller particle sizes. Particle sizes for Phase I simulant are not available to confirm this hypothesis. 
WSRC-STI-2007-00537, REVISION 0

SRNL-RPP-2007-00023, REVISION 0

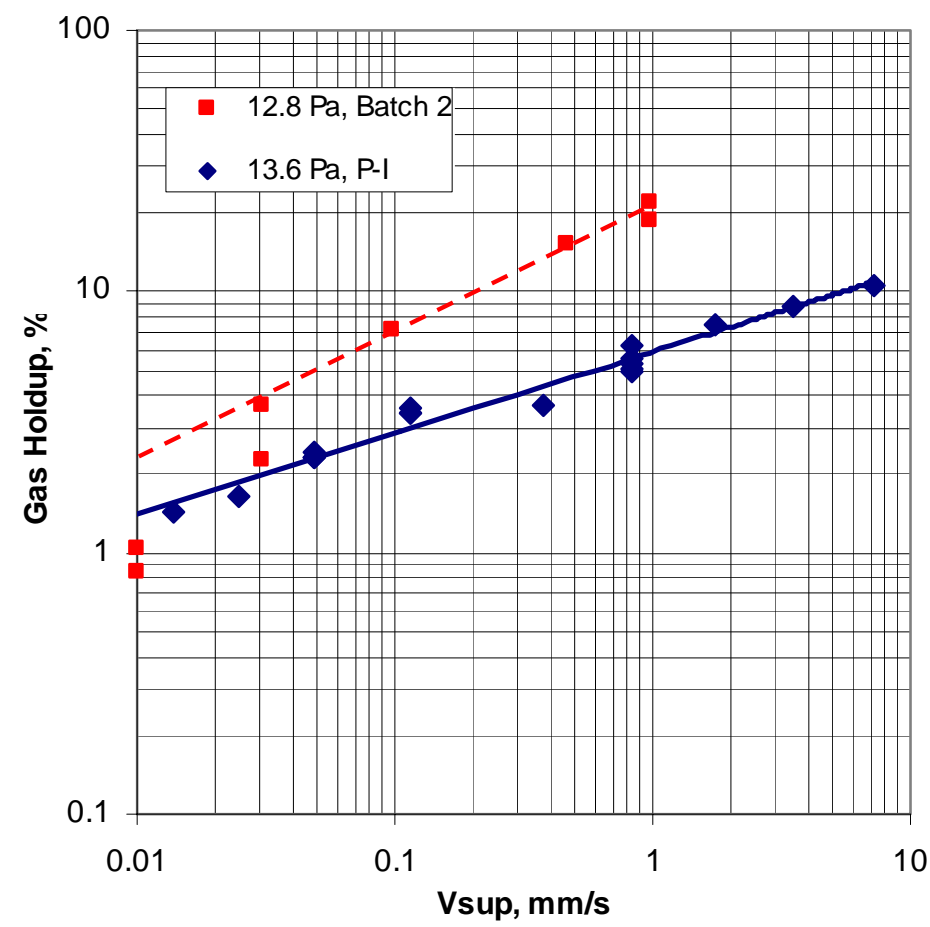

Figure 1-5. Effect of Foaming on Gas Holdup in Batch 2 Simulant at 13 Pa

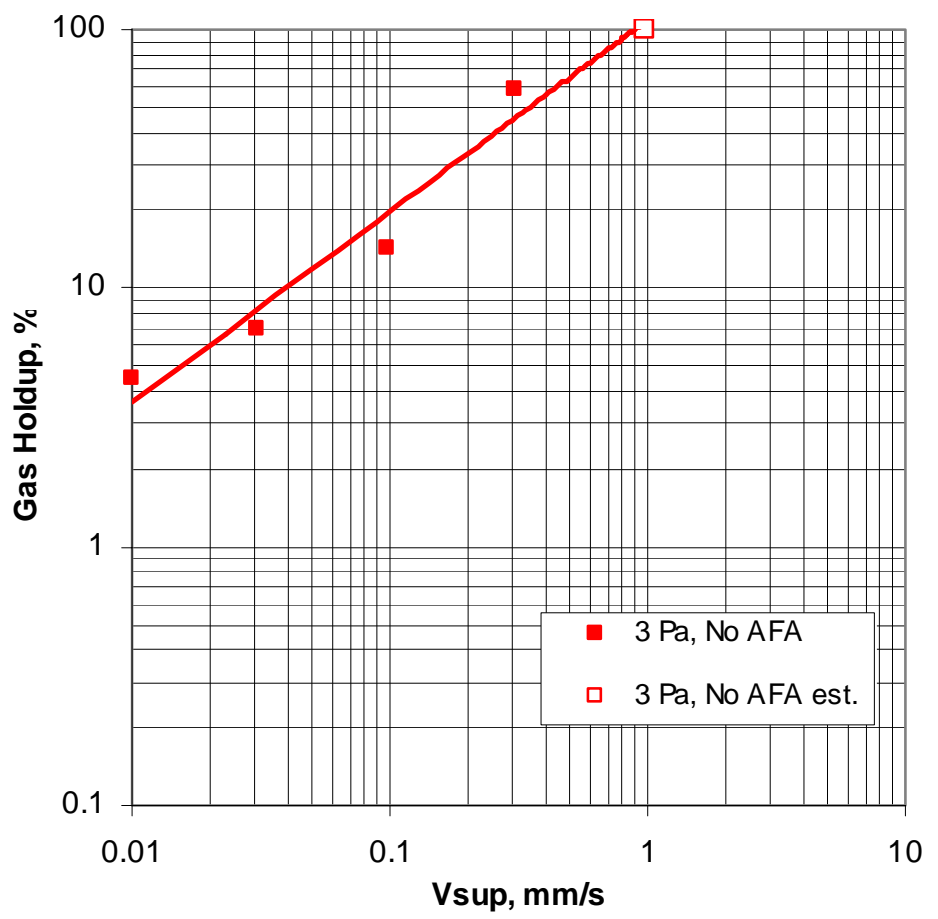

Figure 1-6. Effect of Foaming on Gas Holdup in Batch 2 Simulant at $3 \mathrm{~Pa}$ 


\section{Particle Size Distribution}

The particle size distributions for Optima Az-101 simulants were measured using a Microtrac S3000 Particle Size Analyzer. Figure 1-7 and Figure 1-8 give the distributions for Batch 2 without and with AFA, respectively. Both figures show a sharp peak at 0.65 microns, representing $63 \%$ of all particles, and a much smaller peak around 3 microns. Adding AFA removes a small peak at 40 microns. The large concentration of small particles ( 0.65 microns) would explain the tendency of this batch to foam.

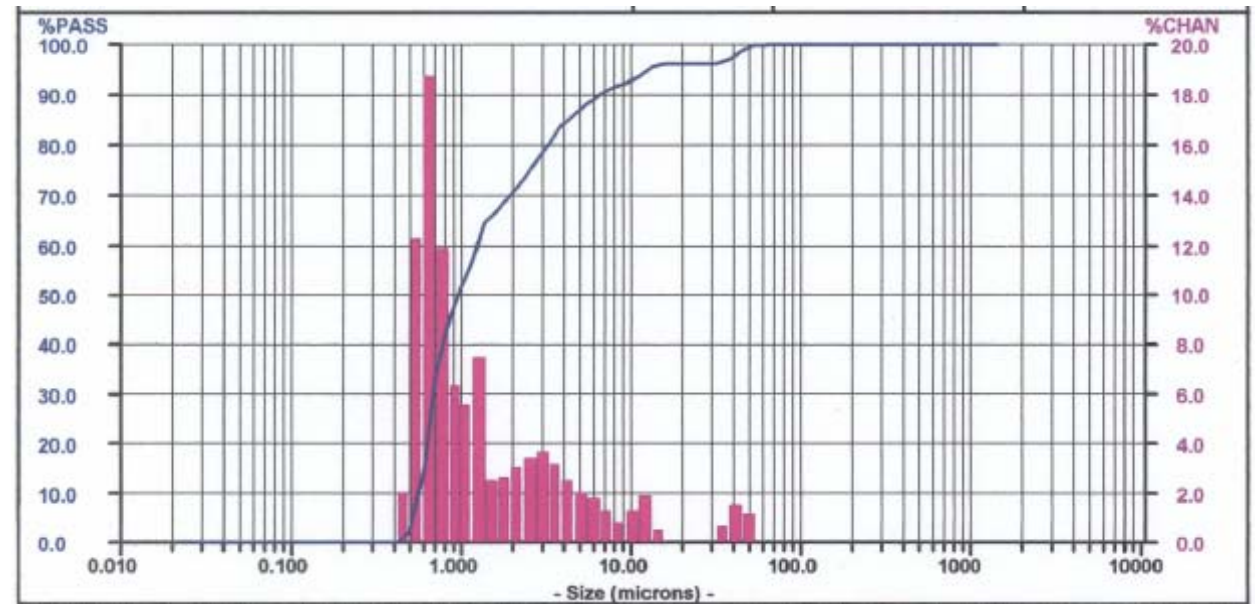

Figure 1-7. Particle Size Distribution for Batch 2 without AFA

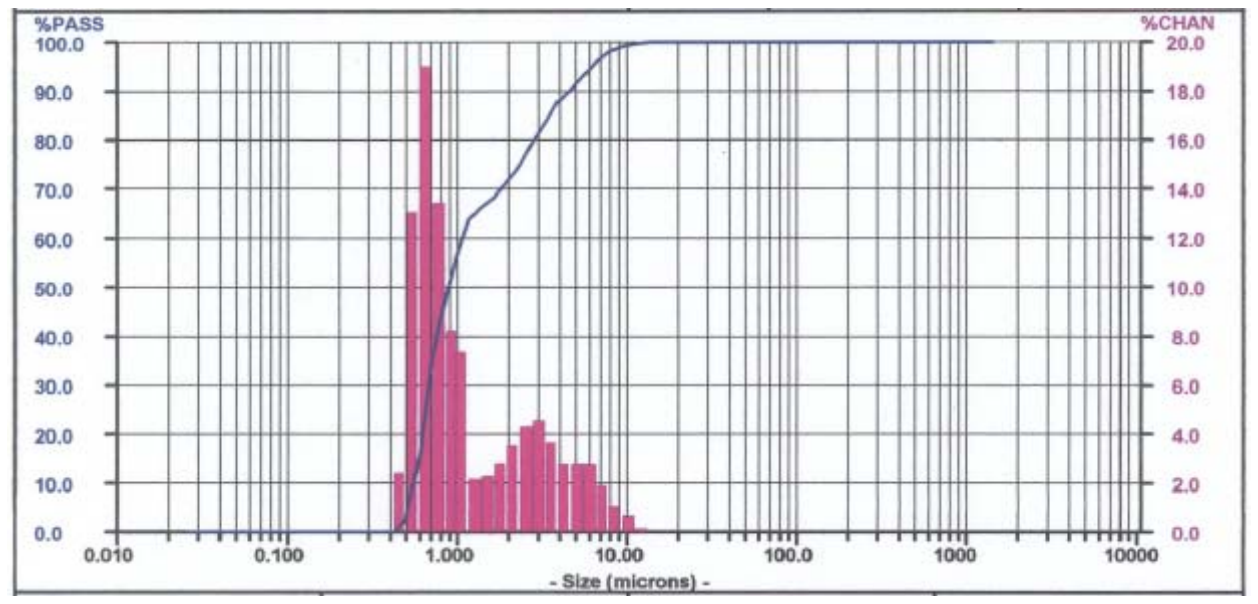

Figure 1-8. Particle Size Distribution for Batch 2 with AFA 
For Batch 3, without and with AFA, Figure 1-9 and Figure 1-10, respectively, the distributions of particles also show similar peaks as for Batch 2, occurring at 0.65 microns, 4 microns, and 50 microns. The 4 micron peak encompassed $58 \%$ of all the particles. Adding AFA also removed the large particles at around 50 microns. The lower concentration of small particles at 0.6 microns compared to Batch 2 would explain the much lower degree of foaming observed with Batch 3, although the two simulants were tested in different equipment.

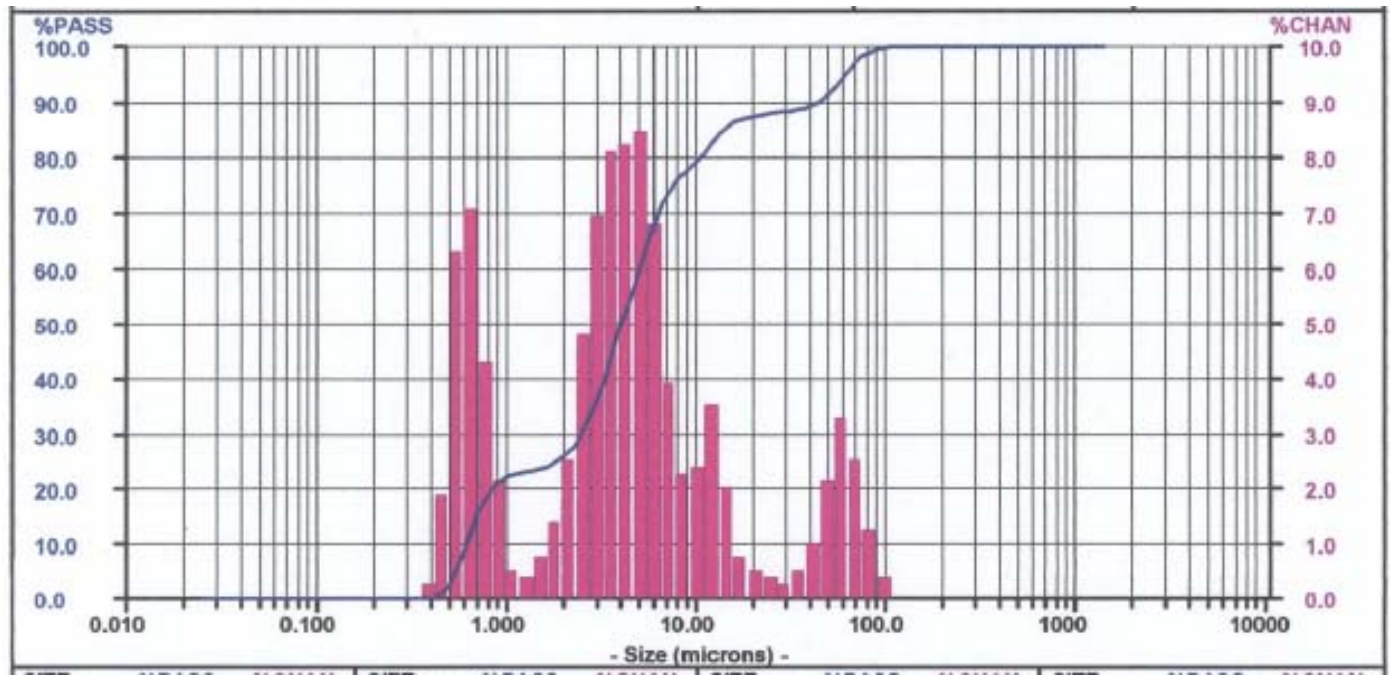

Figure 1-9. Particle Size Distribution for Batch 3 without AFA

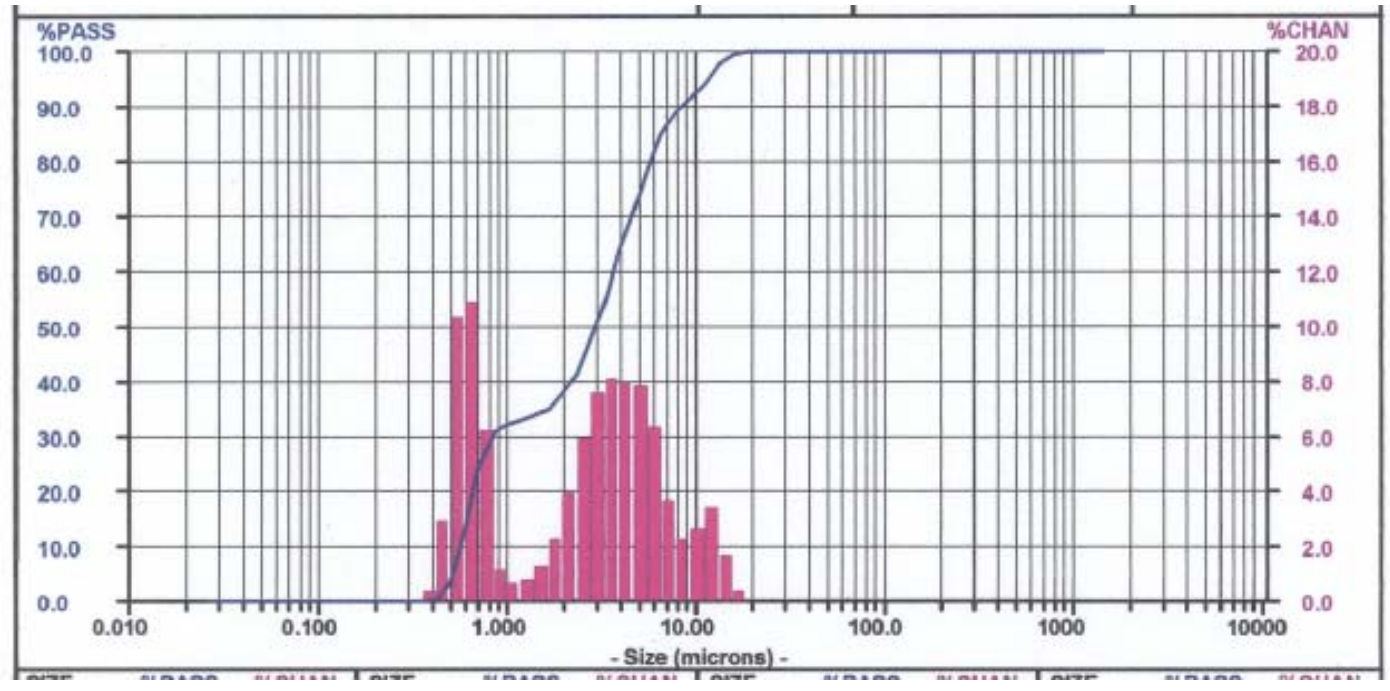

Figure 1-10. Particle Size Distribution for Batch 2 without AFA 
In Figure 1-1, Batch 3 yield stress is higher than Batch 2 for the same total wt $\%$ solids, which is the reverse of what is expected since Batch 2 had a larger concentration of the smaller 0.6 micron particles. However, it has been shown that it is not only particle size that determines yield stress directly but also the solids volume fraction. Shear strength increases with volume fraction.

\subsubsection{Confirmation of Batch 2 Simulant}

While Batch 2 obviously foams, it may still be a valid AZ-101 simulant to use to achieve the test objectives if its gas holdup characteristics with Q2-3183A were similar to the gas holdup in Phase I simulant with AFA, which did not exhibit any foaming. Figures 2.1 to 2.3 provide comparison of the gas holdup characteristics of these two simulants with Q2-3183A for three target rheologies. At $30 \mathrm{~Pa}$ (Figure 1-11), Batch 2 has only about a 10\% higher holdup than Phase I simulant. Apparently, the Q2-3183A antifoam successfully suppressed the surface foam and the bulk holdup was similar to that in Phase I. In the $13 \mathrm{~Pa}$ Batch 2 simulant with AFA test (Figure 1-12), the gas holdup was about 33\% higher than in Phase I. This may indicate that at low wt $\%$ total solids a higher AFA dose may be required for Batch 2. Figure 1-13 gives the holdup at $3 \mathrm{~Pa}$. There appeared to be a history effect, where the first two high air flows $(1 \mathrm{~mm} / \mathrm{s}$ and $0.45 \mathrm{~mm} / \mathrm{s}$ ) had low values and the $1 \mathrm{~mm} / \mathrm{s}$ point which was repeated twice gave a higher void value. A single available point from Phase I is shown for comparison, indicating close correspondence to the present data trend. In general, the gas holdup of Batch 2 simulant is similar to Phase I simulant (although at $13 \mathrm{~Pa}$, Batch 2 has a moderately higher holdup than Phase I. Therefore the use of Batch 2 was deemed acceptable to use by this program. 
WSRC-STI-2007-00537, REVISION 0

SRNL-RPP-2007-00023, REVISION 0

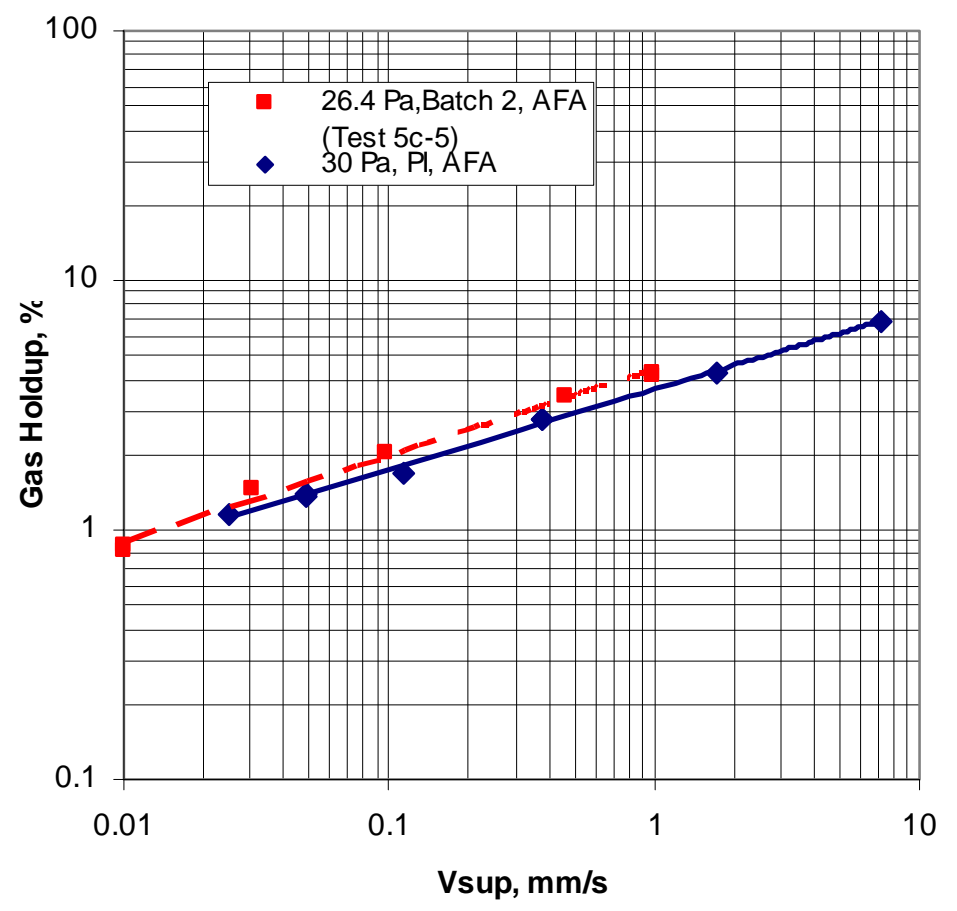

Figure 1-11. Comparison of Batch 2 and Phase I Simulants with AFA at $30 \mathrm{~Pa}$

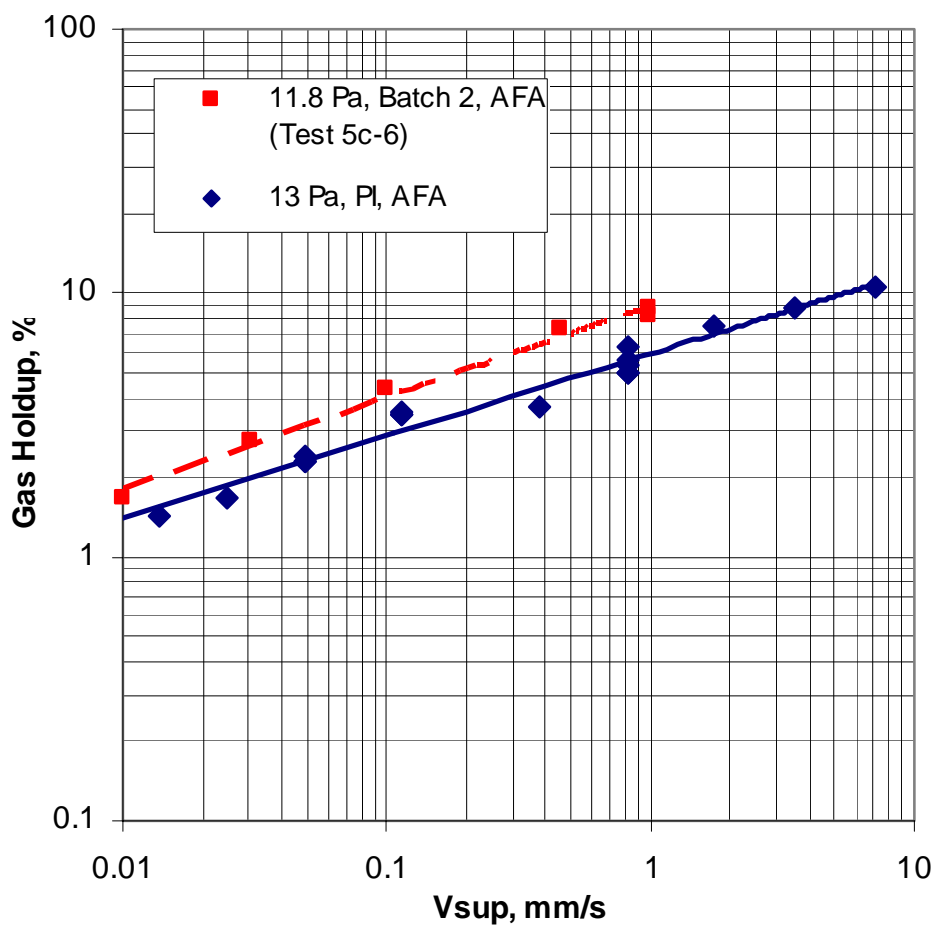

Figure 1-12. Comparison of Batch 2 and Phase I Simulants with AFA at $13 \mathrm{~Pa}$ 
WSRC-STI-2007-00537, REVISION 0

SRNL-RPP-2007-00023, REVISION 0

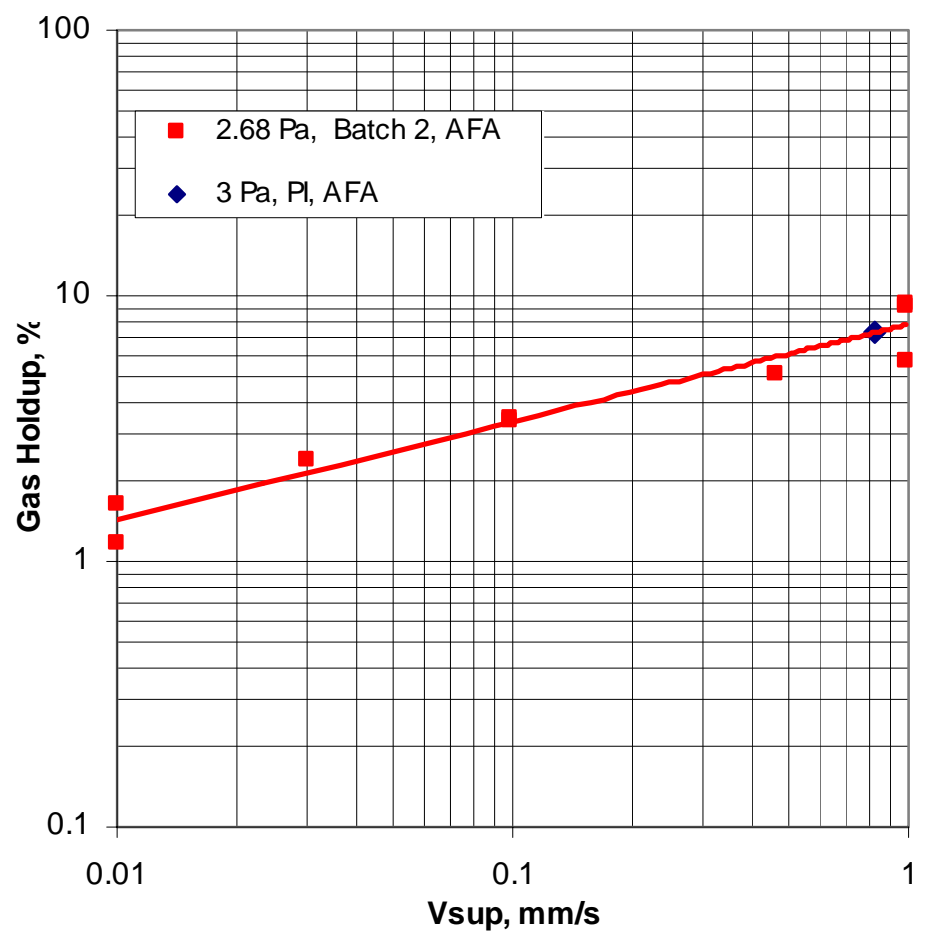

Figure 1-13. Comparison of Batch 2 and Phase I Simulants with AFA at 3 Pa

\subsection{DISCREPANCIES AND FOLLOW-ON TESTS}

No discrepancies were observed with the current tests.

Follow-on bench scale tests should be considered to determine during a post-DBE event:

- if increased AFA additions will be needed for caustic leaching at $100^{\circ} \mathrm{C}$ to suppress foaming, and,

- the degradation rate of AFA components and its impact on gas holdup/release. 
WSRC-STI-2007-00537, REVISION 0

SRNL-RPP-2007-00023, REVISION 0

This page intentionally left blank. 
WSRC-STI-2007-00537, REVISION 0

SRNL-RPP-2007-00023, REVISION 0

\subsection{CD-ROM ENCLOSURES}

CD-ROMs are enclosed which contain:

- data files from Bench scale and SRNL Mixing Test Stand tests listed in the Test Matrix in the Task Technical and QA Plan;

- data files from the Mass Transfer Test including DO sensor, pressure readings and calculated mass transfer coefficients;

- data files from laser measurements from the Mass Transfer Tests;

- photos of water sparging tests during the Mass Transfer Tests.

A DVD is also included that provides videos of mass transfer tests.

The CD-ROM should start automatically within 30 seconds when placed in your CD-ROM drive on an IBM compatible PC. If it does not, then do the following:

1. Double-left-click on MyComputer icon on your desktop

2. Right-click on your CD drive icon

3. Left-click on AutoPlay

The recommended minimum computer system is as follows:

- Pentium II running at $233 \mathrm{MHz}$

- 32 MB ram

- Windows 95 or later. 
WSRC-STI-2007-00537, REVISION 0

SRNL-RPP-2007-00023, REVISION 0

This page intentionally left blank. 


\subsection{ALTERNATE AFA TESTING}

\subsection{OVERVIEW}

\subsubsection{Background}

The WTP project utilizes hybrid PJM/sparger technology for solids mixing, solids suspension, fluid blending, and release of hydrogen gas. The antifoam agent DOW Corning Q2-3183A will be added to waste streams in the WTP to prevent foaming. It consists mostly of the polymers polydimethylsiloxane (PDMS) and polypropylene glycol (PPG). Both these primary compounds and some of the minor compounds (octylphenoxy polyethoxy ethanol and polyether polyol) making up this antifoam agent have organic constituents. PDMS is the silicone polymer $\left(\mathrm{CH}_{3}\right)_{3} \mathrm{SiO}\left[\mathrm{SiO}\left(\mathrm{CH}_{3}\right)_{2}\right]_{\mathrm{n}} \mathrm{Si}\left(\mathrm{CH}_{3}\right)_{3}$ and the hydrophobic part of the DOW Corning Q2-3183A Antifoam agent. PPG is the hydrocarbon polymer $\mathrm{C}_{3} \mathrm{H}_{8} \mathrm{O}_{2}$ and is more hydrophilic than the silicone oil.

Recently completed tests at SRNL [2] with the DOW Corning Q2-3183A in a 60 liter mixing stand $\left(1 / 9^{\text {th }}\right.$ scale $\left.^{2}\right)$ using a mechanical agitator indicate that additions of this AFA to waste simulant increase gas retention by as much as a factor of four in AZ-101 simulant. These results also show that gas retention in non-Newtonian simulants containing AFA

(i) increases with increasing superficial velocity ${ }^{3}$ (that is, increasing bubble generation rate) and

(ii) increases with decreasing shear strength. The gas retention factor relative to no AFA also increases with increasing superficial velocity and decreasing yield stress. Decreasing yield stress is associated with decreasing apparent viscosity, which directly increases bubble rise velocity due to decreased drag coefficient on the gas bubble and should thus decrease gas holdup. That the opposite effect is noted is explained as follows: Visual observations and data imply that one of the mechanisms by which AFA increases gas retention, other parameters such as viscosity being constant, is by reducing bubble size due to a decrease in surface tension, with a corresponding decrease in the bubble rise velocity. This and other factors, such as Marangoni effects, will be discussed in Sec. 3.4. When the shear stress of a slurry with AFA is reduced, the apparent viscosity is also reduced, which promotes the formation of small bubbles, and hence higher gas holdup.

Potential alternate strategies to remediate this include developing an alternative AFA, which reduces surface foaming to acceptable levels in WTP systems without increasing bulk gas retention.

\footnotetext{
2 The vessel dimensions are $1 / 9^{\text {th }}$ linear scale of the plant but no other geometrical similarities exist with the plant.

3. Superficial Velocity = Gas Generation Rate Per Unit Volume $\div$ Slurry Surface Area; the slurry surface area being the area of the slurry at the surface level of the vessel.
} 
These results raise two issues concerning WTP operations. First, the AFA may reduce the size of the sparger gas bubbles injected for the purpose of mixing, or cause them to partially break up into very small bubbles, potentially increasing the holdup of gas bubbles in transit through the slurry. The maximum gas holdup observed in the SRNL tests in simulants with AFA for small bubbles at the same superficial velocity as full-scale air sparging in the plant was $\sim 10 \mathrm{vol} \%$. Though actual gas holdup should be much lower (the entire sparge air flow is unlikely to break up into small bubbles), it would be prudent to determine the effect of AFA on prototypic sparging.

The second issue concerns flammable gas retention and release during the post-design basis event (DBE) period where PJMs and spargers operate intermittently from reduced availability of their air supply. Gas bubbles are essentially immobile when the mixing system is not operating in non-Newtonian materials so the rate of gas retention is equal to the generation rate. The presence of AFA in the system decreases bubble size which decrease bubble rise velocity and thus increases gas holdup. Thus post-DBE operation may require more frequent and longerduration periods of mixing with PJMs and spargers than originally assumed in WTP design calculations. Depending on how much the gas release rate is actually reduced in full-scale systems with AFA additions, the WTP important-to-safety (ITS) air supply may not be adequately sized for the baseline safety strategy. A potential alternate strategy to remediate this is to develop an alternative AFA which reduces surface foaming to acceptable levels in WTP systems without increasing bulk gas retention.

\subsubsection{Test Objectives}

This testing program specified by the Research \& Technology (R\&T) Department WTP will identify:

(i) effects that anti-foam agent additions to Hanford waste simulants have on waste properties associated with gas retention and release

(ii) components of anti-foam agents responsible for these effects

(iii) alternative AFA products and formulations that do not exhibit deleterious gas retention/release behavior when added to the AZ-101 simulant

Bench-scale laboratory experiments and small-scale tests will be used to develop anti-foam agent (AFA) formulations.

The program specified supports Test Specification 24590-WTP-TSP-RT-06-002, Rev. 0 [3] by determining the effect of AFA on gas retention in prototypic vessels with PJM-hybrid mixing systems, providing the technical bases for applying this information to predict plant performance, and resolving the issues presented above. 


\subsection{EXPERIMENTAL METHODS}

\subsubsection{Bench Scale Test Methods}

\section{Bench Scale Test Apparatus}

The test rig (Figure 3-1) consisted of a clear Plexiglas vessel, $178 \mathrm{~mm}$ in diameter and $610 \mathrm{~mm}$ high, filled up to the $419 \mathrm{~mm}$ level with waste simulant. The simulant was mixed with upper and lower radial turbines on a common shaft. The mechanical agitators were powered by a threequarter Hp motor with a variable speed drive. Air was injected through a $6.35 \mathrm{~mm}$ tube fitted with a $5 \mu \mathrm{m}$ fritted stainless steel cup at its end. The injected bubbles were directed at the tip of the lower agitator to break up the large gas bubbles into small bubbles that are similar in size to oxygen bubbles generated by hydrogen peroxide decomposition.

Three different flowmeters were used to measure air flow rates. Three laser level measuring devices were used to measure gas holdup, distributed over the top surface of the slurry. In testing the water-only systems, small Styrofoam floats were used to reflect the laser beams. The entire test vessel was supported on a scale to measure its weight as an aid in adjusting the slurry rheology. A photograph of the rig is shown in Figure 3-2.

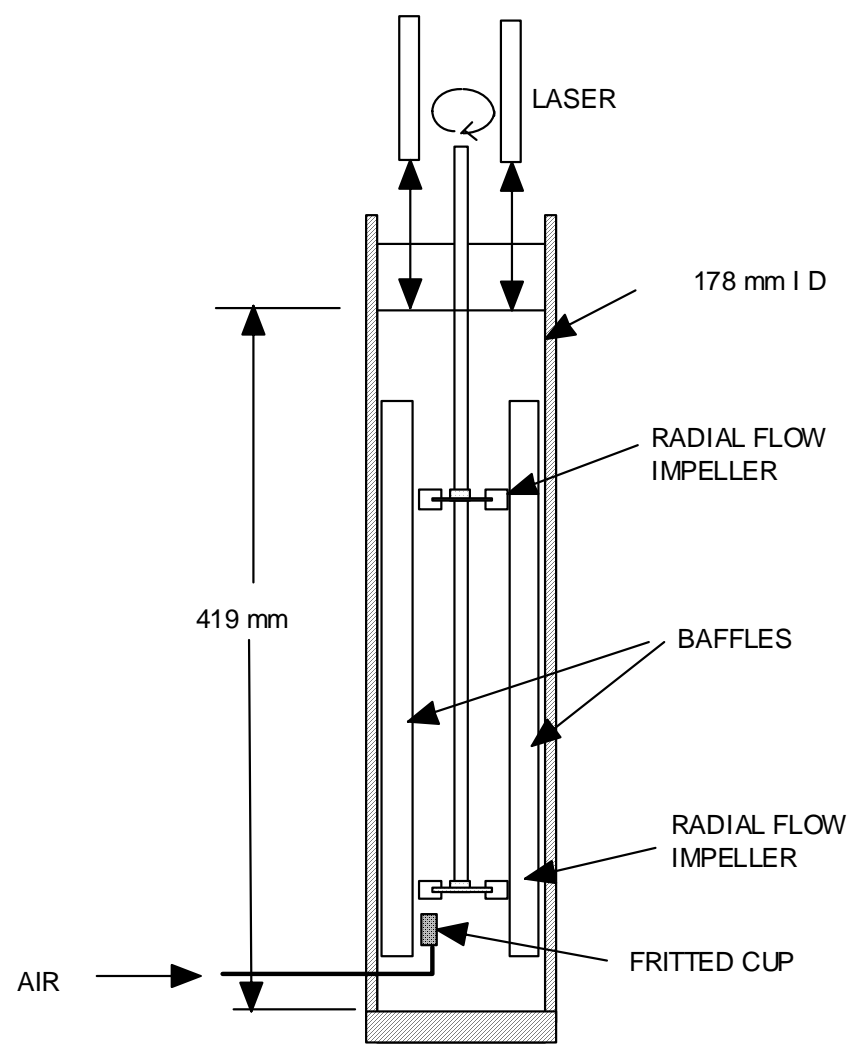

Figure 3-1. Schematic of Bench Scale Test Apparatus 


\section{Bench Scale Test Procedure}

The test method consisted of first achieving the required simulant yield stress by diluting the 40-60 Pa Optima Batch 2 according to the dilution curve in Sec. 1.6.1, mixing for 30 minutes, and taking rheology samples. Initial tank level heights with no mixing were taken with laser readings and measuring tape. The agitator was then turned on at the required minimum speed to turn over the simulant at the top surface. This was usually $900 \mathrm{rpm}$ for $3 \mathrm{~Pa}$ slurry, $1000 \mathrm{rpm}$ for $13 \mathrm{~Pa}$, and $1150 \mathrm{rpm}$ for $30 \mathrm{~Pa}$. Sparger air flow was then turned on at a specified rate to achieve the highest superficial velocity of $1 \mathrm{~mm} / \mathrm{s}$ for a minimum period of 5 minutes with the agitator and lasers on, and then the air flow was stopped for a minimum of 7 minutes for the gas bubbles to release and the slurry level to subside close to its original value.

These sparger on and off times were dictated by the fact that mixing with the two radial turbines raised the temperature of the $30 \mathrm{~Pa}$ slurry from room temperature of nominally $25^{\circ} \mathrm{C}$ to $50^{\circ} \mathrm{C}$ in 3 hours. Maximum temperatures attained in the water runs, $13 \mathrm{~Pa}$ and $3 \mathrm{~Pa}$ slurry testing were in the $30^{\circ}-40^{\circ} \mathrm{C}$ range. This was the maximum allowed in the test to acquire data for 5 flow settings and two repeat points. The temperature rise did not appear to affect the gas holdup since the repeat points at the end of the test run were duplicated.

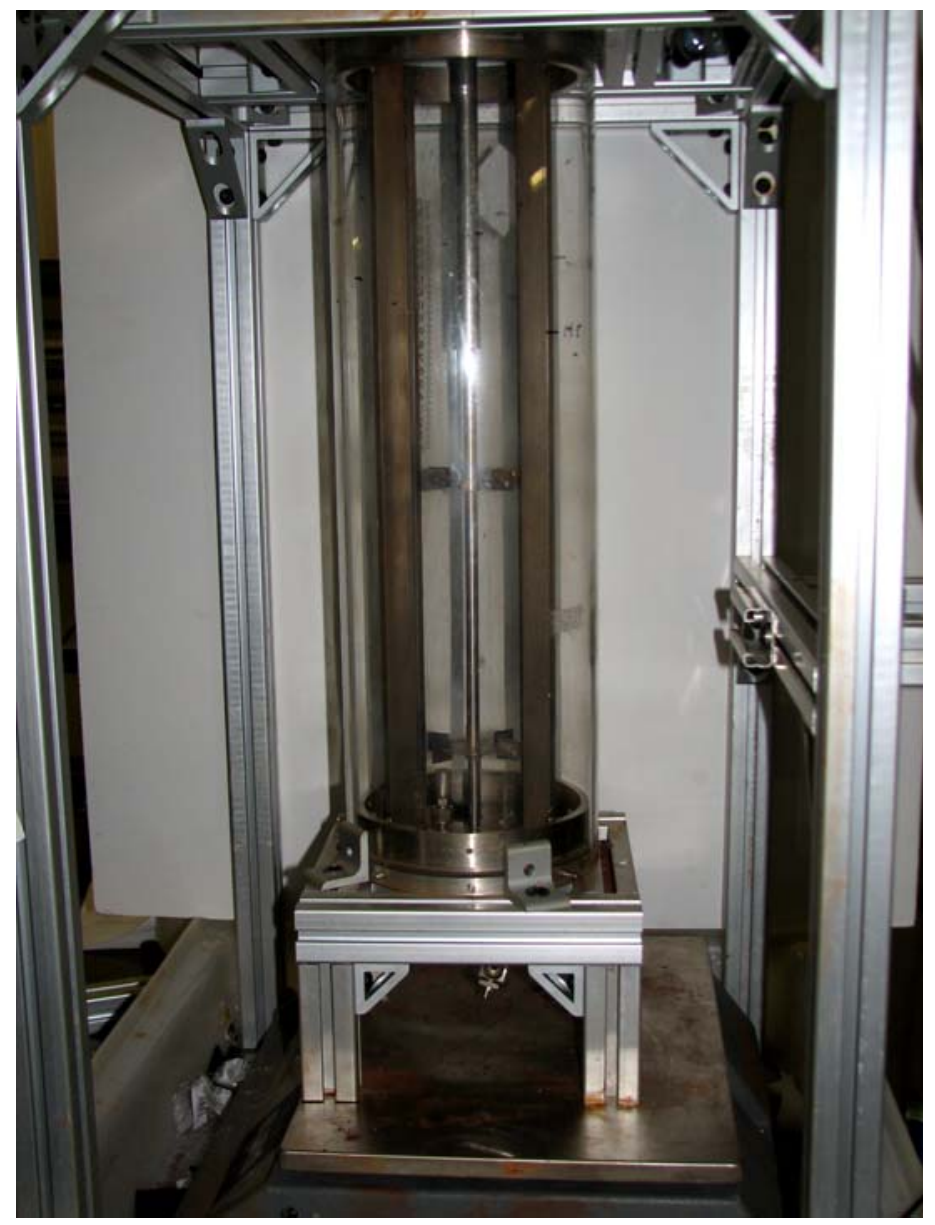

Figure 3-2. Photograph of Bench Scale Test Apparatus 
As previously noted, Batch 2 was strongly foaming. The addition of antifoam would initially suppress foaming and testing for bulk fluid gas holdup could be conducted. However, there were occasions when testing had to be suspended for the day and resumed the following day. In those occasions, the repeat data points would be higher than the previous day's results. This may be due to separation of the AFA components. In these cases, fresh maintenance doses of AFA were added.

\subsubsection{SRNL Mixing Test Stand Test Methods SRNL Mixing Test Stand $\left(1 / 9^{\text {th }}\right.$ scale $)$}

The SRNL Mixing Test Stand, which was also used in Phase I testing, consists of a vessel filled with 60 liters of simulant, a mechanical agitation system, an air sparging system for generating bubbles in the slurry, equipment for determining the height of the slurry in the vessel and several ancillary support systems. These components are shown in Figure 3-3 and described in the following sections.

The vessel has an ID of $438.15 \mathrm{~mm}$ with clear acrylic sides $(9.5 \mathrm{~mm}$ thick) and a stainless steel elliptical bottom (made from an 18-in. schedule 40 pipe cap). The height of the side wall was $978 \mathrm{~mm}$; the overall height was $1090 \mathrm{~mm}$. An integral plug valve at the center of the elliptical bottom provides a flush fit to the surface when sealed. Four equally spaced baffles were installed in the vessel. The baffle width is $38 \mathrm{~mm}$ (baffle width/tank diameter $\sim 1 / 12$ ) and the spacing from the wall is $2.5 \mathrm{~mm}$. The baffles extend from the interface of the cylindrical wall and elliptical bottom to a height of $560 \mathrm{~mm}$ above the interface. Two rings, one on the top and one on the bottom, provide support for the baffles. The baffles are rigidly attached to the tank via four equally spaced flat bars extending and bolted to the top of the tank. A photograph of the test facility is shown in Figure 3-4. 
WSRC-STI-2007-00537, REVISION 0

SRNL-RPP-2007-00023, REVISION 0

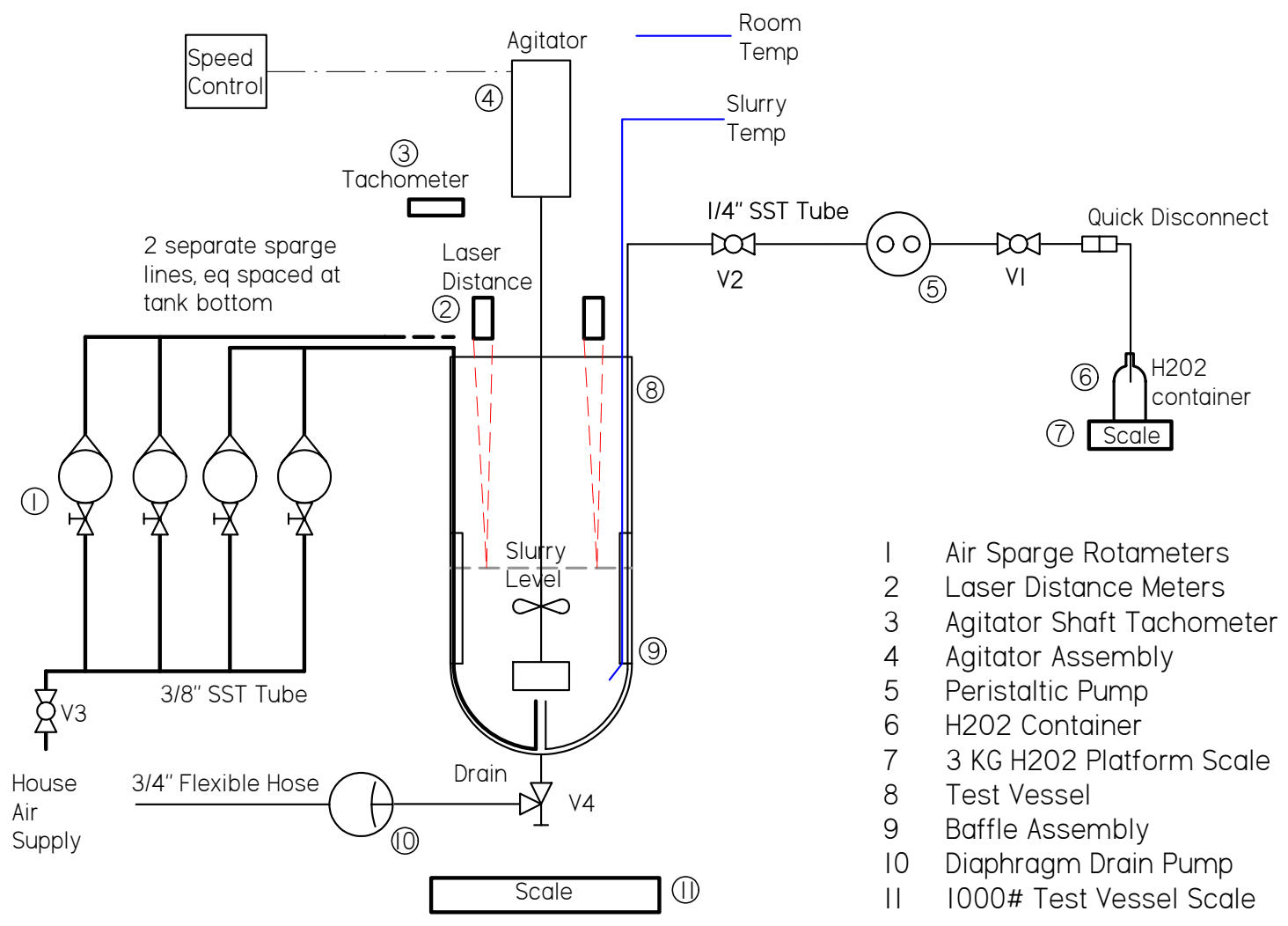

Figure 3-3. SRNL Mixing Test Stand Schematic 


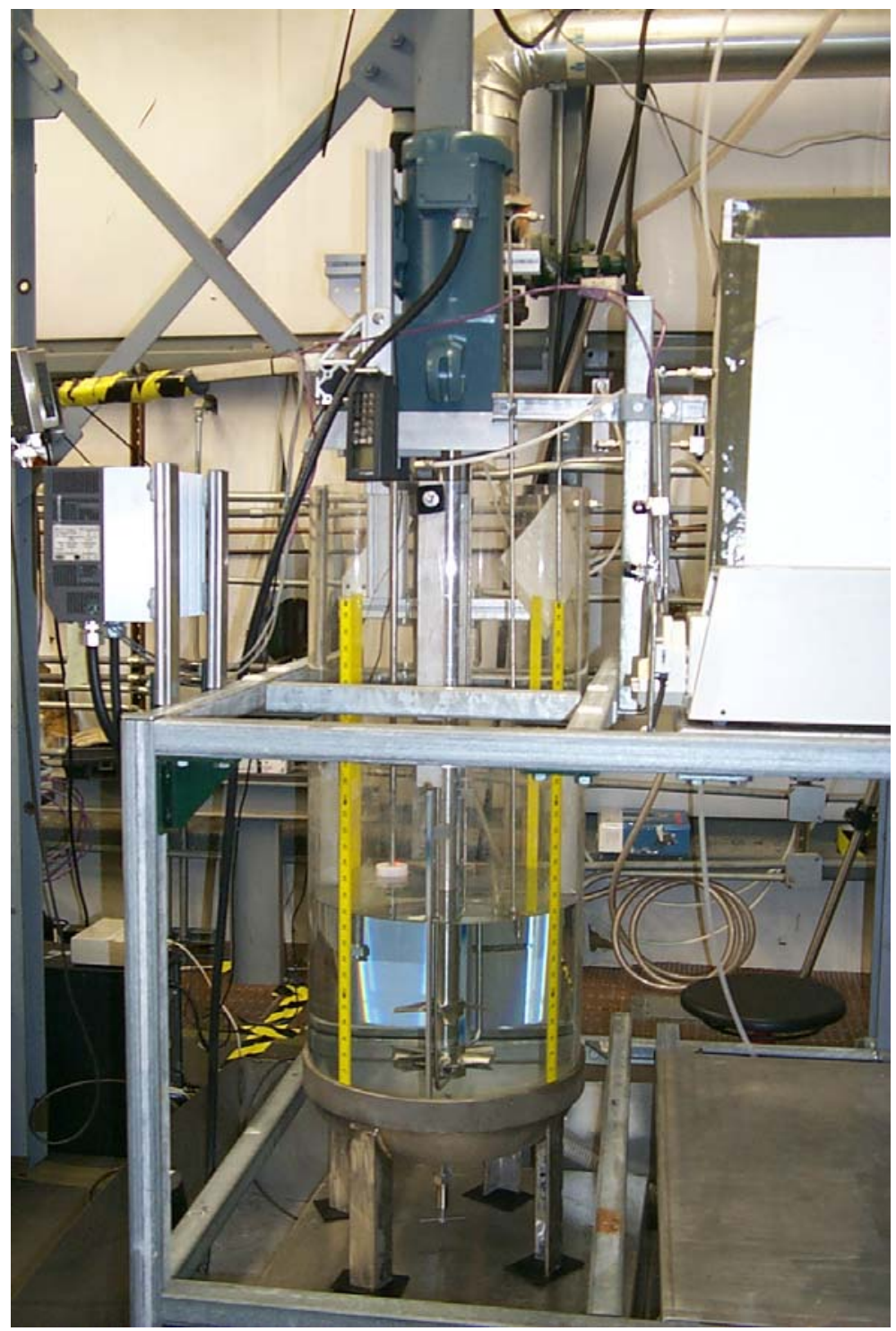

Figure 3-4. Photograph of the SRNL Mixing Test Stand

The agitation system is a top-entry, direct-drive, clamp-mounted mixer provided by Philadelphia Mixers Corp., see Figure 3-5. Power to the agitators is provided by a $3 / 4 \mathrm{hp}$ variable torque motor (model PD-34) connected to a Variable Frequency Drive (VFD), through a $1016 \mathrm{~mm}$ long $\mathrm{x}$ $31.8 \mathrm{~mm}$ diameter stainless steel shaft. The agitators consist of a $133 \mathrm{~mm}$ diameter axial mixing impeller (low shear hydrofoil model 3LS39) for the upper shaft, and a $133 \mathrm{~mm}$ radial flow mixing impeller (Smith Turbine model 6DS90) for the lower shaft. The lower impeller is positioned so that the lower edge is $\sim 127 \mathrm{~mm}$ above the tank bottom. The upper impeller is positioned $\sim 1$ impeller diameter above the lower impeller and directs flow upward to the liquid surface. The impeller system and baffles in the test vessel were selected to provide thorough mixing of a non-Newtonian fluid (yield stress $\sim 30$ pascal) at a tip speed of $\sim 1000 \mathrm{fps}$ ( 727 rpm). 


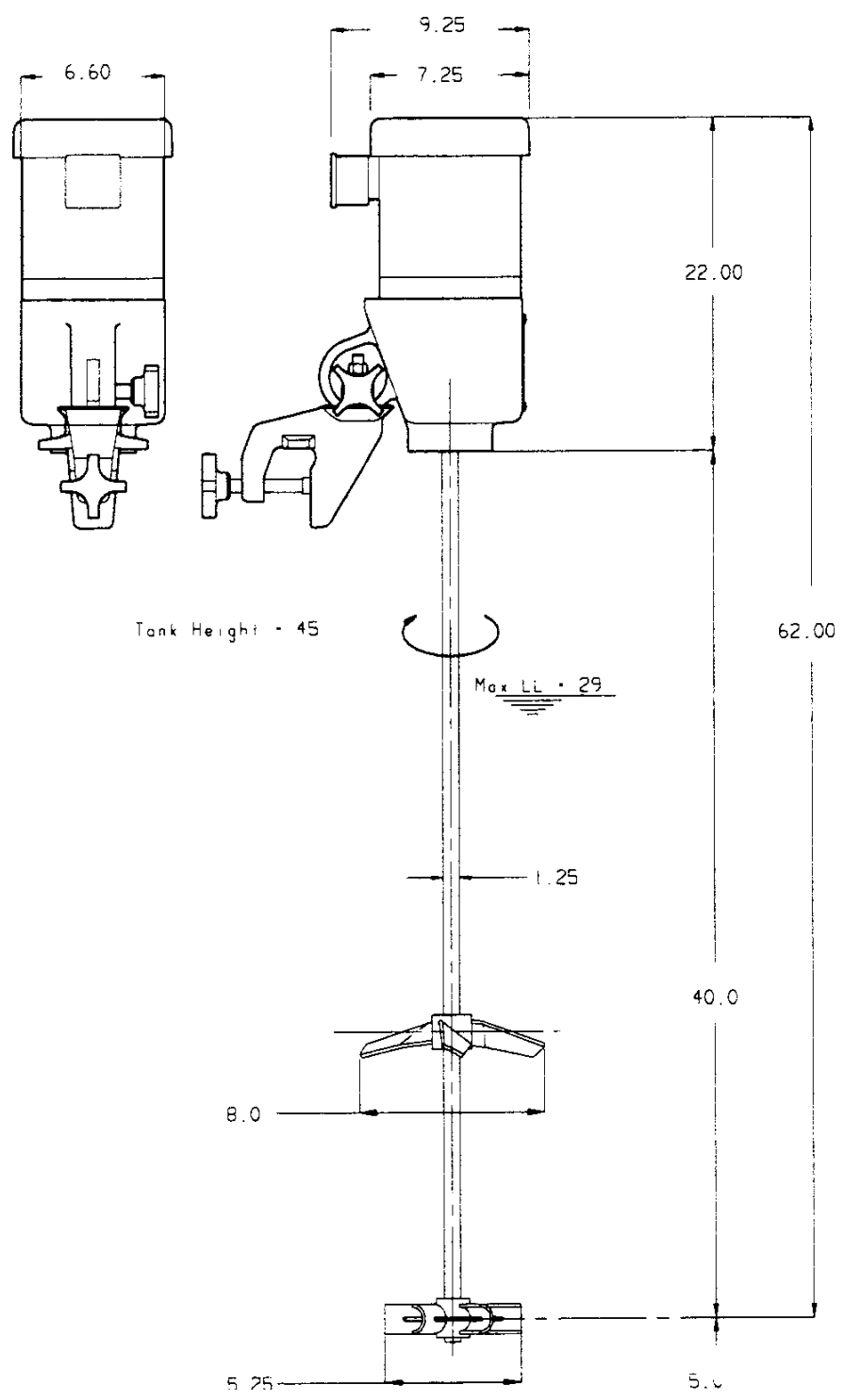

Figure 3-5. Mechanical Agitator System

\section{Air Sparging System}

Air sparging flow was controlled through the use of 3 sets of rotameters; one set for higher flows, one set for medium flows, and one set for lower flows. The low flow set consisted of two Brooks model 1355 series rotameters, using R-2-15-AAA tube and stainless steel floats, with a specified range of $0-140 \mathrm{ml}$.min. The medium flow set consisted of two Cole Parmer 65-mm series rotameters with a specified range of $2-522 \mathrm{ml} / \mathrm{min}$ of air. The high flow set consisted of two Fischer-Porter rotameters with a specified range of $2.5-21$ gpm of liquid (specific gravity $=$ 1 ), but when supplied by $16.6 \mathrm{psig}$ of air at $70^{\circ} \mathrm{F}$ the range was $0.25-2.1 \mathrm{scfm}$. An air regulator was used to provide 16.6 psig and the room air temperature was recorded to correct for temperatures other than $70^{\circ} \mathrm{F}$. 
The sparge outlet was placed under the lower impeller so that the large bubbles from the outlet would be broken up by the radial impeller to create smaller bubbles (including micro-bubbles) that were well dispersed throughout the vessel.

\section{Instrumentation}

The slurry level in the test vessel was monitored by two methods: by four, equally spaced tape measures attached to the outside of the acrylic wall, and by laser distance meters focused on the surface from above. The laser distance measuring devices were Disto 4 and 4 a manufactured by Leica Instruments. These were calibrated to an accuracy of $+/-1.5 \mathrm{~mm}$.

The height of the slurry in the test vessel was related to volume by a pre-test calibration of the vessel that repeatedly added a measured mass of water to various levels (as indicated by the tape measure). The volume of added water was calculated knowing its temperature (density). This elaborate method was required (as opposed to estimating the volume by using the basic dimensions of the vessel) since a relatively significant portion of the vessel interior was occupied by hardware.

\section{SRNL Mixing Test Stand Test Procedure}

A typical test would start by setting the static zero point for each laser with the agitator not running. Next the agitator was energized and after stabilization a dynamic zero point was recorded with no gas production. Setting the zero with the agitator running provided a more representative level rise due to gas production that takes into account the surface contour due to agitation. After the dynamic zero, a gas holdup and release test was started.

Gas holdup and release testing with air sparging involved a sequence of timed events. Typically, air sparging with agitation would last for ten minutes, followed by ten minutes of agitation for gas release. Then the air flow would be changed for the next data point and so on. A series of test points for a given set of simulant rheology and AFA dose would be obtained during a day's testing, as illustrated in Figure 3-6.

Data analysis of the experimental data involved taking time averages for short time intervals, e.g., 0.25 seconds, of the noisy signal (due to agitation of the top surface) from each laser instrument to plot an averaged time history of the level displacement from the zero position. Figure 3-5 shows a typical plot of the averaged history of four lasers. To determine the gas holdup for a given step air flow, the average level rise after the level had stabilized (during the later half of the step) for each laser was subtracted from the initial dynamic zero reading prior to addition of gas. The dynamic zero between data points (or baseline) was not used because the gas release from the previous data point may not have been completed due to the long exponential release time of small bubbles. The long gas release time does not affect the measured level rise or top of the step, as proved by repeated tests (during Phase I) at the same air flow which showed the same level rise. However, there were instances where a small degree of surface foaming was evident. In this case, the baseline similar to Figure 3-6 appeared to increase after each data point and the dynamic zero at the end of the test was higher than at the start. 
Further, the repeat data points at $1 \mathrm{~mm} / \mathrm{s}$ and $0.01 \mathrm{~mm} / \mathrm{s}$ did not repeat but were higher than the earlier points. This suggests that the lasers recorded the additional level rise due to foaming. The indicated level rise therefore was corrected by subtracting from it the average baseline before and after the data point rather than the initial dynamic zero. In this way the repeat points were nearly similar to each other. There is still a small unknown error due to foaming which is a small percent error at large superficial velocities and large holdups but quite noticeable for low superficial velocities and low holdups in the log-log plots of the holdup vs. superficial velocity.

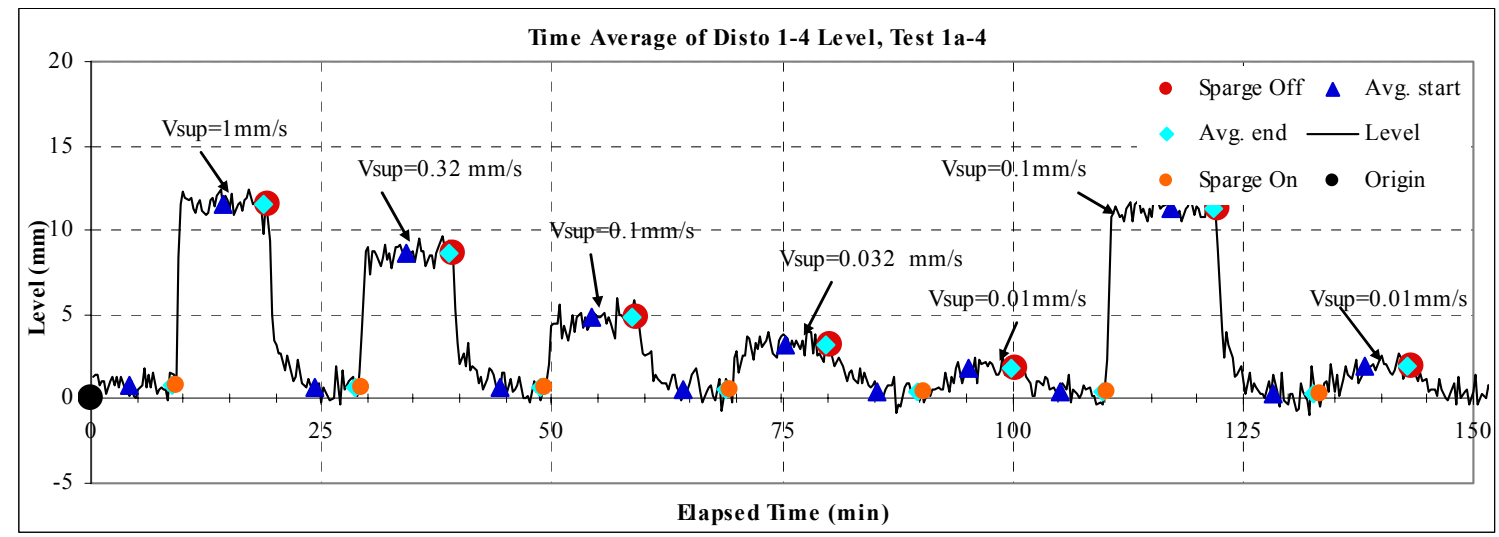

Figure 3-6. Typical Time History Plot of Laser Level Displacement Data with a Number of Air Sparge Flow Injection

\subsubsection{Alternate Antifoams}

Dow Corning Q2-3183A, was selected to control foaming in WTP waste slurries. Previous testing [2] demonstrated that it has an adverse effect in increasing bulk gas holdup, which thus increases radiolytically generated hydrogen inventory in WTP vessels. An objective of this test program is first to investigate what components in the Q2-3183A are directly responsible for increasing gas holdup; then, test other AFAs that do not include the deleterious components.

The base AFA, Q2-3183A, has the following components:

Q2-3183A

Polypropolyne glycol (PPG)

Polydimethyl siloxane (PDMS)

Treated silica

Polyether polyol

Octylphenoxy polyethoxy ethanol

Active ingredients
$40-70 \%$

$40-70 \%$

$3-7 \%$

$3-7 \%$

$3-7 \%$

$100 \%$ 
Several references in the literature indicate that the major components of Q2-3183A, PPG and PDMS, are both frothers and antifoams. PDMS is used as a frother in production of polyurethane foam [10] and PPG is used as a foamer for minerals separation [11]. These contrary properties are actually exhibited at different concentrations. Tan [11] demonstrated increasing foamability of PPG at low surfactant concentrations, which reaches a plateau and then decreases at high concentrations. One major physical effect of surfactants is to reduce surface tension, which favors small gas bubbles and increased holdup due to low rise velocity because small bubbles are less buoyant. This explains the increasing holdup at low surfactant concentrations. At high concentrations, the surfactant reaches its solubility limit and phase separation occurs, forming liquid globules. These puncture the gas/liquid interface and permit the surfactant to spread throughout the gas/liquid interface. This promotes bubble-bubble coalescence by draining the thin liquid film between bubbles, forming larger bubbles, higher rise velocity because larger bubbles are more buoyant and lower holdup.

The objectives of the Alternate AFA task was to determine the relative effects of components of Q2-3183A, evaluate alternate AFAs in a bench scale test apparatus to come up with a selected alternate AFA, and then to confirm the viability of the selected AFA in a larger scale 60 liter test apparatus. The two major components, PPG and PDMS, were tested separately in water and AZ101 simulant to determine which has the greater effect on gas holdup. These tests were performed in a 4 liter bench scale apparatus. Alternate AFAs were also tested in AZ-101 simulant in the bench scale apparatus and the larger 60 liter volume $\left(1 / 9^{\text {th }}\right.$ scale $)$ mixing vessel.

The following alternate AFAs were tested: Dow Corning 1520-US and Dow Corning AF-7500. The compositions are as follows:

\begin{tabular}{|c|c|}
\hline \multicolumn{2}{|l|}{ 1520-US } \\
\hline$\overline{\text { Water }}$ & $>60 \%$ \\
\hline PDMS & $15-40 \%$ \\
\hline Methylated silica & $1-5 \%$ \\
\hline $\begin{array}{l}\text { Polyethelene glycol sorbitan } \\
\text { Tristearate }\end{array}$ & $1-5 \%$ \\
\hline Methyl cellulose & $1-5 \%$ \\
\hline Active ingredients & $20 \%$ \\
\hline \multicolumn{2}{|l|}{ AF-7500 } \\
\hline$\overline{\text { Water }}$ & $0-60 \%$ \\
\hline PDMS & $30-60 \%$ \\
\hline Reaction product of dimethyl & $10-30 \%$ \\
\hline \multicolumn{2}{|l|}{ Siloxane, methyl hydrogen } \\
\hline \multicolumn{2}{|l|}{ Siloxane } \\
\hline Polyethelene glycol stearate ether & $7-13 \%$ \\
\hline Other siloxane & $3-7 \%$ \\
\hline Active ingredients & $20 \%(\mathrm{di}$ \\
\hline
\end{tabular}

These AFAs were selected on the basis that they did not include PPG, shown for example by A. Morao [12] to increase gas holdup. 
WSRC-STI-2007-00537, REVISION 0

SRNL-RPP-2007-00023, REVISION 0

\subsubsection{Test Matrix}

Table 3-1 and Table 3-2 provide the test conditions for Alternate AFA testing in the bench scale and SRNL Mixing Test Stand (1/9 ${ }^{\text {th }}$ scale).

Table 3-1. Test Conditions for Bench Scale Alternate AFA Testing

\begin{tabular}{|c|c|c|c|c|c|}
\hline Test No. & Simulant & AFA & Test Model & Rheology & $\begin{array}{l}\text { Air } \\
\text { Superficial } \\
\text { Vel. } \mathbf{m m} / \mathbf{s}\end{array}$ \\
\hline $5 a-1$ & \multirow[b]{3}{*}{ Water } & No & \multirow[b]{3}{*}{ Bench Scale } & NA & \multirow{3}{*}{$\begin{array}{l}0.01,0.031, \\
0.1,0.31,1.0\end{array}$} \\
\hline $5 a-2$ & & PDMS & & NA & \\
\hline $5 a-3$ & & PPG & & NA & \\
\hline $5 a-4$ & \multirow{2}{*}{$\begin{array}{l}\text { AZ-101 Ppt, No } \\
\text { Noble metals }\end{array}$} & No & \multirow[b]{5}{*}{ Bench Scale } & $30 \mathrm{~Pa}$ & \multirow{2}{*}{$\begin{array}{l}0.01,0.031, \\
0.1,0.31,1.0\end{array}$} \\
\hline $5 a-5$ & & No & & $13 \mathrm{~Pa}$ & \\
\hline $5 a-7$ & \multirow{3}{*}{$\begin{array}{l}\text { AZ-101 Ppt, No } \\
\text { Noble metals }\end{array}$} & PDMS & & $30 \mathrm{~Pa}$ & \multirow{3}{*}{$\begin{array}{l}0.01,0.031, \\
0.1,0.31,1.0\end{array}$} \\
\hline $5 a-8$ & & PDMS & & $13 \mathrm{~Pa}$ & \\
\hline $5 a-9$ & & PDMS & & $3 \mathrm{~Pa}$ & \\
\hline $5 a-10$ & \multirow{3}{*}{$\begin{array}{l}\text { AZ-101 Ppt, No } \\
\text { Noble metals }\end{array}$} & PPG & \multirow[b]{3}{*}{ Bench Scale } & $30 \mathrm{~Pa}$ & \multirow{3}{*}{$\begin{array}{l}0.01,0.031, \\
0.1,0.31,1.0\end{array}$} \\
\hline $5 a-11$ & & PPG & & $13 \mathrm{~Pa}$ & \\
\hline $5 a-12$ & & PPG & & $3 \mathrm{~Pa}$ & \\
\hline $5 b-1$ & \multirow{3}{*}{$\begin{array}{l}\text { AZ-101 Ppt, No } \\
\text { Noble metals }\end{array}$} & Alt. AFA 1 & \multirow[b]{3}{*}{ Bench Scale } & $30 \mathrm{~Pa}$ & \multirow{3}{*}{$\begin{array}{l}0.01,0.031, \\
0.1,0.31,1.0\end{array}$} \\
\hline $5 b-2$ & & Alt. AFA 1 & & $13 \mathrm{~Pa}$ & \\
\hline $5 b-3$ & & Alt. AFA 1 & & $3 \mathrm{~Pa}$ & \\
\hline $5 b-4$ & \multirow{3}{*}{$\begin{array}{l}\text { AZ-101 Ppt, No } \\
\text { Noble metals }\end{array}$} & Alt. AFA 2 & \multirow[b]{3}{*}{ Bench Scale } & $30 \mathrm{~Pa}$ & \multirow{3}{*}{$\begin{array}{l}0.01,0.031 \\
0.1,0.31,1.0\end{array}$} \\
\hline $5 b-5$ & & Alt. AFA 2 & & $13 \mathrm{~Pa}$ & \\
\hline $5 b-6$ & & Alt. AFA 2 & & $3 \mathrm{~Pa}$ & \\
\hline $5 b-7$ & $\begin{array}{l}\text { AZ-101 Ppt, No } \\
\text { Noble metals }\end{array}$ & PNL AFA & Bench Scale & $30 \mathrm{~Pa}$ & $\begin{array}{l}0.01,0.031, \\
0.1,0.31,1.0\end{array}$ \\
\hline
\end{tabular}

Table 3-2. Test Conditions for SRNL Mixing Test Stand Alternate AFA Testing

\begin{tabular}{|c|c|c|c|c|c|}
\hline Test No. & Simulant & AFA & Test Model & Rheology & $\begin{array}{l}\text { Air } \\
\text { Superficial } \\
\text { Vel. } \mathbf{m m} / \mathbf{s}\end{array}$ \\
\hline $5 c-1$ & \multirow{3}{*}{$\begin{array}{l}\text { New AZ-101 } \\
\text { Confirmatory test }\end{array}$} & No & \multirow{6}{*}{$\begin{array}{l}\text { 1/9th scale, } \\
\text { mech. agit. }\end{array}$} & $30 \mathrm{~Pa}$ & \multirow{3}{*}{$\begin{array}{l}0.01,0.031, \\
0.1,0.31,1.0\end{array}$} \\
\hline $5 c-2$ & & No & & $13 \mathrm{~Pa}$ & \\
\hline $5 c-3$ & & No & & $3 \mathrm{~Pa}$ DI w & \\
\hline $5 c-5$ & \multirow{3}{*}{$\begin{array}{l}\text { New AZ-101 } \\
\text { Confirmatory test }\end{array}$} & Q2-3183A & & $30 \mathrm{~Pa}$ & \multirow{3}{*}{$\begin{array}{l}0.01,0.031, \\
0.1,0.31,1.0\end{array}$} \\
\hline $5 c-6$ & & Q2-3183A & & $13 \mathrm{~Pa}$ & \\
\hline $5 c-7$ & & Q2-3183A & & $3 \mathrm{~Pa}$ DI w & \\
\hline $5 c-12$ & \multirow{3}{*}{$\begin{array}{l}\text { New AZ-101 } \\
\text { Confirmatory test }\end{array}$} & Alt. AFA & \multirow{3}{*}{$\begin{array}{l}1 / 9 \text { th scale, } \\
\text { mech. agit. }\end{array}$} & $30 \mathrm{~Pa}$ & \multirow{3}{*}{$\begin{array}{l}0.01,0.031 \\
0.1,0.31,1.0\end{array}$} \\
\hline $5 c-13$ & & Alt. AFA & & $13 \mathrm{~Pa}$ & \\
\hline $5 c-14$ & & Alt. AFA & & $3 \mathrm{~Pa}$ DI w & \\
\hline
\end{tabular}




\subsection{TEST RESULTS}

\subsubsection{Surface Tension Measurements}

The presumed reason for the increased gas holdup in AZ-101 simulant by addition Q2-3183A is the fact that it is a surfactant. The effect is to reduce surface tension and thus produce small bubbles, which leads to increased gas holdup. In order to confirm this premise, several tests were done. PNNL measured surface tension of water with varying concentrations of Q2-3183A, as well as in AZ-101 simulant, and in AZ-101 simulant supernatant, as shown in Figure 3-7. The supernate was obtained by centrifuging AZ-101 simulant to separate solids from the supernatant. Figure 3-7 shows that addition of Q2-3183A in water reduces surface tension rapidly by $40 \%$ at an AFA concentration of less than $10 \mathrm{mg} / \mathrm{l}$. The surface tension then gradually decreases to around $32 \mathrm{mg} / 1$ as the Q2-3183A concentrations increase to around $400 \mathrm{mg} / \mathrm{l}$. SRNL also measured the surface tension of AZ-101 simulant supernatant at 3 concentrations, confirming this trend, with the data points: $72 \mathrm{mN} / \mathrm{m}$ at $0 \mathrm{mg} / 1,38 \mathrm{mN} / \mathrm{m}$ at $900 \mathrm{mg} / 1$, and $30 \mathrm{mg} / \mathrm{l}$ at $2100 \mathrm{mg} / \mathrm{l}$.

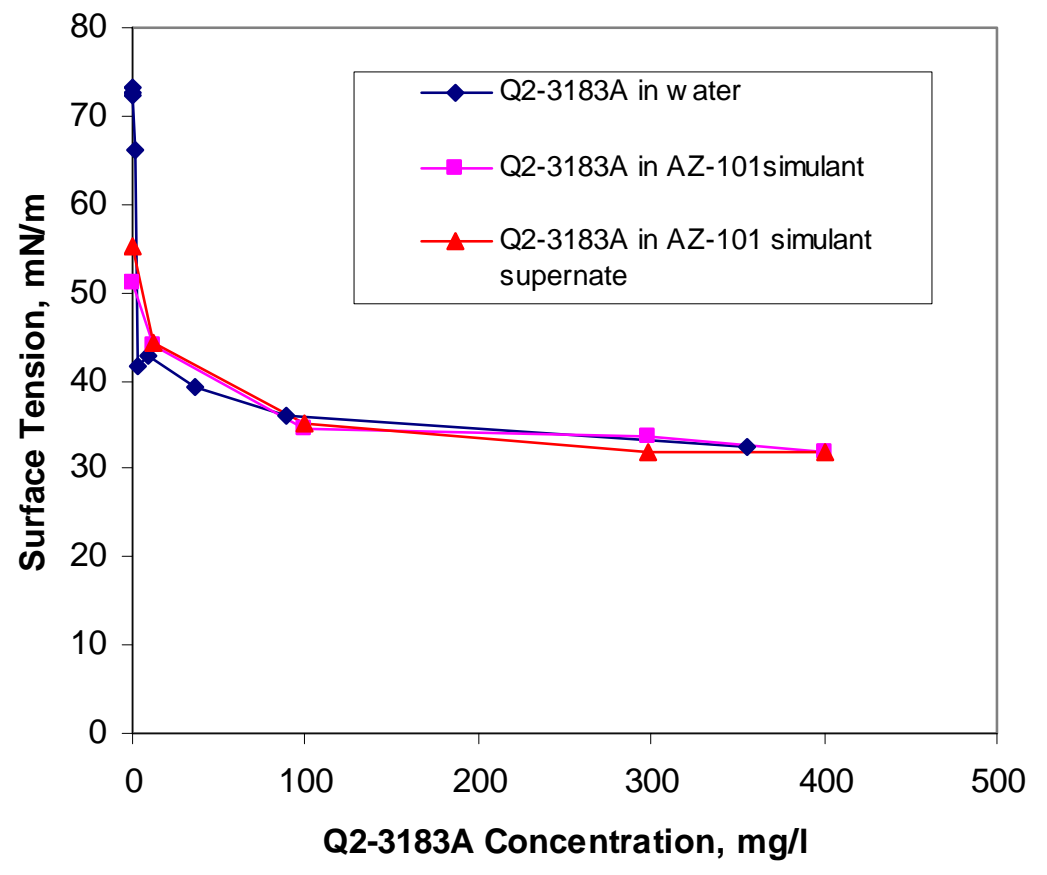

Figure 3-7. Surface Tension Reduction by Addition of Q2-3183A in Water, AZ-101 Simulant, and AZ-101 Simulant Supernate 


\subsubsection{Test Results}

\subsubsection{Component Testing}

\section{Water Testing}

The results of gas holdup testing the components of Q2-3183A, PPG and PDMS, in water are shown in Figure 3-8. The doses of $145 \mathrm{mg} / \mathrm{l}$ and $245 \mathrm{mg} / \mathrm{l}$ correspond to $40 \%$ and $70 \%$ concentration, respectively, of the normal range of PPG and PDMS in Q2-3183A. The data shows that PDMS has no effect at high gas superficial velocities, $0.1 \mathrm{~mm} / \mathrm{s}$ and higher, but increases the gas holdup at lower superficial velocities, relative to the water only case. PPG however has a significant effect, increasing the holdup by $20 \%$ at high superficial velocity of $1 \mathrm{~mm} / \mathrm{s}$ to as much as a factor of 16 at $0.01 \mathrm{~mm} / \mathrm{s}$. No effect of the concentrations used was observed. These results would seem to suggest that PPG is the component that is primarily responsible for increasing gas holdup in these fluids.

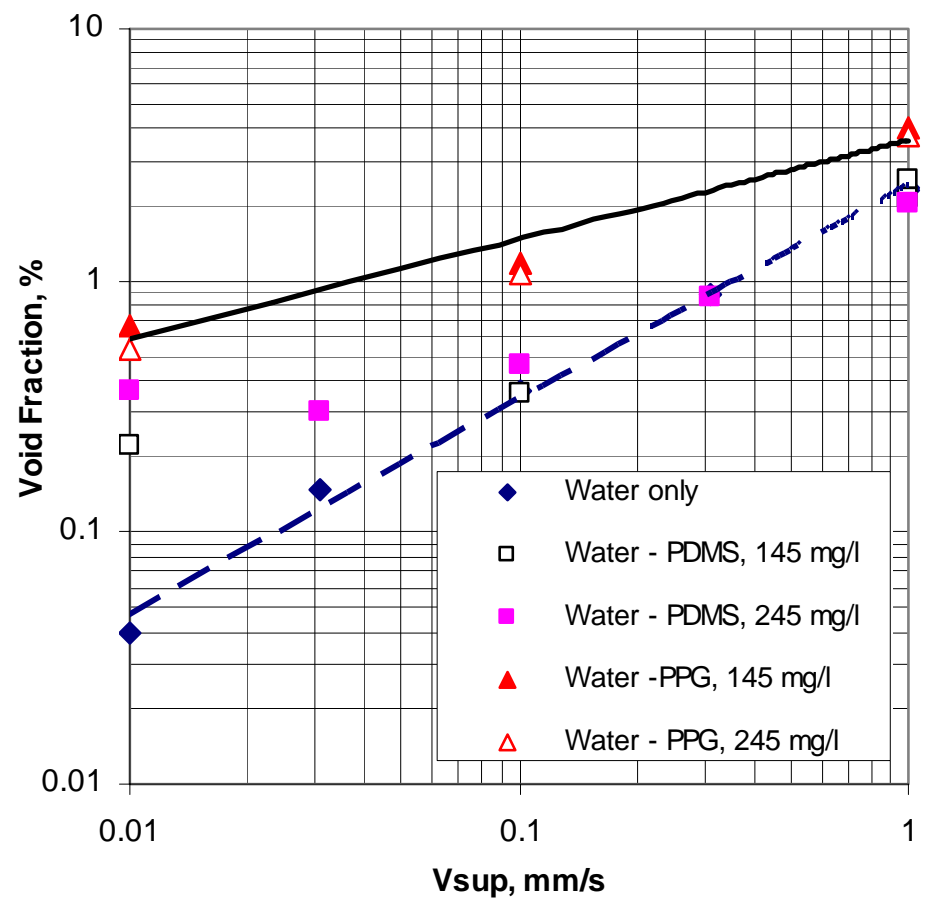

Figure 3-8. Gas Holdup in Water with and without PDMS or PPG

\section{AZ-101 Testing}

Testing in $30 \mathrm{~Pa}$ AZ-101 simulant (Figure 3-9) shows that adding PDMS in the same concentration range of 140-240 mg/l as found in Q2-3183A, gives a slightly lower gas holdup than Q2-3183A. The results at $13 \mathrm{~Pa}$, where the PDMS concentration was maintained at $240 \mathrm{mg} / \mathrm{l}$, are shown in Figure 3-10. A significant drop in gas holdup is shown, where the decrease in gas holdup was as much as a factor of three at the low superficial velocity of $0.01 \mathrm{~mm} / \mathrm{s}$ and becomes similar to Q2-3183A at the highest superficial velocity. 


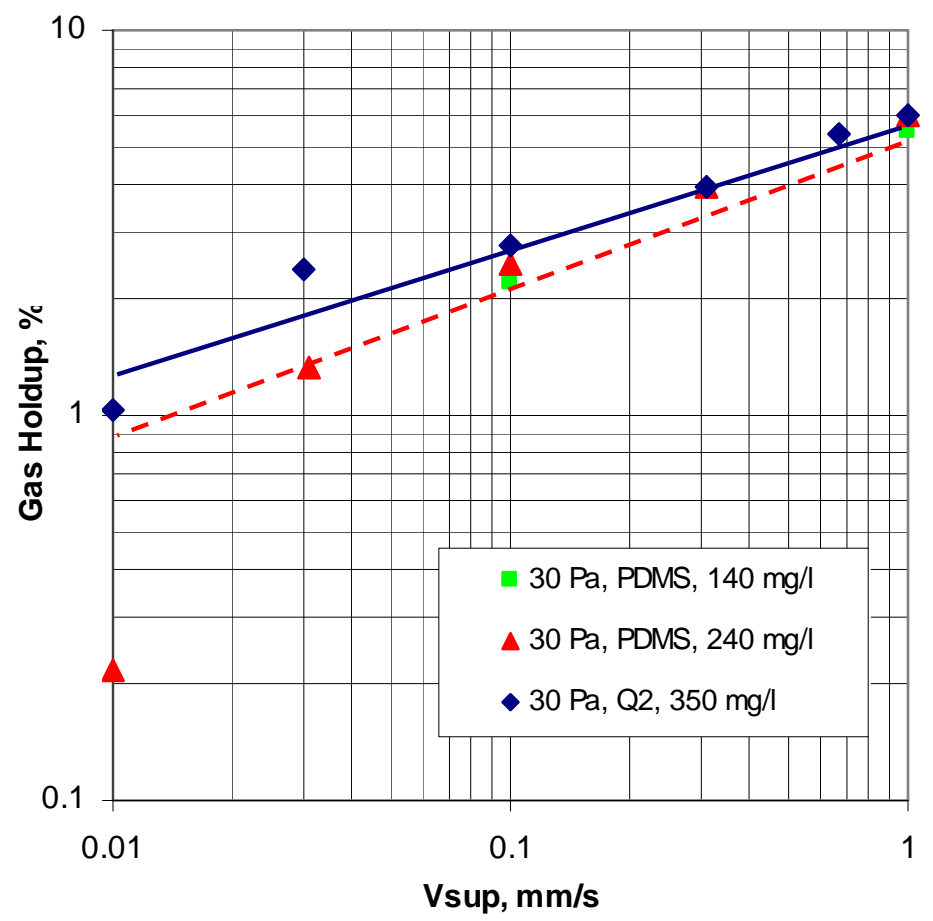

Figure 3-9. Gas Holdup in AZ-101 Simulant with PDMS at 30 Pa

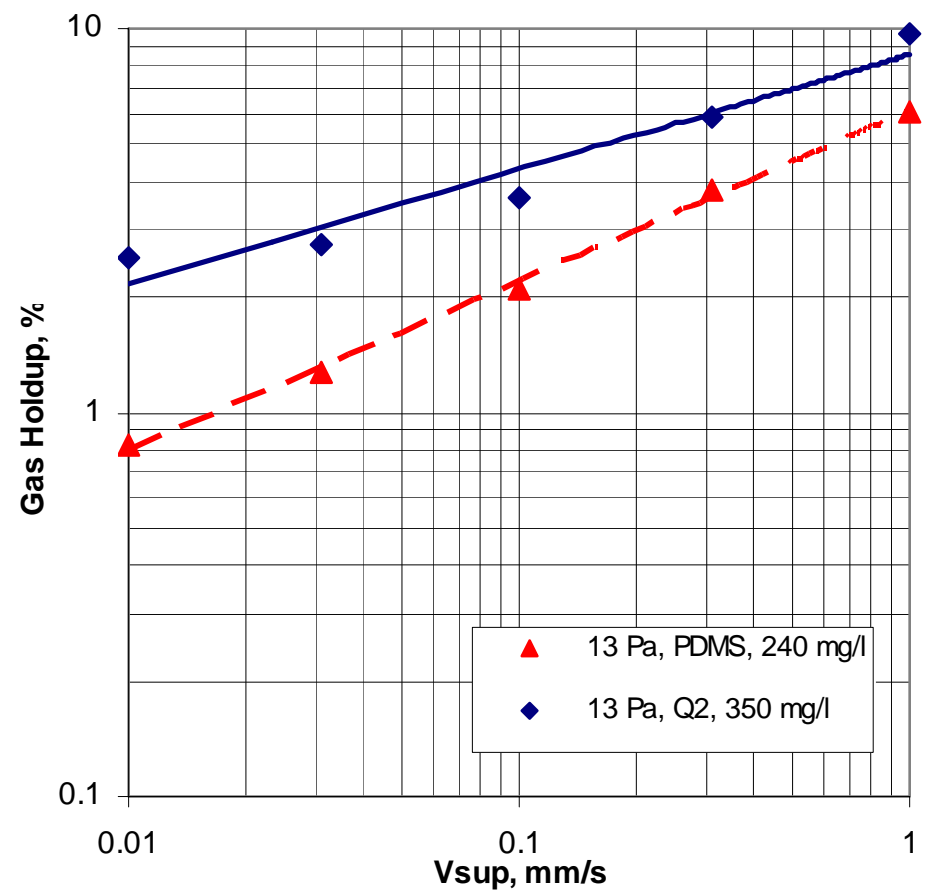

Figure 3-10. Gas Holdup in AZ-101 Simulant with PDMS at 13 Pa 
Figure 3-11 shows the results for the $3 \mathrm{~Pa}$ simulant. Maintaining the PDMS concentration at $240 \mathrm{mg} / \mathrm{l}$, as left from the previous $13 \mathrm{~Pa}$ run but adding PDMS to the dilution water, reduced the holdup relative to a $3 \mathrm{~Pa}$ run with Q2-3183A at the lower air flows. The PDMS concentration was then more than doubled to $490 \mathrm{mg} / \mathrm{l}$. This greatly reduced the holdup by a factor of 1.5 at high flow $(1 \mathrm{~mm} / \mathrm{s})$ and 3.4 at low flow $(0.01 \mathrm{~mm} / \mathrm{s})$.

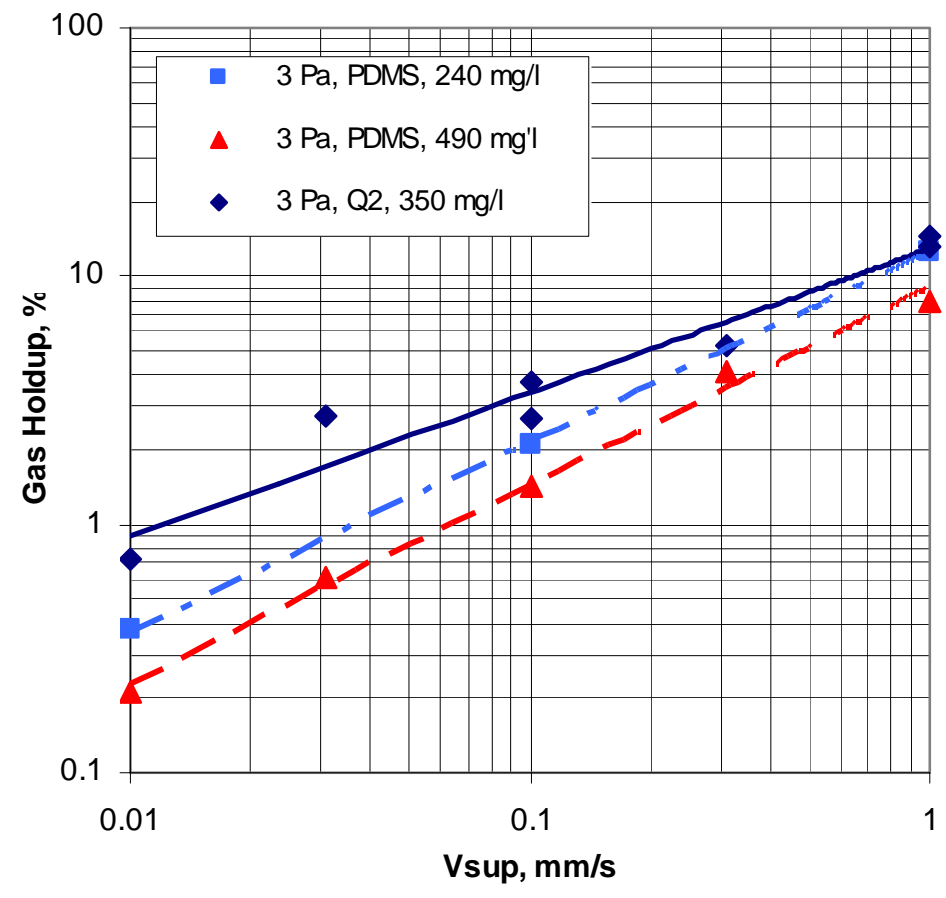

Figure 3-11. Gas Holdup in AZ-101 Simulant with PDMS at 3 Pa

Test results for PPG are shown in Figure 3-12 - Figure 3-14. In Figure 3-12 at $30 \mathrm{~Pa}$, the initial addition of $70 \mathrm{mg} / \mathrm{l}$ of PPG gives a gas holdup similar to $350 \mathrm{mg} / \mathrm{l}$ of Q2-3183A and an increase to $145 \mathrm{mg} / \mathrm{l}$ reduced the gas holdup. This follows the trend where the gas holdup is high at low AFA concentrations, as the surfactant rapidly reduces the surface tension, but decreases with increasing AFA concentration due to the AFA reaching saturation and PPG assumes antifoam properties. As the AFA concentration is increased further to $245 \mathrm{mg} / \mathrm{l}$, a plateau is reached. The equivalent concentration of PPG in Q2-3183A is $145 \mathrm{mg} / \mathrm{l}-245 \mathrm{mg} / \mathrm{l}$.

At $13 \mathrm{~Pa}$ (Figure 3-13), the PPG concentration was maintained at $245 \mathrm{mg} / \mathrm{l}$. The gas holdup was similar to that of Q2-3183A at high superficial velocities but was lower at low velocities. For the $3 \mathrm{~Pa}$ run (Figure 3-14), using the same PPG concentration of $245 \mathrm{mg} / 1$ reduced the gas holdup relative to $\mathrm{Q} 2-3183 \mathrm{~A}$ by a factor of two. 
WSRC-STI-2007-00537, REVISION 0

SRNL-RPP-2007-00023, REVISION 0

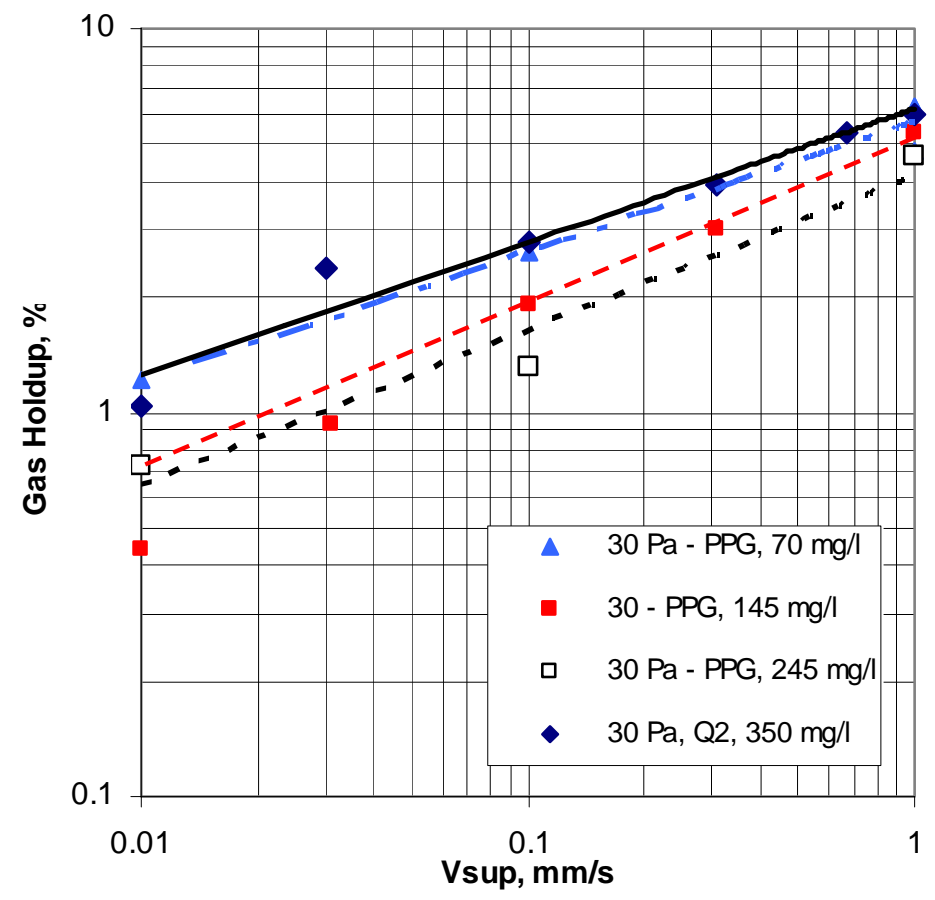

Figure 3-12. Gas Holdup in AZ-101 Simulant with PPG at 30 Pa

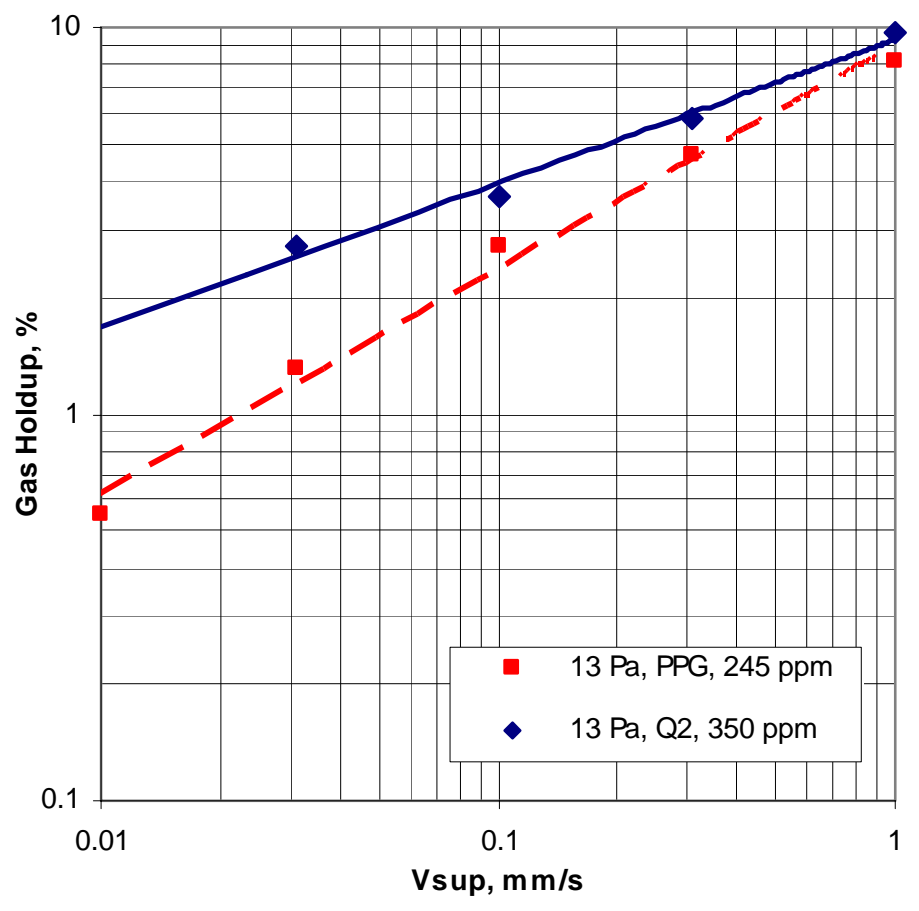

Figure 3-13. Gas Holdup in AZ-101 Simulant with PPG at 13 Pa 


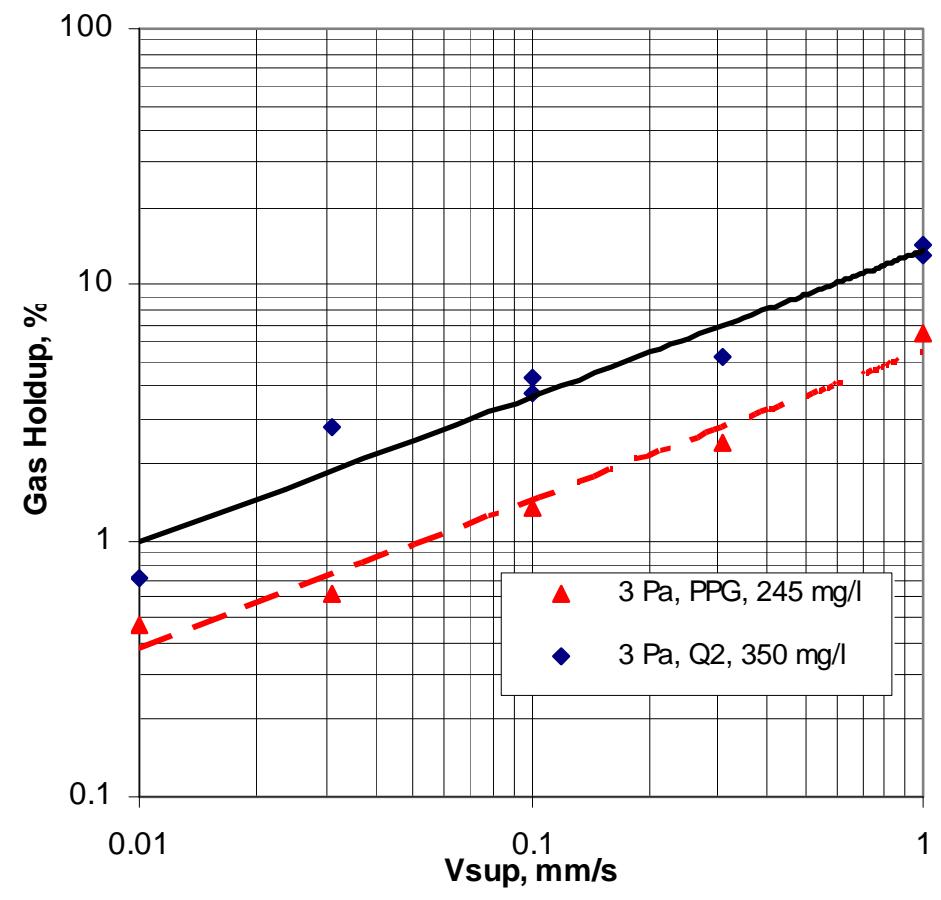

Figure 3-14. Holdup in AZ-101 Simulant with PPG at 3 Pa

\subsubsection{Alternate AFA Testing in Bench Scale Apparatus}

Because there were no established concentrations of the alternative AFAs to control foaming in the WTP waste tanks, testing of the candidate alternative AFAs started at low concentrations progressing to higher concentrations for each simulant rheology. As suggested by the literature, the gas holdup initially increases with concentration, reaches a plateau, and then decreases with further increases in concentration. In order to have a good basis for comparing alternative AFAs with Q2-3183A, our procedure was to determine the minimum AFA concentration where a constant gas holdup is reached, whether it was going up or going down with concentration. However, due to the limited amount of AZ-101 simulant available, the same simulant was used for testing at the three yield stresses. This meant that the AFA concentrations for each of the tests at different rheology could not all start at low concentrations, but in fact increased continuously as the same simulant was diluted to lower yield stresses.

Figure 3-15 illustrates the variation in the gas holdup at one superficial velocity setting of $1 \mathrm{~mm} / \mathrm{s}$, as the cumulative concentration of 1520-US was increased and as the rheology was changed from $30 \mathrm{~Pa}$, then to $13 \mathrm{~Pa}$, and finally to $3 \mathrm{~Pa}$. Each run indicated in the legend is a series of data points taken during the same day. Each day's run are connected to succeeding runs with a dotted line. A complicating factor in interpreting the data is the tendency of the gas holdup to increase after a layover or at the start of a new run. 
A dramatic example is the increase in holdup from $7.7 \%$ to $16 \%$ when the test was repeated at a concentration of $874 \mathrm{mg} / \mathrm{l}$. This may be due to separation of the AFA mixture over $24 \mathrm{hrs}$, which had been observed in previous testing of 1520-US for the Hanford Evaporator so that a maintenance dose of $10 \%$ every $24 \mathrm{hrs}$ was recommended. Disregarding the spikes, there appears to be a general trend where the holdup starts high at low AFA concentration and decreases to an equilibrium value at high AFA concentration. This is reached at $750 \mathrm{mg} / \mathrm{l}$ at $30 \mathrm{~Pa}, 1250 \mathrm{mg} / \mathrm{lat}$ $13 \mathrm{~Pa}$, and $2214 \mathrm{mg} / \mathrm{l}$ at $3 \mathrm{~Pa}$.

The behavior of the gas holdup for AF-7500 is shown in Figure 3-16. In this case, the holdup increases and levels off with concentration, in the concentration range, $180-540 \mathrm{mg} / \mathrm{l}$ range for $30 \mathrm{~Pa}$ simulant. For $13 \mathrm{~Pa}$, the trend is decreasing in the range $540-720 \mathrm{mg} / 1$, while for $3 \mathrm{~Pa}$, it is increasing slowly or have reached a plateau at $2124 \mathrm{mg} / \mathrm{l}$.

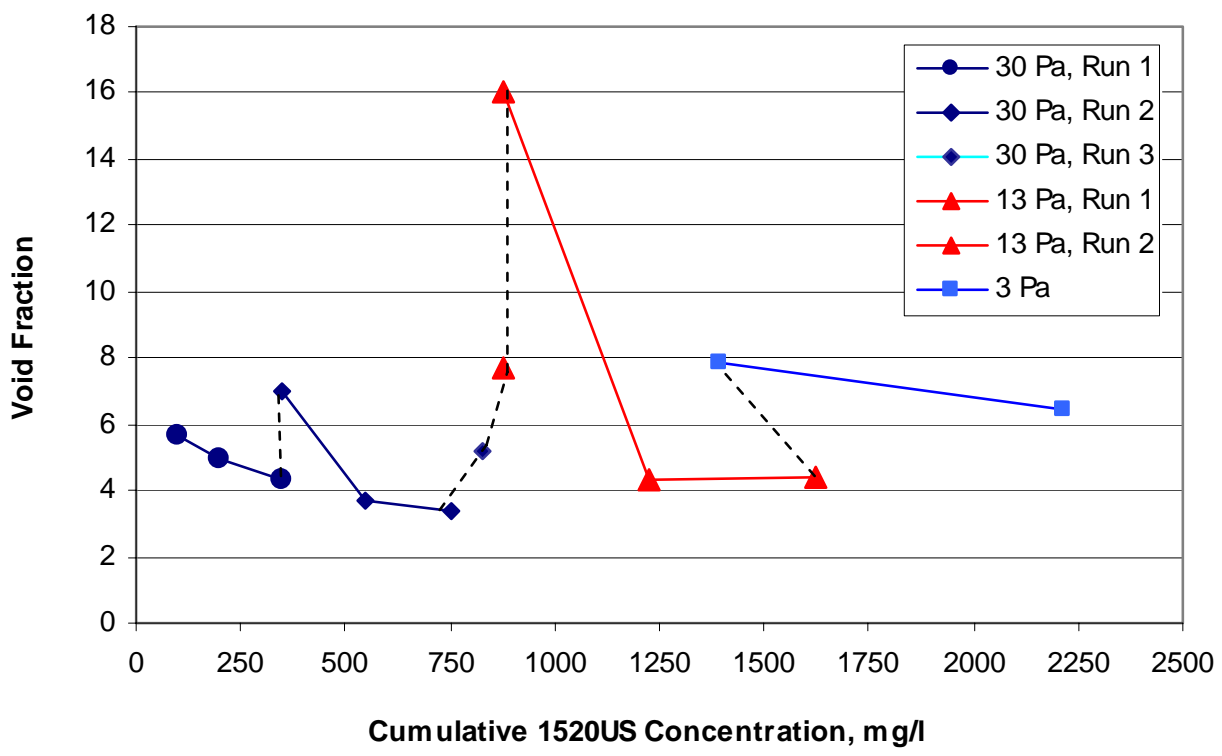

Figure 3-15. Gas Holdup History at $1 \mathrm{~mm} / \mathrm{s}$ Superficial Velocity During Incremental Addition of 1520-US Antifoam to 30, 13, and 3 Pa AZ-101 Simulants 
WSRC-STI-2007-00537, REVISION 0

SRNL-RPP-2007-00023, REVISION 0

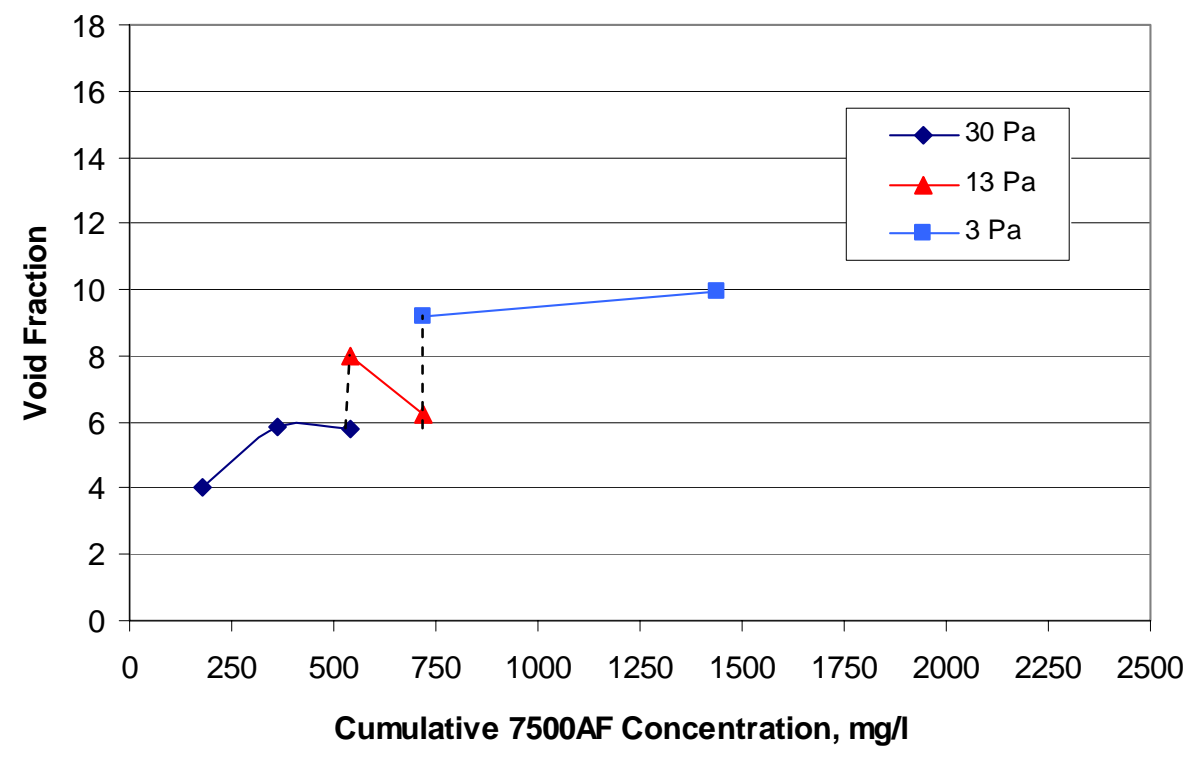

Figure 3-16. Gas Holdup History at $1 \mathrm{~mm} / \mathrm{s}$ Superficial Velocity during Incremental Addition of AF-7500 Antifoam to 30, 13, and 3 Pa AZ-101 Simulant

Plots of the gas holdup at various gas superficial velocities for Q2-3183A, 1520-US and AF-7500 are given in Figure 3-17 to Figure 3-19 at three nominal yield stresses: 30, 13 and $3 \mathrm{~Pa}$.

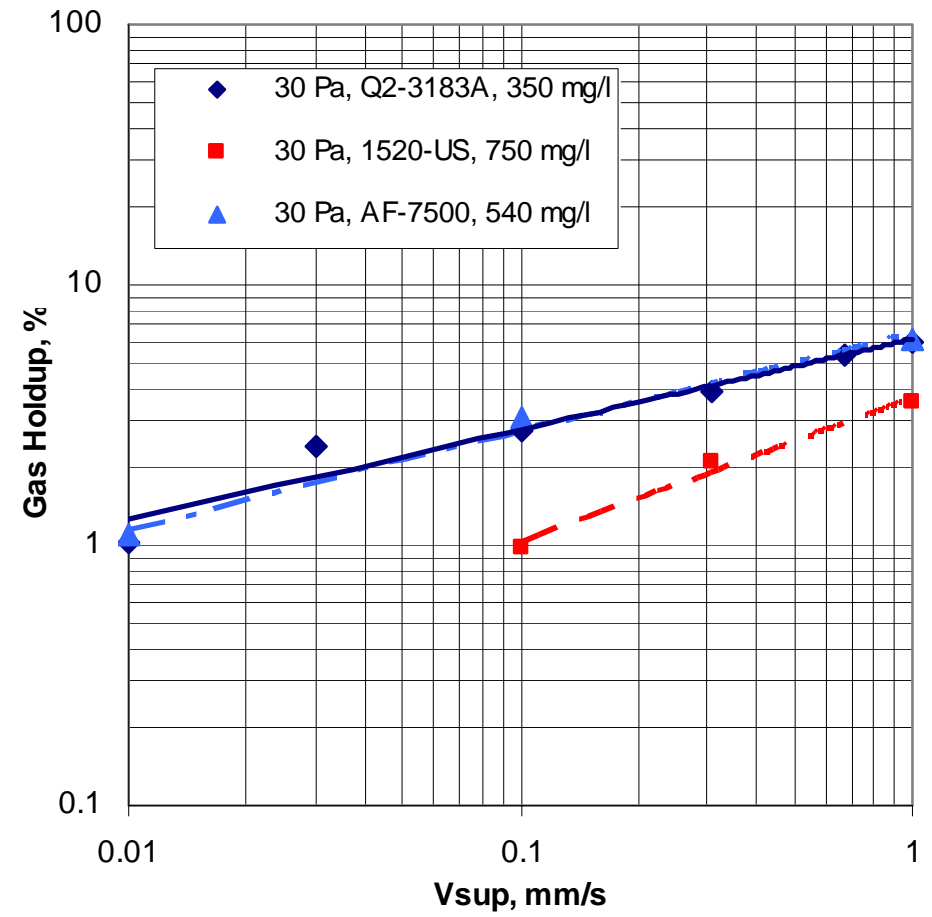

Figure 3-17. Gas Holdup in AZ-101 Simulant with 1520-US and AF-7500 at $30 \mathrm{~Pa}$ 
WSRC-STI-2007-00537, REVISION 0

SRNL-RPP-2007-00023, REVISION 0

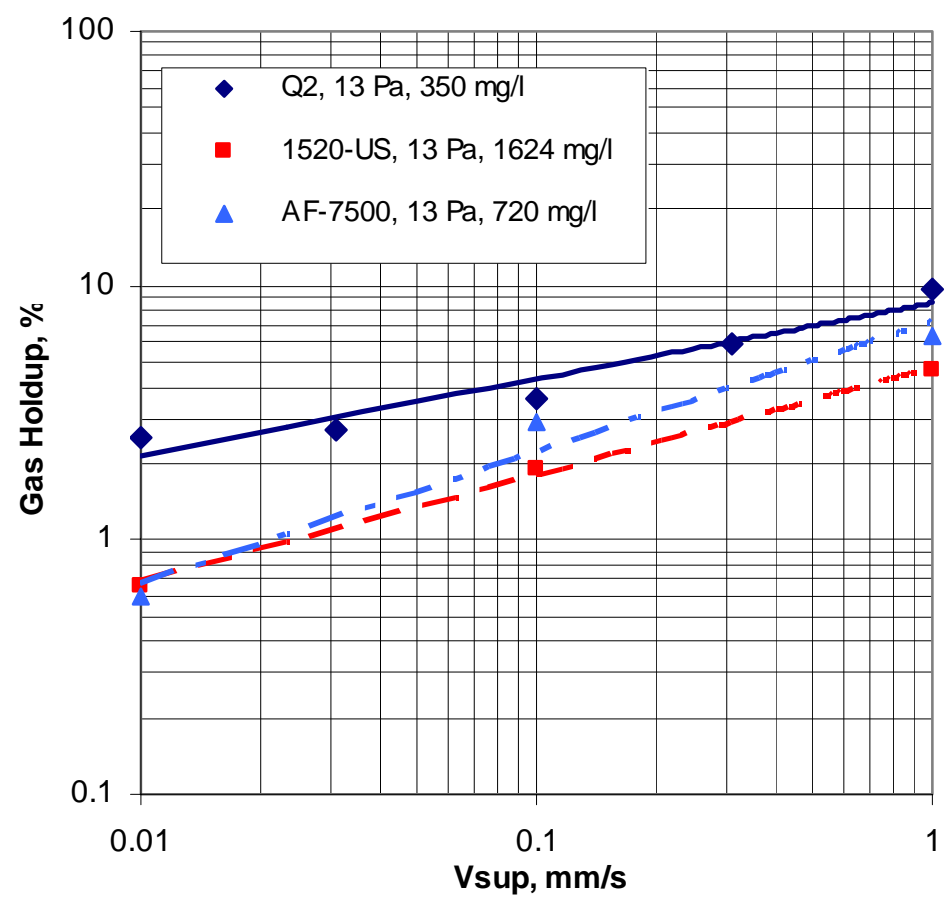

Figure 3-18. Gas Holdup in AZ-101 Simulant with 1520-US and AF-7500 at $13 \mathrm{~Pa}$

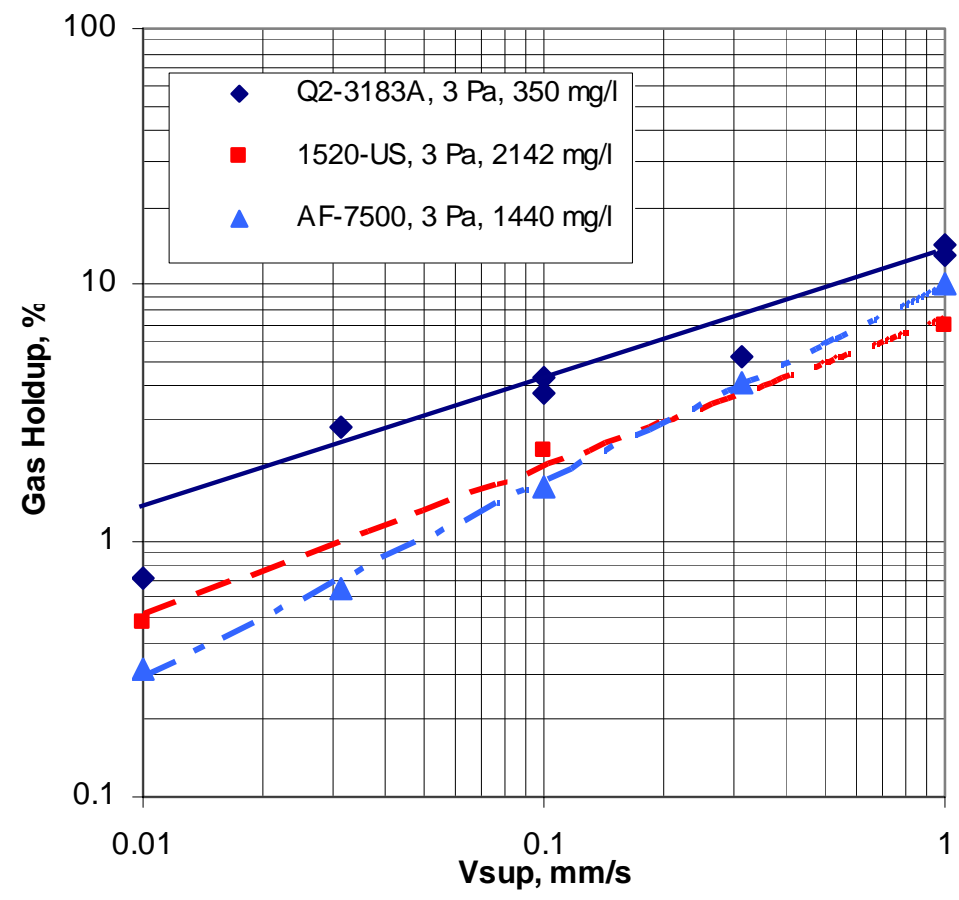

Figure 3-19. Gas Holdup in AZ-101 Simulant with 1520-US and AF-7500 at $3 \mathrm{~Pa}$ 
For comparison with the base concentration of Q2-3183A, the doses for 1520-US and AF-7500 were chosen to be where the gas holdup was constant with concentration. At $30 \mathrm{~Pa}$ (Figure 3-17) addition of $540 \mathrm{mg} / \mathrm{l}$ of AF-7500 results in similar gas holdup as Q2-3183A, while $750 \mathrm{mg} / \mathrm{l}$ of 1520-US reduced the holdup by a factor of 1.7 at $1 \mathrm{~mm} / \mathrm{s}$ superficial velocities and by a larger reduction at low velocities. At $13 \mathrm{~Pa}$ (Figure 3-18), the holdup vs. superficial velocity trend line for AF7500 is steeper than for 1520-US. The holdup for AF-7500 is slightly higher at $1 \mathrm{~mm} / \mathrm{s}$ superficial velocity and close to that of $1520-\mathrm{US}$ at $0.01 \mathrm{~mm} / \mathrm{s}$. 1520 -US reduced the holdup relative to Q2-3183A by a factor of two at $1 \mathrm{~mm} / \mathrm{s}$ and a factor of three at a velocity of 0.01 $\mathrm{mm} / \mathrm{s}$. For the 3 Pa slurry (Figure 3-19), the holdups for AF-7500 and 1520-US are similar except for the difference in slope. 1520-US reduced the holdup by a factor of 1.8 to 3 in the superficial velocity range 1 to $0.01 \mathrm{~mm} / \mathrm{s}$.

To compare the dosage requirements of 1520-US and AF-7500 to Q2-3183A in the bench scale runs, the effectiveness of the ingredients, stated in the Dow-Corning information sheets in terms of Active Ingredients (listed earlier in this section), may be used to multiply the actual doses to come up with an effective dosage in Table 3-3, Table 3-4, and Table 3-5.

Table 3-3. Alternate AFA Doses at $30 \mathrm{~Pa}$

\begin{tabular}{|c|c|c|c|}
\hline AFA & $\begin{array}{c}\text { Effectiveness of } \\
\text { Ingredients }\end{array}$ & $\begin{array}{c}\text { Dose, } \\
\text { mg/l }\end{array}$ & $\begin{array}{c}\text { Effective dose, } \\
\text { mg/ll }\end{array}$ \\
\hline Q2-3183A & $100 \%$ & 350 & 350 \\
\hline 1520-US & $20 \%$ & 1264 & 253 \\
\hline AF-7500 & $20 \%$ & 2000 & 400 \\
\hline
\end{tabular}

Table 3-4. Alternate AFA Doses at 13 Pa

\begin{tabular}{|c|c|c|c|}
\hline AFA & $\begin{array}{c}\text { Effectiveness of } \\
\text { Ingredients }\end{array}$ & $\begin{array}{c}\text { Dose, } \\
\mathbf{m g} / \mathbf{l}\end{array}$ & $\begin{array}{c}\text { Effective dose, } \\
\mathbf{m g} / \mathbf{l}\end{array}$ \\
\hline Q2-3183A & $100 \%$ & 350 & 350 \\
\hline $1520-$ US & $20 \%$ & 750 & 150 \\
\hline AF-7500 & $20 \%$ & 1000 & 200 \\
\hline
\end{tabular}

Table 3-5. Alternate AFA Doses at 3 Pa

\begin{tabular}{|c|c|c|c|}
\hline AFA & $\begin{array}{c}\text { Effectiveness of } \\
\text { Ingredients }\end{array}$ & $\begin{array}{c}\text { Dose, } \\
\mathbf{m g} / \mathbf{l}\end{array}$ & $\begin{array}{c}\text { Effective dose, } \\
\mathbf{m g} / \mathbf{l}\end{array}$ \\
\hline Q2-3183A & $100 \%$ & 350 & 350 \\
\hline 1520-US & $20 \%$ & 2120 & 424 \\
\hline AF-7500 & $20 \%$ & 2000 & 400 \\
\hline
\end{tabular}


The actual doses of 1520-US and AF-7500 from the AFA container have much larger volumes than Q2-3183A because the water content is greater than $60 \%$. But based on effectiveness, the alternate AFAs and the Q2-3183A AFA have similar effective doses for similar gas holdups.

\subsubsection{SRNL Mixing Test Stand Results}

From the results of the bench scale tests, both 1520-US and AF-7500 are viable alternatives to Q2-3183A. 1520-US provides a larger reduction of gas holdup relative to Q2-3183A. AF-7500 doesn't appear to lose effectiveness as much as 1520-US. Due to the fact that 1520-US is used in Hanford evaporators, it was selected as the Alternate AFA to be tested in the larger scale, SRNL Mixing Stand, using the mechanical agitator. The gas holdup behavior for 1520-US compared to Q2-3183A is shown in Figure 3-20, Figure 3-21, and Figure 3-22.

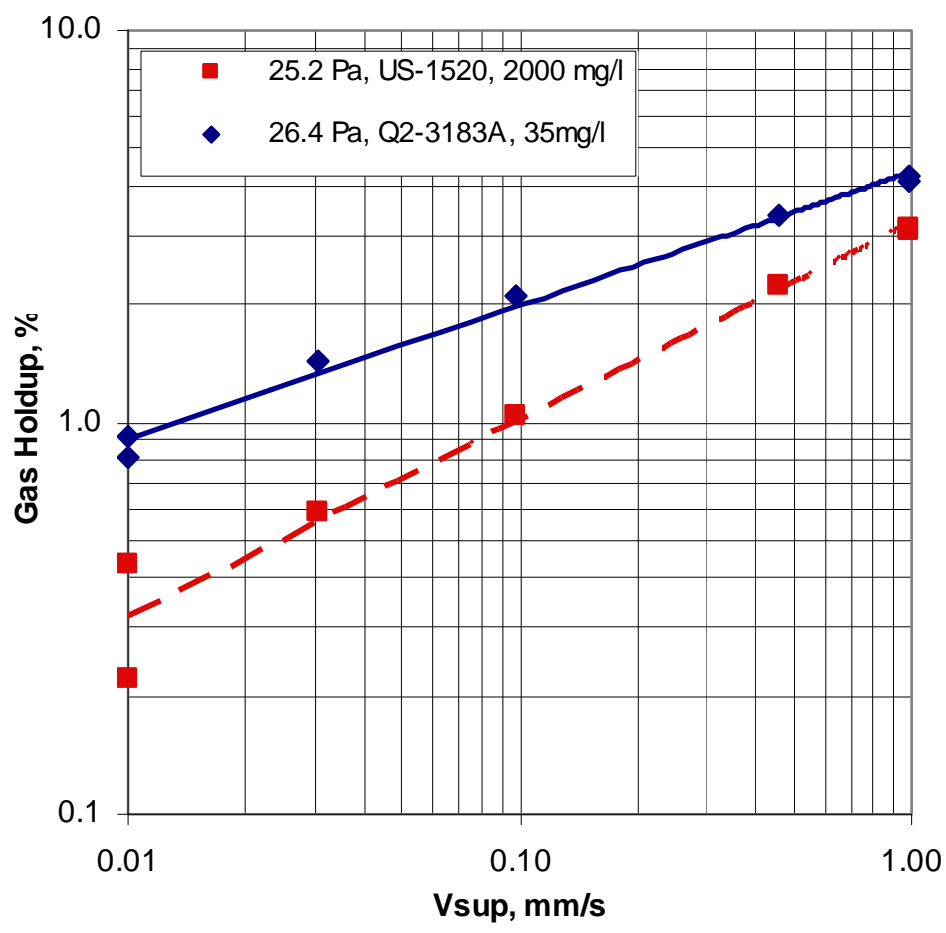

Figure 3-20. Gas Holdup Behavior of 1520-US and Q2-3183A in SRNL Mixing Stand at 25-26 Pa 
WSRC-STI-2007-00537, REVISION 0

SRNL-RPP-2007-00023, REVISION 0

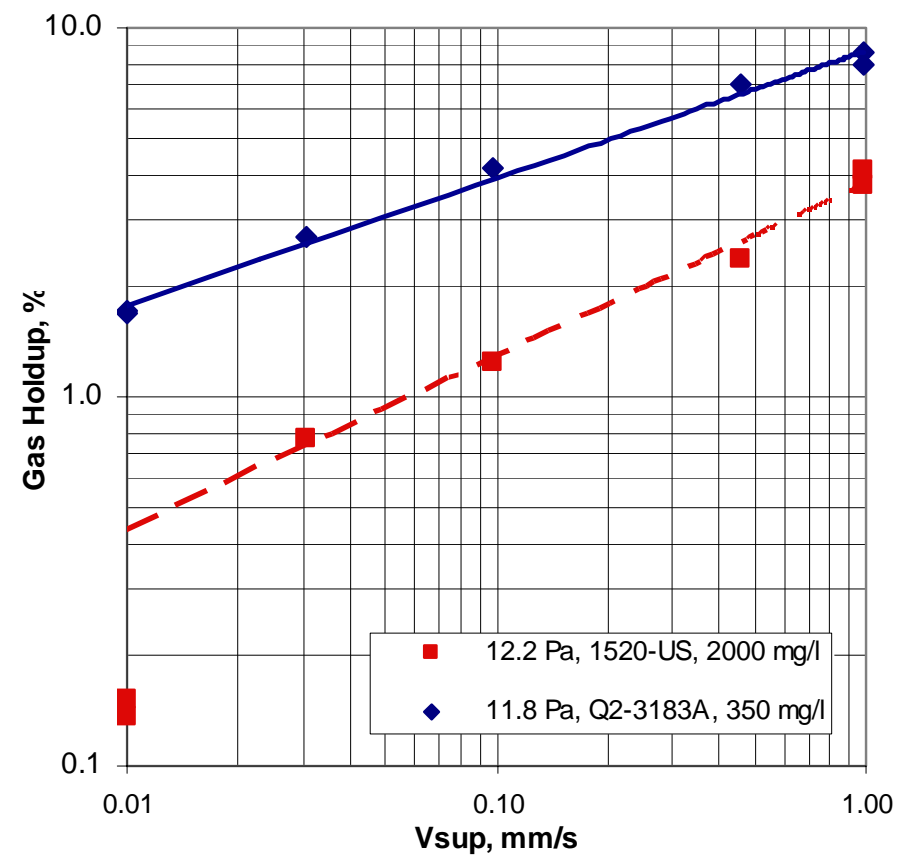

Figure 3-21. Gas Holdup Behavior of 1520-US and Q2-3183A in SRNL Mixing Stand at 12 Pa

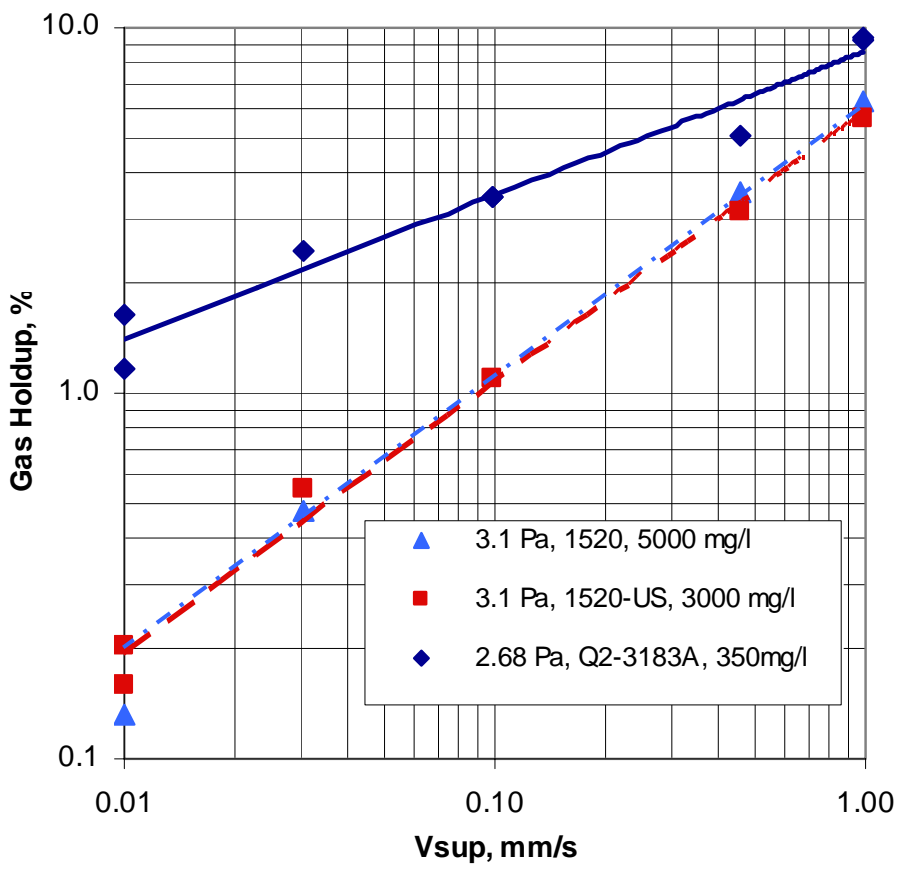

Figure 3-22. Gas Holdup Behavior of 1520-US and Q2-3183A in SRNL Mixing Stand at 3.1 Pa 
A starting dose of $2000 \mathrm{mg} / \mathrm{l}$ for 1520 -US in the nominal $30 \mathrm{~Pa}$ test was chosen since this was the final dose in the $3 \mathrm{~Pa}$ bench scale test. This is also close to the recommended dose for the Hanford evaporators (1750 mg/l). At nominal $30 \mathrm{~Pa}$ (Figure 3-20), the void reduction relative to Q2-3183A was a factor of 1.3 at $1 \mathrm{~mm} / \mathrm{s}$ superficial velocity and 3 at $0.01 \mathrm{~mm} / \mathrm{s}$.

At nominal $13 \mathrm{~Pa}$ (Figure 3-21), the same concentration was used, but the data showed signs of a small surface foam layer affecting the zero baseline in between changes in air flow. This was corrected by subtracting the average of the baseline before and after each air flow setting from the indicated level for that air flow. Repeat points at $1 \mathrm{~mm} / \mathrm{s}$ had the same holdup after the correction was made. Due to the foam layer, a small error in the $0.01 \mathrm{~mm} / \mathrm{s}$ data point would make the point appear much lower than the trend line for the higher velocity points due to the logarithmic scale. The void reduction relative to the Q2-3183A trend line is a factor of 2 to 4 in the velocity range, 1 to $0.01 \mathrm{~mm} / \mathrm{s}$.

In the $3 \mathrm{~Pa}$ testing, the concentration of $2000 \mathrm{mg} / \mathrm{l}$ of $1520-\mathrm{US}$ used in the 30 and $13 \mathrm{~Pa}$ tests resulted in significant foaming. As had been observed in the bench scale tests, 1520-US appears to lose effectiveness with time. A fresh dose of half the initial dose, or $1000 \mathrm{mg} / \mathrm{l}$, for a cumulative dose of $3000 \mathrm{mg} / \mathrm{l}$ was added to the simulant. Figure 3-22 shows a void reduction by a factor of 1.4 at $1 \mathrm{~mm} / \mathrm{s}$ and a factor of 8 at $0.01 \mathrm{~mm} / \mathrm{s}$. Adding another full dose of $2000 \mathrm{mg} / 1$ (5000 $\mathrm{mg} / \mathrm{l}$ cumulative dose) did not change the gas holdup.

\subsection{SUMMARY}

The search for an alternative AFA in place of Q2-3183A should properly start at an understanding of why an antifoam agent would paradoxically increase gas holdup. Due to time constraints and large amounts of variables to consider, as well as different AFAs to test, detailed investigation of the mechanism for this phenomenon was not possible. However, some insight was gained during this testing.

The antifoam agent Q2-3183A contains surfactants such as PPG and PDMS which are used both as frothers and antifoams. PDMS is used as a frother in the production of polyurethane foam [10] and PPG is used as a foamer for minerals separation [11]. The mechanisms by which a surfactant controls foaming also occur in the bulk fluid and some of these also affect bulk gas holdup [11, 13]. An antifoam consists of a surface-active but insoluble oil, such as PDMS or PPG, and usually includes hydrophobic solids such as treated silica. The surface active materials spread rapidly onto any air-water interfaces, and thin the liquid films between adjoining foam bubbles. The hydrophobic solids rupture the foam bubbles, causing them to coalesce to form bigger bubbles. Larger bubbles rise more rapidly than small bubbles, and so a gas emulsion of larger bubbles would tend to have lower holdup. The surface active property directly reduces surface tension and leads to production of small bubbles, increasing holdup. Therefore these two properties counteract each other and actual gas holdup depends on concentration of the antifoam. Tan [11] found that surface foaming increased with increasing concentration of the antifoam at low concentrations. Then a plateau region is reached where Marangoni effects counteract film thinning effects of the surfactant and foaming characteristics remain constant with AFA concentration. 


\section{WSRC-STI-2007-00537, REVISION 0 \\ SRNL-RPP-2007-00023, REVISION 0}

Finally, a critical point is reached at a higher concentration where the surfactant exceeds its solubility limit and phase separation occurs as solid particles. PPG forms polymeric solid particles [13] that act as antifoamer to rupture films between coalescing bubbles. Similar behavior in the bulk fluid that affects bulk holdup would be expected:

Results of Alternate AFA testing provide the following observations:

- Surface tension measurements of Q2-3183A in water, AZ-101 simulant, and AZ-101 simulant supernate showed similar surface tension reductions with concentration of Q2-3183A, by as much as 58\%. This supports the hypothesis that the cause of gas holdup increase after addition of Q2-3183A to AZ-101 simulant is the production of small bubbles.

- The effect of the alternate AFAs on gas holdup is a function of AFA concentration. As the concentration is increased from a low value, gas holdup either decreases or increases but appears to reach a constant value at high concentrations. Results of the noble metals testing in Sec. 3.3 also suggest that to reduce the gas holdups, the Q2-3183A concentration should be increased.

- Gas holdup in a slurry with AFA increases as either the yield stress or total solids content decrease. This could be explained by the increasing apparent viscosity of the slurry with total solids content which promotes formation of large bubbles. Bekish [14], for example, measured the gas holdup of $\mathrm{N}_{2}$ and $\mathrm{He}$ in Isopar-M/alumina slurry and found that increasing the solids content above $20 \%$ reduced gas holdup by $50-65 \%$.

- Adding PPG to water caused high gas holdup, while adding PDMS showed a much smaller effect. In $30 \mathrm{~Pa}$ AZ-101 simulant, adding PDMS and PPG at the same concentrations as used in the base Q2-3183A dosage had similar effects, which were slight reductions in gas holdup compared to that with Q2-3183A. At $13 \mathrm{~Pa}, \mathrm{PPG}$ had a higher holdup than PDMS. At 3 Pa however, PPG had a lower holdup than PDMS. Increasing the PDMS concentration beyond the base concentration also reduced holdup. These results may be due to different transitions from frother to antifoam characteristics of both AFAs as a function of solids wt $\%$.

- Both 1520-US and AF-7500 have lower gas holdup than Q2-3183A. 1520-US was selected as for testing in the larger scale SRNL Mixing Test Stand since it had consistently lower gas holdup at all waste rheologies than AF-7500 and it is already in use at the Hanford Tank Farm. Testing in the larger scale SRNL Mixing Test Stand also showed 1520-US has less gas holdup as in the bench scale test. 
Thus, 1520-US is a viable alternative to Q2-3183A. However, larger volumes of 1520-US (about $2000 \mathrm{mg} / \mathrm{l})$ than the base Q2-3183A (350 mg/l) are required to reduce foaming because of the high water content (60\%) and lower effectiveness (20\% vs. 100\%) of the 1520 -US ingredients than Q2-3183A. This has the effect of increasing the antifoam solids of 1520-US to about $700 \mathrm{mg} / 1$ (0.07 wt \% solids) (compared to $350 \mathrm{mg} / 1$ for Q2-3183A) and additional 1300 $\mathrm{mg} / \mathrm{l}(0.13 \mathrm{wt} \%)$ of water. Using the dilution curve of Figure 1-1, the yield stress at an initial value of $13 \mathrm{~Pa}$ would be slightly decreased by $0.5 \mathrm{~Pa}$ due to additional water but slightly increased by $0.28 \mathrm{~Pa}$ by the solids content of the AFA, assuming a similar effect on yield stress as the simulant solids. 
WSRC-STI-2007-00537, REVISION 0

SRNL-RPP-2007-00023, REVISION 0

This page intentionally left blank. 


\subsection{NOBLE METALS EFFECT TESTING}

\subsection{OVERVIEW}

Phase I testing did not include the effect of noble metals and the concern is that noble metals could catalyze chemical reactions with the simulant and AFA, immediately affecting physical properties, such as surface tension and plastic (apparent) viscosity that influence gas holdup. A second concern is that normal aging, where the dilution curve or the variation in yield stress with solids concentration changes with time is accelerated by the catalyzing effect of noble metals. This may also affect gas holdup characteristics of the simulant. A series of tests was thus performed to investigate effect of noble metals.

\subsection{EXPERIMENTAL METHODS}

Rhodium chloride, silver nitrate, ruthenium chloride, and palladium nitrate in quantities specified in [7] as added to the Batch 2 simulant used in Tests $5 c-1$ through $5 c-8$ while mixing with the agitator. Since the chloride solutions were acidic, additional $\mathrm{NaNO}_{3}$ was added to maintain the same $\mathrm{pH}$ in the base simulant. The SRNL Mixing Test Stand using the mechanical agitator system was used for this purpose. Air sparging was used to introduce gas bubbles, which were broken up into smaller bubbles by the radial impeller. Holdup measurements were obtained from the level rise with laser level measuring equipment. Testing followed the procedure described in Sec. 3.1.2.

The test matrix, Table 4-1, started with testing the fresh 30 Pa Optima Batch 2 simulant with added noble metals, to determine its gas holdup properties without AFA. Similar testing at a lower yield stress was not conducted since there were only enough noble metals to make one batch.

Table 4-1. Noble Metals Testing Test Matrix

\begin{tabular}{|c|c|c|c|c|c|}
\hline $\begin{array}{l}\text { Test } \\
\text { No. }\end{array}$ & Simulant & AFA & $\begin{array}{l}\text { Test } \\
\text { Model }\end{array}$ & Rheology & $\begin{array}{l}\text { Air } \\
\text { Superficial } \\
\text { Vel. mm/s }\end{array}$ \\
\hline $1 \mathrm{a}-4$ & \multirow{4}{*}{$\begin{array}{l}\text { AZ-101 } \\
\text { Batch } 2 \text { with } \\
\text { noble metals }\end{array}$} & No & \multirow{4}{*}{$\begin{array}{l}1 / 9 \text { th } \\
\text { scale, } \\
\text { mech. } \\
\text { agit. }\end{array}$} & $30 \mathrm{~Pa}$ & \multirow{4}{*}{$\begin{array}{l}0.01,0.031, \\
0.1,0.31,1.0\end{array}$} \\
\hline $1 \mathrm{a}-7$ & & Q2-3183A & & $30 \mathrm{~Pa}$ & \\
\hline $1 \mathrm{a}-8$ & & Q2-3183A & & $13 \mathrm{~Pa}$ & \\
\hline $1 \mathrm{a}-9$ & & Q2-3183A & & $3 \mathrm{~Pa}$ & \\
\hline
\end{tabular}

After the $30 \mathrm{~Pa}$ with noble metals test, Q2-3153A antifoam in the usual dose of $350 \mathrm{mg} / \mathrm{l}$ was added and three tests at $30 \mathrm{~Pa}, 13 \mathrm{~Pa}$ and $3 \mathrm{~Pa}$ were performed. 


\subsection{TEST RESULTS}

\subsubsection{Effect of Adding Noble Metals to AZ-101 Simulant}

Figure 4-1 shows that adding noble metals to AZ-101 Batch 2 simulant significantly reduces the gas holdup relative to plain Batch 2 simulant. When compared to Phase I data, Batch 2 data with noble metals is closely similar to this original data, and even slightly lower. The trend line for $22.3 \mathrm{~Pa}$, Batch 2 with noble metals is drawn through the 4 higher air superficial velocities. This tends to keep the trend line parallel to other trend lines. The holdup at the lowest velocity, $0.01 \mathrm{~mm} / \mathrm{s}$, sometimes drops below the trend line of the four higher flows. This is believed to be due to a small layer of foam still remaining on the surface. The baseline for no air is therefore indeterminate and a small error of $0.1 \%$ void shows up as a big effect at low holdups, but insignificant at high holdups.

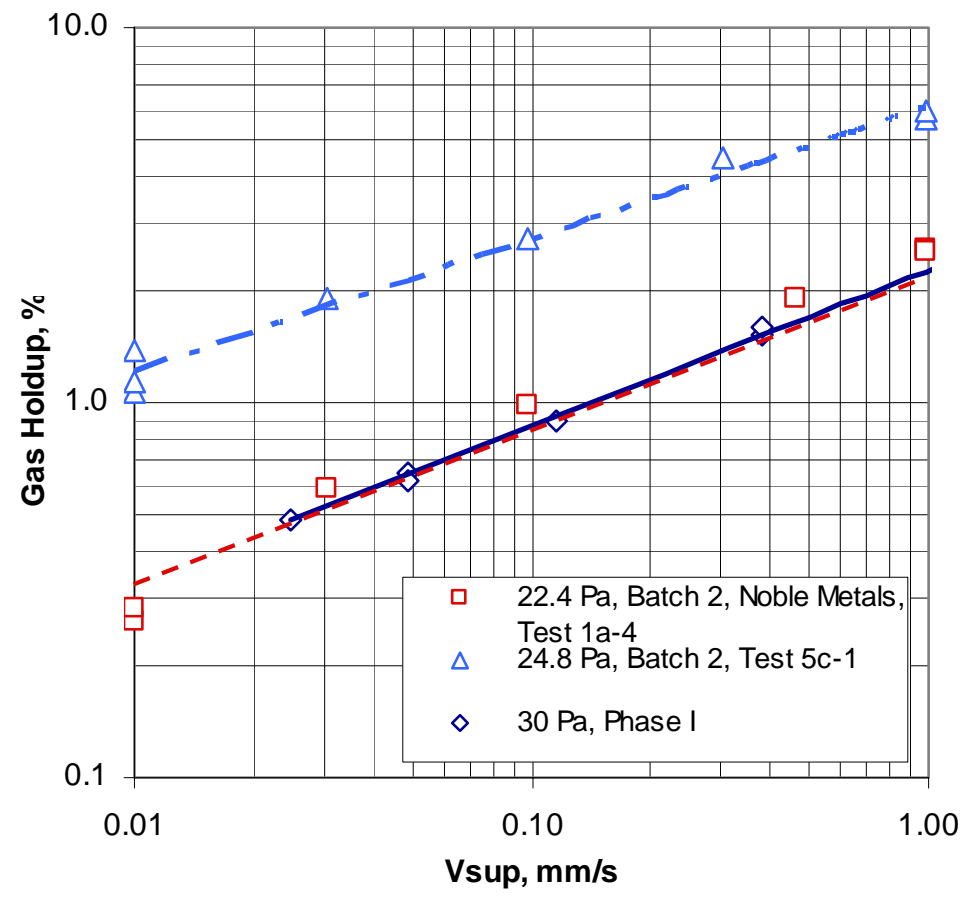

Figure 4-1. Effect of Adding Noble Metals to Batch 2 AZ-101 Simulant without AFA

\subsubsection{Effect of Adding Antifoam to AZ-101 Simulant with Noble Metals}

Figure 4-2 and 4.3 show the effects of adding Q2-3183A antifoam to Batch 2 AZ-101 simulant with noble metals at approximately $30 \mathrm{~Pa}$. In Figure 4-2, the holdup with noble metals appears to be almost identical to that in Phase I testing. The noble metals also reduced the holdup below the value for Batch 2 with AFA but without noble metals. 


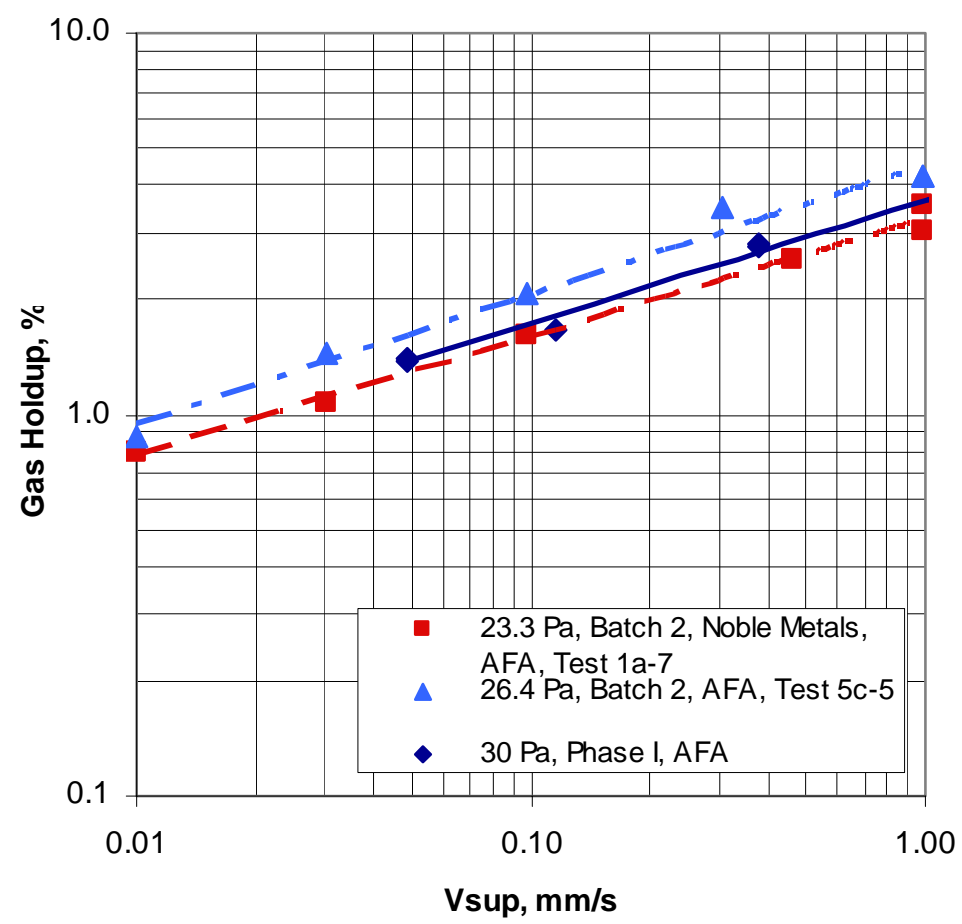

Figure 4-2. Effect of Adding Noble Metals to 22.3 Pa AZ-101 Simulant with AFA

\section{Pa Testing}

Figure 4-3 compares the holdup with noble metals, with and without AFA, with the same conditions in Phase I without noble metals at $30 \mathrm{~Pa}$. Both sets of data appear identical. This shows that noble metals eliminated the problem of surface foaming of Batch 2 simulant completely. Bulk gas holdup still exists with noble metals and is similar to holdup without noble metals.

\section{Pa Testing}

At $13 \mathrm{~Pa}$, the gas holdup in Batch 2 simulant with noble metals and AFA was very close to the Phase I data with AFA but without noble metals, as shown in Figure 4-4. There was no data for Batch 2 with noble metals but without AFA for the reason stated in Sec. 3.2.2. The plot of Figure 4-4 shows that there is no effect of noble metals on gas holdup in the $13 \mathrm{~Pa}$ range.

\section{Pa Testing}

At $3 \mathrm{~Pa}$ (Figure 4-5), the addition of noble metals reduced the gas holdup in the Batch 2 simulant with AFA, although there were only small differences. A single data point was available from Phase I testing at $3 \mathrm{~Pa}$ with AFA. This point falls on the trend line of the noble metals with AFA. 
WSRC-STI-2007-00537, REVISION 0

SRNL-RPP-2007-00023, REVISION 0

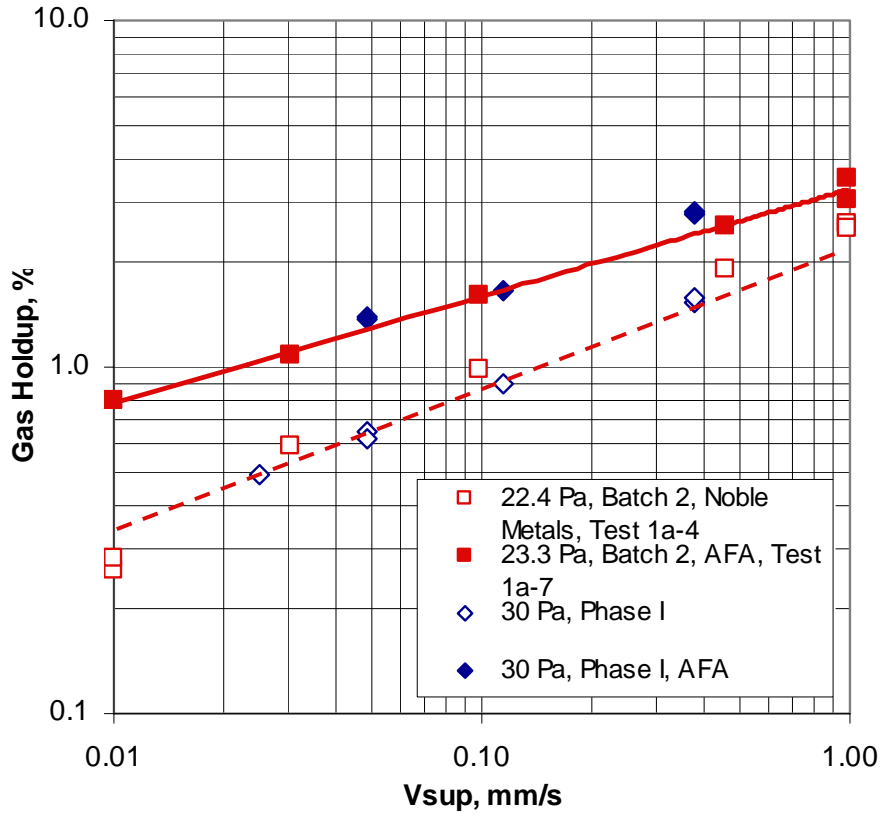

Figure 4-3. Effect of Adding Noble Metals with and without AFA at 22.4 Pa Compared to Phase I Results

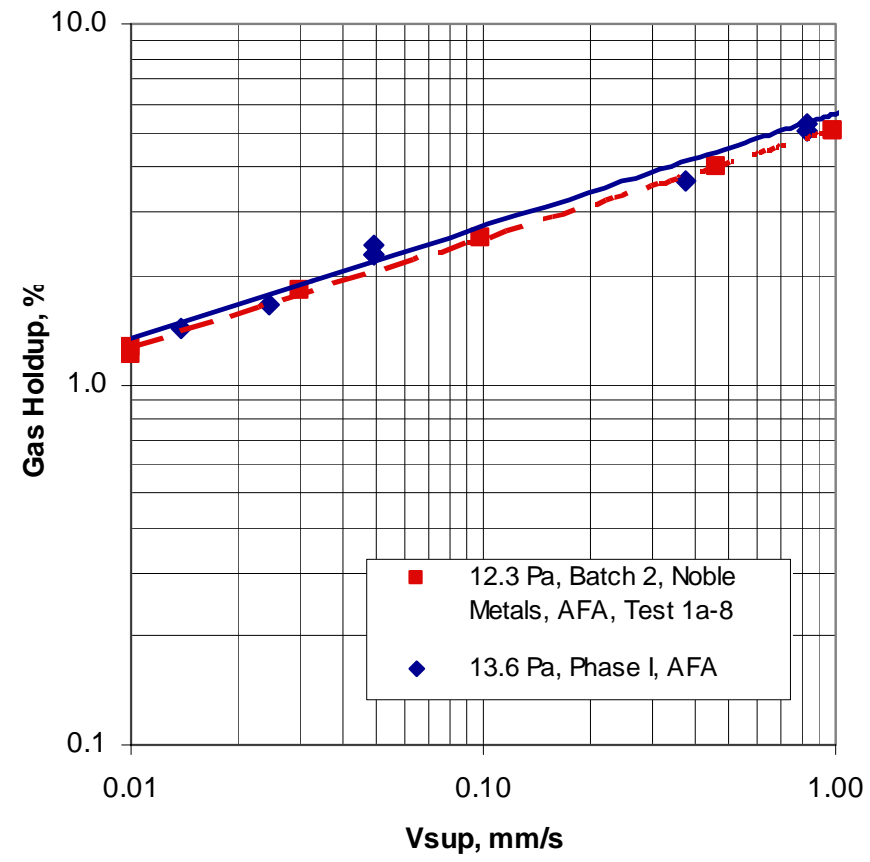

Figure 4-4. Effect of Adding Noble Metals with and without AFA at 13 Pa 


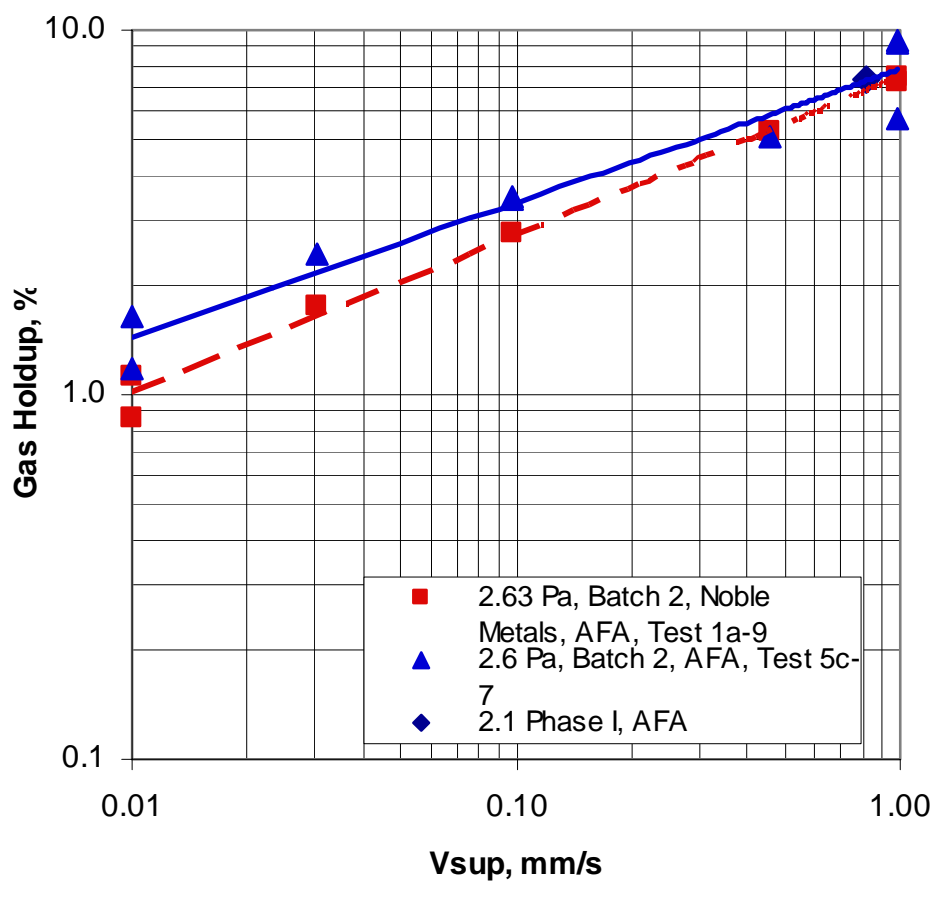

Figure 4-5. Effect of Adding Noble Metals with AFA at 3 Pa

\subsubsection{Effect of Time on Gas Holdup for Simulant with Noble Metals (3 Pa Retest)}

Since the effect of noble metals may be a function of time, the intent was to repeat Tests 1a-7, $1 \mathrm{a}-8$, and 1a- after 9 weeks. Results of the retesting of the 3 Pa simulant (the yield stress at the end of the original testing) are given in Figure 4-6. This shows that the gas holdup increased 37\% for the same simulant stored for the aforementioned period. The increase in holdup may have been due to some physical or chemical change in the simulant brought about by the noble metals. However, the measured yield stress and $\mathrm{pH}$ prior to and after the retest showed no change in these properties. A second possible reason is degradation of the AFA. The retest was repeated while adding half the usual dose of AFA (175 ppm) as a maintenance dose. This brought the gas holdup back to its original value. The curves are parallel if the holdup values at the lowest air flow are not included in the trend line. As discussed previously, a small foam layer obscures the zero air baseline and introduces error at low holdups. 


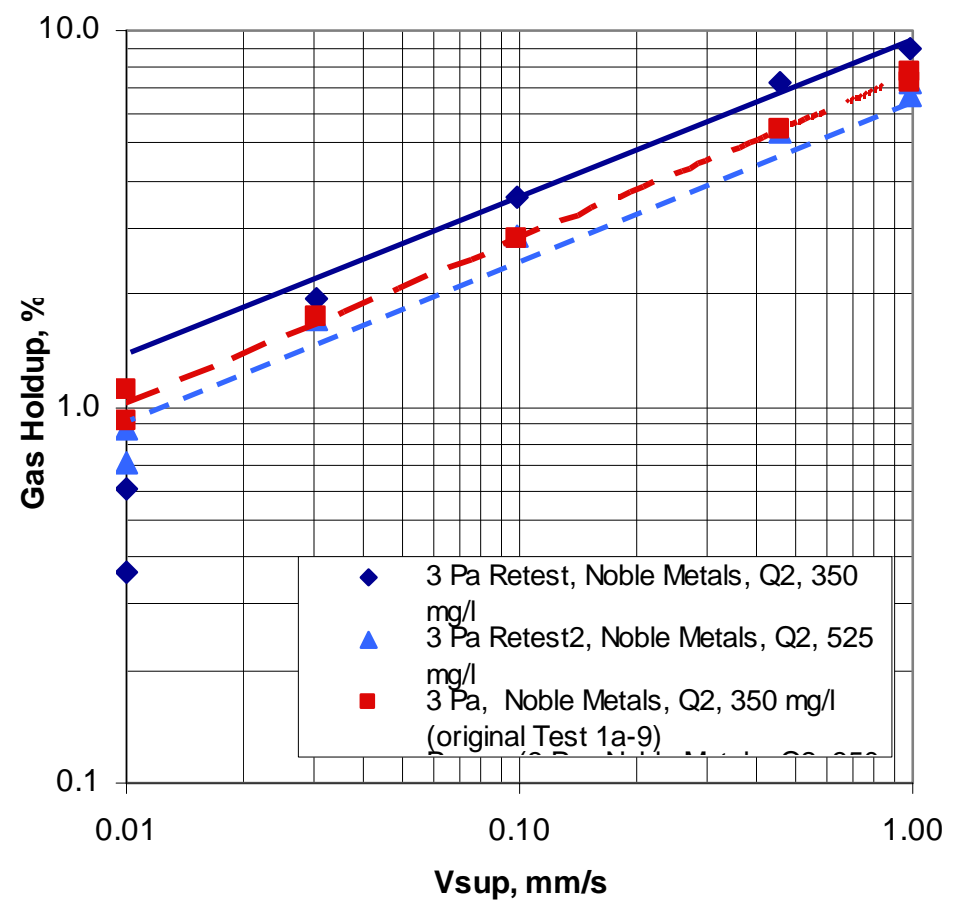

Figure 4-6. Retest of Noble Metals Test with AFA at 3 Pa

\subsubsection{Higher Yield Stresses}

In order to attain the yield stresses 13 and $22 \mathrm{~Pa}$ for comparison with the previous tests, the simulant was sparged with air while being agitated for several days to remove excess water. While the target of 26.3 total $\mathrm{wt} \%$ solids was attained, the yield stress was measured at $8.6 \mathrm{~Pa}$, below the original dilution curve value for Batch 2 with noble metals of $13 \mathrm{~Pa}$. The $\mathrm{pH}$ of this aged simulant decreased from 11.5 of the previous test to 10.5 , suggesting that a chemical change in the simulant had occurred. Possibly, chemical reaction between oxygen in the air and the simulant, catalyzed by the noble metals, produced carbonates in large enough quantities to change the $\mathrm{pH}$ and rheology. An attempt was made to try to increase the $\mathrm{pH}$ by adding NaNO3 to the simulant. Testing this procedure with a small sample indicated that 10 times the estimated amount of $\mathrm{NaNO}_{3}$ based on acid chemistry was required. The simulant chemistry with noble metals appears to be much more involved. Archived samples from the $3 \mathrm{~Pa}$ and $22.3 \mathrm{~Pa}$ original tests were retested; and the yield stress and $\mathrm{pH}$ were found not to have changed. Consequently, it was concluded that the property changes in the $8.6 \mathrm{~Pa}$ simulant were from the air sparging and not by any aging effect. Further since it was apparent that the simulant chemistry had changed and adding more chemicals would make a large deviation from the original chemistry, the higher yield stress tests were not repeated. 
Results of the tests with the 8.6 Pa simulant are shown in Figure 4-7. The gas holdup increased by $40 \%$ at the high air flows but was closer to the original values at low air flows. The gas holdup increase at high air flows may be due to the lower yield stress or degradation of the AFA so that a small amount of foaming returned. Adding another $175 \mathrm{ppm}$ of Q2-3183A to the simulant decreased the holdup relative to the first repeat and even decreased it below the original test, except for the highest air flow. This is additional evidence that increasing Q2-3183A base concentration can decrease the gas holdup.

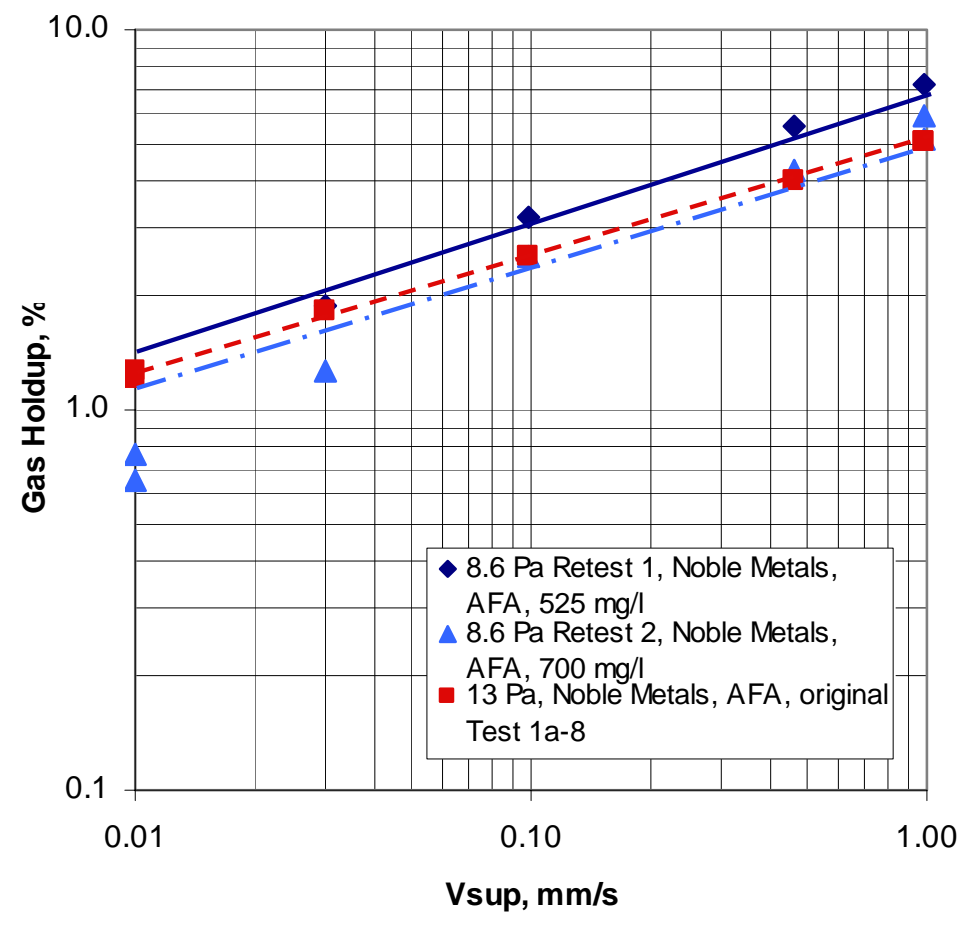

Figure 4-7. Retest of Noble Metals Test with AFA at Nominal 13 Pa 


\subsection{SUMMARY}

Addition of noble metals to the Batch 2 simulant eliminated its foaming characteristic. The result was matching of the gas holdup values obtained with the Phase I (30 Pa) simulant. Similarly by adding AFA to the Batch 2 simulant with noble metals, gas holdups from Phase I were duplicated for nominal $30 \mathrm{~Pa}, 13 \mathrm{~Pa}$, and $3 \mathrm{~Pa}$ simulants.

A definite conclusion about the effect of aging with noble metals cannot be made due to the obscuring effect of foaming by the Batch 2 simulant at $3 \mathrm{~Pa}$ and lack of additional data at high yield stresses. As discussed previously in Sec. 3.1, Batch 2 foaming tends to return even with addition of AFA after a layoff period or dilution to lower yield stress. This could explain the increase in holdup in the $3 \mathrm{~Pa}$ simulant with noble metals after 9 weeks. After a maintenance dose of half the usual dose of Q2-3183A was added, the gas holdups returned to the values in the original test. It should be noted however that the $3 \mathrm{~Pa}$ retest showed only a modest $37 \%$ increase in gas holdup after the layoff period. The archived Batch 2 samples' rheology and $\mathrm{pH}$ did not change, suggesting further that gas holdup characteristics would not change.

Thus, these small scale tests confirm that addition of noble metals does not catalyze the AFA and gas holdup is similar to that in simulant without noble metals. 


\subsection{PJM TESTING VS. MECHANICAL AGITATOR TESTING}

\section{OVERVIEW}

The thrust of this test program was to determine the effect of antifoam agent on gas holdup characteristics in AZ-101 simulant and to be able to translate the results to the WTP. The original PNNL test that first suggested a strongly increasing effect of AFA on gas holdup used a fritted disc for sparging air. This system thus performed both functions of generating air bubbles and providing fluid mixing in the apparatus. High air superficial velocities were required, providing data possibly in a different flow regime than for the WTP where the gas superficial velocities are low. The SRNL Mixing Test Stand was designed to provide separate bubble generating and mixing functions with a mechanical agitation system that provides constant mixing conditions while changing air superficial velocities. Large air bubbles injected by a sparger at the tip of a radial turbine are broken up into smaller bubbles to represent radiolytically generated hydrogen bubbles in the plant.

The pulse jet mixer is a cylindrical vessel with a nozzle at the bottom and connections to compressed air and vacuum at the top. Mixing at lower levels is performed by drawing in slurry through the bottom nozzle and then expelling it back at high velocity through the nozzle. Additionally, air spargers provide mixing at higher elevations for WTP vessels and the prototypic experimental systems operated by PNNL. Thus flow fields and turbulence levels in the two systems differ drastically from each other. The tests described in this section were designed to address the effect of type of mixing on gas holdup and release. Also, the length scale of the SRNL vessel is $1 / 9^{\text {th }}$ of the WTP vessel. While velocity profiles may be similar in the scaled PJM systems, the time scales are reduced. The effect of these differences will be addressed in the following sections.

\subsection{EXPERIMENTAL METHODS}

\subsubsection{Test Apparatus Description}

For PJM mixing, the mechanical agitator and baffles from Figure 3-3 were removed from the vessel and the 4 PJM pulse tubes used in previous PJM mixing tests were installed (Figure 5-1). The four PJM tubes are $63.5 \mathrm{~mm}(2-1 / 2$-inch) NPS, Schedule 10, stainless steel pipe, $1170 \mathrm{~mm}$ (43-in.) internal height, spaced equally on a $270 \mathrm{~mm}$ (10.64-in.) pitch circle. Average internal diameter is $66.7 \mathrm{~mm}(2.625-\mathrm{in}$.). The bottom nozzles are cones with 60 degree included angle and the nozzle diameter is $11.3 \mathrm{~mm}(0.445$-in.). The operation of the PJMs was controlled by a computer Data Acquisition and Control system using LabView to open and close a 3-way solenoid valve. 
A cycle starts with the PJMs connected to the vacuum pump. When the level reaches an upper limit inside the PJM as measured by a capacitance probe, the vacuum line is closed and compressed air admitted to the PJMs. A pulse drive time of $1 \mathrm{sec}$ was selected to achieve a nozzle velocity of $12 \mathrm{~m} / \mathrm{s}$. Then the compressed air system is closed and the vent opened. Finally, the vacuum system is connected. The cycle time was set at 10 seconds as in the previous test program.

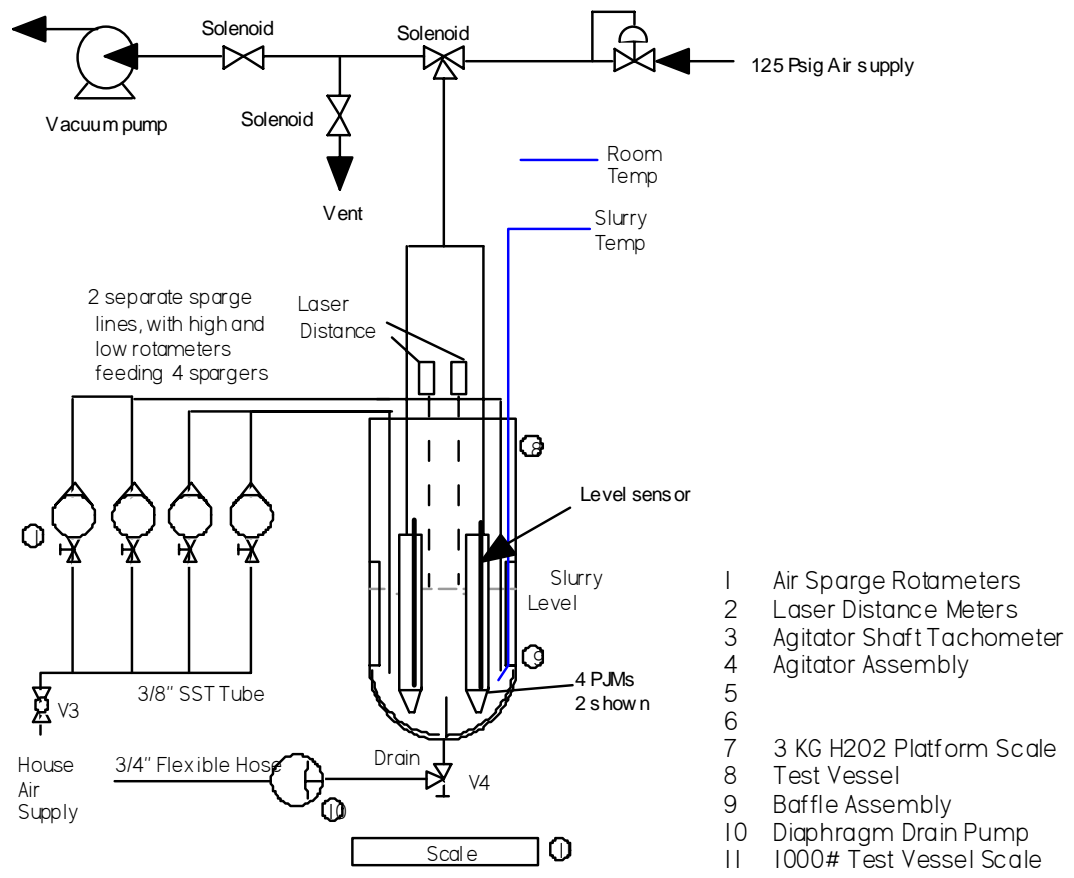

Figure 5-1. Schematic of the SRNL Mixing Test Stand with PJM Agitators

\subsubsection{Test Procedure}

The procedure was to inject a $30 \mathrm{wt} \% \mathrm{H}_{2} \mathrm{O}_{2}$ solution into the bottom of the test vessel with the PJMs operating. As the growing inventory of liquid $\mathrm{H}_{2} \mathrm{O}_{2}$ in the vessel reacted with the AZ-101 simulant, an increasing amount of oxygen bubbles were generated by $\mathrm{H}_{2} \mathrm{O}_{2}$ decomposition, raising the level and holdup. The laser level measurements were monitored to determine when a steady state level was reached because oxygen bubbles created by $\mathrm{H}_{2} \mathrm{O}_{2}$ decomposition balanced the gas bubbles released from the surface. The level kept on increasing at a linear rate during steady state due to conversion of $\mathrm{H}_{2} \mathrm{O}_{2}$ to water, in addition to oxygen. Analysis of the data included subtracting this increase in liquid inventory from the laser reading to determine the gas holdup. The slurry temperature was monitored continuously. The $\mathrm{H}_{2} \mathrm{O}_{2}$ injection was stopped after a sufficient time to obtain a good average level reading, but not too long as to change the rheology significantly due to addition of converted $\mathrm{H}_{2} \mathrm{O}_{2}$ to water.

Instrumentation and data analysis procedures were similar to the Alternate AFA Testing described in Sec. 3.1. 


\subsubsection{Test Matrix}

The test conditions for PJM testing are given in Table 5-1.

Table 5-1. Test Conditions for PJM Testing

\begin{tabular}{|c|c|c|c|c|c|}
\hline $\begin{array}{l}\text { Test } \\
\text { No. }\end{array}$ & Simulant & AFA & $\begin{array}{l}\text { Test } \\
\text { Model }\end{array}$ & $\begin{array}{l}\text { Rheology, } \\
\text { yield } \\
\text { stress }\end{array}$ & $\begin{array}{l}\text { Oxygen } \\
\text { Superficial Vel. } \\
\text { mm/s }\end{array}$ \\
\hline $1 c-4$ & \multirow{3}{*}{$\begin{array}{l}\text { New AZ- } \\
101 \\
\text { simulant }\end{array}$} & Q2-3183A & \multirow{3}{*}{$\begin{array}{l}1 / 9 \text { th } \\
\text { scale, } \\
\text { mech. } \\
\text { agit. }\end{array}$} & $30 \mathrm{~Pa}$ & $0.03,0.09,0.25$ \\
\hline $1 c-5$ & & Q2-3183A & & $13 \mathrm{~Pa}$ & $0.036,0.096,0.27$ \\
\hline $1 c-6$ & & Q2-3183A & & $3 \mathrm{~Pa} \mathrm{DI}$ & $0.03,0.06,0.09,0.25$ \\
\hline
\end{tabular}

The $\mathrm{H}_{2} \mathrm{O}_{2}$ injection rates to produce equivalent gas superficial velocities are:

\begin{tabular}{lc}
$\begin{array}{l}\mathrm{H}_{2} \mathrm{O}_{2} \text { flow rate } \\
\mathrm{ml} / \mathrm{min}\end{array}$ & $\underline{\mathrm{O}}_{2}$ superficial velocity \\
\hline 1.97 & $\mathrm{~mm} / \mathrm{s}$ \\
4.14 & 0.03 \\
6.2 & 0.06 \\
16.8 & 0.09 \\
& 0.25
\end{tabular}

Oxygen gas superficial velocities were calculated assuming complete $\mathrm{H}_{2} \mathrm{O}_{2}$ decomposition due to high levels of transition metals (which act as catalysts) in the simulant and equilibrium gas release with $\mathrm{H}_{2} \mathrm{O}_{2}$ injection when steady state is reached.

\subsection{TEST RESULTS}

\section{Pa PJM Testing}

Typical laser level measurements as a function of time for the $30 \mathrm{~Pa}$ simulant are shown in Figure 5-2 for $3 \mathrm{H}_{2} \mathrm{O}_{2}$ injection rates. These curves are averages of four laser measurements that are in turn time averaged over short time increments of $0.25 \mathrm{~min}$ and corrected for peroxide decomposition. The lowest injection rate, resulting in $0.0293 \mathrm{~mm} / \mathrm{s}$ superficial gas velocity, exhibits a somewhat constant level, but is still decreasing at the end of injection at $85 \mathrm{~min}$. The second curve for $0.092 \mathrm{~mm} / \mathrm{s}$ superficial velocity may still have been increasing at the end of injection. The third and highest injection rate for $0.25 \mathrm{~mm} / \mathrm{s}$ shows a delay of 15 minutes before the level ramps up rapidly and appears to peak and then decrease, with large variations around the mean. During the test the thick slurry appeared to not be mixing very well; it moved up and down like a piston in conjunction with the PJM up and down strokes. The top surface was also not turning over as well as in mechanical mixing. The low level of mixing would mean a longer time to reach steady state. And since the level rise curves for the higher injection rates (shorter injection times) show downward trends after the peaks are reached, the actual steady state holdups may be lower than what the data indicate. The plot of the average holdup vs. superficial velocity, Figure 5-3, shows close agreement with the void data under mechanical agitation at low superficial velocity but higher values than corresponding mechanical agitator data at higher velocity, probably because the steady state was not attained. 
WSRC-STI-2007-00537, REVISION 0

SRNL-RPP-2007-00023, REVISION 0

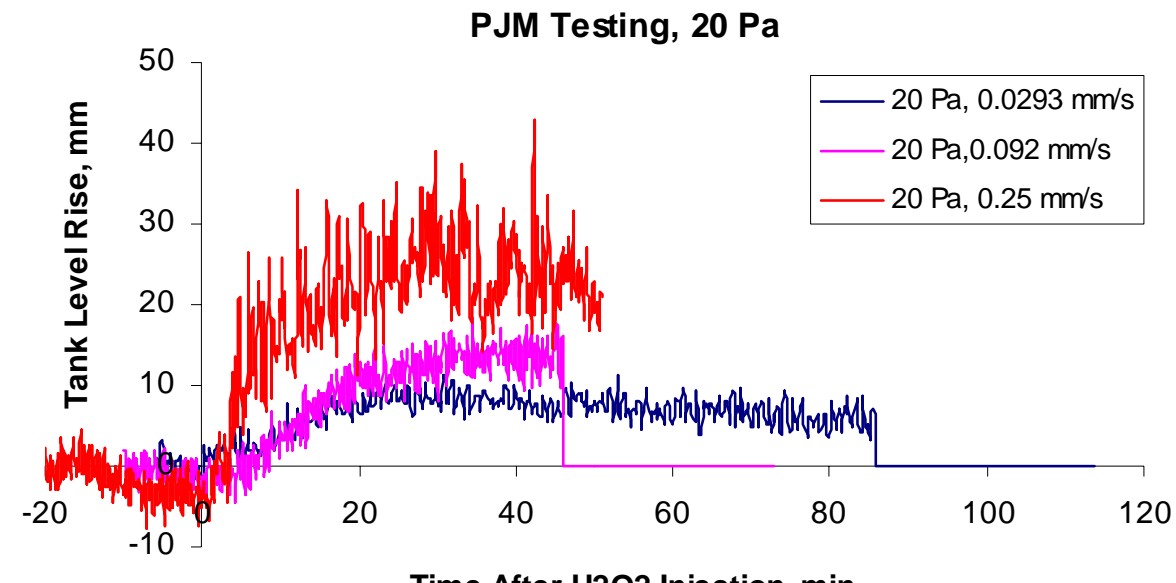

Time After H2O2 Injection, min.

Figure 5-2. Tank Level Rise History after H2O2 Injection in 20 Pa AZ-101 Simulant

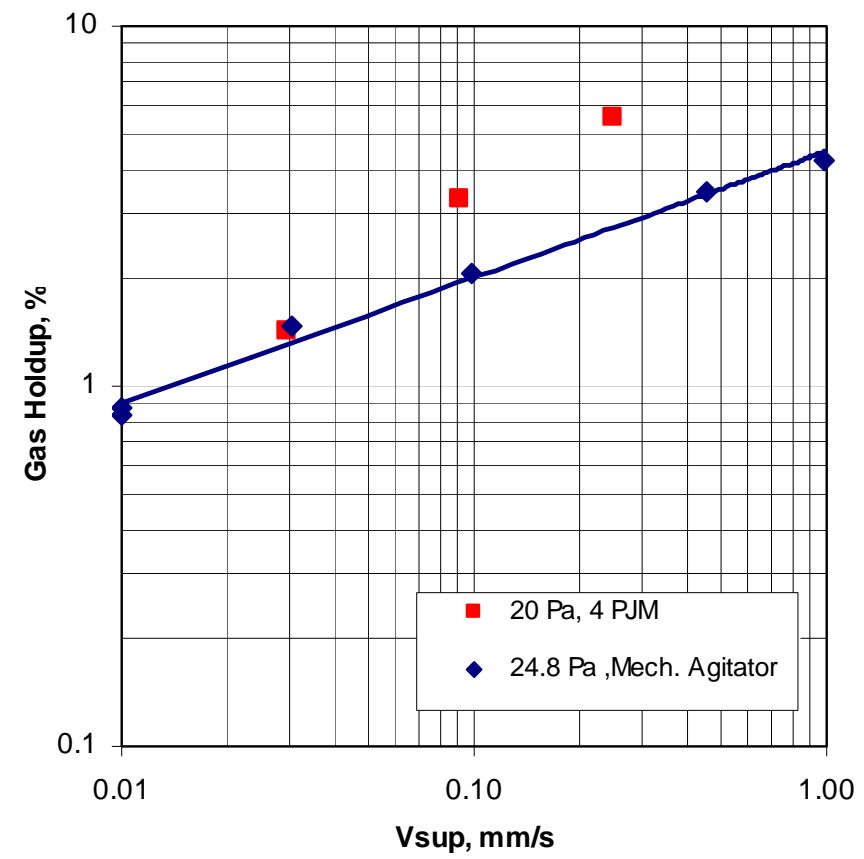

Figure 5-3. Gas Holdup in 20-25 Pa AZ-101 Simulant under PJM Mixing Conditions

\section{Pa PJM Testing}

Figure 5-4 gives the histories of the tank level measurements for four peroxide injection rates with PJM mixing at $11 \mathrm{~Pa}$. The average steady state holdups are plotted in Figure 5-5; these are about $33 \%$ lower than the corresponding mechanical mixing data. There was considerably better mixing than during the $30 \mathrm{~Pa}$ test, which could explain the lower holdup. 
WSRC-STI-2007-00537, REVISION 0

SRNL-RPP-2007-00023, REVISION 0

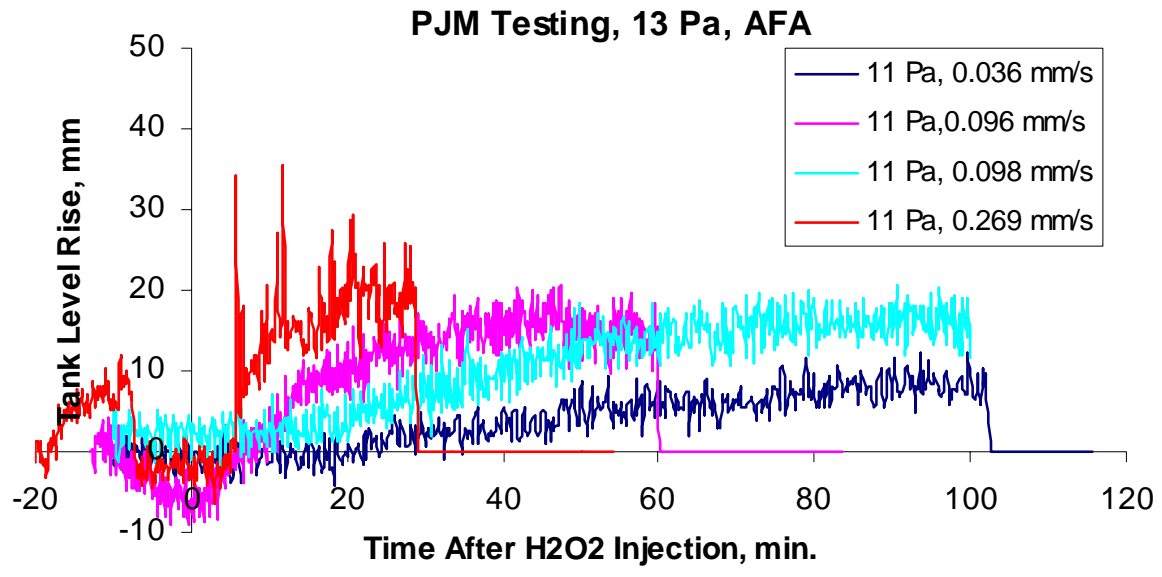

Figure 5-4. Tank Level Rise History after $\mathrm{H2O}$ Injection in 11 Pa AZ-101 Simulant

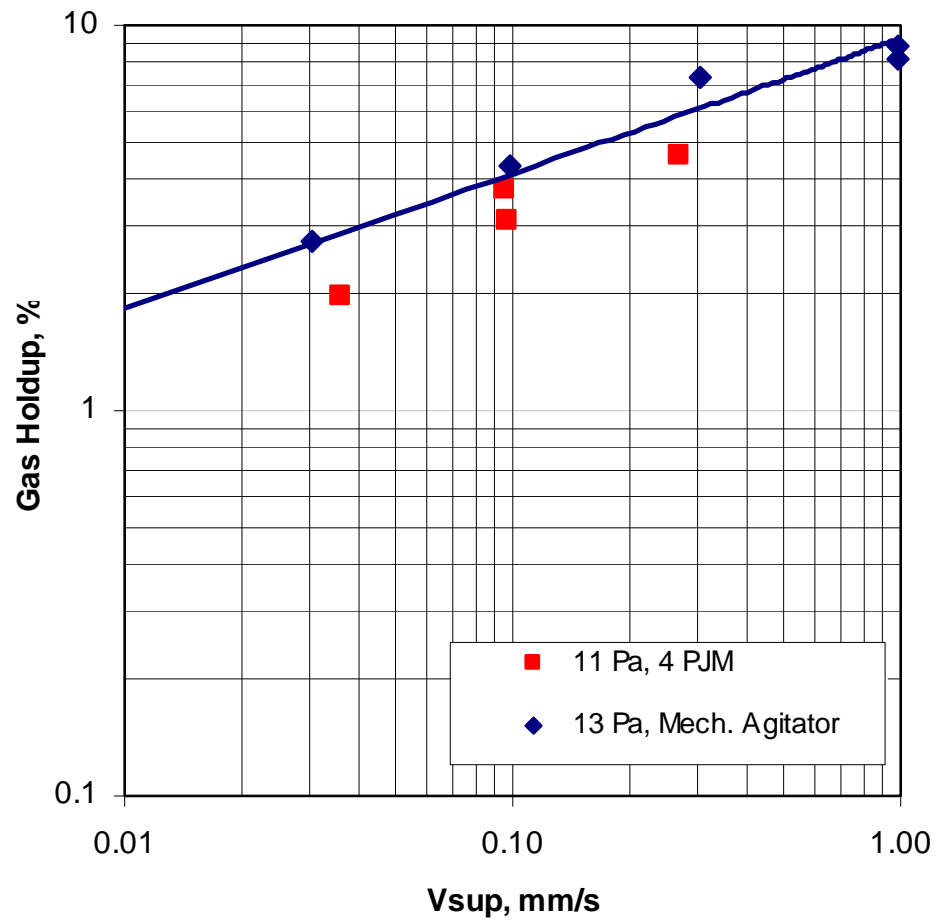

Figure 5-5. Gas Holdup in 11 Pa AZ-101 Simulant under PJM Mixing Conditions 


\section{Pa PJM Testing}

Figure 5-6 gives the histories of the tank level measured for four $\mathrm{H}_{2} \mathrm{O}_{2}$ injection rates in $3 \mathrm{~Pa}$ simulant. The holdup data are plotted in Figure 5.7. Considerable foaming was observed during this test, especially for the high injection rates. Foaming was often observed when the simulant rheology was adjusted to lower yield stress by dilution with water. During later mechanical agitation tests, additional AFA was added to counteract this foaming, but in this test, no new dose of AFA was added. At the highest superficial velocity of $0.255 \mathrm{~mm} / \mathrm{s}$, the surface level rise rises to a high peak of $50 \mathrm{~mm}$ in Figure 5-6, but then decreases continuously until the end of peroxide injection to about $20 \mathrm{~mm}$. A specific mechanism for this decrease is not known, but it is interesting to note that the lowest value of the holdup reached, $4.4 \%$ (plotted in Figure 5-7) is below the value (6\%) for the next lower superficial velocity of $0.092 \mathrm{~mm} / \mathrm{s}$. While there appears to be a plateau in the level rise curve for the $0.092 \mathrm{~mm} / \mathrm{s}$ velocity run, the run was not continued for a long enough time and a level decrease could have also followed the peak. The high peaks of the two highest $\mathrm{H} 2 \mathrm{O} 2$ injection runs may be due to the foaminess of the simulant which subsided with continued agitation and bubble coalescence and collapse. If the lowest holdup at the end of the test runs is used, then except for the test point for $0.092 \mathrm{~mm} / \mathrm{s}$ superficial velocity, the data points still cluster around the line for the mechanical agitator runs.

PJM Testing, 3 Pa, AFA

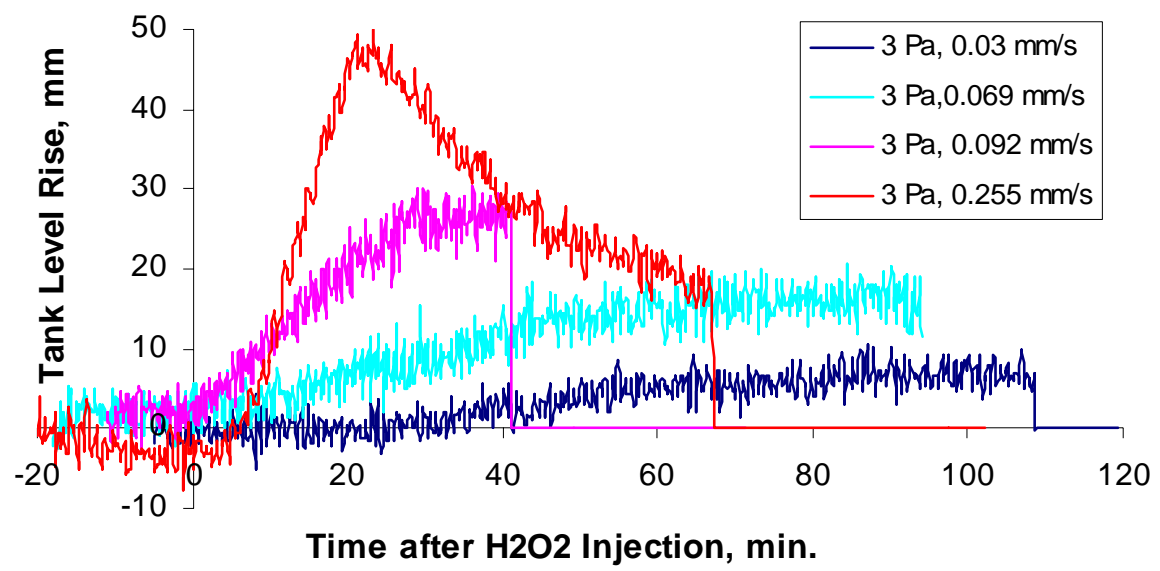

Figure 5-6. Tank Level Rise History after H2O2 Injection in 3 Pa AZ-101 Simulant 


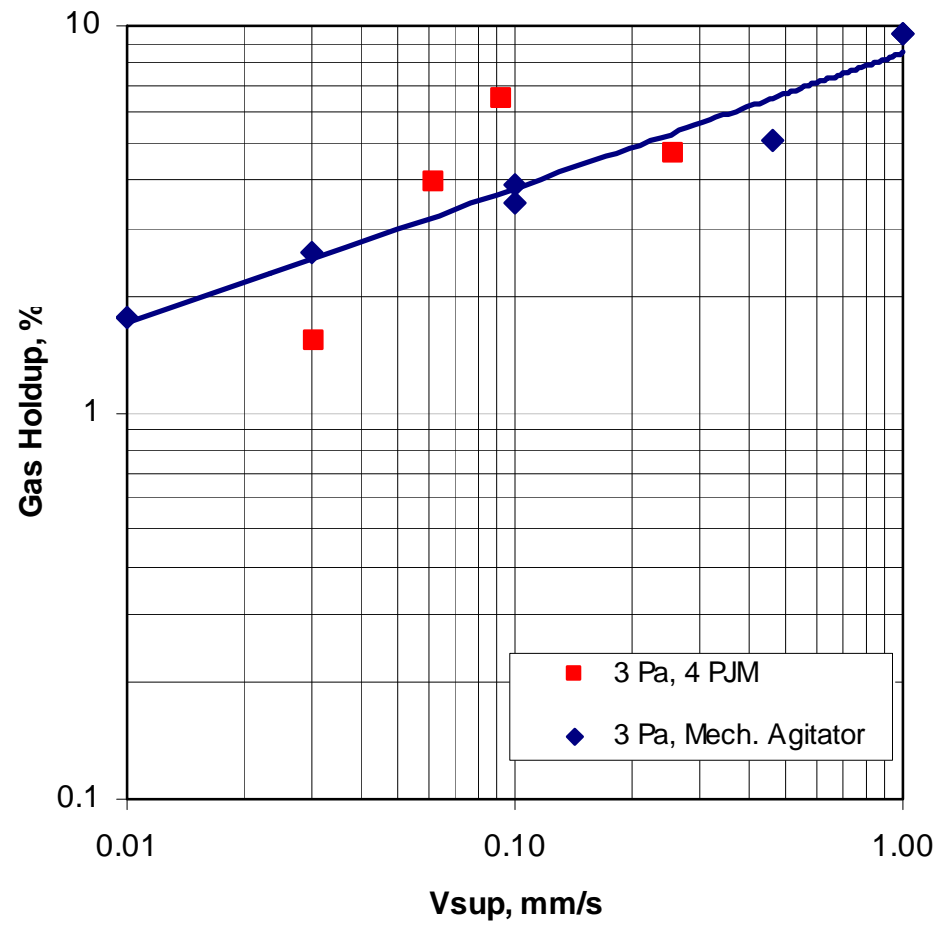

Figure 5-7. Gas Holdup in 3 Pa AZ-101 Simulant under PJM Mixing Conditions

\subsection{SUMMARY}

The effect of mixing using PJMs was compared to mechanical agitators with the SRNL Mixing Test Stand. During testing with the 30 Pa simulant with AFA, mixing with the PJM system was very poor, which resulted in higher gas holdups compared to values obtained with the mechanical agitator system. At 13 Pa good PJM mixing was observed and gas holdups were 30\% below those for mechanical agitation. For the $3 \mathrm{~Pa}$ testing however, significant foaming at high $\mathrm{H}_{2} \mathrm{O}_{2}$ injection rates was observed. However, if the testing was continued long enough, foaming subsided and gas holdups were similar to those obtained with mechanical agitation. In general, PJM agitation in the SRNL Mixing Test Stand resulted in similar to slightly lower gas holdup than with mechanical agitation.

A source of differences between the two types of mixing is the manner of generating bubbles. In PJM mixing, oxygen bubbles generated in-situ are probably smaller than sparged air bubbles broken up by the mechanical agitator. However, both methods of bubble generation were used in Phase I testing with mechanical agitation. The data at $13 \mathrm{~Pa}$ showed similar or slightly lower void values for the peroxide bubbles compared to air sparging. 
A second source of difference is that the mechanical agitator provides a large region of high shear rate, which could prevent bubbles from coalescing thus maintaining their small sizes and leading to higher holdup. In PJM mixing, except for the region adjacent to the PJM nozzles, shear rates are low. The tank volume averaged and time average shear rate would be low and promote bubble coalescence.

Applying the small scale data of the SRNL Mixing Test Stand for both PJM and mechanical agitation tests to the larger scale PJM systems such as the $1 / 4$ scale PJM model or the WTP may not be valid for the following reason: While velocity profiles may be similar for the SRNL PJM system to that of the larger systems, the time scale is reduced by the scale factor. The cycle time for each PJM pulse is half of the $1 / 4$ scale model and 1/9th that of the WTP. There is less time for the oxygen bubbles to collide and coalesce to larger bubbles. Thus small bubbles are favored which leads to lower bubble rise velocity (higher holdup) in the smaller scale system. Bubble coalescence does occur as shown in the mechanical agitation tests where adding more antifoam (or a different antifoam) reduced the holdup. This is the basic function of an antifoam, to promote bubble coalescence. 


\subsection{MASS TRANSFER TESTS}

\subsection{OVERVIEW}

The simulants for mass transfer testing included process water, process water with AFA which was cloudy white in color (Dow Corning, Q2-3183, antifoam agent), and AZ-101 simulant which was reddish brown in color. The simulants were tested in a 28 feet tall by 30 inch diameter column, shown in Figure 6-1 and Figure 6-2. The column, or tank, was filled to various levels and the simulants were injected with oxygen to saturation. Once saturated, air was introduced through a concentric, vertical sparger tube to strip the oxygen from solution. Air removed oxygen from solution as it bubbled up from the bottom of the column through each simulant to the surface. Oxygen was used as the dissolved gas since hydrogen has inherent safety problems, and oxygen mass transfer properties are related to hydrogen dissolution through mass transfer modeling. In fact, the primary purpose of these experiments is to provide experimental data to PNNL for further modeling of gas retention and release in waste tanks, which contain radiolytically generated hydrogen [3].

Data is provided herein for modeling in the form of mass transfer coefficients and holdups or void fractions. To determine these quantities, measurements of the pressure at various column levels, laser measurements of the surface level, and dissolved oxygen concentration (DO) were recorded for the simulants at different superficial velocities, where the superficial velocity is the volumetric flow rate of air divided by the cross sectional surface area of the column. Different simulant levels and superficial velocities were used in testing, as specified in Table 6.1. In addition to transfer coefficients and void fractions, photos and videos provide further insight into the mass transfer processes occurring in the column. Along with this report, electronic files are supplied with this report, which contain the photos, videos, and calculations: MT Test1 - MT Test 9; MT Test 16 - MT Test 30; Laser...Test 1 - Laser...Test 9; Laser...Test 16 Laser...Test 30; kLa Summary; Void Summary_rev; Void Uncertainty, Mass transfer videos, and Photos of water tests at all three test levels. To support these calculations, required definitions for the mass transfer coefficients, gas holdups and void fractions follow. 


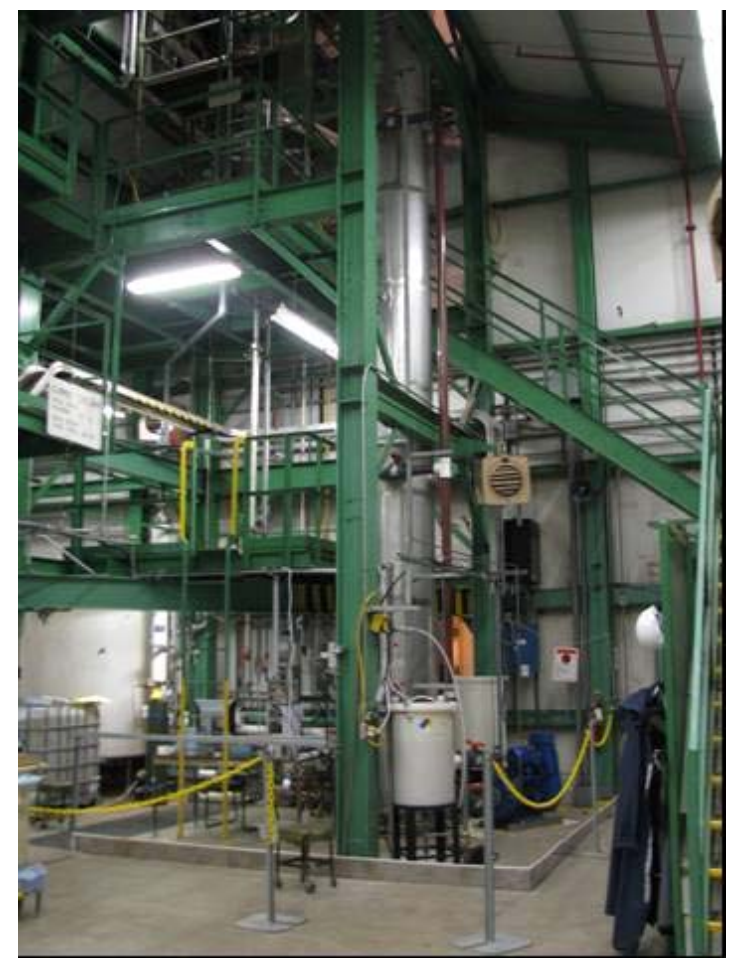

Figure 6-1. Column and Equipment Installation for Large Scale Mass Transfer Testing

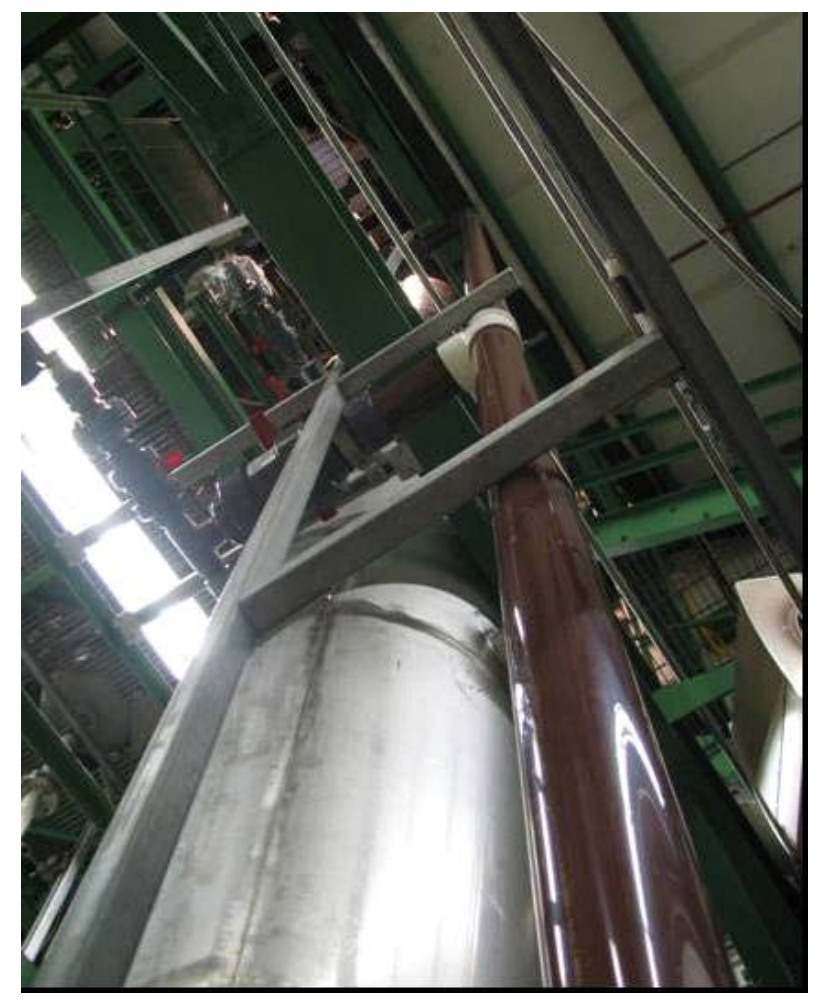

Figure 6-2. Close-up View of Column Installation 
Table 6-1. Mass Transfer Test Matrix

\begin{tabular}{|c|c|c|c|c|c|c|}
\hline $\begin{array}{c}\text { Test } \\
\text { Number }\end{array}$ & $\begin{array}{c}\text { Fluid / } \\
\text { Simulant }\end{array}$ & $\begin{array}{c}\text { AFA } \\
\mathbf{3 5 0} \\
\mathbf{m g} / \mathbf{L}\end{array}$ & $\begin{array}{c}\text { Column Fill } \\
\text { Depth } \\
\text { Feet (meters) }\end{array}$ & $\begin{array}{c}\text { Yield } \\
\text { Stress, } \\
\text { Pascals }\end{array}$ & $\begin{array}{c}\text { Sparger Air } \\
\text { Flow Rate, } \\
\text { scfm }\end{array}$ & $\begin{array}{c}\text { Superficial } \\
\text { velocity, } \\
\text { mm/sec }\end{array}$ \\
\hline 1 & Water & No & $4.3(1.31)$ & 0 & 2.09 & 2 \\
\hline 2 & Water & No & $4.3(1.31)$ & 0 & 5.23 & 5 \\
\hline 3 & Water & No & $4.3(1.31)$ & 0 & 10.46 & 10 \\
\hline 4 & Water & No & $11.9(3.63)$ & 0 & 2.09 & 2 \\
\hline 5 & Water & No & $11.9(3.63)$ & 0 & 5.23 & 5 \\
\hline 6 & Water & No & $11.9(3.63)$ & 0 & 10.46 & 10 \\
\hline 7 & Water & No & $24.3(7.41)$ & 0 & 2.09 & 2 \\
\hline 8 & Water & No & $24.3(7.41)$ & 0 & 5.23 & 5 \\
\hline 9 & Water & No & $24.3(7.41)$ & 0 & 10.46 & 10 \\
\hline 16 & Water & Yes & $4.3(1.31)$ & 0 & 2.09 & 2 \\
\hline 17 & Water & Yes & $4.3(1.31)$ & 0 & 5.23 & 5 \\
\hline 18 & Water & Yes & $4.3(1.31)$ & 0 & 10.46 & 10 \\
\hline 19 & Water & Yes & $11.9(3.63)$ & 0 & 2.09 & 2 \\
\hline 20 & Water & Yes & $11.9(3.63)$ & 0 & 5.23 & 5 \\
\hline 21 & Water & Yes & $11.9(3.63)$ & 0 & 10.46 & 10 \\
\hline 22 & Water & Yes & $24.3(7.41)$ & 0 & 2.09 & 2 \\
\hline 23 & Water & Yes & $24.3(7.41)$ & 0 & 5.23 & 5 \\
\hline 24 & Water & Yes & $24.3(7.41)$ & 0 & 10.46 & 10 \\
\hline 25 & AZ-101 & Yes & $4.3(1.31)$ & 13 & 2.09 & 2 \\
\hline 26 & AZ-101 & Yes & $4.3(1.31)$ & 13 & 5.23 & 5 \\
\hline 27 & AZ-101 & Yes & $4.3(1.31)$ & 13 & 10.46 & 10 \\
\hline 28 & AZ-101 & Yes & $24.3(7.41)$ & 13 & 2.09 & 2 \\
\hline 29 & AZ-101 & Yes & $24.3(7.41)$ & 13 & 5.23 & 5 \\
\hline 30 & AZ-101 & Yes & $24.3(7.41)$ & 13 & 10.46 & 10 \\
\hline
\end{tabular}

This Test Matrix meets the requirements of Table 1.5.2, Tests 8-1, 8-2, 8-4, and 8-13 [3].

\subsubsection{Mass Transfer Coefficient}

The mass transfer equation is defined as [15],

$$
\frac{d C}{d t}=-k_{L} a(C-C a)
$$

where

$\mathrm{t}-$ time, min

$\mathrm{C}, \mathrm{C}(\mathrm{t})$ - dissolved oxygen concentration

$\mathrm{Ca}$ - oxygen concentration at equilibrium

$\mathrm{C}^{*}$ - dissolved oxygen concentration at saturation

$\mathrm{kLa}$ - mass transfer coefficient, min-1 
Integrating from $\mathrm{C}=\mathrm{C}^{*}$ to $\mathrm{C}(\mathrm{t})$ gives

$$
\frac{C(t)-C a}{C^{*}-C a}=\exp \left(-k_{L} a \cdot t\right)
$$

Solving for the natural logarithm,

$$
k_{L} a \cdot t=-\ln \left(\frac{C(t)-C a}{C^{*}-C a}\right)
$$

Mass transfer coefficients are experimentally determined using Eq. 6.2. The terms $\mathrm{C}^{*}$ and $\mathrm{C}_{\mathrm{a}}$ are experimentally determined constants. Once these constants are known, the change in concentration, $\mathrm{C}(\mathrm{t})$, is measured with respect to time, and $\mathrm{k}_{\mathrm{L}} \mathrm{a}$ is plotted as a straight line with respect to time, such that $\mathrm{y}=\mathrm{mx}+\mathrm{b}$, where y equals the natural logarithmic term in Eq. 6.2, $\mathrm{m}=-\mathrm{k}_{\mathrm{L}} \mathrm{a}$, and $\mathrm{b}$ is theoretically zero but was experimentally observed to have a finite value. The mass transfer coefficients are then determined from the slope of the straight line plots of experimental results.

\subsubsection{Void Fraction}

The gas holdup, $\varphi$, is defined as

$$
\phi=\frac{V_{g}}{V_{s}}
$$

where

$\mathrm{V}_{\mathrm{g}}$ - gas volume

$\mathrm{V}_{\mathrm{s}}$ - simulant volume

The gas holdup was determined by the laser meters which measure the change in tank level. The void fraction is defined as

$$
\alpha=\frac{V_{g}}{V_{g}+V_{s}}
$$

and was measured by differential pressure measurements. The specific calculations are given in Eqs. 6.8 and 6.11. The calculated terms $(\alpha, \varphi)$ are numerically close at the low air injection rates used in the tests.

The gas holdups, void fractions, and mass transfer coefficients were established experimentally as follows. 


\subsection{EXPERIMENTAL METHODS}

The experimental procedure consisted of several basic steps [16], which can be explained using the simplified schematic shown in Figure 6-3. First, the mixing tank, referred to as the bubble column, was filled to one of the three levels shown in the figure. Oxygen was then added through the oxygen sparger, which is a sintered metal filter that produces oxygen micro-bubbles. To distribute the oxygen, the recirculation pump moved the simulant past the oxygen sparger and into the static mixer, which evenly distributed the oxygen bubbles throughout the pipe cross section. The simulant flowed upward through the column and back to the recirculation pump through the recirculation loop, which is shown as a heavy line in the figure. Four pairs of view ports and transparent piping permitted viewing of the simulant during processing. The recirculation pump continued to operate until the simulant was saturated with oxygen, which was measured with DO sensors located at three of the six locations shown in the figure (DOT1 DOT6). Once the simulant was saturated, air entered the simulant through the sparger pipe at the top of the open top column, and the oxygen was stripped. The DO sensors provided data to determine the mass transfer coefficients.

The five pressure transducers, PT1 - PT5 and the three laser level indicators determined changes in pressure and level to find void fractions for the simulants. The lasers were used to monitor level changes during testing, as well as determining gas holdup. In particular, process water was added between some tests to compensate evaporation during testing. Typically, less than $1 \mathrm{~mm}$ was lost per test from evaporation during the air sparge. Process water was added as required for water and water plus AFA tests, but not for AZ-101 tests. 
WSRC-STI-2007-00537, REVISION 0

SRNL-RPP-2007-00023, REVISION 0

At the $7.41 \mathrm{~m}$ level

System volume $=916$ gallons

column volume $=883$ gallons

(3.028 gallons /inch)
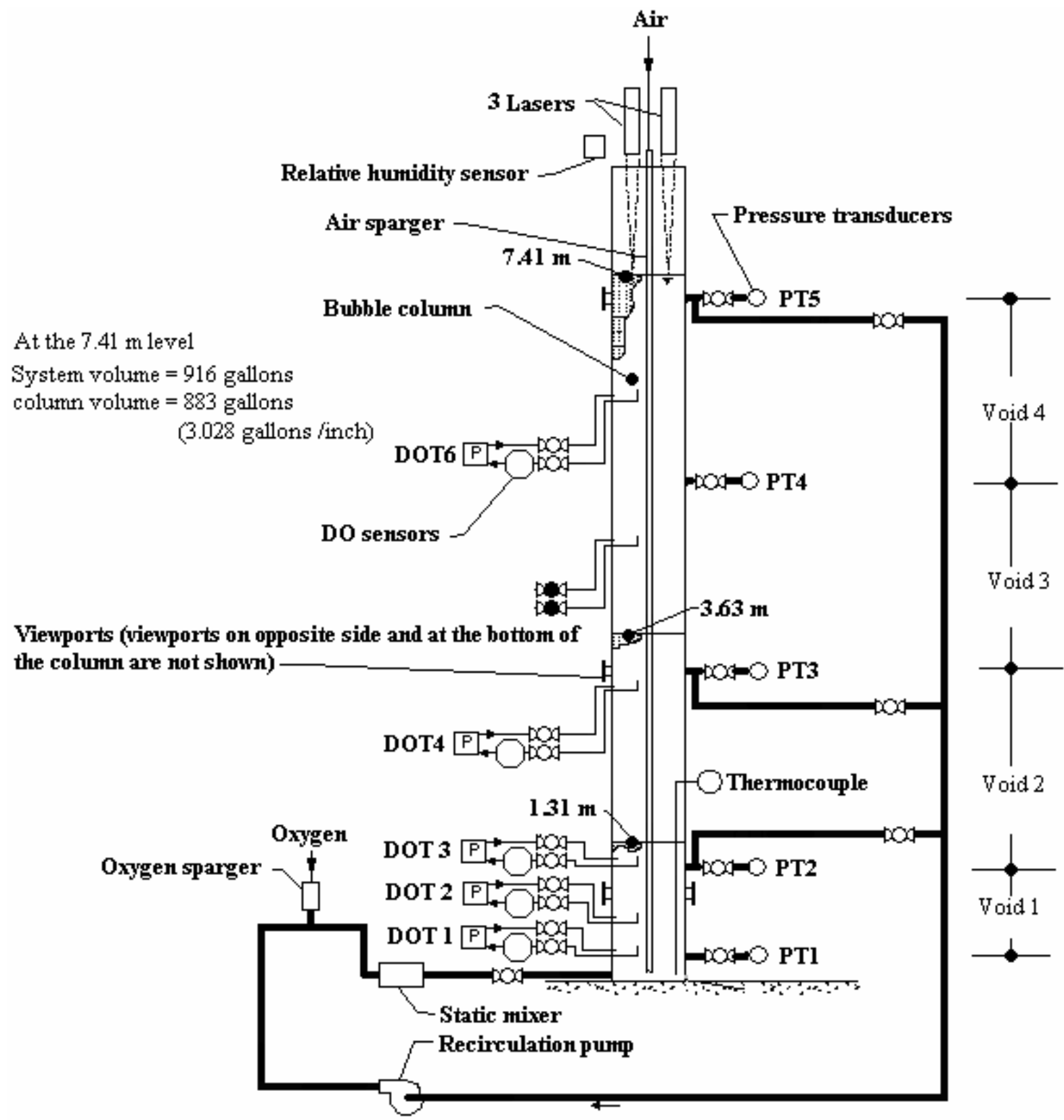

Figure 6-3. Simplified Mass Transfer System Schematic 


\subsubsection{Equipment Description}

The complete system schematic is shown in Figure 6-4. Details of design, assembly, and operation are included in ITS-WI-0021, WSRC-NB-2007-00049, and WSRC-NB-2007-00150. Part of that documentation is provided here. The general layout of the equipment is shown in Figure 6-5 and Figure 6-6, and the following discussions clarify specifics of the assembly.

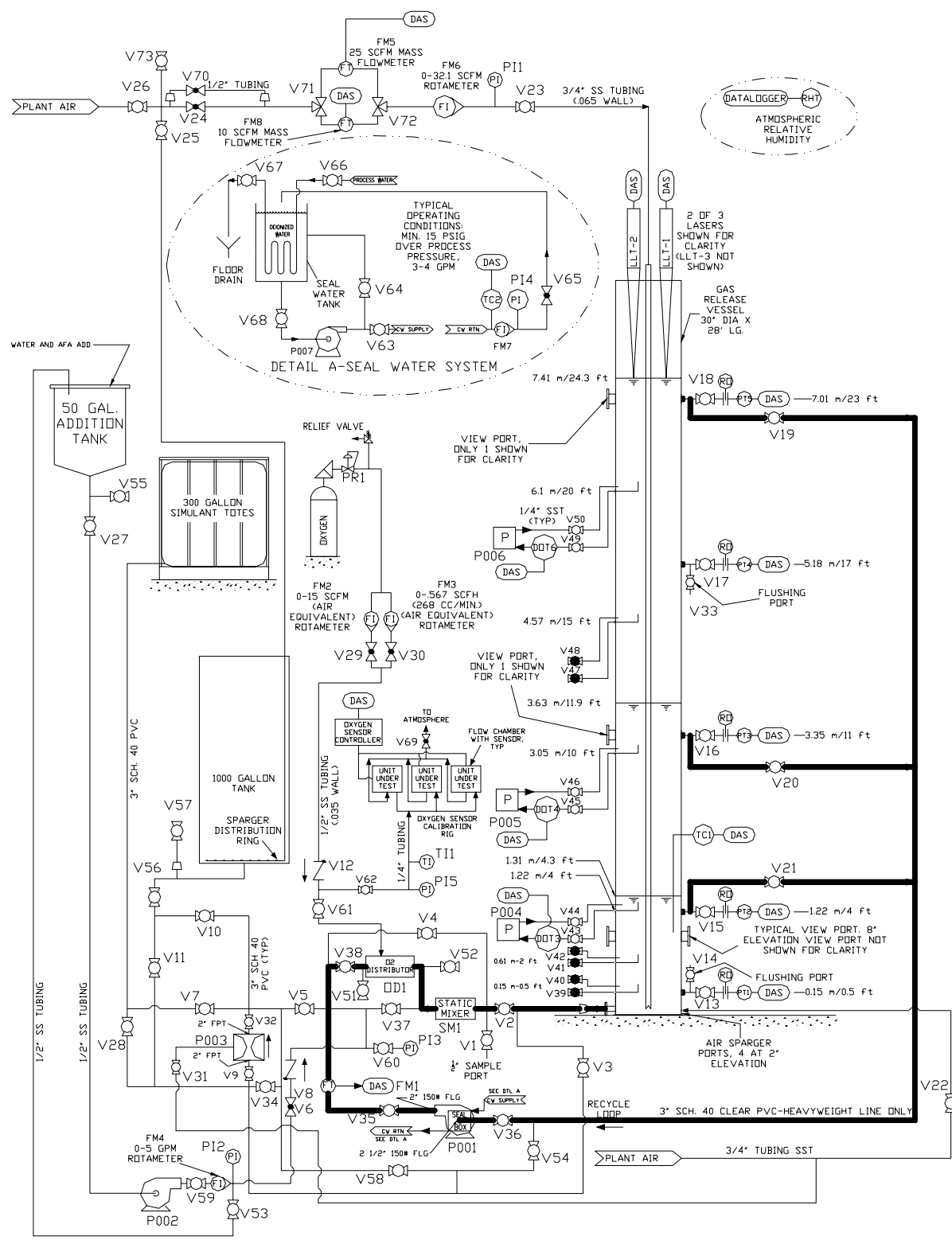

Figure 6-4. System Schematic for Large Scale Mass Transfer Testing 
WSRC-STI-2007-00537, REVISION 0

SRNL-RPP-2007-00023, REVISION 0

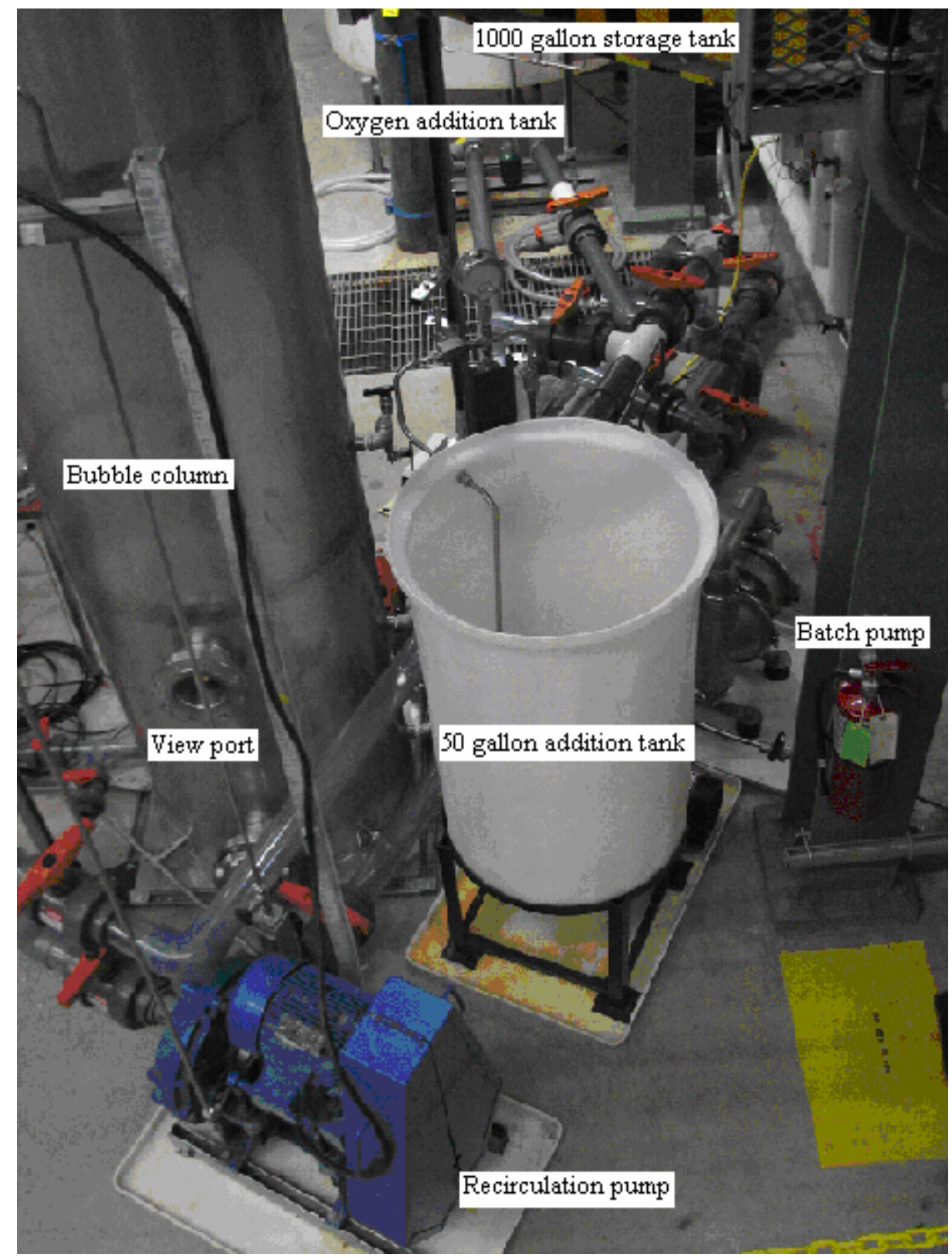

Figure 6-5. Equipment Layout - View 1 


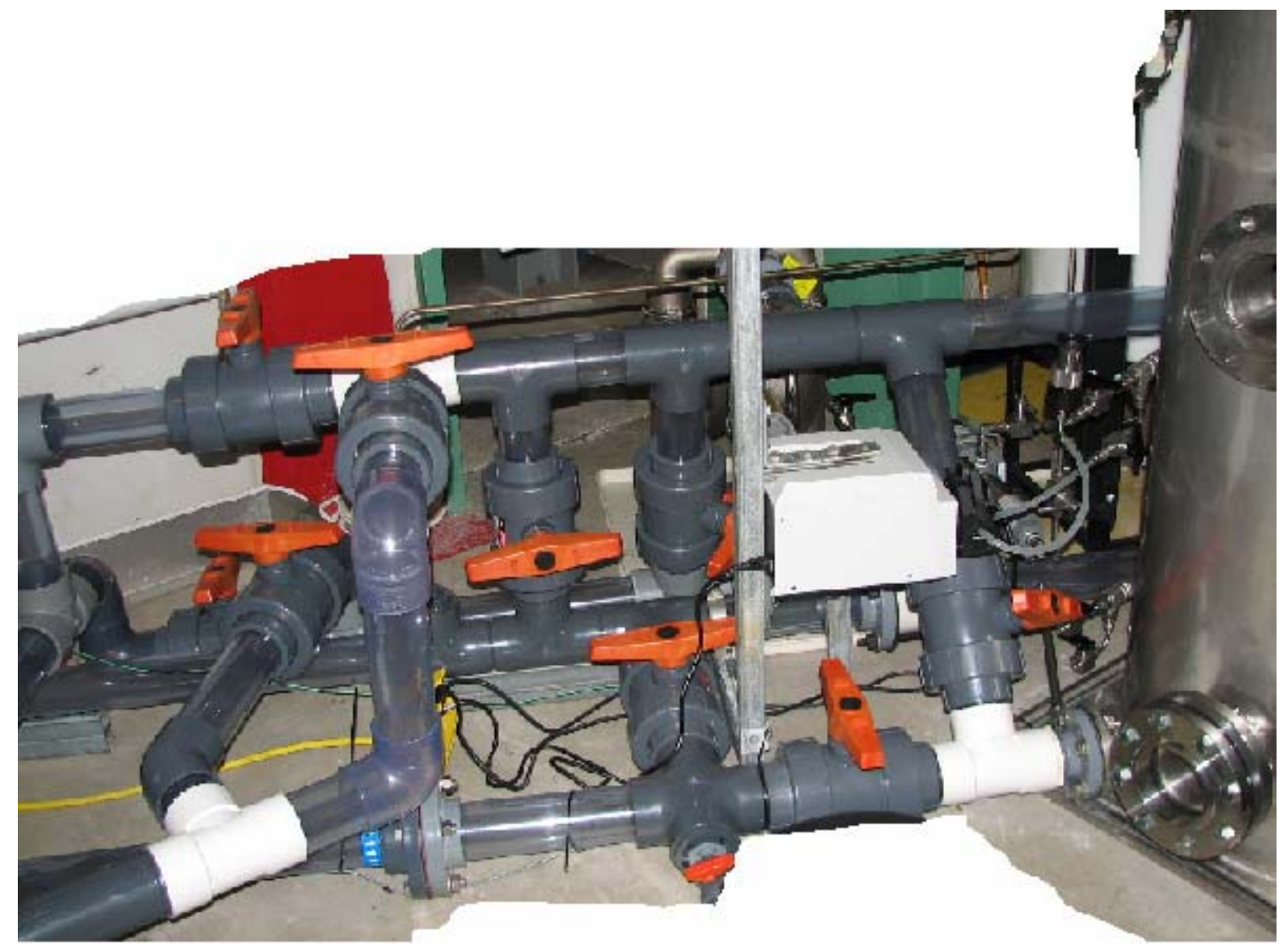

Figure 6-6. Equipment Layout - View 2

\subsubsection{Bubble Column}

The 28 feet tall, 30 inch outside diameter, 14 gauge bubble column was constructed as shown in Figure 6-7. The column was installed and leveled to within 1/8 inch of plumb, which was excellent given the $+/-1 / 16$ inch tolerances of construction. Using a plumb bob, measurements were taken between the upper and lower view ports and upper and lower nozzles, which were at right angles to the view ports. Due to slight ovality of the sheet metal column, straightness of the column varied by $+/-1 / 4$ inch up and down the length of the column. View ports, DO sensors, and pressure transducers are attached on the column as shown in Figure 6-4. A typical 4.026 inch inside diameter view port is shown in Figure 6-8. The DO sensors and pressure transducers are discussed below. 
WSRC-STI-2007-00537, REVISION 0

SRNL-RPP-2007-00023, REVISION 0

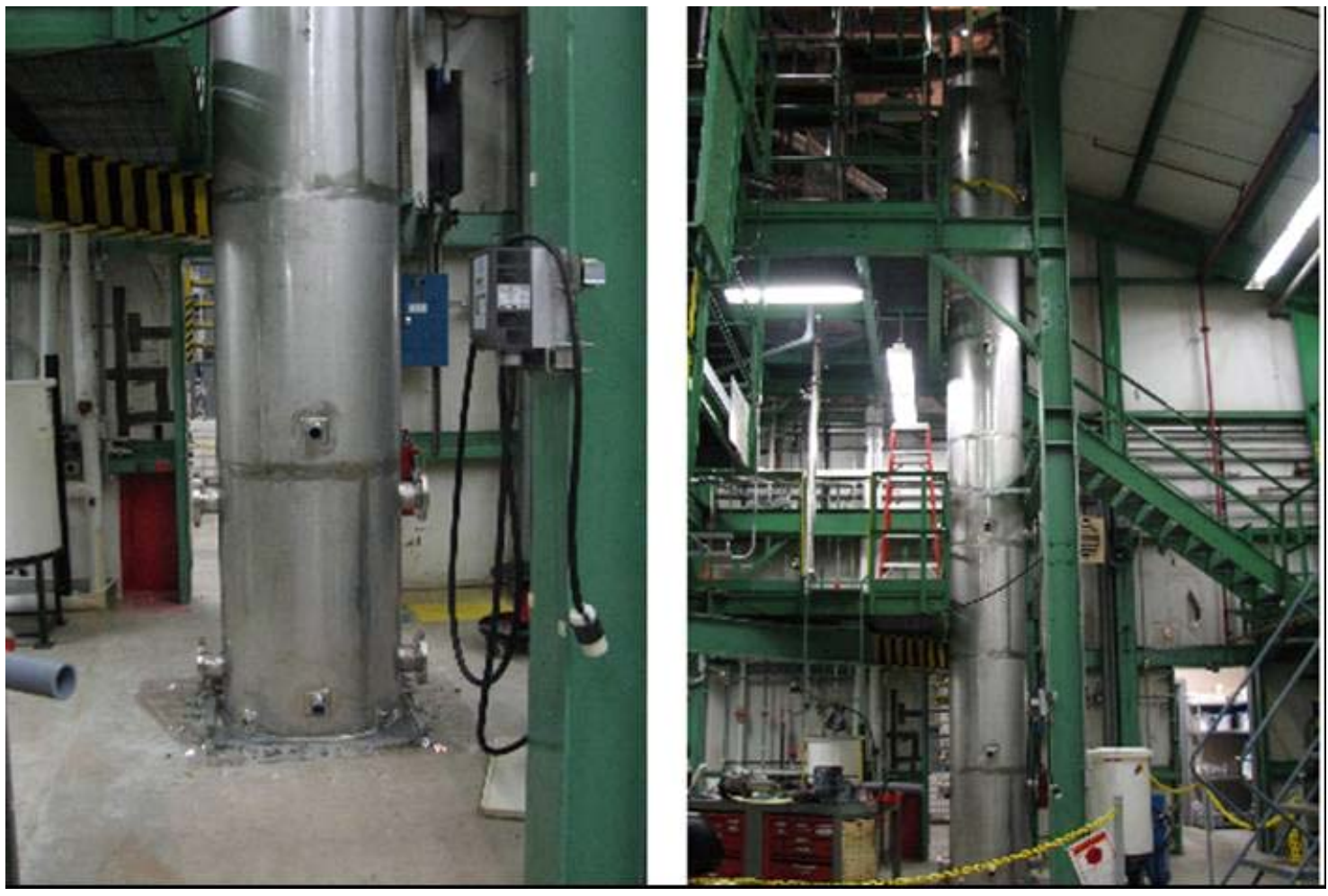

Figure 6-7. Bubble Column Installation

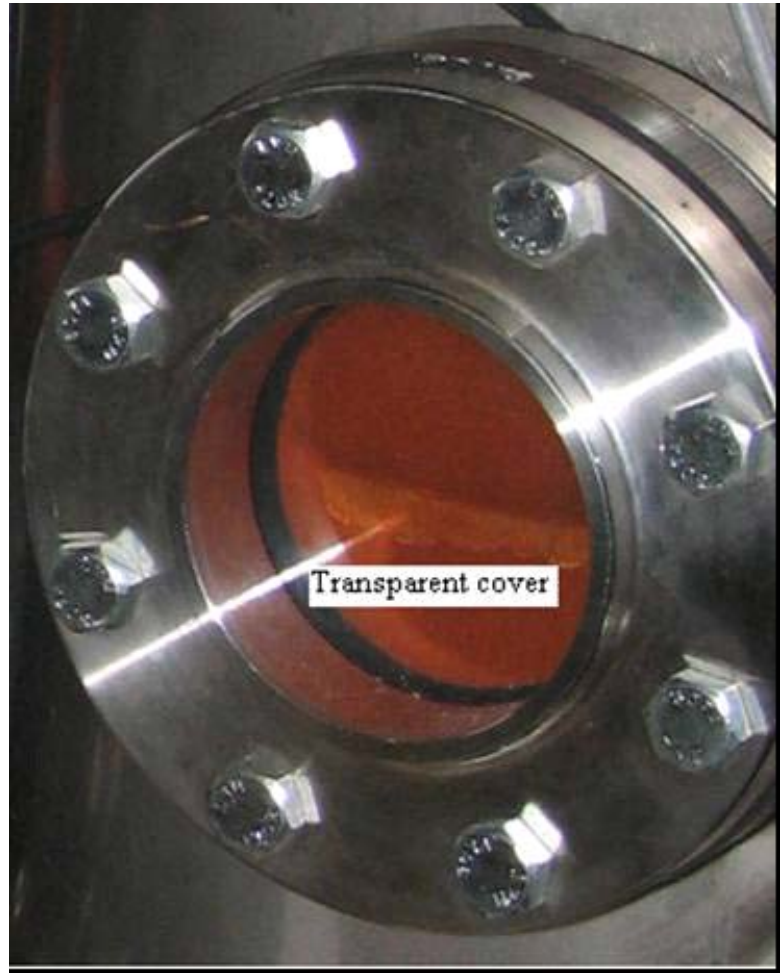

Figure 6-8. Typical View Port 


\subsubsection{Data Acquisition System (DAS)}

LabView ${ }^{\circledR}$ was used for the DAS, and typical on-line displays are shown in Figure 6-9 and Figure 6-10. Figure 6-11 displays the processor output from the DO sensor. Appropriate transfer functions were programmed into the DAS to ensure that accurate data was displayed and recorded. Data was converted for display using Excel® for this report. Figure 6-9 displays temperatures near the bottom of the bubble column (Tank), pressures for PT1 to PT5, and the DO concentration for channels 1 to 3, which are indicated as O2 Sens 1 to O2 Sens 3 respectively. In addition, DO concentrations are monitored real time using the DO graphic display shown in Figure 6-11. Flow rates are shown for the air flow rate using either AFM 1 or AFM 2, and the recirculation pump flow rate using LFM 1. The use of the DAS screen shown in Figure 6-10 permits online monitoring of simulant level during tests. In other words, the DAS provides continuous monitoring of critical data as well as a recorded history of that data.

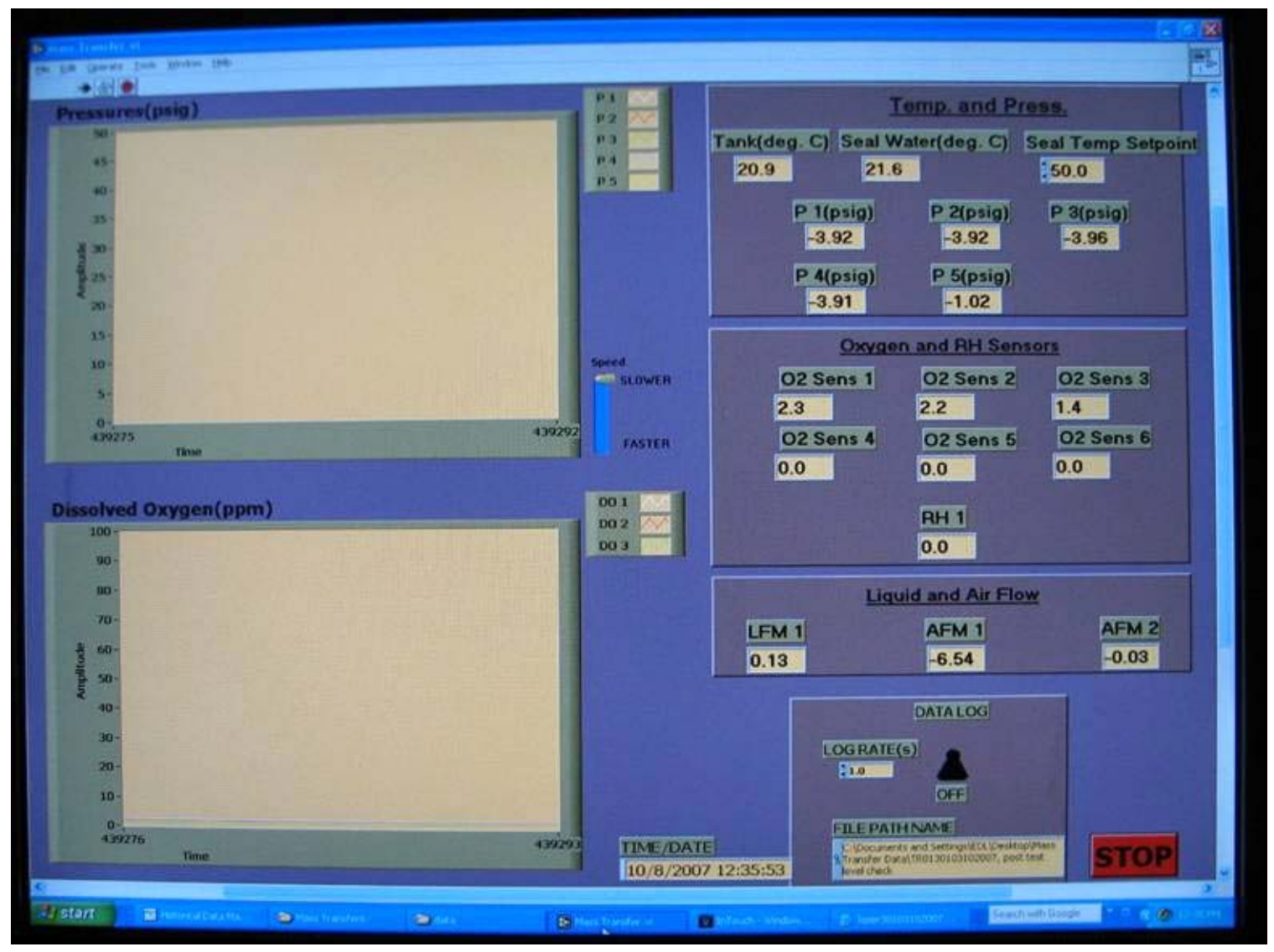

Figure 6-9. DAS Display - View 1 
WSRC-STI-2007-00537, REVISION 0

SRNL-RPP-2007-00023, REVISION 0

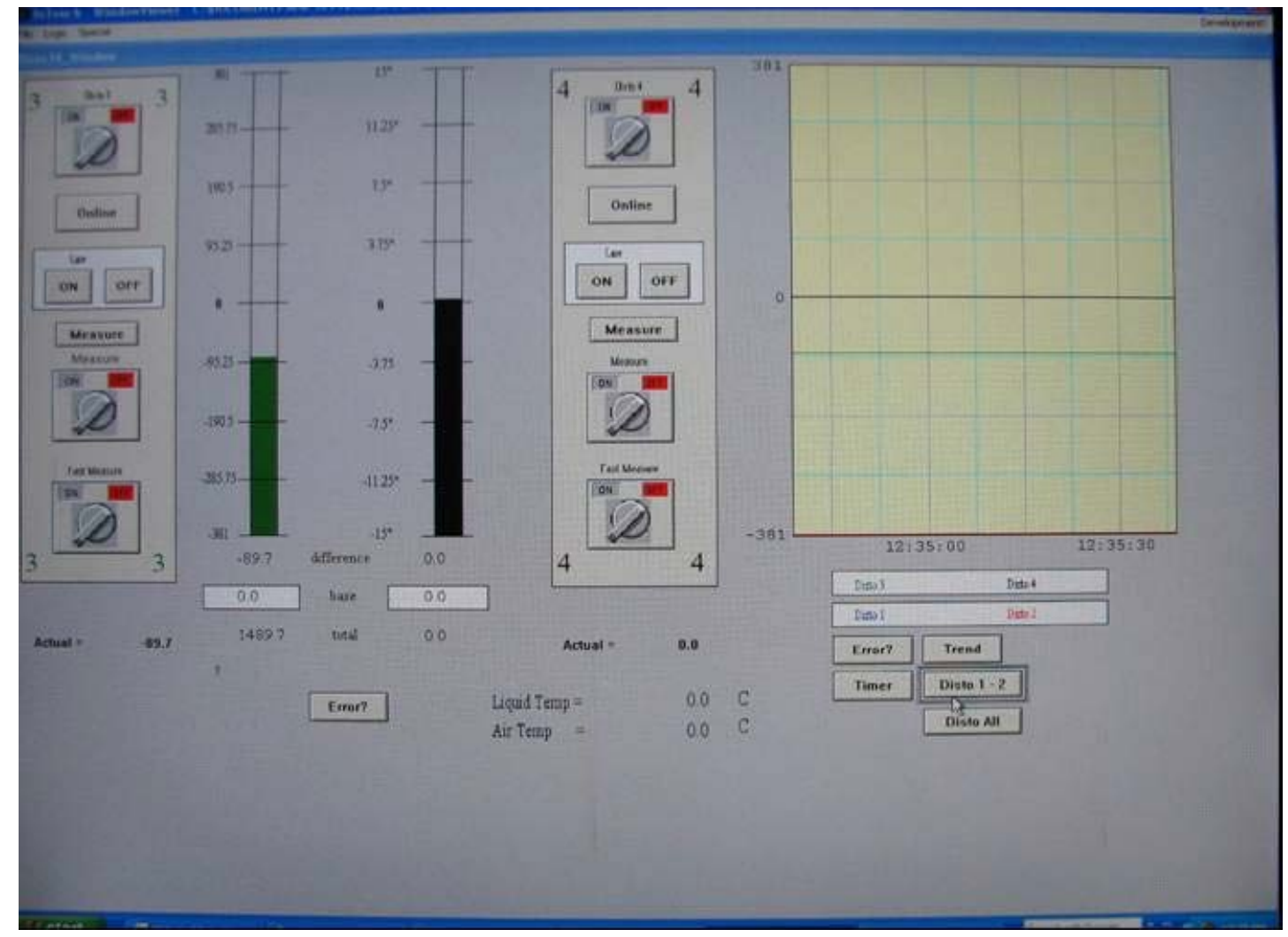

Figure 6-10. DAS Display - View 2

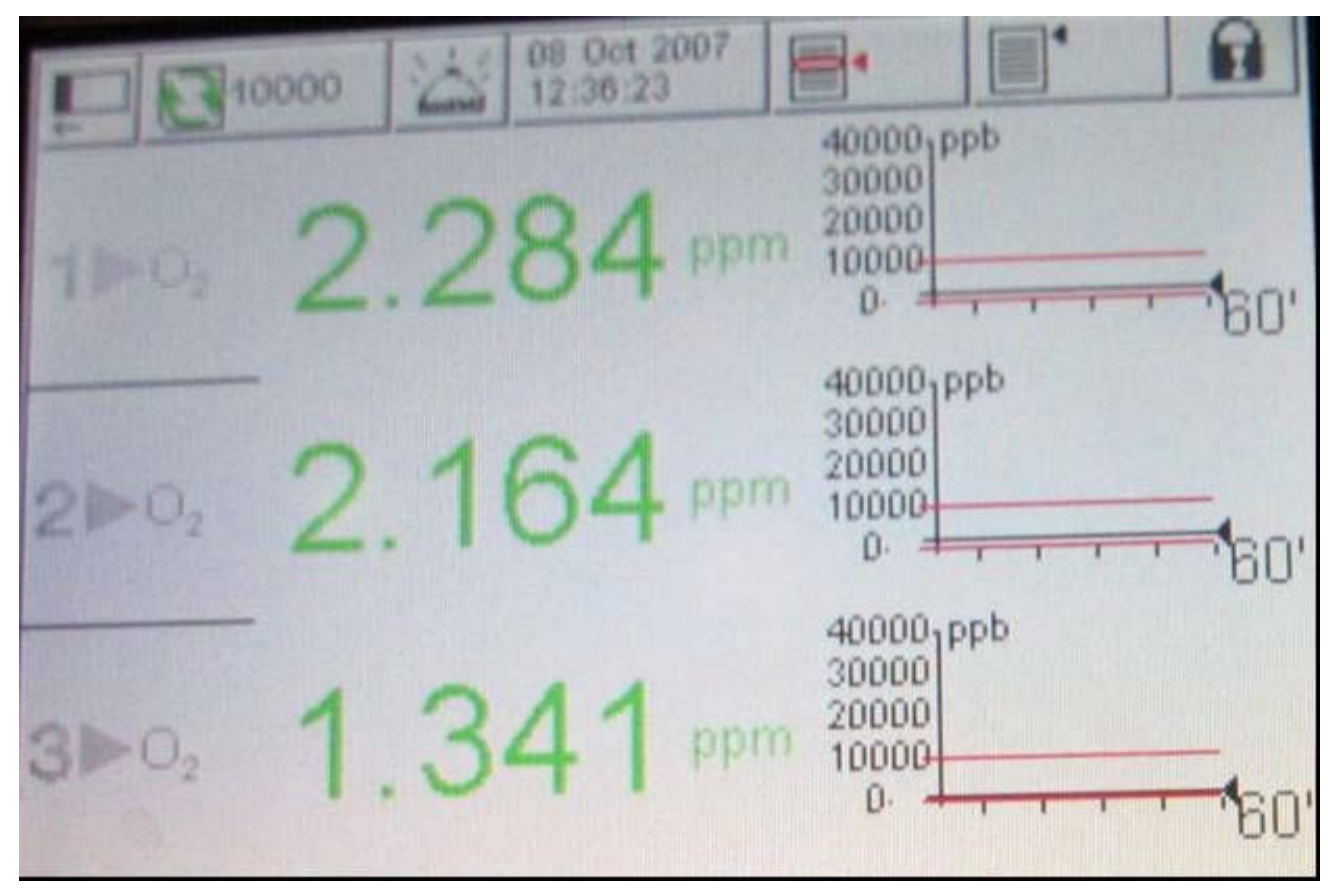

Figure 6-11. DO Processor Display 


\subsubsection{Pressure Transducers, PT1 - PT5}

GP-50 sanitary, flush diaphragm, pressure transducers (0-15 psig, +/- $0.1 \%$ accuracy) were installed after receipt, even though the transducer tolerances exceeded the vendor specification for calibration accuracy as received. The tolerances were considered acceptable because the lead time for replacement parts would unacceptably delay the schedule. Initial accuracy of the installed transducers varied from $0.122 \%$ to $0.273 \%$. Post calibration accuracy varied between $0.122 \%$ and $0.583 \%$ after all testing was complete.

\subsubsection{DO Sensors, DOT1 - DOT6}

Hach Ultra DO sensors were installed. The sensors had a specified range of $0-80 \mathrm{ppm}$ and a response time of 38 seconds. This application was atypical for Hach's design, since these sensors are typically used at atmospheric conditions where DO concentrations are $7-8 \mathrm{ppm}$. In this application, the DO concentrations were above $50 \mathrm{ppm}$. Vendor experience was nonexistent for using these sensors at either high DO concentrations or in caustic environments, such as in the AZ-101 simulant.

Even so, satisfactory performance was demonstrated by the sensors in these tests. The sensors consist of electrodes submersed in an electrolyte, referred to as zero oxygen solution. The solution and electrodes are isolated from the simulant by a $25 \mu \mathrm{m}$ thick Tefzel enclosing membrane, which permits oxygen to pass from the simulant into the zero oxygen solution to react at the electrode. The induced voltage at the electrodes is converted by the DO processor into a DO concentration, expressed in ppm. The motive force for the reaction is the oxygen pressure at the membrane of the sensor. The higher the partial pressure of the oxygen, the higher the indicated DO concentration. As a result, the measured DO concentration is nearly independent of the simulant, even though the actual DO concentration varies between simulants. Similar DO concentrations corrected for specific gravity are expected at a specified level in the column, regardless of whether water or AZ-101 are tested. That is, as the level of simulant increases above a point in the column, the DO concentration increases at that point as a function of specific gravity. Processor calibrations are performed as if water is always the tested fluid. Determination of the actual DO concentration for AZ-101was beyond the scope of this project, and was unnecessary for determining mass transfer coefficients. Since only the ratio of concentrations is required (Eq. 6.2), the absolute value of the DO concentration is irrelevant, and the $\mathrm{DO}$ sensor indications are adequate.

\section{DO Sensor Calibrations}

The DO sensors were calibrated using the setup shown in Figure 6-13. Calibrations were performed using vendor calibration procedures combined with calculations to establish the expected DO concentration at a specified pressure and measured temperature. Essentially, the sensor was set to a calculated theoretical value. Once the sensor was calibrated, the DO concentration was lowered and raised back to the calibration conditions, which demonstrated that the instrument provided repeatable results within $1.8 \mathrm{ppm}$ throughout the range of interest. 
For water, a relationship is well known to relate the partial pressure of oxygen to the parts per million, ppm, of oxygen in solution at ambient conditions for low oxygen concentrations. When water is exposed to air, the concentration is related to the pressure and temperature, using Henry's Law, such that $\mathrm{x}=\mathrm{P} / \mathrm{H}$, where $\mathrm{x}$ is the concentration, $\mathrm{P}$ is the partial pressure of the gas (oxygen), and H is Henry's constant. Hach, Inc. provided the attached air tables. This data was experimentally validated [15].

To obtain oxygen concentrations at higher pressures, data was extrapolated as shown in Figure 612 , which gives the theoretical $\mathrm{O}_{2}$ concentration as a function of pressure and temperature. The mass percent of oxygen in air is 0.2315 percent. The quantities listed in the Hach data table were then each be divided by this quantity to obtain the discrete points shown in the lower left corner of the figure. Assuming Henry's Law to hold true at all concentrations at any given temperature, the data at each temperature was then extrapolated to obtain the relationship between pressure and oxygen concentration for each temperature. This figure can be used to measure oxygen concentrations in water and to initially calibrate the DO sensors in oxygen.

To find the concentration, the temperature and pressure of oxygen are required. Specifically, calibration was initially required near $75-80 \mathrm{ppm}$ as the upper range of the DO sensors are $80 \mathrm{ppm}$. Subsequently, the test range was lowered to approximately $63 \mathrm{ppm}$ to maximize reliability of the sensors. From Figure 6-12, approximately 15 psig is required at ambient temperatures. Barometric pressure must be considered to use this figure, since 0 psig $=14.696$ psia. For example, a pressure of 15 psig oxygen pressure and 29.5" $\mathrm{Hg}$ barometric pressure, find $15+(29.5) *(14.696 / 29.92)=15+14.49=29.49 \mathrm{psia}$, and then determine the ppm for the measured temperature at $29.49-14.696=14.79 \mathrm{psig}$ If the temperature is $25^{\circ} \mathrm{C}$, then the concentration is $\approx 73 \mathrm{ppm}$. 
WSRC-STI-2007-00537, REVISION 0

SRNL-RPP-2007-00023, REVISION 0

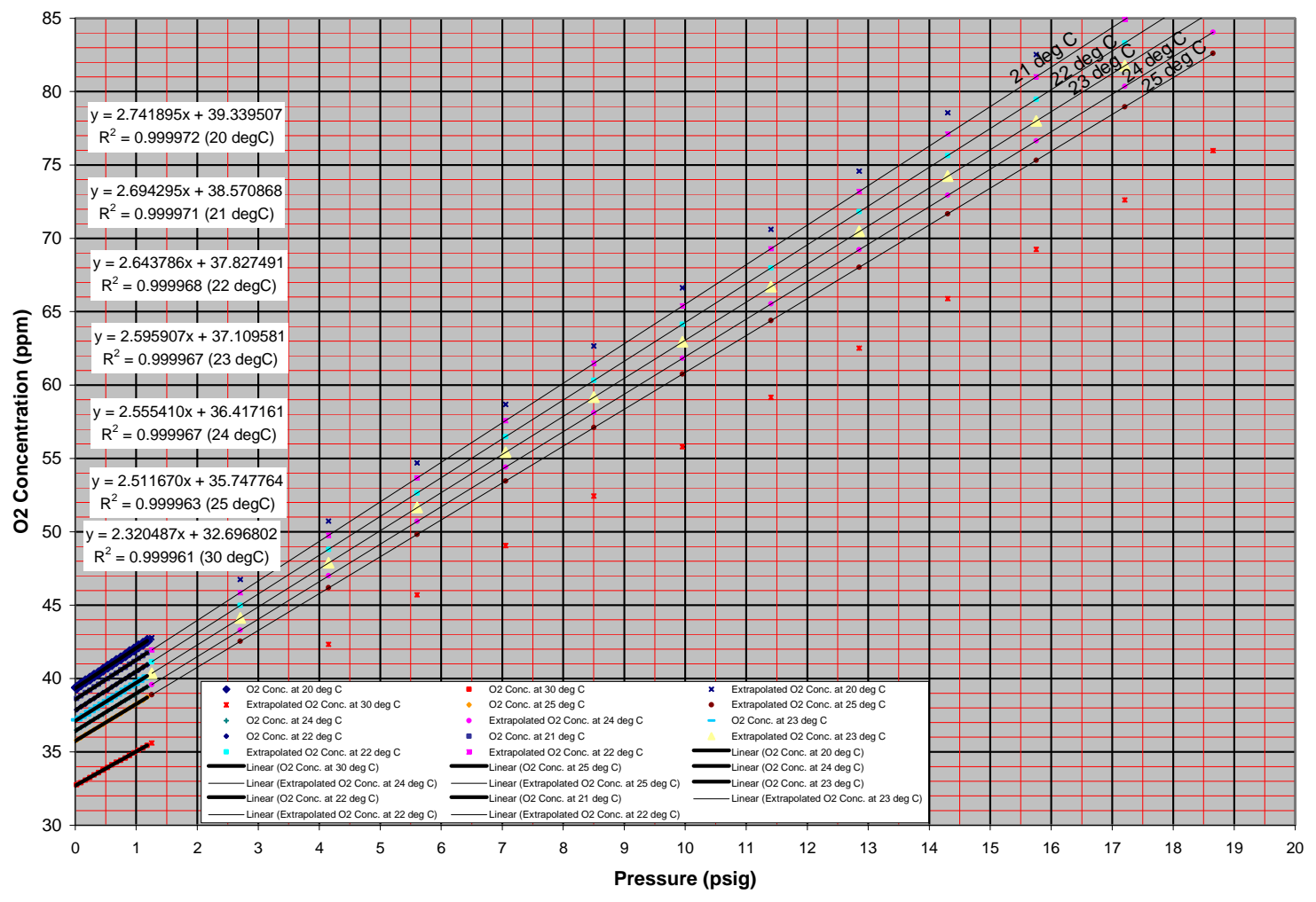

Figure 6-12. Theoretical Oxygen Concentration in Water

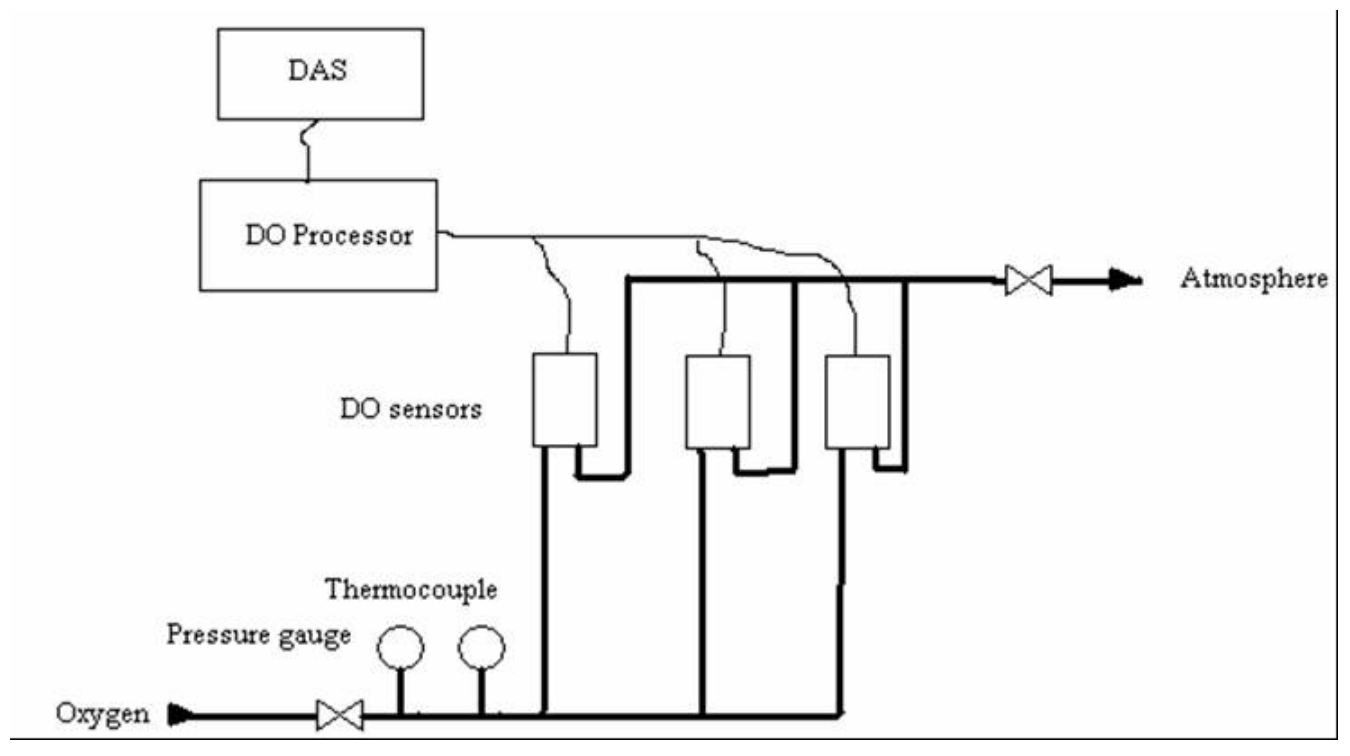

Figure 6-13. DO Sensor Calibration Rig 
The sensor reliability was noted to decrease during calibration because the oxygen rich environment used during calibration accelerated the chemical reactions at the electrodes of the sensor, and decreased their useful life. The longer the sensor was exposed to calibration conditions the shorter the sensor life. Chemical cleaning was performed to refurbish the sensor electrodes when they were initially purchased, but cleaning potentially shortened sensor life. To maximize sensor life, a minimum of calibrations was performed. During water and water with AFA tests, the level was repeatedly returned to the 7.41 meter level, and the oxygen concentrations at that level were verified to ensure that the sensors were still operating properly. When AZ-101 testing started, this option was unavailable. All of the sensors were tested before and after testing of all of the simulants, and one sensor was tested a second time immediately before AZ-101 testing after all water and water with AFA tests were completed.

The pre-test calibration results for water and water with AFA testing are shown in Figure 6-14, and the post test results are shown in Figure 6-15. The pre-test results indicated that the tolerance for DO concentration was $1.8 \mathrm{ppm}$ throughout the sensor range. At $55 \mathrm{ppm}$ the error is $1.8 \mathrm{ppm} / 55 \mathrm{ppm}=3.3 \%$. At atmospheric conditions the error is closer to $1.8 \mathrm{ppm} / 8 \mathrm{ppm}$ $=22 \%$. Similar post calibration results were found after water and water with AFA tests were complete. However, electrode degradation occurred during AZ-101 testing, and post test calibrations indicated that the sensors drifted below the expected concentration by $6-11 \mathrm{ppm}$. Discoloration of the transparent sensor electrolyte was noted, and was assumed to be due to AZ-101 contamination of the electrolyte. Presumably, this contamination accelerated electrode degradation. A thorough review of the DO sensor data concluded that there were no sudden drifts in DO concentration during testing. Accordingly, a conclusion was reached that the DO sensor degradation occurred following water with AFA testing, when the sensors were subjected to the AZ-101 prior to disassembly of the sensors. Even though the sensors were considered adequate throughout testing, the calculated uncertainties of the sensors are based on the most conservative conditions of service. 
WSRC-STI-2007-00537, REVISION 0

SRNL-RPP-2007-00023, REVISION 0

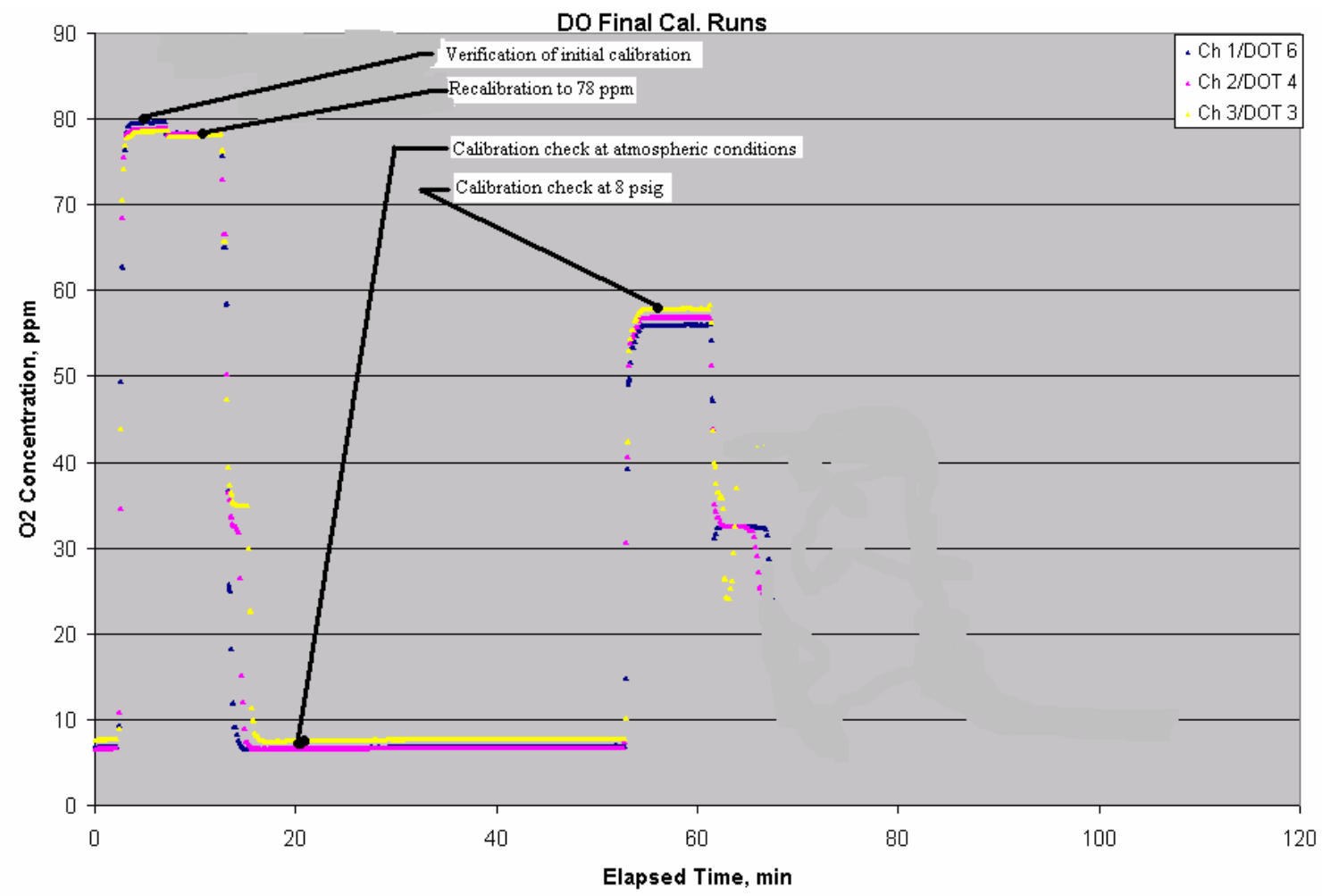

Figure 6-14. Initial Calibration of DO Sensors

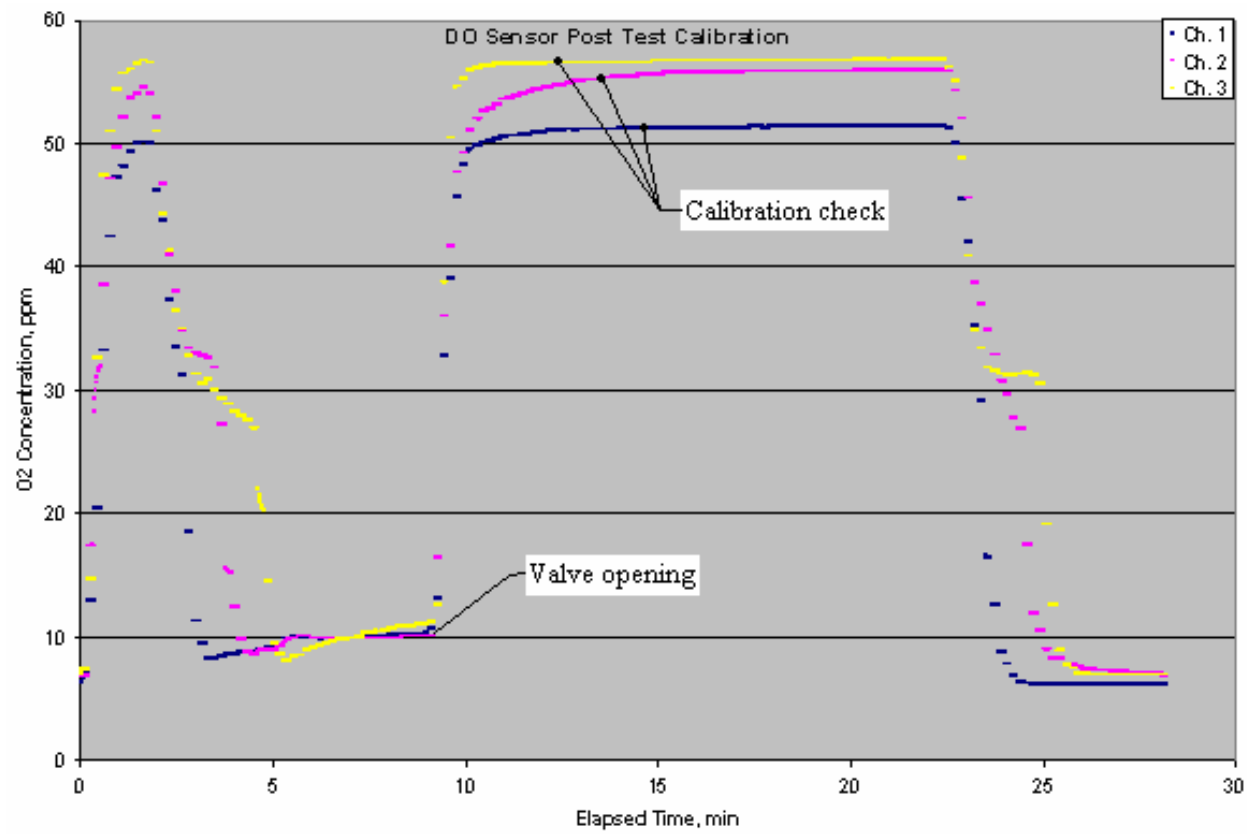

Figure 6-15. DO Post Calibration Where the Expected DO Concentration was 63 ppm 


\section{DO Sensor Installation}

Sensors were installed at the locations shown in Figure 6-4. A typical installation is shown in Figure 6-16. Figure 6-17 and Figure 6-18 show the sample probes for the DO sensors, their installation in the column, and the flow path of simulant through the sensor. The sensors were adequate for water tests, but the vendor's sensor housing was redesigned to prevent blockage by the AZ-101 simulant. The modifications to their design are shown in Figure 6-19.

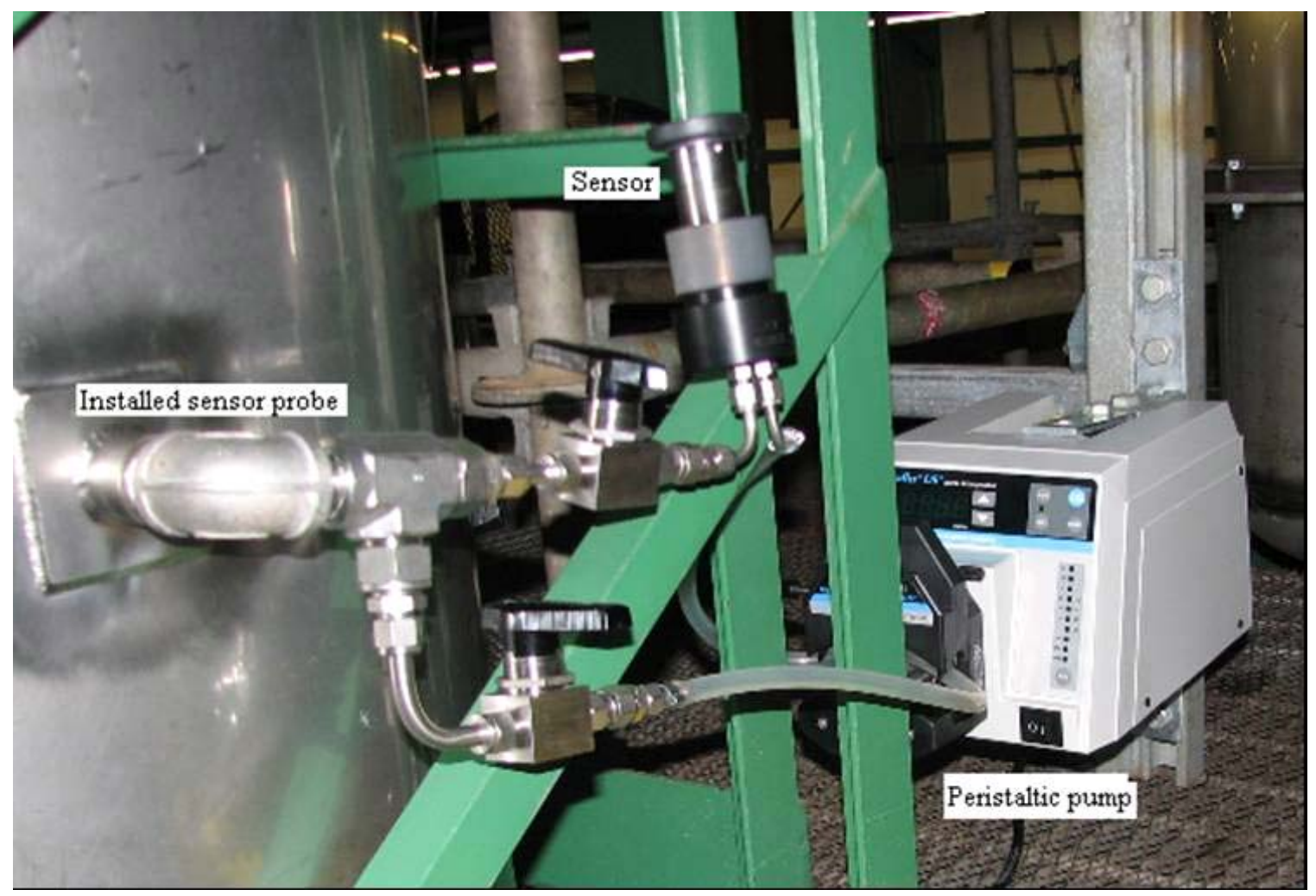

Figure 6-16. DO Sensor Installation 
WSRC-STI-2007-00537, REVISION 0

SRNL-RPP-2007-00023, REVISION 0

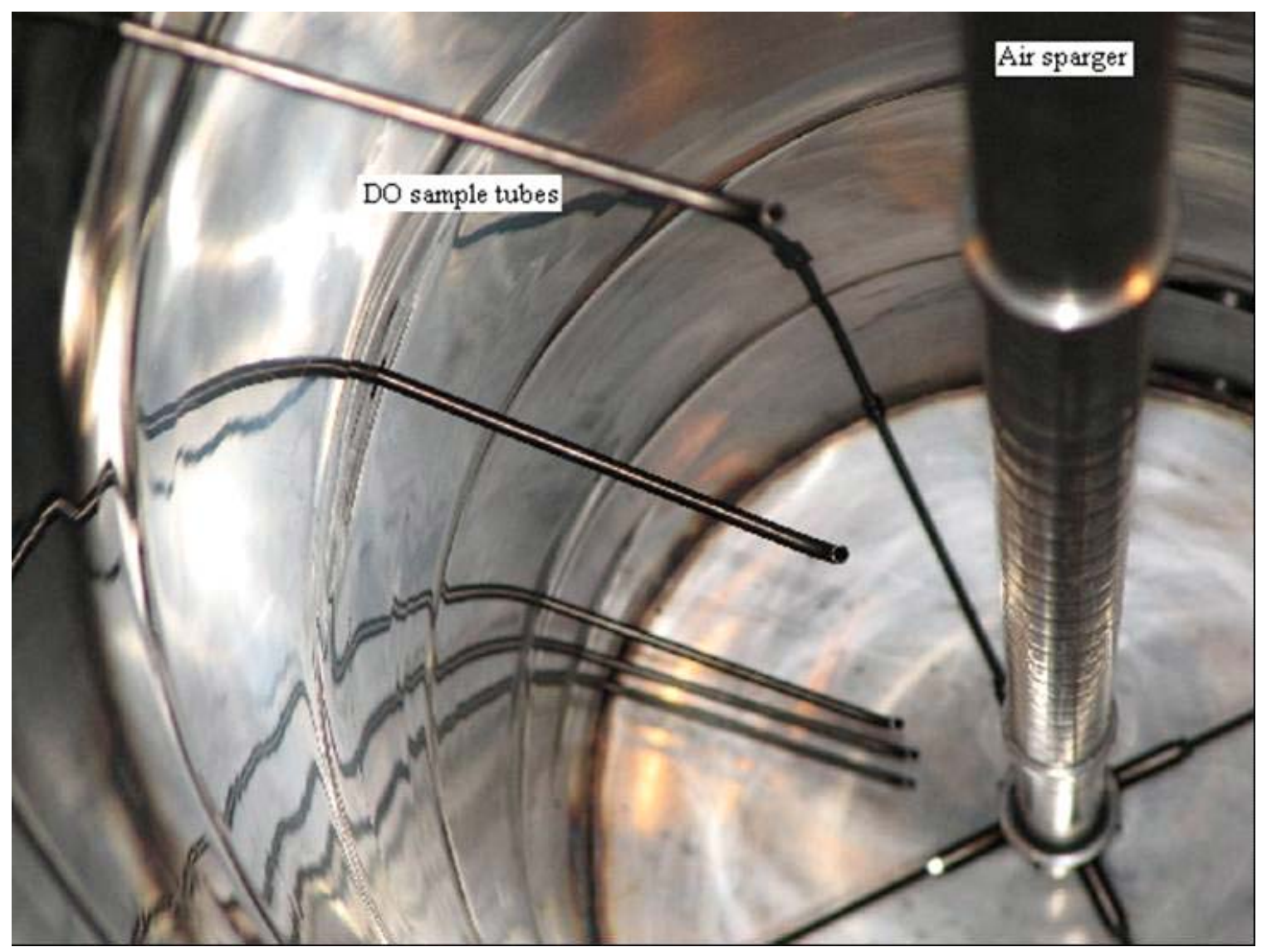

Figure 6-17. Installed DO Sensor Probes

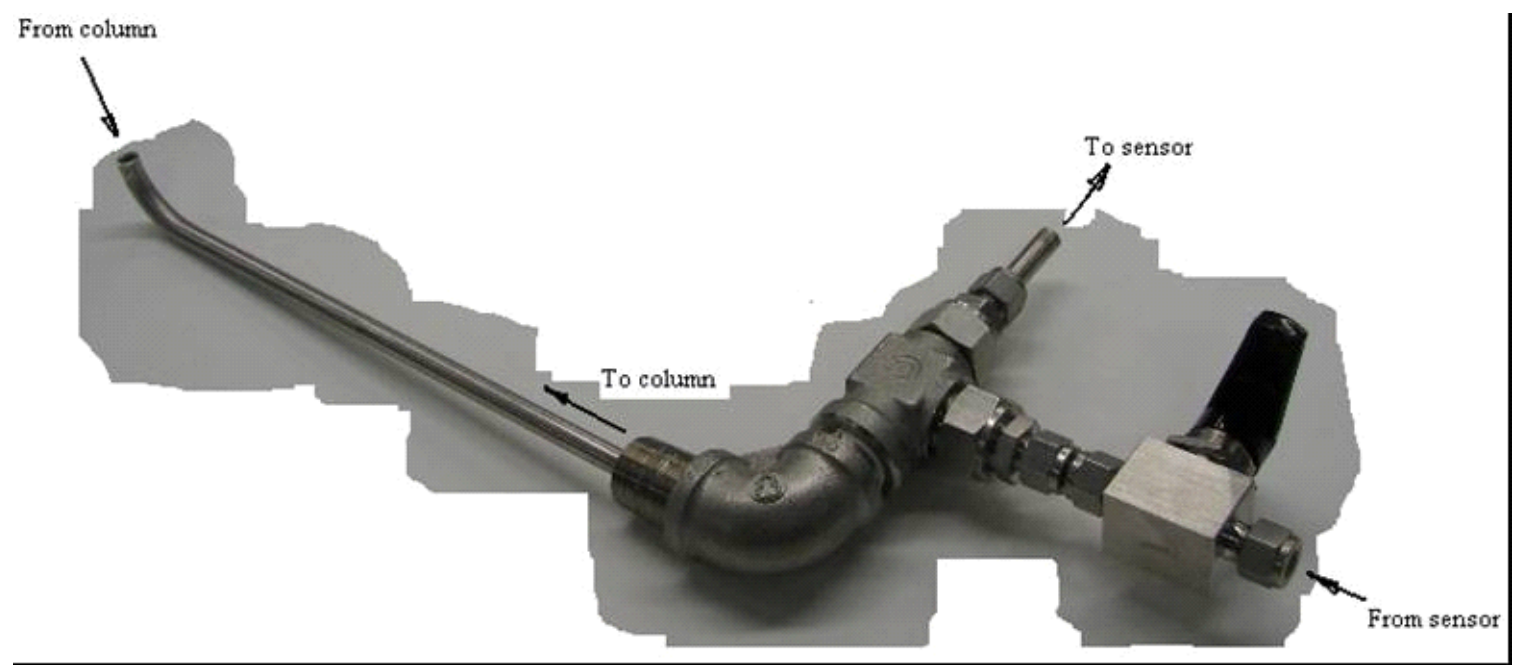

Figure 6-18. Uninstalled DO Sensor Probe 


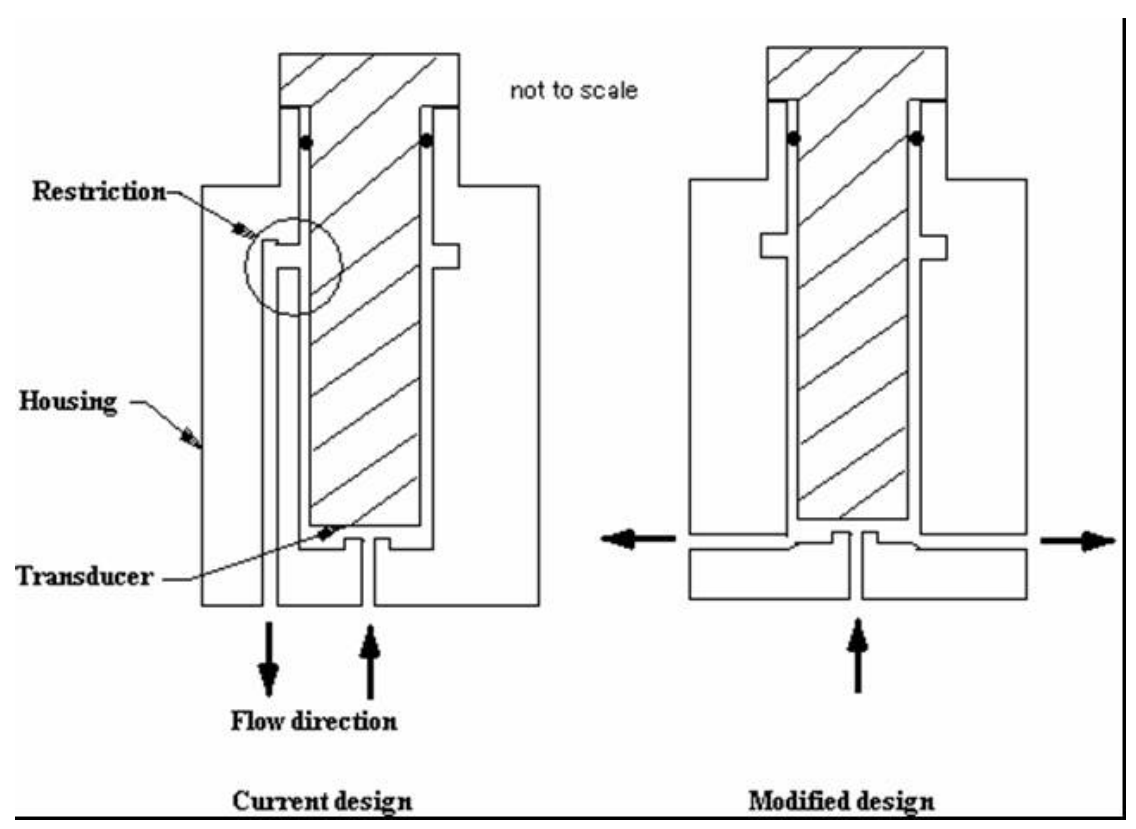

Figure 6-19. Modified DO Sensor

\section{DO Sensor Application}

The three sensors were applied, or moved, as required to accommodate testing. Only three DO sensors with a processor were purchased due to equipment costs. Since the DO sensor calibration is sensitive to the attached wiring, channels 1,2 , and 3 were used interchangeably with DOT1 DOT6 (see Figure 6-3), and the data was processed accordingly. For example, the channel 1 DO sensor (O2 sens 1) was initially installed at the DOT 6 position when tests were performed with 7.41 meters of simulant in the column. When the level was lowered to 1.31 meters, the channel 1 sensor was moved to the DOT 2 position. Correspondingly, the channel 2 sensor (O2 sens 2) was moved from the DOT 4 position to the DOT 1 position. The channel 3 sensor (O2 sens 3 ) remained in the same location throughout testing. Similarly, when tests were performed at the 3.63 meter level, channels 1, 2, and 3 (O2 sens 1, O2 sens 2, and $\mathrm{O} 2$ sens 3 ) were installed at DOT2, DOT4, and DOT3 respectively. In this manner, at least three DO sensor readings were performed during each of the 24 tests. This better summarizes the placement of probes for specific tests.

\subsubsection{Laser Level Indication, LLT1 - LLT3}

Column simulant level was measured using Disto Pro and Pro a laser meters, which have specified accuracies of $+/-5 \mathrm{~mm}$ and $+/-2 \mathrm{~mm}$ respectively. The calibration was verified to be within $+/-1 / 8$ inch $(3.18 \mathrm{~mm})$ for the three meters based on available standards. For water, floats were used as the reflective surface to measure the simulant level, as shown in Figure 6-20. Erroneous readings are obtained due to the transparency of water. Floats were also used for the water with AFA, even though this solution was nearly opaque. Floats were removed during AZ-101 testing, since the opaque AZ-101 completely reflects the laser back to the sensor. During sparging, air bubbles at the surface occasionally cause spurious readings when lasers are reflected away from the sensors. Spurious data as shown in Figure 6-21 is deleted from final data and graphs as required. Average values of laser data are used to estimate the surface level. 
WSRC-STI-2007-00537, REVISION 0

SRNL-RPP-2007-00023, REVISION 0

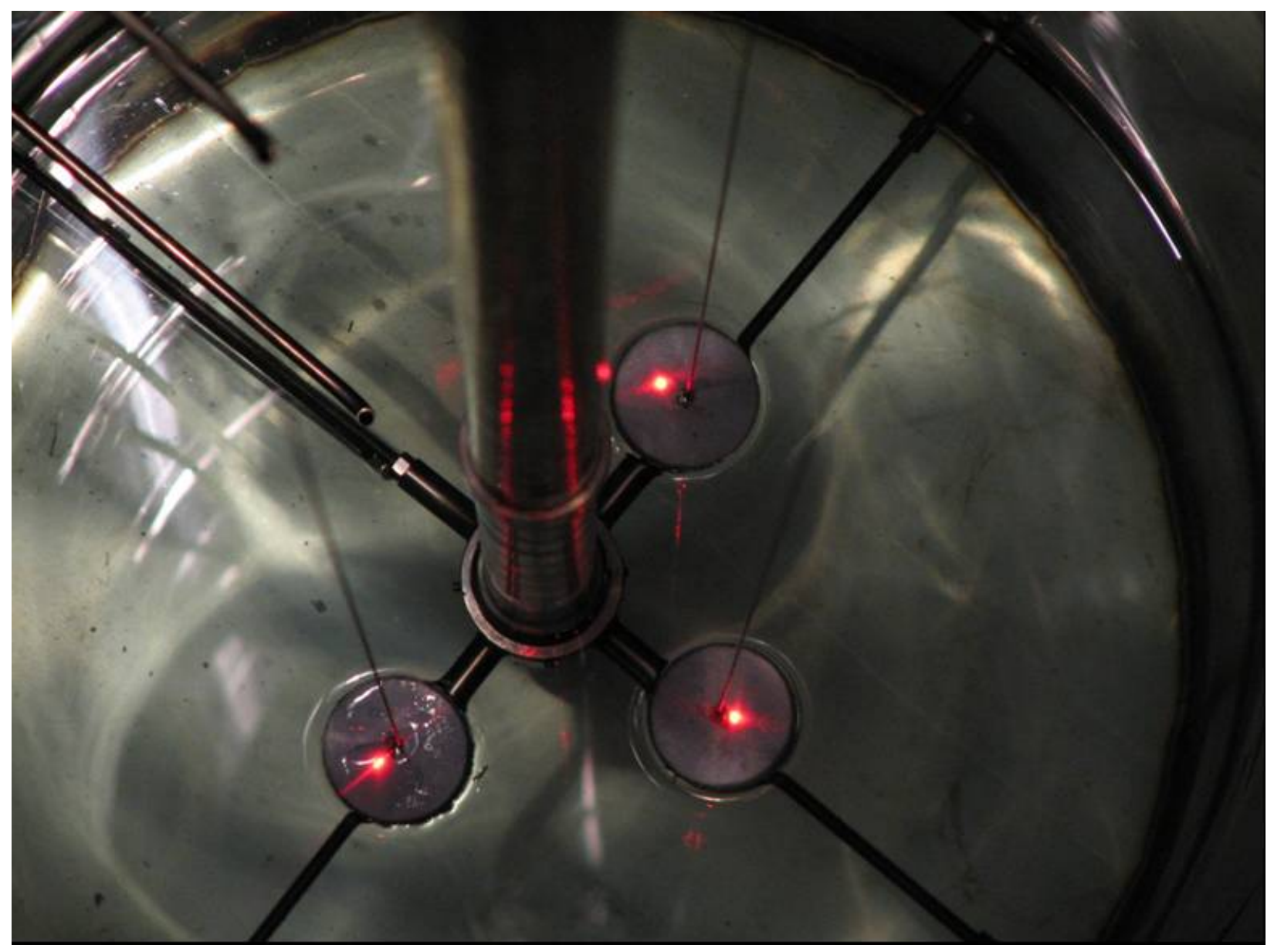

Figure 6-20. Laser Measurements of Water Level 
Test 9, Laser Level Indication

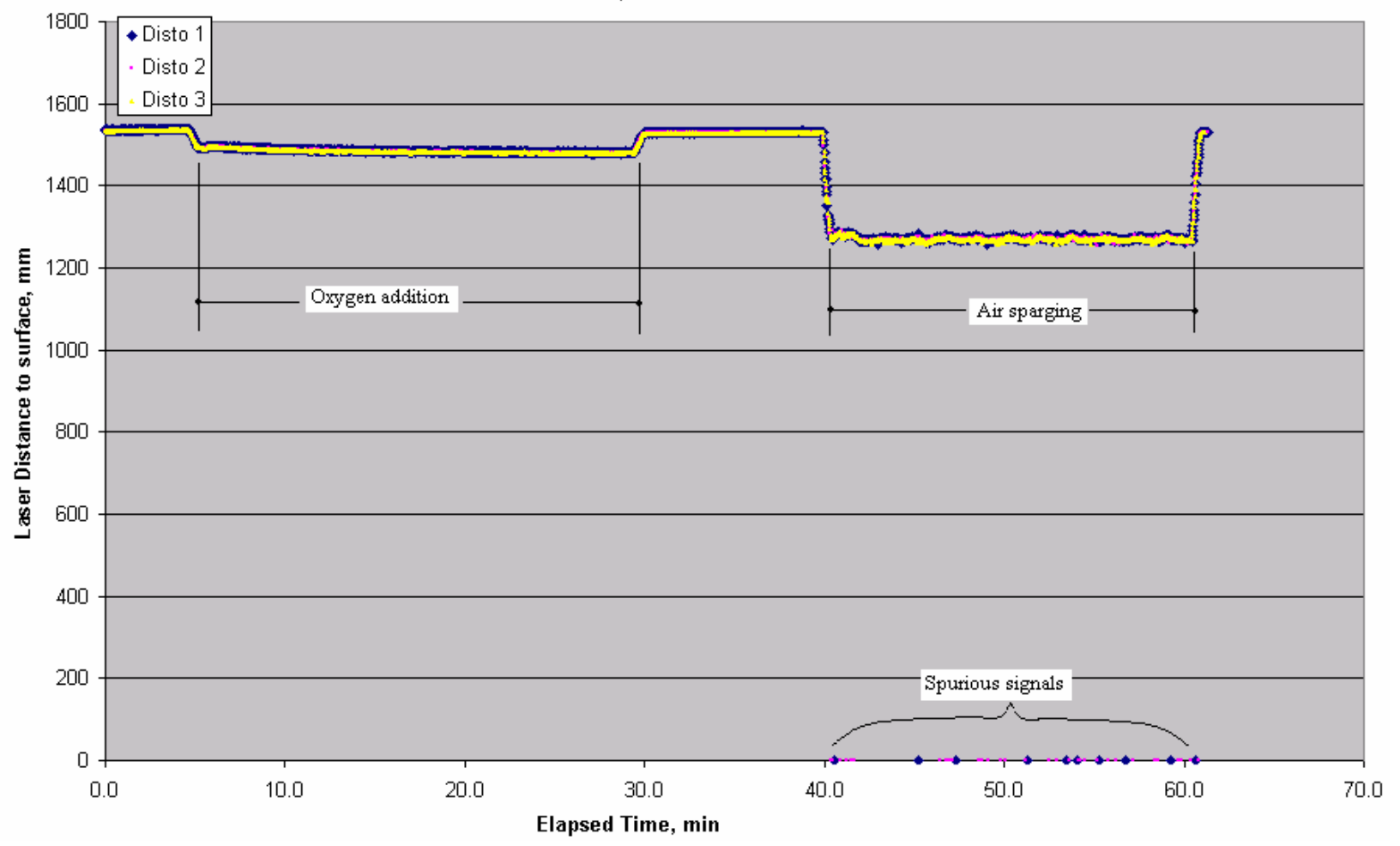

Figure 6-21. Typical Plot for Laser Level Indication

\subsubsection{Flow Meters and Uncertainty of Superficial Velocity}

Two different flow meters were used to improve accuracy of flow measurements, depending on flow rate. The reported flow rate accuracy is a function of both instrumentation accuracy and control of the flow rate, using the flow control needle valves. The accuracy at each of the flow rates for testing is shown Table 6-2. Figure 6-22 shows typical variations in air flow during testing. The variance is described in the table as data bias and precision errors. During the first test, the instrument error was noted to be higher than expected, and the flow control valve was replaced with a smaller diameter valve for better flow control.

Combining the maximum flow variation with the calibration uncertainty of the two flow meters showed that the preferred accuracy of less than $+/-1 / 2 \mathrm{scfm}$ was obtained at all 2 and $5 \mathrm{~mm} / \mathrm{second}$ tests, but that the accuracy changed for the $10 \mathrm{~mm} / \mathrm{second}$ tests from approximately one half an scfm before tests to slightly over one scfm after test. Proportional to the flow rate, the approximate uncertainty of the superficial velocities ranges between $1,1.5$, and $14 \%$ for the 2,5 , and $10 \mathrm{~mm} / \mathrm{sec}$ velocities respectively. 
WSRC-STI-2007-00537, REVISION 0

SRNL-RPP-2007-00023, REVISION 0

Table 6-2. Uncertainty of Superficial Velocities

\begin{tabular}{|c|c|c|c|c|c|c|c|c|}
\hline Test & Fluid/level & $\begin{array}{l}\text { Superficial } \\
\text { velocity, } \\
\mathrm{mm} / \mathrm{sec}\end{array}$ & $\begin{array}{l}\text { Required } \\
\text { flow rate, } \\
\text { scfm }\end{array}$ & $\begin{array}{c}\text { Average } \\
\text { measured } \\
\text { flow rate, } \\
\text { scfm }\end{array}$ & $\begin{array}{c}\text { Data bias } \\
\text { error, } \%\end{array}$ & $\begin{array}{c}\text { Data } \\
\text { precision } \\
\text { error, }+/-\%\end{array}$ & $\begin{array}{c}\text { Instrument } \\
\text { precision } \\
\text { error, }+/-\%\end{array}$ & $\begin{array}{c}\text { Total } \\
\text { maximum } \\
\text { uncertainty, } \\
\%\end{array}$ \\
\hline 1 & $1.31 \mathrm{~m}$ & 2 & 2.09 & 2.33 & 11.71 & 3.20 & 3.761 & 12.71 \\
\hline 2 & $1.31 \mathrm{~m}$ & 5 & 5.23 & 5.19 & -0.69 & 0.15 & 1.503 & 1.66 \\
\hline 3 & $1.31 \mathrm{~m}$ & 10 & 10.46 & 10.49 & 0.30 & 0.15 & 13.974 & 13.98 \\
\hline 4 & Water, & 2 & 2.09 & 2.11 & 0.94 & 0.08 & 3.761 & 3.88 \\
\hline 5 & Water, & 5 & 5.23 & 5.15 & -1.55 & 0.11 & 1.503 & 2.16 \\
\hline 6 & Water, & 10 & 10.46 & 10.41 & -0.46 & 0.21 & 13.974 & 13.98 \\
\hline 7 & Water, & 2 & 2.09 & 2.15 & 2.86 & 0.07 & 3.761 & 4.72 \\
\hline 8 & Water, & 5 & 5.23 & 5.23 & -0.08 & 0.02 & 1.503 & 1.51 \\
\hline 9 & Water, & 10 & 10.46 & 10.45 & -0.09 & 0.21 & 13.974 & 13.98 \\
\hline 16 & Water, AFA, $1.31 \mathrm{~m}$ & 2 & 2.09 & 2.07 & -0.95 & 0.06 & 3.761 & 3.88 \\
\hline 17 & Water, AFA, $1.31 \mathrm{~m}$ & 5 & 5.23 & 5.23 & -0.04 & 0.09 & 1.503 & 1.51 \\
\hline 18 & Water, AFA, $1.31 \mathrm{~m}$ & 10 & 10.46 & 10.42 & -0.39 & 0.08 & 13.974 & 13.98 \\
\hline 19 & Water, AFA, $3.63 \mathrm{~m}$ & 2 & 2.09 & 2.10 & 0.64 & 0.11 & 3.761 & 3.82 \\
\hline 20 & Water, AFA, $3.63 \mathrm{~m}$ & 5 & 5.23 & 5.18 & -1.05 & 0.07 & 1.503 & 1.83 \\
\hline 21 & Water, AFA, $3.63 \mathrm{~m}$ & 10 & 10.46 & 10.38 & -0.80 & 0.07 & 13.974 & 14.00 \\
\hline 22 & Water, AFA, $7.41 \mathrm{~m}$ & 2 & 2.09 & 2.12 & 1.66 & 0.18 & 3.761 & 4.12 \\
\hline 23 & Water, AFA, $7.41 \mathrm{~m}$ & 5 & 5.23 & 5.21 & -0.38 & 0.12 & 1.503 & 1.56 \\
\hline 24 & Water, AFA, $7.41 \mathrm{~m}$ & 10 & 10.46 & 10.53 & 0.71 & 0.09 & 13.974 & 13.99 \\
\hline 25 & AZ101, AFA, $1.31 \mathrm{~m}$ & 2 & 2.09 & 1.96 & -6.20 & 0.93 & 3.761 & 7.32 \\
\hline 26 & AZ101, AFA, $1.31 \mathrm{~m}$ & 5 & 5.23 & 5.20 & -0.62 & 0.05 & 1.503 & 1.63 \\
\hline 27 & AZ101, AFA, $1.31 \mathrm{~m}$ & 10 & 10.46 & 10.43 & -0.32 & 0.05 & 13.974 & 13.98 \\
\hline 28 & AZ101, AFA, $7.41 \mathrm{~m}$ & 2 & 2.09 & 2.09 & 0.06 & 0.03 & 3.761 & 3.76 \\
\hline 29 & AZ101, AFA, $7.41 \mathrm{~m}$ & 5 & 5.23 & 5.16 & -1.35 & 0.06 & 1.503 & 2.02 \\
\hline 30 & AZ101, AFA, $7.41 \mathrm{~m}$ & 10 & 10.46 & 10.47 & 0.12 & 0.08 & 13.974 & 13.97 \\
\hline
\end{tabular}




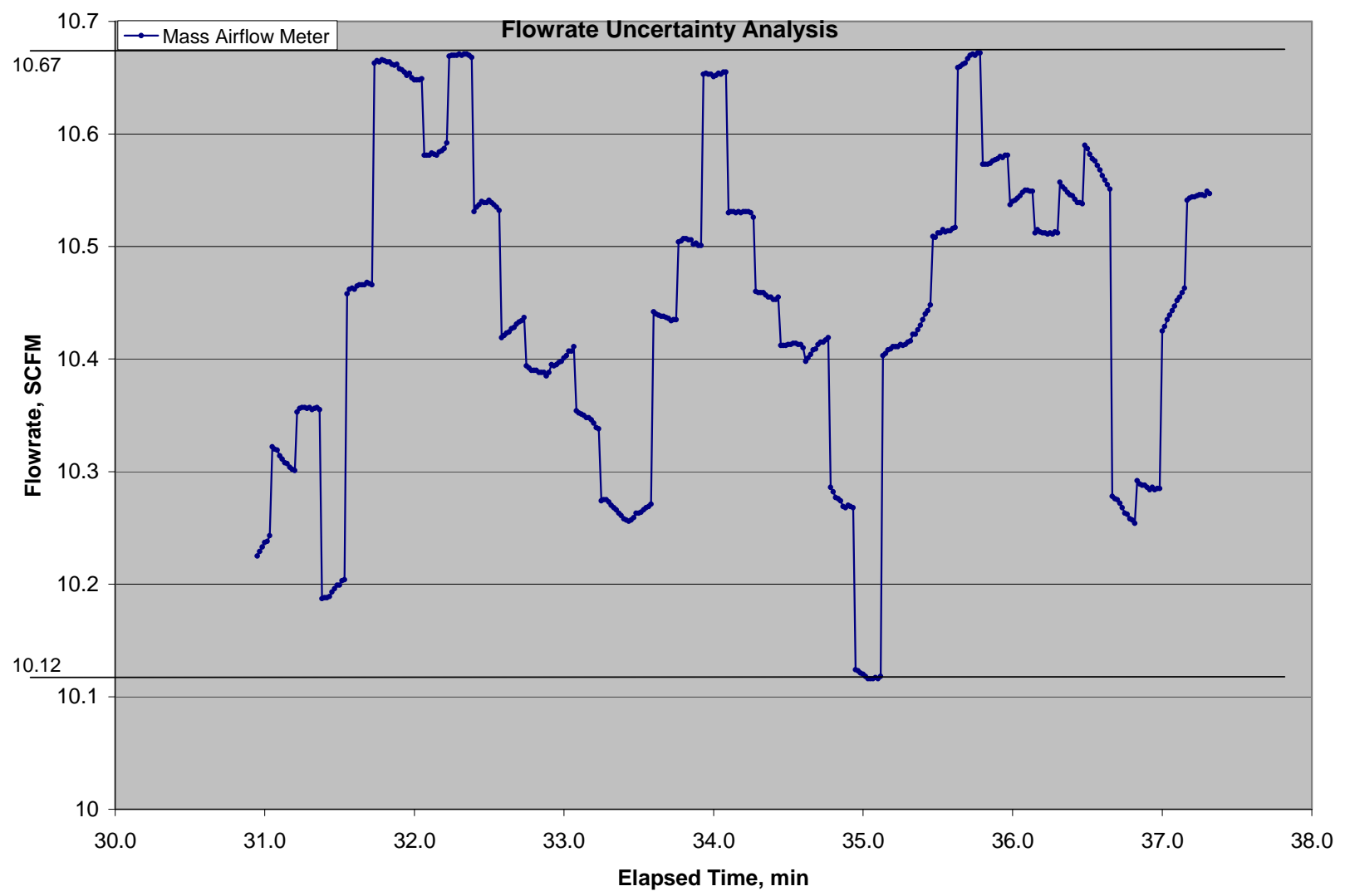

Figure 6-22. Typical Variance in Measured Flow Rate through an Installed Needle Valve Due to Facility Pressure Fluctuations

\subsubsection{Environmental Test Conditions}

Instrumentation was installed to measure the temperature of the column contents, the temperature of the supplied air, and the relative humidity and temperature inside and above the column. Two relative humidity sensors were installed. One was above and outside of the column, and the other was inside the column near the top. Typical temperatures above the column varied from $23-33^{\circ} \mathrm{C}$ and the relative humidity varied from $40-80 \%$. Inside the column, the relative humidity was frequently $100 \%$ due to evaporation of simulants. Data from the two sensors is displayed in Figure 6-23 and Figure 6-24. Temperature of the simulant in the column typically varied between 23 and $28^{\circ} \mathrm{C}$, and minimally increased when the recirculation pump operated as shown in Figure 6-25. Air flow through the flow meter to the column was typically measured at $22.3+/-1 / 2{ }^{\circ} \mathrm{C}$, as measured by temporarily installed temperature gauges. Uncertainties due to temperature and relative humidity were considered to be negligible with respect to void fraction, since level changes in the column were typically less than $1 \mathrm{~mm}$ between tests. Water was added between tests to re-establish the level in the column for water and water with AFA tests, but was not added between AZ-101 tests. 
WSRC-STI-2007-00537, REVISION 0

SRNL-RPP-2007-00023, REVISION 0

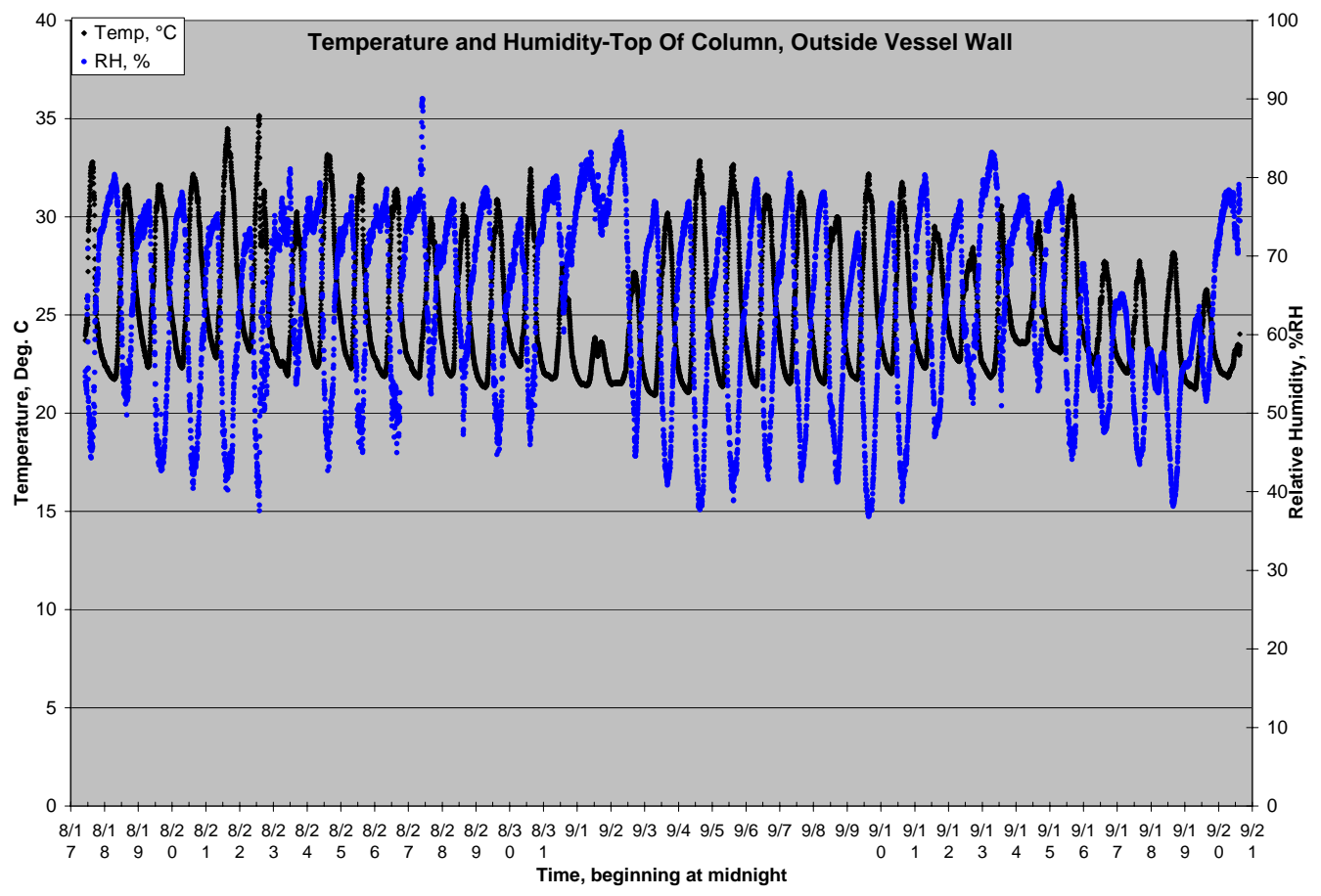

Figure 6-23. Typical Environmental Conditions above the Column

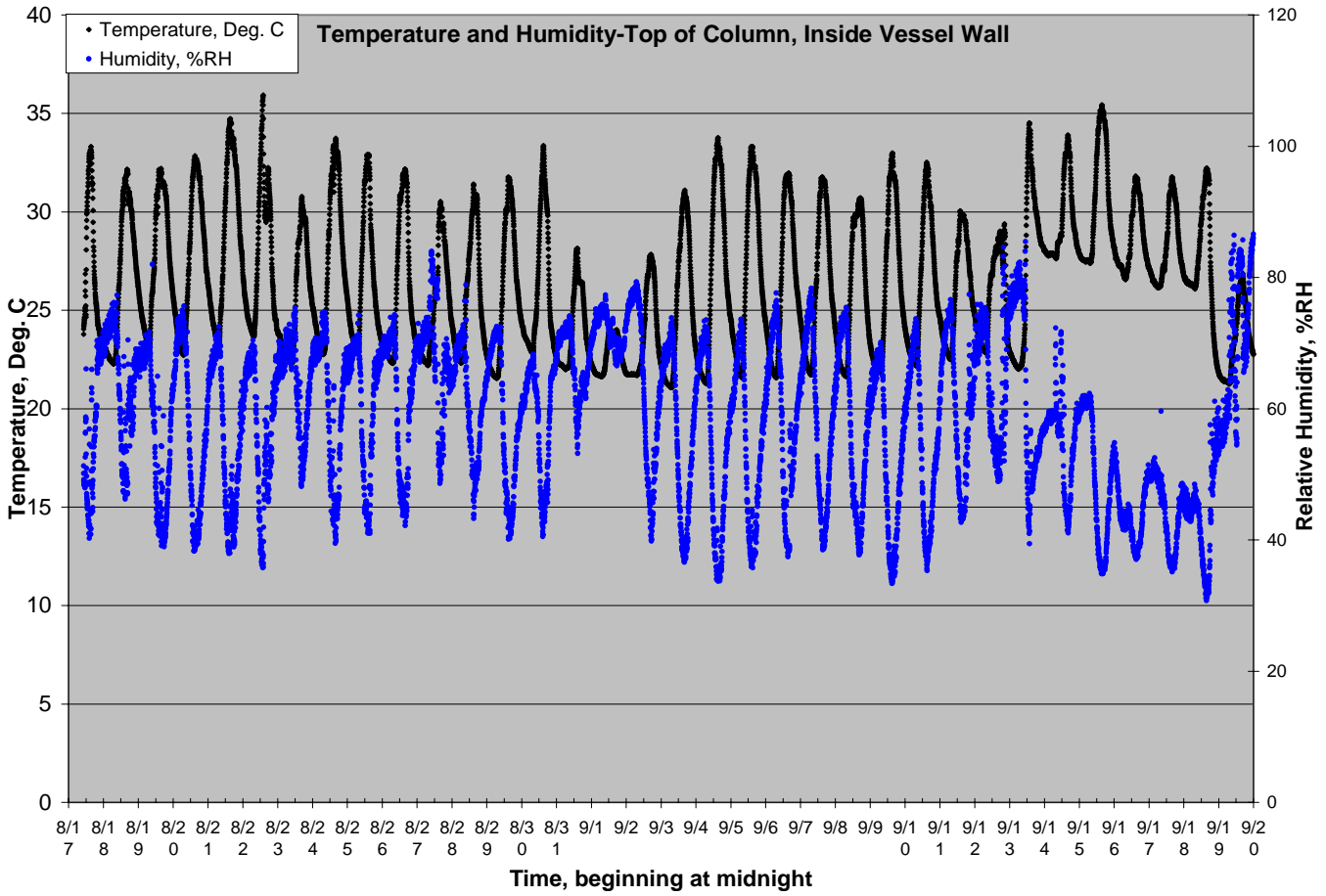

Figure 6-24. Typical Environmental Conditions inside the Column near the Top 
WSRC-STI-2007-00537, REVISION 0

SRNL-RPP-2007-00023, REVISION 0

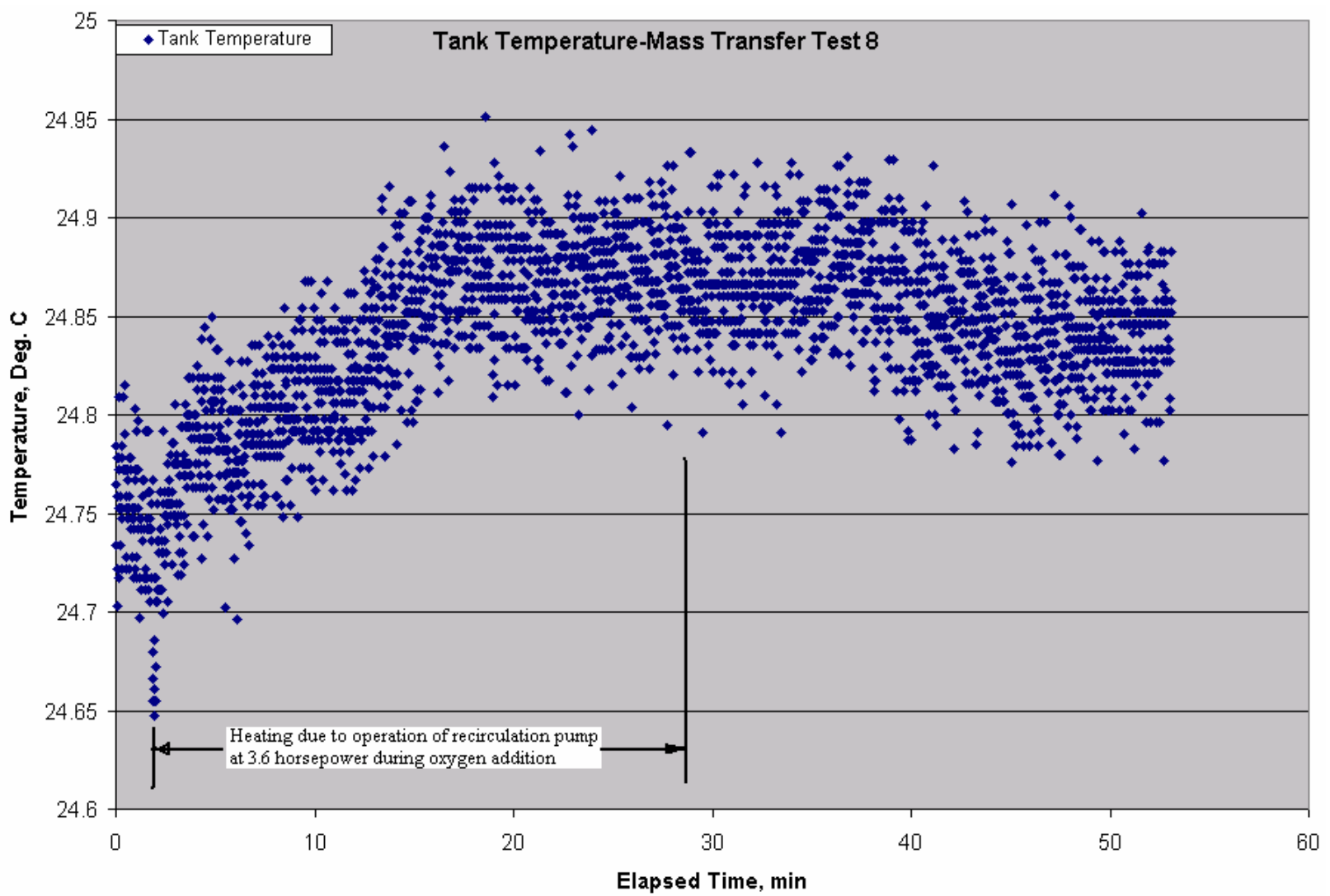

Figure 6-25. Typical Temperature Monitoring of the Column Contents

\subsubsection{Experimental Processes}

Although numerous processes required to complete testing are described in ITS-WI-0021, the primary processes with respect to this report are oxygen mixing and air sparging of the column. These two processes are described here.

\subsubsection{Oxygen Addition and Mixing}

Considering Figure 6-3, the flow passes through the recirculation pump past the oxygen sparger, through the static mixer into the column, and then back to the recirculation pump. Since water was the only transparent simulant used, photos of oxygen mixing assist clarification of mixing mechanisms. These photos were extracted from videos, which are provided with this report. When oxygen is mixed into solution, the recirculation flow rate is $100 \mathrm{gpm}$, and the oxygen addition rate is $3.12 \mathrm{acfm}$ ( $2 \mathrm{scfm}$ indicated on the rotameter). These values were found by trial and error during shake down testing to provide adequate mixing, while minimizing required oxygen. The oxygen bubble sizes are dependent on fluid properties and flow rate, but at these flow rates the expected bubble size in water is 2 microns. The bubbles are forced through an oxygen sparger, which is a sintered metal filter used to create small oxygen bubbles in water. 
As the bubbles are injected into a 4.34 feet/second velocity flow in the 3 inch diameter pipe, a non-uniform flow field of bubbles is observed as shown in Figure 6-26. The bubbles are then mixed in the static mixer, as shown in Figure 6-27. The design of this static mixer is shown in Figure 6-28. When the bubbles exit the static mixer, the flow field is nearly uniform, while mixing of the oxygen in water commences as shown in Figure 6-28. As the bubbles enter the column, the pressure decreases slightly, the bubbles coalesce, and randomly distributed, larger bubbles are formed as shown in Figure 6-30. These bubbles rise to the surface in less than 30 seconds $(24.3 \mathrm{feet} / 30 \mathrm{sec}=0.81 \mathrm{feet} / \mathrm{sec})$. As the bubbles rise in the column, the flow field becomes more uniform, and additional mixing occurs in the column as the bubbles rise to the surface, evidenced by the fact that oxygen concentrations increase throughout the column at the time the bubbles reach the DO sensors. When oxygen addition was stopped, most of the $1 / 8$ to $1 / 4$ inch bubbles exited at the surface, and only some micro-bubbles remained in solution. Mixing is somewhat different when AZ-101 is mixed. Mixing still occurs at the oxygen sparger and static mixer, but $1 / 4$ inch bubbles were not created when the flow entered the column. Larger $2-4$ inch diameter bubbles were created as observed at the AZ-101 surface. The oxygen sensors slowly indicated an increase in concentration, indicating that an increased oxygen concentration occurred as the simulant moved up the column at $100 \mathrm{gpm}$, or at a $0.046 \mathrm{feet} / \mathrm{second}$ average velocity.

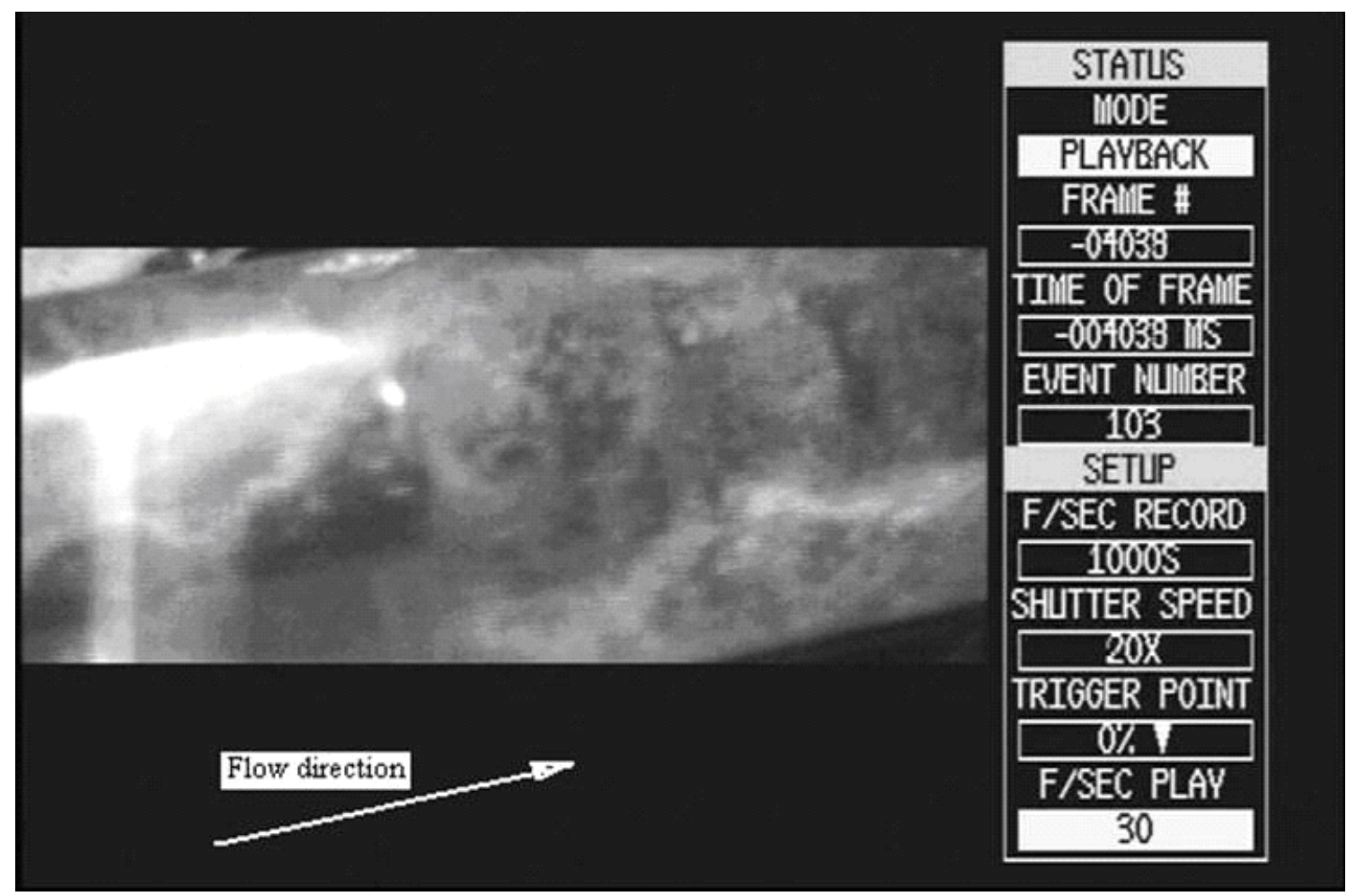

Figure 6-26. Oxygen Sparger and the Oxygen Bubbles Before Entering the Static Mixer 
WSRC-STI-2007-00537, REVISION 0

SRNL-RPP-2007-00023, REVISION 0

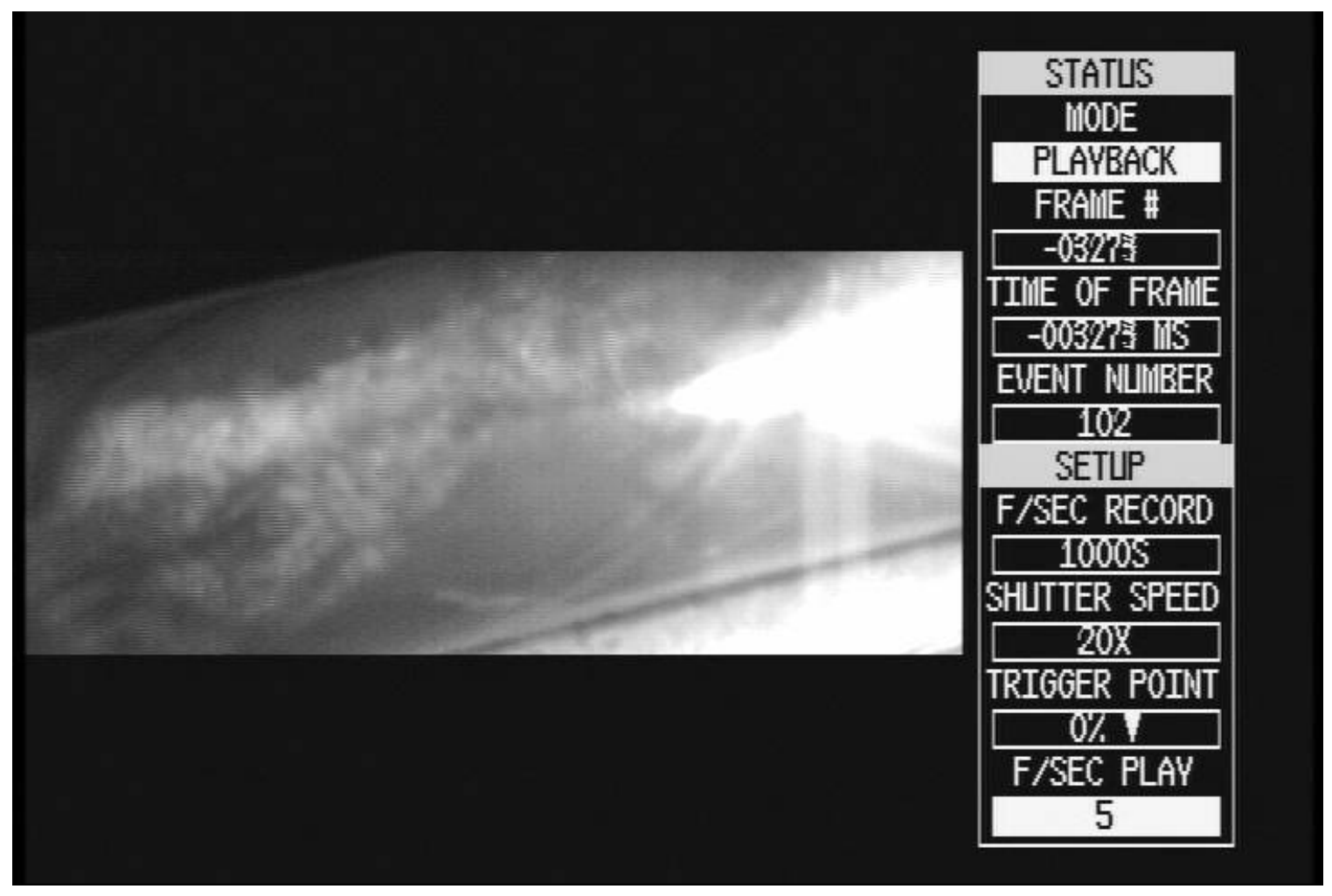

Figure 6-27. Air Swirling in the Static Mixer

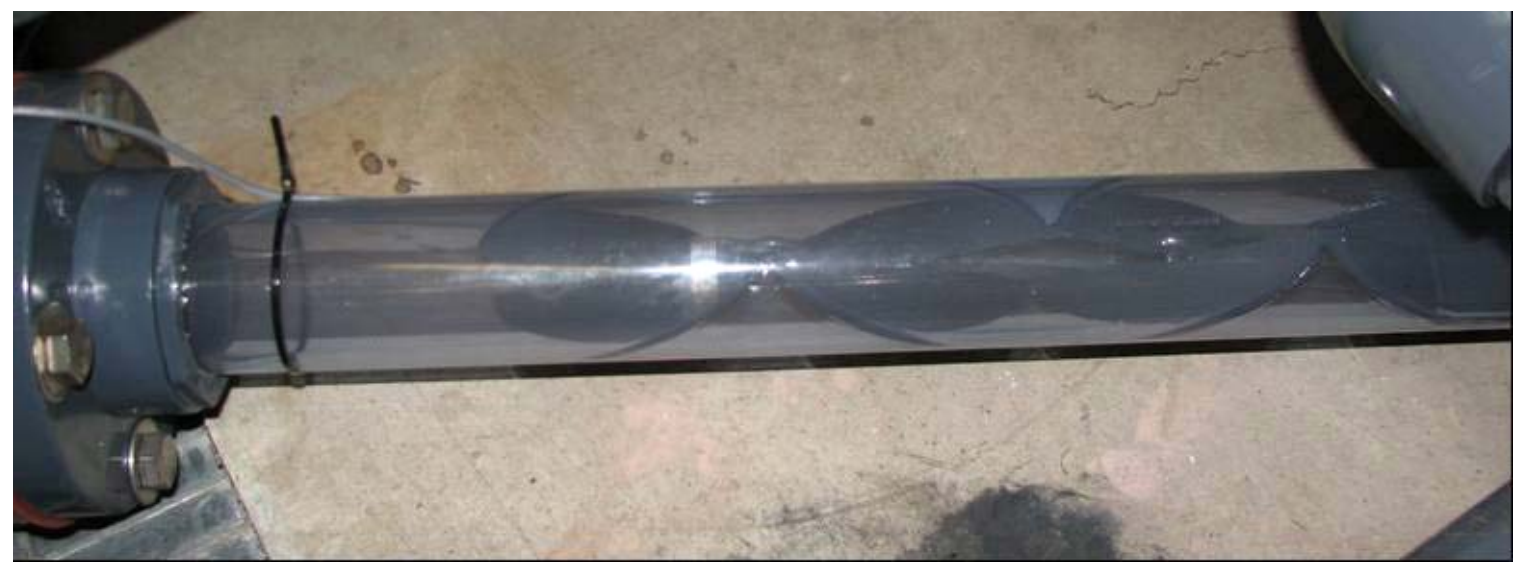

Figure 6-28. Static Mixer Design, Koflo 
WSRC-STI-2007-00537, REVISION 0

SRNL-RPP-2007-00023, REVISION 0

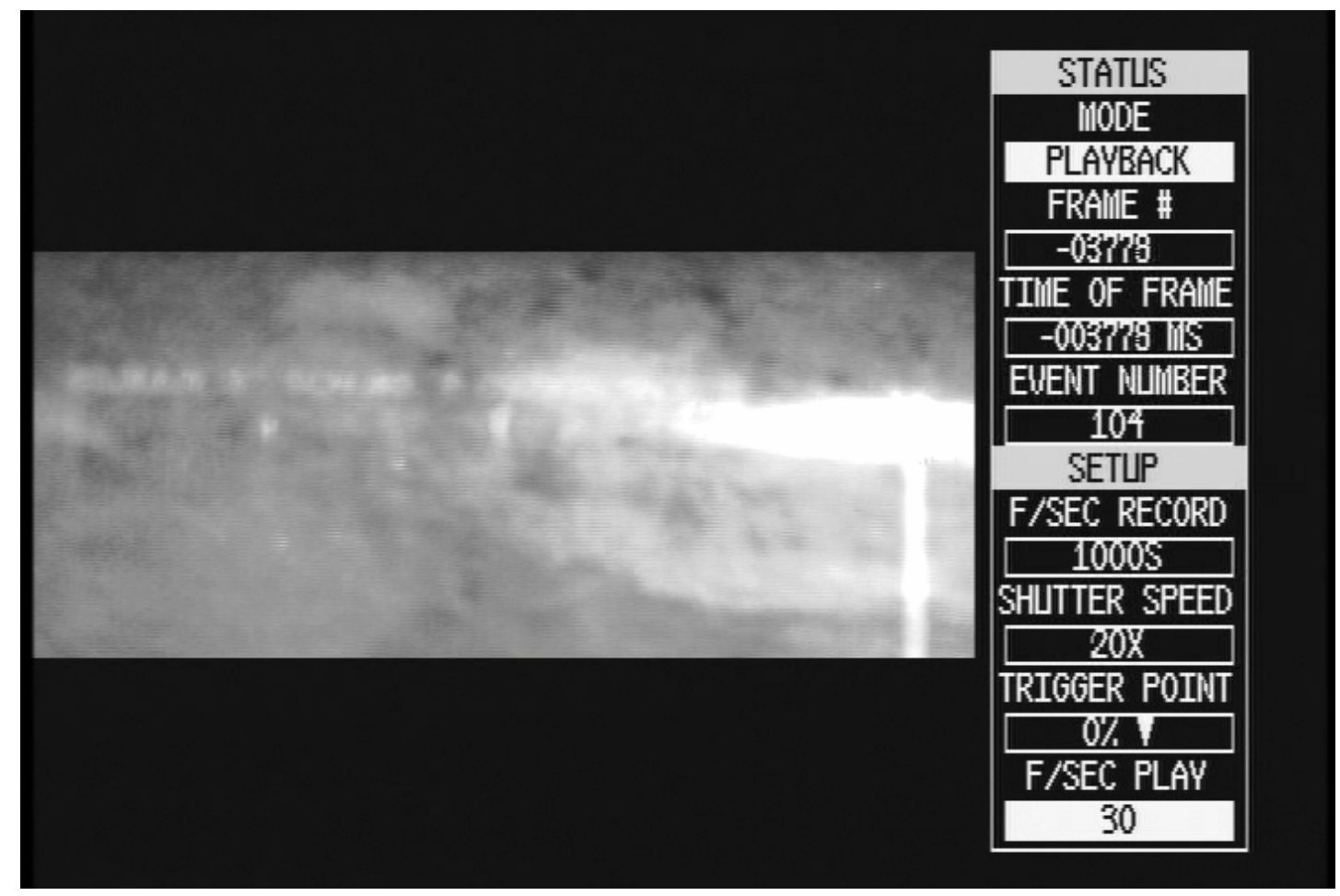

Figure 6-29. Nearly Uniform Bubble Distribution in the Piping after the Static Mixer

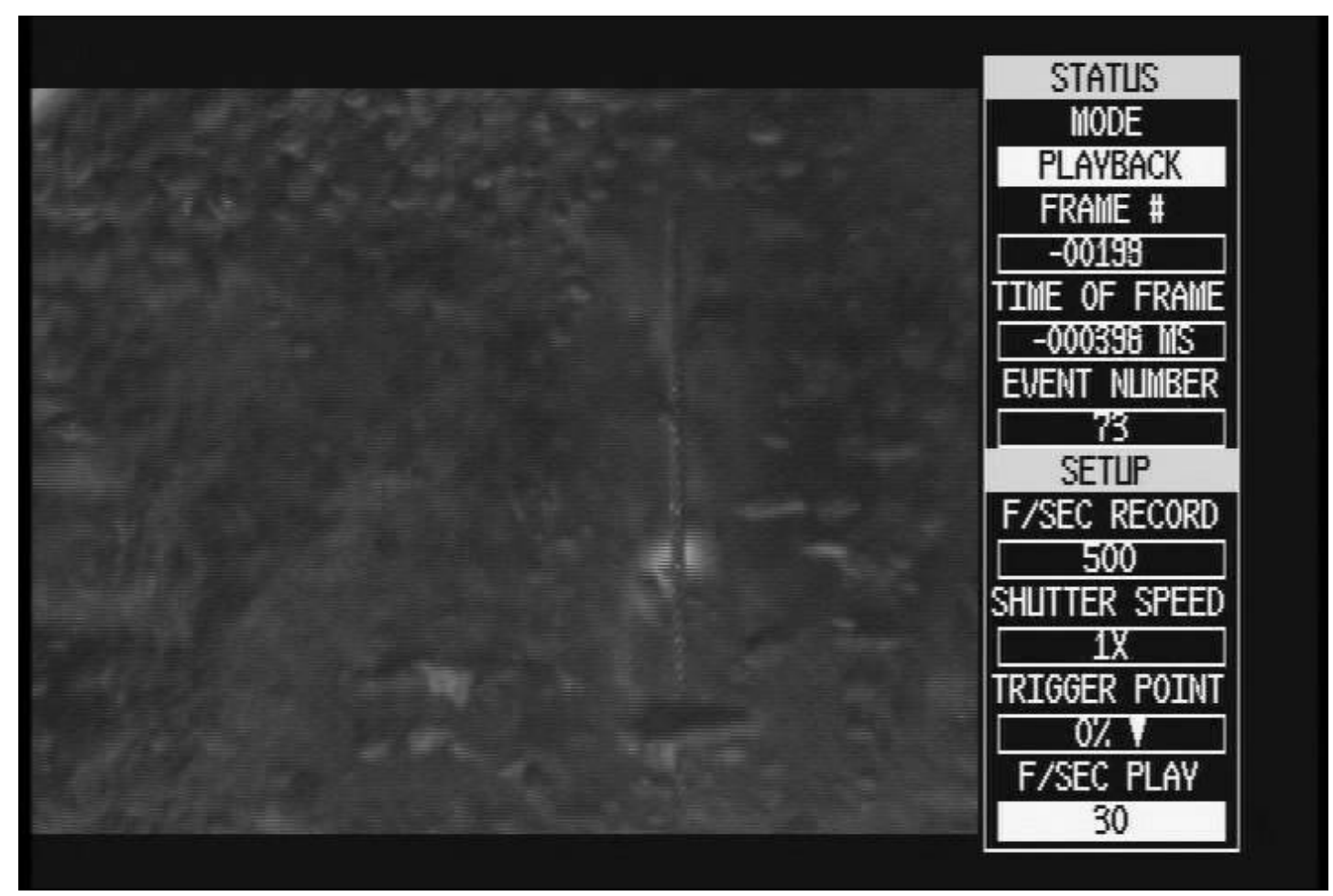

Figure 6-30. Bubbles near the Bottom of the Column after Entering the Column 


\subsubsection{Air Sparging}

Installation details of the air sparger are shown in Figure 6-31. The air flows specified in Table 6-1 are injected down through the sparger to obtain the superficial velocities noted in that table. A typical sparger flow is shown in Figure 6-32.

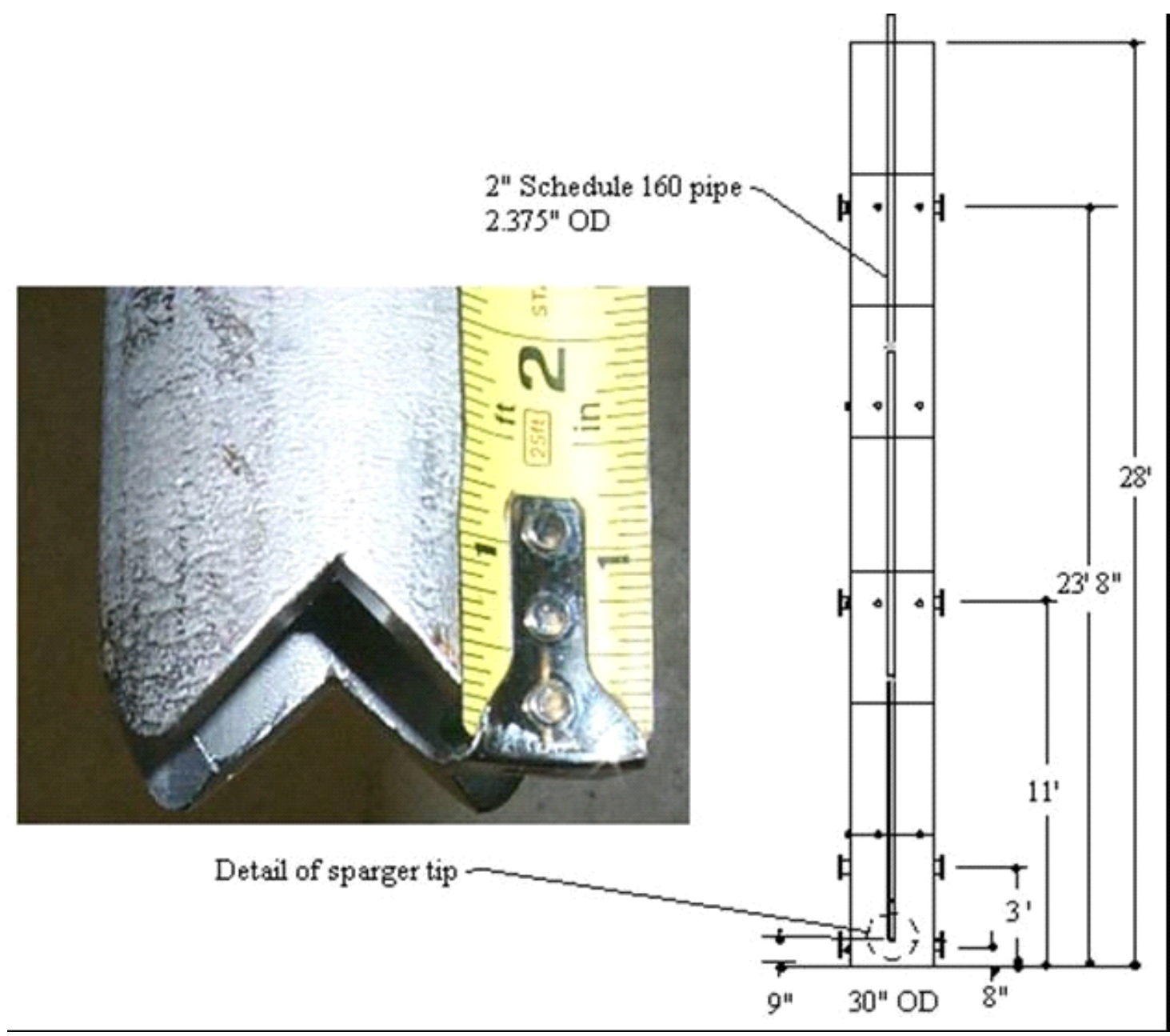

Figure 6-31. Sparger Details 


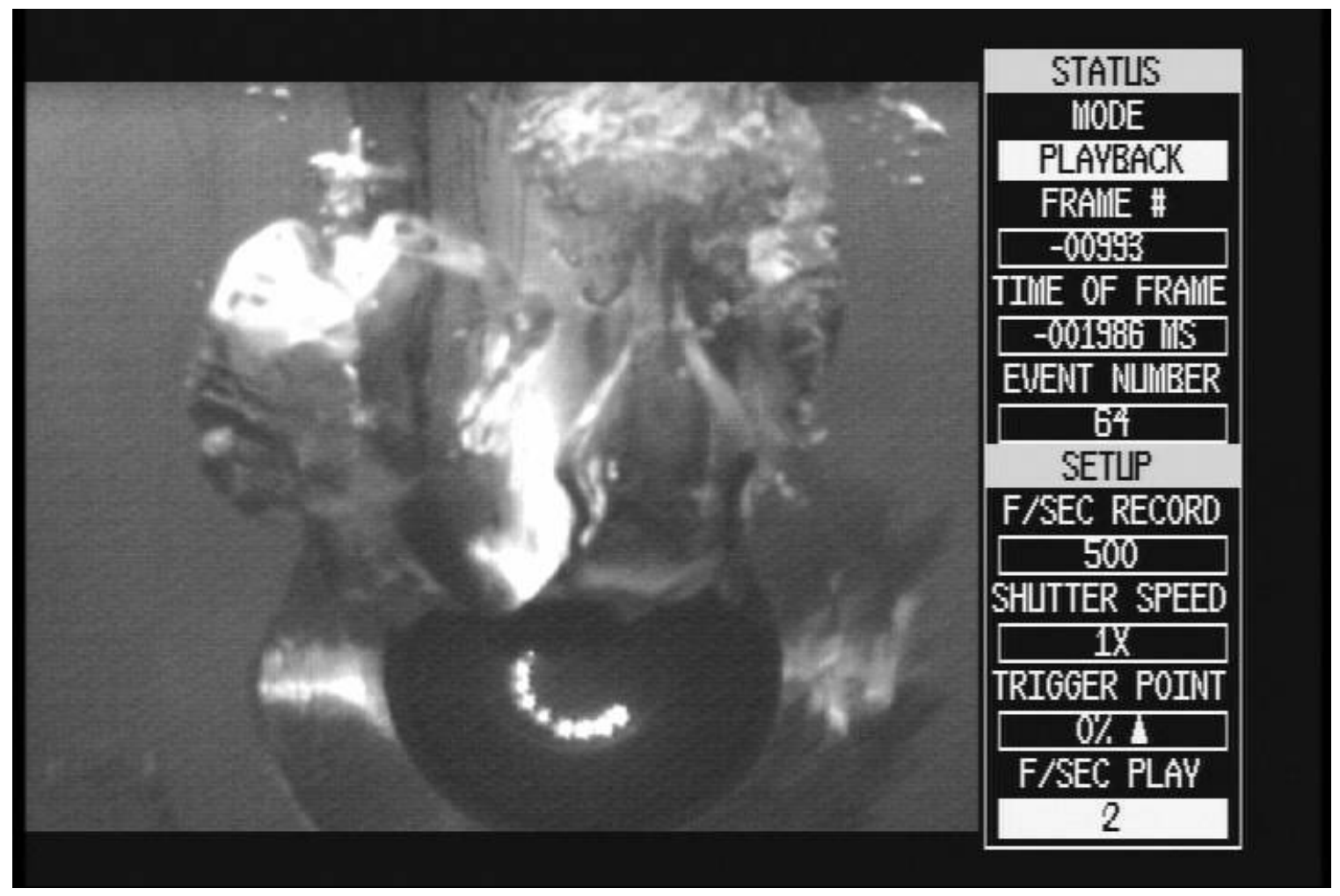

Figure 6-32. Air Discharge from the Sparger for a $10 \mathrm{~mm} / \mathrm{second}$ Superficial Velocity

\subsubsection{Simulants}

Three simulants were tested: process water, process water with $350 \mathrm{mg} / \mathrm{l}$ of Dow Corning Q23183A AFA added, and AZ-101 simulant with $350 \mathrm{mg} / 1$ of AFA added.

\subsubsection{Water and Water with AFA}

Process SRNL well water was used, which contains some minor quantities of minerals. The AFA was mixed with process water when the tank was filled to nearly the 24.3 feet level, using the 50 gallon addition tank shown in Figure 6-4 and Figure 6-5. While the recirculation pump was operating, the addition pump proportionally added diluted AFA to the process water. Uniformity of mixing was noted by observing the mixture in the transparent recirculation pipe, which runs vertically up the side of the column. The mixed fluid was white in color and somewhat translucent through the 3 inch diameter pipe, which can be seen in Figure 6-2. When viewed through the view ports, the solution was opaque. Effective mixing of the AFA with water demonstrated that effective mixing was also expected when mixing AFA with AZ-101, where the mixing could not be readily observed. For tests of both water and water with AFA, evaporation was compensated by adding process water between tests to return the level to its original level. Level changes due to evaporation were noted to typically be less than $1 \mathrm{~mm}$ during any given test. Some evaporation is expected, since both the sparge air and oxygen are dry when they enter the simulant and saturated with water vapor when the bubbles exit the surface of the simulant. 


\subsubsection{AZ-101 Simulant}

The properties of the AZ-101 simulant bear more detailed consideration. The AZ-101 was delivered to EDL in four 250 gallon totes, and it settled for 60 days prior to use. During this time, a layer of nearly clear supernate formed above the settling solids, referred to as sludge. In fact, some settling of the simulant occurs overnight, and totes mixed in place and the simulant in the column were noticed to have some supernate accumulation within one hour. Also, recirculation through the pump nearly stopped when solids were permitted to settle for a couple of days in the column. As shown in Table 6-4, the settled sludge layer had a yield stress of 92.8 Pascals. The yield stress nearly tripled during 60 days of storage. In other words, the solids settle quickly, and settling characteristics may affect void fractions and mass transfer coefficients.

When uniformly mixed in the column, the as received simulant had an average yield stress of 33.7 Pascals. To obtain uniform mixing, the simulant was recirculated at $100 \mathrm{gpm}$, and both the primary central air sparger and the secondary air sparge ports at the bottom of the column were used at $10 \mathrm{scfm}$ each $(20 \mathrm{scfm}$ total). The recirculation flow rate was then adjusted to obtain three samples at equal time intervals to ensure that samples were obtained from three equally spaced column levels. Samples were taken at the sample port on the recirculation pump discharge piping, shown in Figure 6-4, rather than at different levels in the column. Dilution was then performed using process water deionized to less than $10 \mu$ Siemens, which was mixed with AFA prior to addition to the column. Three more samples were taken after dilution, and evaluated for uniformity of mixing. Adequate mixing to obtain a yield stress of $13+/-2$ Pascals is demonstrated in Table 6-3:

Table 6-3. Uncertainties in Yield Stress Measurement

\begin{tabular}{|c|c|c|c|c|c|}
\hline & \multirow{2}{*}{$\begin{array}{l}\text { yield } \\
\text { stress }(\mathrm{Pa}) \\
\quad \text { Run } 1\end{array}$} & \multirow{2}{*}{$\begin{array}{l}\text { yield } \\
\text { stress }(\mathrm{Pa}) \\
\quad \text { Run } 2\end{array}$} & \multirow{2}{*}{$\begin{array}{l}\text { yield } \\
\text { stress }(\mathrm{Pa}) \\
\quad \text { Avg }\end{array}$} & \multicolumn{2}{|c|}{$\begin{array}{c}\text { yield } \\
4.23 \% \text { stress }(\mathrm{Pa})\end{array}$} \\
\hline & & & & Error & Corrected \\
\hline 09132007-11 & 14.13 & 14.02 & 14.075 & 0.60 & 13.48 \\
\hline 09132007-12 & 14.46 & 14 & 14.23 & 0.60 & 13.63 \\
\hline 09132007-13 & 14.54 & 14.24 & 14.39 & 0.61 & 13.78 \\
\hline Average & & & 14.23 & & 13.63 \\
\hline
\end{tabular}

The listed errors are associated with calibration errors of the utilized test equipment. Anova: Single Factor

\begin{tabular}{|c|c|c|c|c|}
\hline Groups & Count & Sum & Average & Variance \\
\hline Row 1 & 2 & 28.15 & 14.075 & 0.00605 \\
\hline Row 2 & 2 & 28.46 & 14.23 & 0.1058 \\
\hline Row 3 & 2 & 28.78 & 14.39 & 0.045 \\
\hline
\end{tabular}

\begin{tabular}{|c|c|c|c|c|c|c|}
\hline Source of Variation & SS & $d f$ & $M S$ & $F$ & P-value & F crit \\
\hline Between Groups & 0.099233333 & 2 & 0.049616667 & 0.948995856 & 0.479352297 & 9.552081792 \\
\hline Within Groups & 0.15685 & 3 & 0.052283333 & & & \\
\hline Total & 0.256083333 & 5 & & & & \\
\hline
\end{tabular}


The statistics demonstrate good mixing, since

$$
\text { F } \quad<<\text { F crit. } 0.05<<9.55
$$

When the AZ-101 level was lowered to perform tests at the $1.31 \mathrm{~m}$ level, the yield stress increased from an average value of 14.23 to 16.1 Pascals, due to rapid settling of the solids while the contents of the column were transferred to the 1000 gallon temporary storage tank, which is shown in Figure 6-4 and Figure 6-5. Since uniform mixing was established, single samples were adequate. A final sample of the diluted simulant was shown to have an acceptable yield stress of 14.37 Pa.

Evaporation was not compensated during AZ-101 testing. Once air or oxygen was added to the simulant, the simulant volume was permanently altered due to entrapped gas, and determination of the exact volume of simulant was impractical during testing. As a matter of fact, the measured simulant volume occasionally varied before and after a single test due to entrapped gas. To better understand the effects of entrapped gas on simulant properties, a sample was thoroughly mixed to release the trapped gas from solution, and the density of the sample changed by $1.7 \%$ $(1.1667 \mathrm{~g} / \mathrm{ml} / 1.1472 \mathrm{~g} / \mathrm{ml}=1.017)$. In other words, the system design itself prevented removal of entrapped gas between tests, since the mixing mechanism utilized the gas of concern to perform mixing. 
Table 6-4. AZ-101 Rheology During Mass Transfer Testing

\begin{tabular}{|l|l|l|l|l|l|}
\hline $\begin{array}{l}\text { Sample } \\
\text { number }\end{array}$ & $\begin{array}{l}\text { Percent } \\
\text { solids }\end{array}$ & $\begin{array}{l}\text { Density } \\
\mathbf{( g / m )}\end{array}$ & $\begin{array}{l}\text { Yield } \\
\text { stress } \\
\mathbf{( P a )}\end{array}$ & $\begin{array}{l}\text { Plastic } \\
\text { viscosity } \\
\mathbf{( c P )}\end{array}$ & $\begin{array}{l}\text { Comments } \\
\text { Conductivity }=13.1 \mathrm{mMhos} / \mathrm{cm}\end{array}$ \\
\hline $09122007-1$ & 27.99 & 1.2740 & 92.835 & 120.900 & $\begin{array}{l}\text { Settled sludge sample after settling for } \\
\text { 60 days }\end{array}$ \\
\hline $09132007-2$ & 23.33 & 1.2001 & 33.310 & 26.625 & $\begin{array}{l}\text { Second of three samples following } \\
\text { receipt and mixing in the column at the } \\
7.41 \mathrm{~m} \text { level. }\end{array}$ \\
\hline $09132007-3$ & 23.38 & 1.2024 & 33.705 & 27.770 & $\begin{array}{l}\text { Third of three samples following receipt } \\
\text { and mixing in the column at the 7.41 m } \\
\text { level. }\end{array}$ \\
\hline $09132007-4$ & 23.29 & 1.1968 & 34.115 & 27.750 & $\begin{array}{l}\text { First of three samples following receipt } \\
\text { and mixing in the column at the 7.41 m } \\
\text { level. }\end{array}$ \\
\hline $09202007-11$ & 19.80 & 1.1703 & 14.075 & 11.385 & $\begin{array}{l}\text { First of three uniformly mixed samples } \\
\text { after dilution }\end{array}$ \\
\hline $09202007-12$ & 19.70 & 1.1527 & 14.230 & 11.545 & $\begin{array}{l}\text { Second of three uniformly mixed } \\
\text { samples after dilution }\end{array}$ \\
\hline $09202007-13$ & 19.69 & 1.15275 & 14.390 & 11.49 & $\begin{array}{l}\text { Third of three uniformly mixed samples } \\
\text { after dilution }\end{array}$ \\
\hline $09262007-19$ & 19.93 & 1.1472 & 16.055 & 10.925 & $\begin{array}{l}\text { Sample following the lowering of the } \\
\text { column level to 1.31 m }\end{array}$ \\
\hline $09262007-19$ & ---- & 1.1667 & ----- & ----- & $\begin{array}{l}\text { Sample to verify density after mixing to } \\
\text { release trapped gas from solution }\end{array}$ \\
\hline $09272007-20$ & 19.30 & 1.1193 & 14.370 & 9.7405 & $\begin{array}{l}\text { Sample after dilution and test } \\
\text { completions at the 1.31 m level }\end{array}$ \\
\hline
\end{tabular}

\subsection{TEST RESULTS}

The primary test results include discussions of DO concentrations during oxygen mixing and air sparging; bubble formation during testing; mass transfer coefficients; and void fractions.

\subsubsection{DO Concentrations During Oxygen Mixing and Air Sparging}

Figures describing DO concentrations during oxygen mixing and air sparging were extracted from test data, provided in Appendix C. In particular, test data using a common superficial velocity of $5 \mathrm{~mm} / \mathrm{sec}$ is presented. Also included in Appendix $\mathrm{C}$ are differential level and pressure transducer data. 


\subsubsection{DO Measurements for Water Tests}

DO concentrations needed to be considered for different liquid levels. Typical DO concentrations are shown at different column levels in Figure 6-33 for testing at the 7.41 meter level. To further demonstrate the system response to oxygen addition and air sparging, the differential changes in surface level and the differential changes in pressure are shown in Figure 6-34 and Figure 6-35. The figures demonstrate that DO concentrations increase with increasing depth as expected when the tank is filled to the 7.41 meter level. The level and volume of the simulant also increase due to bubbles in suspension during gas addition, or increased void fraction. The level decreases rapidly when oxygen addition and air sparging are stopped. Results are similar for tests at the 3.63 meter level, as shown in Figure 6-36. However, the DO concentrations at the two lower sensors are starting to overlap, indicating that oxygen mixing is different than it was at the higher test levels for the column. In fact, at the 1.31 meter level the DO concentrations vary significantly from expectation. As shown in Figure 6-37, the DO concentration appears to decrease with level, when an increase is expected. Again, mixing of the oxygen is considered to be the cause.

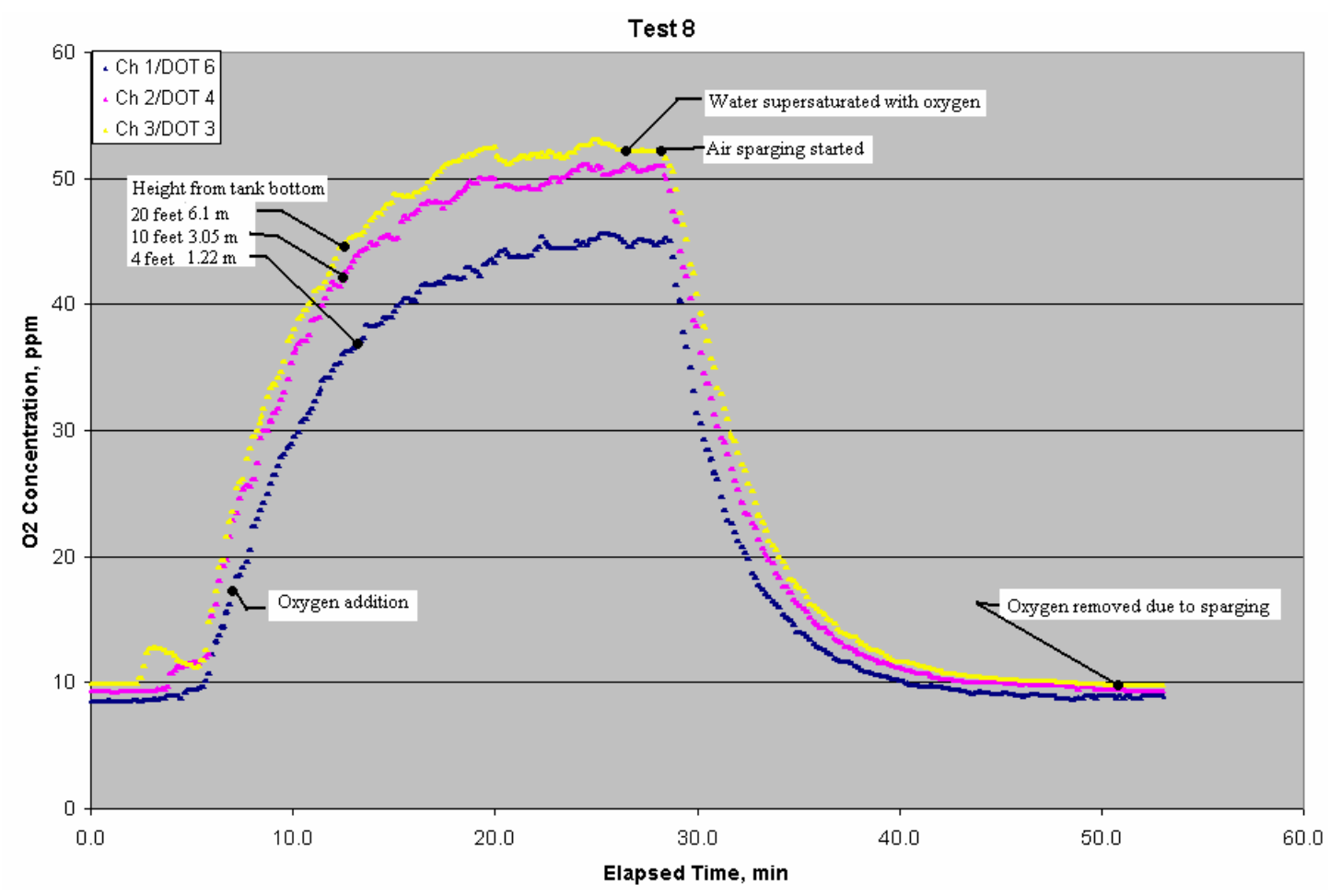

Figure 6-33. Oxygen Addition and Air Sparging Effects on DO Concentration When the Column is Filled to 24.3 Feet (7.41m) During Water Testing 
WSRC-STI-2007-00537, REVISION 0

SRNL-RPP-2007-00023, REVISION 0

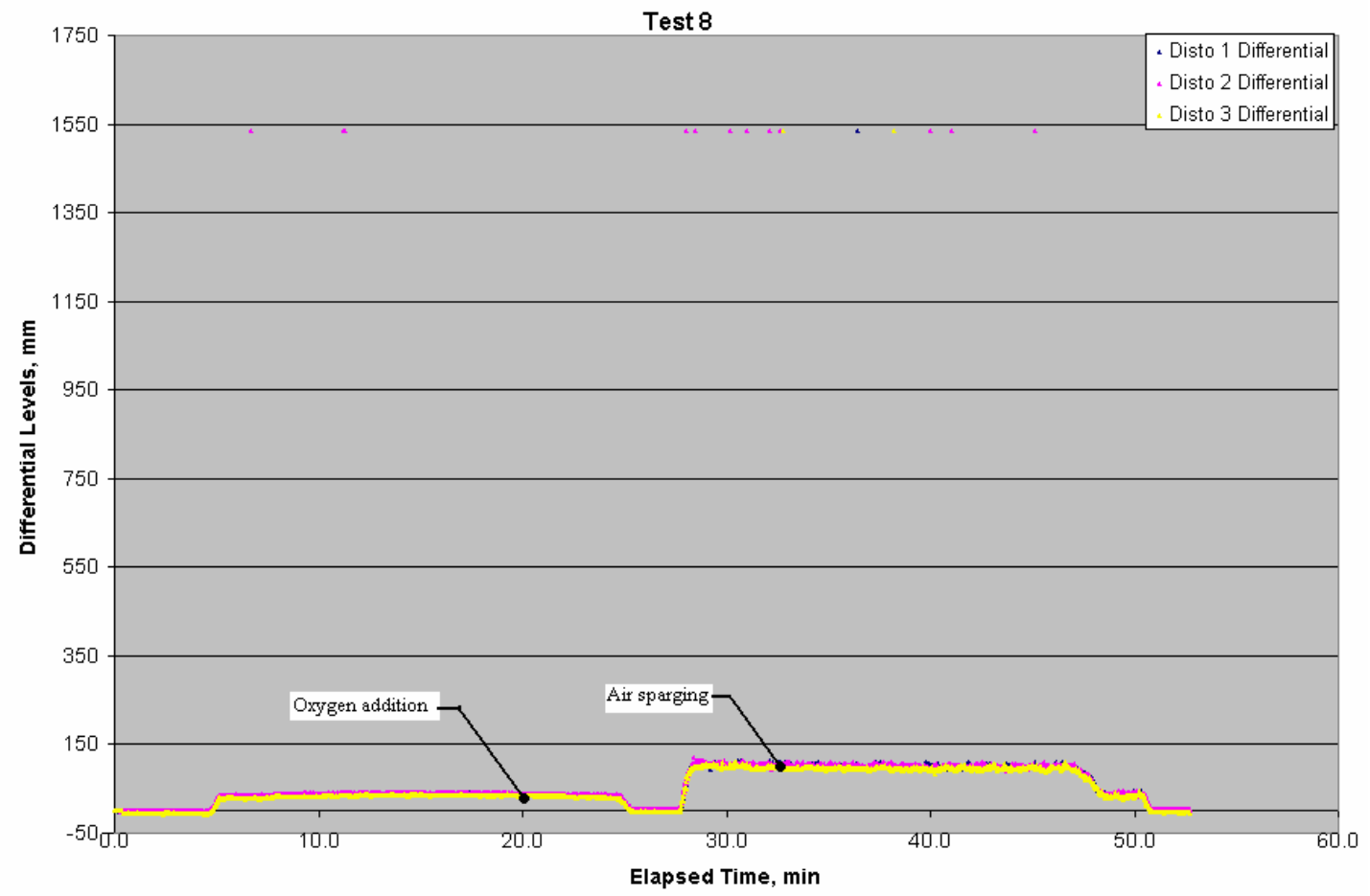

Figure 6-34. Typical Level Changes Indicated by Lasers During Water Testing

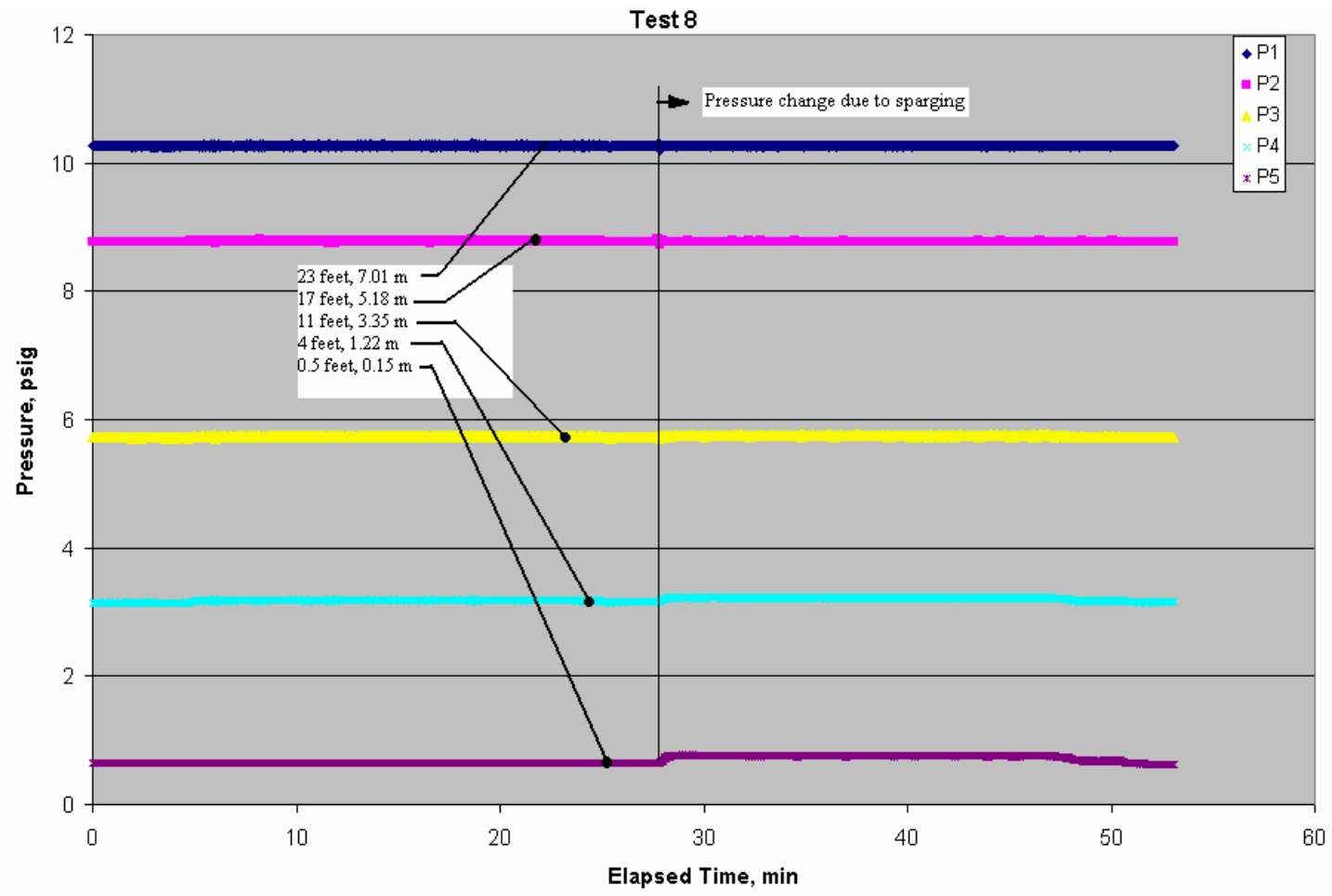

Figure 6-35. Typical Changes in Pressure at Different Column Depths During Water Testing 
WSRC-STI-2007-00537, REVISION 0

SRNL-RPP-2007-00023, REVISION 0

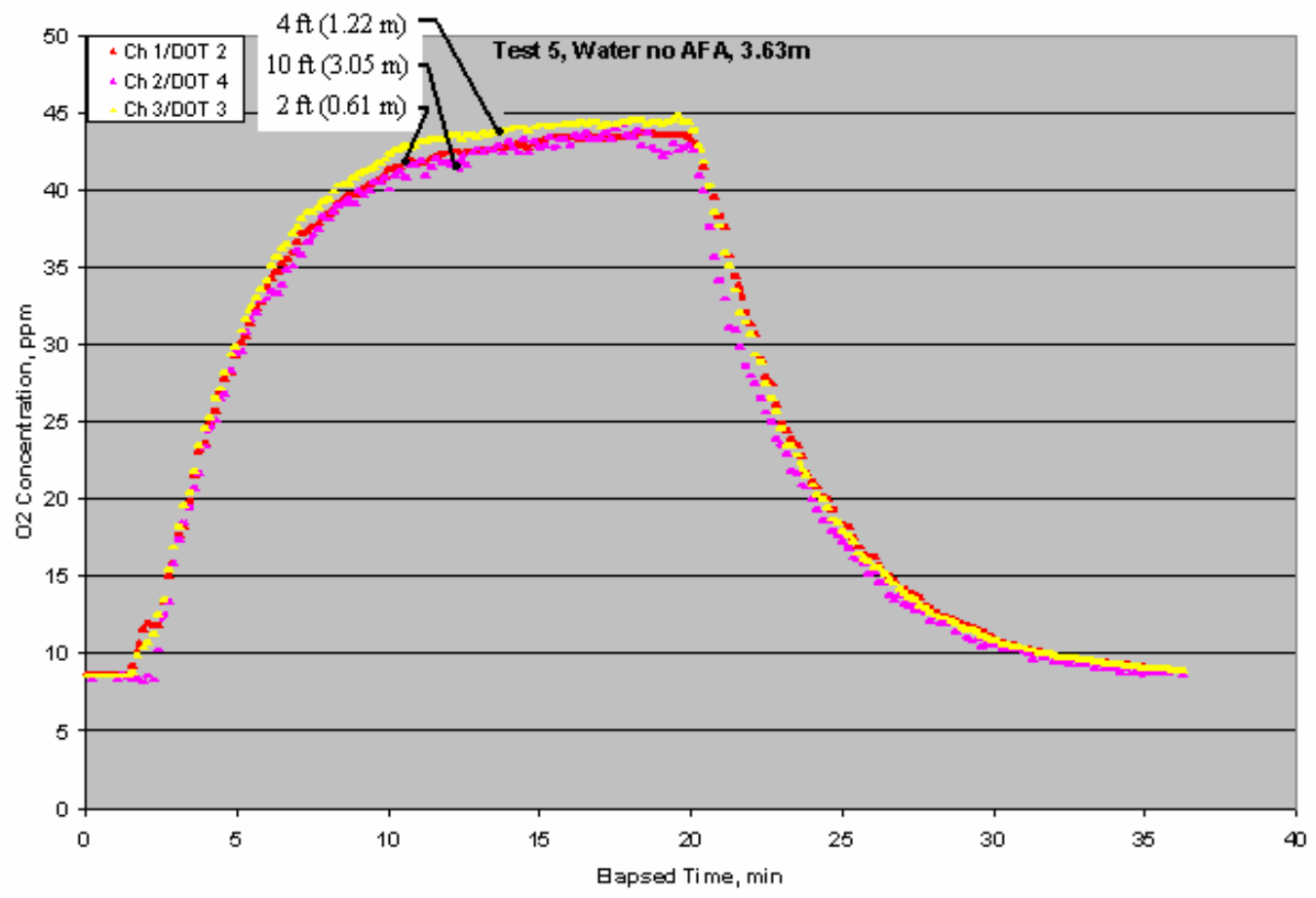

Figure 6-36. Test Results for Water when the Column was Filled to the 3.63 Meter Level

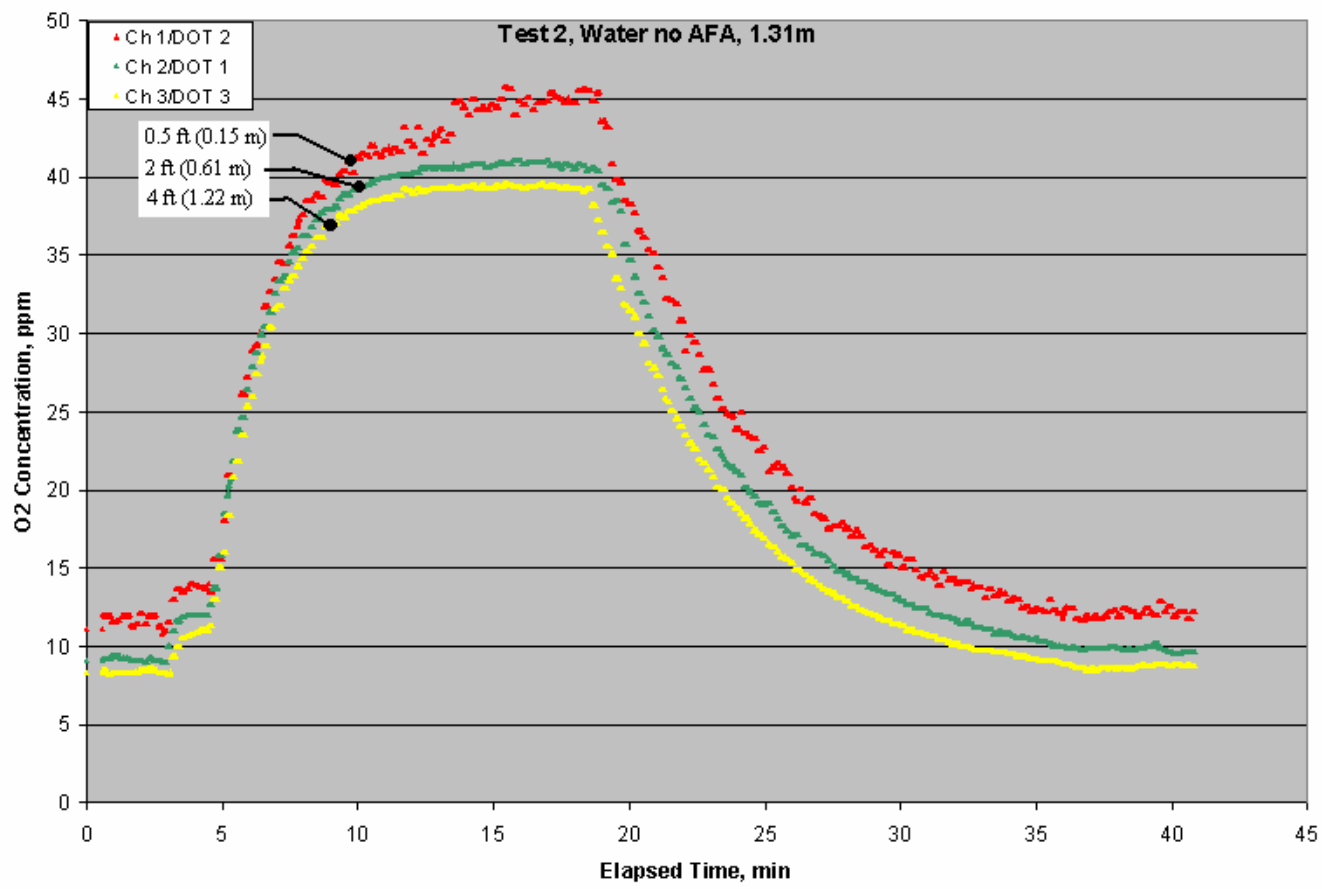

Figure 6-37. Test Results for Water when the Column was Filled to the 1.31 Meter Level 


\subsubsection{DO Measurements for Testing of Water with AFA}

A typical test is shown for water with AFA in Figure 6-38 (Test 20). The test conditions are similar to those for the test results shown in Figure 6-36 (Test 5). As the DO concentration increases, the two tests converge to similar maximum oxygen concentrations. Testing for water and water with AFA provided similar results with respect to maximum obtainable DO concentrations, since the DO sensors were calibrated to standards for water and the fluids were similar. The actual DO concentrations may vary slightly since the conductivity of the process water was measured at $36.2 \mu$ Siemens and the water with AFA was measured at $54.9 \mu$ Siemens. When sparging started, the results are similar except that the time required for the $\mathrm{DO}$ concentration to return to equilibrium is longer when AFA is present. That is, the DO concentration takes longer to be sparged from solution when AFA is present. This observation is important to the mass transfer coefficient determination, since this coefficient is proportional to the DO concentration. DO concentrations were observed to take more than a day to return to atmospheric conditions if sparging was not performed. In other words, there was still significant oxygen in solution when the simulant was left to stand overnight. Within about 24 hours, all of the DO was released from solution.

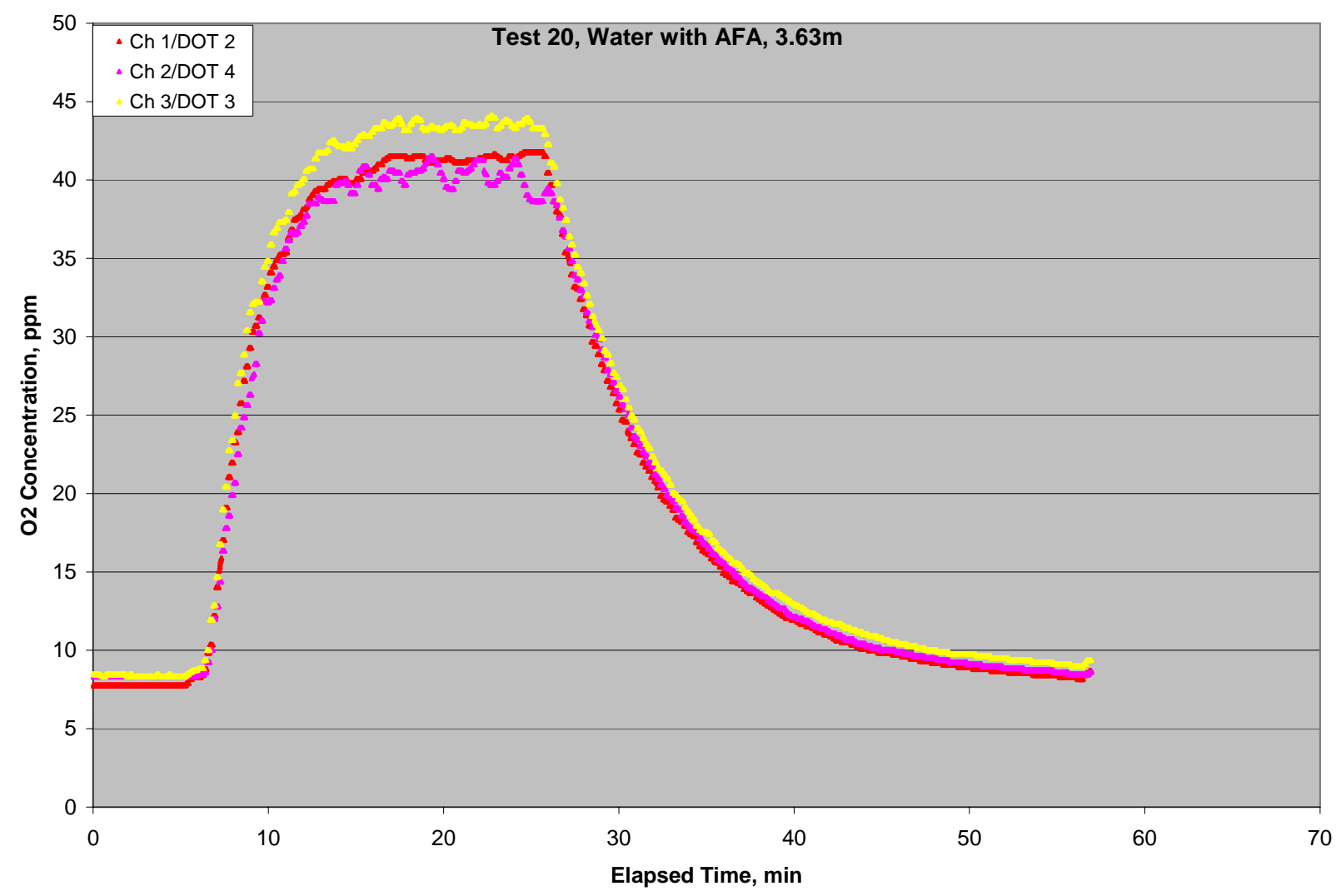

Figure 6-38. Test Results for Water with AFA when the Column was Filled to the 3.63 Meter Level 


\subsubsection{DO Measurements for AZ-101 Tests}

AZ-101 tests were performed at two simulant levels. DO concentrations at the highest simulant level are shown in Figure 6-39, and these results have test conditions similar to water test results shown in Figure 6-33. The results are similar in form, but the AZ-101 has a higher oxygen concentration, and the oxygen takes a significantly longer time to purge from solution. For water the DO concentration was reduced to atmospheric equilibrium conditions in less than half an hour. For AZ-101, atmospheric conditions were reached in over an hour. DO concentrations at the lower simulant level are shown in Figure 6-40. The general shape of the DO response curve is similar to other data with the exception of the response at the lowest, DOT1, sensor. The response indicates that the air sparger provides ineffective mixing of the sludge on the tank bottom. This fact is reasonable given the fact that the air sparge does not contact the sludge on the column bottom, as discerned from Figure 6-32. In fact, occasional peaks in the DO concentration were observed as trapped bubbles were released from the sludge.

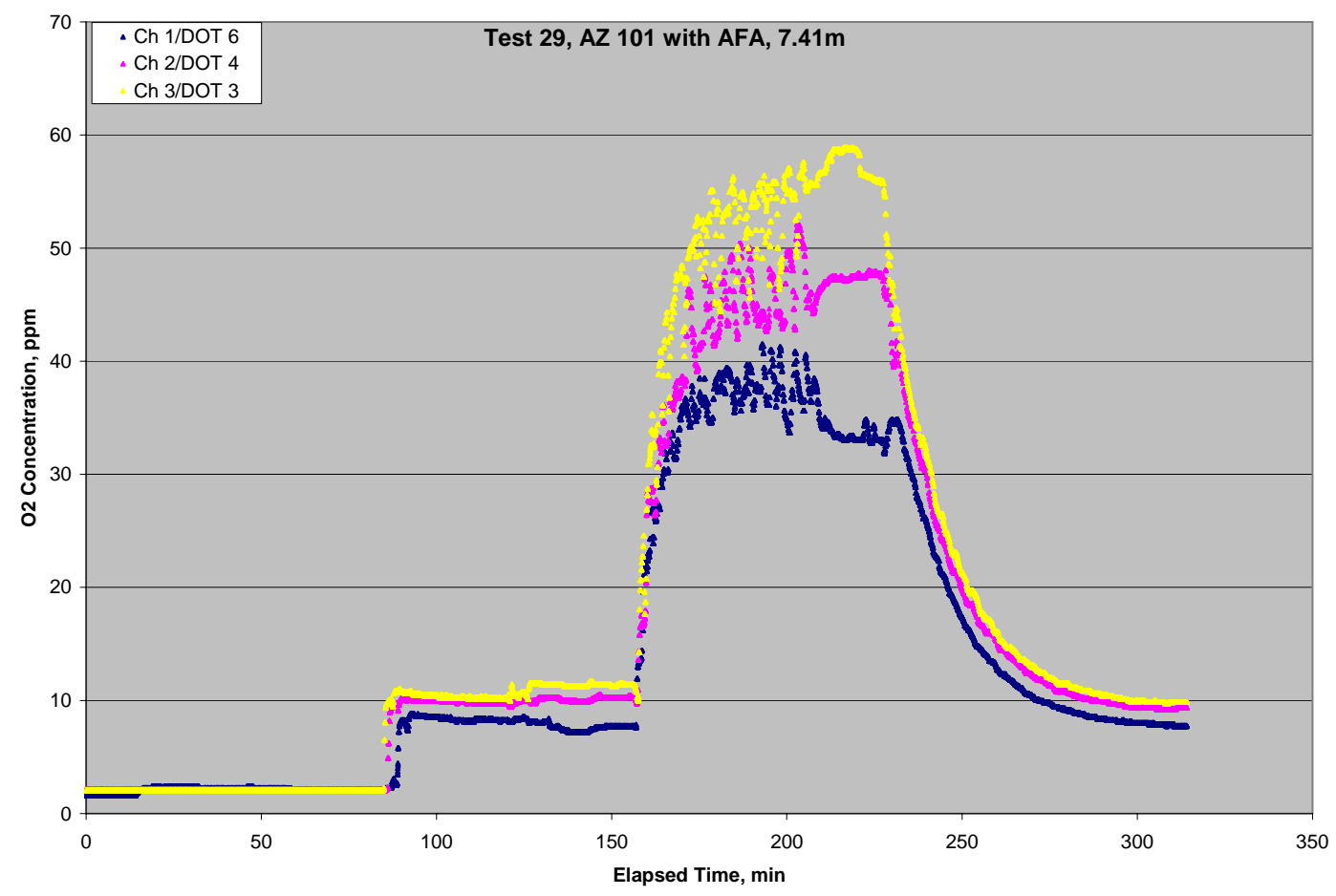

Figure 6-39. DO Concentration when the Simulant is at the Higher Test Level 


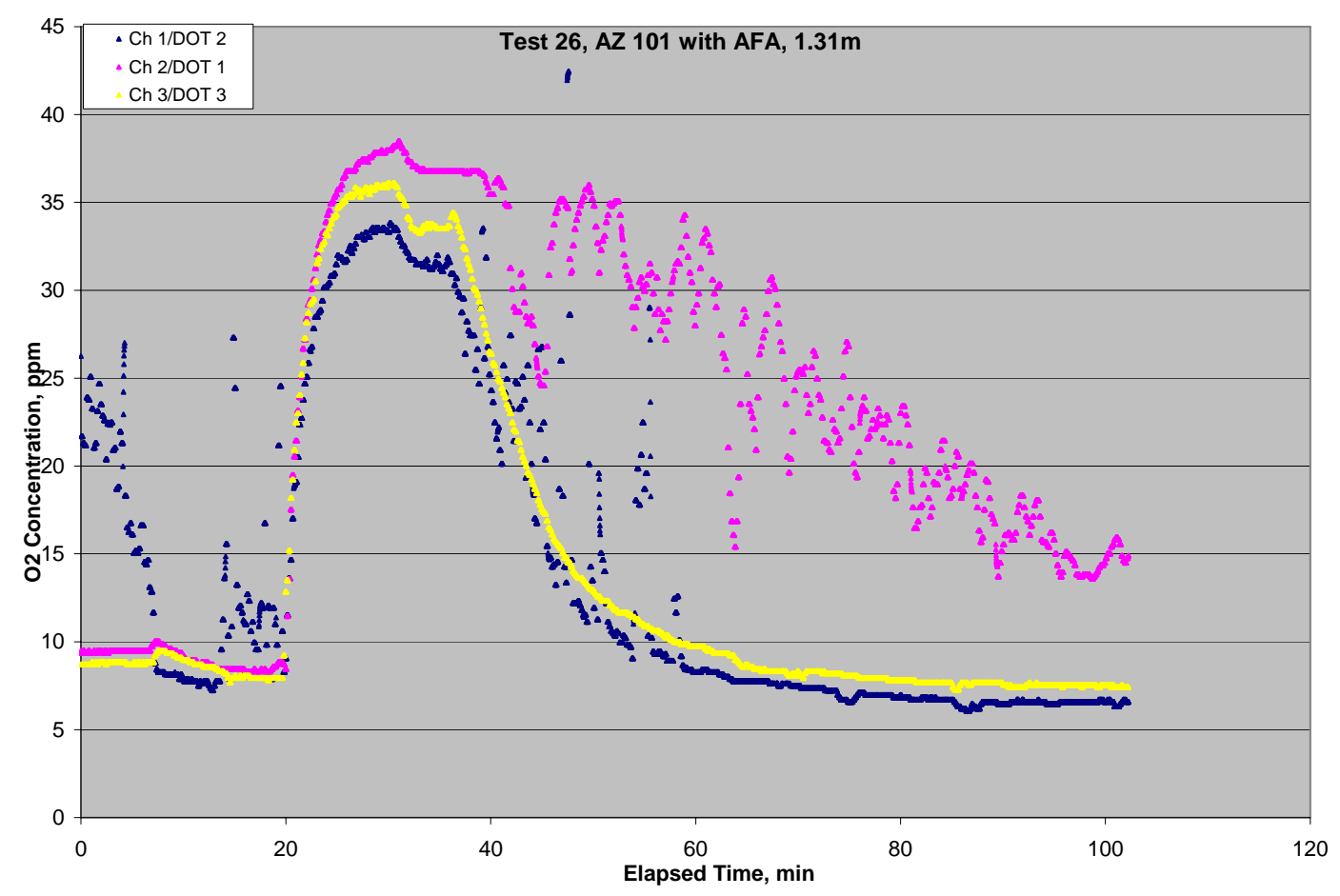

Figure 6-40. DO Concentration when the Simulant is at the Lower Test Level

\subsubsection{Bubble Formation During Tests}

Photos and videos were taken to depict bubble formations in the simulants. Extensive photos were taken for the water tests, since the transparent fluid was readily photographed. For the AZ101 simulant, photos were only taken of the upper surface. For the water with AFA, photos were taken through the view ports of the column which are dimensioned in Figure 6-31, but the opaque nature of this fluid rendered the photos useless. Photos were not taken of the surface of the water with AFA solution. The bubble photos presented here were obtained from videos and photo collections, which are provided in a DVD format along with this report.

\section{Bubble Formation During Water Tests}

Along with videos, approximately 250 photos are provided with this report in files formatted as shown in Figure 6-41. The lowered tier files typically contain 8 photos providing a representative sample to portray the bubble dynamics for each test level, view port, and superficial velocity. For example, a set of photos for a $10 \mathrm{~mm} / \mathrm{second}$ superficial velocity for a test at 7.41 meters is obtained from the 24.3 foot level file, at the bottom port, and the second, third, and fourth ports from the bottom, and from the top of the column at $10 \mathrm{scfm}(10 \mathrm{~mm} / \mathrm{second})$ for each port. Since each file contains 8 photos, only one photo from each file is displayed in Figure 6-42 Figure 6-46. 
An additional photo (Figure 6-43) shows the formation of a cone of bubbles at the second port. The diameter of the cone at the second view port level was approximated as $20-24$ inches in diameter. By comparison, the cone for a $2 \mathrm{~mm} / \mathrm{second}$ superficial velocity was less than 18 inches at this port. Also, video displays are provided with this report, which were only filmed at a 9 to $10 \mathrm{~mm} /$ second superficial velocity for a 7.41 meter level test at the bottom and second from the bottom ports. The pictures clearly show that bubbles are formed in a cone rising from the sparger tip until a uniform field of bubbles is formed throughout the column cross section, as demonstrated by Figure 6-47. At the higher column elevations, the bubbles were observed to rise toward the center of the pipe and fall near the column wall. 
$\square \square$ Photos of water tests at all three test levels

$\square 11.9$ Foot Level (7.41 meters)

믈 2nd port

$+\square 10$ SCFM (10 mm per sec)

+02 SCFM (2 mm per sec)

$+5 \mathrm{scfm}$ ( $5 \mathrm{~mm}$ per sec)

† BL 5 scfm

1 3rd port

$+\square 10$ SCFM

$\oplus \bigcirc 2$ SCFM

$+\square 5$ SCFM

$\square \square$ Bottom port

$+\square 10$ SCFM

$+\bigcirc 2$ SCFM

†. 5 SCFM

- 24.3 Foot Level (3.63 meters)

曰- 2nd Port

$+\square 10 \mathrm{scfm}$

$\oplus \circlearrowright 2 \mathrm{scfm}$

$+\square 5 \mathrm{scfm}$

미 3rd Port
†. 10 scfm
$+02 \mathrm{scfm}$
$+05 \mathrm{scm}$

브 4th port
+10 scfm
$+02 \mathrm{scfm}$
$+\square$ scfm

Bottom Port

† $10 \mathrm{scfm}$

$+\square 2 \mathrm{scfm}$

$+\bigcirc 5 \mathrm{scfm}$

$\square$ From Top
$\oplus \square 10 \mathrm{scfm}$
$+\square 2 \mathrm{scfm}$
$+\square 5 \mathrm{scm}$

- 4.3 foot level (1.31 meters)

† 2nd Port
† $10 \mathrm{scfm}$
$\oplus \square 2 \mathrm{scm}$
$+05 \mathrm{scfm}$

曰 Bottom Port

† $10 \mathrm{scfm}$

$+\square 2$ scfm

$+\bigcirc 5$ scfm

Figure 6-41. Files for Photos of Water Testing

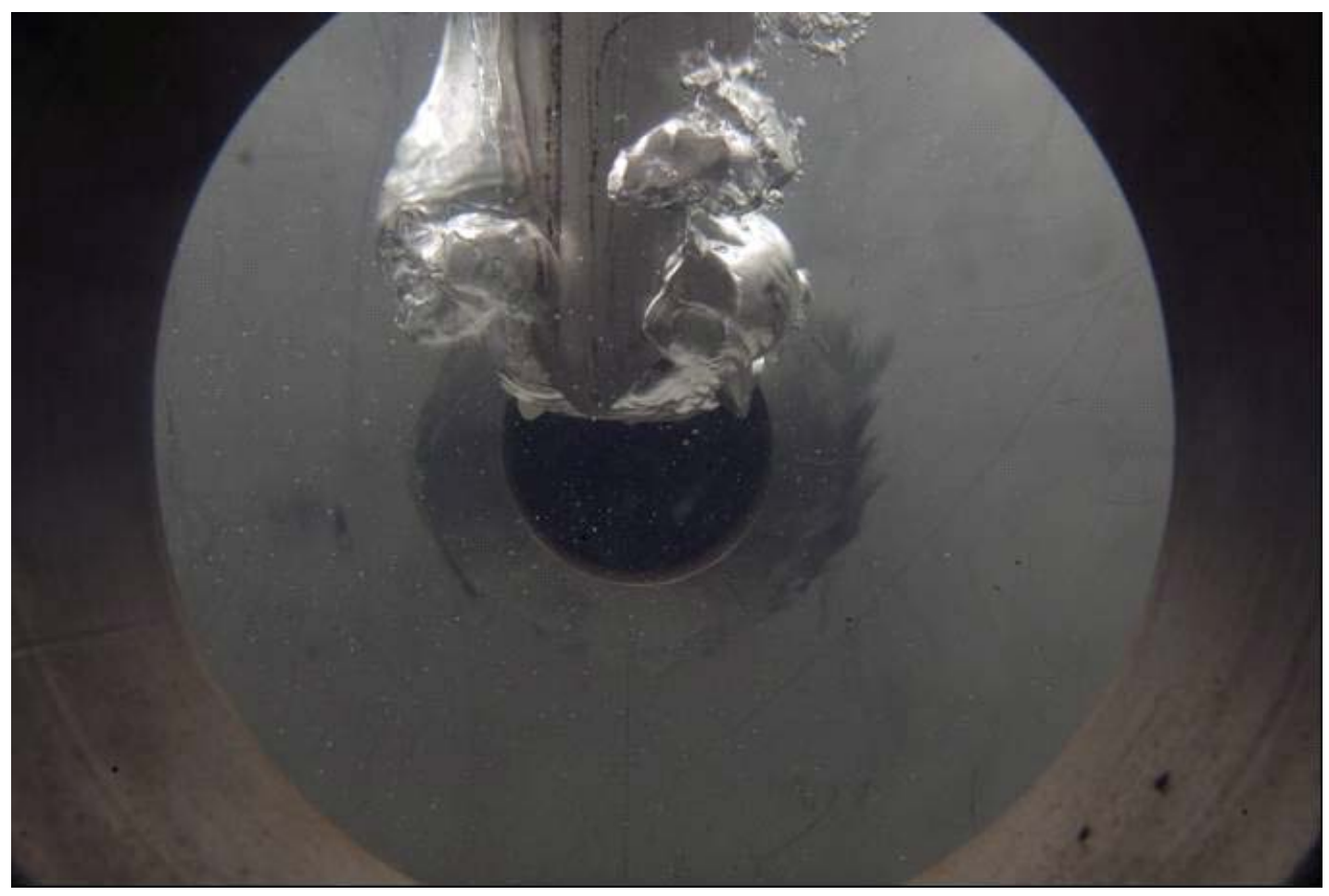

Figure 6-42. Photo at the Bottom Port 
WSRC-STI-2007-00537, REVISION 0

SRNL-RPP-2007-00023, REVISION 0

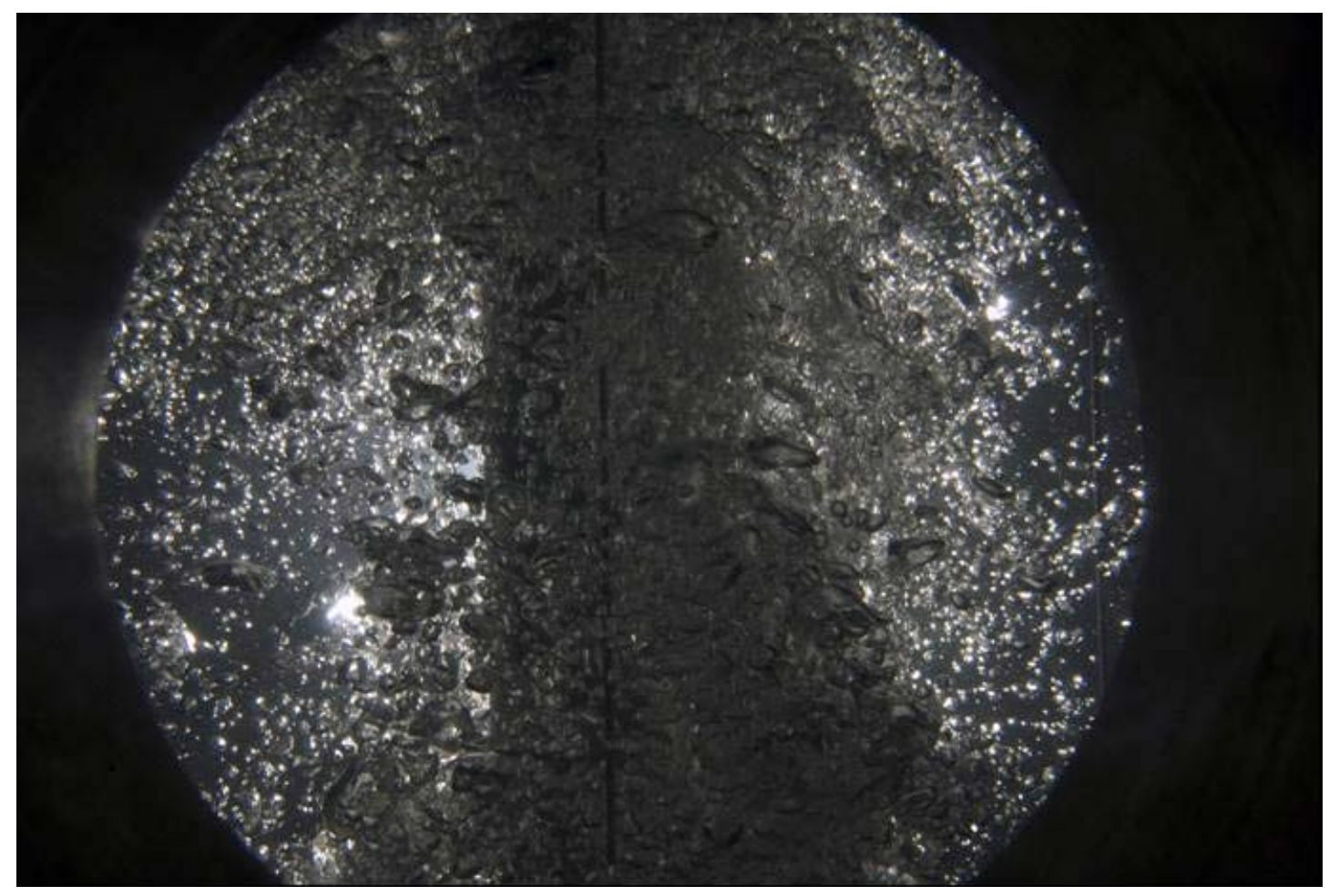

Figure 6-43. Photo at the Second Port from the Bottom

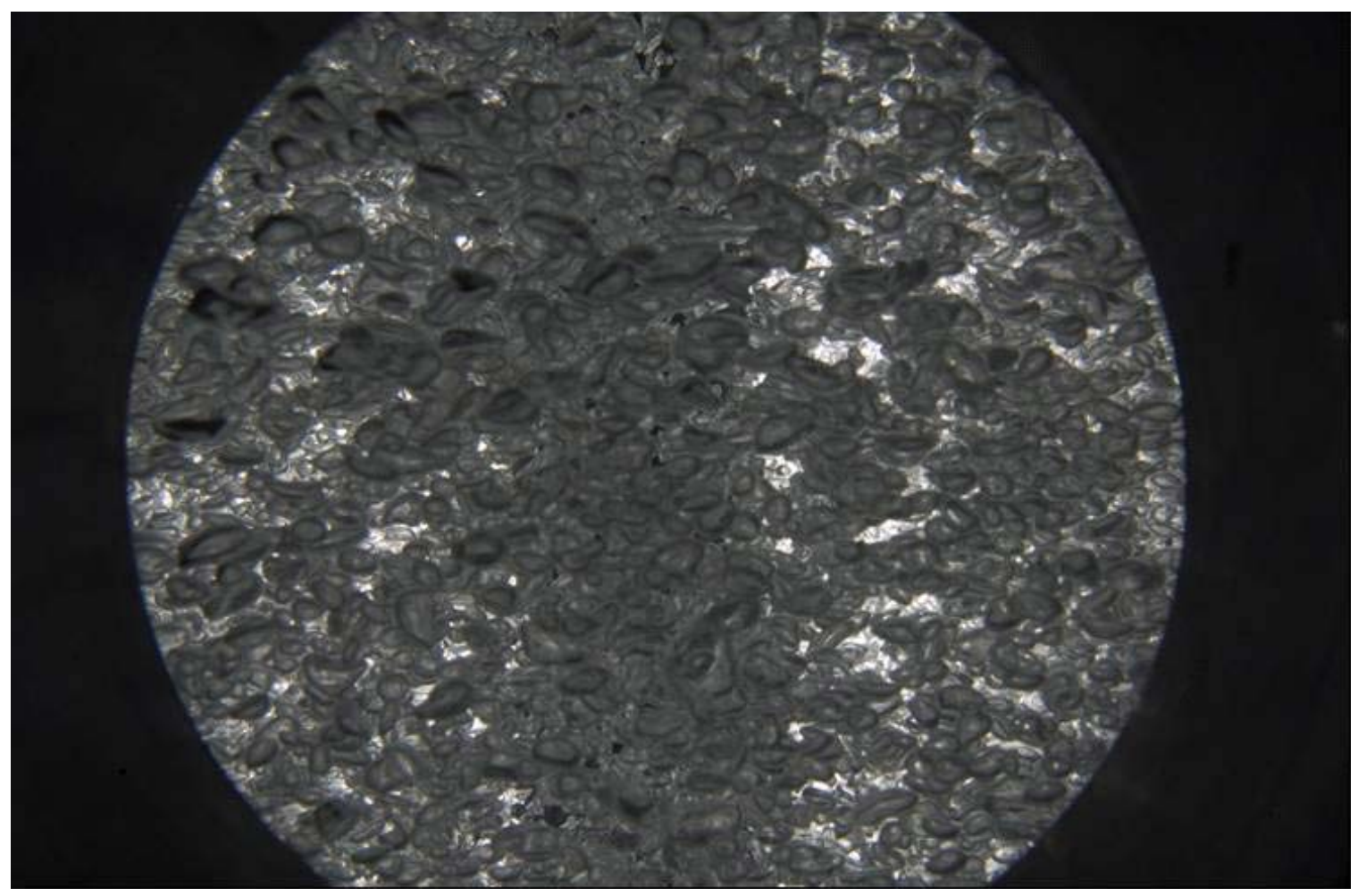

Figure 6-44. Photo at the Third Port from the Bottom 


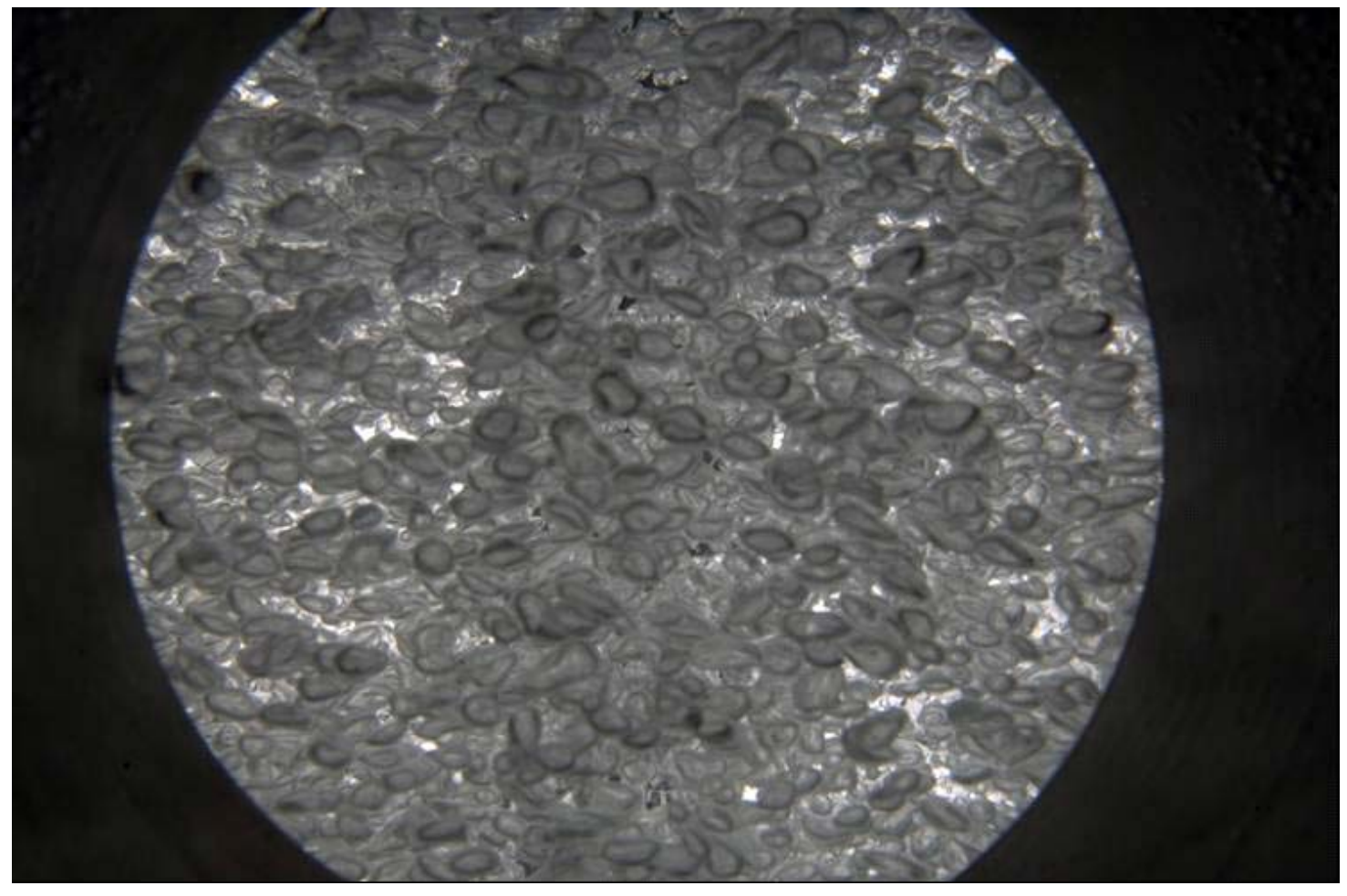

Figure 6-45. Photo at the Fourth Port from the Bottom

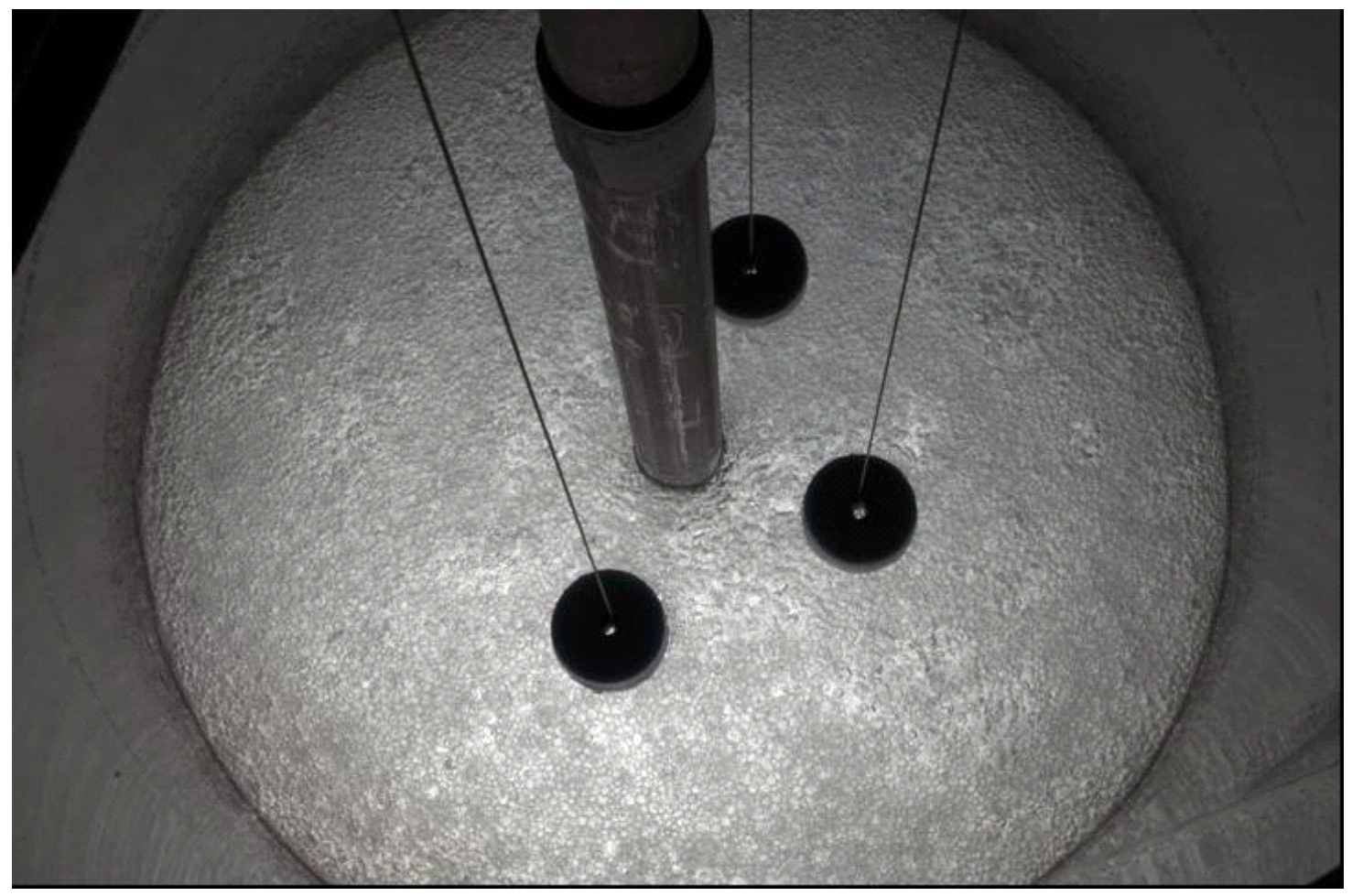

Figure 6-46. Photo from the Top of the Column 


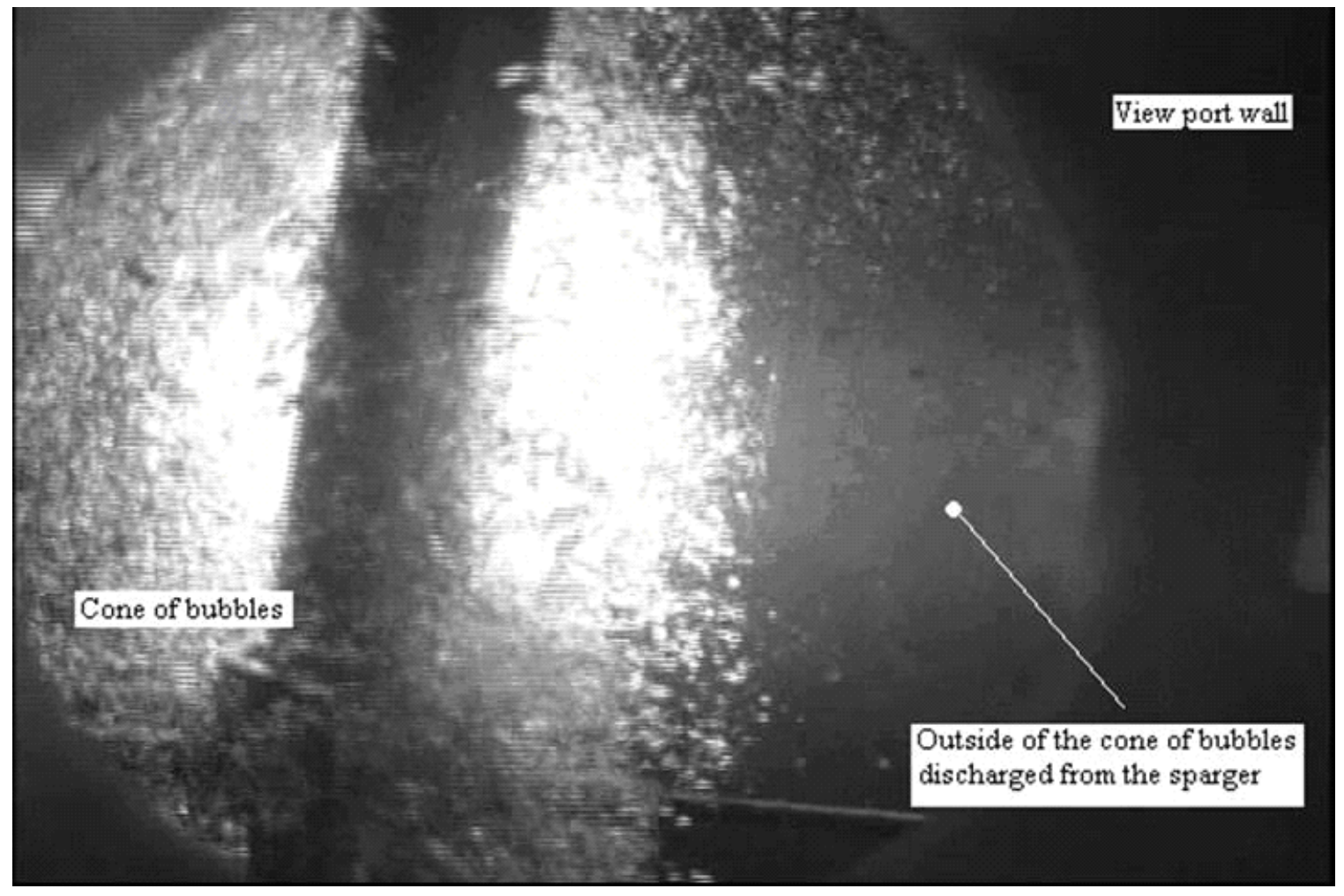

Figure 6-47. Formation of a Cone of Bubbles Above the Sparger, 3 Feet Above the Column Bottom

\section{Bubble Formation During AZ-101 Tests}

Bubbles formed during AZ-101 testing were markedly different than those formed during water testing. In water which is a Newtonian fluid, 1 - 2 inch, irregular shaped bubbles were formed at the sparger, and these bubbles rapidly broke up into smaller rising bubbles with sizes on the order of $1 / 4$ inch in diameter. Testing in the Bingham plastic AZ-101 solution showed that the bubbles formed at the sparger and remained intact as they rose and expanded through the simulant, The bubble diameters at the surface ranged in size from about 8 inches in diameter at a

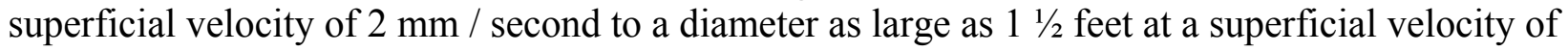
$10 \mathrm{~mm} / \mathrm{second}$. Although not filmed, higher superficial velocities yielded $2-1 / 2$ feet diameter bubbles, which were the diameter of the column. Excerpts from videos provided with this report are shown in Figure 6-48 - Figure 6-51. The film clips show bubbles formed in the as received 33 Pascal simulant without AFA and also show bubbles in the 13 Pascal test simulant with AFA. Videos are provided with this report for testing at both simulant levels for the 13 Pascal material (1.31 and 3.63 meters) but only at the 7.41 meter level for the 33 Pascal simulant. 
Videos at these levels were taken for all three superficial velocities $(2,5$, and $10 \mathrm{~mm} /$ second). Reviewing the available videos, sparger bubble sizes did not appear to be significantly affected by AFA. The movement of bubbles through the simulant may actually be similar to bubble motion in Laponite, which was previously tested at SRNL. In that high yield stress material, the simulant actually formed shear planes along which the air bubbles traveled to the surface from a similarly designed sparger at low superficial velocities. As the superficial velocities increased, large diameter bubbles formed similar to those observed in the present testing [17].

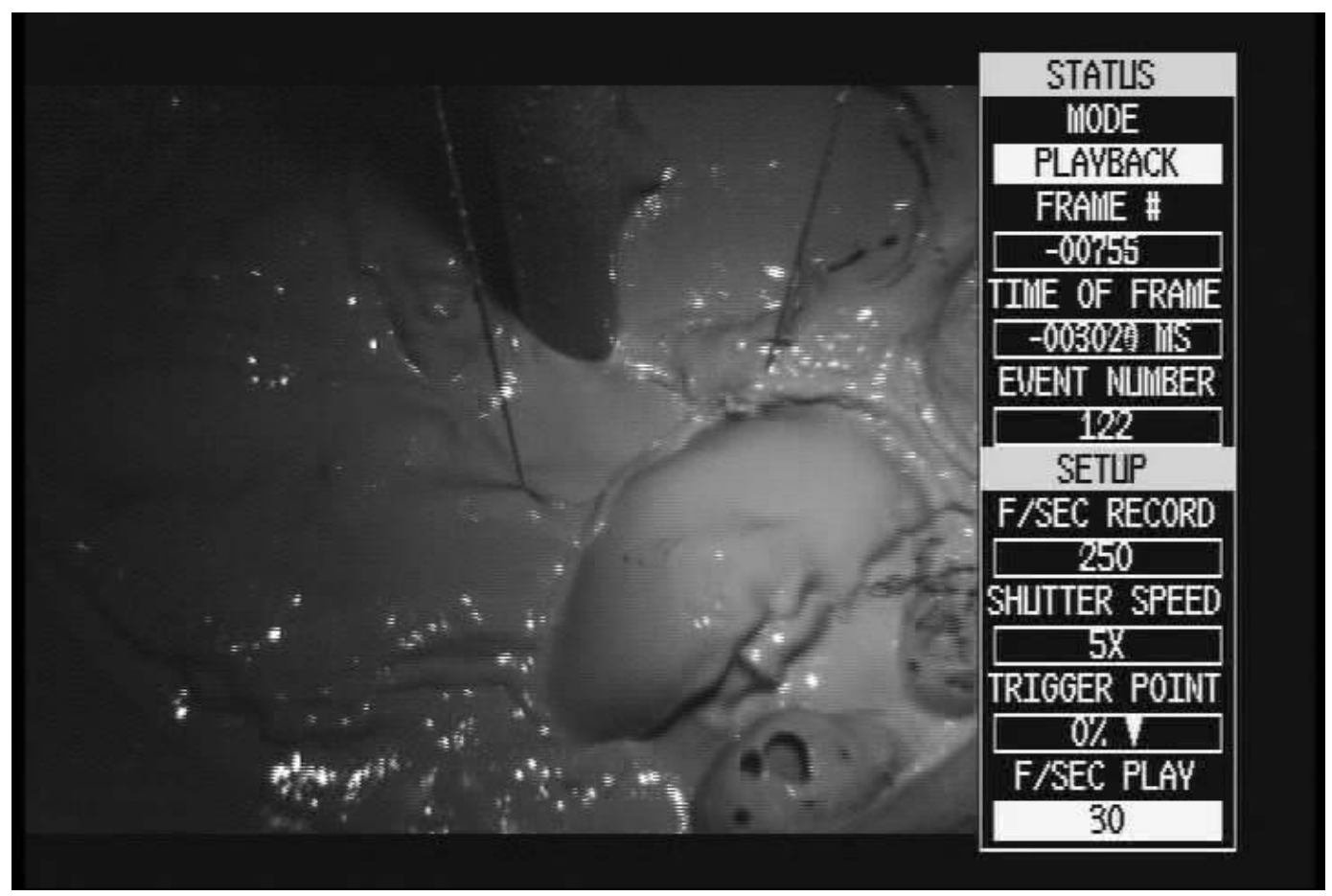

Figure 6-48. 10 mm/second Superficial Velocity, 7.41 Feet Level, 13 Pascal AZ-101 Simulant with AFA 
WSRC-STI-2007-00537, REVISION 0

SRNL-RPP-2007-00023, REVISION 0

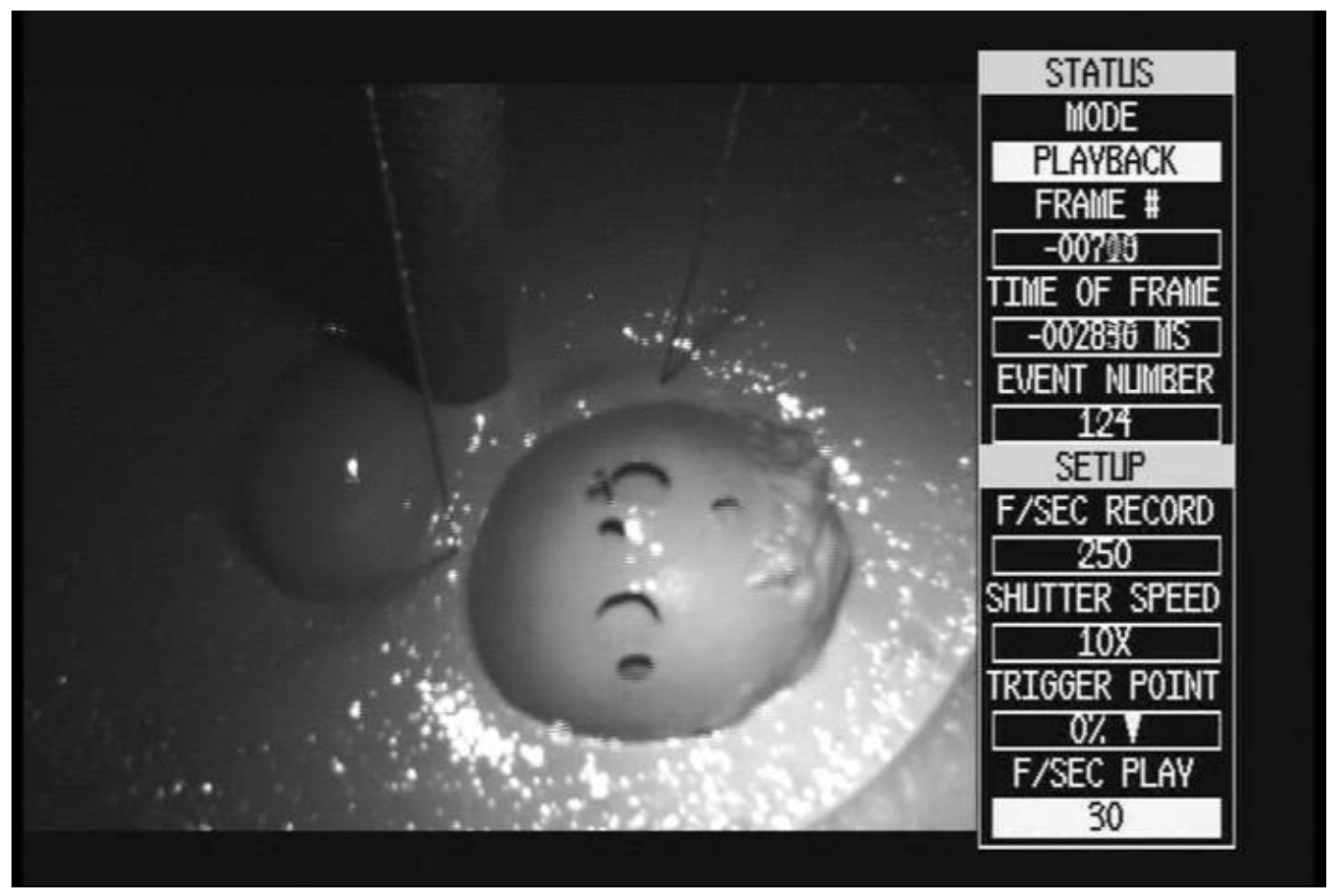

Figure 6-49. 2 mm/second Superficial Velocity, 7.41 Feet Level, 13 Pascal AZ-101 Simulant with AFA

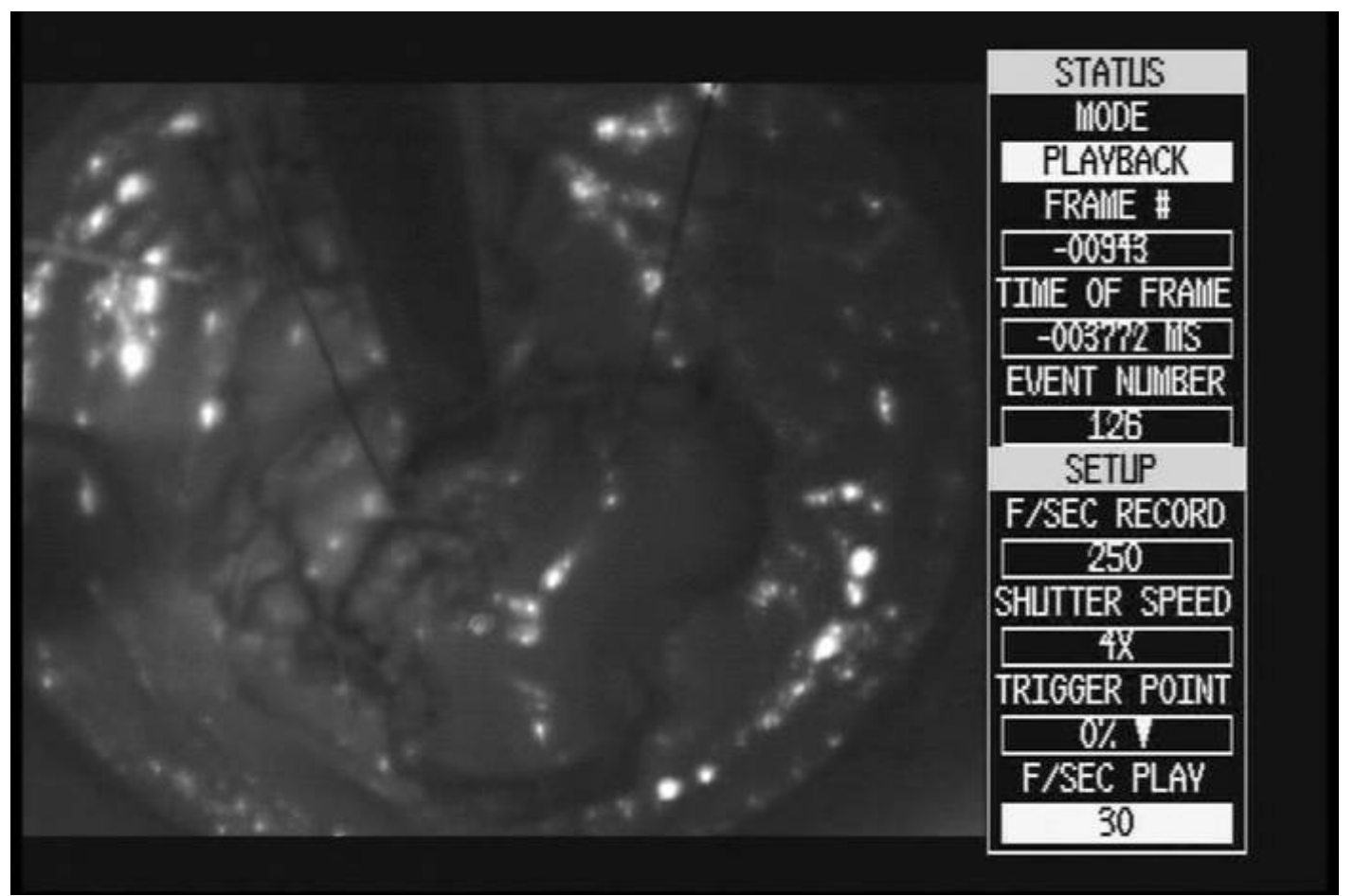

Figure 6-50. $10 \mathrm{~mm} /$ second Superficial Velocity, 7.41 Feet Level, 33 Pascal AZ-101 Simulant without AFA 


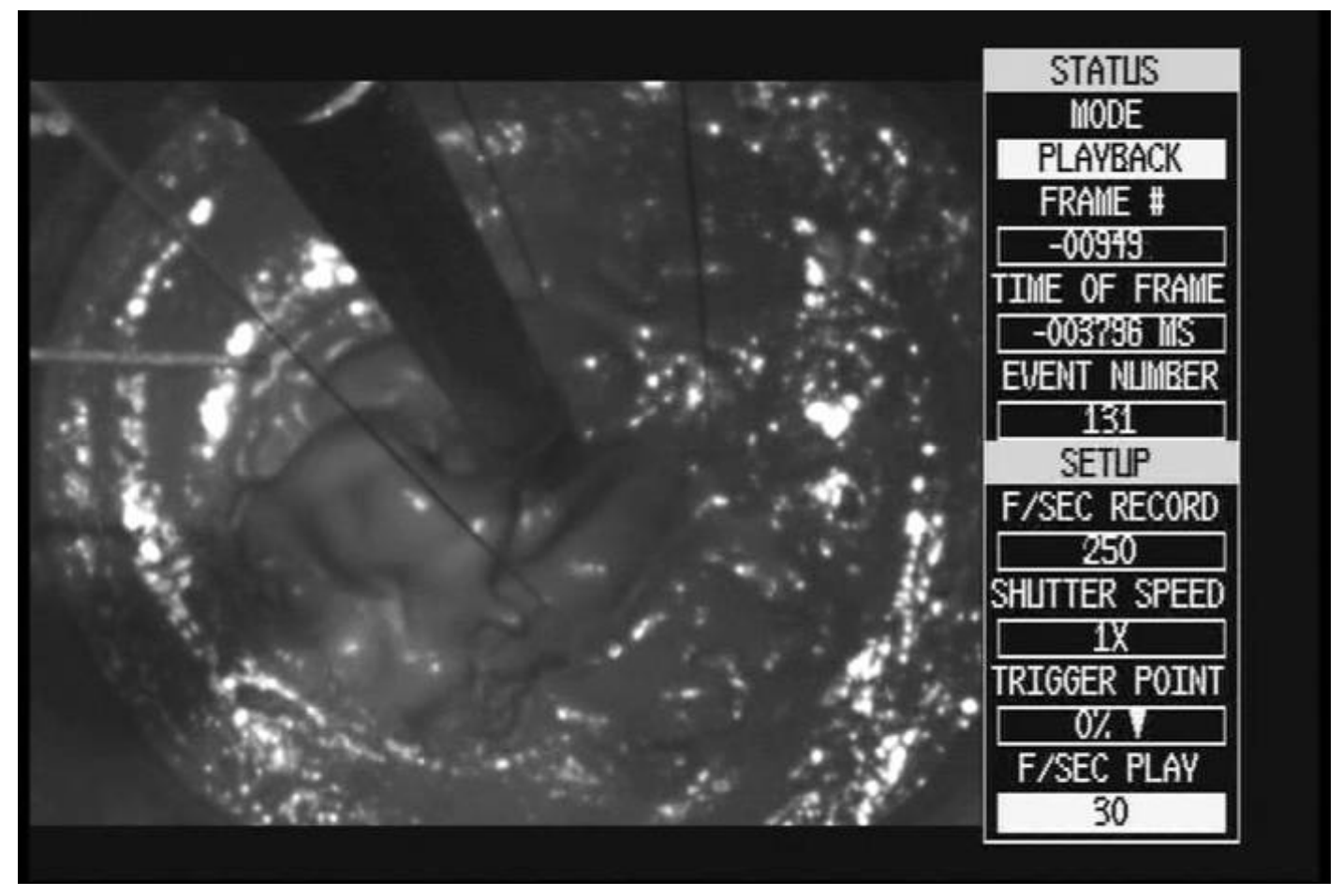

Figure 6-51. 10 mm/second Superficial Velocity, 7.41 Feet Level, 33 Pascal AZ-101 Simulant without AFA

\subsubsection{Mass Transfer Coefficients}

The raw data in Appendix C and Eq. 6.2 were used to find the mass transfer coefficients, $\mathrm{k}_{\mathrm{L}} \mathrm{a}$. An uncertainty calculation is also provided to ascertain the accuracy of solution. In all cases, $\mathrm{k}_{\mathrm{L}} \mathrm{a}$ is lower when the simulant contains AFA. The plot of $\mathrm{k}_{\mathrm{L}}$ a versus superficial velocity, Vsup, was expected to be linear. Probably, the nonlinearity is associated with the fact that the mass transfer equation assumes that the bubbles are distributed uniformly as they rise in solution. In the lower several feet of the column, the cone of bubbles from the sparger is created as waves of bubbles pass through the non-uniform flow field. In addition, secondary flows exist outside of the cone of bubbles. Together, these conditions create a flow field dissimilar from the tacit assumptions of Eq. 6.2.

\subsubsection{Calculations for $k_{L} a$}

Calculation results for $\mathrm{k}_{\mathrm{L}} \mathrm{a}$ are provided in Figure 6-52 - Figure 6-58 and summarized in Table 6-5. 
WSRC-STI-2007-00537, REVISION 0

SRNL-RPP-2007-00023, REVISION 0

Table 6-5. Mass Transfer Coefficients and Uncertainties for $k_{L} a$

\begin{tabular}{|c|c|c|c|c|c|c|c|c|c|c|c|c|c|c|c|}
\hline \multirow[t]{2}{*}{ Test } & \multirow[t]{2}{*}{$\begin{array}{c}\text { Fluid / Level / } \\
\text { Superficial } \\
\text { velocity }\end{array}$} & \multicolumn{2}{|c|}{$\begin{array}{c}\text { D0T1, } 0.15 \mathrm{~m} \text {, } \\
2.21 \% \text { Instrument } \\
\text { error }\end{array}$} & \multicolumn{2}{|c|}{$\begin{array}{c}\text { D0T2, } 0.61 \mathrm{~m} \\
5.35 \% \text { Instrument } \\
\text { error }\end{array}$} & \multicolumn{2}{|c|}{$\begin{array}{c}\text { D0T3, } 1.22 \text { m, } \\
1.68 \% \text { Instrument } \\
\text { error }\end{array}$} & \multicolumn{2}{|c|}{$\begin{array}{c}\text { D0T4, } 0.15 \mathrm{~m} \\
2.21 \% \text { Instrument } \\
\text { error }\end{array}$} & \multicolumn{2}{|c|}{ DOT5, $4.57 \mathrm{~m}$} & \multicolumn{2}{|c|}{$\begin{array}{c}\text { D0T6, } 6.1 \mathrm{~m} \text {, } \\
\begin{array}{c}5.35 \% \text { Instrument } \\
\text { error }\end{array}\end{array}$} & \multirow[b]{2}{*}{$\begin{array}{c}\text { Average } \\
k L a\end{array}$} & \multirow{2}{*}{$\begin{array}{c}\text { Total } \\
\text { Instrument } \\
\text { errors and } \\
\text { data errors } \\
\text { Total kLa } \\
\text { Uncertainty } \\
+/ . \% \\
\end{array}$} \\
\hline & & kLa & $\begin{array}{c}\text { Data error } \\
+/-\%\end{array}$ & kLa & $\begin{array}{c}\text { Data } \\
\text { error }+/- \\
\%\end{array}$ & kLa & $\begin{array}{c}\text { Data error } \\
+/-\%\end{array}$ & kLa & $\begin{array}{c}\text { Data error } \\
+/-\%\end{array}$ & kLa & $\begin{array}{c}\text { Data error } \\
+/-\%\end{array}$ & kLa & $\begin{array}{c}\text { Data error } \\
+/-\%\end{array}$ & & \\
\hline 1 & $\begin{array}{l}\text { Water, } 1.31 \mathrm{~m} \\
2 \mathrm{~mm} / \mathrm{sec}\end{array}$ & 0.0602 & 0.3289 & 0.0679 & 0.8944 & 0.0811 & 0.3151 & & & & & & & 0.070 & 1.483 \\
\hline 2 & $\begin{array}{l}\text { Water, } \\
5 \mathrm{~mm} / \mathrm{sec}\end{array}$ & 0.2117 & 0.3187 & 0.2139 & 0.6783 & 0.2399 & 0.4670 & & & & & & & 0.222 & 1.851 \\
\hline 3 & $\begin{array}{l}\text { Water, } 1.31 \mathrm{~m} \\
10 \mathrm{~mm} / \mathrm{sec}\end{array}$ & 0.5227 & 0.6494 & 0.5032 & 1.4247 & 0.6430 & 1.3488 & & & & & & & 0.556 & 3.247 \\
\hline 4 & $\begin{array}{l}\text { Water, } 3.63 \mathrm{~m} \\
2 \mathrm{~mm} / \mathrm{sec}\end{array}$ & & & 0.0913 & 0.0956 & 0.0887 & 0.0917 & 0.0870 & 0.1469 & & & & & 0.089 & 1.247 \\
\hline 5 & $\begin{array}{l}\text { Water, } \\
5 \mathrm{~mm} / \mathrm{sec}\end{array}$ & & & 0.3016 & 0.4506 & 0.3035 & 0.3996 & 0.2999 & 0.6142 & & & & & 0.302 & 2.095 \\
\hline 6 & $\begin{array}{l}\text { Water, } 3.63 \mathrm{~m} \\
10 \mathrm{~mm} / \mathrm{sec}\end{array}$ & & & 0.6748 & 0.9623 & 0.7006 & 0.8116 & 0.7186 & 0.9131 & & & & & 0.698 & 3.227 \\
\hline 7 & $\begin{array}{l}\text { Water, } \\
2 \mathrm{~mm} / \mathrm{sec}\end{array}$ & & & & & 0.1103 & 0.1302 & 0.1177 & 1.3159 & & & 0.1067 & 0.1009 & 0.112 & 1.728 \\
\hline 8 & $\begin{array}{l}\text { Water, } \\
5 \mathrm{~mm} / \mathrm{sec}\end{array}$ & & & & & 0.2636 & 0.3671 & 0.2826 & 0.5481 & & & 0.2958 & 0.2737 & 0.281 & 2.189 \\
\hline 9 & $\begin{array}{l}\text { Water, } 7.41 \mathrm{~m} \\
10 \mathrm{~mm} / \mathrm{sec}\end{array}$ & & & & & 0.5485 & 0.6799 & 0.6635 & 0.7190 & & & 0.6962 & 0.7051 & 0.636 & 2.702 \\
\hline 16 & $\begin{array}{l}\text { Water, AFA, } 1.31 \mathrm{~m} \\
2 \mathrm{~mm} / \mathrm{sec}\end{array}$ & 0.0579 & 0.1534 & 0.0536 & 0.1517 & 0.0526 & 0.1361 & & & & & & & 0.055 & 1.138 \\
\hline 17 & $\begin{array}{l}\text { Water, AFA, } 1.31 \mathrm{~m} \\
5 \mathrm{~mm} / \mathrm{sec}\end{array}$ & 0.1585 & 0.2004 & 0.1467 & 0.1387 & 0.1368 & 0.1210 & & & & & & & 0.147 & 1.340 \\
\hline 18 & $\begin{array}{l}\text { Water, AFA, } 1.31 \mathrm{~m} \\
10 \mathrm{~mm} / \mathrm{sec}\end{array}$ & 0.3717 & 0.9229 & 0.2773 & 0.6303 & 0.2554 & 0.6789 & & & & & & & 0.301 & 2.178 \\
\hline 19 & $\begin{array}{l}\text { Water, AFA, } 3.63 \mathrm{~m} \\
2 \mathrm{~mm} / \mathrm{sec}\end{array}$ & & & 0.0649 & 0.6839 & 0.0631 & 0.7919 & 0.0575 & 0.9323 & & & & & 0.062 & 2.499 \\
\hline 20 & $\begin{array}{l}\text { Water, AFA, } 3.63 \mathrm{~m} \\
5 \mathrm{~mm} / \mathrm{sec}\end{array}$ & & & 0.1434 & 0.1769 & 0.1346 & 0.2190 & 0.1527 & 0.1278 & & & & & 0.144 & 1.369 \\
\hline 21 & $\begin{array}{l}\text { Water, AFA, } 3.63 \mathrm{~m} \\
10 \mathrm{~mm} / \mathrm{sec}\end{array}$ & & & 0.4861 & 0.7241 & 0.3923 & 0.3428 & 0.4602 & 0.6095 & & & & & 0.446 & 0.987 \\
\hline 22 & $\begin{array}{l}\text { Water, AFA, } 7.41 \mathrm{~m} \\
2 \mathrm{~mm} / \mathrm{sec}\end{array}$ & & & & & 0.0682 & 0.6989 & 0.0632 & 0.4849 & & & 0.0517 & 0.7805 & 0.061 & 2.369 \\
\hline 23 & $\begin{array}{l}\text { Water, AFA, } 7.41 \mathrm{~m} \\
5 \mathrm{~mm} / \mathrm{sec}\end{array}$ & & & & & 0.1574 & 0.4887 & 0.1644 & 0.3147 & & & 0.1510 & 0.4518 & 0.158 & 2.207 \\
\hline 24 & $\begin{array}{l}\text { Water, AFA, } 7.41 \mathrm{~m} \\
10 \mathrm{~mm} / \mathrm{sec}\end{array}$ & & & & & 0.3816 & 0.4171 & 0.4149 & 0.3116 & & & 0.4212 & 0.4035 & 0.406 & 2.172 \\
\hline 25 & $\begin{array}{l}\text { AZ101, AFA, } 1.31 \mathrm{~m} \\
2 \mathrm{~mm} / \mathrm{sec}\end{array}$ & & & 0.0465 & 0.3578 & 0.0477 & 0.3870 & & & & & & & 0.047 & 5.102 \\
\hline 26 & $\begin{array}{l}\text { AZ101, AFA, } 1.31 \mathrm{~m} \\
5 \mathrm{~mm} / \mathrm{sec}\end{array}$ & & & 0.108 & 2.4067 & 0.1064 & 0.5122 & & & & & & & 0.107 & 7.556 \\
\hline 27 & $\begin{array}{l}\text { AZ101, AFA, } 1.31 \mathrm{~m} \\
10 \mathrm{~mm} / \mathrm{sec}\end{array}$ & 0.0132 & & 0.2956 & & 0.2823 & 0.7688 & & & & & & & 0.282 & 11.606 \\
\hline 28 & $\begin{array}{l}\text { AZ101, AFA, } 7.41 \mathrm{~m} \\
2 \mathrm{~mm} / \mathrm{sec}\end{array}$ & & & & & 0.0233 & 0.1704 & 0.0225 & 0.1254 & & & 0.0200 & 0.1168 & 0.022 & 3.387 \\
\hline 29 & $\begin{array}{l}\text { AZ101, AFA, } 7.41 \mathrm{~m} \\
5 \mathrm{~mm} / \mathrm{sec}\end{array}$ & & & & & 0.0632 & 0.1851 & 0.0633 & 0.2262 & & & 0.0636 & 0.1491 & 0.063 & 5.089 \\
\hline 30 & $\begin{array}{l}\text { AZ101, AFA, } 7.41 \mathrm{~m} \\
10 \mathrm{~mm} / \mathrm{sec}\end{array}$ & & & & & 0.1632 & 0.4472 & 0.1584 & 0.4126 & & & 0.1583 & 0.3192 & 0.160 & 11.244 \\
\hline
\end{tabular}




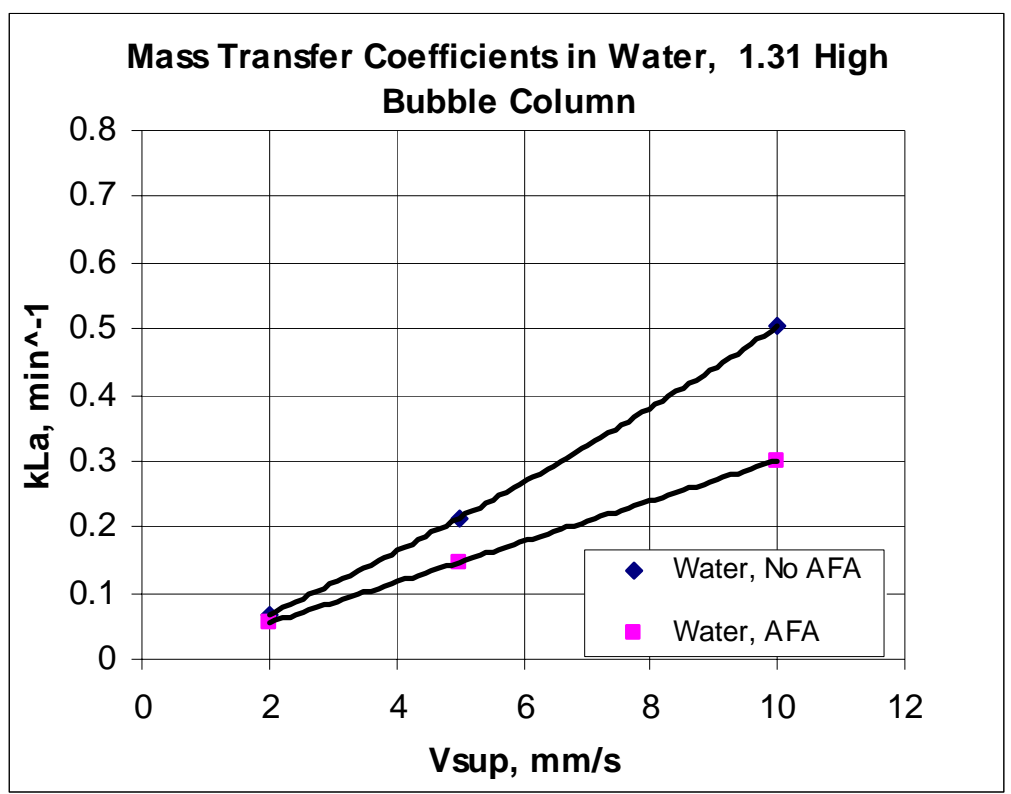

Figure 6-52. Mass Transfer Coefficients for Tests in Water for $1.31 \mathrm{~m}$ High Column

Figure 6-52 through Figure 6-54 show that the mass transfer coefficient in water is reduced by the addition of AFA, from an average $20 \%$ reduction at a superficial gas velocity of $2 \mathrm{~mm} /$ second to a $40 \%$ reduction at $10 \mathrm{~mm} / \mathrm{second}$. Figure 6-55 shows that the variation of the mass transfer coefficient in water without AFA for all column heights is a strong function of superficial velocity but much less so a function of column height. In Figure 6-56, addition of AFA again appears has a larger effect at higher superficial velocities.

Comparing the mass transfer coefficient in AZ-101 with AFA to that in water with AFA, Figure 6-57 shows a $60 \%$ reduction in void fraction when AZ-101 is compared to water with AFA in the $7.41 \mathrm{~m}$ tall column, while Figure $6-58$ for the $1.31 \mathrm{~m}$ column level indicates roughly similar values for both media. The mass transfer reduction in the tall column filled with AZ-101 may be explained by visual observations of small $1 / 4$-inch bubbles in the case of water and large 8-inch to $1.5 \mathrm{ft}$ diameter bubbles in AZ-101 at the top surface of the simulants. The large bubbles at the surface in the case of AZ-101 are due to the tendency of bubbles to coalesce in high viscosity fluids when they form at the sparger and rise through the column. Small bubble sizes lead to high values of the mass transfer coefficient [18]. For the lower $1.31 \mathrm{~m}$ column level, mixing characteristics due to the conical shape of the bubble distribution apparently affects mass transfer regardless of bubble size. The holdup is also higher in AZ-101 than in water, as shown later in Figure 6-70. Bello [18] also predicts $\mathrm{k}_{\mathrm{L}}$ a to be proportional to gas holdup. 


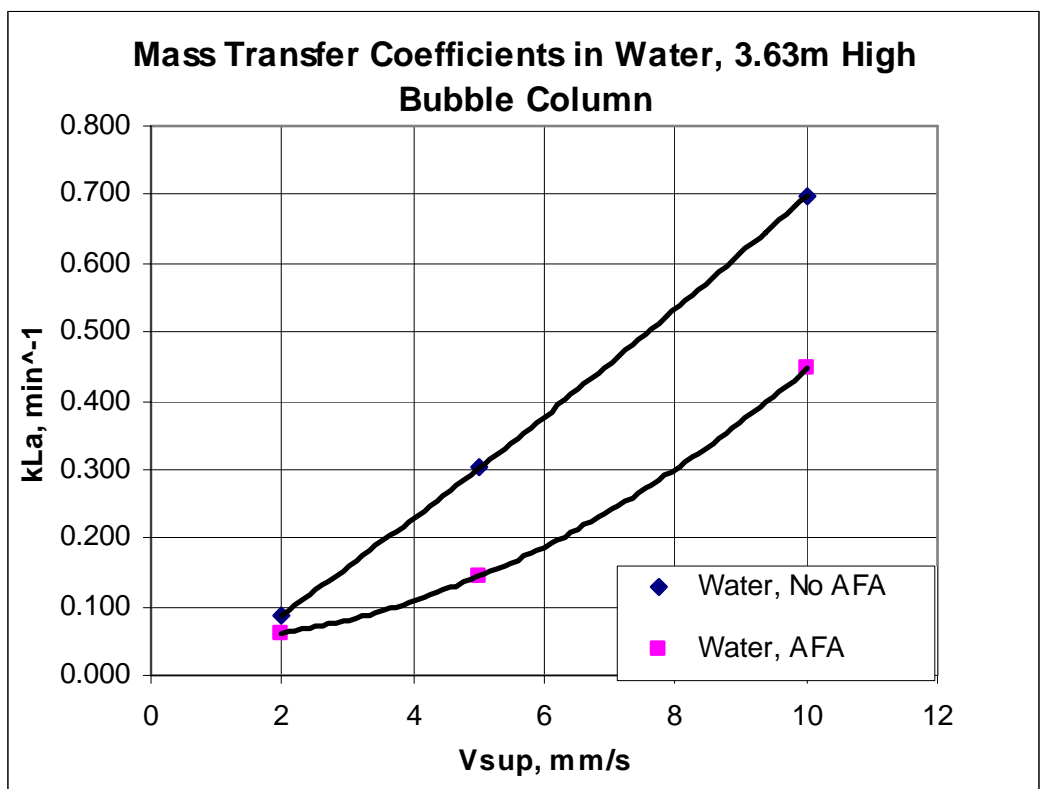

Figure 6-53. Mass Transfer Coefficients for Tests in Water in 3.63m High Column

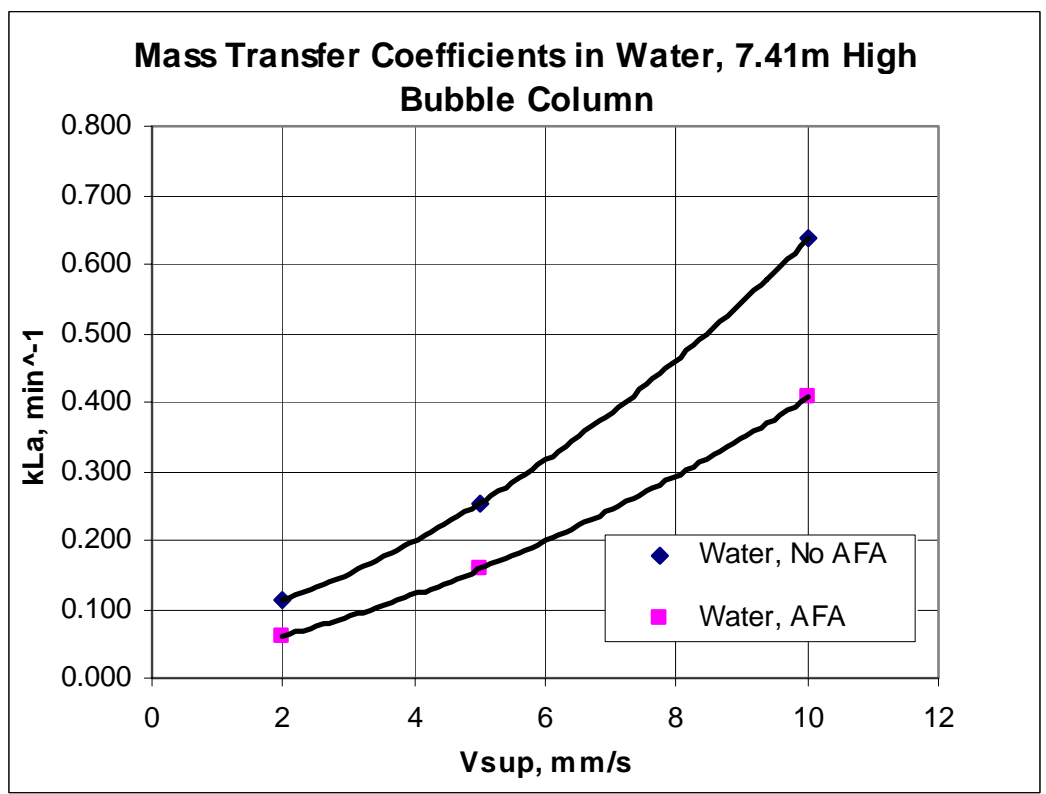

Figure 6-54. Mass Transfer Coefficients for Tests in Water for 7.41m High Column 
WSRC-STI-2007-00537, REVISION 0

SRNL-RPP-2007-00023, REVISION 0

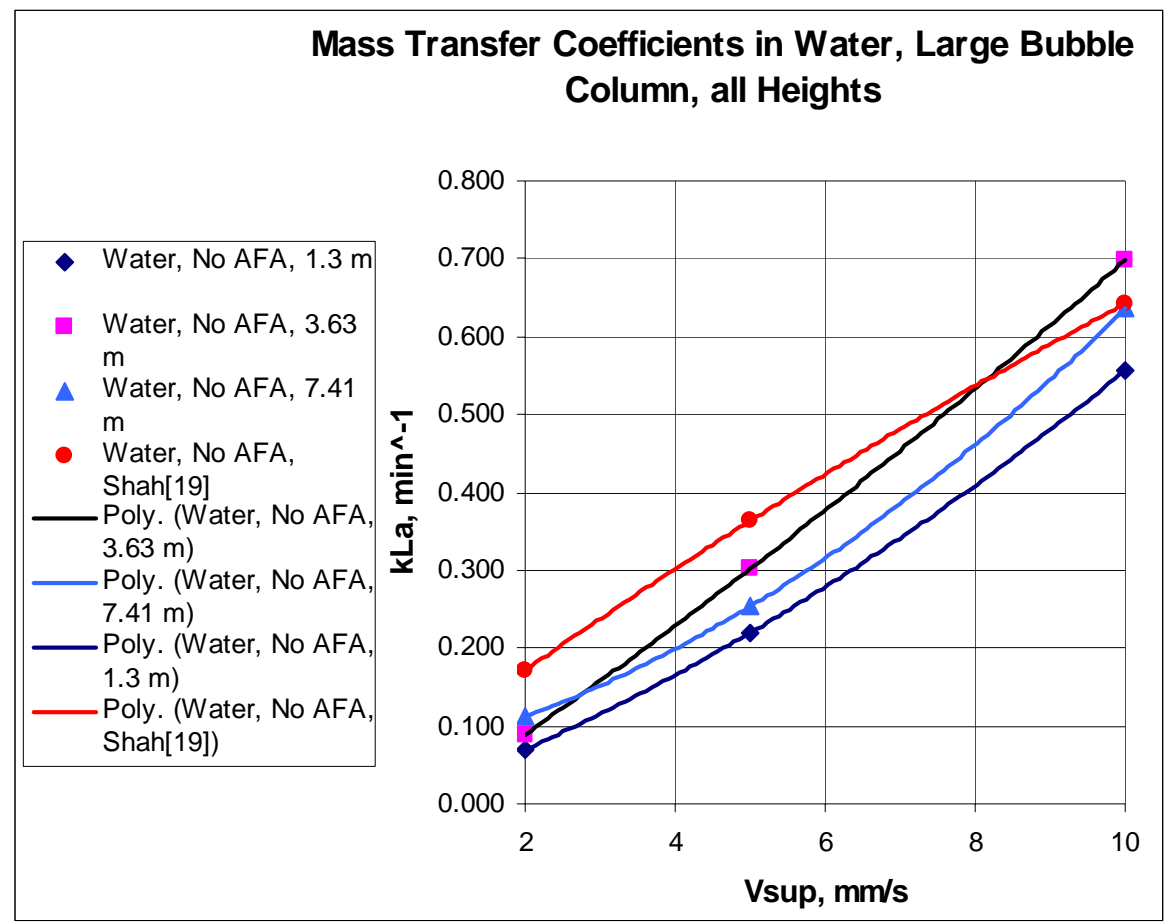

Figure 6-55. Mass Transfer Coefficients for Tests in Water, No AFA, for Different Column Heights

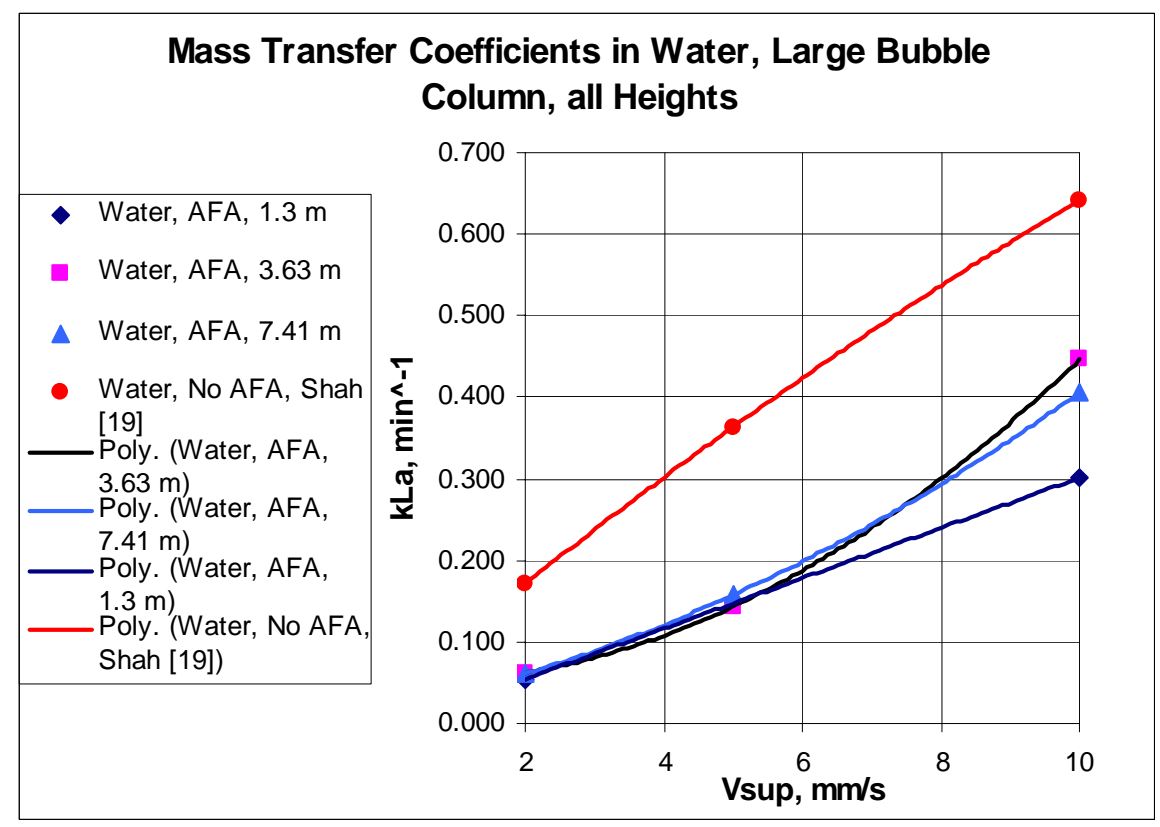

Figure 6-56. Mass Transfer Coefficients for Tests in Water with AFA for Different Column Heights 
WSRC-STI-2007-00537, REVISION 0

SRNL-RPP-2007-00023, REVISION 0

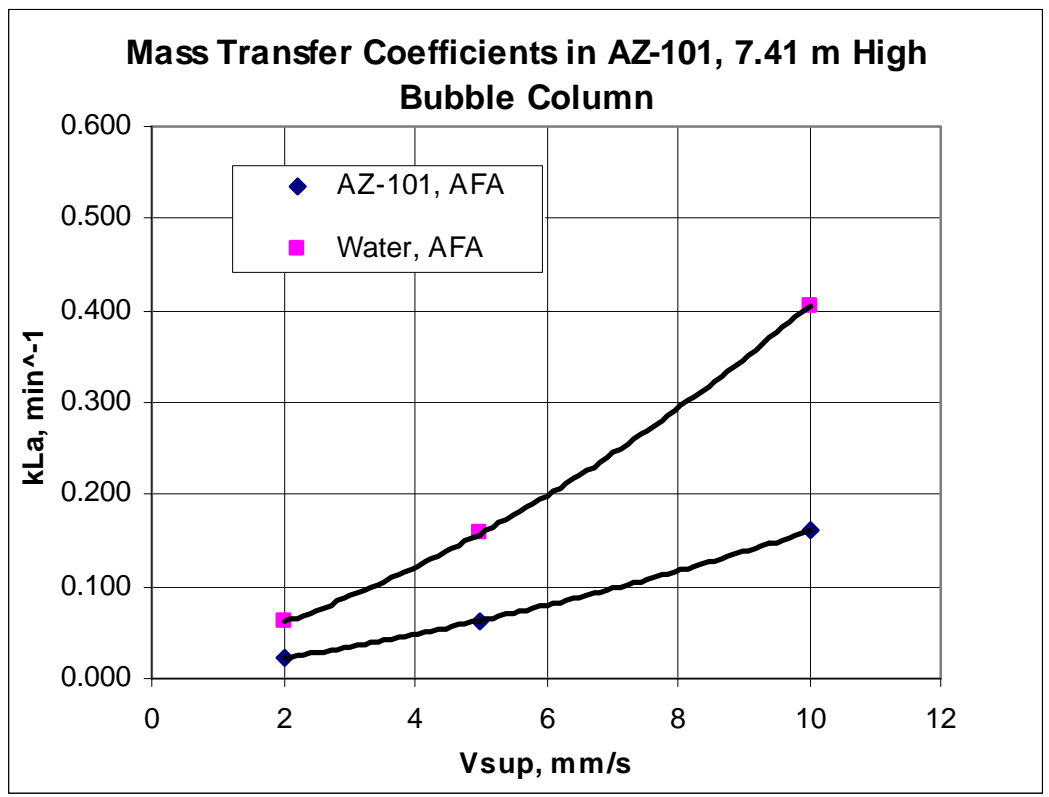

Figure 6-57. Comparison of Mass Transfer Coefficients in Water and AZ-101 Simulant with AFA for 7.41m High Column

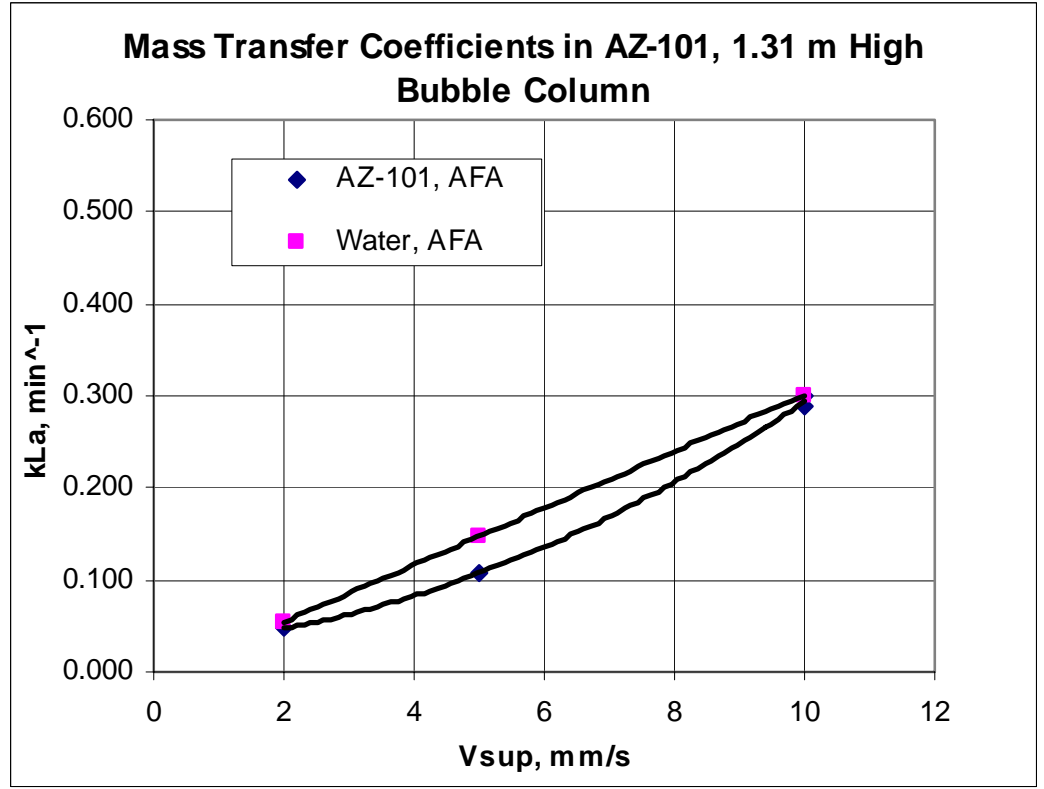

Figure 6-58. Comparison of Mass Transfer Coefficients in Water and AZ-101 Simulant with AFA for $1.31 \mathrm{~m}$ High Column 


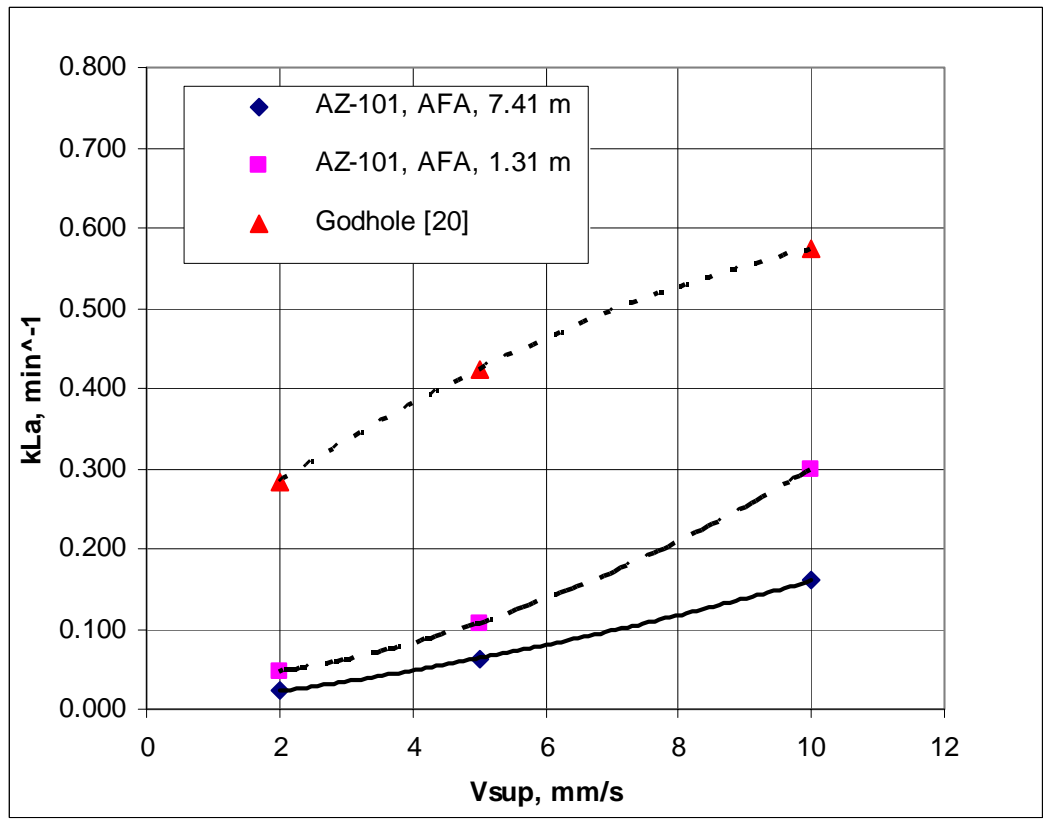

Figure 6-59. Comparison of Mass Transfer Coefficients in AZ-101 for $7.41 \mathrm{~m}$ and $1.31 \mathrm{~m}$ column levels with the Godhole Correlation

In Figures Figure 6-55 and Figure 6-56, the mass transfer coefficients in water are compared to the Shah correlation [19], which is specifically for water only. The Shah correlation is given by,

$$
k_{L} a=0.467 V_{\text {sup }}^{0.82}
$$

where $\mathrm{V}_{\text {sup }}$ - superficial gas velocity

A more general correlation is given by Godhole [20], which includes the effect of viscosity.

$$
k_{L} a=8.35 \times 10^{-4} \frac{V_{\text {sup }}^{0.44}}{\mu_{\text {eff }}^{1.01}}
$$

where $\mu_{\text {eff }}-$ effective viscosity.

Figure 6-55 shows that the present data for a tall column with a single sparger is slightly lower than that given by the Shah correlation which is based on smaller columns, with multiple uniformly distributed spargers. Figure 6-56 indicates a 31-46\% reduction in mass transfer coefficient with addition of AFA. In Figure 6-59, the mass transfer coefficient in AZ-101 in a $7.41 \mathrm{~m}$ tall column is reduced by a factor of 4 to 6 from the Godhole correlation and the coefficient has a slightly lower reduction in the $1.31 \mathrm{~m}$ column. 


\subsubsection{Uncertainty Calculation for $k_{L} a$}

The uncertainty in $\mathrm{k}_{\mathrm{L}} \mathrm{a}$ is given by:

$$
\begin{gathered}
U_{k L a}=\left[\left(\frac{\partial k_{L} a}{\partial t} U_{t}\right)^{2}+\left(\frac{\partial k_{L} a}{\partial C} U_{C}\right)^{2}\right]^{1 / 2} \\
\frac{\frac{\partial k_{L} a}{\partial C} U_{c}}{k_{L} a}=\frac{\frac{U_{c}}{\left(C-C_{a}\right)}}{\ln \left(\frac{C-C_{a}}{C^{*}-C_{a}}\right)} \\
\frac{U k_{L} a}{k_{L} a}=\left[\left(\frac{U_{t}}{t}\right)^{2}+\left(\frac{\frac{U_{c}}{\left(C-C_{a}\right)}}{\ln \left(\frac{\left.C-C_{a}\right)}{\left(C^{*}-C_{a}\right.}\right)}\right]^{1 / 2}\right.
\end{gathered}
$$

Since the uncertainties in the time measurements are negligible, $U_{t}=0$. Then, the uncertainty in the mass transfer varies throughout a test, such that

$$
U_{k L a}=\frac{U_{c}}{\left(C-C_{a}\right) t}
$$

The uncertainty in the concentration measurement, $\mathrm{U}_{\mathrm{kL}} \mathrm{a}$ is primarily affected by two factors: One factor is instrument calibration error which was determined during calibration with oxygen to have a maximum value of $\mathrm{U}_{\mathrm{C}}=+/-1.8 \mathrm{ppm}$ throughout the required operating range during water tests. For the AZ-101 tests, the instrument uncertainty lowered over only a few days of operation to a value of approximately $18 \%$ of the operating range. The instrument uncertainty value of $\mathrm{U}_{\mathrm{kL}} \mathrm{a}$ can be found directly from Eq. 6.9. Errors associated with the rise time of the sensors were neglected. The second factor is the data error, which is the variance of the data with respect to the mean value of the mass transfer coefficient, $\mathrm{k}_{\mathrm{L}} \mathrm{a}$. Typical test results are shown in Figure 6-60, and results for all tests are provided in Appendix D. The error with respect to the linear value of $\mathrm{k}_{\mathrm{L}} \mathrm{a}$ is calculated directly using Excel's ${ }^{\mathbb{B}}$ statistical regression technique. Uncertainties in $\mathrm{C}^{*}$ and $\mathrm{Ca}$ were neglected, and their average value was determined by test. 


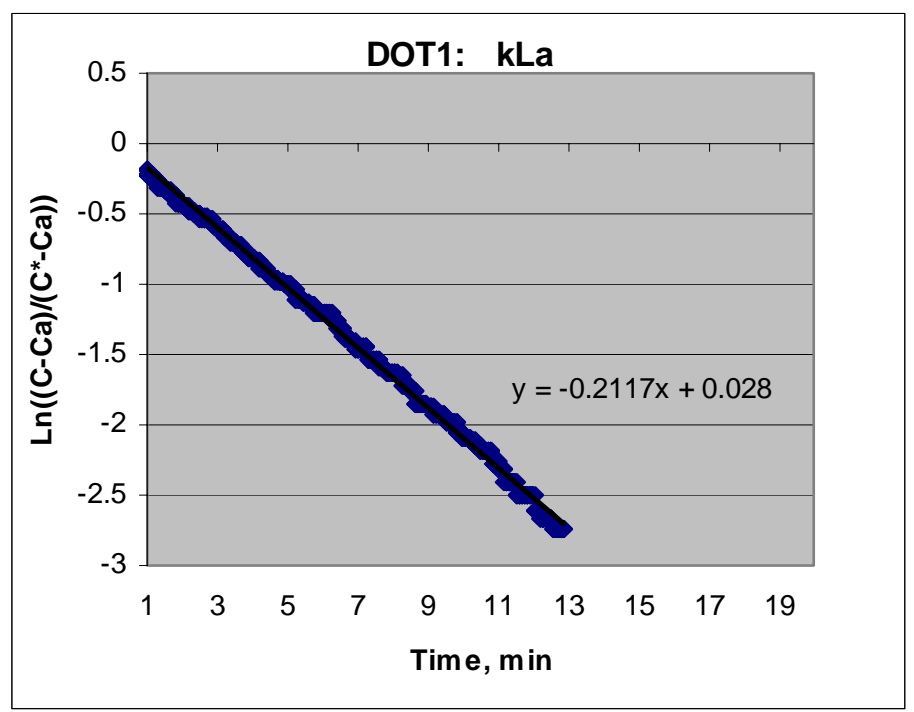

Figure 6-60. Determination of the Mass Transfer Coefficient from the Slope of the Curve $\operatorname{Ln}\left(\left(C-C_{a}\right) /\left(C^{*}-C_{a}\right)\right)$ vs. Time

All of the mass transfer coefficients and associated uncertainties are tabulated in Table 6-5. From the table, the typical uncertainty for the mass transfer coefficient for water and water with AFA testing is less than $3 \%$. For AZ-101, the errors are less than $12 \%$. Most of the error is due to the instrument uncertainty. In fact, the higher errors for the AZ-101 tests are due to the drift in the error of the air flow meter during testing, which was determined during post calibration testing. A complete description of the uncertainty for the mass transfer tests is provided by both the kLa and superficial velocity uncertainties in Table 6-5 and Table 6-2 respectively. A typical display of mass transfer uncertainty is provided in Figure 6-61. 


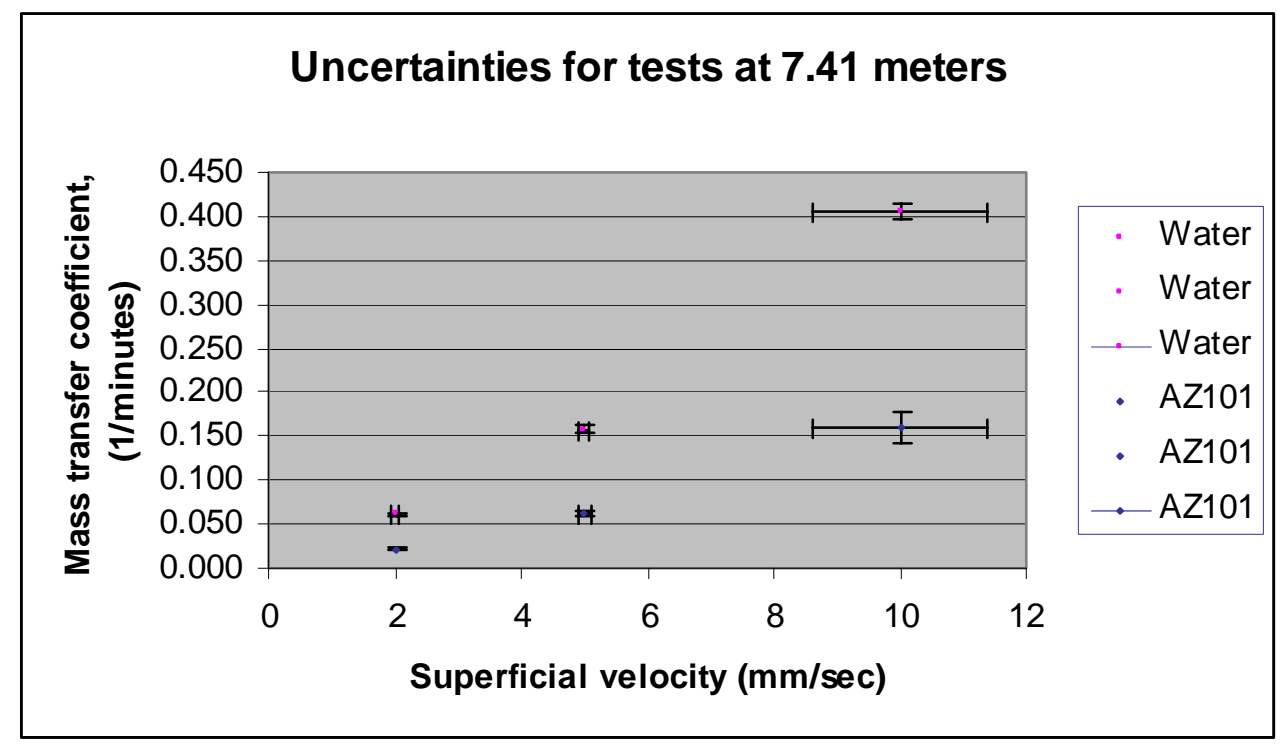

Figure 6-61. Typical Uncertainty for Mass Transfer Tests

Several entries in the table have been omitted from the uncertainty calculations. The test results show large data scatter near the bottom of the column at the lowest DO sensor (DOT1), as shown in Figure 6-62. The mass transfer coefficients near the column bottom are affected as the fast settling solids fall to the bottom of the column. The amount of settled solids apparently depends on the amount of mixing and settling time between tests. As the tests progressed, the non-linear aspect of $\mathrm{k}_{\mathrm{L}}$ a seemed to diminish, as the column contents became better mixed. An implication of this result is that mass transfer coefficients are probably different for settled sludges when compared to the tests discussed here, since one of the test objectives was to obtain a uniform, homogeneous mixture prior to each test. In fact, the $\mathrm{k}_{\mathrm{L}}$ a values were lowered by as much as a factor of 18 during the three first performed AZ-101 tests (Tests $25-27)$. Another inference is that slow settling materials, such as Kaolin clays, may provide misleading comparison results for mass transfer coefficient determinations for cases where the settling characteristics of the sludge are of concern. Even so, for well mixed, homogeneous sludges comparisons between Kaolin mass transfer results and actual sludges appears reasonable. 


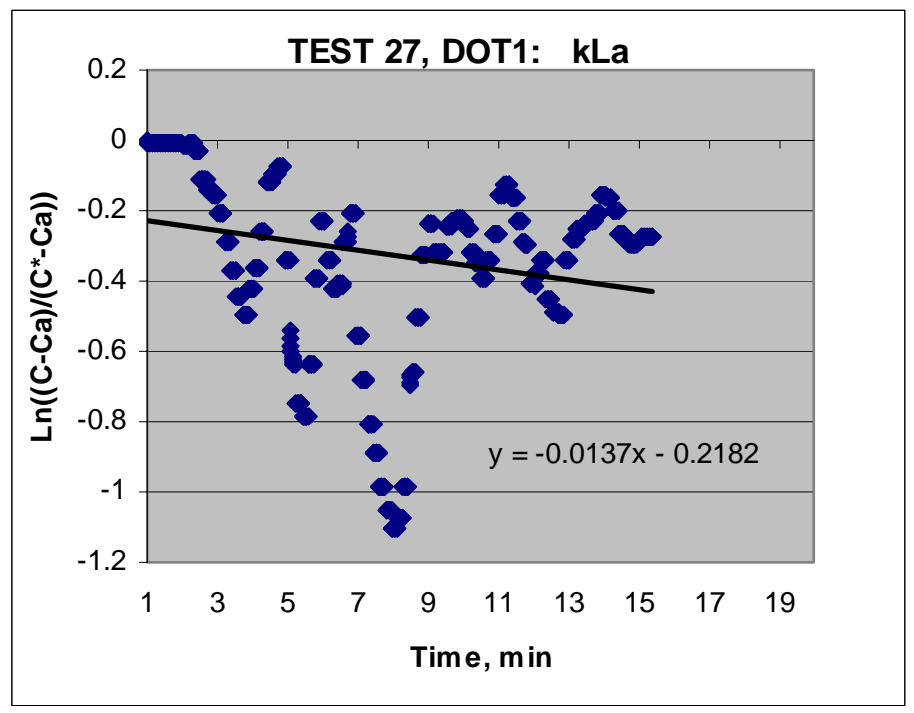

Figure 6-62. Large Data Scatter in Test 27

\subsubsection{Void Fractions and Gas Holdups}

The raw data in Appendix C and Eq. 6.3 were used to find the void fractions and gas holdups. The laser meters measure gas holdup and the differential pressure transducers measure void fraction. Since there is only a small difference at low values, the two terms are used interchangeably in this section. An uncertainty calculation is also provided below to ascertain the accuracy of solution at $95 \%$ confidence.

\subsubsection{Calculations for Void Fractions}

A summary of the void fraction calculation results is presented in Table 6-6. Note that some of the entries are marked $\mathrm{n} / \mathrm{a}$, since eddy currents form near the bottom of the column due to the conical upward flow of bubbles in that area. These swirling currents affect the pressures at the column wall, which in turn affect the pressures measured by the transducers. In fact, calculations indicated in some cases that the void fraction was negative, which is physically impossible. This may be due to swirling currents or to uncertainties in the instrument readings. Consequently, judicious review of the results was in order to ensure that valid results were reported. Comparisons between void fraction calculations obtained from lasers and pressure transmitters were used to this end. 
A typical void fraction calculation result is shown in Figure 6-63. The bubbles rise to the top of the cylinder in less than thirty seconds after the sparger air supply is opened, and a pressure increase is observed at each pressure transmitter as the bubbles rise. Similar figures for all of the void fractions for each of the tests are provided in Appendix C. The appendix figures provide void fractions in terms of the overall void fraction and the local void fractions between the differential pressure transducers, PT1 - PT5 (see Figure 6-4). The noted voids 1 - 5 are the voids between pressure transducers from the bottom to the top of the column respectively. The reported average void fractions are determined from this data, and the average void fractions are summarized in Figure 6-64 - Figure 6-71. 
WSRC-STI-2007-00537, REVISION 0 SRNL-RPP-2007-00023, REVISION 0

Table 6-6. Void Fraction Results

\begin{tabular}{|c|c|c|c|c|c|c|c|c|c|c|c|}
\hline Test No. & Simulant & AFA & $\begin{array}{l}\text { Liquid } \\
\text { level, } m\end{array}$ & $\begin{array}{l}\text { Vsup, } \\
\text { mm/s }\end{array}$ & $\begin{array}{c}\text { Void } \\
\text { fraction1, } \\
(0.15- \\
0.61) \mathrm{m} \\
\end{array}$ & 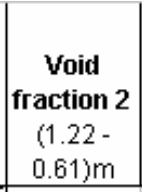 & $\begin{array}{c}\begin{array}{c}\text { Void } \\
\text { fraction }\end{array} \\
\mathbf{3}(5.18- \\
3.05) \mathrm{m} \\
\end{array}$ & $\begin{array}{c}\text { Void } \\
\text { fraction } \\
4(7.01- \\
5.18) \mathrm{m} \\
\end{array}$ & $\begin{array}{l}\text { Overall } \\
\text { void } \\
\text { fraction } \\
(7.01- \\
.15) \mathrm{m} \\
\end{array}$ & $\begin{array}{l}\text { Overall } \\
\text { void } \\
\text { fraction, } \\
\text { laser } \\
\end{array}$ & $\begin{array}{l}\text { Difference } \\
\text { (laser-DP) }\end{array}$ \\
\hline 1 & Water & No & 1.31 & 2 & $\Rightarrow 7+5$ & & & & 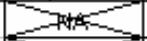 & 0.427241 & \\
\hline 2 & Water & No & 1.31 & 5 & 78485 & & & & $7 \times 48=$ & 0.989804 & \\
\hline 3 & Water & No & 1.31 & 10 & $7+46$ & & & & $=7 x+5=$ & 1.787381 & \\
\hline 4 & Water & No & 3.63 & 2 & 0 & 0.379347 & & & 0.23034 & 0.122233 & -0.10811 \\
\hline 5 & Water & No & 3.63 & 5 & 0 & \begin{tabular}{|l|}
1.381398 \\
\end{tabular} & & & 0.894119 & 1.010 & 0.116091 \\
\hline 6 & Water & No & 3.63 & 10 & 0 & 3.544939 & & & 2.292749 & 2.804 & 0.510944 \\
\hline 7 & Water & No & 7.41 & 2 & 0 & 0.266626 & 0.598683 & 0.801 & 0.440025 & 0.494759 & 0.054734 \\
\hline 8 & Water & No & 7.41 & 5 & 0 & 0.829775 & 1.583117 & 1.944 & 1.17804 & 1.323422 & 0.145382 \\
\hline 9 & Water & No & 7.41 & 10 & 0 & 2.606607 & \begin{tabular}{|l|}
4.02815 \\
\end{tabular} & \begin{tabular}{|l|}
5.033242 \\
\end{tabular} & 3.196299 & 3.378969 & 0.18267 \\
\hline 16 & Water & Yes & 1.31 & 2 & 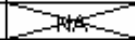 & & & & $=7 \times 8=$ & 0.518758 & \\
\hline 17 & Water & Yes & 1.31 & 5 & $7 \times 4<$ & & & & $=7+4<5$ & 0.776972 & \\
\hline 18 & Water & Yes & 1.31 & 10 & 748 & & & & 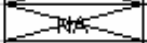 & 2.437501 & \\
\hline 19 & Water & Yes & 3.63 & 2 & 0 & 0.521436 & & & 0.328221 & 0.248 & -0.08034 \\
\hline 20 & Water & Yes & 3.63 & 5 & 0 & \begin{tabular}{|l|}
1.742021 \\
\end{tabular} & & & 1.145537 & 1.143 & -0.00206 \\
\hline 21 & Water & Yes & 3.63 & 10 & 0 & \begin{tabular}{|l|l|}
4.181329 \\
\end{tabular} & & & 2.77363 & 3.279 & 0.505071 \\
\hline 22 & Water & Yes & 7.41 & 2 & 0 & 0.248846 & 0.619516 & 0.750 & 0.400927 & 0.562914 & 0.161988 \\
\hline 23 & Water & Yes & 7.41 & 5 & 0 & \begin{tabular}{|l|}
1.217799 \\
\end{tabular} & \begin{tabular}{|l|}
1.890547 \\
\end{tabular} & \begin{tabular}{|l|}
2.072 \\
\end{tabular} & 1.4064 & 1.640687 & 0.234287 \\
\hline 24 & Water & Yes & 7.41 & 10 & 0 & 3.231298 & 4.683959 & 5.950513 & 4.441024 & 4.110486 & -0.33054 \\
\hline 25 & $\mathrm{AZ}-101$ & Yes & 1.31 & 2 & & & & & 1.69 & 0.922948 & 0.767052 \\
\hline 26 & AZ-101 & Yes & 1.31 & 5 & & & & & 2.014 & 2.091976 & -0.07798 \\
\hline 27 & AZ-101 & Yes & 1.31 & 10 & & & & & 2.65 & 2.957438 & -0.30744 \\
\hline $27 \mathrm{rpt}$ & AZ-101 & Yes & 1.31 & 10 & & & & & 2.95 & 3.434076 & -0.48408 \\
\hline 28 & AZ-101 & Yes & 7.41 & 2 & & & & & 0.961 & \begin{tabular}{|l|}
0.248514 \\
\end{tabular} & 0.712486 \\
\hline 29 & $\mathrm{AZ}-101$ & Yes & 7.41 & 5 & & & & & 1.305 & 0.464518 & 0.840482 \\
\hline 30 & AZ-101 & Yes & 7.41 & 10 & & & & & 1.438531 & 1.259679 & 0.178852 \\
\hline
\end{tabular}




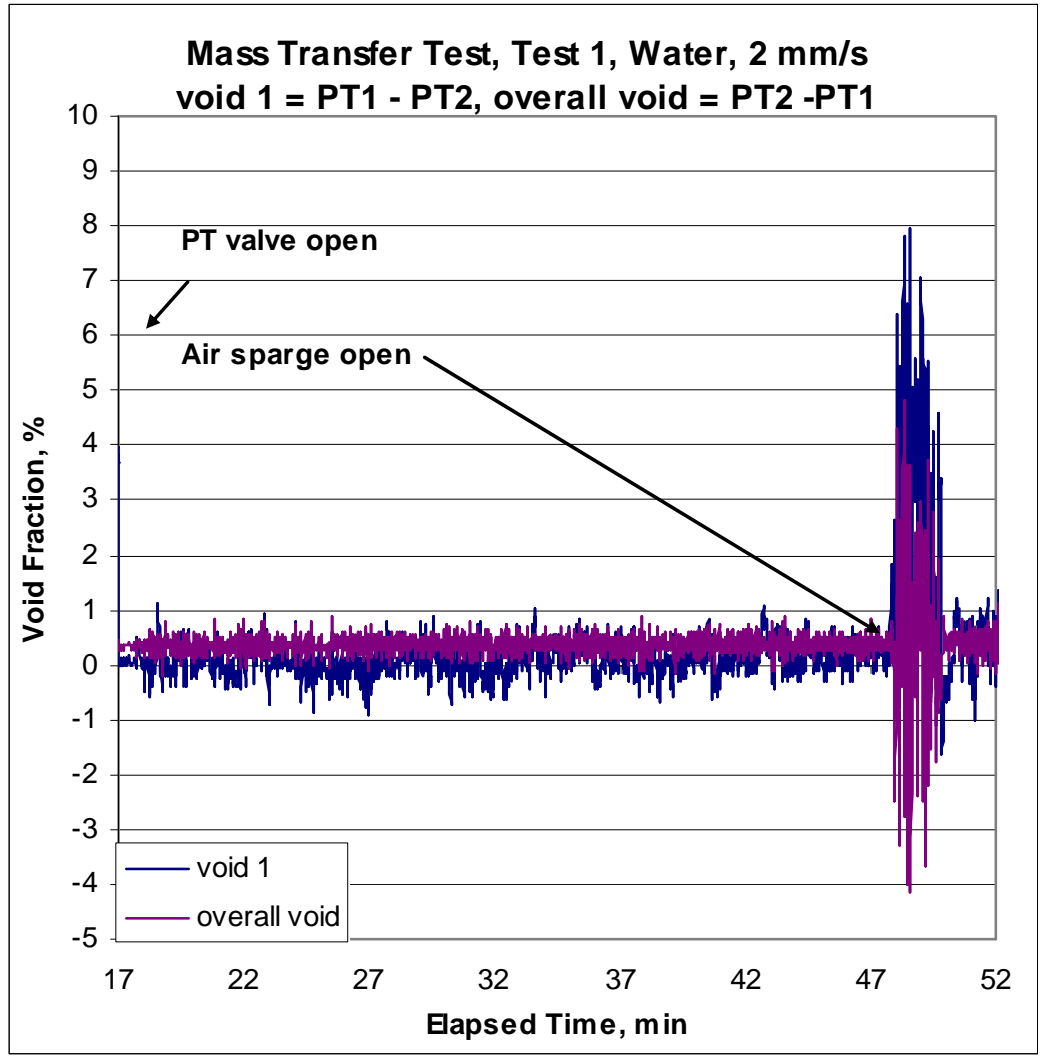

Figure 6-63. Typical Void Fraction Calculation

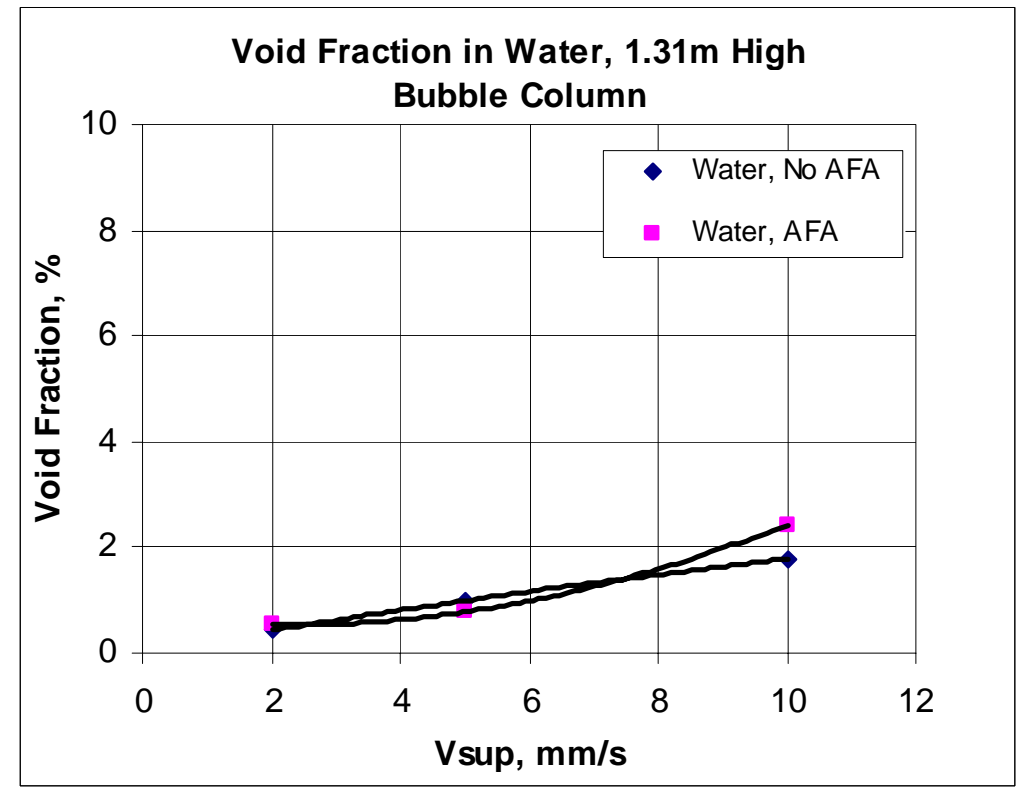

Figure 6-64. Average Void Fractions for Tests in Water with and without AFA in $1.31 \mathrm{~m}$ High Column 
WSRC-STI-2007-00537, REVISION 0

SRNL-RPP-2007-00023, REVISION 0

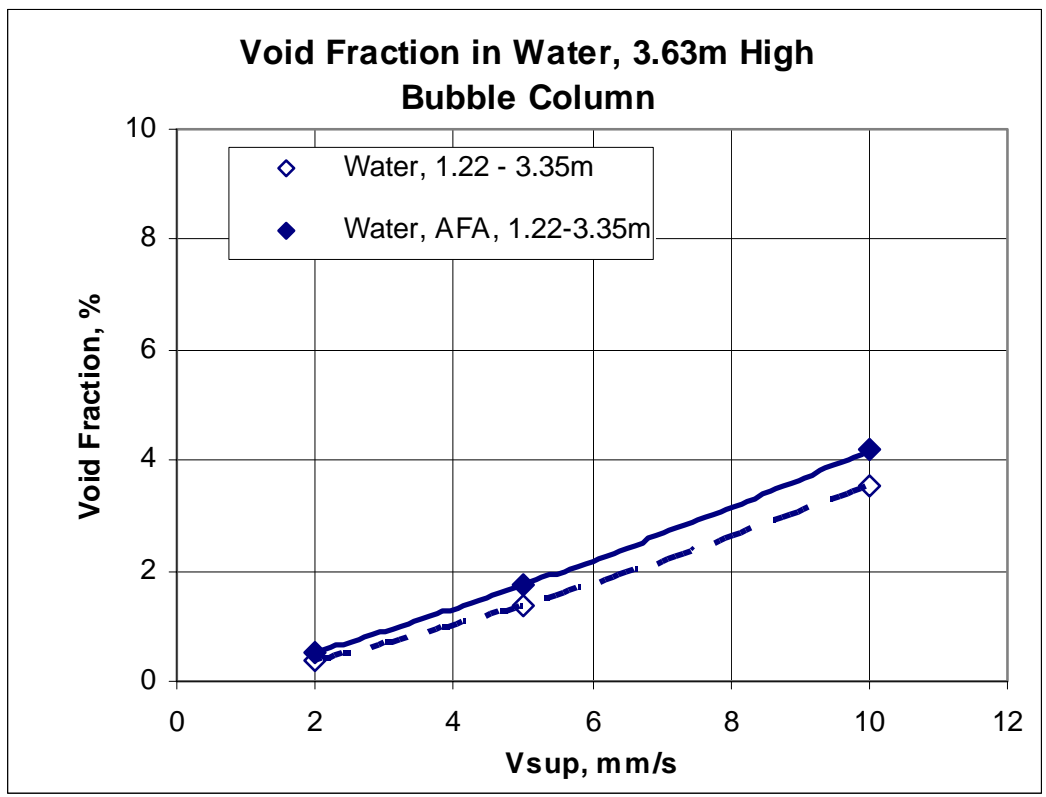

Figure 6-65. Average Void Fractions for Water with and without AFA for 3.63m High Column

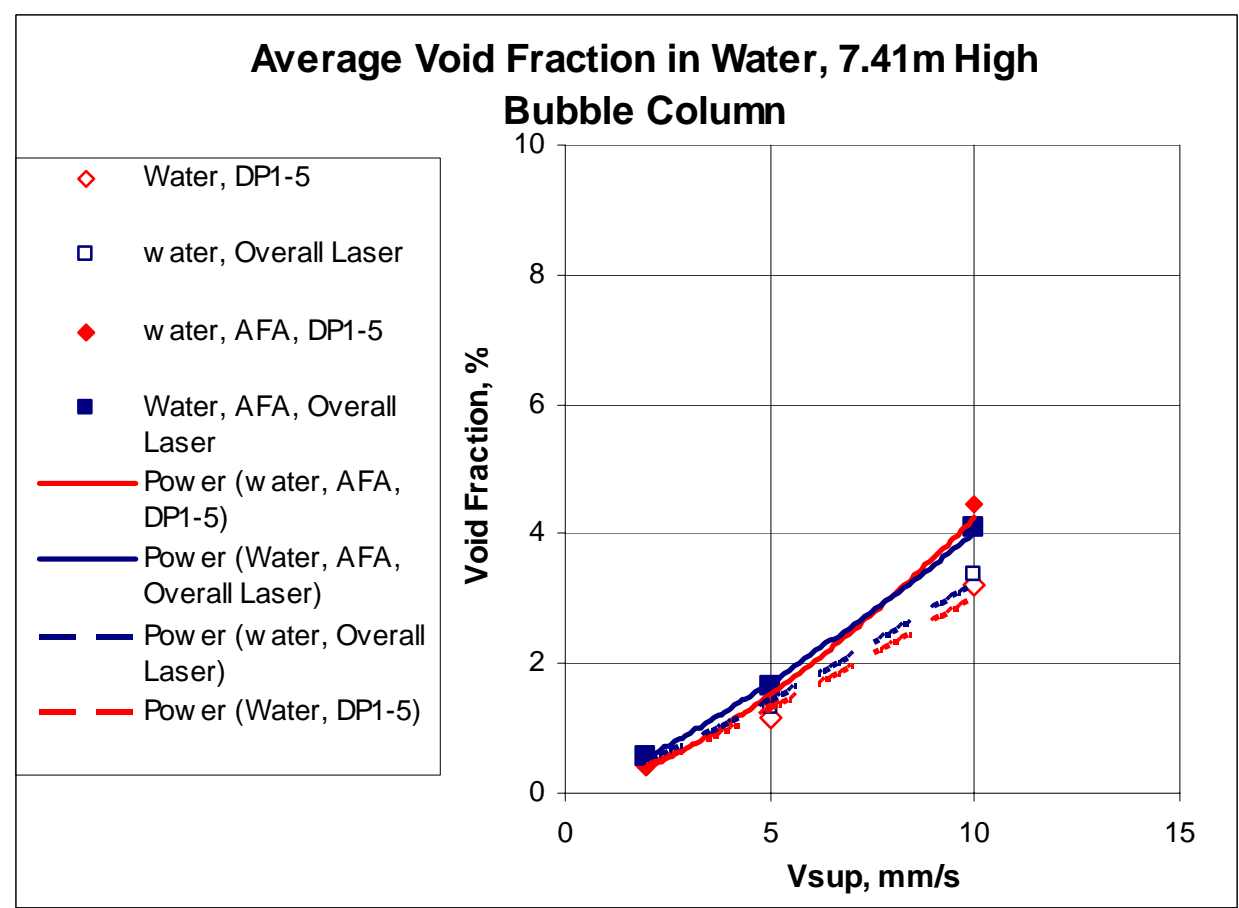

Figure 6-66. Comparison of Average Void Fractions in Water in $7.41 \mathrm{~m}$ High Column Obtained from Laser and Differential Pressure Measurements 
WSRC-STI-2007-00537, REVISION 0

SRNL-RPP-2007-00023, REVISION 0

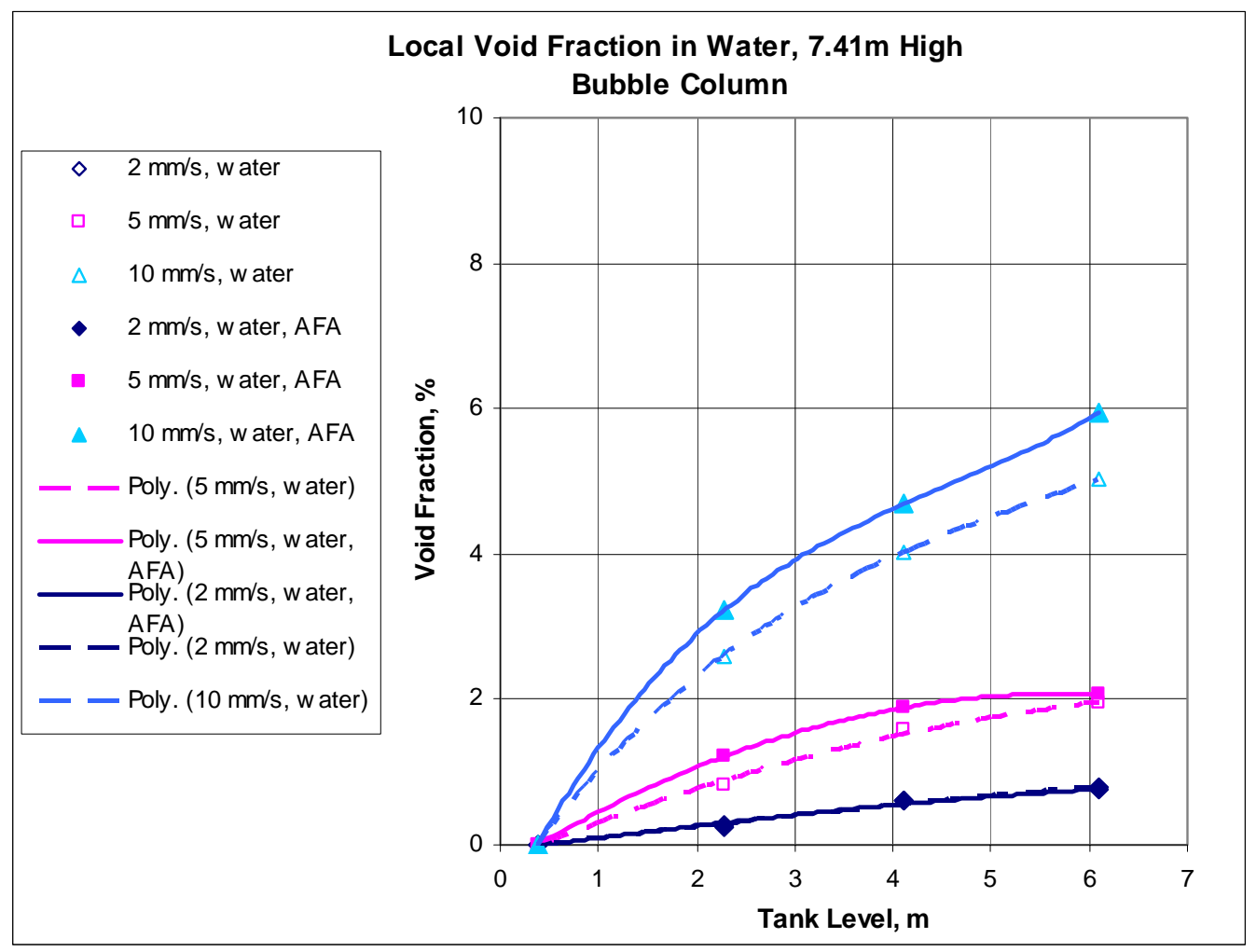

Figure 6-67. Local Void Fraction for Tests in Water with and without AFA at Different Superficial Velocities in 7.41m High Column

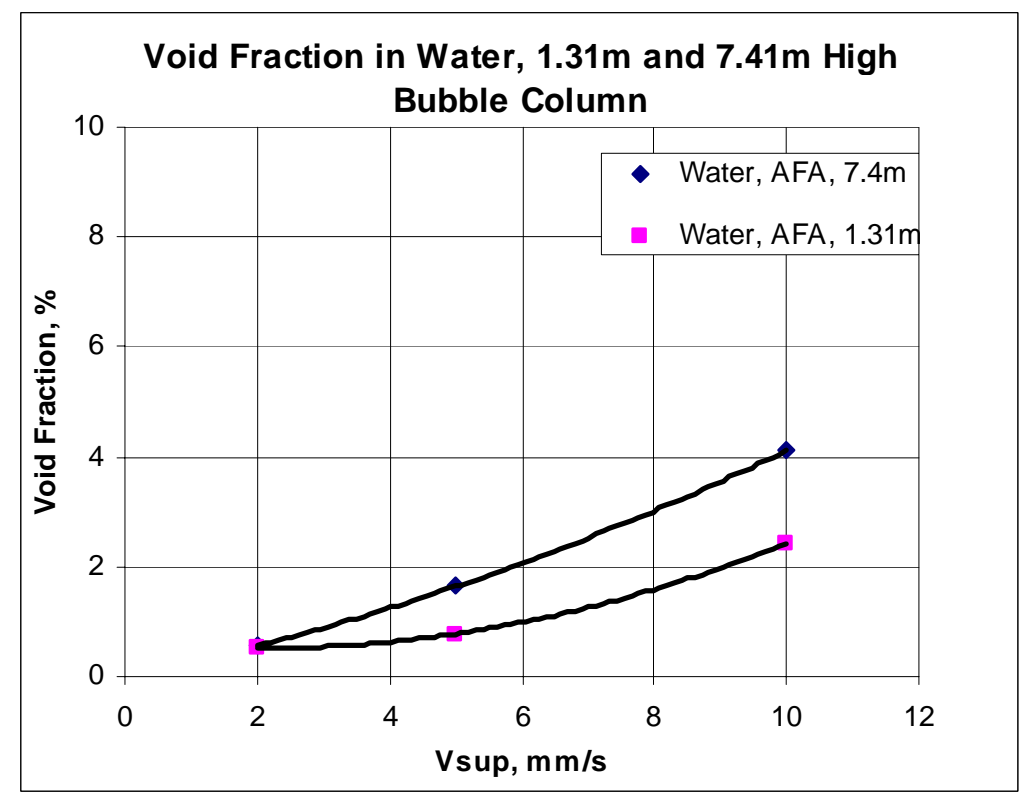

Figure 6-68. Comparison of Average Void Fractions for Tests in Water with AFA in $1.31 \mathrm{~m}$ and $7.41 \mathrm{~m}$ High Columns 
WSRC-STI-2007-00537, REVISION 0

SRNL-RPP-2007-00023, REVISION 0

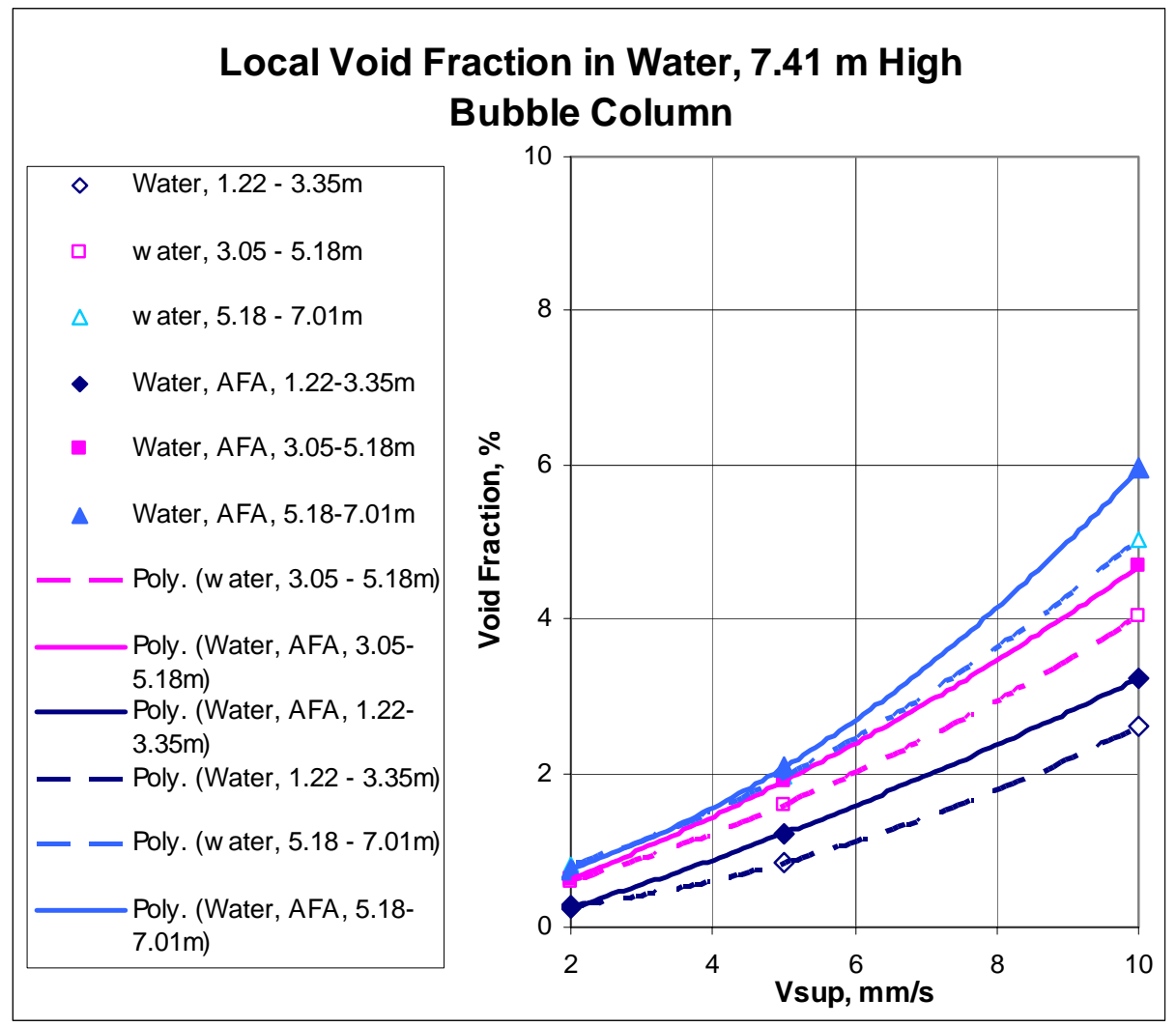

Figure 6-69. Local Void Fractions for Tests in Water in $7.41 \mathrm{~m}$ High Column

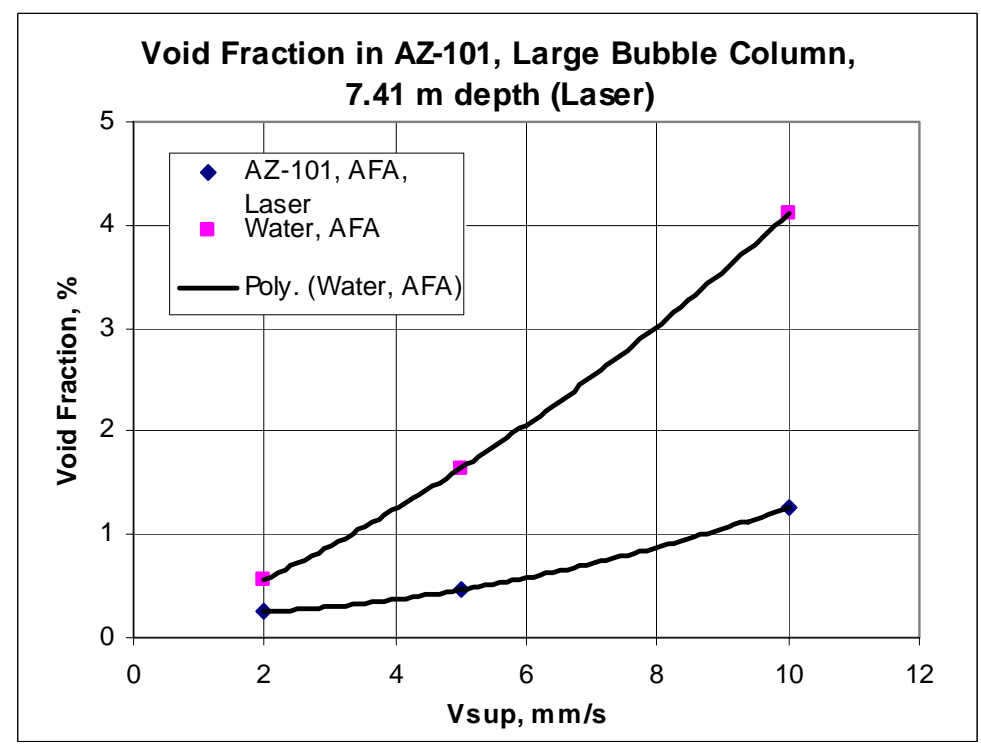

Figure 6-70. Comparison of Void Fractions for Water and AZ-101 Tests in 7.41m High Column 


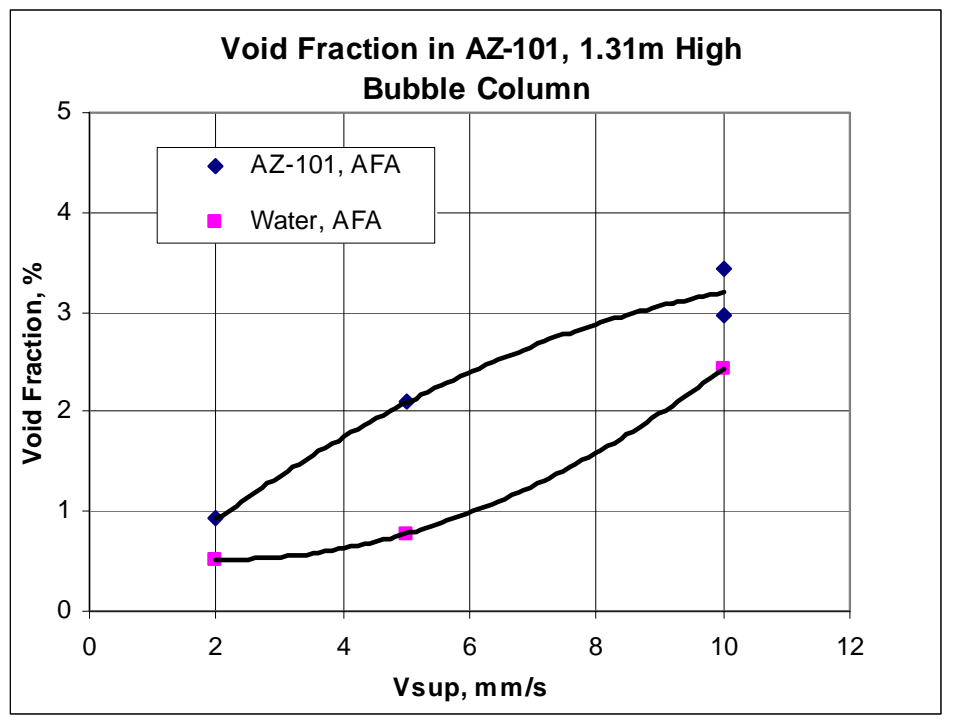

Figure 6-71. Local Void Fractions for AZ-101 Tests in 1.31m High Column

\subsubsection{Measurement Uncertainty Calculation for Void Fraction and Gas Holdup}

Uncertainty calculations were performed for using either laser level meters or pressure transducers. Slightly different results were obtained, depending on the measuring instrument.

Uncertainties in Void Fraction Measurements using Differential Pressure Readings The void fraction between two pressure taps is calculated from the difference in pressure readings at the two taps by the equation:

$$
\alpha=1-\frac{\Delta P}{\rho g z}
$$

Where, $\alpha$ - void fraction

$\Delta \mathrm{P}$ - difference in pressure readings

$\rho-$ density

g - gravitational constant

$\mathrm{Z}$ - distance between pressure taps

The uncertainty, $\mathrm{U}_{\dot{\alpha}}$, is given by

$$
\begin{gathered}
U_{\alpha}=\frac{\partial \alpha}{\partial \Delta P} U_{\Delta P} \\
U_{\alpha}=\frac{U_{\Delta P}}{\rho g z}
\end{gathered}
$$


The $0-15$ psig pressure transducers had manufacturer's specified accuracies of $0.1 \%$ full scale. Table 6-7 lists the actual calibration uncertainties which were typically in the range, 0.12 $0.265 \%$. PT5 however had an increased post test calibration uncertainty of $0.58 \%$. The void fraction uncertainties depend on the segment of the bubble column between pressure taps being considered, and typically is around $1.48 \%$ void or less. However, due to the increase in PT5 uncertainty during the testing, the void uncertainty at the top segment between PT4 and PT5 is $3 \%$ and the overall void fraction uncertainty from top to bottom, PT1 - PT5, is $0.9 \%$ as shown in Table 6-7. Uncertainties due to data scatter for the lasers and pressure transmitters are expected to be $1-2 \%$, but those uncertainties were not calculated.

Table 6-7. Void Fraction Uncertainties from $\Delta P$ Measurements

\begin{tabular}{|c|c|c|l|c|c|}
\hline $\begin{array}{c}\text { Press. } \\
\text { transducer }\end{array}$ & $\begin{array}{c}\mathbf{U} \boldsymbol{\Delta} \mathbf{P}, \text { pretest, } \\
\text { psig }\end{array}$ & $\begin{array}{c}\mathbf{U} \mathbf{\Delta P}, \\
\text { posttest, psig }\end{array}$ & $\begin{array}{l}\text { Void fraction } \\
\text { location }\end{array}$ & $\mathbf{z}(\mathbf{m})$ & $\mathbf{U} \boldsymbol{\alpha}$ \\
\hline PT1 & 0.0189 & 0.0183 & void (PT1-2) & 1.22 & 1.482 \\
\hline PT2 & 0.0183 & 0.0232 & void (PT2-3) & 2.134 & 1.142 \\
\hline PT3 & 0.0234 & 0.0324 & void (PT3-4) & 1.829 & 1.394 \\
\hline PT4 & 0.0225 & 0.0262 & void (PT4-5) & 1.829 & 3.055 \\
\hline PT5 & 0.0398 & 0.0875 & void (PT1-5) & 6.86 & 0.797 \\
\hline & & & void (PT1-3) & 3.354 & 1.631 \\
\hline
\end{tabular}

The void fraction measurement, void (PT1-2), corresponds to testing with the $1.31 \mathrm{~m}$ column level, void (PT1-3) corresponds to testing with the $3.63 \mathrm{~m}$ column level, and void (PT1-5) to the $7.43 \mathrm{~m}$ column level.

\section{Uncertainties in Gas Holdup Measurements using Laser Distance Meters}

The gas holdup is the increase in bubble column height, $\Delta \mathrm{Z}_{2 \mathrm{P}}$, divided by the initial column height, H. Some gas was already dissolved in solution when the initial height was measured.

$$
\phi=\frac{\Delta Z_{2 P}}{H}
$$

The uncertainty in $\varphi$ is given by,

$$
U_{\vartheta}=\left[\left(\frac{U_{\Delta Z 2 P}}{H} \vartheta\right)^{2}+\left(\frac{U_{H}}{H} \vartheta\right)^{2}\right]^{1 / 2}
$$


The laser distance meters have typical accuracies of $+/-1.5 \mathrm{~mm}$, when calibrated with traceable standards of higher accuracy. However, due to the lack of such standards for distances up to $7500 \mathrm{~mm}$, a standard tape measure was used to determine an accuracy of $+/-3.2 \mathrm{~mm}$. This is also the calibration uncertainty for column height measurement.

The uncertainty in the initial column height would normally be the measurement uncertainty of this height. However, in the AZ-101 tests, the initial column height prior to each test sometimes dropped after testing, by as much as 1.5 inches at a given column height. The level drop was due to trapped air or oxygen bubbles during initial mixing and oxygen sparging, which released during the actual sparging test. The level changes brought up the issue of what base column height to use to calculate the two phase level rise. Should it be the lowest column height at the end of all three tests in a series, the initial level at the start of the test, or the final level at the end of a test. It was found that using the lowest column height (smallest amount of bubbles) resulted in high gas holdups compared to the differential pressure method. Using the initial level at the start of the test gave similar results for two identical runs, Test 27 and Test 27 rpt. This result implies that the trapped bubbles released very slowly and did not participate in the flowing two phase mixture during sparging. Consequently, this was the method used to calculate holdup in the AZ runs.

For the water runs, trapped air was not an issue. Representative uncertainties in gas holdup are given in Table $6-8$. The uncertainties range from $0.03 \%$ to $0.6 \%$ holdup.

Table 6-8. Uncertainties in Gas Holdup Measured with Laser Meters during Water Testing

\begin{tabular}{|c|c|c|c|c|}
\hline Tests & $\begin{array}{c}\text { Col. } \\
\text { Height, } \mathbf{m}\end{array}$ & $\begin{array}{c}\text { Uncer. Due to } \\
\text { laser cal., \% }\end{array}$ & $\begin{array}{c}\text { to col. hgt., } \\
\%\end{array}$ & $\begin{array}{c}\text { Total uncert., } \\
\text { \% holdup }\end{array}$ \\
\hline 1 & 1.31 & 0.104 & 0.104 & 0.146 \\
\hline 2 & 1.31 & 0.240 & 0.240 & 0.339 \\
\hline 3 & 1.31 & 0.433 & 0.433 & 0.612 \\
\hline 4 & 3.63 & 0.022 & 0.022 & 0.031 \\
\hline 5 & 3.63 & 0.088 & 0.088 & 0.125 \\
\hline 6 & 3.63 & 0.245 & 0.245 & 0.347 \\
\hline 7 & 7.41 & 0.021 & 0.021 & 0.030 \\
\hline 8 & 7.41 & 0.057 & 0.057 & 0.080 \\
\hline 9 & 7.41 & 0.145 & 0.145 & 0.205 \\
\hline 16 & 1.31 & 0.126 & 0.126 & 0.178 \\
\hline 17 & 1.31 & 0.188 & 0.188 & 0.266 \\
\hline 18 & 1.31 & 0.591 & 0.590 & 0.835 \\
\hline 19 & 3.63 & 0.022 & 0.022 & 0.031 \\
\hline 20 & 3.63 & 0.100 & 0.100 & 0.141 \\
\hline 21 & 3.63 & 0.287 & 0.286 & 0.405 \\
\hline 22 & 7.41 & 0.024 & 0.024 & 0.034 \\
\hline 23 & 7.41 & 0.070 & 0.070 & 0.099 \\
\hline 24 & 7.41 & 0.176 & 0.176 & 0.249 \\
\hline & & & & \\
\hline
\end{tabular}


For the AZ-101 tests, the uncertainties in gas holdup are given in Table 6-9.

Table 6-9. Uncertainties in Gas Holdup Measured with Laser Meters during AZ-101 Simulant Testing

\begin{tabular}{|c|c|c|c|c|c|c|}
\hline Test & $\begin{array}{c}\text { Col. } \\
\text { Height, m }\end{array}$ & $\begin{array}{c}\text { Unc. In initial } \\
\text { col. height, } \\
\mathbf{m}\end{array}$ & Laser cal., \% & $\begin{array}{c}\text { Uncert. in } \\
\text { col. hgt., \% }\end{array}$ & $\begin{array}{c}\text { Tot. holdup } \\
\text { uncer., \% }\end{array}$ \\
\hline 25 & 1.31 & & 0.010 & 0.242 & 0.763 & 0.801 \\
\hline 26 & 1.31 & & 0.010 & 0.242 & 0.763 & 0.801 \\
\hline 27 & 1.31 & & 0.010 & 0.242 & 0.763 & 0.801 \\
\hline 28 & 7.41 & & 0.033 & 0.043 & 0.445 & 0.447 \\
\hline 29 & 7.41 & & 0.025 & 0.043 & 0.343 & 0.345 \\
\hline 30 & 7.41 & & 0.025 & 0.043 & 0.343 & 0.345 \\
\hline
\end{tabular}

Comparing the laser and differential pressure measurement uncertainties, it seemed that the laser measurements had better accuracy than the DP measurements. In the water tests, the laser and DP void measurements differed by only a maximum of $0.5 \%$. (See for example, Figure 6-65.) In the AZ-101 tests, the maximum difference between the two was $0.8 \%$ void. These observations are consistent with the uncertainty analysis above. However, trapped gas in the AZ-101 simulant is always present unless mechanical agitation is applied, and void fractions are affected.

\subsubsection{Evaluation of Results}

Testing with respect to water and water with AFA provided reasonable results, but the AZ-101 testing raised concerns. In all testing, mixing at the lower levels of the column affected test results, due to bubble distribution and flow turbulence. For AZ-101 tests, the void fraction uncertainty is affected by the way that the tests are performed. The calculated uncertainty showed that the maximum uncertainty with respect to the void fraction is $0.5 \%$ for the water tests and $0.9 \%$ for the AZ-101 tests. The value for water is reasonable, but the value for AZ-101 has uncertainty beyond the measurement uncertainty. Following initial uncertainty calculations, a sample of the AZ-101 was retested after mechanical agitation to determine if trapped air was present in the fluid. Testing showed that approximately $1.7 \%$ of the volume was trapped air. The measured gas holdups from laser measurements are actually based on the initial tank level at the start of the test, which included trapped air. A 1.7\% volume of trapped air could cause the column level to increase by 5 inches for AZ-101 tests at 24.3 feet. The measured overall void fractions based on differential pressure measurements should provide actual void fractions, although the measurement uncertainties depend on both the instrument accuracies and the initial conditions, where the initial air concentration in solution was undetermined. In other words, the accuracy of the tests was very good, but the void fraction can be significantly affected by the initially, indeterminate, trapped air in solution. 
This phenomenon affects any void fraction measurement in laboratory testing or elsewhere. Once air is sparged into solution, there will always be trapped air, unless mechanical agitation is introduced. The quantity of trapped air is variable. Bubbles are released from AZ-101 solution after sparging has stopped, which further complicates the situation. In addition, as soon as sparging stops, the simulant begins to settle rapidly. For the tests performed here, the simulant was mixed to obtain homogeneity immediately prior to test. Actual field results may vary for cases where settling has occurred prior to sparging. For example, in 60 days the yield stress of the material tripled during storage, which implies that additional gas holdup may initially exist in radioactive environments prior to sparging, since a higher yield stress material will hold up more gas. In short, trapped air affects gas holdup results.

Mass transfer coefficients were calculated and provide a reasonable prediction of the change in oxygen concentration during sparging, but the initial oxygen concentration was not established for the AZ-101 simulant. Turbulence, bubble distribution, and bubble size are each expected to affect the mass transfer coefficients. Also, settling of the AZ-101 simulant solids was observed which introduced a solids wt $\%$ gradient, rather than a homogeneous mixture. This is reflected in the variation of mass transfer coefficients measured by the individual DO sensors at different elevations as shown in Table 6-5. An implication of the observed settling of AZ-101 is that lower mass transfer may occur when settled sludges are compared to homogeneous, well mixed sludges similar to the simulant tested here.

\subsection{SUMMARY}

Large scale mass transfer tests were performed on several fluids, which included process water, water with anti-foam agent (AFA), and an AZ-101 waste simulant with AFA. The AZ-101 waste simulant was manufactured to emulate waste in one of the double-shell underground storage tanks at the Hanford Site. Research focused on determining mass transfer coefficients and gas volume fractions for these fluids. A 28 -feet-tall by 30 -inch-diameter, stainless steel column was constructed, along with supporting equipment to perform the required tests. The tests required simulant testing at various levels in the column. The tests consisted of saturating the simulants with oxygen to simulate trapped hydrogen in a WTP vessel. Oxygen was injected into the system, rather than generated in situ, using chemical reactions to create distributed oxygen throughout the solution. The resulting saturated solution was assumed to represent an actual waste environment since oxygen was injected into solution until monitored saturation occurred. Once saturation was obtained, a vertical, centrally located sparge tube injected air into solution at the bottom of the column to obtain specified superficial velocities, which are the average velocities across the fluid surface. The injected air displaced the oxygen from solution, and the effects of this process were measured: Dissolved oxygen concentration, differential pressures along the vertical column axis, and differential surface level were measured to calculate mass transfer coefficients, holdups of in situ gas, and volume fractions of sparged air. Gas holdups in all the fluids were increased with the AFA addition. 
Mass transfer tests in water showed the mass transfer coefficient to be reduced by AFA additions by $20-40 \%$. In AZ-101 with AFA, the coefficient is reduced by as much as $60 \%$ compared to that in water for the 7.41 column level. The change in mass transfer is probably due to larger bubble sizes in AZ-101, providing smaller total bubble surface area when compared to holdup in water. . Similar results were found for water with AFA and AZ-101 with AFA when tested at the $1.31 \mathrm{~m}$ column level, probably as a result of similar turbulence levels for the two simulants in the short column.

Also noted, values for the mass transfer coefficients were affected by mixing and settling characteristics near the bottom of the column, during AZ101 testing. A cone of bubbles is formed from the sparger tip up through the lower meter of the column. The circulating flows, due to the rising cone of bubbles, apparently affected the mass transfer when tests were performed at different levels. In particular, comparison of test results at the 1.31 meter level showed that the mass transfer coefficients were nearly doubled when the fluid level was lowered from 7.41 to 1.31 meters. The additional flow turbulence at the lower test level is attributed with these changes in mass transfer. With respect to settling, several experimental values for mass transfer were excluded from mass transfer calculations. These excessively low mass transfer coefficients were attributed to simulant settling. As the sludge settles near the tank bottom, the mass transfer coefficients were shown to decrease by as much as a factor of 16 . The effects of settling were not fully evaluated, since tests were performed to minimize settling. Together, mixing and settling characteristics near the column bottom are not clearly understood. 


\subsection{CONCLUSIONS}

Principal results emerging from this work are:

- The increased gas holdup due to addition of AFA to WTP waste simulant reported in 2006 for a small-scale agitation system is confirmed. The gas holdup data from smallscale and bench-scale impeller-type mixing systems reported herein are somewhat higher than obtained from the prototypic sparger-PJM mixing system tested in the PNNL APEL facility. This difference in holdup behavior between the two different mixing systems is not known at this time. Consequently, data from the small mechanical agitation systems should not be extrapolated to prototypic plant conditions until further work is done to correlate results between the two types of mixing systems.

- Bench-scale and small-scale tests conducted with Dow Corning 1520-US AFA show it to be a viable replacement to Dow Corning Q2-3183A AFA. This alternative AFA will, however, require significantly higher dosage (concentration) to perform the same antifoam function.

- Initially the assumption was that addition of noble metals to the AZ-101 waste simulant could produce a catalytic gas retention effect with the AFA. The test results show that the gas holdup is similar whether or not noble metals are present in the AZ-101 simulant. Therefore, data from prototypic $1 / 4$-scale tests (conducted at PNNL) using the simulant without any noble metals are considered valid.

- Mass transfer tests were performed in a large ( $0.76 \mathrm{~m}$ diameter) bubble column filled to $1.3,3.4$, and $7.4 \mathrm{~m}$ elevations with water and the AZ-101 waste simulant. Mass transfer coefficients for air bubbles emanating from a prototypic $0.051 \mathrm{~m}$ diameter sparger were obtained from the transient decay of dissolved oxygen concentration in the initially saturated fluids.

As expected, adding AFA to water reduces the mass transfer coefficient slightly, by an average of 30\%. For AZ-101 simulant, mass transfer correlations are available that include the effect of apparent viscosity but not the effect of bubble size or bubble size distribution. Test results show AFA addition to AZ-101 simulant reduces the mass transfer coefficient by about $60 \%$ compared to that in water with AFA for a tall column, but produce about the same values in a short column. This is because the shear strength of the AZ-101 simulant allows for coalescence of small bubbles to larger bubbles in the tall column and larger bubbles have smaller surface area for mass transfer than small bubbles for the same volume fraction. In the short column, the cone of bubbles does not expand across the whole tank diameter, which changes the mixing and mass transfer coefficient as compared to the tall column. Gas holdup also has a significant effect on mass transfer.

Thus to apply the mass transfer effect obtained in scaled prototypic systems to the WTP, the mass transfer coefficient data used in calculations must include the effect of bubble size, bubble size distribution, and gas holdup based on vessel height. 
WSRC-STI-2007-00537, REVISION 0

SRNL-RPP-2007-00023, REVISION 0

This page intentionally left blank. 


\subsection{FUTURE WORK}

One of the observations in the present work is the difference in trend in gas holdup performance obtained with the small bench scale and $1 / 9^{\text {th }}$ scale mechanically agitated mixing systems and the $1 / 4^{\text {th }}$ scale prototypic mixing system used at PNNL. Due to the utility and lower expense of testing in a small scale system, it would be useful to investigate the causes of this difference for future work. Perhaps it is the high shear environment of the radial turbines used to break up large bubbles to smaller ones that keep the bubbles from coalescing and helps to maintain high holdup. The use of a fritted disc to produce small bubbles and axial flow turbines to provide mixing may be considered. The effect of physical height of the vessel, allowing for more time for the bubbles to coalesce, and the diameter of the spargers may also have an effect on holdup.

Follow-on bench scale tests should also be considered to determine, in the radioactive waste environment during a post-DBE event:

- if increased AFA additions will be needed for caustic leaching at $100^{\circ} \mathrm{C}$ to suppress foaming, and,

- the degradation rate of AFA components and its impact on gas holdup/release.

Additional observations were the facts that settling of the sludge and trapped air in the sludge may have significant effects on the mass transfer coefficients and void fractions respectively. If time elapses between successive sparger operations, the gas release rate from a settled sludge would be much slower than results predicted from the well mixed sludges tested here. If investigation is warranted:

- Perform additional testing to determine the relationship between mass transfer coefficients and sludge settling.

- Perform additional testing to better understand the effects of trapped gas on void fractions. 
WSRC-STI-2007-00537, REVISION 0

SRNL-RPP-2007-00023, REVISION 0

This page intentionally left blank. 


\subsection{REFERENCES}

1. Baich, M. A., M. E. Stone, T. L. White, T. B. Calloway, and J. C. George, "Waste Treatment Plant Evaporation: Antifoam Performance (U), WSRC-TR-2003-00216, Rev. 0, also SRT-RPP2003-00095, Rev. 0, August, 2003.

2. Stewart, C., P.A. Meyer, M. S. Fountain, C.E. Guzman-Leong, S. A. Hartley-McBride, J. L. Huckaby, and B. E. Wells, "Effect of Antifoam on Gas Retention and Release in Simulated High Level Waste”, WTP-RPT-147, PDC \#"24590-101-TSA-W000-0004-150-00005 Rev00" Battelle Pacific Northwest Division, Richland, WA

3. Sherwood, D. J., WTP Project Test Specification 24590-WTP-RT-06-002, Rev. 0,'Large Scale Testing for Effects of Anti-foam Agent on Gas Retention/Release," February 5, 2007.

4. Bernards, J. K., R\&T Test Exception Number 24590-WTP-TEF-RT-07-00010, “Test Exception to 24590-WTP-RT-06-002, Rev. 0, Large Scale Testing for Effects of Anti-foam Agent on Gas Retention/Release," September, 2007.

5. D. J. Sherwood, “Test Exception to WSRC-TR-2007-00038, Rev. 0, Task Technical and Quality Assurance Plan in Support of RPP Test Specification, "Gas Release Testing to Determine the Effect of Antifoam Agent on Gas Release Rate from non-Newtonian Slurries (U)," October 11, 2007.

6. Guerrero, H. N., WSRC-TR-2007-00038 Rev. 0, and SRNL-RPP-2007-00009, Rev. 0, “Task Technical and QA Plan in Support of the RPP Test Specification, "Gas Release and Holdup Testing to Determine the Effect of Antifoam Agent on Gas Release Rate from non-Newtonian Slurries (U)," March 5, 2007.

7. Eibling, R. E., R. F. Schumacher, and E. K. Hanser, WTP Project Document No. SCTM0SRLE60-00-193-02, Rev. 00A, "Development of Simulants to Support Mixing Tests for High Level Waste and Low Activity Waste," SRNL Doc. No. WSRC-TR-2003-00220, Rev. 0 and SRT-RPP-2003-00098, Rev. 0, Savannah River National Laboratory, Aiken, SC. 29808, December, 2003.

8. PNNL, "Statement of Work, AZ-101 HLW Waste Simulant Formulation," February, 2007.

9. Personal Communication from Consuelo Guzman-Leong to H. N. Guerrero, October 22, 2007. This data will be presented formally in PNNL's final report on their part of the test program.

10. Zhang, X, C. Macosko, H. Davis, A. Nikolov, and D. Wasan, "Role of Silicone Surfactant in Flexible Polyurethane Foam”, Journal of Colloid and Interface Science, 215 (1999) 270-279. 
11. Tan, S. N., R. Pugh, D. Fornasiero, R. Sedev, J. Ralston, "Foaming of polypropylene glycols and glycol/MIBC mixtures", Minerals Engineering 18(2005) 179-188.

12. Morao, A., C. Maia, M. Fonseca, J. Vasconcelos, S. Alves, "Effect of antifoam addition on gas-liquid mass transfer in stirred fermenters," Bioprocess Engineering 20 (1999) 165-172.

13. Denkov, N., "Mechanisms of Foam Destruction by Oil-Based Antifoams", Langmuir, 20 (2004) 9463-9505.

14. Bekish, A., R. Lemoine, L. Schabiague, R. Oukaci, B. Morsi, "Gas holdup and bubble size behavior in a large scale slurry bubble column reactor operating with an organic liquid under elevated pressures and temperatures', Chemical Engineering Journal, 128 (2007) 69-84.

15. Yagi and Voshido, “Oxygen Absorption in Fermenter”, Fermentation Technology, Vol. 53, no.12, pp. 905-916, 1974.

16. Leishear, R. A., WTS-WI-0021, Rev. 1, "Large Scale Testing for Effects of Anti-foam on Gas Retention”, SRNL, 2007.

17. Restivo, M., “Full Scale UFP Test Results,” WSRC-TR-2004-00412, SRNL-RPP-200400064.

18. Bello, Ade R., C. W. Robinson and M. Moo-Young, "Prediction of the Volumetric Mass Transfer Coefficient in Pneumatic Contactors", Chemical Engineering Science, Vo. 40, pp. 53$58,1985$.

19. Shah, Y. T., B. G. Kelkar and S.P. Godbole, Design Parameters Estimation for Bubble Column Reactors, Aiche J. (vol. 28,. No. 3) pp. 353-379, May, 1982.

20. Godbole, S. P., A. Schumpe, and Y. T. Shah, "Hydrodynamics and Mass Transfer in NonNewtonian Solutions in a Bubble Column", AiChe J (Vol. 30, No. 2) March, 1084, pp 213-220. 
WSRC-STI-2007-00537, REVISION 0

SRNL-RPP-2007-00023, REVISION 0

\section{APPENDIX A. BENCH SCALE TEST RESULTS}

\section{Table A-1 Bench Scale Test Conditions and Results}

\begin{tabular}{|c|c|c|c|c|c|c|c|c|c|c|c|c|c|c|c|}
\hline Item \# & Test ID & Date & Time & Simulant & $\begin{array}{c}\text { Yield } \\
\text { strength, } \\
\text { Pa }\end{array}$ & $\mathrm{Wt} \%$ TS & RPM & $\begin{array}{l}\text { sparging } \\
\text { flow rate } \\
\text { slm }\end{array}$ & $\begin{array}{c}\text { Desired } \\
\text { AntiFoam } \\
\text { mg/l }\end{array}$ & $\begin{array}{c}\text { Anti Foam } \\
\text { Type }\end{array}$ & $\begin{array}{l}\mathrm{H} 2 \mathrm{O} 2 \\
\mathrm{ml} / \mathrm{sec}\end{array}$ & $\begin{array}{l}\text { Noble } \\
\text { Metals }\end{array}$ & Data file(s) & $\begin{array}{c}\text { Sup } \\
\text { Vel, } \\
\mathrm{mm} / \mathrm{s}\end{array}$ & $\begin{array}{c}\text { Gas Holdup, } \\
\%\end{array}$ \\
\hline 1 & $5 \mathrm{~b}-2$ & $5 / 25 / 2007$ & $14: 10$ & AZ-101, New batch 2 & 13.71 & 22.15 & 900 & 1.49 & 350 & Q2-3183A & NA & NO & 053007_13PaQ2 & 1 & 9.765 \\
\hline 2 & & $5 / 25 / 2007$ & $14: 32$ & AZ-101, New batch 2 & 13.96 & 22.2 & 900 & 0.462 & 350 & Q2-3183A & NA & NO & 053007_13PaQ2 & 0.31 & 5.838 \\
\hline 3 & & $5 / 25 / 2007$ & $14: 48$ & AZ-101, New batch 2 & 13.96 & 22.2 & 900 & 0.149 & 350 & Q2-3183A & NA & NO & 053007_13PaQ2 & 0.1 & 3.641 \\
\hline 4 & & $5 / 25 / 2007$ & $15: 04$ & AZ-101, New batch 2 & 13.96 & 22.2 & 900 & 0.046 & 350 & Q2-3183A & NA & NO & 053007_13PaQ2 & 0.031 & 2.727 \\
\hline 5 & & $5 / 25 / 2007$ & $15: 20$ & AZ-101, New batch 2 & 14.2 & 22.25 & 900 & 0.015 & 350 & Q2-3183A & NA & NO & 053007_13PaQ2 & 0.01 & 2.585 \\
\hline 6 & $5 b-1$ & $5 / 30 / 2007$ & 8:51 & AZ-101, New batch 2 & 30.545 & 24.79 & 1180 & 1.49 & 350 & Q2-3183A & NA & No & 053007_30PaQ2 & 1 & 6.018 \\
\hline 7 & & $5 / 30 / 2007$ & $9: 10$ & AZ-101, New batch 2 & 30.18 & 24.96 & 1180 & 0.462 & 350 & Q2-3183A & NA & NO & 053007_30PaQ2 & 0.31 & 3.931 \\
\hline 8 & & $5 / 30 / 2007$ & $9: 28$ & AZ-101, New batch 2 & 30.18 & 24.96 & 1180 & 0.149 & 350 & Q2-3183A & NA & NO & 053007_30PaQ2 & 0.1 & 2.781 \\
\hline 9 & & $5 / 30 / 2007$ & $9: 46$ & AZ-101, New batch 2 & 30.18 & 24.96 & 1180 & 0.046 & 350 & Q2-3183A & NA & NO & 053007_30PaQ2 & 0.031 & 2.362 \\
\hline 10 & & $5 / 30 / 2007$ & 10:04 & AZ-101, New batch 2 & 30.18 & 24.96 & 1180 & 0.015 & 350 & Q2-3183A & NA & NO & 053007_30PaQ2 & 0.01 & 1.032 \\
\hline 11 & & $5 / 30 / 2007$ & 10:24 & AZ-101, New batch 2 & 30.18 & 24.96 & 1180 & 1.49 & 350 & Q2-3183A & NA & No & 053007_30PaQ2 & 1 & 5.510 \\
\hline 12 & & $5 / 30 / 2007$ & $10: 46$ & AZ-101, New batch 2 & 29.82 & 25.12 & 1180 & 0.015 & 350 & Q2-3183A & NA & NO & 053007_30PaQ2 & 0.01 & 0.497 \\
\hline 13 & $5 b-3$ & $6 / 1 / 2007$ & 8:56 & AZ-101, New batch 2 & 3.932 & 17.82 & 700 & 1.49 & 350 & Q2-3183A & NA & NO & 060107_3PaQ2 & 1 & 14.405 \\
\hline 14 & & $6 / 1 / 2007$ & $9: 19$ & AZ-101, New batch 2 & 4.04 & 17.89 & 700 & 0.149 & 350 & Q2-3183A & NA & NO & 060107_3PaQ2 & 0.1 & 4.316 \\
\hline 15 & & $6 / 1 / 2007$ & 9:54 & AZ-101, New batch 2 & 4.04 & 17.89 & 700 & 0.149 & 350 & Q2-3183A & NA & NO & 060107_3PaQ2 & 0.1 & 3.741 \\
\hline 16 & & $6 / 1 / 2007$ & 10:15 & AZ-101, New batch 2 & 4.04 & 17.89 & 700 & 0.046 & 350 & Q2-3183A & NA & No & 060107_3PaQ2 & 0.031 & 2.754 \\
\hline 17 & & $6 / 1 / 2007$ & 10:34 & AZ-101, New batch 2 & 4.04 & 17.89 & 700 & 0.015 & 350 & Q2-3183A & NA & No & 060107_3PaQ2 & 0.01 & 0.717 \\
\hline 18 & & $6 / 1 / 2007$ & 10:59 & AZ-101, New batch 2 & 4.1425 & 17.96 & 700 & 0.015 & 350 & Q2-3183A & NA & NO & 060107_3PaQ2 & 0.01 & 0.242 \\
\hline 19 & $5 b-7$ & $6 / 4 / 2007$ & $9: 23$ & AZ-101, New batch 2 & 28.285 & 24.68 & 1150 & 1.49 & 100 & 1520-US & NA & NO & 060407_30Pa_1520_t1 & 1 & 5.993 \\
\hline 20 & & $6 / 4 / 2007$ & 10:02 & AZ-101, New batch 2 & 29.54 & 25.28 & 1150 & 1.49 & 200 & 1520-US & NA & NO & 060407_30Pa_1520_t1 & 1 & 5.139 \\
\hline 21 & & $6 / 4 / 2007$ & 10:36 & AZ-101, New batch 2 & 29.54 & 25.28 & 1150 & 1.49 & 350 & 1520-US & NA & NO & 060407_30Pa_1520_t1 & 1 & 4.514 \\
\hline 22 & & $6 / 4 / 2007$ & 11:06 & AZ-101, New batch 2 & 29.54 & 25.28 & 1150 & 0.015 & 350 & 1520-US & NA & No & 060407_30Pa_1520_t1 & 0.1 & 1.684 \\
\hline 23 & & $6 / 4 / 2007$ & $11: 40$ & AZ-101, New batch 2 & 29.54 & 25.28 & 1150 & 0.046 & 350 & 1520-US & NA & No & 060407 30Pa_1520_t1 & 0.031 & 2.317 \\
\hline 24 & & $6 / 4 / 2007$ & $14: 03$ & AZ-101, New batch 2 & 29.54 & 25.28 & 1180 & 0.149 & 350 & 1520-US & NA & NO & 060407_30Pa_1520_t2 & 0.1 & 4.228 \\
\hline 25 & & $6 / 4 / 2007$ & $14: 30$ & AZ-101, New batch 2 & 29.54 & 25.28 & 1180 & 0.462 & 350 & 1520-US & NA & NO & 060407_30Pa_1520_t2 & 0.31 & 5.661 \\
\hline 26 & & $6 / 4 / 2007$ & 15:00 & AZ-101, New batch 2 & 29.54 & 25.28 & 1180 & 1.49 & 350 & 1520-US & NA & NO & 060407_30Pa_1520_t2 & 1 & 7.529 \\
\hline 27 & & $6 / 4 / 2007$ & $15: 25$ & AZ-101, New batch 2 & 29.54 & 25.28 & 1180 & 1.49 & 550 & 1520-US & NA & No & $060407 \_30 \mathrm{~Pa} \_1520 \_\mathrm{t} 2$ & 1 & 3.851 \\
\hline 28 & & 6/4/2007 & $15: 47$ & AZ-101, New batch 2 & 29.54 & 25.28 & 1180 & 1.49 & 750 & 1520-US & NA & No & 060407_30Pa_1520_t2 & 1 & 3.523 \\
\hline 29 & & $6 / 4 / 2007$ & 16:05 & AZ-101, New batch 2 & 29.54 & 25.28 & 1180 & 0.462 & 750 & 1520-US & NA & No & 060407_30Pa_1520_t2 & 0.31 & 2.098 \\
\hline 30 & $5 b-7$ & $6 / 4 / 2007$ & $16: 15$ & AZ-101, New batch 2 & 29.54 & 25.28 & 1180 & 0.149 & 750 & 1520-US & NA & NO & 060407_30Pa_1520_t2 & 0.1 & 0.983 \\
\hline 31 & & $6 / 5 / 2007$ & $8: 40$ & AZ-101, New batch 2 & 29.54 & 25.28 & 1150 & 0.149 & 825 & 1520-US & NA & NO & $06040730 \mathrm{~Pa} \_1520 \mathrm{t} 3$ & 0.1 & 2.133 \\
\hline 32 & & $6 / 5 / 2007$ & 9:08 & AZ-101, New batch 2 & 29.54 & 25.28 & 1150 & 0.015 & 825 & 1520-US & NA & No & 060407_30Pa_1520_t3 & 0.01 & 0.819 \\
\hline 33 & & $6 / 5 / 2007$ & 9:35 & AZ-101, New batch 2 & 29.54 & 25.28 & 1150 & 0.046 & 825 & 1520-US & NA & No & 060407_30Pa_1520_t3 & 0.031 & 1.388 \\
\hline 34 & & 6/5/2007 & $10: 00$ & AZ-101, New batch 2 & 29.54 & 25.28 & 1150 & 1.49 & 825 & 1520-US & NA & NO & 060407_30Pa_1520_t3 & 1 & 5.508 \\
\hline 35 & & $6 / 5 / 2007$ & 13:54 & AZ-101, New batch 2 & 29.54 & 25.28 & 1150 & 1.49 & 825 & 1520-US & NA & NO & 660407_30Pa_1520_tpn & 1 & 6.343 \\
\hline 36 & & $6 / 5 / 2007$ & 14:12 & AZ-101, New batch 2 & 29.54 & 25.28 & 1150 & 0.462 & 825 & 1520-US & NA & NO & 660407_30Pa_1520_tpm & 0.31 & 4.466 \\
\hline 37 & & $6 / 5 / 2007$ & 14:31 & AZ-101, New batch 2 & 29.54 & 25.28 & 1150 & 0.149 & 825 & 1520-US & NA & No & 660407_30Pa_1520_tpm & 0.1 & 2.962 \\
\hline 38 & & $6 / 5 / 2007$ & 14:50 & AZ-101, New batch 2 & 29.54 & 25.28 & 1150 & 0.046 & 825 & 1520-US & NA & No & 660407_30Pa_1520_tpn & 0.031 & 1.208 \\
\hline 39 & & $6 / 5 / 2007$ & $15: 17$ & AZ-101, New batch 2 & 30.825 & 25.88 & 1150 & 0.015 & 825 & 1520-US & NA & NO & b60407_30Pa_1520_tpm & 0.01 & 0.651 \\
\hline 40 & $5 b-8$ & $6 / 11 / 2007$ & 9:00 & AZ-101, New batch 2 & 12.28 & 22.21 & 1200 & 1.49 & 874 & 1520-US & NA & NO & 061107_30Pa_1520_r2 & 1 & 19.948 \\
\hline 41 & & $6 / 11 / 2007$ & 9:30 & AZ-101, New batch 2 & 13.31 & 22.95 & 1050 & 0.149 & 874 & 1520-US & NA & NO & 061107_30Pa_1520_r2 & 0.1 & 7.135 \\
\hline 42 & & $6 / 11 / 2007$ & 9:40 & AZ-101, New batch 2 & 13.31 & 22.95 & 850 & 0.015 & 874 & 1520-US & NA & NO & 061107_30Pa_1520_r2 & 0.01 & 2.317 \\
\hline 43 & & $6 / 11 / 2007$ & 10:22 & AZ-101, New batch 2 & 13.31 & 22.95 & 850 & 1.49 & 1224 & 1520-US & NA & No & 061107_30Pa_1520_r2 & 1 & 4.527 \\
\hline 44 & & $6 / 11 / 2007$ & 10:39 & AZ-101, New batch 2 & 13.31 & 22.95 & 850 & 0.149 & 1224 & 1520-US & NA & NO & 061107_30Pa_1520_r2 & 0.1 & 1.890 \\
\hline 45 & & $6 / 11 / 2007$ & 10:55 & AZ-101, New batch 2 & 13.31 & 22.95 & 900 & 0.015 & 1224 & 1520-US & NA & NO & 061107_30Pa_1520_r2 & 0.01 & 0.919 \\
\hline 46 & & $6 / 11 / 2007$ & $12: 20$ & AZ-101, New batch 2 & 13.31 & 22.95 & 950 & 1.49 & 1624 & 1520-US & NA & NO & 061107_30Pa_1520_t2 & 1 & 4.644 \\
\hline 47 & & $6 / 11 / 2007$ & $12: 43$ & AZ-101, New batch 2 & 13.31 & 22.95 & 850 & 0.149 & 1624 & 1520-US & NA & NO & 061107_30Pa_1520_t2 & 0.1 & 1.904 \\
\hline 48 & & $6 / 11 / 2007$ & 13:06 & AZ-101, New batch 2 & 14.35 & 22.98 & 850 & 0.015 & 1624 & 1520-US & NA & NO & 061107_30Pa_1520_t2 & 0.01 & 0.667 \\
\hline 49 & $5 b-9$ & $6 / 11 / 2007$ & $14: 50$ & AZ-101, New batch 2 & 5.289 & 17.67 & 1000 & 1.49 & 1392 & 1520-US & NA & No & 061107_3Pa_1520 & 1 & 8.517 \\
\hline 50 & & $6 / 11 / 2007$ & $15: 08$ & AZ-101, New batch 2 & 5.37 & 17.72 & 900 & 0.462 & 1392 & 1520-US & NA & NO & 061107_3Pa_1520 & 0.31 & 5.472 \\
\hline 51 & & $6 / 11 / 2007$ & $15: 25$ & AZ-101, New batch 2 & 5.37 & 17.72 & 850 & 0.149 & 1392 & 1520-US & NA & NO & 061107_3Pa_1520 & 0.1 & 3.389 \\
\hline 52 & & $6 / 11 / 2007$ & $15: 43$ & AZ-101, New batch 2 & 5.37 & 17.72 & 750 & 0.046 & 1392 & 1520-US & NA & NO & 061107_3Pa_1520 & 0.031 & 2.296 \\
\hline 53 & & $6 / 11 / 2007$ & $16: 03$ & AZ-101, New batch 2 & 5.37 & 17.72 & 750 & 0.015 & 1392 & 1520-US & NA & No & 061107_3Pa_1520 & 0.01 & 1.434 \\
\hline 54 & & $6 / 12 / 2007$ & $8: 47$ & AZ-101, New batch 2 & 5.37 & 17.72 & 1250 & 1.49 & 1392 & 1520-US & NA & No & $061107 \_3 \mathrm{~Pa} \_1520 \_\mathrm{r} 2$ & 1 & 7.833 \\
\hline 55 & & $6 / 12 / 2007$ & 9:08 & AZ-101, New batch 2 & 5.37 & 17.72 & 1000 & 1.49 & 1392 & 1520-US & NA & NO & 061107_3Pa_1520_r2 & 1 & 4.215 \\
\hline 56 & & $6 / 12 / 2007$ & 9:31 & AZ-101, New batch 2 & 5.37 & 17.72 & 950 & 0.149 & 1392 & 1520-US & NA & NO & 061107_3Pa_1520_r2b & 0.1 & 2.700 \\
\hline 57 & & $6 / 12 / 2007$ & 9:05 & AZ-101, New batch 2 & 5.37 & 17.72 & 750 & 0.015 & 1392 & 1520-US & NA & No & 061107_3Pa_1520_r2b & 0.01 & 0.322 \\
\hline 58 & & $6 / 12 / 2007$ & 10:25 & AZ-101, New batch 2 & 5.37 & 17.72 & 1000 & 1.49 & 2142 & 1520-US & NA & No & 061107_3Pa_1520_r3 & 1 & 6.854 \\
\hline 59 & & $6 / 12 / 2007$ & $10: 40$ & AZ-101, New batch 2 & 5.37 & 17.72 & 850 & 0.149 & 2142 & 1520-US & NA & NO & 061107_3Pa_1520_r3 & 0.1 & 2.239 \\
\hline 60 & & $6 / 12 / 2007$ & 10:56 & AZ-101, New batch 2 & 5.445 & 17.76 & 750 & 0.015 & 2142 & 1520-US & NA & NO & 061107_3Pa_1520_r3 & 0.01 & 0.479 \\
\hline
\end{tabular}


WSRC-STI-2007-00537, REVISION 0 SRNL-RPP-2007-00023, REVISION 0

Table A-1 Bench Scale Test Conditions and Results (Cont'd.)

\begin{tabular}{|c|c|c|c|c|c|c|c|c|c|c|c|c|c|c|c|}
\hline Item \# & Test ID & Date & Time & Simulant & $\begin{array}{c}\text { Yield } \\
\text { strength, } \\
\mathrm{Pa}\end{array}$ & $\mathrm{W} t \% \mathrm{TS}$ & RPM & $\begin{array}{c}\text { Alr } \\
\text { sparging } \\
\text { flow rate } \\
\text { slm }\end{array}$ & $\begin{array}{c}\text { Desired } \\
\text { AntiFoam } \\
\mathrm{mg} / \mathrm{l}\end{array}$ & $\begin{array}{c}\text { Anti Foam } \\
\text { Type }\end{array}$ & $\begin{array}{l}\mathrm{H} 2 \mathrm{O} 2 \\
\mathrm{ml} / \mathrm{sec}\end{array}$ & $\begin{array}{l}\text { Noble } \\
\text { Metals }\end{array}$ & Data file(s) & \begin{tabular}{c|} 
Sup \\
Vel, \\
$\mathrm{mm} / \mathrm{s}$
\end{tabular} & $\begin{array}{c}\text { Gas Holdup, } \\
\%\end{array}$ \\
\hline 61 & $5 a-1$ & $6 / 13 / 2007$ & $9: 22$ & Water & NA & NA & 900 & 0.015 & 0 & NA & NA & NO & 0613-wat2 & 0.01 & 0.040 \\
\hline 62 & & $6 / 13 / 2007$ & $9: 40$ & Water & NA & NA & 900 & 0.046 & 0 & NA & NA & NO & 0613-wat2 & 0.031 & 0.147 \\
\hline 63 & & $6 / 13 / 2007$ & 9:56 & Water & NA & NA & 900 & 0.149 & 0 & NA & NA & NO & 0613-wat2 & 0.1 & 0.369 \\
\hline 64 & & $6 / 13 / 2007$ & $10: 12$ & Water & NA & NA & 900 & 0.462 & 0 & NA & NA & NO & 0613-wat2 & 0.31 & 0.889 \\
\hline 65 & & $6 / 13 / 2007$ & $10: 30$ & Water & NA & NA & 900 & 1.49 & 0 & NA & NA & NO & 0613-wat2 & 1 & 2.406 \\
\hline 66 & & $6 / 13 / 2007$ & $10: 46$ & Water & NA & NA & 900 & 1.49 & 0 & NA & NA & NO & 0613-wat2 & 1 & 2.315 \\
\hline 67 & $5 a-2$ & $6 / 13 / 2007$ & $12: 40$ & Water & NA & NA & 900 & 1.49 & 140 & PDMS & NA & NO & 0613_watPDMS & 1 & 2.565 \\
\hline 68 & & $6 / 13 / 2007$ & 13:03 & Water & NA & NA & 900 & 1.49 & 140 & PDMS & NA & NO & 0613_watPDMS & 1 & 2.178 \\
\hline 69 & & $6 / 13 / 2007$ & 13:24 & Water & NA & NA & 900 & 0.149 & 140 & PDMS & NA & NO & 0613_watPDMS & 0.1 & 0.354 \\
\hline 70 & & $6 / 13 / 2007$ & $13: 40$ & Water & NA & NA & 900 & 0.015 & 140 & PDMS & NA & NO & 0613_watPDMS & 0.01 & 0.222 \\
\hline 71 & & $6 / 13 / 2007$ & $13: 59$ & Water & NA & NA & 900 & 0.015 & 245 & PDMS & NA & NO & 0613_watPDMS & 0.01 & 0.366 \\
\hline 72 & & $6 / 13 / 2007$ & $14: 15$ & Water & NA & NA & 900 & 0.046 & 245 & PDMS & NA & NO & 0613_watPDMS & 0.031 & 0.304 \\
\hline 73 & & $6 / 13 / 2007$ & 14:31 & Water & NA & NA & 900 & 0.149 & 245 & PDMS & NA & NO & 0613_watPDMS & 0.1 & 0.465 \\
\hline 74 & & $6 / 13 / 2007$ & $14: 47$ & Water & NA & NA & 900 & 0.462 & 245 & PDMS & NA & NO & 0613_watPDMS & 0.31 & 0.859 \\
\hline 75 & & $6 / 13 / 2007$ & $15: 03$ & Water & NA & NA & 900 & 1.49 & 245 & PDMS & NA & NO & 0613_watPDMS & 1 & 2.054 \\
\hline 76 & $5 a-3$ & $6 / 14 / 2007$ & 12:13 & Water & NA & NA & 900 & 1.49 & 70 & PPG & NA & NO & 061407_watPPG2 & 1 & 1.863 \\
\hline 77 & & $6 / 14 / 2007$ & $12: 30$ & Water & NA & NA & 900 & 1.49 & 140 & PPG & NA & NO & 061407 watPPG2 & 1 & 3.421 \\
\hline 78 & & $6 / 14 / 2007$ & $12: 40$ & Water & NA & NA & 900 & 0.462 & 140 & PPG & NA & NO & 061407_watPPG2 & 0.31 & 1.320 \\
\hline 79 & & $6 / 14 / 2007$ & $12: 50$ & Water & NA & NA & 900 & 0.149 & 140 & PPG & NA & NO & 061407_watPPG2 & 0.1 & 0.603 \\
\hline 80 & & $6 / 14 / 2007$ & $13: 00$ & Water & NA & NA & 900 & 0.046 & 140 & PPG & NA & NO & 061407_watPPG2 & 0.031 & 0.211 \\
\hline 81 & & $6 / 14 / 2007$ & 13:10 & Water & NA & NA & 900 & 0.015 & 245 & PPG & NA & NO & 061407_watPPG2 & 0.01 & 0.211 \\
\hline 82 & & $6 / 14 / 2007$ & $13: 40$ & Water & NA & NA & 900 & 1.49 & 245 & PPG & NA & NO & 061407_watPPG2 & 1 & 3.266 \\
\hline 83 & & $6 / 14 / 2007$ & 13:50 & Water & NA & NA & 900 & 0.462 & 245 & PPG & NA & NO & 061407_watPPG2 & 0.31 & 1.269 \\
\hline 84 & & $6 / 14 / 2007$ & $14: 00$ & Water & NA & NA & 900 & 0.149 & 245 & PPG & NA & NO & 061407_watPPG2 & 0.1 & 0.715 \\
\hline 85 & & $6 / 14 / 2007$ & $14: 10$ & Water & NA & NA & 900 & 0.046 & 245 & PPG & NA & NO & 061407 watPPG2 & 0.031 & 0.377 \\
\hline 86 & & $6 / 14 / 2007$ & $14: 20$ & Water & NA & NA & 900 & 0.015 & 245 & PPG & NA & NO & 061407_watPPG2 & 0.01 & 0.222 \\
\hline 87 & $5 a-10$ & $6 / 18 / 2007$ & $11: 50$ & AZ-101, New batch 2 & 28.105 & 24.67 & 1250 & 1.49 & 0 & NA & NA & NO & 061807-30PaPPG & 1 & 6.220 \\
\hline 88 & & $6 / 18 / 2007$ & $12: 00$ & AZ-101, New batch 2 & 28.08 & 24.88 & 1250 & 1.49 & 0 & NA & NA & NO & 061807-30PaPPG & 1 & 6.291 \\
\hline 89 & & $6 / 18 / 2007$ & 12:26 & AZ-101, New batch 2 & 28.08 & 24.88 & 1150 & 1.49 & 70 & PPG & NA & NO & 061807-30PaPPG & 1 & 4.783 \\
\hline 90 & & $6 / 18 / 2007$ & $12: 45$ & AZ-101, New batch 2 & 28.08 & 24.88 & 1250 & 0.15 & 70 & PPG & NA & NO & 061807-30PaPPG & 0.1 & 2.632 \\
\hline 91 & & $6 / 18 / 2007$ & 13:02 & AZ-101, New batch 2 & 28.08 & 24.88 & 1200 & 0.015 & 70 & PPG & $\mathrm{NA}$ & NO & 061807-30PaPPG & 0.01 & 1.210 \\
\hline 92 & & $6 / 18 / 2007$ & 13:45 & AZ-101, New batch 2 & 28.08 & 24.88 & 1250 & 1.49 & 140 & PPG & NA & NO & 061807-30PaPPG & 1.00 & 5.571 \\
\hline 93 & & $6 / 18 / 2007$ & $14: 03$ & AZ-101, New batch 2 & 28.08 & 24.88 & 1150 & 0.15 & 140 & PPG & NA & NO & 061807-30PaPPG & 0.10 & 3.442 \\
\hline 94 & & $6 / 18 / 2007$ & $14: 18$ & AZ-101, New batch 2 & 28.08 & 24.88 & 1150 & 0.046 & 140 & PPG & NA & NO & 061807-30PaPPG & 0.032 & 2.508 \\
\hline 95 & & $6 / 18 / 2007$ & $14: 28$ & AZ-101, New batch 2 & 28.08 & 24.88 & 1150 & 0.015 & 140 & PPG & NA & NO & 061807-30PaPPG & 0.01 & 1.733 \\
\hline 96 & & $6 / 18 / 2007$ & 16:00 & AZ-101, New batch 2 & 28.08 & 24.88 & 1150 & 1.490 & 245 & PPG & $\mathrm{NA}$ & NO & 061807-30PaPPG2 & 1 & 4.997 \\
\hline 97 & & $6 / 18 / 2007$ & $16: 10$ & AZ-101, New batch 2 & 28.08 & 24.88 & 1250 & 0.149 & 245 & PPG & NA & NO & 061807-30PaPPG2 & 0.1 & 2.225 \\
\hline 98 & & $6 / 18 / 2007$ & $16: 20$ & AZ-101, New batch 2 & 28.045 & 25.10 & 1250 & 0.015 & 245 & PPG & NA & NO & 061807-30PaPPG2 & 0.01 & 0.324 \\
\hline 99 & 5a-11 & $6 / 19 / 2007$ & 12:08 & AZ-101, New batch 2 & 11.81 & 21.82 & 1100 & 1.490 & 245 & PPG & NA & NO & 061907_PPG_13Pa & 1 & 9.765 \\
\hline 100 & & $6 / 19 / 2007$ & 12:25 & AZ-101, New batch 2 & 12.16 & 21.81 & 1000 & 0.462 & 245 & PPG & NA & NO & 061907_PPG_13Pa & 0.31 & 5.838 \\
\hline 101 & & $6 / 19 / 2007$ & $12: 42$ & AZ-101, New batch 2 & 12.16 & 21.81 & 950 & 0.149 & 245 & PPG & $\mathrm{NA}$ & NO & 061907_PPG_13Pa & 0.1 & 3.641 \\
\hline 102 & & $6 / 19 / 2007$ & $13: 00$ & AZ-101, New batch 2 & 12.16 & 21.81 & 850 & 0.046 & 245 & PPG & NA & NO & 061907_PPG_13Pa & 0.031 & 2.727 \\
\hline 103 & & $6 / 19 / 2007$ & $13: 20$ & AZ-101, New batch 2 & 12.515 & 21.81 & 850 & 0.015 & 245 & PPG & NA & NO & 061907_PPG_13Pa & 0.01 & 2.547 \\
\hline 104 & $5 a-12$ & $6 / 20 / 2007$ & $9: 46$ & AZ-101, New batch 2 & 3.529 & 17.40 & 700 & 0.046 & 245 & PPG & NA & NO & 062007_3Pa PPG2 & 0.031 & 0.622 \\
\hline 105 & & $6 / 20 / 2007$ & 10:02 & AZ-101, New batch 2 & 3.569 & 17.32 & 700 & 0.149 & 245 & PPG & NA & NO & 062007_3Pa PPG2 & 0.1 & 1.356 \\
\hline 106 & & $6 / 20 / 2007$ & $10: 18$ & AZ-101, New batch 2 & 3.569 & 17.32 & 700 & 0.015 & 245 & PPG & $\mathrm{NA}$ & NO & 062007_3Pa PPG2 & 0.01 & 0.466 \\
\hline 107 & & $6 / 20 / 2007$ & 10:34 & AZ-101, New batch 2 & 3.569 & 17.32 & 700 & 0.462 & 245 & PPG & NA & NO & 062007_3Pa PPG2 & 0.31 & 2.429 \\
\hline 108 & & $6 / 20 / 2007$ & $10: 50$ & AZ-101, New batch 2 & 3.569 & 17.32 & 700 & 1.490 & 245 & PPG & NA & NO & 062007_3Pa PPG2 & 1 & 6.533 \\
\hline 109 & & $6 / 20 / 2007$ & $12: 46$ & AZ-101, New batch 2 & 3.569 & 17.32 & 750 & 0.015 & 245 & PPG & NA & NO & 062007_3Pa PPG2 & 0.01 & 0.092 \\
\hline 110 & & $6 / 20 / 2007$ & 12:59 & AZ-101, New batch 2 & 3.569 & 17.32 & 750 & 0.149 & 245 & PPG & NA & NO & 062007_3Pa PPG2 & 0.10 & 1.064 \\
\hline 111 & & $6 / 20 / 2007$ & $13: 16$ & AZ-101, New batch 2 & 3.6085 & 17.23 & 900 & 1.490 & 245 & PPG & NA & NO & 062007_3Pa PPG2 & 1.00 & 5.280 \\
\hline 112 & $5 a-7$ & $6 / 21 / 2007$ & $12: 24$ & AZ-101, New batch 2 & 29.335 & 24.76 & 1300 & 1.490 & 0 & PDMS & NA & No & 062107_PDMS_30Pa & 1.000 & 7.147 \\
\hline 113 & & $6 / 21 / 2007$ & $12: 42$ & AZ-101, New batch 2 & 30 & 25.04 & 1150 & 1.490 & 0 & PDMS & NA & NO & 062107_PDMS_30Pa & 1.000 & 6.688 \\
\hline 114 & & $6 / 21 / 2007$ & 13:01 & AZ-101, New batch 2 & 30 & 25.04 & 1250 & 1.490 & 70 & PDMS & NA & NO & 062107_PDMS_30Pa & 1.000 & 6.003 \\
\hline 115 & & $6 / 21 / 2007$ & 13:13 & AZ-101, New batch 2 & 30 & 25.04 & 1150 & 0.149 & 70 & PDMS & NA & NO & 062107_PDMS_30Pa & 0.100 & 3.282 \\
\hline 116 & & $6 / 21 / 2007$ & 13:29 & AZ-101, New batch 2 & 30 & 25.04 & 1150 & 0.015 & 70 & PDMS & NA & NO & 062107_PDMS_30Pa & 0.010 & 1.209 \\
\hline 117 & & $6 / 21 / 2007$ & 13:48 & AZ-101, New batch 2 & 30 & 25.04 & 1200 & 1.490 & 140 & PDMS & NA & NO & 062107_PDMS_30Pa & 1.000 & 5.493 \\
\hline 118 & & $6 / 21 / 2007$ & 14:01 & AZ-101, New batch 2 & 30 & 25.04 & 1150 & 0.149 & 140 & PDMS & NA & NO & 062107_PDMS_30Pa & 0.100 & 2.205 \\
\hline 119 & & $6 / 21 / 2007$ & $14: 20$ & AZ-101, New batch 2 & 30 & 25.04 & 1150 & 0.015 & 190 & PDMS & NA & NO & 062107_PDMS_30Pa & 0.010 & 0.530 \\
\hline 120 & & $6 / 21 / 2007$ & $14: 31$ & AZ-101, New batch 2 & 30 & 25.04 & 1150 & 0.046 & 190 & PDMS & NA & NO & 062107_PDMS_30Pa & 0.031 & 1.816 \\
\hline 121 & & $6 / 21 / 2007$ & $14: 46$ & AZ-101, New batch 2 & 30 & 25.04 & 1150 & 0.149 & 190 & PDMS & NA & NO & 062107_PDMS_30Pa & 0.1 & 2.844 \\
\hline 122 & & $6 / 21 / 2007$ & 14:58 & AZ-101, New batch 2 & 30 & 25.04 & 1150 & 0.462 & 190 & PDMS & $\mathrm{NA}$ & NO & 062107_PDMS_30Pa & 0.31 & 4.065 \\
\hline 123 & & $6 / 21 / 2007$ & $15: 05$ & AZ-101, New batch 2 & 30 & 25.04 & 1150 & 1.490 & 190 & PDMS & NA & NO & 062107_PDMS_30Pa & 1 & 6.576 \\
\hline
\end{tabular}


WSRC-STI-2007-00537, REVISION 0 SRNL-RPP-2007-00023, REVISION 0

\begin{tabular}{|c|c|c|c|c|c|c|c|c|c|c|c|c|c|c|c|}
\hline Item \# & Test ID & Date & Time & Simulant & $\begin{array}{c}\text { Yield } \\
\text { strength, } \\
\mathrm{Pa}\end{array}$ & $\mathrm{Wt} \% \mathrm{TS}$ & RPM & $\begin{array}{c}\text { sparging } \\
\text { flow rate } \\
\text { slm }\end{array}$ & $\begin{array}{c}\text { Desired } \\
\text { AntiFoam } \\
\mathrm{mg} / \mathrm{l}\end{array}$ & $\begin{array}{c}\text { Anti Foam } \\
\text { Type }\end{array}$ & $\begin{array}{l}\mathrm{H} 2 \mathrm{O} 2 \\
\mathrm{~m} / \mathrm{sec}\end{array}$ & $\begin{array}{l}\text { Noble } \\
\text { Metals }\end{array}$ & Data file(s) & $\begin{array}{c}\text { Sup } \\
\text { Vel, } \\
\mathrm{mm} / \mathrm{s}\end{array}$ & $\begin{array}{c}\text { Gas Holdup, } \\
\%\end{array}$ \\
\hline 124 & $5 a-7$ & $6 / 25 / 2007$ & $8: 47$ & AZ-101, New batch 2 & 30 & 25.04 & 1000 & 1.490 & 0 & PDMS & $\mathrm{NA}$ & NO & 062507_PDMS_30Pa & 1.000 & 6.487 \\
\hline 125 & & $6 / 25 / 2007$ & 9:04 & AZ-101, New batch 2 & 30 & 25.04 & 1200 & 0.149 & 0 & PDMS & NA & NO & 062507_PDMS_30Pa & 0.100 & 2.543 \\
\hline 126 & & $6 / 25 / 2007$ & $9: 19$ & AZ-101, New batch 2 & 30 & 25.04 & 1100 & 0.015 & 0 & PDMS & NA & NO & 062507_PDMS_30Pa & 0.010 & 0.654 \\
\hline 127 & $5 a-7$ & $6 / 25 / 2007$ & 9:43 & AZ-101, New batch 2 & 30 & 25.04 & 1100 & 0.015 & 240 & PDMS & NA & NO & 062507_PDMS_30Pa & 0.010 & 0.202 \\
\hline 128 & & $6 / 25 / 2007$ & 9:56 & AZ-101, New batch 2 & 30 & 25.04 & 1100 & 0.046 & 240 & PDMS & NA & NO & 062507_PDMS_30Pa & 0.031 & 1.316 \\
\hline 129 & & $6 / 25 / 2007$ & 10:06 & AZ-101, New batch 2 & 30 & 25.04 & 1200 & 0.149 & 240 & PDMS & $\mathrm{NA}$ & NO & 062507_PDMS_30Pa & 0.100 & 2.404 \\
\hline 130 & & $6 / 25 / 2007$ & $10: 16$ & AZ-101, New batch 2 & 30 & 25.04 & 1200 & 0.462 & 240 & PDMS & NA & NO & 062507_PDMS_30Pa & 0.310 & 3.923 \\
\hline 131 & & $6 / 25 / 2007$ & $10: 26$ & AZ-101, New batch 2 & 30.635 & 25.33 & 1250 & 1.490 & 240 & PDMS & NA & NO & 062507_PDMS_30Pa & 1.000 & 6.010 \\
\hline 132 & $5 a-8$ & 6/25/2007 & $13: 27$ & AZ-101, New batch 2 & 14.67 & 22.46 & 1100 & 1.490 & 240 & PDMS & NA & NO & 062507_PDMS_13Pa & 1.0 & 6.069 \\
\hline 133 & & $6 / 25 / 2007$ & $13: 43$ & AZ-101, New batch 2 & 15.3 & 22.58 & 1000 & 0.462 & 240 & PDMS & NA & NO & 062507_PDMS_13Pa & 0.31 & 3.819 \\
\hline 134 & & $6 / 25 / 2007$ & 13:57 & AZ-101, New batch 2 & 15.3 & 22.58 & 950 & 0.149 & 240 & PDMS & NA & NO & 062507_PDMS_13Pa & 0.1 & 2.105 \\
\hline 135 & & $6 / 25 / 2007$ & $14: 12$ & AZ-101, New batch 2 & 15.3 & 22.58 & 950 & 0.046 & 240 & PDMS & NA & NO & 062507_PDMS_13Pa & 0.031 & 0.750 \\
\hline 136 & & $6 / 25 / 2007$ & $14: 26$ & AZ-101, New batch 2 & 15.3 & 22.58 & 950 & 0.015 & 240 & PDMS & NA & NO & 062507_PDMS_13Pa & 0.01 & 0.304 \\
\hline 137 & & 6/26/2007 & $8: 25$ & AZ-101, New batch 2 & 15.3 & 22.58 & 1200 & 1.490 & 240 & PDMS & NA & NO & 062507_13Pa_PDMS & 1.00 & 7.728 \\
\hline 138 & & $6 / 26 / 2007$ & $8: 35$ & AZ-101, New batch 2 & 15.3 & 22.58 & 950 & 0.149 & 240 & PDMS & NA & NO & 062507_13Pa_PDMS & 0.10 & 2.423 \\
\hline 139 & & $6 / 26 / 2007$ & $9: 45$ & AZ-101, New batch 2 & 15.94 & 22.69 & 950 & 0.015 & 240 & PDMS & $\mathrm{NA}$ & NO & 062507_13Pa_PDMS & 0.01 & 0.747 \\
\hline 140 & $5 a-9$ & $6 / 26 / 2007$ & $12: 59$ & AZ-101, New batch 2 & 3.9185 & 17.78 & 700 & 0.015 & 245 & PDMS & NA & No & 062607_PDMS_3Pa & 0.01 & 0.528 \\
\hline 141 & & $6 / 26 / 2007$ & 13:11 & AZ-101, New batch 2 & 4 & 17.8 & 700 & 0.046 & 245 & PDMS & NA & NO & 062607_PDMS_3Pa & 0.031 & 1.276 \\
\hline 142 & & $6 / 26 / 2007$ & $13: 23$ & AZ-101, New batch 2 & 4 & 17.8 & 700 & 0.149 & 245 & PDMS & NA & NO & 062607_PDMS_3Pa & 0.1 & 2.472 \\
\hline 143 & & $6 / 26 / 2007$ & 13:35 & AZ-101, New batch 2 & 4 & 17.8 & 800 & 0.462 & 245 & PDMS & NA & NO & 062607_PDMS_3Pa & 0.31 & 7.253 \\
\hline 144 & & $6 / 26 / 2007$ & $13: 49$ & AZ-101, New batch 2 & 4 & 17.8 & 1100 & 1.490 & 245 & PDMS & NA & NO & 062607_PDMS_3Pa & 1 & 12.067 \\
\hline 145 & & $6 / 26 / 2007$ & 14:02 & AZ-101, New batch 2 & 4 & 17.8 & 800 & 0.149 & 245 & PDMS & $\mathrm{NA}$ & NO & 062607_PDMS_3Pa & 0.1 & 2.456 \\
\hline 146 & & $6 / 26 / 2007$ & $14: 14$ & AZ-101, New batch 2 & 4.0855 & 17.80 & 800 & 0.149 & 245 & PDMS & NA & NO & 062607_PDMS_3Pa & 0.1 & 2.446 \\
\hline 147 & & $6 / 27 / 2007$ & $8: 33$ & AZ-101, New batch 2 & 3 & 17.80 & 800 & 0.015 & 245 & PDMS & NA & NO & 062707_PDMS_3Pa & 0.01 & 0.688 \\
\hline 148 & & $6 / 27 / 2007$ & $8: 45$ & AZ-101, New batch 2 & 3.54 & 17.80 & 800 & 0.149 & 245 & PDMS & NA & NO & 062707_PDMS_3Pa & 0.1 & 3.853 \\
\hline 149 & & $6 / 27 / 2007$ & 8:57 & AZ-101, New batch 2 & 3.54 & 17.80 & 1100 & 1.490 & 245 & PDMS & NA & NO & 062707_PDMS_3Pa & 1 & 23.123 \\
\hline 150 & & $6 / 27 / 2007$ & $9: 18$ & AZ-101, New batch 2 & 3.54 & 17.80 & 800 & 0.015 & 490 & PDMS & NA & NO & 062707_PDMS_3Pa & 0.01 & 0.385 \\
\hline 151 & & $6 / 27 / 2007$ & 9:31 & AZ-101, New batch 2 & 3.54 & 17.80 & 800 & 0.046 & 490 & PDMS & NA & NO & 062707_PDMS_3Pa & 0.031 & 1.118 \\
\hline 152 & & $6 / 27 / 2007$ & 9:43 & AZ-101, New batch 2 & 3.54 & 17.80 & 800 & 0.149 & 490 & PDMS & NA & NO & 062707_PDMS_3Pa & 0.1 & 2.622 \\
\hline 153 & & $6 / 27 / 2007$ & 9:55 & AZ-101, New batch 2 & 3.54 & 17.80 & 900 & 0.462 & 490 & PDMS & NA & NO & 062707_PDMS_3Pa & 0.31 & 7.482 \\
\hline 154 & & 6/27/2007 & $10: 07$ & AZ-101, New batch 2 & 4.0855 & 17.83 & 1200 & 1.490 & 490 & PDMS & $\mathrm{NA}$ & NO & 062707_PDMS_3Pa & & 14.634 \\
\hline 155 & $5 b-4$ & $6 / 28 / 2007$ & 10:51 & AZ-101, New batch 2 & 27.41 & 24.64 & 1200 & 1.490 & 0 & AFA 7500 & NA & NO & 062807_7500_30Pa & 1.00 & 7.310 \\
\hline 156 & & $6 / 28 / 2007$ & 11:10 & AZ-101, New batch 2 & 28.4 & 25 & 1300 & 1.490 & 0 & AFA 7500 & NA & NO & 062807_7500_30Pa & 1.00 & 7.463 \\
\hline 157 & & $6 / 28 / 2007$ & $13: 20$ & AZ-101, New batch 2 & 28.4 & 25 & 1200 & 1.490 & 180 & AFA 7500 & NA & No & 062607_7500_30Pa & 1.000 & 3.906 \\
\hline 158 & & $6 / 28 / 2007$ & $13: 36$ & AZ-101, New batch 2 & 28.4 & 25 & 1200 & 0.149 & 180 & AFA 7500 & NA & NO & $062607 \quad 7500 \quad 30 \mathrm{~Pa}$ & 0.100 & 1.320 \\
\hline 159 & & $6 / 28 / 2007$ & $14: 00$ & AZ-101, New batch 2 & 28.4 & 25 & 1150 & 0.015 & 180 & AFA 7500 & NA & NO & 062607_7500_30Pa & 0.010 & 0.302 \\
\hline 160 & & $6 / 28 / 2007$ & $14: 22$ & AZ-101, New batch 2 & 28.4 & 25 & 1150 & 1.490 & 180 & AFA 7500 & NA & NO & 062607_7500_30Pa & 1.00 & 4.408 \\
\hline 161 & & $6 / 28 / 2007$ & $15: 37$ & AZ-101, New batch 2 & 28.4 & 25 & 1250 & 1.490 & 360 & AFA 7500 & NA & NO & 662807_7500_pm2_30P & 1.00 & 5.676 \\
\hline 162 & & $6 / 28 / 2007$ & 15:53 & AZ-101, New batch 2 & 28.4 & 25 & 1150 & 0.149 & 360 & AFA 7500 & NA & No & 662807_7500_pm2_30P & 0.10 & 2.470 \\
\hline 163 & & $6 / 28 / 2007$ & $16: 10$ & AZ-101, New batch 2 & 28.4 & 25 & 1150 & 0.015 & 360 & AFA 7500 & NA & NO & 662807_7500_pm2_30P & 0.01 & 0.931 \\
\hline 164 & & $6 / 29 / 2007$ & $8: 37$ & AZ-101, New batch 2 & 28.4 & 25 & 1150 & 0.015 & 360 & AFA 7500 & NA & NO & 062907_7500_30Pa & 0.01 & 0.976 \\
\hline 165 & & $6 / 29 / 2007$ & $8: 59$ & AZ-101, New batch 2 & 28.4 & 25 & 1150 & 0.046 & 360 & AFA 7500 & NA & No & 062907_7500_30Pa & 0.031 & 1.947 \\
\hline 166 & & $6 / 29 / 2007$ & $9: 16$ & AZ-101, New batch 2 & 28.4 & 25 & 1150 & 0.149 & 360 & AFA 7500 & NA & No & $062907 \_7500 \_30 \mathrm{~Pa}$ & 0.1 & 2.582 \\
\hline 167 & & $6 / 29 / 2007$ & 9:35 & AZ-101, New batch 2 & 28.4 & 25 & 1250 & 0.462 & 360 & AFA 7500 & NA & NO & 062907_7500_30Pa & 0.31 & 3.965 \\
\hline 168 & & $6 / 29 / 2007$ & 9:57 & AZ-101, New batch 2 & 28.4 & 25 & 1250 & 1.490 & 360 & AFA 7500 & NA & NO & 062907_7500_30Pa & 1 & 6.132 \\
\hline 169 & & $6 / 29 / 2007$ & 12:02 & AZ-101, New batch 2 & 28.4 & 25 & 1150 & 0.015 & 540 & AFA 7500 & NA & NO & 062907_7500_30Pa_2 & 0.01 & 1.086 \\
\hline 170 & & $6 / 29 / 2007$ & $12: 24$ & AZ-101, New batch 2 & 28.4 & 25 & 1200 & 0.149 & 540 & AFA 7500 & NA & NO & $062907 \quad 750030 \mathrm{~Pa} \_2$ & 0.10 & 3.085 \\
\hline 171 & & $6 / 29 / 2007$ & 12:44 & AZ-101, New batch 2 & 29.46 & 25.45 & 1250 & 1.490 & 540 & AFA 7500 & NA & NO & 062907_7500_30Pa_2 & 1.00 & 6.164 \\
\hline 172 & $5 b-5$ & $7 / 2 / 2007$ & $12: 00$ & AZ-101, New batch 2 & 14.72 & 22.77 & 850 & 0.015 & 540 & AFA 7500 & NA & NO & 070207_13Pa_7500 & 0.01 & 1.802 \\
\hline 173 & & $7 / 2 / 2007$ & $12: 20$ & AZ-101, New batch 2 & 15.4 & 22.8 & 950 & 0.015 & 540 & AFA 7500 & NA & NO & 070207_13Pa_7500 & 0.01 & 2.111 \\
\hline 174 & & $7 / 2 / 2007$ & $12: 40$ & AZ-101, New batch 2 & 15.4 & 22.8 & 950 & 0.045 & 540 & AFA 7500 & NA & NO & $070207 \_13 \mathrm{~Pa} 7500$ & 0.03 & 3.494 \\
\hline 175 & & $7 / 2 / 2007$ & $13: 00$ & AZ-101, New batch 2 & 15.4 & 22.8 & 950 & 0.149 & 540 & AFA 7500 & NA & NO & 070207_13Pa_7500 & 0.1 & 4.598 \\
\hline 176 & & $7 / 2 / 2007$ & $13: 20$ & AZ-101, New batch 2 & 15.4 & 22.8 & 1100 & 0.462 & 540 & AFA 7500 & NA & No & 070207_13Pa_7500 & 0.31 & 5.983 \\
\hline 177 & & $7 / 2 / 2007$ & $13: 40$ & AZ-101, New batch 2 & 15.4 & 22.8 & 1250 & 1.490 & 540 & AFA 7500 & NA & No & 070207_13Pa_7500 & 1 & 8.714 \\
\hline 178 & & $7 / 2 / 2007$ & $13: 50$ & AZ-101, New batch 2 & 15.4 & 22.8 & 1250 & 1.490 & 540 & AFA 7500 & NA & NO & 070207_13Pa_7500 & 1 & 8.043 \\
\hline 179 & & $7 / 2 / 2007$ & $15: 15$ & AZ-101, New batch 2 & 15.4 & 22.8 & 950 & 0.015 & 720 & AFA 7500 & NA & NO & 070207_13Pa_7500r2 & 0.01 & 0.599 \\
\hline 180 & & $7 / 2 / 2007$ & $15: 35$ & AZ-101, New batch 2 & 15.4 & 22.8 & 1050 & 0.149 & 720 & AFA 7500 & NA & NO & 070207_13Pa_7500r2 & 0.10 & 2.886 \\
\hline 181 & & $7 / 2 / 2007$ & 15:55 & AZ-101, New batch 2 & 15.4 & 22.8 & 1000 & 1.490 & 720 & AFA 7500 & NA & NO & 070207_13Pa_7500r2 & 1.00 & 6.367 \\
\hline 182 & & $7 / 3 / 2007$ & $8: 40$ & AZ-101, New batch 2 & 15.4 & 22.8 & 950 & 0.015 & 720 & AFA 7500 & NA & NO & $070307 \_13 \mathrm{~Pa} \_7500$ & 0.01 & 0.657 \\
\hline 183 & & $7 / 3 / 2007$ & 9:00 & AZ-101, New batch 2 & 15.4 & 22.8 & 1050 & 0.149 & 720 & AFA 7500 & NA & NO & 070307_13Pa_7500 & 0.1 & 3.037 \\
\hline 184 & & $7 / 3 / 2007$ & 9:21 & AZ-101, New batch 2 & 16.135 & 22.82 & 1250 & 1.490 & 720 & AFA 7500 & NA & NO & 070307_13Pa_7500 & 1 & 6.637 \\
\hline 185 & $5 b-6$ & $7 / 3 / 2007$ & 13:24 & AZ-101, New batch 2 & 3.5805 & 17.37 & 700 & 0.015 & 720 & AFA 7500 & NA & No & 070307_3Pa_7500r2 & 0.01 & 0.303 \\
\hline 186 & & $7 / 3 / 2007$ & $13: 45$ & AZ-101, New batch 2 & 3.76 & 17.64 & 700 & 0.046 & 720 & AFA 7500 & NA & NO & 070307 3Pa_7500r2 & 0.031 & 0.629 \\
\hline 187 & & $7 / 3 / 2007$ & 14:04 & AZ-101, New batch 2 & 3.76 & 17.64 & 700 & 0.149 & 720 & AFA 7500 & NA & No & 070307_3Pa_7500r2 & 0.10 & 1.567 \\
\hline 188 & & $7 / 3 / 2007$ & $14: 24$ & AZ-101, New batch 2 & 3.76 & 17.64 & 800 & 0.462 & 720 & AFA 7500 & NA & NO & 070307_3Pa_7500r2 & 0.31 & 3.923 \\
\hline 189 & & $7 / 3 / 2007$ & $14: 44$ & AZ-101, New batch 2 & 3.76 & 17.64 & 1000 & 1.490 & 720 & AFA 7500 & NA & NO & 070307_3Pa_7500r2 & 1 & 9.690 \\
\hline 190 & & $7 / 3 / 2007$ & $15: 35$ & AZ-101, New batch 2 & 3.76 & 17.64 & 750 & 0.015 & 1440 & AFA 7500 & NA & NO & 070307_3Pa_7500r3 & 0.01 & 0.064 \\
\hline 191 & & $7 / 3 / 2007$ & $15: 55$ & AZ-101, New batch 2 & 3.76 & 17.64 & 800 & 0.149 & 1440 & AFA 7500 & NA & No & 070307_3Pa_7500r3 & 0.10 & 2.001 \\
\hline 192 & & $7 / 3 / 2007$ & $16: 14$ & AZ-101, New batch 2 & 3.9365 & 17.91 & 1100 & 1.490 & 1440 & AFA 7500 & NA & NO & 070307_3Pa_7500r3 & 1.00 & 11.072 \\
\hline
\end{tabular}


WSRC-STI-2007-00537, REVISION 0

SRNL-RPP-2007-00023, REVISION 0

This page intentionally left blank. 
WSRC-STI-2007-00537, REVISION 0

SRNL-RPP-2007-00023, REVISION 0

\section{APPENDIX B. SRNL MIXING TEST STAND TEST RESULTS}

Table B-1 SRNL Mixing Test Stand Test Conditions and Results

\begin{tabular}{|c|c|c|c|c|c|c|c|c|c|c|c|c|c|c|c|}
\hline Item \# & Test ID & Date & Time & Simulant & $\begin{array}{c}\text { initial yield } \\
\text { strength, } \\
\mathrm{Pa}\end{array}$ & $\begin{array}{c}\text { initial } \\
\text { wt } \% \text { TS }\end{array}$ & RPM & $\begin{array}{c}\text { Air } \\
\text { sparging } \\
\text { flow rate, } \\
\text { slm }\end{array}$ & $\begin{array}{c}\text { Desired } \\
\text { AntiFoam } \\
\mathrm{mg} / \mathrm{l}\end{array}$ & $\begin{array}{c}\text { Anti Foam } \\
\text { Type }\end{array}$ & $\begin{array}{l}\mathrm{H} 2 \mathrm{O} 2 \\
\mathrm{ml} / \mathrm{sec}\end{array}$ & $\begin{array}{l}\text { Noble } \\
\text { Metals }\end{array}$ & Data file(s) & $\begin{array}{c}\text { Sup Vel, } \\
\mathrm{mm} / \mathrm{s}\end{array}$ & $\begin{array}{c}\text { Gas } \\
\text { Holdup, \% }\end{array}$ \\
\hline 1 & \multirow{8}{*}{$5 c-1$} & $5 / 15 / 2007$ & $13: 47$ & AZ-101, New batch 2 & 24.15 & 23.95 & 880 & 9.056 & 0 & NA & NA & No & GH1330150507 & 0.98144 & 5.702 \\
\hline 2 & & $5 / 15 / 2007$ & $14: 07$ & AZ-101, New batch 2 & 23.5 & 24.2 & 880 & 2.802 & 0 & NA & NA & No & " & 0.303633 & 4.510 \\
\hline 3 & & $5 / 15 / 2007$ & $14: 27$ & AZ-101, New batch 2 & 23.5 & 24.2 & 880 & 0.906 & 0 & NA & NA & No & $"$ & 0.098144 & 2.754 \\
\hline 4 & & $5 / 15 / 2007$ & $14: 48$ & AZ-101, New batch 2 & 23.5 & 24.2 & 880 & 0.280 & 0 & NA & NA & No & $"$ & $1^{*}$ & 1.900 \\
\hline 5 & & $5 / 15 / 2007$ & $15: 13$ & AZ-101, New batch 2 & 23.5 & 24.2 & 880 & 0.091 & 0 & NA & NA & No & $"$ & 0.0098144 & 1.374 \\
\hline 6 & & $5 / 15 / 2007$ & $15: 43$ & AZ-101, New batch 2 & 23.5 & 24.2 & 880 & 9.056 & 0 & NA & NA & No & $"$ & 0.98144 & 5.973 \\
\hline 7 & & $5 / 15 / 2007$ & $16: 10$ & AZ-101, New batch 2 & 23.5 & 24.2 & 880 & 0.091 & 0 & NA & NA & No & $"$ & 0.0098144 & 1.070 \\
\hline 8 & & $5 / 15 / 2007$ & $16: 38$ & AZ-101, New batch 2 & 22.86 & 24.41 & 880 & 0.091 & 0 & NA & NA & No & $"$ & 0.0098144 & 1.130 \\
\hline 9 & \multirow[t]{2}{*}{$5 c-1$} & $5 / 16 / 2007$ & 9:01 & AZ-101, New batch 2 & 22.86 & 24.41 & 950 & 9.056 & 0 & NA & NA & No & GX0850160507 & 0.98144 & 3.283 \\
\hline 10 & & $5 / 16 / 2007$ & 9:15 & AZ-101, New batch 2 & 22.86 & 24.41 & 950 & 0.906 & 0 & NA & NA & No & " & 0.095077 & 0.329 \\
\hline 11 & \multirow{8}{*}{$5 c-2$} & $5 / 16 / 2007$ & $11: 46$ & AZ-101, New batch 2 & 12.26 & 21.81 & 650 & 9.056 & 0 & NA & NA & No & GH1140160507 & 0.98144 & 21.724 \\
\hline 12 & & $5 / 16 / 2007$ & $12: 11$ & AZ-101, New batch 2 & 12.3 & 21.87 & 650 & 2.802 & 0 & NA & NA & No & " & 0.303633 & 15.279 \\
\hline 13 & & $5 / 16 / 2007$ & $12: 32$ & AZ-101, New batch 2 & 12.3 & 21.87 & 650 & 0.906 & 0 & NA & NA & No & $"$ & 0.098144 & 6.512 \\
\hline 14 & & $5 / 16 / 2007$ & $12: 55$ & AZ-101, New batch 2 & 12.3 & 21.87 & 650 & 0.280 & 0 & NA & NA & No & $"$ & 0.0303633 & 3.389 \\
\hline 15 & & $5 / 16 / 2007$ & 13:47 & AZ-101, New batch 2 & 12.3 & 21.87 & 650 & 0.280 & 0 & NA & NA & No & Z1340160507 & 0.0303633 & 2.017 \\
\hline 16 & & $5 / 16 / 2007$ & $14: 25$ & AZ-101, New batch 2 & 12.3 & 21.87 & 650 & 0.091 & 0 & NA & NA & No & $"$ & 0.0098144 & 0.842 \\
\hline 17 & & $5 / 16 / 2007$ & $15: 12$ & AZ-101, New batch 2 & 12.3 & 21.87 & 650 & 9.056 & 0 & NA & NA & No & $"$ & 0.98144 & 18.714 \\
\hline 18 & & $5 / 16 / 2007$ & $15: 37$ & AZ-101, New batch 2 & 12.35 & 21.93 & 650 & 0.091 & 0 & NA & NA & No & $"$ & 0.0098144 & 0.705 \\
\hline 19 & \multirow{5}{*}{$5 c-3$} & $5 / 17 / 2007$ & $9: 36$ & AZ-101, New batch 2 & 2.45 & 16.03 & 525 & 9.056 & 0 & NA & NA & No & GH0910170507 & 0.98144 & NA \\
\hline 20 & & $5 / 17 / 2007$ & $10: 18$ & AZ-101, New batch 2 & 2.5 & 16.02 & 525 & 2.802 & 0 & NA & NA & No & $"$ & 0.303633 & 58.836 \\
\hline 21 & & $5 / 17 / 2007$ & 11:06 & AZ-101, New batch 2 & 2.5 & 16.02 & 525 & 0.906 & 0 & NA & NA & No & $"$ & 0.098144 & 14.316 \\
\hline 22 & & $5 / 17 / 2007$ & $12: 07$ & AZ-101, New batch 2 & 2.5 & 16.02 & 525 & 0.280 & 0 & NA & NA & No & $"$ & 0.0303633 & 6.897 \\
\hline 23 & & $5 / 17 / 2007$ & $13: 26$ & AZ-101, New batch 2 & 2.54 & 16.01 & 525 & 0.091 & 0 & NA & NA & No & $"$ & 0.01 & 4.487 \\
\hline 24 & \multirow{9}{*}{$5 c-7$} & $5 / 18 / 2007$ & $9: 40$ & AZ-101, New batch 2 & 2.54 & 16.01 & 525 & 9.056 & 350 & Q2-3183A & NA & No & GH0930180507 & 0.98144 & 5.732 \\
\hline 25 & & $5 / 18 / 2007$ & $10: 00$ & AZ-101, New batch 2 & 2.54 & 16.01 & 525 & 2.802 & 350 & Q2-3183A & NA & No & $"$ & 0.46005 & 5.061 \\
\hline 26 & & $5 / 18 / 2007$ & $10: 20$ & AZ-101, New batch 2 & 2.54 & 16.01 & 525 & 0.906 & 350 & Q2-3183A & NA & No & $"$ & 0.098144 & 3.420 \\
\hline 27 & & $5 / 18 / 2007$ & $10: 45$ & AZ-101, New batch 2 & 2.54 & 16.01 & 525 & 0.280 & 350 & Q2-3183A & NA & No & $"$ & 0.0303633 & 2.436 \\
\hline 28 & & $5 / 18 / 2007$ & $11: 15$ & AZ-101, New batch 2 & 2.54 & 16.01 & 525 & 0.091 & 350 & Q2-3183A & NA & No & $"$ & 0.0098144 & 1.628 \\
\hline 29 & & $5 / 18 / 2007$ & $12: 02$ & AZ-101, New batch 2 & 2.54 & 16.01 & 525 & 9.056 & 350 & Q2-3183A & NA & No & $"$ & 0.98144 & 9.433 \\
\hline 30 & & $5 / 18 / 2007$ & $12: 36$ & AZ-101, New batch 2 & 2.54 & 16.01 & 525 & 0.906 & 350 & Q2-3183A & NA & No & $"$ & 0.110412 & 3.468 \\
\hline 31 & & $5 / 18 / 2007$ & $13: 10$ & AZ-101, New batch 2 & 2.54 & 16.01 & 525 & 0.280 & 350 & Q2-3183A & NA & No & $"$ & 0.0098144 & 1.173 \\
\hline 32 & & $5 / 18 / 2007$ & $13: 56$ & AZ-101, New batch 2 & 2.55 & 16 & 525 & 9.056 & 350 & Q2-3183A & NA & No & $"$ & \begin{tabular}{|l|}
0.98144 \\
\end{tabular} & 9.220 \\
\hline 33 & \multirow{7}{*}{$5 c-5$} & $5 / 21 / 2007$ & $13: 35$ & AZ-101, New batch 2 & 25.48 & 24.17 & 950 & 9.056 & 350 & Q2-3183A & NA & No & GH1330210507 & 0.98144 & 4.195 \\
\hline 34 & & $5 / 21 / 2007$ & $13: 55$ & AZ-101, New batch 2 & 25.1 & 24.26 & 950 & 2.802 & 350 & Q2-3183A & NA & No & " & 0.303633 & 3.474 \\
\hline 35 & & $5 / 21 / 2007$ & $14: 15$ & AZ-101, New batch 2 & 25.1 & 24.26 & 950 & 0.906 & 350 & Q2-3183A & NA & No & $"$ & 0.098144 & 2.061 \\
\hline 36 & & $5 / 21 / 2007$ & $14: 35$ & AZ-101, New batch 2 & 25.1 & 24.26 & 950 & 0.280 & 350 & Q2-3183A & NA & No & $"$ & 0.0303633 & 1.457 \\
\hline 37 & & $5 / 21 / 2007$ & $15: 00$ & AZ-101, New batch 2 & 25.1 & 24.26 & 950 & 0.091 & 350 & Q2-3183A & NA & No & $"$ & 0.0098144 & 0.876 \\
\hline 38 & & $5 / 21 / 2007$ & $15: 27$ & AZ-101, New batch 2 & 25.1 & 24.26 & 950 & 9.056 & 350 & Q2-3183A & NA & No & $"$ & 0.98144 & 4.231 \\
\hline 39 & & $5 / 21 / 2007$ & $15: 52$ & AZ-101, New batch 2 & 24.77 & 24.35 & 950 & 0.091 & 350 & Q2-3183A & NA & No & $"$ & 0.098144 & 0.826 \\
\hline 40 & \multirow{7}{*}{$5 c-6$} & $5 / 22 / 2007$ & $10: 01$ & AZ-101, New batch 2 & 11.26 & 21.41 & 650 & 9.056 & 350 & Q2-3183A & $\overline{N A}$ & No & GH0966220507 & 0.98144 & 8.820 \\
\hline 41 & & $5 / 22 / 2007$ & $10: 24$ & AZ-101, New batch 2 & 11.34 & 21.45 & 650 & 2.802 & 350 & Q2-3183A & NA & No & " & 0.303633 & 7.285 \\
\hline 42 & & $5 / 22 / 2007$ & $10: 45$ & AZ-101, New batch 2 & 11.34 & 21.45 & 650 & 0.906 & 350 & Q2-3183A & NA & No & $"$ & 0.098144 & 4.304 \\
\hline 43 & & $5 / 22 / 2007$ & $11: 20$ & AZ-101, New batch 2 & 11.34 & 21.45 & 650 & 0.280 & 350 & Q2-3183A & NA & No & $"$ & 0.0303633 & 2.746 \\
\hline 44 & & $5 / 22 / 2007$ & $11: 55$ & AZ-101, New batch 2 & 11.34 & 21.45 & 650 & 0.091 & 350 & Q2-3183A & NA & No & $"$ & 0.0098144 & 1.687 \\
\hline 45 & & $5 / 22 / 2007$ & $12: 29$ & AZ-101, New batch 2 & 11.34 & 21.45 & 650 & 9.056 & 350 & Q2-3183A & NA & No & $"$ & 0.98144 & 8.125 \\
\hline 46 & & $5 / 22 / 2007$ & $12: 56$ & AZ-101, New batch 2 & 11.43 & 21.49 & 650 & 0.091 & 350 & Q2-3183A & NA & No & $"$ & 0.098144 & 1.752 \\
\hline 47 & \multirow{7}{*}{$1 a-4$} & $5 / 23 / 2007$ & 9:58 & AZ-101, New batch 2 & 22.66 & 24.73 & 950 & 9.056 & 0 & NA & NA & Yes & GH1000230507 & 0.9814400 & 2.632 \\
\hline 48 & & $5 / 23 / 2007$ & $10: 18$ & AZ-101, New batch 2 & 22.18 & 25.48 & 950 & 2.802 & 0 & NA & NA & Yes & " & 0.303633 & 1.916 \\
\hline 49 & & $5 / 23 / 2007$ & $10: 38$ & AZ-101, New batch 2 & 22.18 & 25.48 & 950 & 0.906 & 0 & NA & NA & Yes & $"$ & 0.098144 & 0.942 \\
\hline 50 & & $5 / 23 / 2007$ & $10: 58$ & AZ-101, New batch 2 & 22.18 & 25.48 & 950 & 0.280 & 0 & NA & NA & Yes & $"$ & 0.0303633 & 0.547 \\
\hline 51 & & $5 / 23 / 2007$ & $11: 19$ & AZ-101, New batch 2 & 22.18 & 25.48 & 950 & 0.091 & 0 & NA & NA & Yes & $"$ & 0.0098144 & 0.199 \\
\hline 52 & & $5 / 23 / 2007$ & $11: 39$ & AZ-101, New batch 2 & 22.18 & 25.48 & 950 & 9.056 & 0 & NA & NA & Yes & $"$ & 0.98144 & 2.549 \\
\hline 53 & & $5 / 23 / 2007$ & $12: 02$ & AZ-101, New batch 2 & 21.69 & 26.23 & 950 & 0.091 & 0 & NA & NA & Yes & $"$ & \begin{tabular}{|l|}
0.0981440 \\
\end{tabular} & 0.236 \\
\hline
\end{tabular}


WSRC-STI-2007-00537, REVISION 0 SRNL-RPP-2007-00023, REVISION 0

Table B-1 SRNL Mixing Test Stand Test Conditions and Results (Cont'd.)

\begin{tabular}{|c|c|c|c|c|c|c|c|c|c|c|c|c|c|c|c|}
\hline Item \# & Test ID & Date & Time & Simulant & $\begin{array}{c}\text { initial yield } \\
\text { strength, } \\
\mathrm{Pa}\end{array}$ & $\begin{array}{c}\text { initial } \\
\text { wt } \% \text { TS }\end{array}$ & $\begin{array}{c}\mathrm{H} 2 \mathrm{O} 2 \\
\text { density } \\
\mathrm{gm} / \mathrm{ml}\end{array}$ & $\begin{array}{c}\text { Air } \\
\text { sparging } \\
\text { flow rate, } \\
\text { slm } \\
\end{array}$ & $\begin{array}{c}\text { Desired } \\
\text { AntiFoam } \\
\mathrm{mg} / \mathrm{l}\end{array}$ & $\begin{array}{c}\text { Anti Foam } \\
\text { Type }\end{array}$ & \begin{tabular}{|c|}
$\mathrm{H} 2 \mathrm{O} 2$ \\
injection \\
rate \\
$\mathrm{m} / \mathrm{min}$ \\
\end{tabular} & $\begin{array}{l}\text { Noble } \\
\text { Metals }\end{array}$ & Data file(s) & $\begin{array}{c}\text { Sup Vel, } \\
\mathrm{mm} / \mathrm{s}\end{array}$ & $\begin{array}{c}\text { Gas } \\
\text { Holdup, \% }\end{array}$ \\
\hline 54 & \multirow{7}{*}{$1 \mathrm{a}-7$} & $5 / 23 / 2007$ & 13:29 & AZ-101, New batch 2 & 20.85 & 24.59 & 950 & 9.056 & 350 & Q2-3183A & $\mathrm{NA}$ & Yes & GH1320230507 & 0.98144 & 3.081 \\
\hline 55 & & $5 / 23 / 2007$ & $13: 49$ & AZ-101, New batch 2 & 21 & 24.69 & 950 & 2.802 & 350 & Q2-3183A & NA & Yes & $"$ & 0.303633 & 2.568 \\
\hline 56 & & $5 / 23 / 2007$ & $14: 09$ & AZ-101, New batch 2 & 21 & 24.69 & 950 & 0.906 & 350 & Q2-3183A & NA & Yes & $"$ & 0.098144 & 1.614 \\
\hline 57 & & $5 / 23 / 2007$ & $14: 29$ & AZ-101, New batch 2 & 21 & 24.69 & 950 & 0.280 & 350 & Q2-3183A & NA & Yes & $"$ & 0.0303633 & 1.123 \\
\hline 58 & & $5 / 23 / 2007$ & $14: 50$ & AZ-101, New batch 2 & 21 & 24.69 & 950 & 0.091 & 350 & Q2-3183A & NA & Yes & $"$ & 0.0098144 & 0.758 \\
\hline 59 & & $5 / 23 / 2007$ & $15: 10$ & AZ-101, New batch 2 & 21 & 24.69 & 950 & 9.056 & 350 & Q2-3183A & NA & Yes & $"$ & 0.98144 & 3.624 \\
\hline 60 & & $5 / 23 / 2007$ & $15: 30$ & AZ-101, New batch 2 & 21.09 & 24.8 & 950 & 0.091 & 350 & Q2-3183A & NA & Yes & $"$ & 0.098144 & 0.746 \\
\hline 61 & \multirow{7}{*}{$1 \mathrm{a}-8$} & $5 / 24 / 2007$ & $9: 23$ & AZ-101, New batch 2 & 12.33 & 22.65 & 650 & 9.056 & 350 & Q2-3183A & NA & Yes & GH0915240507 & 0.98144 & 5.114 \\
\hline 62 & & $5 / 24 / 2007$ & $9: 44$ & AZ-101, New batch 2 & 12.31 & 22.63 & 650 & 2.802 & 350 & Q2-3183A & NA & Yes & $"$ & 0.303633 & 4.140 \\
\hline 63 & & $5 / 24 / 2007$ & $10: 04$ & AZ-101, New batch 2 & 12.31 & 22.63 & 650 & 0.906 & 350 & Q2-3183A & NA & Yes & $"$ & 0.098144 & 2.617 \\
\hline 64 & & $5 / 24 / 2007$ & $10: 24$ & AZ-101, New batch 2 & 12.31 & 22.63 & 650 & 0.280 & 350 & Q2-3183A & NA & Yes & $"$ & 0.0303633 & 1.830 \\
\hline 65 & & $5 / 24 / 2007$ & $10: 48$ & AZ-101, New batch 2 & 12.31 & 22.63 & 650 & 0.091 & 350 & Q2-3183A & NA & Yes & $"$ & 0.0098144 & 1.229 \\
\hline 66 & & $5 / 24 / 2007$ & 11:14 & AZ-101, New batch 2 & 12.31 & 22.63 & 650 & 9.056 & 350 & Q2-3183A & NA & Yes & $"$ & 0.98144 & 5.187 \\
\hline 67 & & $5 / 24 / 2007$ & $11: 42$ & AZ-101, New batch 2 & 12.29 & 22.62 & 650 & 0.091 & 350 & Q2-3183A & NA & Yes & $"$ & 0.098144 & 1.287 \\
\hline 68 & \multirow{7}{*}{$1 a-9$} & $5 / 24 / 2007$ & $14: 11$ & AZ-101, New batch 2 & 2.63 & 17.01 & 525 & 9.056 & 350 & Q2-3183A & NA & Yes & GH1410240507 & 0.98144 & 7.281 \\
\hline 69 & & $5 / 24 / 2007$ & 14:31 & AZ-101, New batch 2 & 2.63 & 16.98 & 525 & 2.802 & 350 & Q2-3183A & NA & Yes & $"$ & 0.303633 & 5.445 \\
\hline 70 & & $5 / 24 / 2007$ & $14: 51$ & AZ-101, New batch 2 & 2.63 & 16.98 & 525 & 0.906 & 350 & Q2-3183A & NA & Yes & $"$ & 0.098144 & 2.794 \\
\hline 71 & & $5 / 24 / 2007$ & $15: 11$ & AZ-101, New batch 2 & 2.63 & 16.98 & 525 & 0.280 & 350 & Q2-3183A & NA & Yes & $"$ & 0.0303633 & 1.743 \\
\hline 72 & & $5 / 24 / 2007$ & 15:36 & AZ-101, New batch 2 & 2.63 & 16.98 & 525 & 0.091 & 350 & Q2-3183A & NA & Yes & $"$ & 0.0098144 & 1.107 \\
\hline 73 & & $5 / 24 / 2007$ & 16:01 & AZ-101, New batch 2 & 2.63 & 16.98 & 525 & 9.056 & 350 & Q2-3183A & NA & Yes & $"$ & 0.98144 & 7.733 \\
\hline 74 & & $5 / 24 / 2007$ & $16: 25$ & AZ-101, New batch 2 & 2.63 & 16.94 & 525 & 0.091 & 350 & Q2-3183A & NA & Yes & $"$ & 0.098144 & 0.909 \\
\hline 78 & \multirow{3}{*}{$1 c-4$} & $6 / 26 / 2007$ & \begin{tabular}{l|l}
$15: 25$ \\
\end{tabular} & AZ-101, New batch 2 & 18.94 & 23.12 & 1.1124 & 56.600 & 350 & \begin{tabular}{|l|} 
Q2-3183A \\
\end{tabular} & 1.97 & No & GH1510062607 & 0.0293 & 1.529 \\
\hline 81 & & $6 / 28 / 2007$ & 10:50:05 & AZ-101, New batch 2 & 15.965 & 22.73 & & 169.800 & 350 & \begin{tabular}{|l|} 
Q2-3183A \\
\end{tabular} & 6.16 & No & GH1040062807 & 0.091521 & 3.333 \\
\hline 82 & & $6 / 29 / 2007$ & \begin{tabular}{|l|}
$11: 50$ \\
\end{tabular} & AZ-101, New batch 2 & 15.255 & 22.76 & 1.1126 & 452.800 & 350 & Q2-3183A & 16.8 & No & GH1115062907 & 0.249584 & 5.582 \\
\hline 83 & \multirow{4}{*}{$1 c-5$} & $7 / 3 / 2007$ & $9: 55$ & AZ-101, New batch 2 & 10.98 & 21.35 & 1.11261 & 56.600 & 350 & \begin{tabular}{|l|} 
Q2-3183A \\
\end{tabular} & 2.41 & No & GH0935070307 & \begin{tabular}{|l|}
0.035815 \\
\end{tabular} & 1.988 \\
\hline 84 & & $7 / 3 / 2007$ & $13: 43$ & AZ-101, New batch 2 & 10.895 & 21.53 & " & 169.800 & 350 & \begin{tabular}{|l|} 
Q2-3183A \\
\end{tabular} & 6.44 & No & GH1330070307 & \begin{tabular}{|l|}
0.095701 \\
\end{tabular} & 3.771 \\
\hline 85 & & $7 / 10 / 2007$ & $14: 43$ & AZ-101, New batch 2 & 10.395 & 21.41 & 1.11221 & 452.800 & 350 & \begin{tabular}{|l|} 
Q2-3183A \\
\end{tabular} & 18.14 & No & GH1415071007 & 0.269438 & 1.238 \\
\hline 86 & & $7 / 11 / 2007$ & $10: 43$ & AZ-101, New batch 2 & 10.745 & 21.37 & " & 169.800 & 350 & Q2-3183A & 6.58 & No & GH1022071107 & 0.097738 & 2.944 \\
\hline 87 & & $7 / 12 / 2007$ & $9: 55$ & AZ-101, New batch 2 & 3.993 & 17.78 & $"$ & 56.600 & 350 & \begin{tabular}{|l|} 
Q2-3183A \\
\end{tabular} & 2.04 & No & GH0920071207 & \begin{tabular}{|l|}
0.302412 \\
\end{tabular} & 1.539 \\
\hline 88 & $1 c-6$ & $7 / 12 / 2007$ & $15: 00$ & AZ-101, New batch 2 & 3.9955 & 17.81 & $"$ & 169.800 & 350 & \begin{tabular}{|l|} 
Q2-3183A \\
\end{tabular} & 6.2 & No & GH1445071207 & 0.092099 & 6.453 \\
\hline 89 & & $7 / 13 / 2007$ & $9: 47$ & AZ-101, New batch 2 & 3.9065 & 17.76 & " & 452.800 & 350 & \begin{tabular}{|l|} 
Q2-3183A \\
\end{tabular} & 17.16 & No & GH0920071307 & \begin{tabular}{|l|}
0.254873 \\
\end{tabular} & 10.896 \\
\hline 90 & & $7 / 16 / 2007$ & $10: 39$ & AZ-101, New batch 2 & 3.682 & 17.55 & 1.11223 & 113.200 & 350 & \begin{tabular}{|l|} 
Q2-3183A \\
\end{tabular} & 4.14 & No & GH1020071607 & 0.061543 & 3.769 \\
\hline 91 & & $7 / 18 / 2007$ & $10: 12$ & AZ-101, New batch 2 & 25.4 & 24.42 & 947 & 9.056 & 2000 & 1520 & NA & No & GH1000071807 & 0.9814 & 3.183 \\
\hline 92 & & $7 / 18 / 2007$ & $10: 43$ & AZ-101, New batch 2 & 25.16 & 24.48 & 947 & 2.802 & 2000 & 1520 & $\mathrm{NA}$ & No & " & 0.4601 & 2.636 \\
\hline 93 & & $7 / 18 / 2007$ & $11: 03$ & AZ-101, New batch 2 & 25.16 & 24.48 & 947 & 0.906 & 2000 & 1520 & $\mathrm{NA}$ & No & 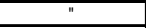 & 0.0981 & 1.721 \\
\hline 94 & $5 c-12$ & $7 / 18 / 2007$ & $11: 25$ & AZ-101, New batch 2 & 25.16 & 24.48 & 947 & 0.280 & 2000 & 1520 & NA & No & $"$ & 0.0304 & 1.337 \\
\hline 95 & & $7 / 18 / 2007$ & 11:51 & AZ-101, New batch 2 & 25.16 & 24.48 & 947 & 0.091 & 2000 & 1520 & $\mathrm{NA}$ & No & $"$ & 0.0098 & 1.266 \\
\hline 96 & & $7 / 18 / 2007$ & $12: 17$ & AZ-101, New batch 2 & 25.16 & 24.48 & 947 & 9.056 & 2000 & 1520 & $\mathrm{NA}$ & No & 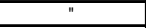 & 0.9814 & 3.962 \\
\hline 97 & & $7 / 18 / 2007$ & $12: 48$ & AZ-101, New batch 2 & 24.93 & 24.53 & 947 & 0.091 & 2000 & 1520 & NA & No & " & 0.0098 & 1.359 \\
\hline 98 & & $7 / 19 / 2007$ & $9: 03$ & AZ-101, New batch 2 & 12.23 & 21.85 & 650 & 9.056 & 2000 & 1520 & $\mathrm{NA}$ & No & GH0855071907 & 0.9814 & 4.335 \\
\hline 99 & & $7 / 19 / 2007$ & $9: 25$ & AZ-101, New batch 2 & 12.18 & 21.82 & 650 & 2.802 & 2000 & 1520 & NA & No & " & 0.4601 & 3.655 \\
\hline 100 & & $7 / 19 / 2007$ & $9: 46$ & AZ-101, New batch 2 & 12.18 & 21.82 & 650 & 0.906 & 2000 & 1520 & $\mathrm{NA}$ & No & $"$ & 0.0981 & 2.679 \\
\hline 101 & $5 c-13$ & $7 / 19 / 2007$ & $10: 13$ & AZ-101, New batch 2 & 12.18 & 21.82 & 650 & 0.280 & 2000 & 1520 & $\mathrm{NA}$ & No & " & 0.0859 & 2.350 \\
\hline 102 & & $7 / 19 / 2007$ & $10: 46$ & AZ-101, New batch 2 & 12.18 & 21.82 & 650 & 0.091 & 2000 & 1520 & NA & No & $"$ & 0.0098 & 1.933 \\
\hline 103 & & $7 / 19 / 2007$ & $11: 11$ & AZ-101, New batch 2 & 12.18 & 21.82 & 650 & 9.056 & 2000 & 1520 & NA & No & $"$ & 0.9814 & 5.875 \\
\hline 104 & & $7 / 19 / 2007$ & $11: 57$ & AZ-101, New batch 2 & 12.14 & 21.8 & 650 & 0.091 & 2000 & 1520 & $\mathrm{NA}$ & No & $"$ & 0.0098 & 2.107 \\
\hline 105 & & $7 / 19 / 2007$ & $14: 13$ & AZ-101, New batch 2 & 3.34 & 17.08 & 524 & 9.056 & 2000 & 1520 & $\mathrm{NA}$ & No & GH1504071907 & 0.9814 & 22.968 \\
\hline 106 & & $7 / 19 / 2007$ & $14: 46$ & AZ-101, New batch 2 & 3.3 & 17.05 & 524 & 2.802 & 2000 & 1520 & NA & No & " & 0.4601 & 19.818 \\
\hline 127 & & $7 / 19 / 2007$ & $15: 05$ & AZ-101, New batch 2 & 3.3 & 17.05 & 524 & 0.906 & 2000 & 1520 & $\mathrm{NA}$ & No & $"$ & 0.0981 & 2.062 \\
\hline 128 & $5 c-14$ & $7 / 19 / 2007$ & $15: 22$ & AZ-101, New batch 2 & 3.3 & 17.05 & 524 & 0.280 & 2000 & 1520 & NA & No & " & 0.0304 & 1.546 \\
\hline 129 & & $7 / 19 / 2007$ & $15: 43$ & AZ-101, New batch 2 & 3.3 & 17.05 & 524 & 0.091 & 2000 & 1520 & $\mathrm{NA}$ & No & $"$ & 0.0098 & 1.731 \\
\hline 130 & & $7 / 19 / 2007$ & $16: 11$ & AZ-101, New batch 2 & 3.3 & 17.05 & 524 & 9.056 & 2000 & 1520 & $\mathrm{NA}$ & No & $"$ & 0.9814 & 21.959 \\
\hline 131 & & $7 / 19 / 2007$ & $16: 35$ & AZ-101, New batch 2 & 3.26 & 17.01 & 524 & 0.091 & 2000 & 1520 & $\mathrm{NA}$ & No & $"$ & 0.0098 & 2.241 \\
\hline 132 & & $7 / 30 / 2007$ & $13: 16$ & AZ-101, New batch 2 & 3.27 & 17.00 & 525 & 9.056 & 3000 & 1520 & $\mathrm{NA}$ & No & GH1310073007 & 0.9814 & 5.669 \\
\hline 133 & & $7 / 30 / 2007$ & 13:36 & AZ-101, New batch 2 & 3.17 & 17.03 & 525 & 2.802 & 3000 & 1520 & NA & No & " & 0.4601 & 3.142 \\
\hline 134 & & $7 / 30 / 2007$ & 13:56 & AZ-101, New batch 2 & 3.17 & 17.03 & 525 & 0.906 & 3000 & 1520 & $\mathrm{NA}$ & No & $"$ & 0.0981 & 1.093 \\
\hline 135 & $5 c-14$ & $7 / 30 / 2007$ & $14: 16$ & AZ-101, New batch 2 & 3.17 & 17.03 & 525 & 0.280 & 3000 & 1520 & NA & No & $"$ & 0.0304 & 0.549 \\
\hline 136 & & $7 / 30 / 2007$ & $14: 38$ & AZ-101, New batch 2 & 3.17 & 17.03 & 525 & 0.091 & 3000 & 1520 & NA & No & $"$ & 0.0098 & 0.204 \\
\hline 137 & & $7 / 30 / 2007$ & 15:08 & AZ-101, New batch 2 & 3.17 & 17.03 & 525 & 9.056 & 3000 & 1520 & $\mathrm{NA}$ & No & $"$ & 0.9814 & 12.892 \\
\hline 138 & & $7 / 30 / 2007$ & $15: 30$ & AZ-101, New batch 2 & 3.07 & 17.06 & 525 & 0.091 & 3000 & 1520 & NA & No & " & 0.0098 & 0.158 \\
\hline 139 & & $7 / 31 / 2007$ & $9: 41$ & AZ-101, New batch 2 & 3.12 & 16.94 & 525 & 9.056 & 5000 & 1520 & $\mathrm{NA}$ & No & GH0925073107 & 0.9814 & 6.316 \\
\hline 140 & $5 c-14$ & $7 / 31 / 2007$ & 10:01 & AZ-101, New batch 2 & 3.12 & 17 & 525 & 2.802 & 5000 & 1520 & $\mathrm{NA}$ & No & " & 0.4601 & 3.543 \\
\hline 141 & & $7 / 31 / 2007$ & $10: 21$ & AZ-101, New batch 2 & 3.12 & 17 & 525 & 0.906 & 5000 & 1520 & $\mathrm{NA}$ & No & $"$ & 0.0304 & 0.477 \\
\hline 142 & & $7 / 31 / 2007$ & 10:55 & AZ-101, New batch 2 & 3.11 & 17.07 & 525 & 0.280 & 5000 & 1520 & NA & No & " & 0.0098 & 0.133 \\
\hline 143 & & $8 / 1 / 2007$ & $9: 20$ & AZ-101, New batch 2 & 2.34 & 16.59 & 525 & 9.056 & 350 & Q2-3183A & NA & Yes & GH0905080107 & 0.9814 & 10.697 \\
\hline 144 & & $8 / 1 / 2007$ & $9: 40$ & AZ-101, New batch 2 & 2.33 & 16.6 & 525 & 2.802 & 350 & \begin{tabular}{|l|} 
Q2-3183A \\
\end{tabular} & $\mathrm{NA}$ & Yes & " & 0.4601 & 7.264 \\
\hline 145 & & $8 / 1 / 2007$ & $10: 00$ & AZ-101, New batch 2 & 2.33 & 16.6 & 525 & 0.906 & 350 & \begin{tabular}{|l|} 
Q2-3183A \\
\end{tabular} & $\mathrm{NA}$ & Yes & " & 0.0981 & 3.595 \\
\hline 146 & $1 a-9$ & $8 / 1 / 2007$ & $10: 25$ & AZ-101, New batch 2 & 2.33 & 16.6 & 525 & 0.280 & 350 & \begin{tabular}{|l|} 
Q2-3183A \\
\end{tabular} & $\mathrm{NA}$ & Yes & $"$ & 0.0304 & 1.933 \\
\hline 147 & & $8 / 1 / 2007$ & $11: 00$ & AZ-101, New batch 2 & 2.33 & 16.6 & 525 & 0.091 & 350 & Q2-3183A & $\mathrm{NA}$ & Yes & $"$ & 0.0098 & 0.609 \\
\hline 148 & & $8 / 1 / 2007$ & $11: 33$ & AZ-101, New batch 2 & 2.33 & 16.6 & 525 & 9.056 & 350 & \begin{tabular}{|l|} 
Q2-3183A \\
\end{tabular} & $\mathrm{NA}$ & Yes & $"$ & 0.9814 & 8.888 \\
\hline 149 & & $8 / 1 / 2007$ & 11:57 & AZ-101, New batch 2 & 2.32 & 16.61 & 525 & 0.091 & 350 & \begin{tabular}{|l|} 
Q2-3183A \\
\end{tabular} & $\mathrm{NA}$ & Yes & " & 0.0098 & 0.364 \\
\hline
\end{tabular}


WSRC-STI-2007-00537, REVISION 0 SRNL-RPP-2007-00023, REVISION 0

Table B-1 SRNL Mixing Test Stand Test Conditions and Results (Cont'd.)

\begin{tabular}{|c|c|c|c|c|c|c|c|c|c|c|c|c|c|c|c|}
\hline Item \# & Test ID & Date & Time & Simulant & $\begin{array}{c}\text { initial yield } \\
\text { strength, } \\
\mathrm{Pa}\end{array}$ & $\begin{array}{c}\text { initial } \\
\text { wt } \% \text { TS }\end{array}$ & RPM & $\begin{array}{c}\text { Air } \\
\text { sparging } \\
\text { flow rate, } \\
\text { slm } \\
\end{array}$ & $\begin{array}{c}\text { Desired } \\
\text { AntiFoam } \\
\mathrm{mg} / \mathrm{l}\end{array}$ & $\begin{array}{c}\text { Anti Foam } \\
\text { Type }\end{array}$ & \begin{tabular}{|c|}
$\mathrm{H} 2 \mathrm{O} 2$ \\
injection \\
rate \\
$\mathrm{ml} / \mathrm{min}$ \\
\end{tabular} & $\begin{array}{l}\text { Noble } \\
\text { Metals }\end{array}$ & Data file(s) & $\begin{array}{c}\text { Sup Vel, } \\
\mathrm{mm} / \mathrm{s}\end{array}$ & $\begin{array}{c}\text { Gas } \\
\text { Holdup, \% }\end{array}$ \\
\hline 150 & \multirow{7}{*}{$1 a-9$} & $8 / 2 / 2007$ & $9: 5: 53$ & AZ-101, New batch 2 & 2.32 & $\begin{array}{ll}16.6 \\
\end{array}$ & 525 & 9.056 & 2525 & Q2-3183A & NA & Yes & GH0940080207 & $\begin{array}{l}0.9814 \\
\end{array}$ & $\begin{array}{ll}6.741 \\
\end{array}$ \\
\hline 151 & & $8 / 2 / 2007$ & $10: 13$ & AZ-101, New batch 2 & 2.33 & 16.61 & 525 & 2.802 & 525 & Q2-3183A & NA & Yes & " & 0.4601 & 5.395 \\
\hline 152 & & $8 / 2 / 2007$ & $10: 43$ & AZ-101, New batch 2 & 2.33 & 16.61 & 525 & 0.906 & 525 & Q2-3183A & NA & Yes & $"$ & 0.0981 & 2.818 \\
\hline 154 & & $8 / 2 / 2007$ & $10: 57$ & AZ-101, New batch 2 & 2.33 & 16.61 & 525 & 0.280 & 525 & Q2-3183A & $\mathrm{NA}$ & Yes & $"$ & 0.0859 & 1.713 \\
\hline 155 & & $8 / 2 / 2007$ & $11: 27$ & AZ-101, New batch 2 & 2.33 & 16.61 & 525 & 0.091 & 525 & Q2-3183A & NA & Yes & $"$ & 0.0098 & 0.867 \\
\hline 156 & & $8 / 2 / 2007$ & $11: 58$ & AZ-101, New batch 2 & 2.33 & 16.61 & 525 & 0.091 & 525 & Q2-3183A & NA & Yes & $"$ & 0.0098 & 0.710 \\
\hline 157 & & $8 / 2 / 2007$ & $13: 03$ & AZ-101, New batch 2 & 2.34 & 16.62 & 525 & 9.056 & 525 & Q2-3183A & $\mathrm{NA}$ & Yes & 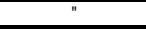 & 0.9814 & 7.238 \\
\hline 158 & \multirow{4}{*}{$1 a-8$} & $8 / 22 / 2007$ & $10: 57$ & AZ-101, New batch 2 & 8.65 & 22.39 & 650 & 9.056 & 625 & Q2-3183A & $\mathrm{NA}$ & Yes & GH1045082207 & 0.98144 & 7.140 \\
\hline 159 & & $8 / 22 / 2007$ & 11:17 & AZ-101, New batch 2 & 8.7 & 22.37 & 650 & 2.802 & 625 & Q2-3183A & $\mathrm{NA}$ & Yes & " & 0.46005 & 5.622 \\
\hline 160 & & $8 / 22 / 2007$ & $11: 37$ & AZ-101, New batch 2 & 8.7 & 22.37 & 650 & 0.906 & 625 & Q2-3183A & $\mathrm{NA}$ & Yes & $"$ & $\begin{array}{l}0.098144 \\
\end{array}$ & 3.204 \\
\hline 161 & & $8 / 22 / 2007$ & $12: 00$ & AZ-101, New batch 2 & 8.75 & 22.36 & 650 & 0.280 & 625 & Q2-3183A & NA & Yes & $"$ & 0.0303633 & 1.892 \\
\hline 162 & \multirow{7}{*}{$1 a-8$} & $8 / 22 / 2007$ & $13: 48$ & AZ-101, New batch 2 & 8.75 & 22.36 & 650 & 9.056 & 625 & \begin{tabular}{|l|} 
Q2-3183A \\
\end{tabular} & $\mathrm{NA}$ & Yes & GH1335082207 & \begin{tabular}{|l|}
0.98144 \\
\end{tabular} & 5.139 \\
\hline 163 & & $8 / 22 / 2007$ & $14: 08$ & AZ-101, New batch 2 & 8.67 & 22.45 & 650 & 2.802 & 625 & Q2-3183A & NA & Yes & " & 0.46005 & 4.246 \\
\hline 164 & & $8 / 22 / 2007$ & $14: 29$ & AZ-101, New batch 2 & 8.67 & 22.45 & 650 & 0.906 & 625 & Q2-3183A & NA & Yes & $"$ & $\begin{array}{l}0.098144 \\
\end{array}$ & 2.550 \\
\hline 165 & & $8 / 22 / 2007$ & $14: 49$ & AZ-101, New batch 2 & 8.67 & 22.45 & 650 & 0.280 & 625 & Q2-3183A & $\mathrm{NA}$ & Yes & $"$ & \begin{tabular}{|l|}
0.0303633 \\
\end{tabular} & 1.261 \\
\hline 166 & & $8 / 22 / 2007$ & $15: 19$ & AZ-101, New batch 2 & 8.67 & 22.45 & 650 & 0.091 & 625 & Q2-3183A & $\mathrm{NA}$ & Yes & $"$ & \begin{tabular}{|l|}
0.01 \\
\end{tabular} & 0.770 \\
\hline 167 & & $8 / 22 / 2007$ & $16: 00$ & AZ-101, New batch 2 & 8.67 & 22.45 & 650 & 0.091 & 625 & \begin{tabular}{|l|} 
Q2-3183A \\
\end{tabular} & NA & Yes & $"$ & 0.01 & 0.652 \\
\hline 168 & & $8 / 22 / 2007$ & $16: 40$ & AZ-101, New batch 2 & 8.59 & 22.47 & 650 & 9.056 & 625 & Q2-3183A & $\mathrm{NA}$ & Yes & $"$ & 0.98144 & 5.969 \\
\hline
\end{tabular}


WSRC-STI-2007-00537, REVISION 0

SRNL-RPP-2007-00023, REVISION 0

This page intentionally left blank. 
WSRC-STI-2007-00537, REVISION 0

SRNL-RPP-2007-00023, REVISION 0

\section{APPENDIX C. MASS TRANSFER TEST RAW DATA}


APPENDIX C. MASS TRANSFER TEST RAW DATA

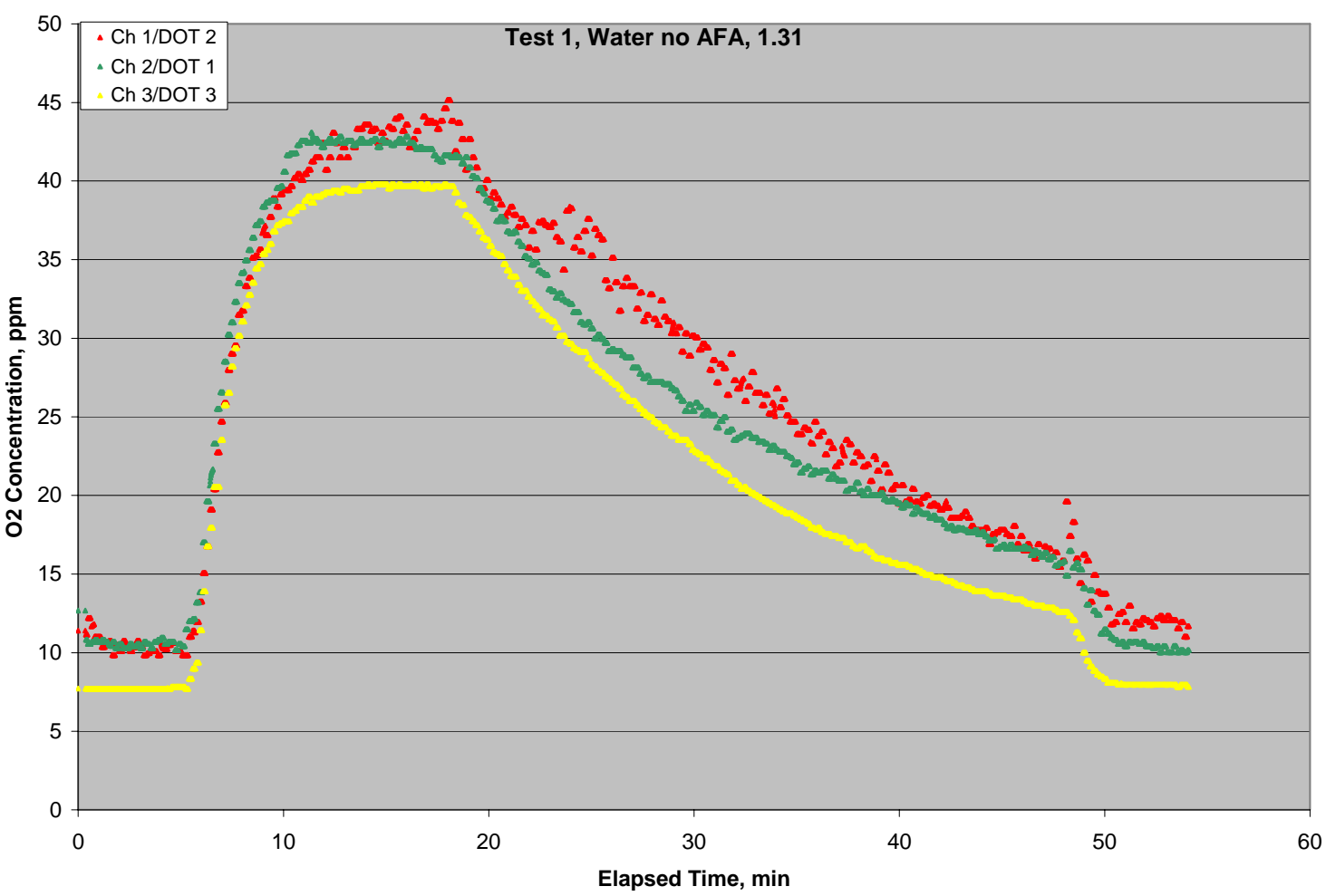

Figure -Test 1 Dissolved Oxygen Concentrations

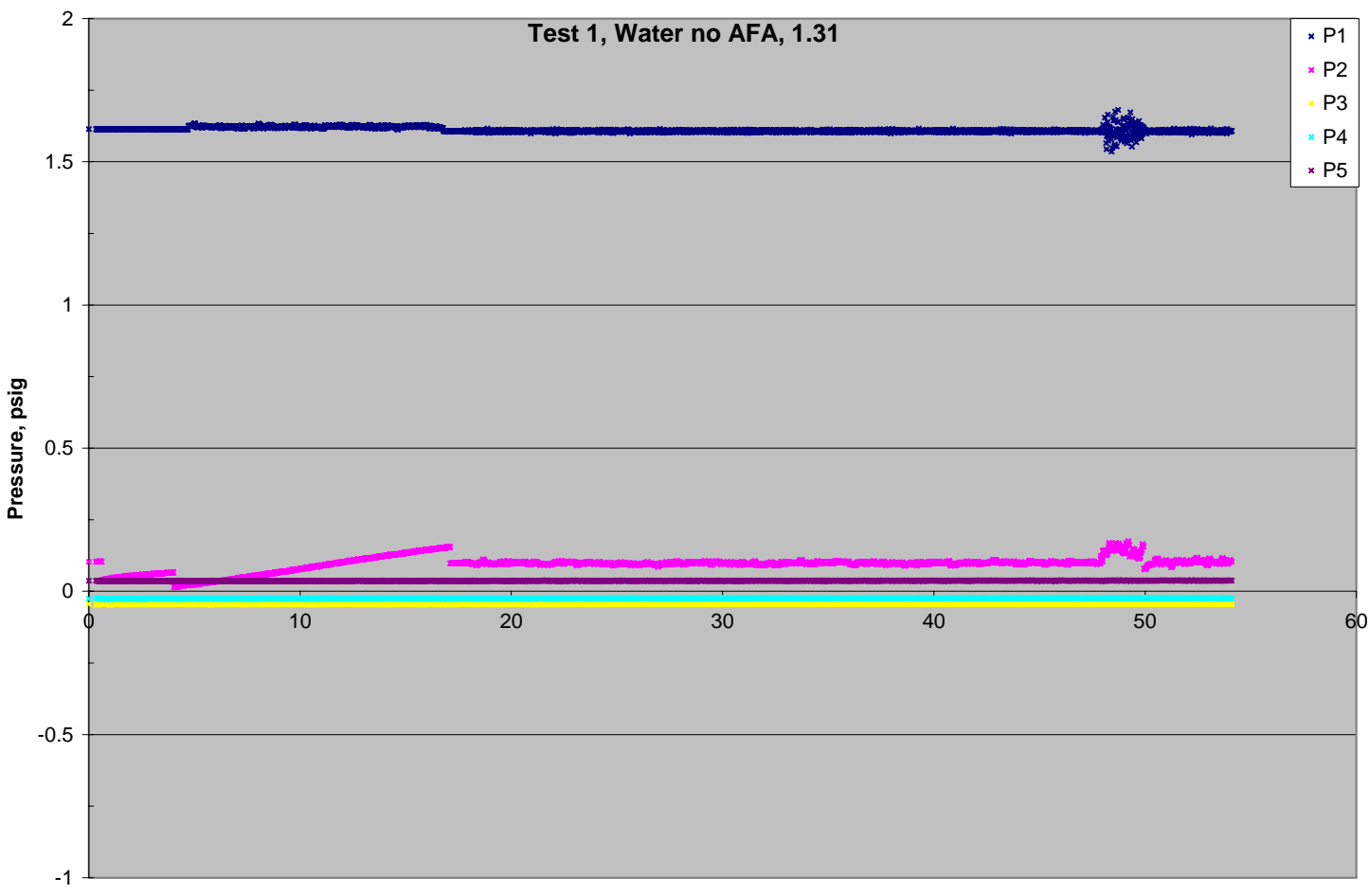

Elapsed Time, $\min$

Figure -Test 1 Pressure Transducer Measurements 


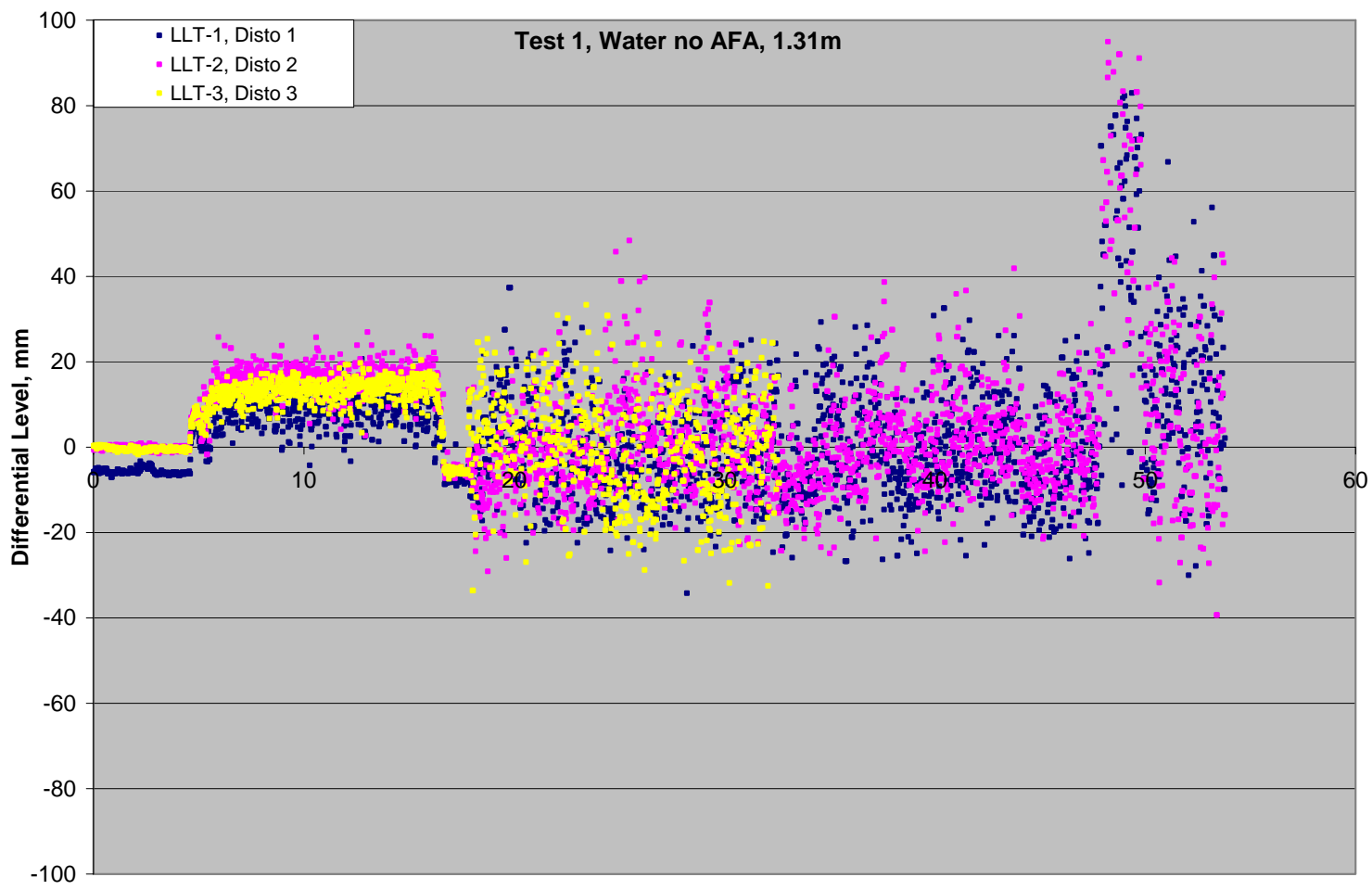

Elapsed Time, $\min$

Figure -Test 1 Differential Laser Measurements

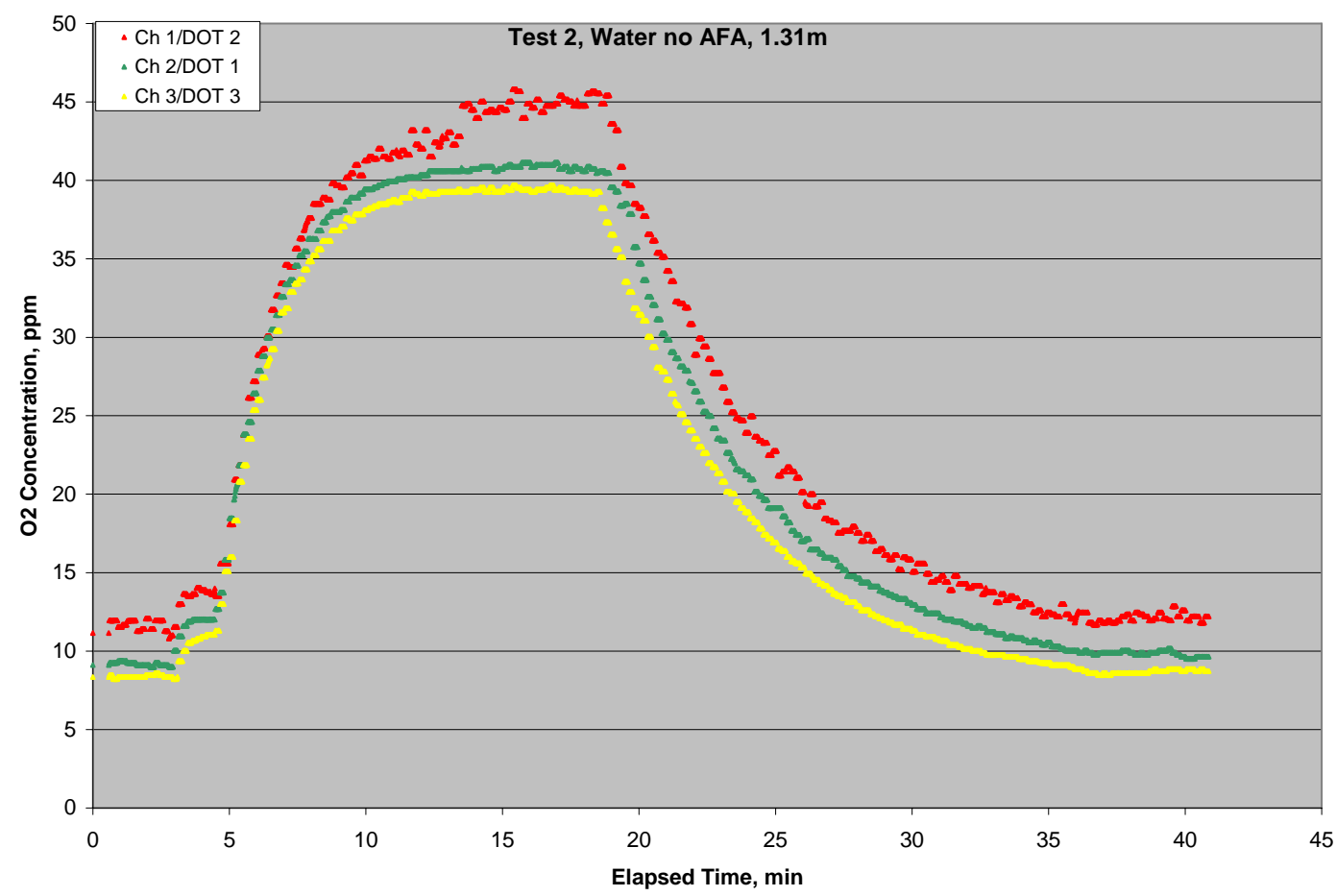

Figure Test 2 Dissolved Oxygen Concentrations 


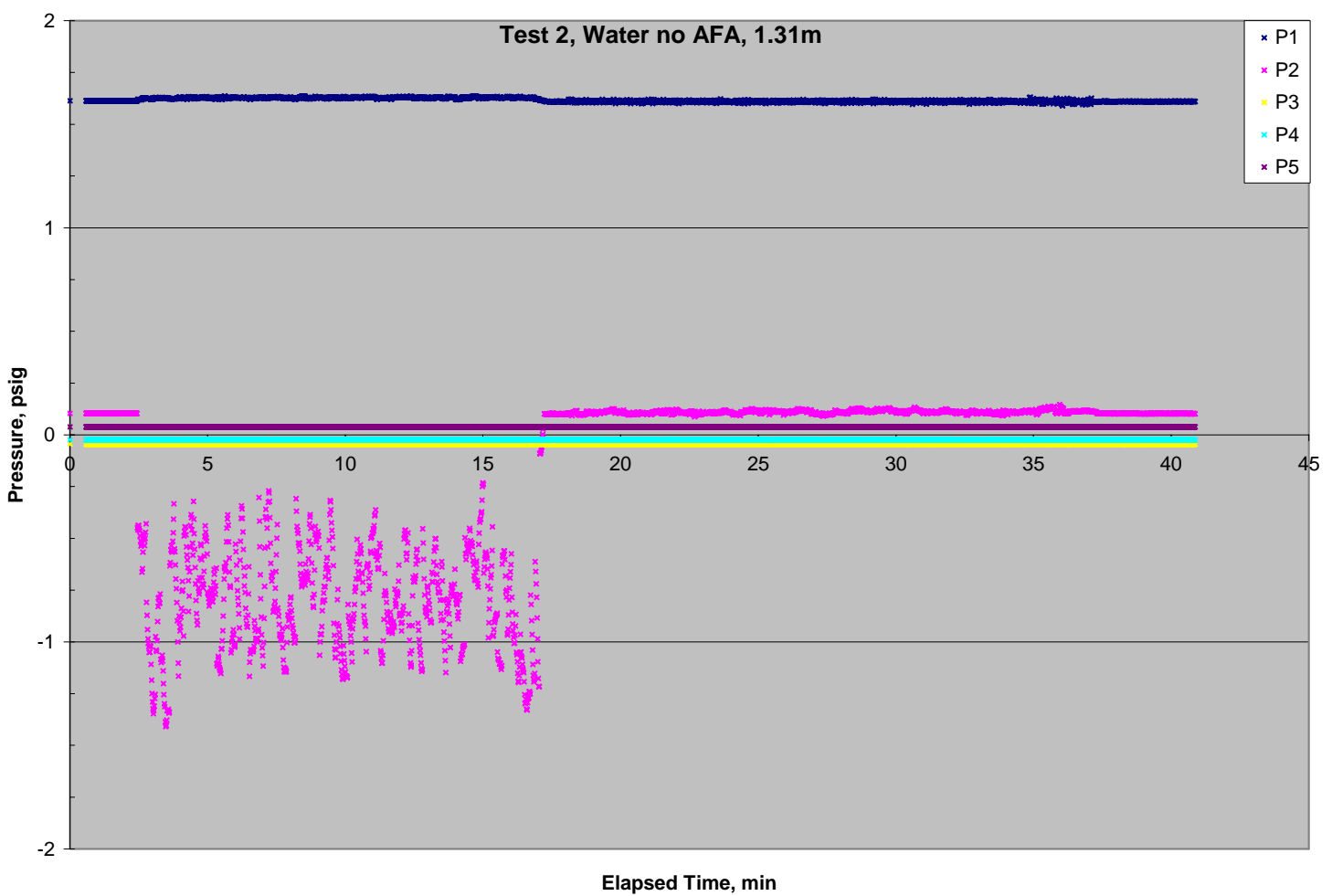

Figure Test 2 Pressure Transducer Measurements

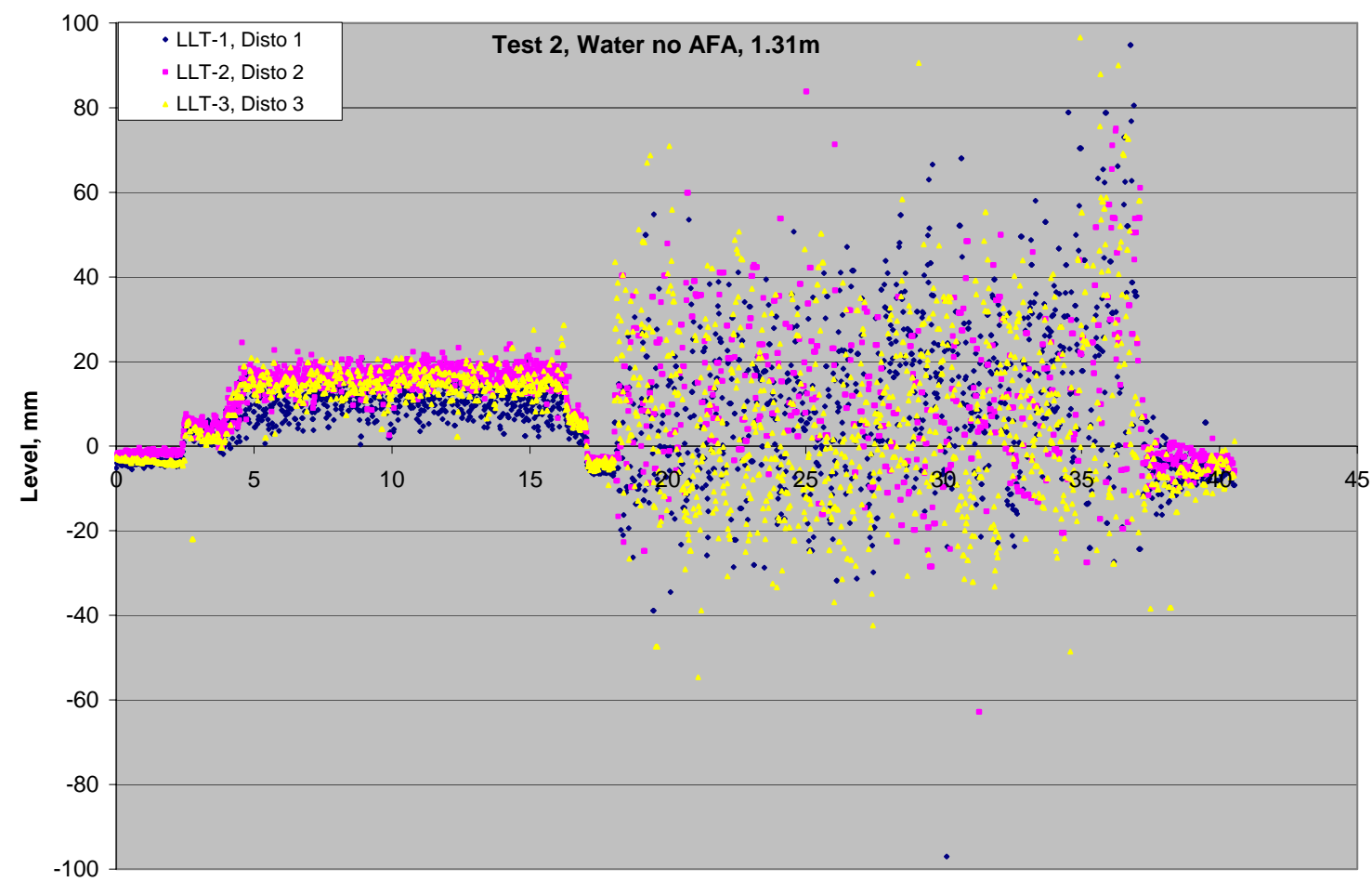

Elapsed Time, min

Figure Test 2 Differential Laser Measurements 


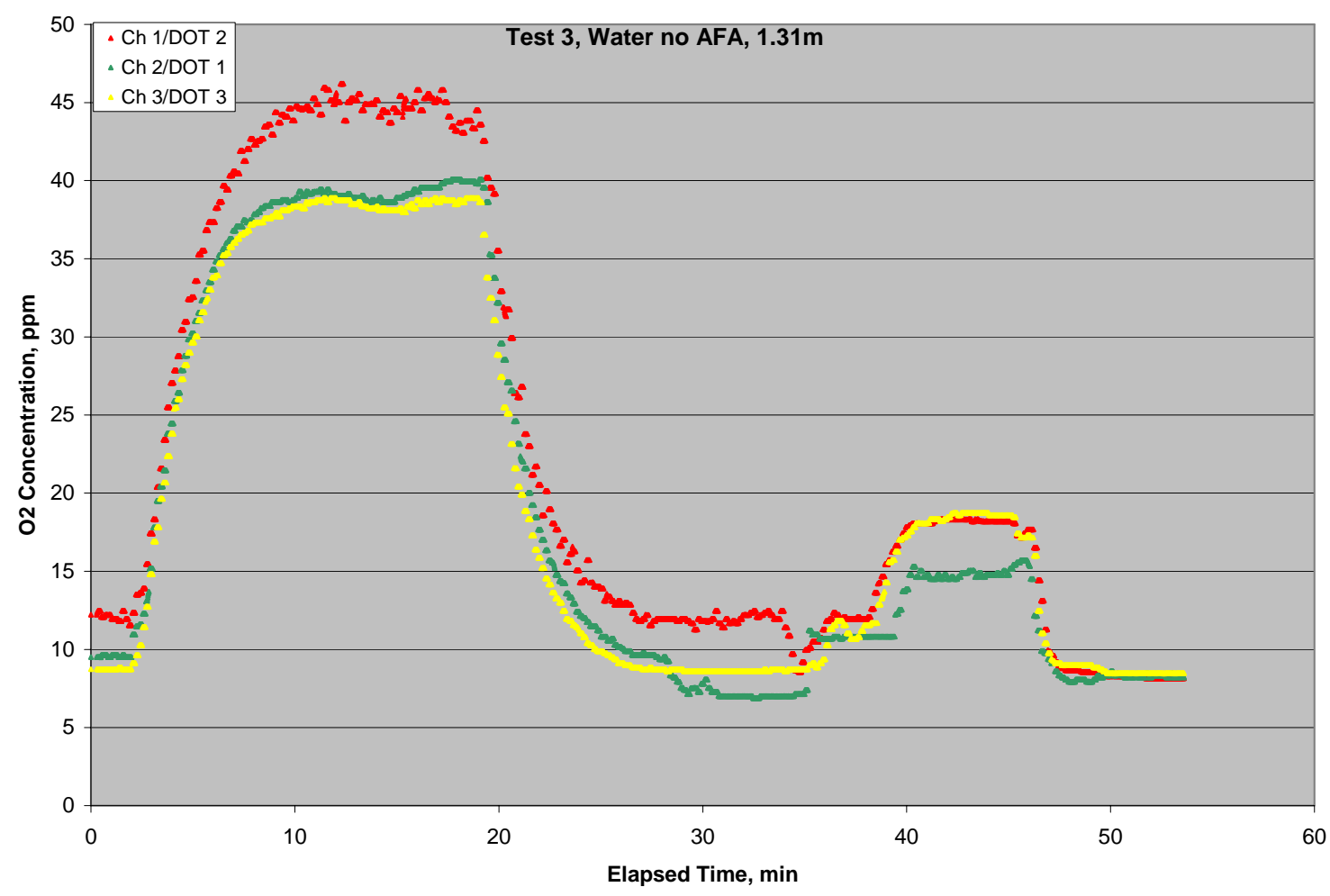

Figure Test 3 Dissolved Oxygen 


\section{Concentrations}

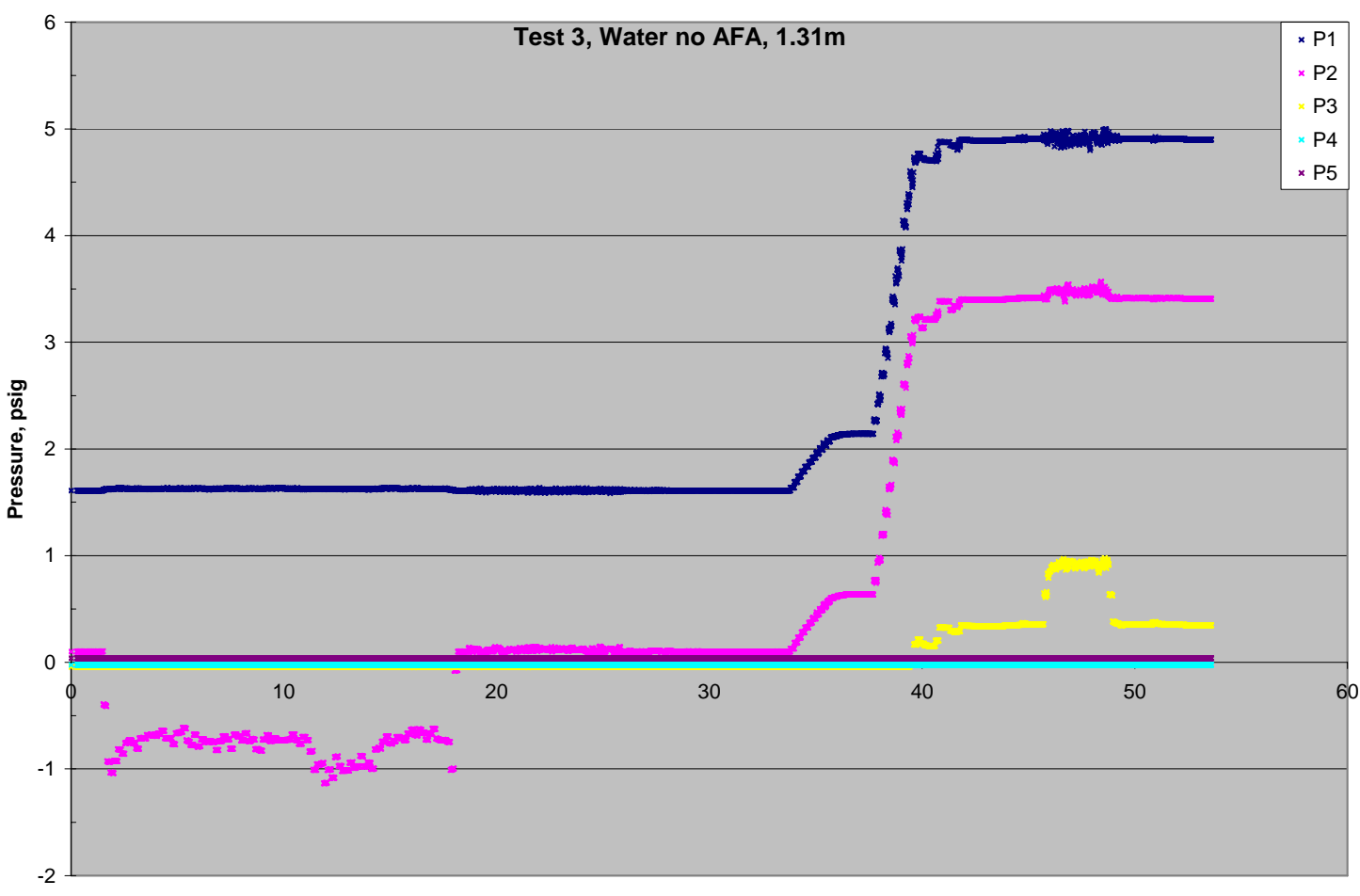

Elapsed Time, $\min$

Figure -Test 3 Pressure Transducer Measurements

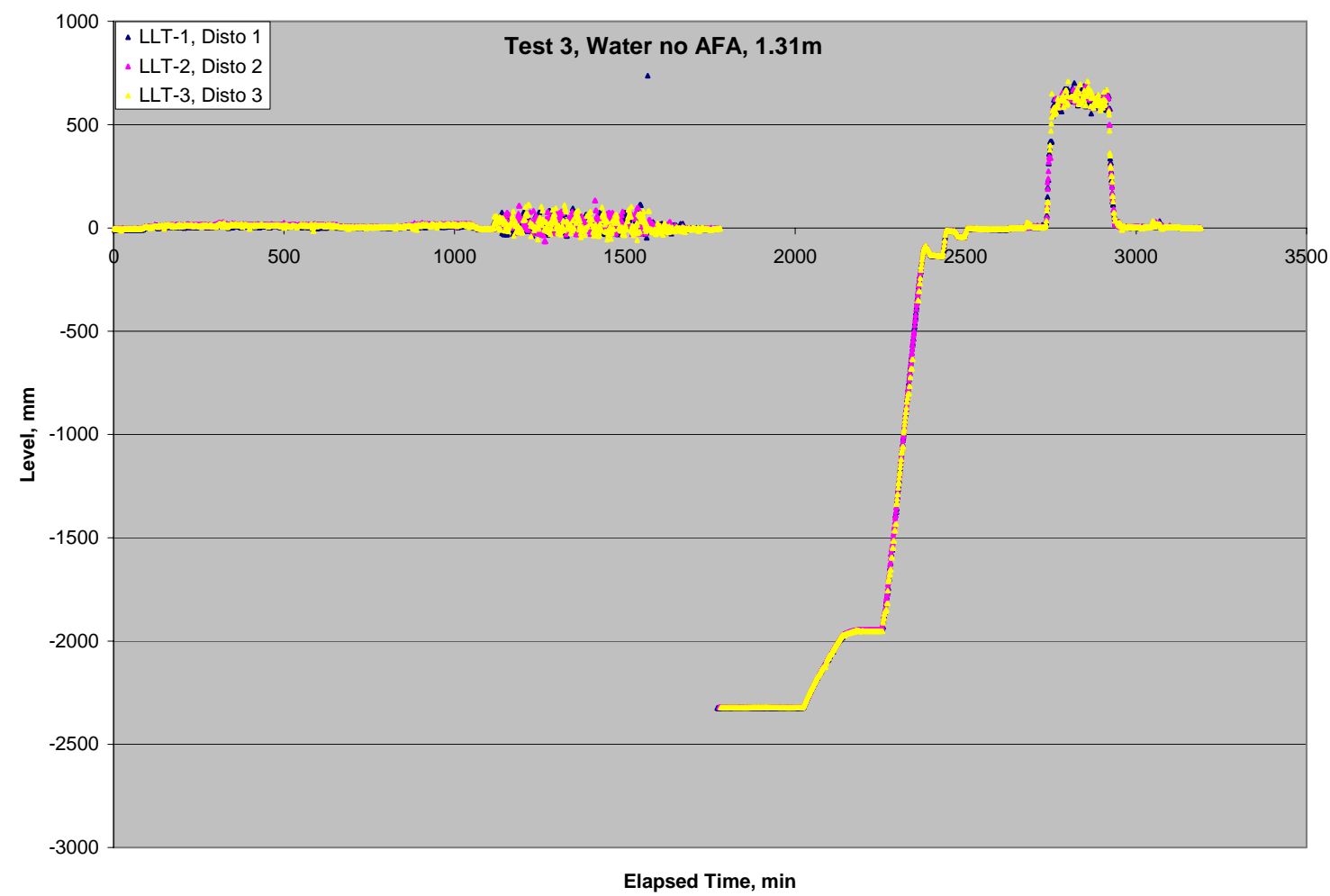

Figure -Test 3 Differential Laser Measurements 


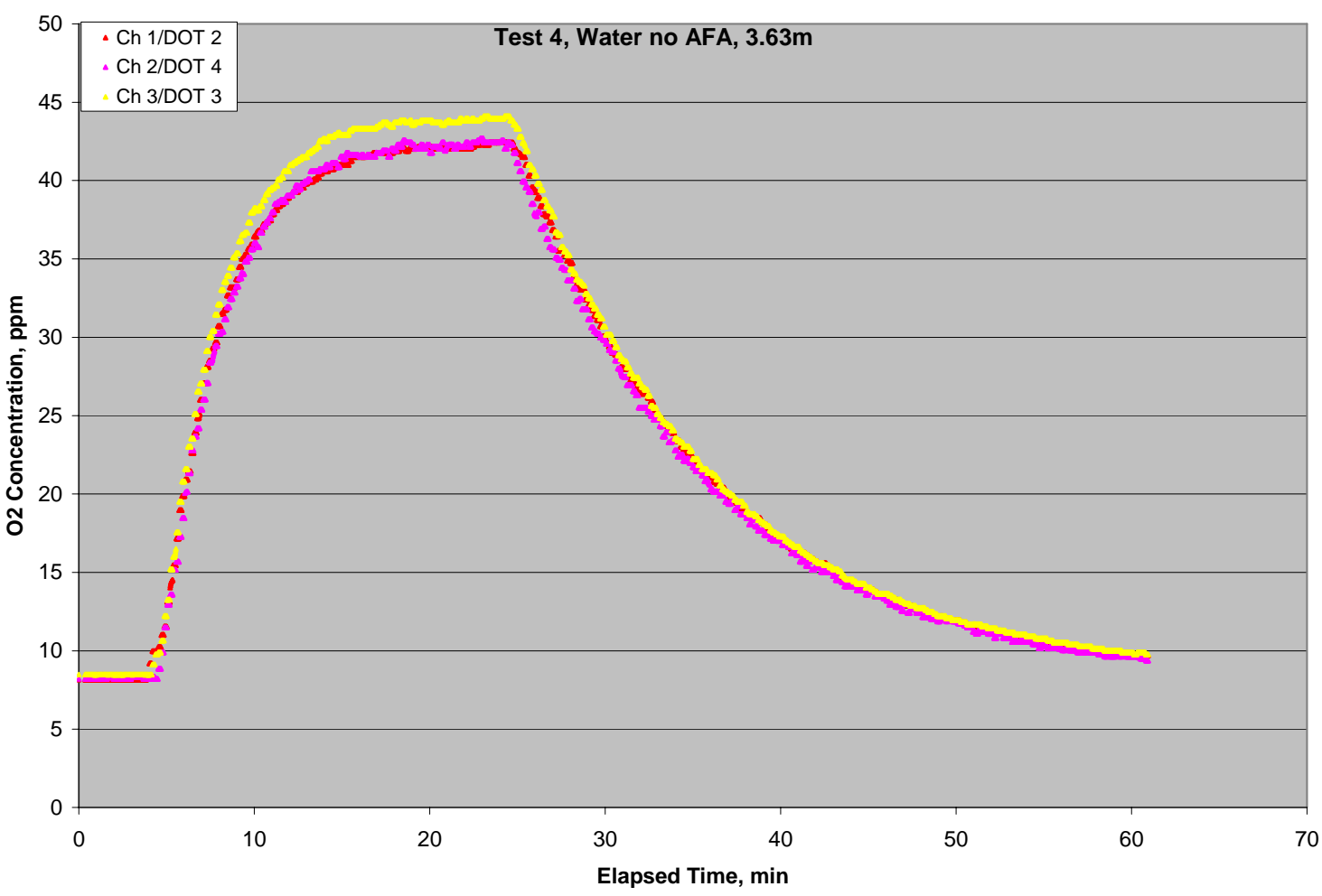

Figure -Test 4 Dissolved Oxygen Concentrations

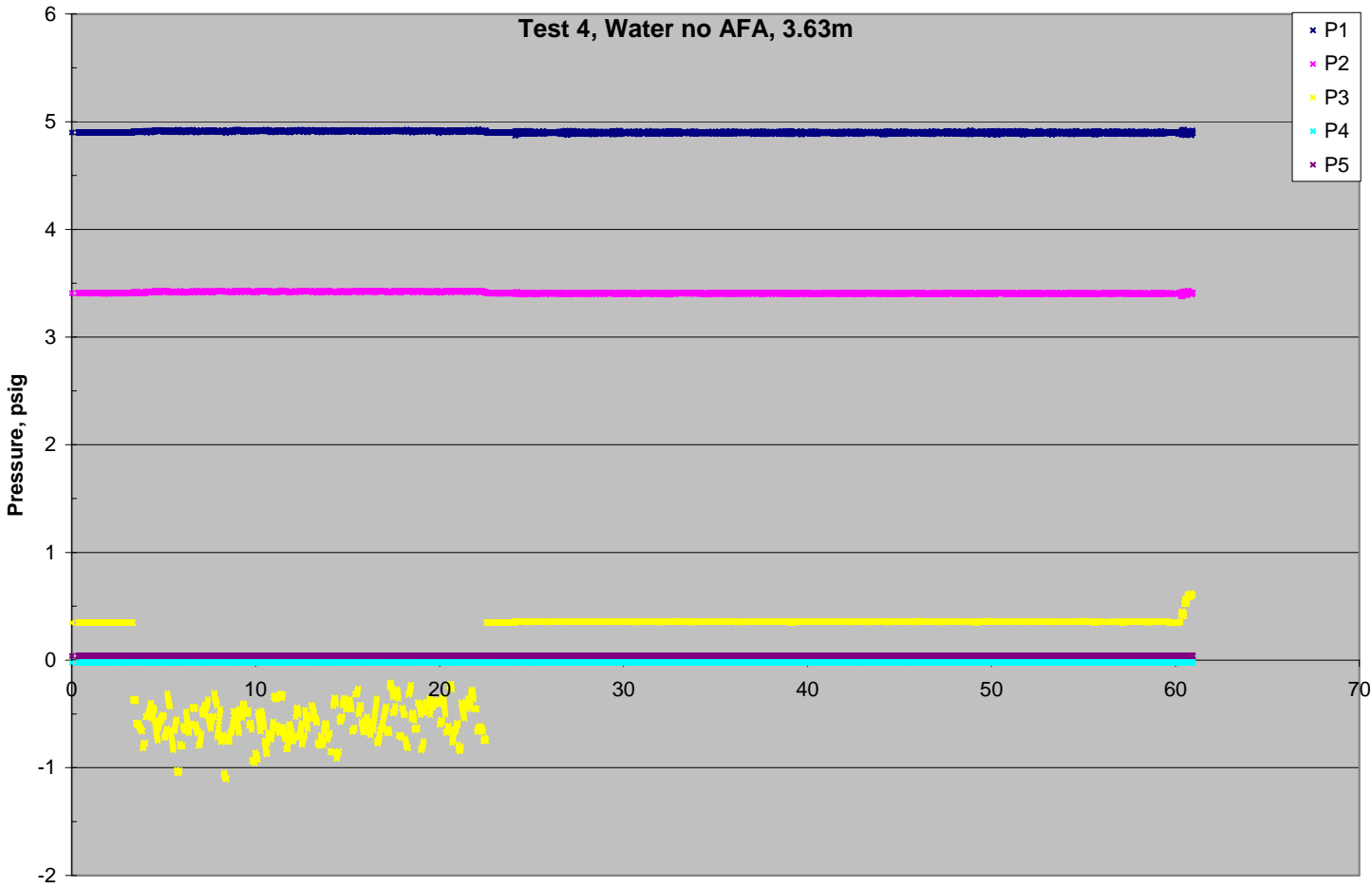

Elapsed Time, $\min$

Figure Test 4 Pressure Transducer Measurements 


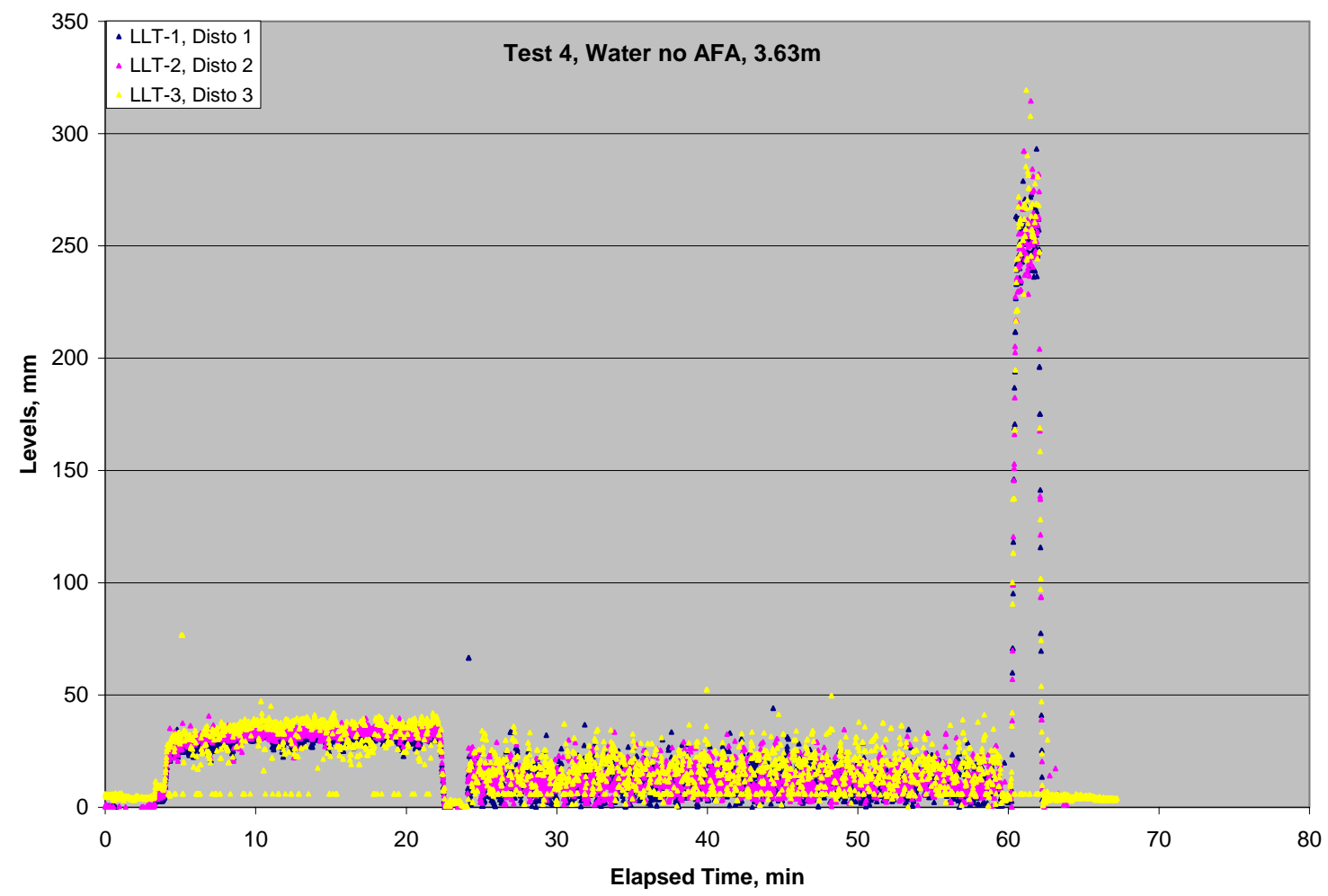

Figure Test 4 Differential Laser Measurements

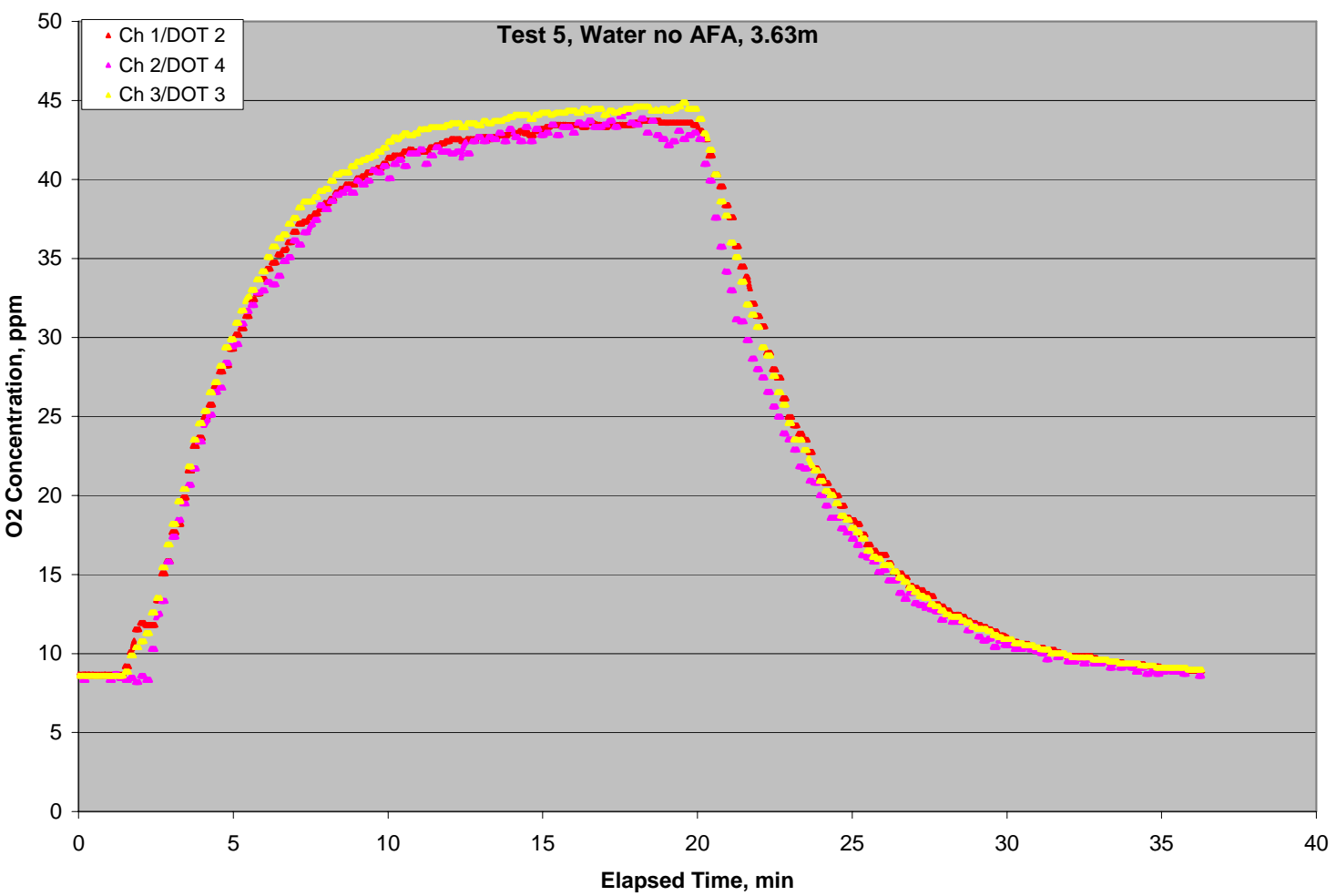

Figure Test 5 Dissolved Oxygen Concentrations 


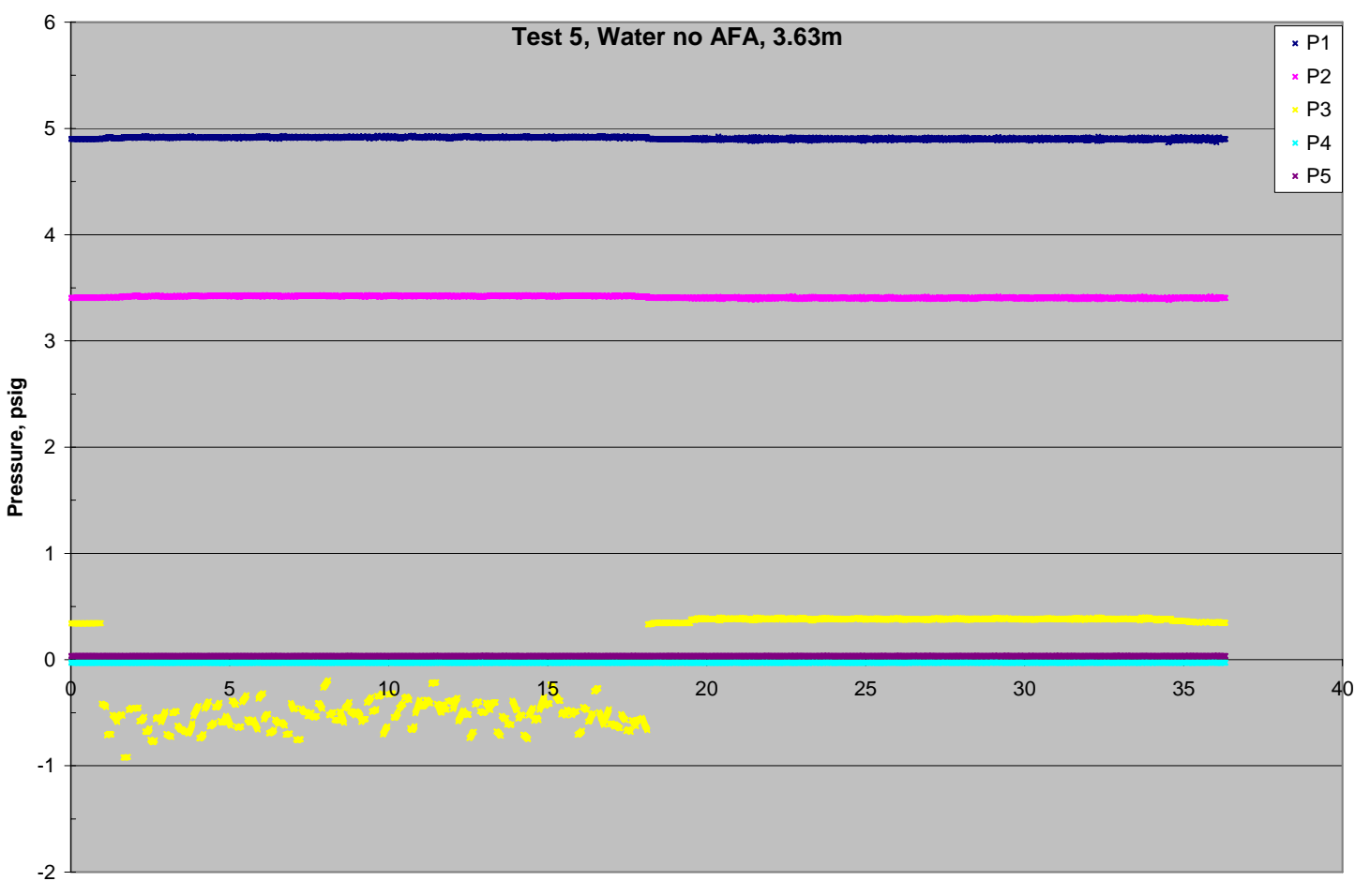

Elapsed Time, min

Figure Test 5 Pressure Transducer Measurements

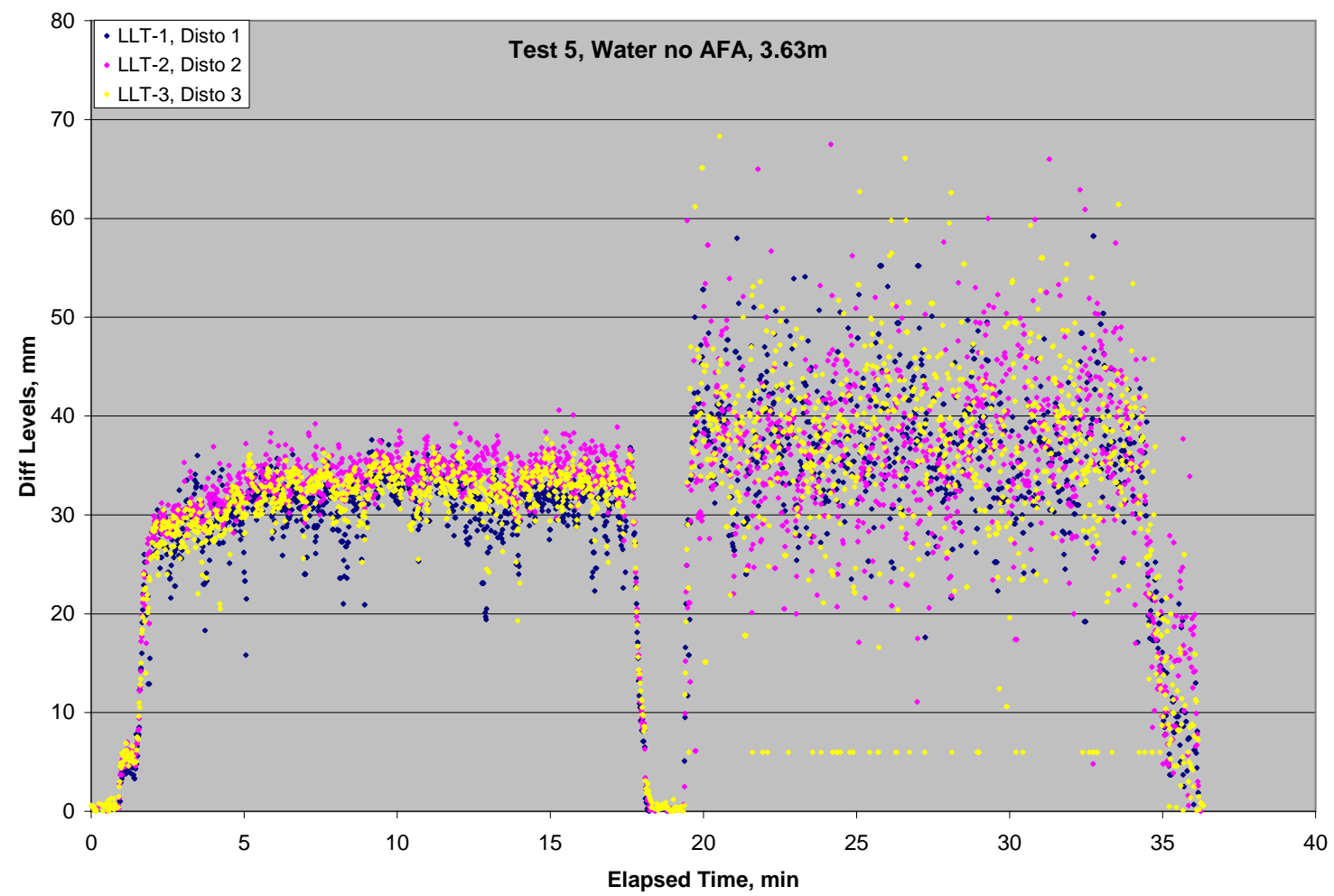

Figure Test 5 Differential Laser Measurements 


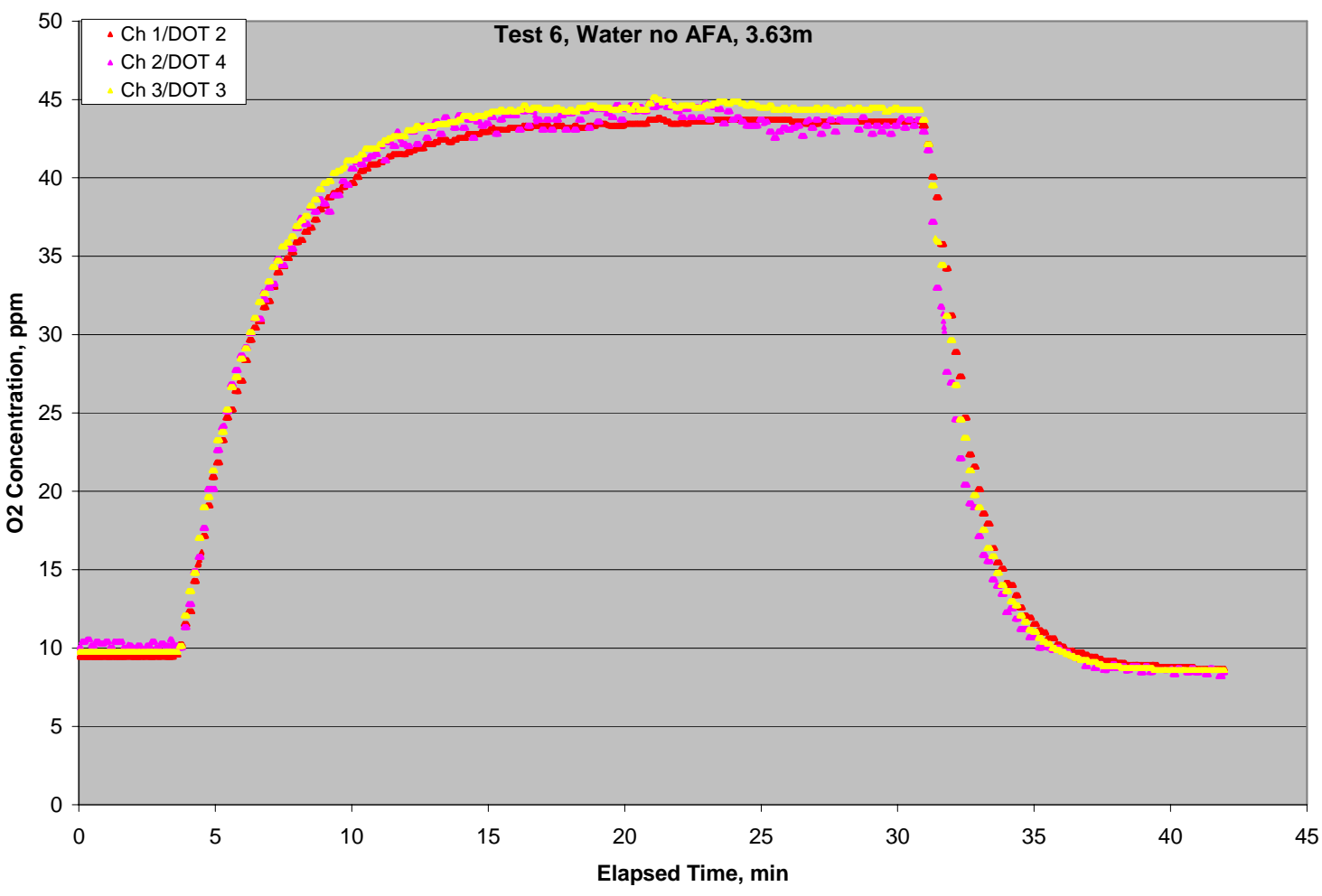

Figure Test 6 Dissolved Oxygen Concentrations

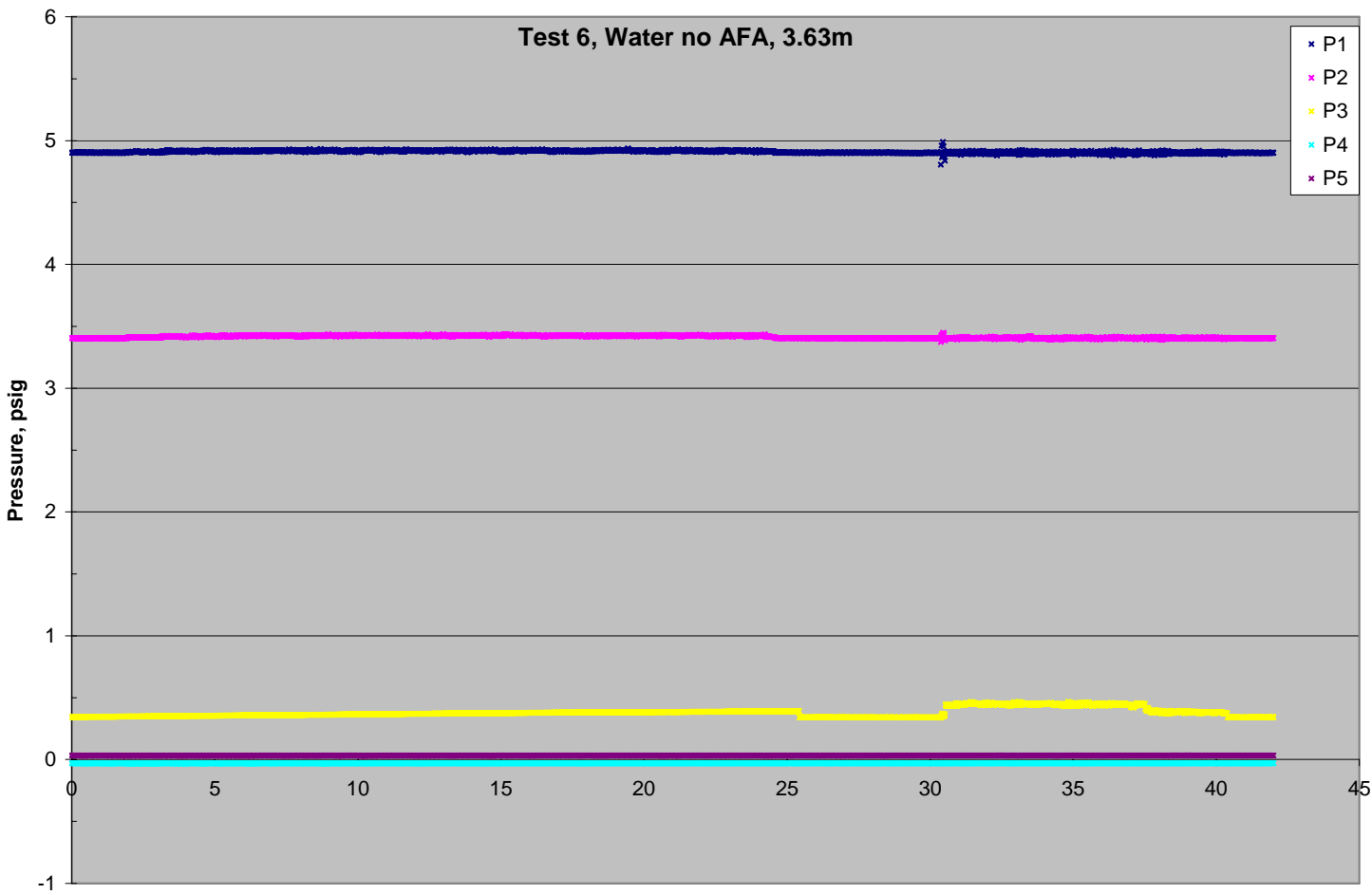

Elapsed Time, $\min$

Figure Test 6 Pressure Transducer Measurements 


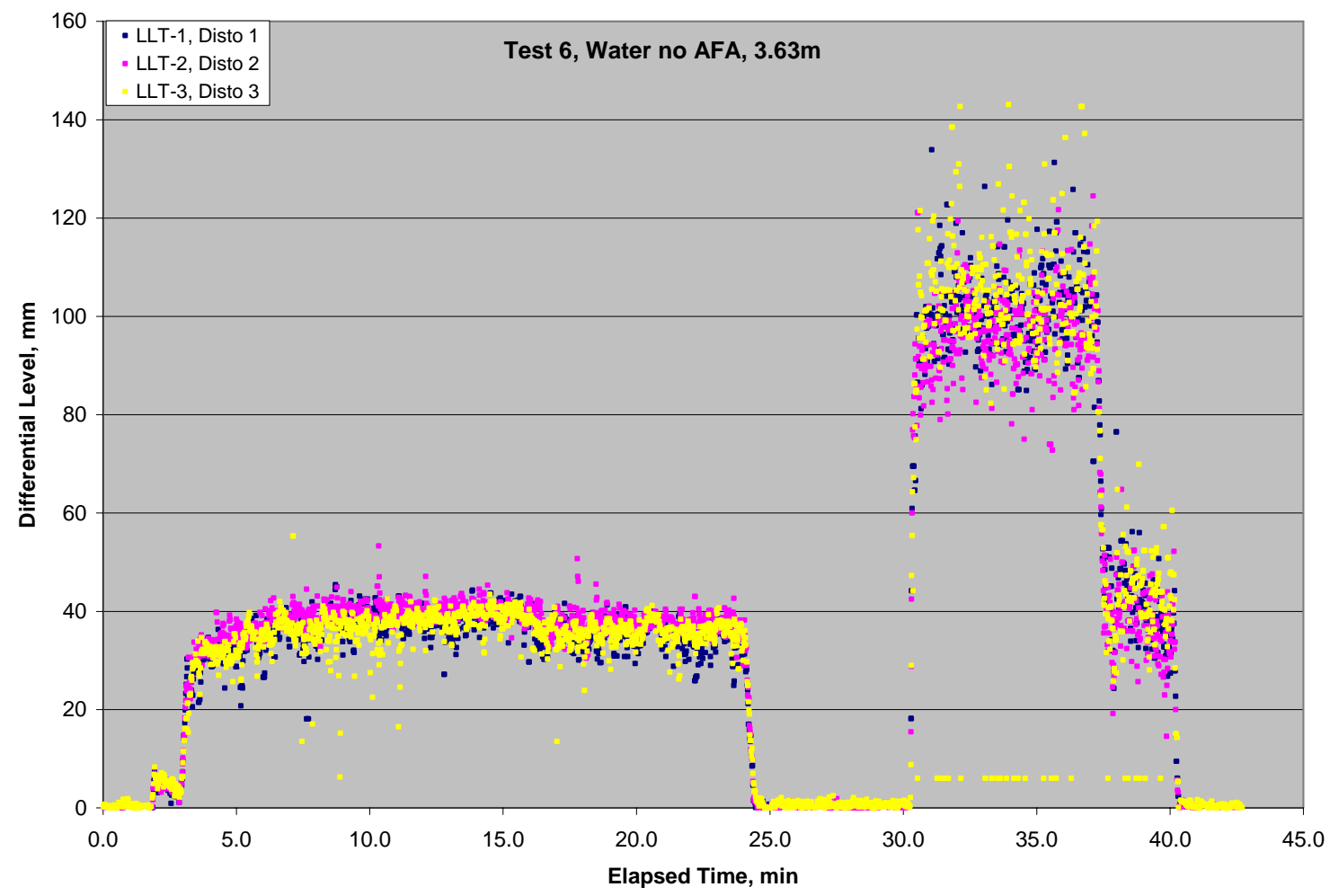

Figure Test 6 Differential Laser Measurements

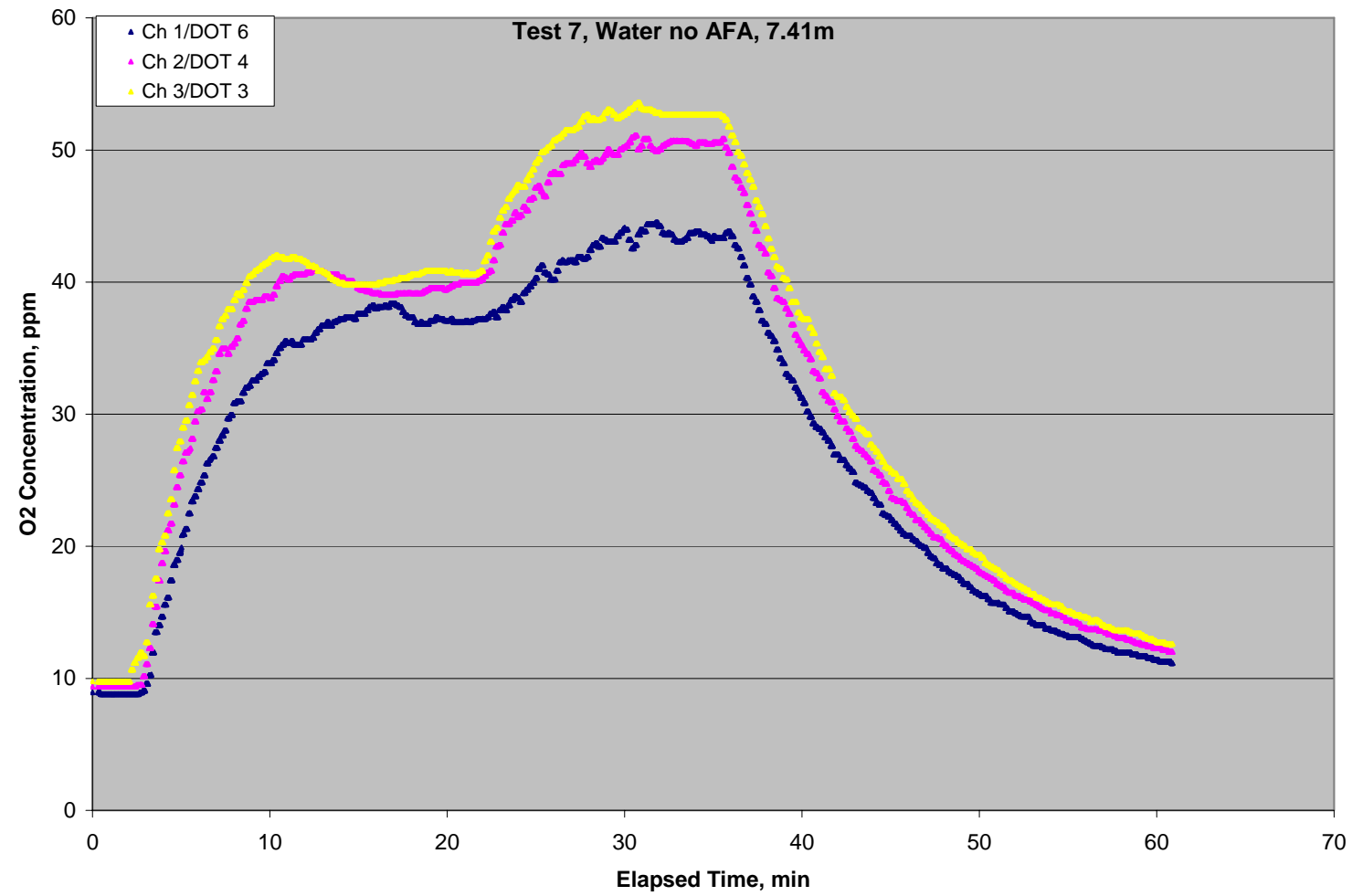

Figure Test 7 Dissolved Oxygen Concentrations 


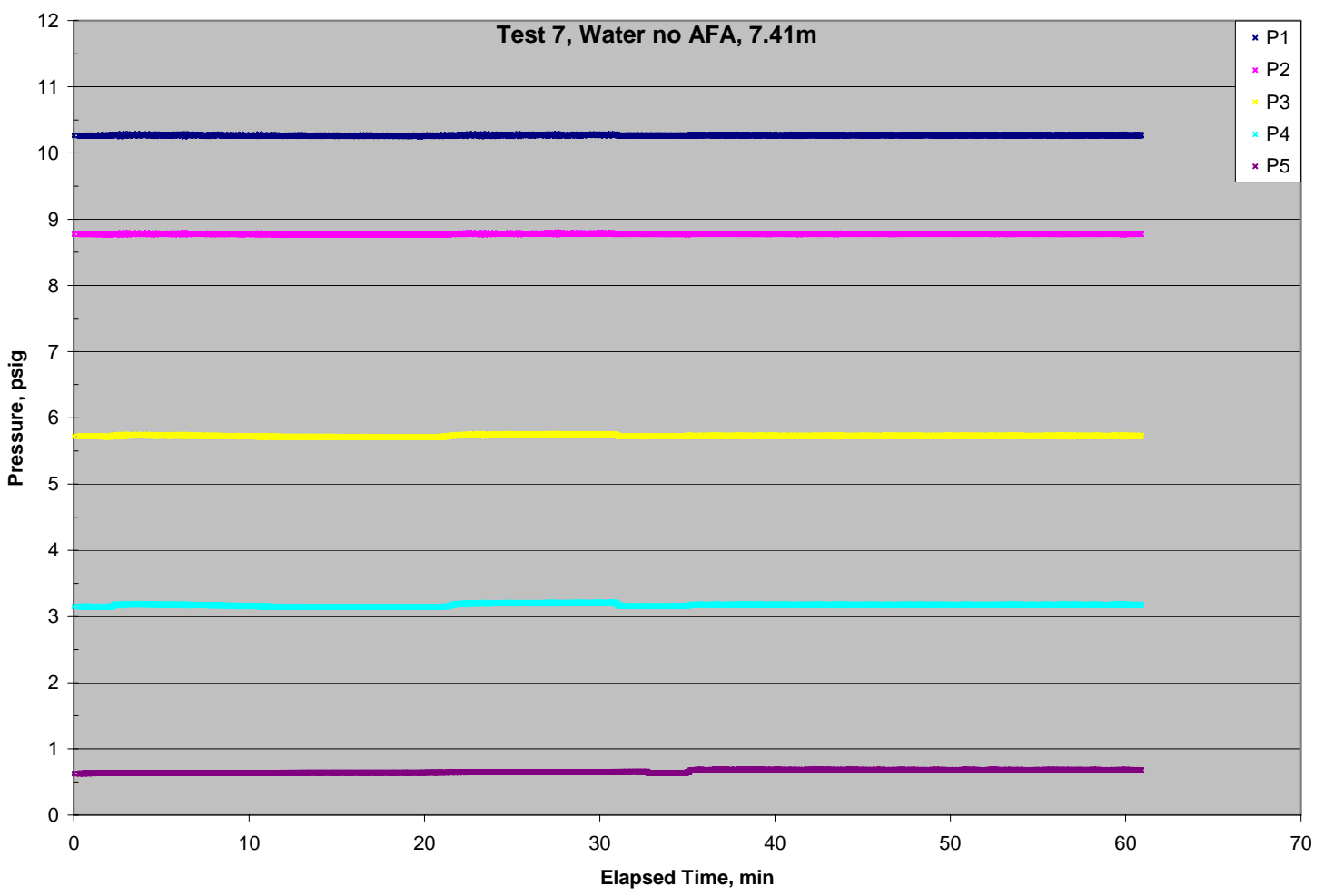

Figure Test 7 Pressure Transducer Measurements

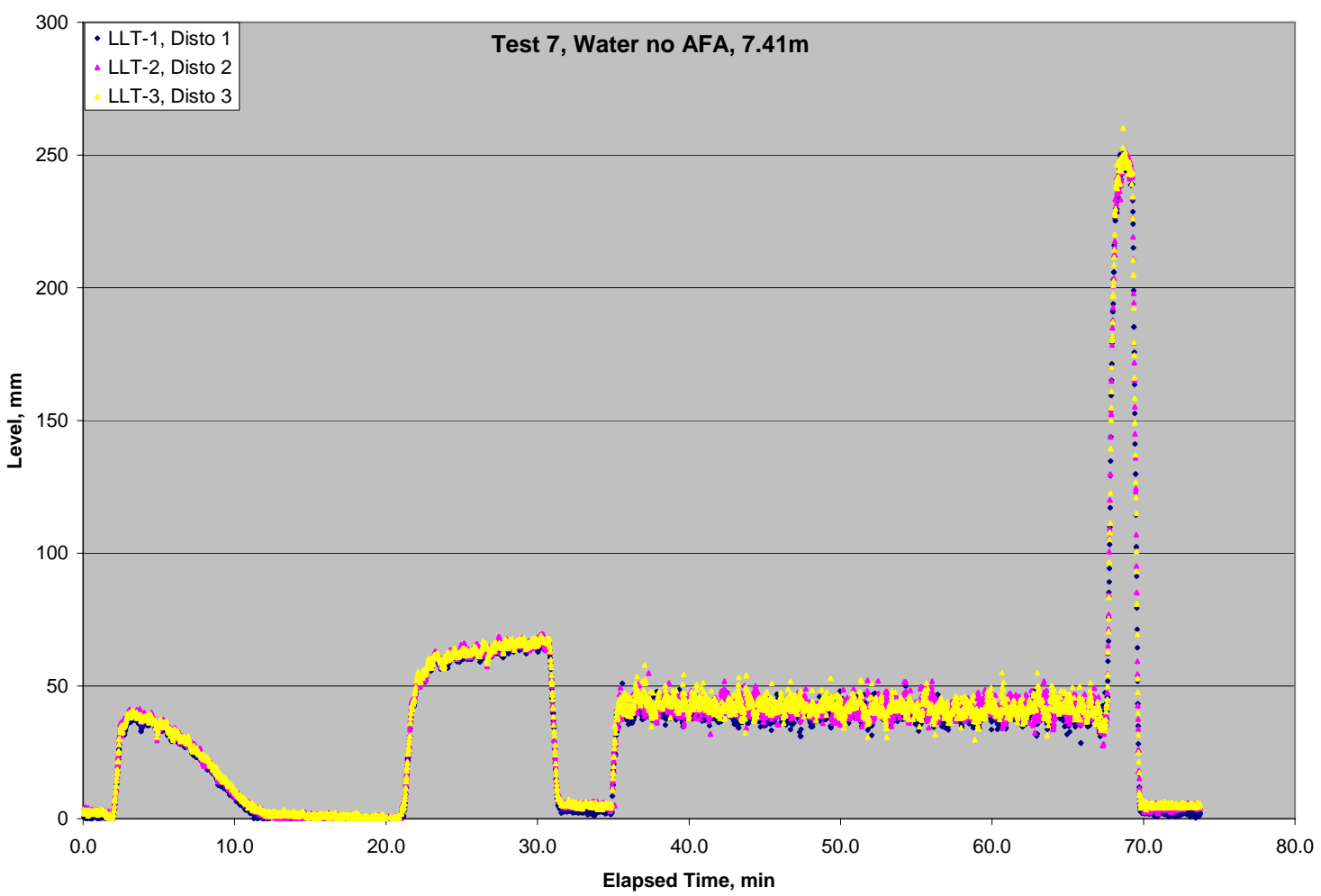

Figure Test 7 Differential Laser Measurements 


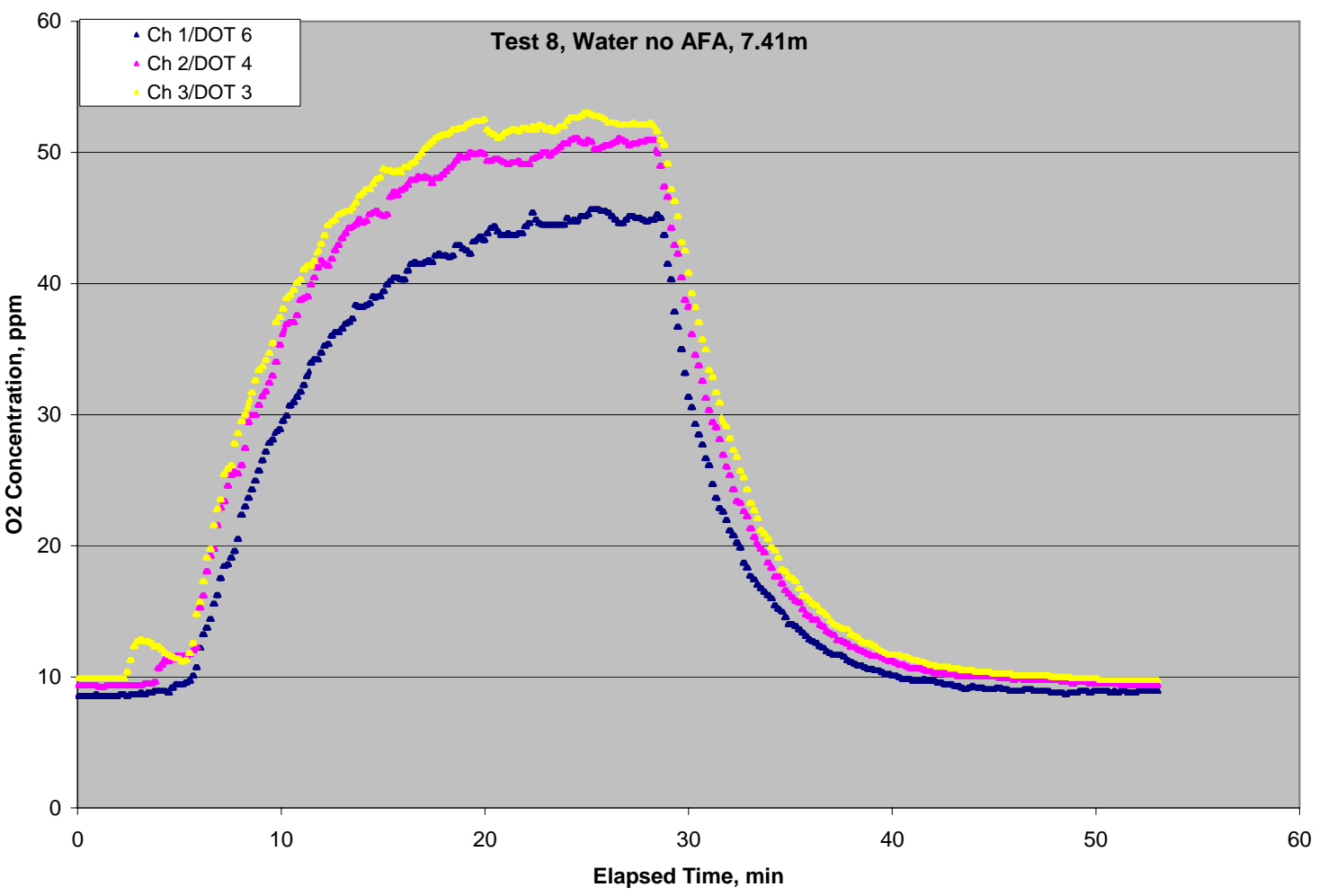

Figure -Test 8 Dissolved Oxygen Concentrations

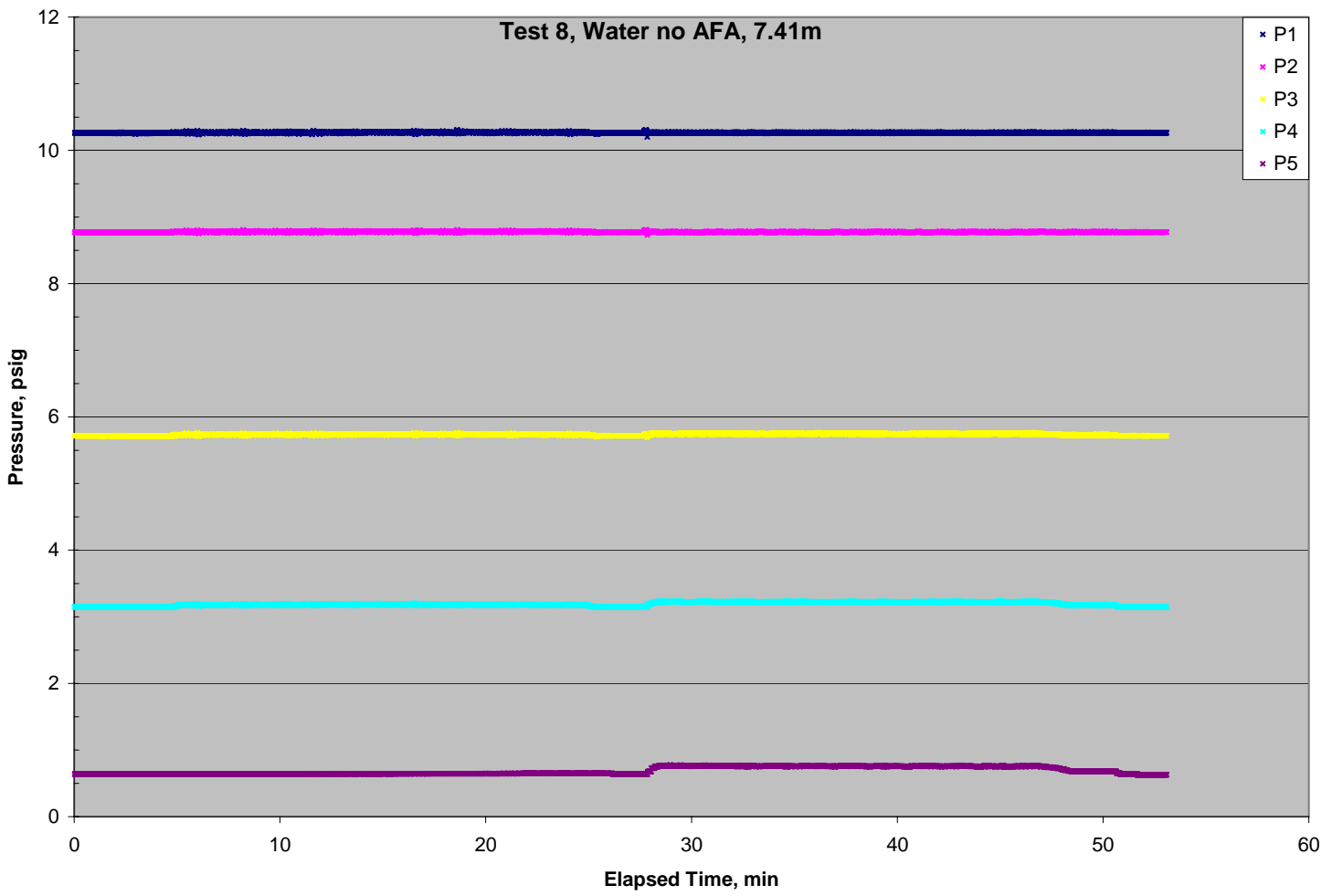

Figure -Test 8 Pressure Transducer Measurements 


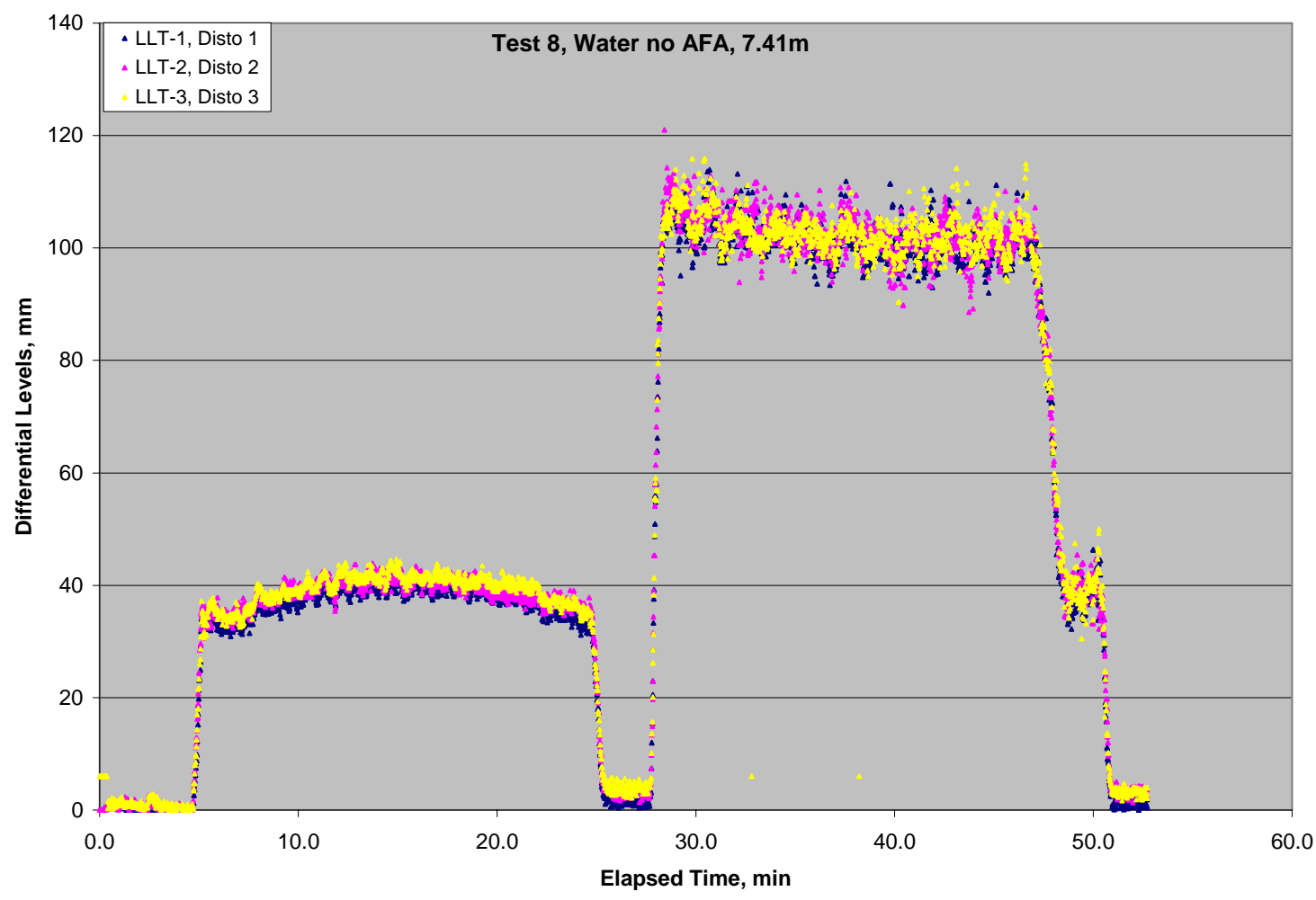

Figure -Test 8 Differential Laser Measurements

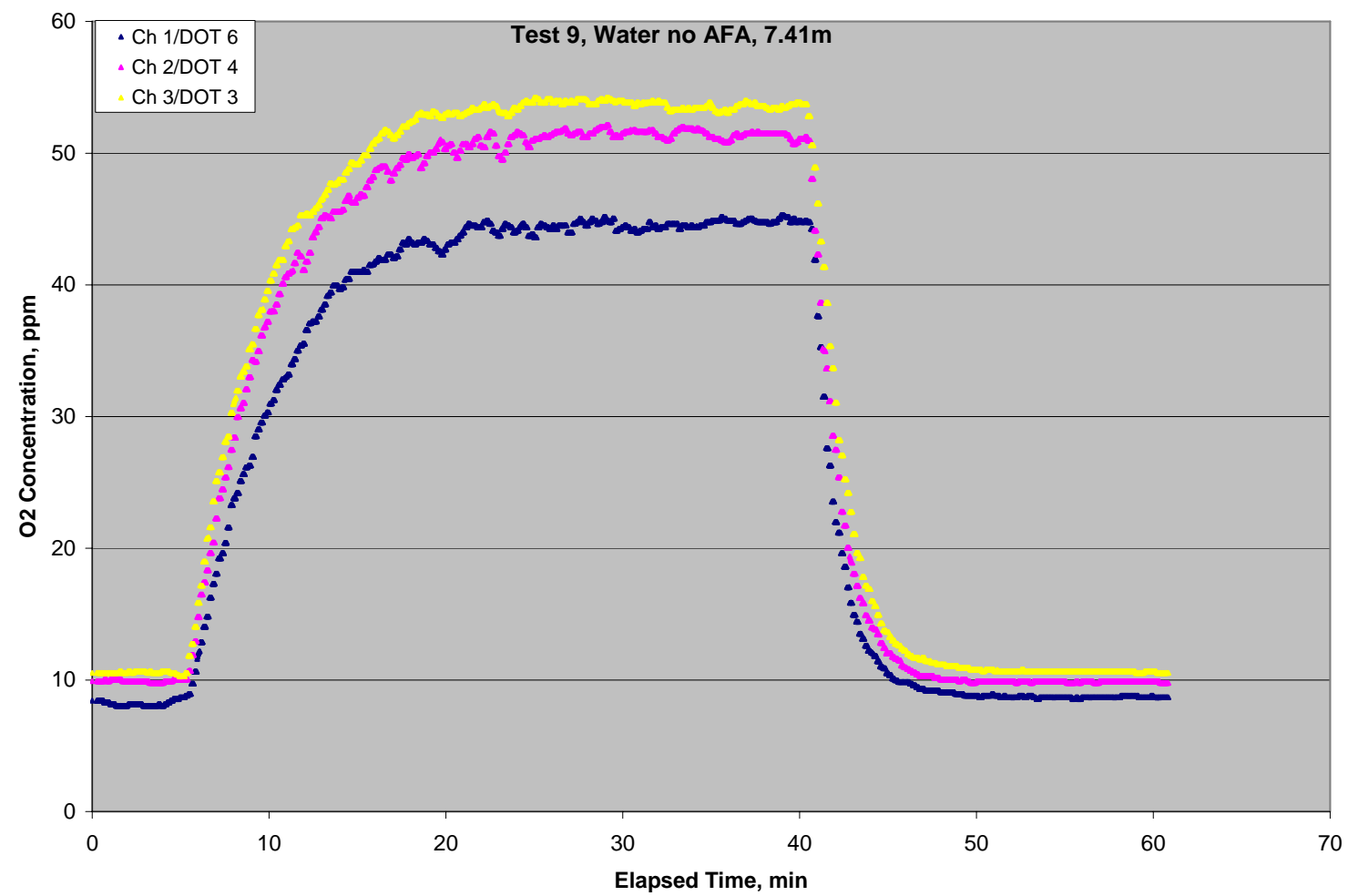

Figure -Test 9 Dissolved Oxygen Concentrations 


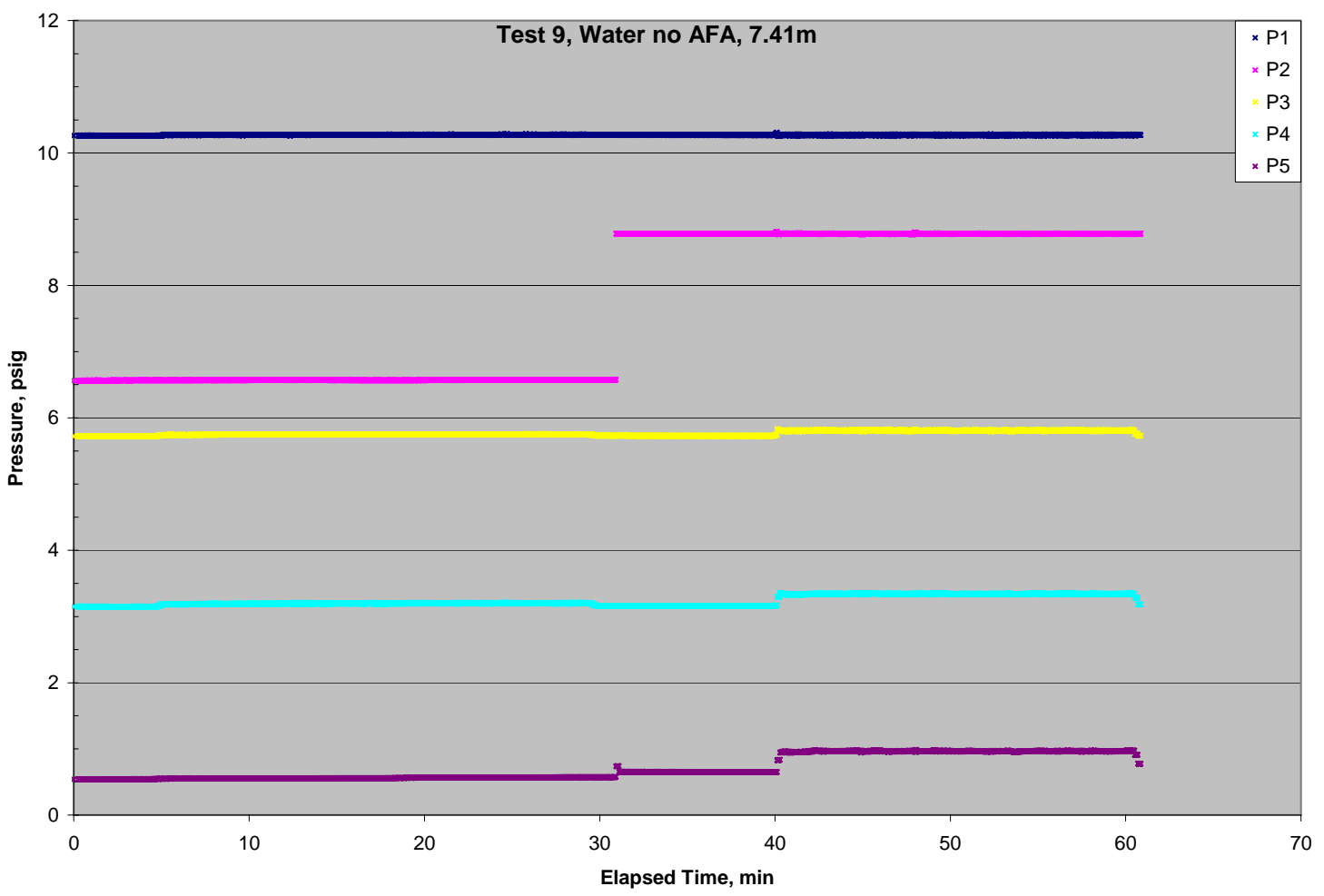

Figure Test 9 Pressure Transducer Measurements

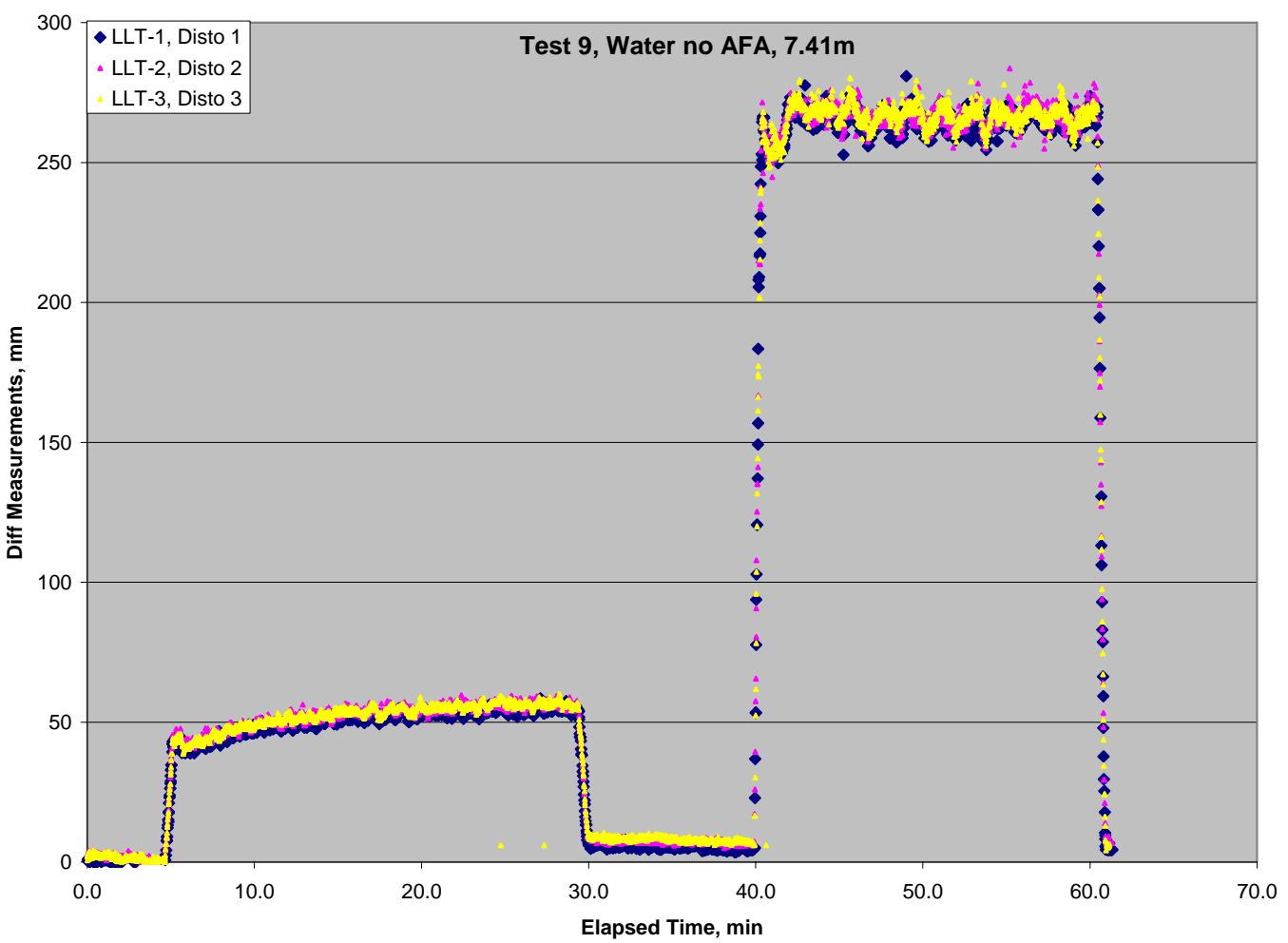

Figure Test 9 Differential Laser Measurements 


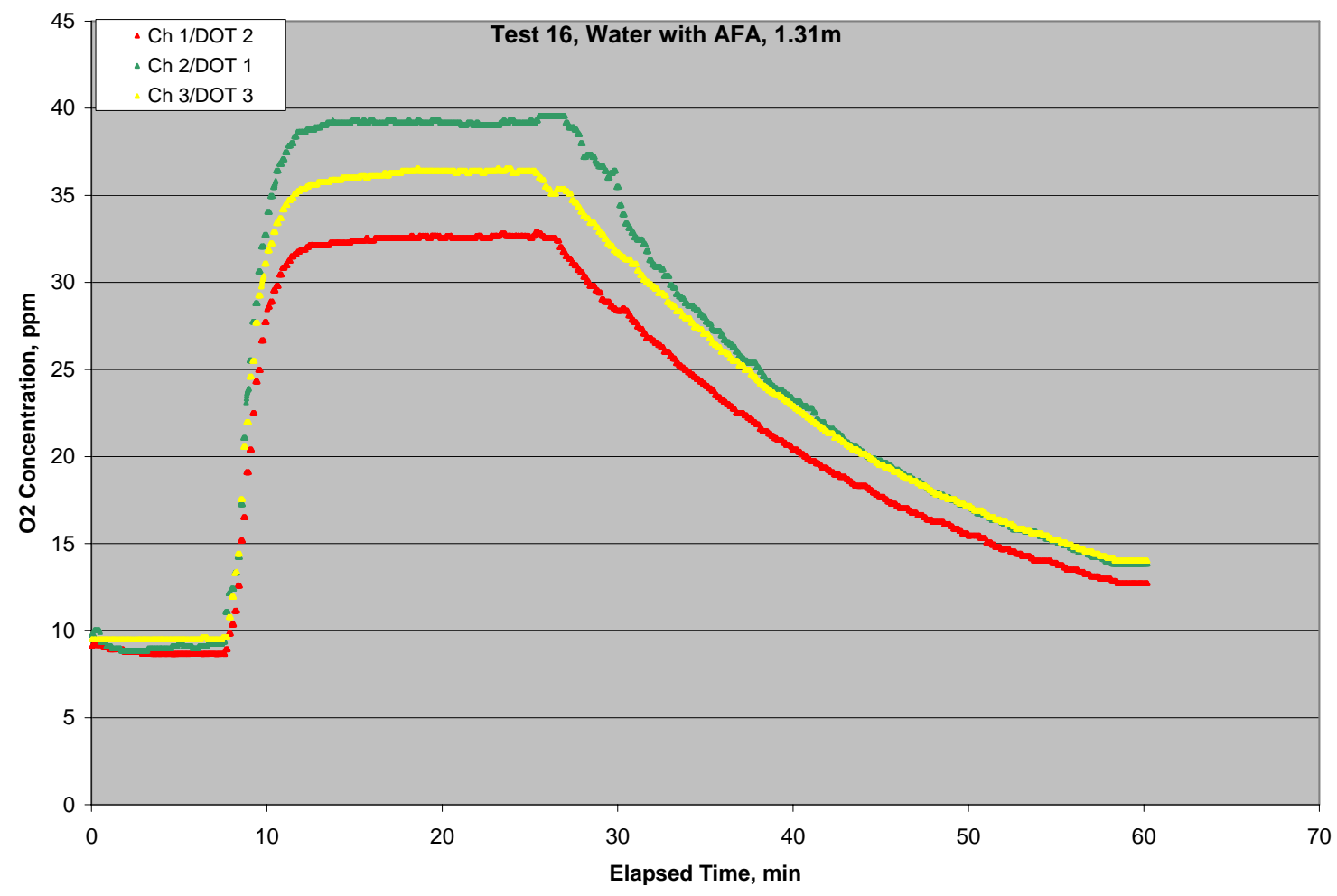

Figure Test 16 Dissolved Oxygen Concentrations

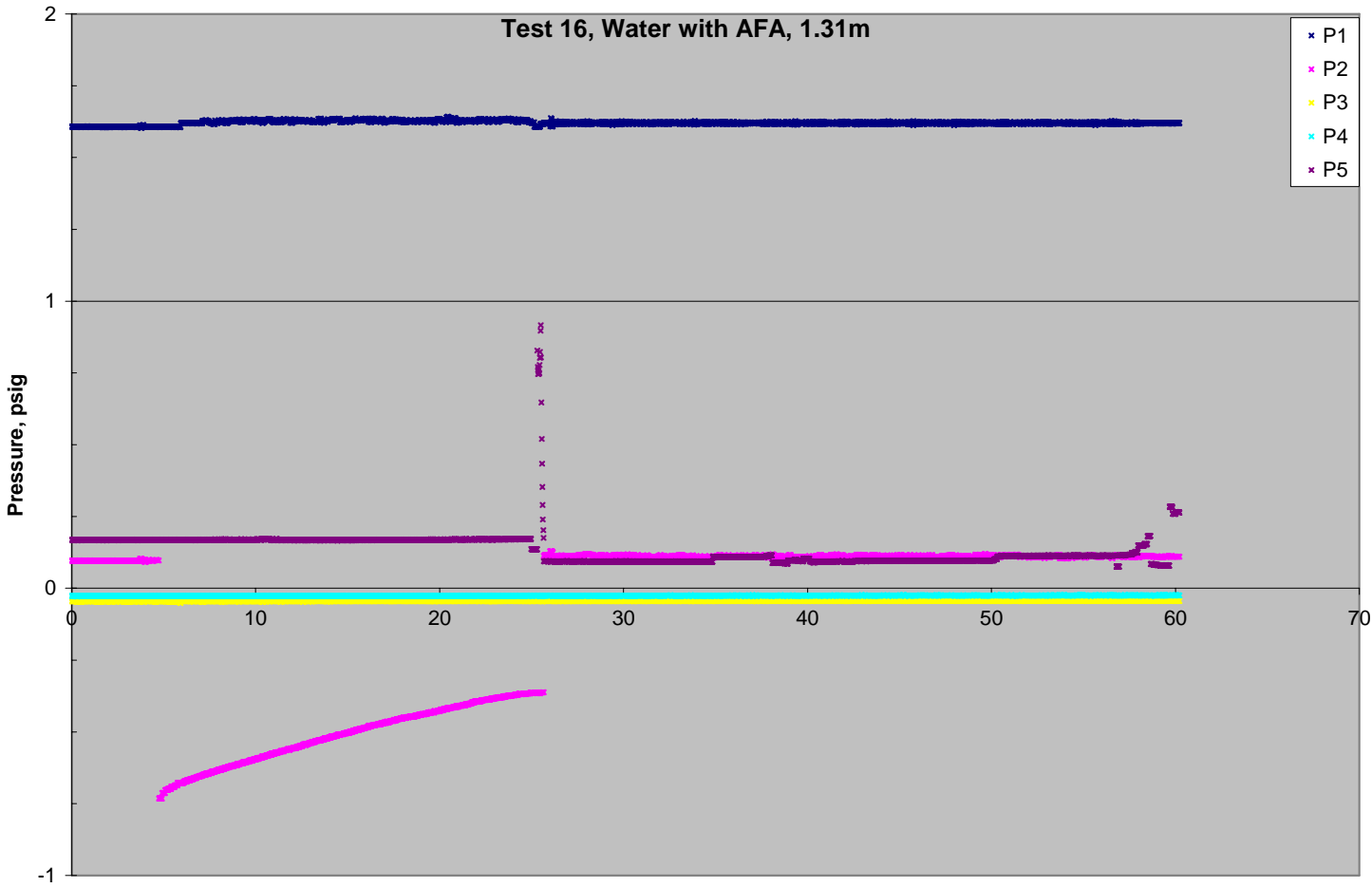

Elapsed Time, $\min$

Figure Test 16 Pressure Transducer Measurements 


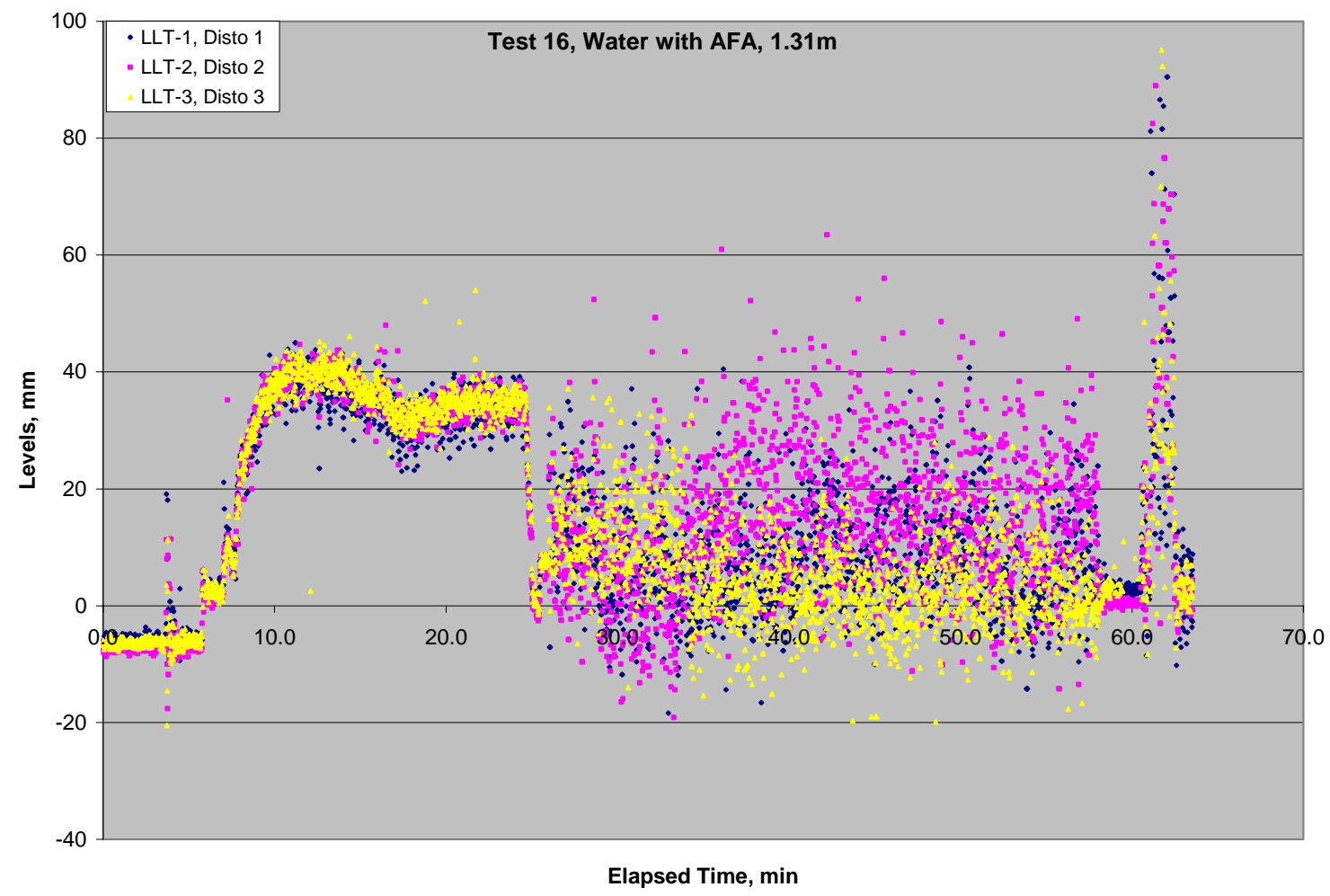

Figure Test 16 Differential Laser Measurements

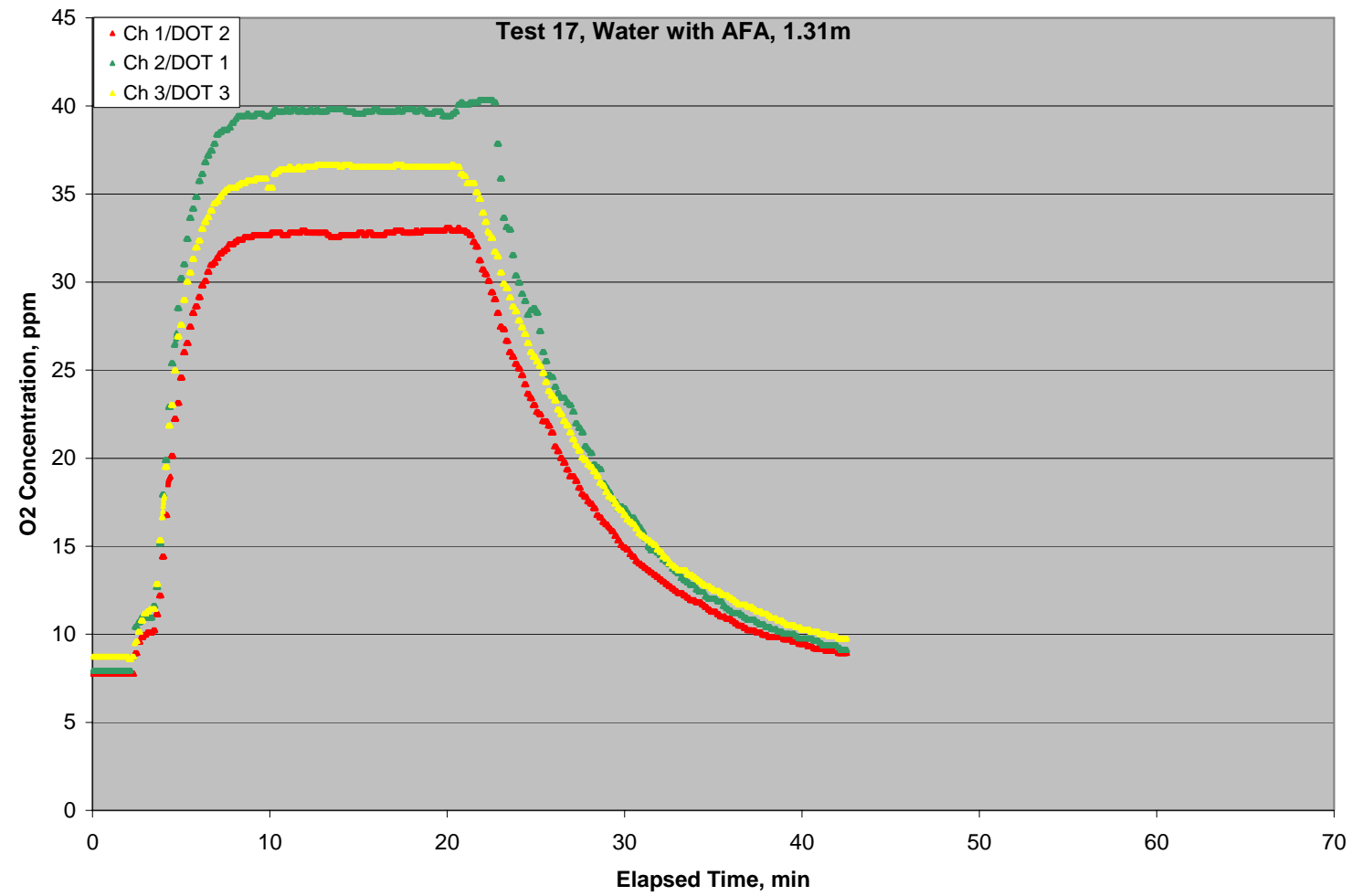

Figure Test 17 Dissolved Oxygen Concentrations 


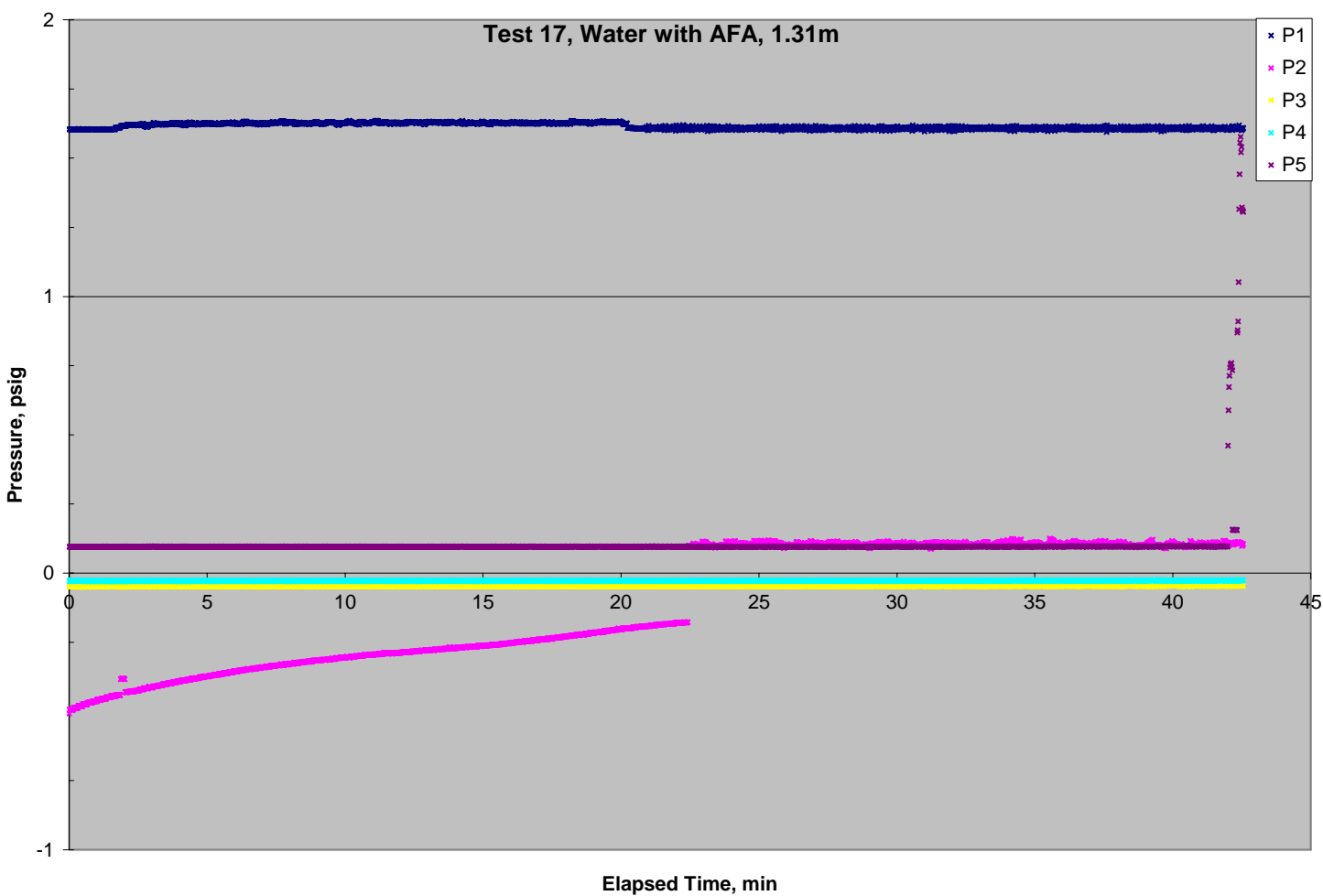

Figure Test 17 Pressure Transducer Measurements

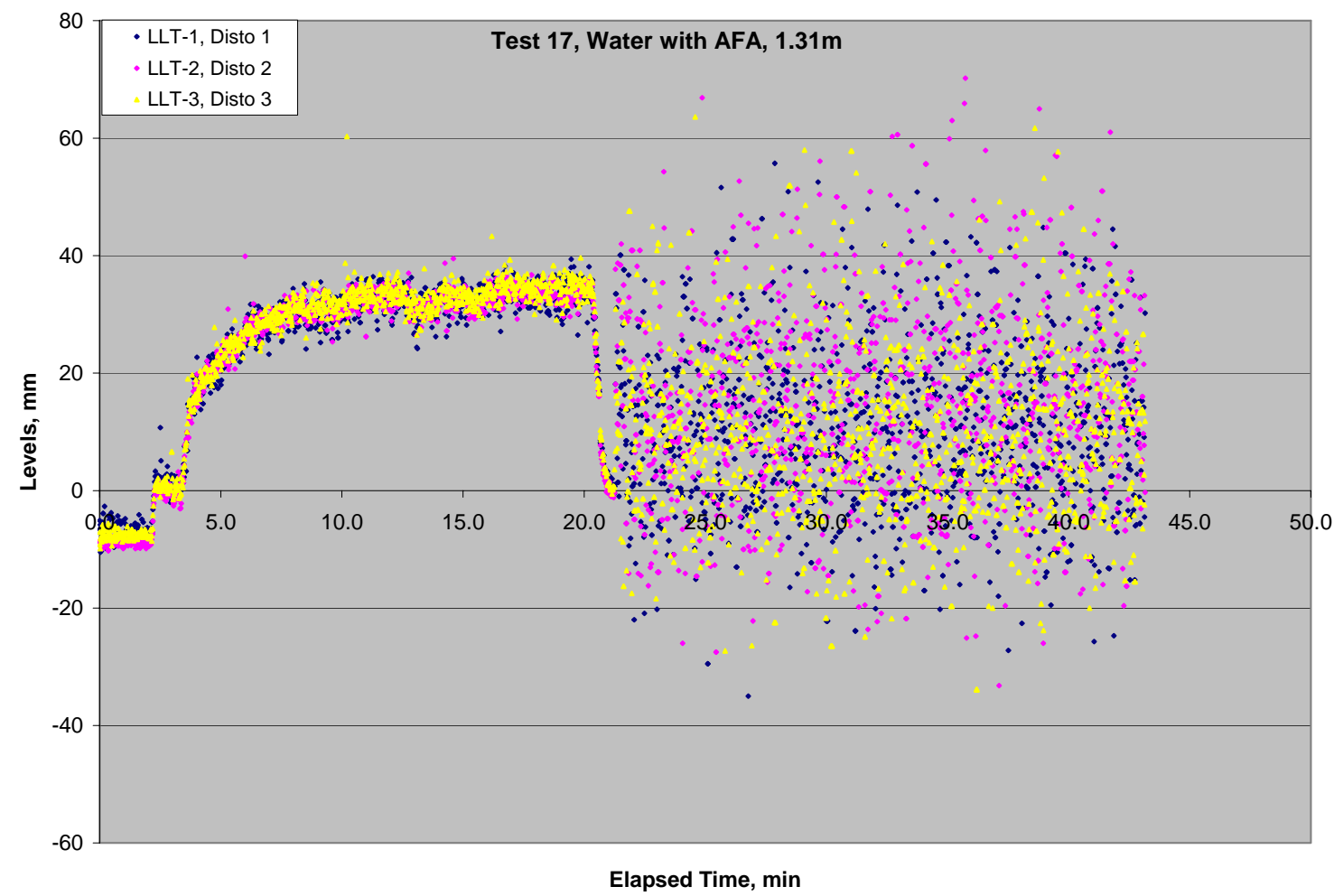

Figure Test 17 Differential Laser Measurements 


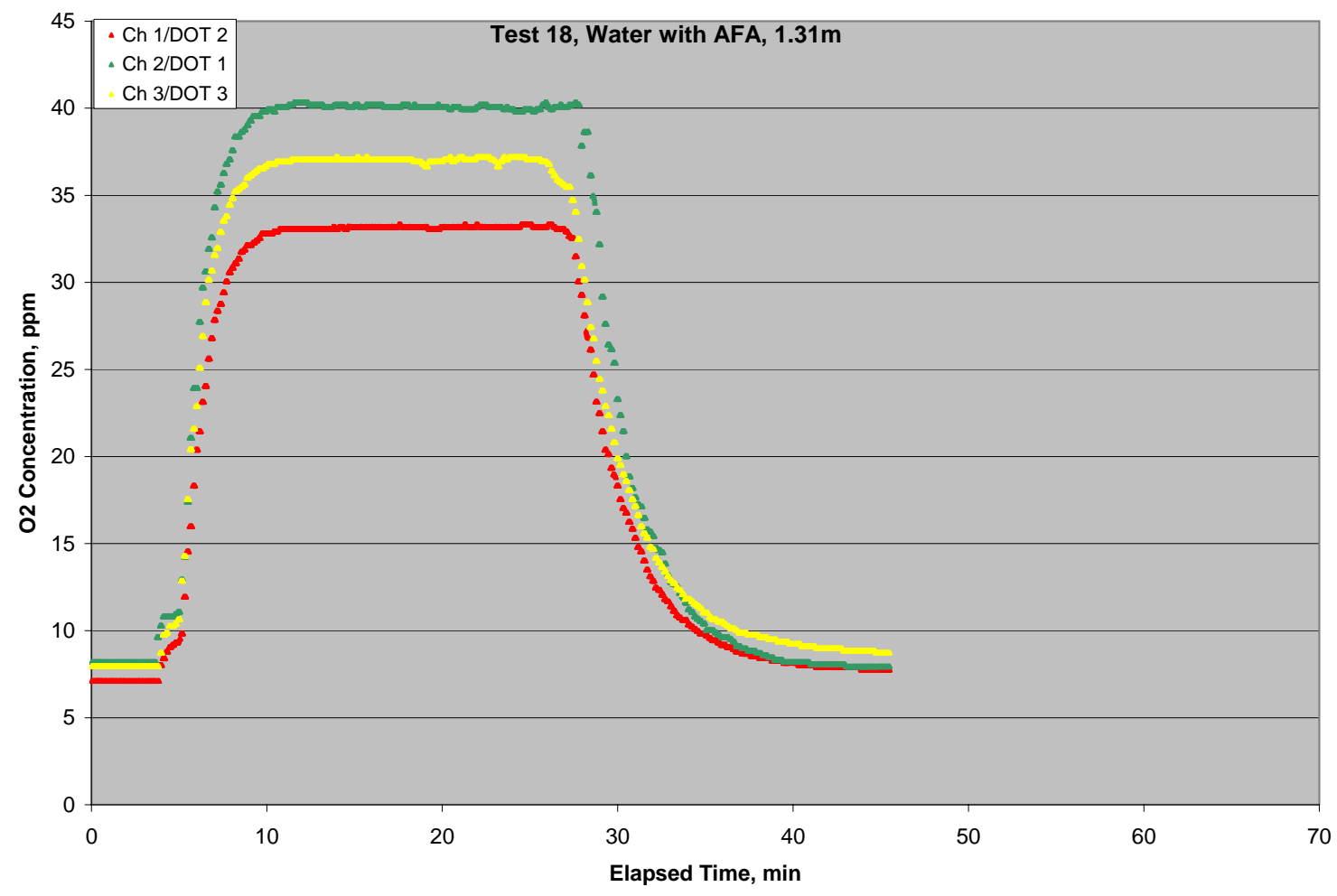

Figure Test 18 Dissolved Oxygen Concentrations

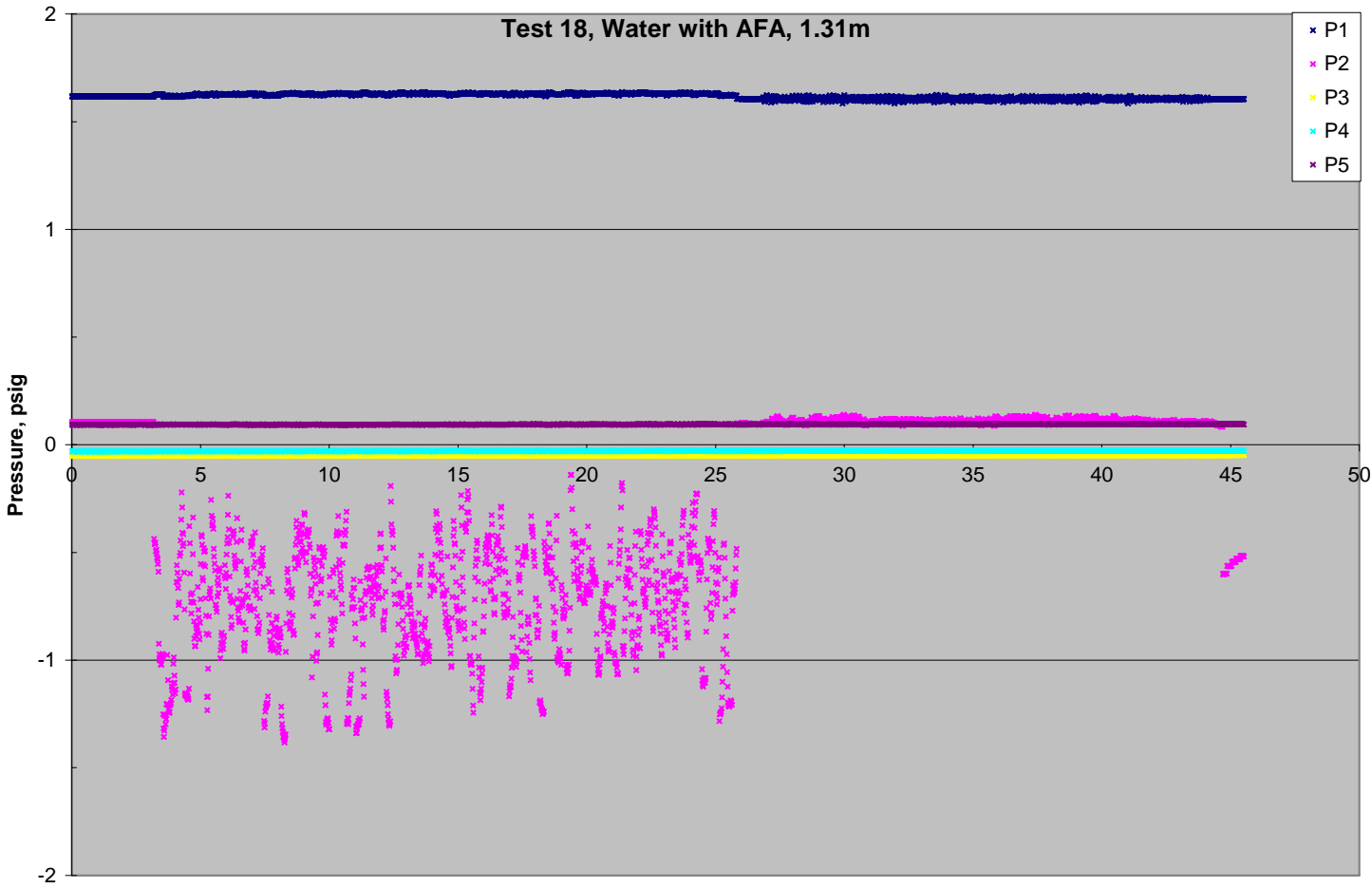

Elapsed Time, $\min$

FigureTest 18 Pressure Transducer Measurements 


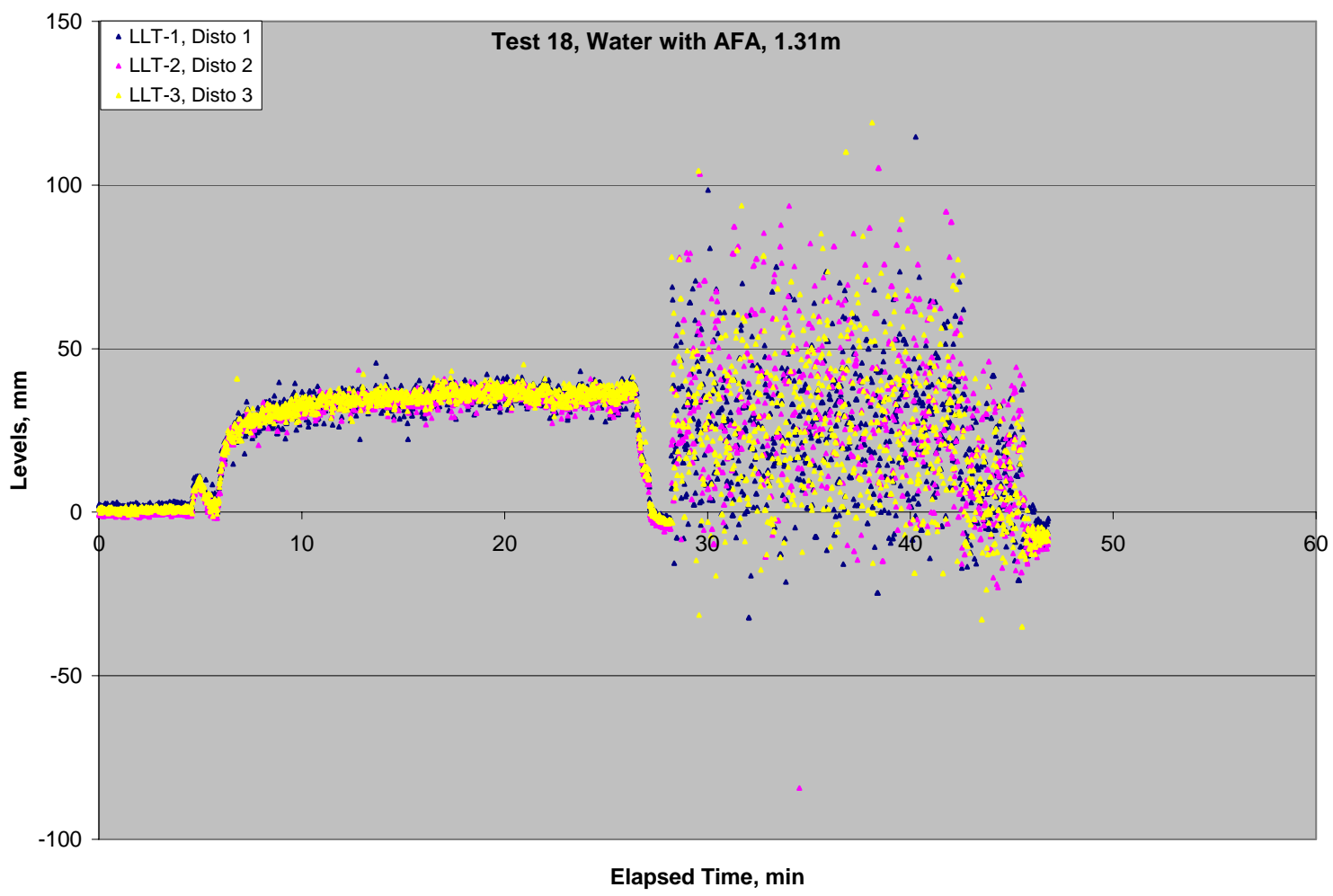

Figure Test 18 Differential Laser Measurements

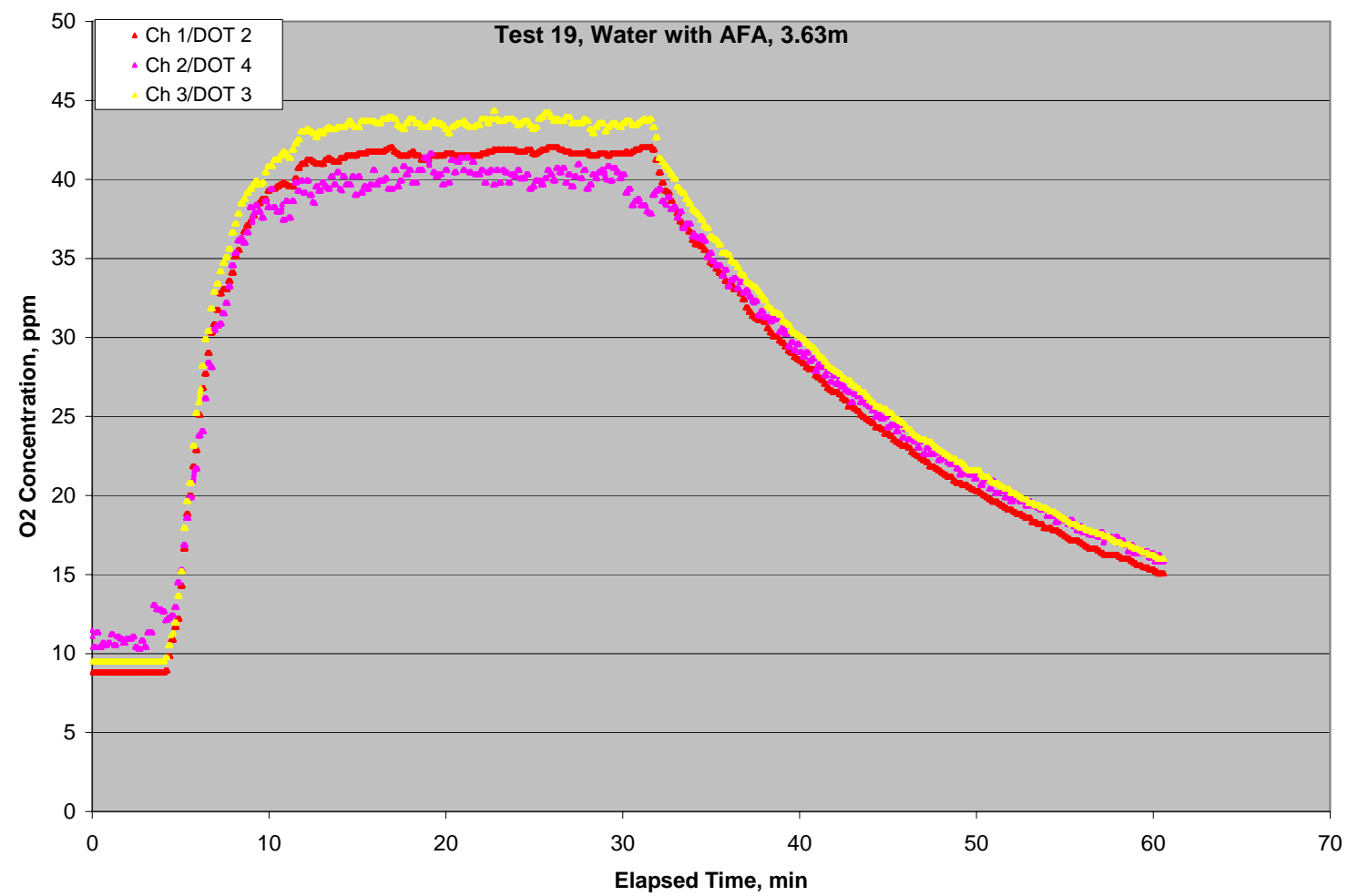

Figure Test 19 Dissolved Oxygen Concentrations 


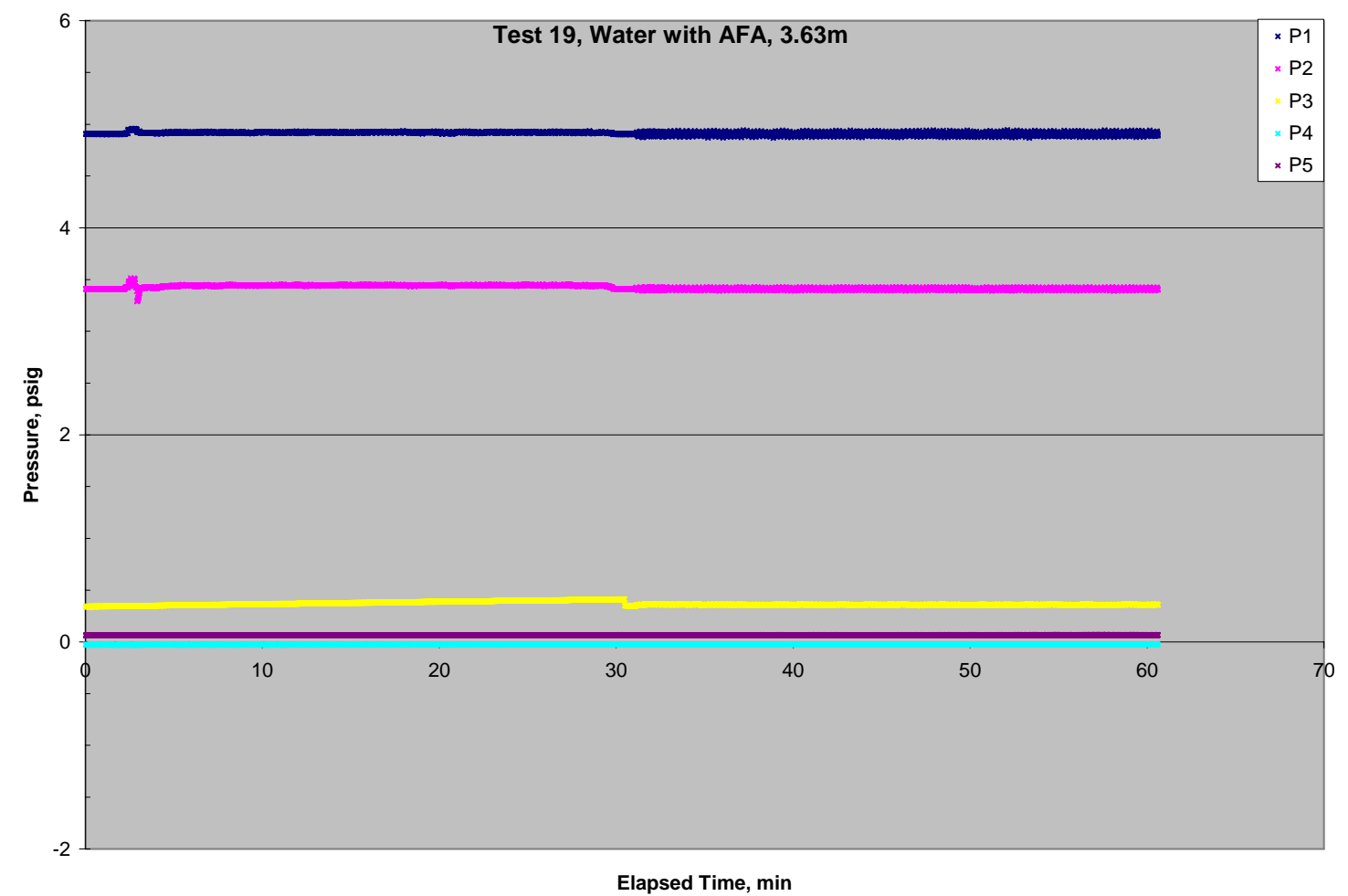

Figure -Test 19 Pressure Transducer Measurements

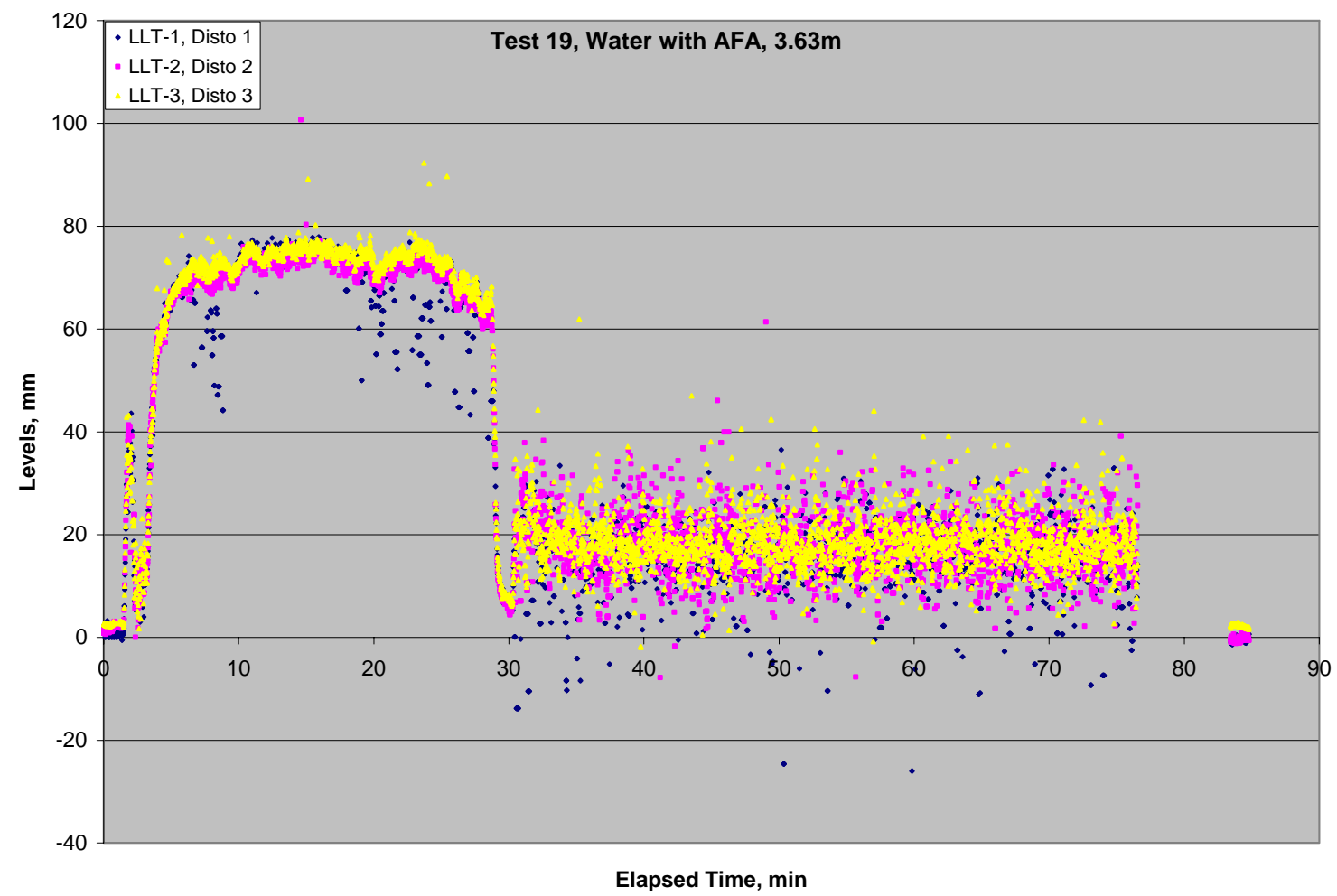

Figure -Test 19 Differential Laser Measurements 


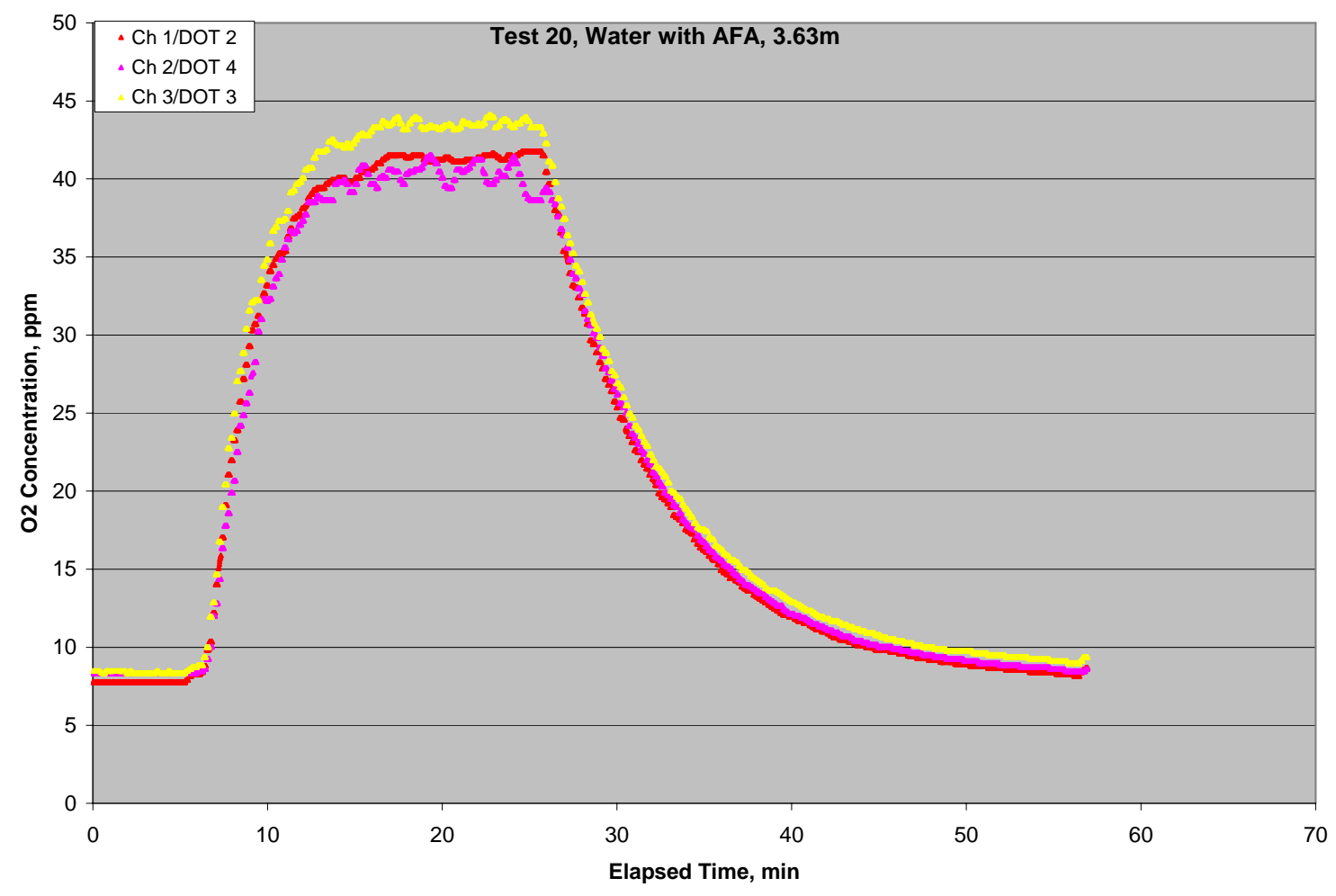

Figure Test 20 Dissolved Oxygen Concentrations

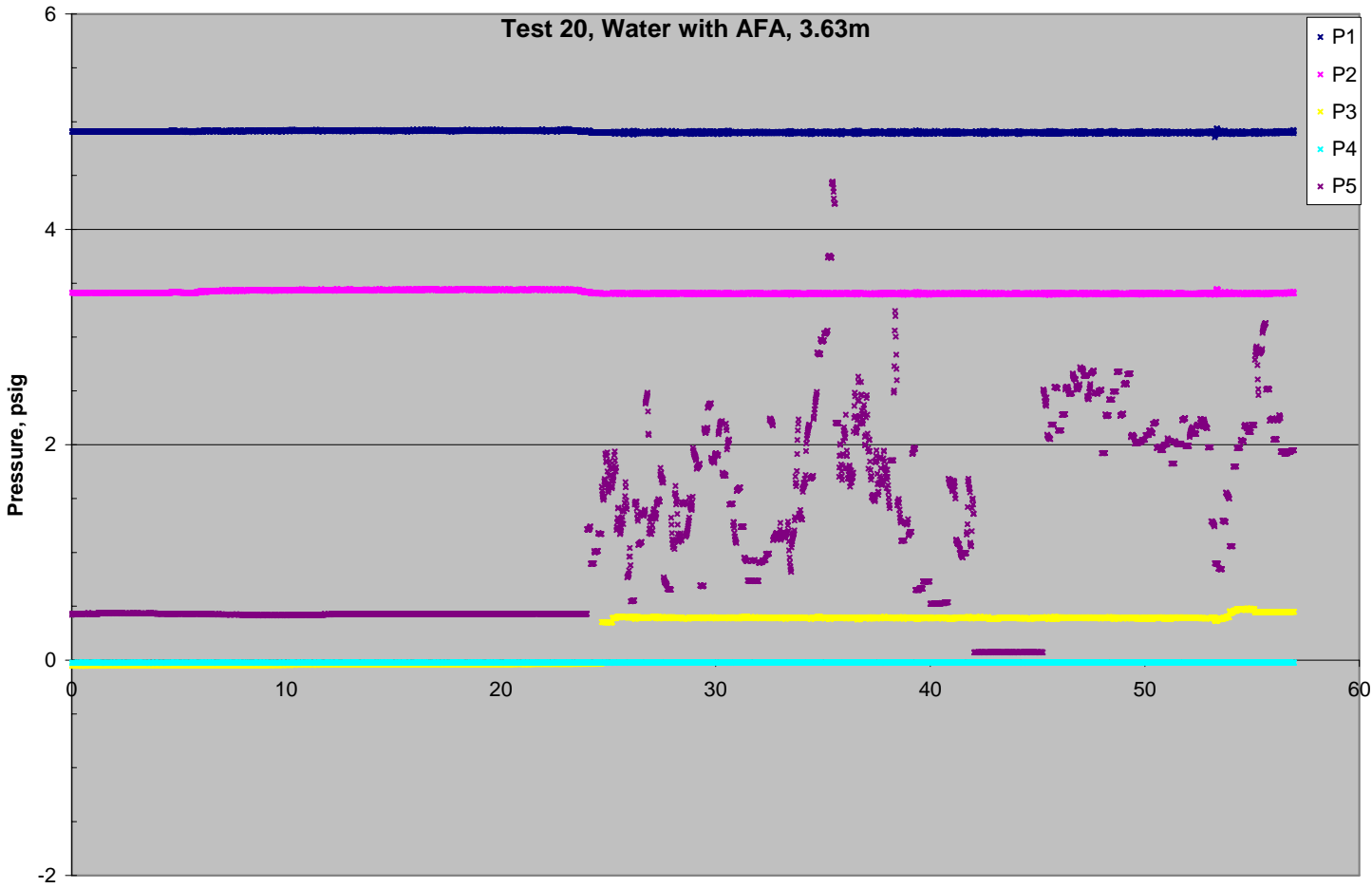

Elapsed Time, $\min$

Figure Test 20 Pressure Transducer Measurements 


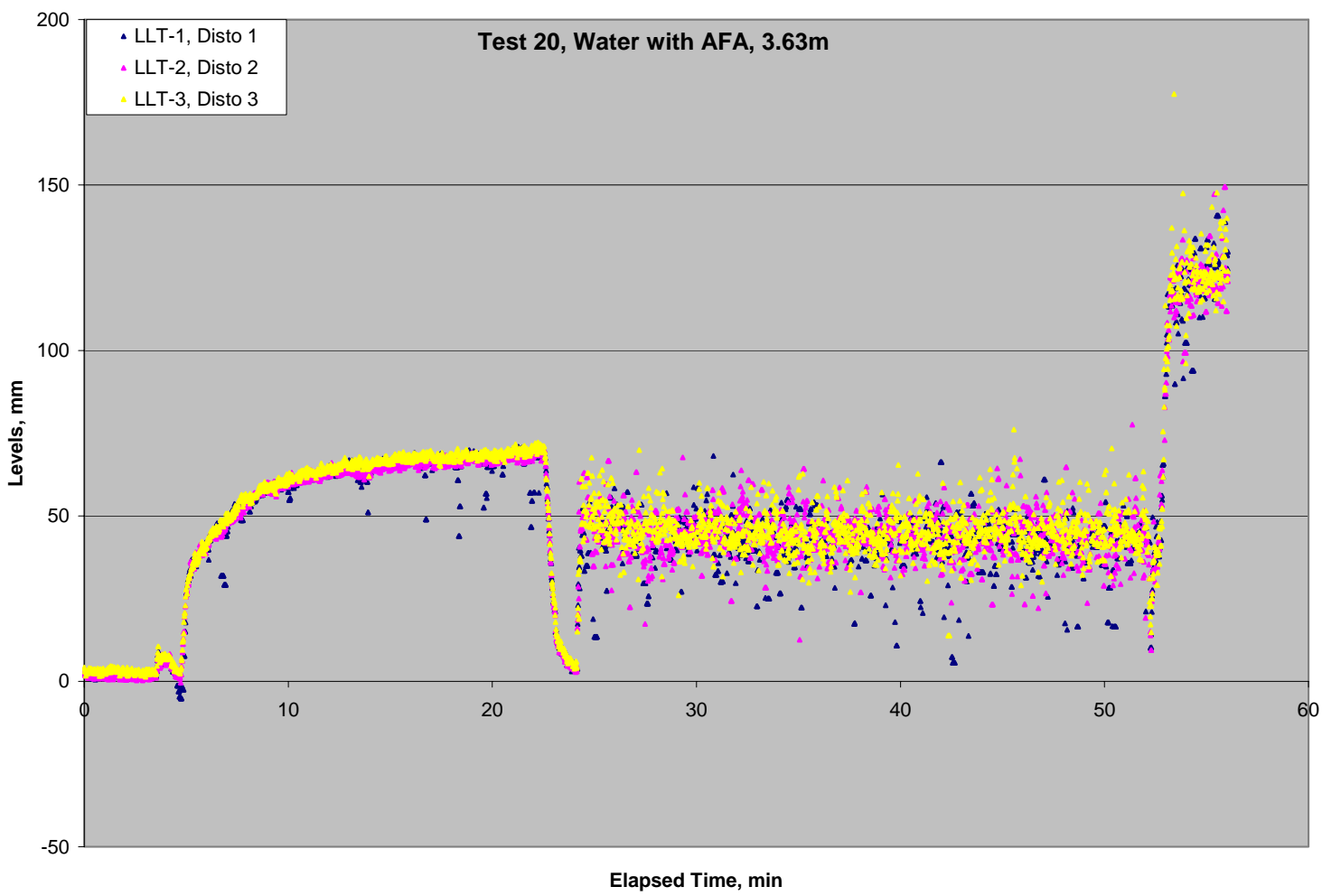

Figure Test 20 Differential Laser Measurements

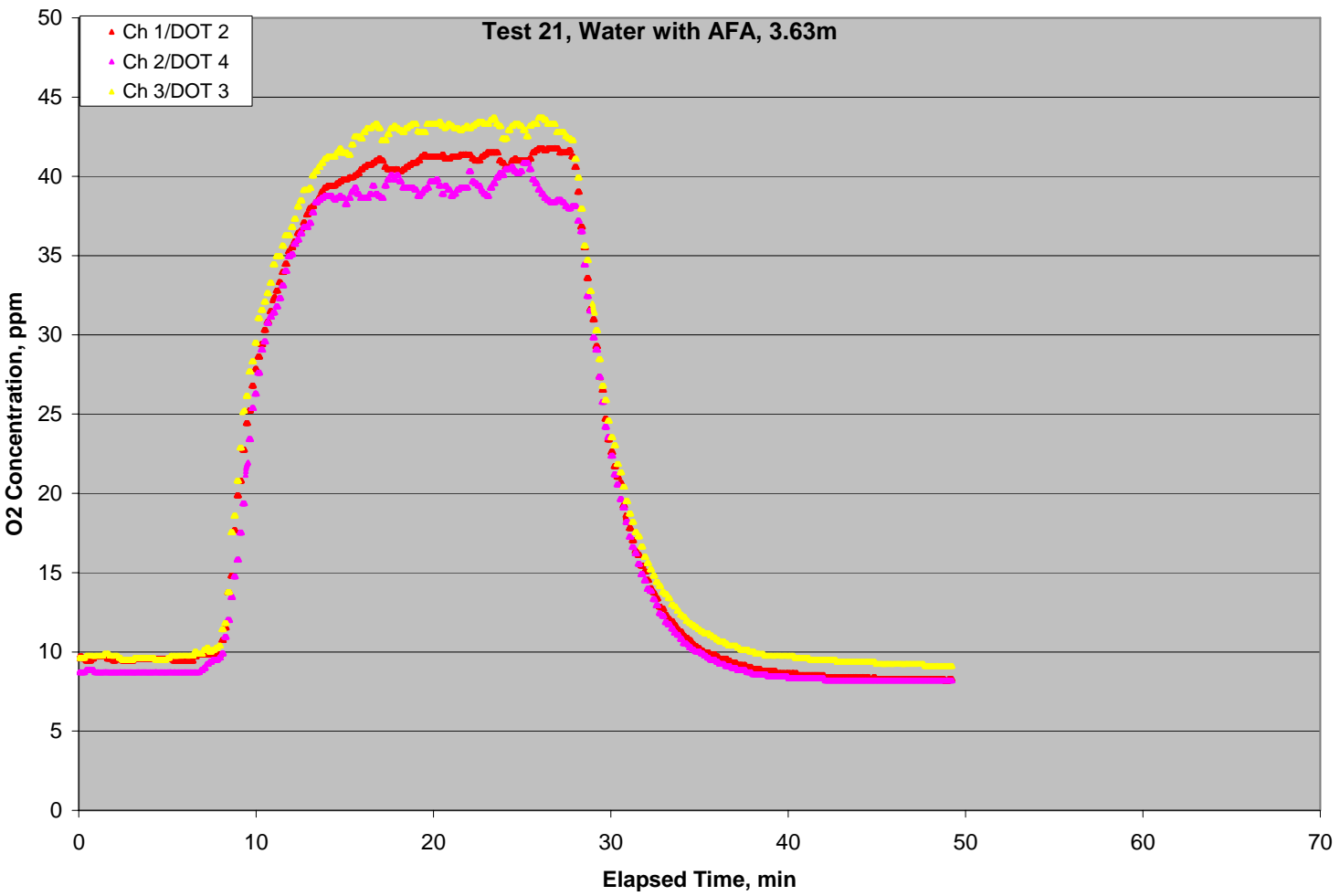

Figure Test 21 Dissolved Oxygen Concentrations 


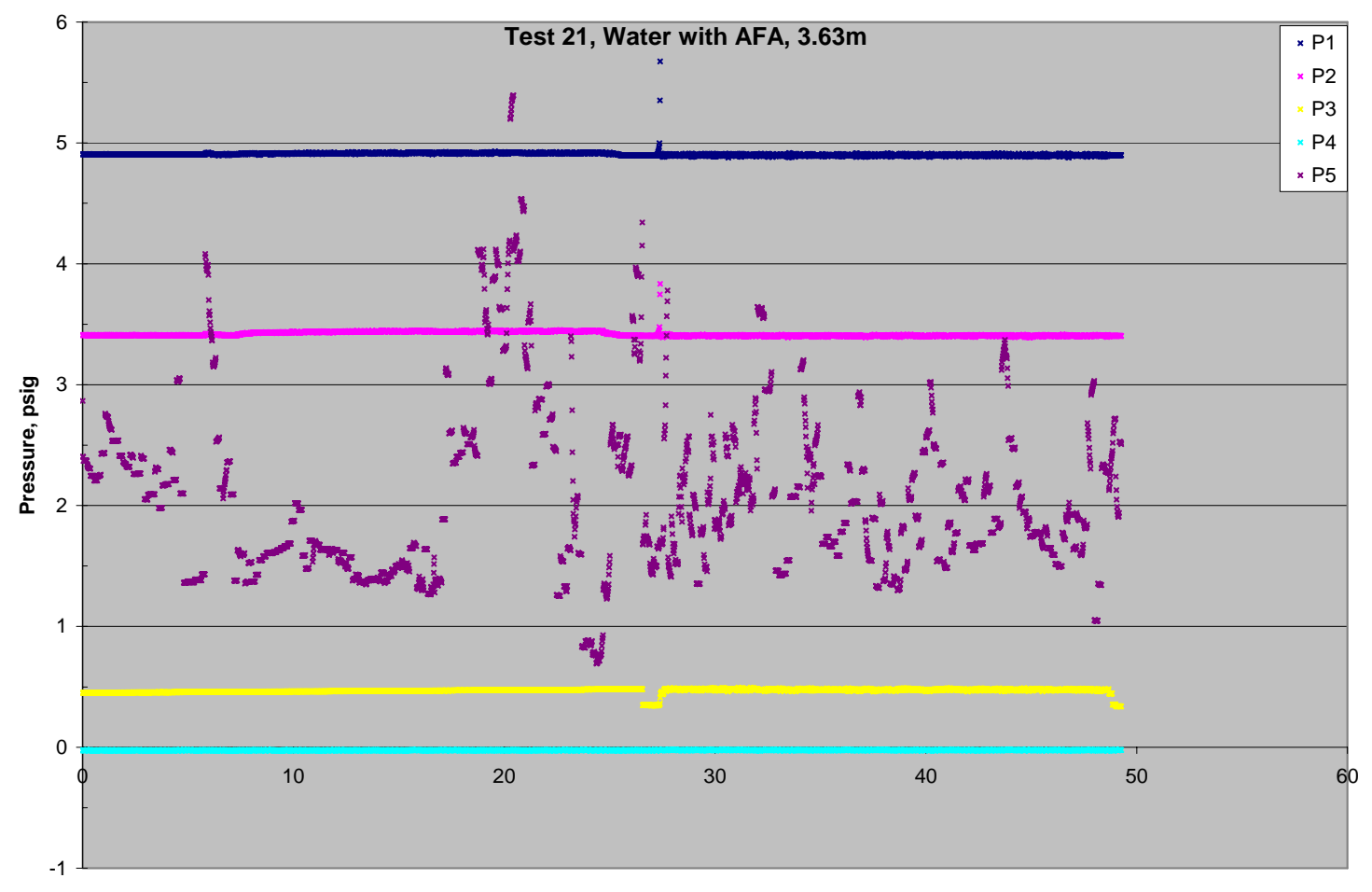

Elapsed Time, $\min$

Figure Test 21 Pressure Transducer Measurements

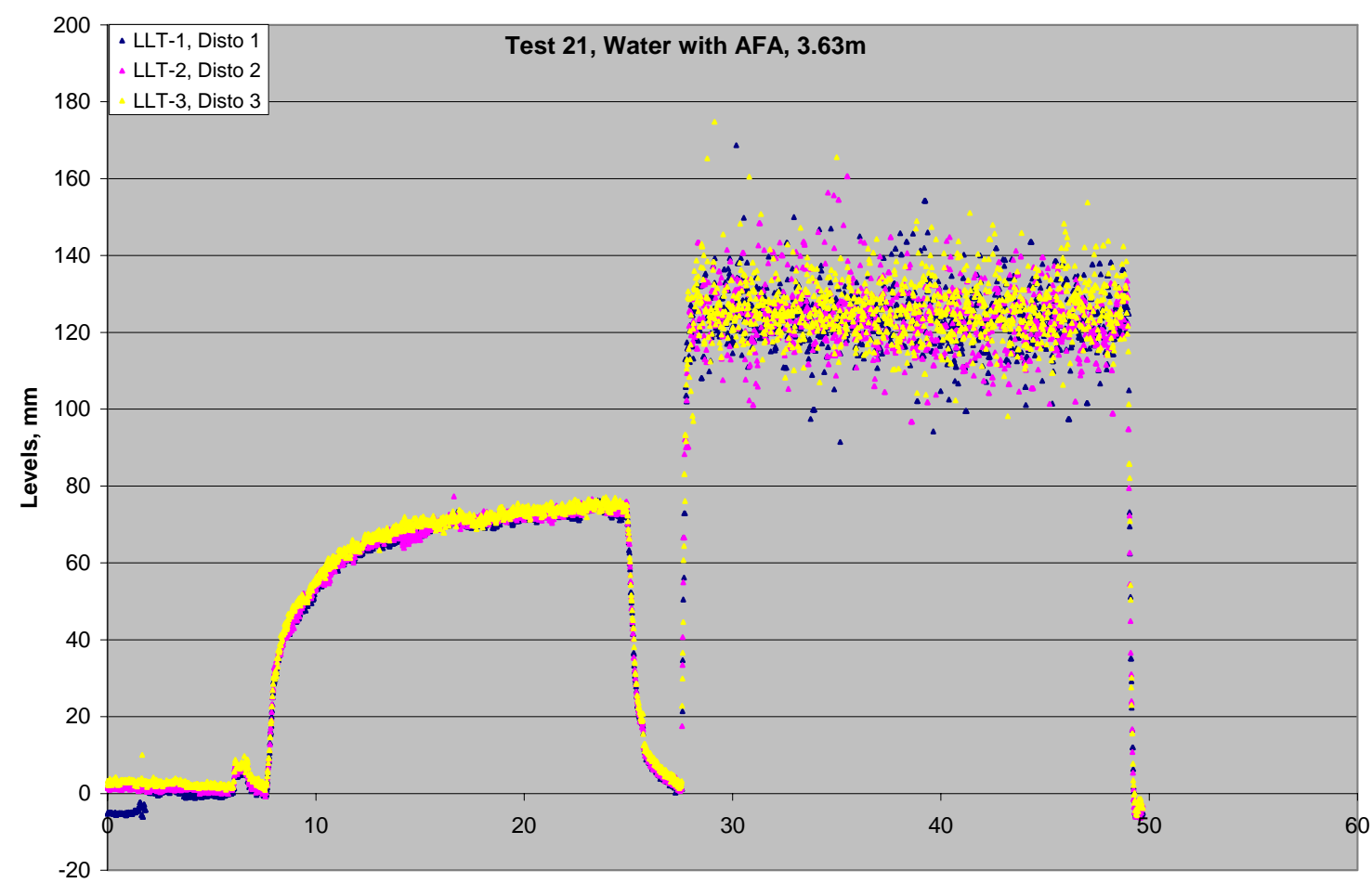

Elapsed Time, min

Figure Test 21 Differential Laser Measurements 


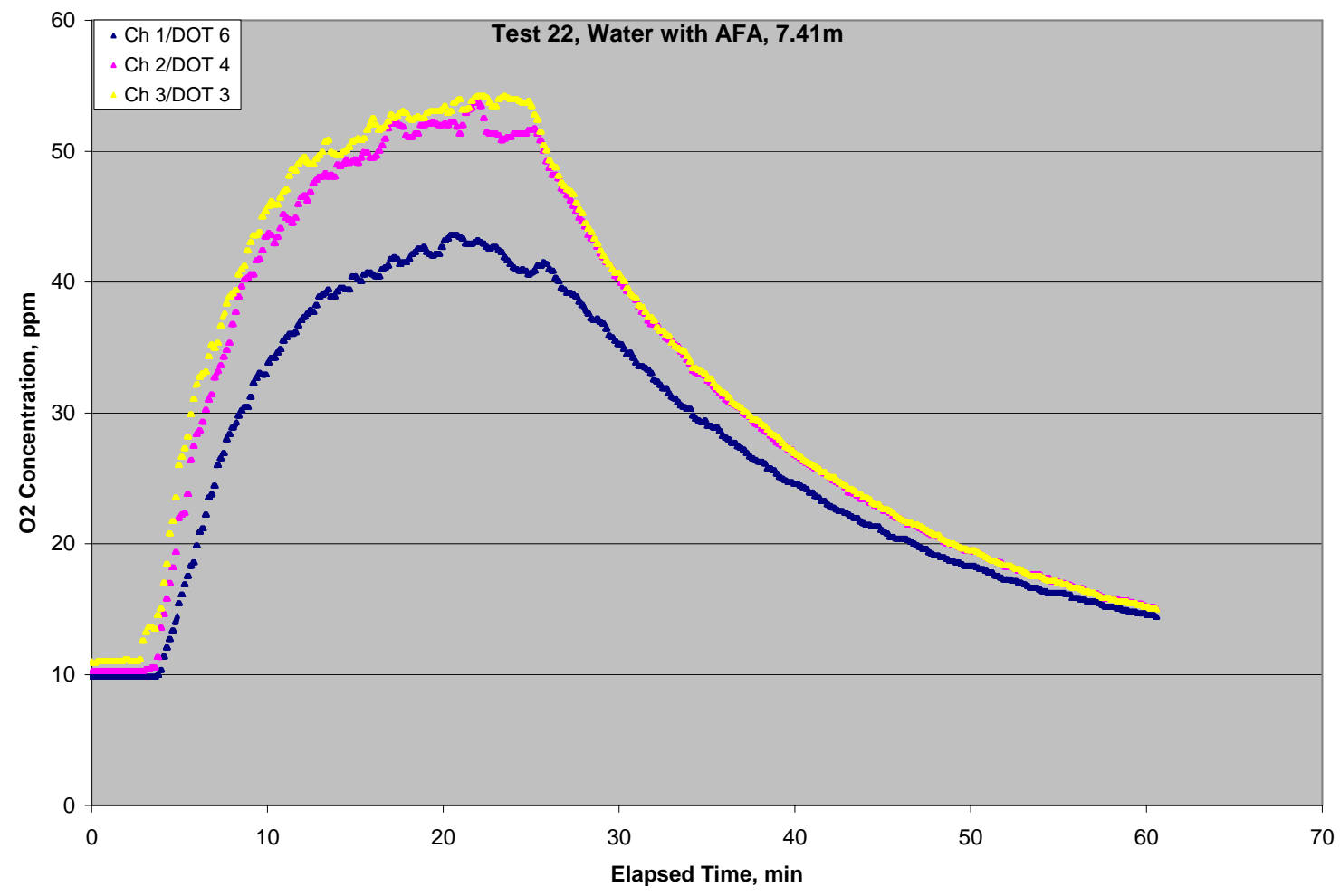

Figure Test 22 Dissolved Oxygen Concentrations

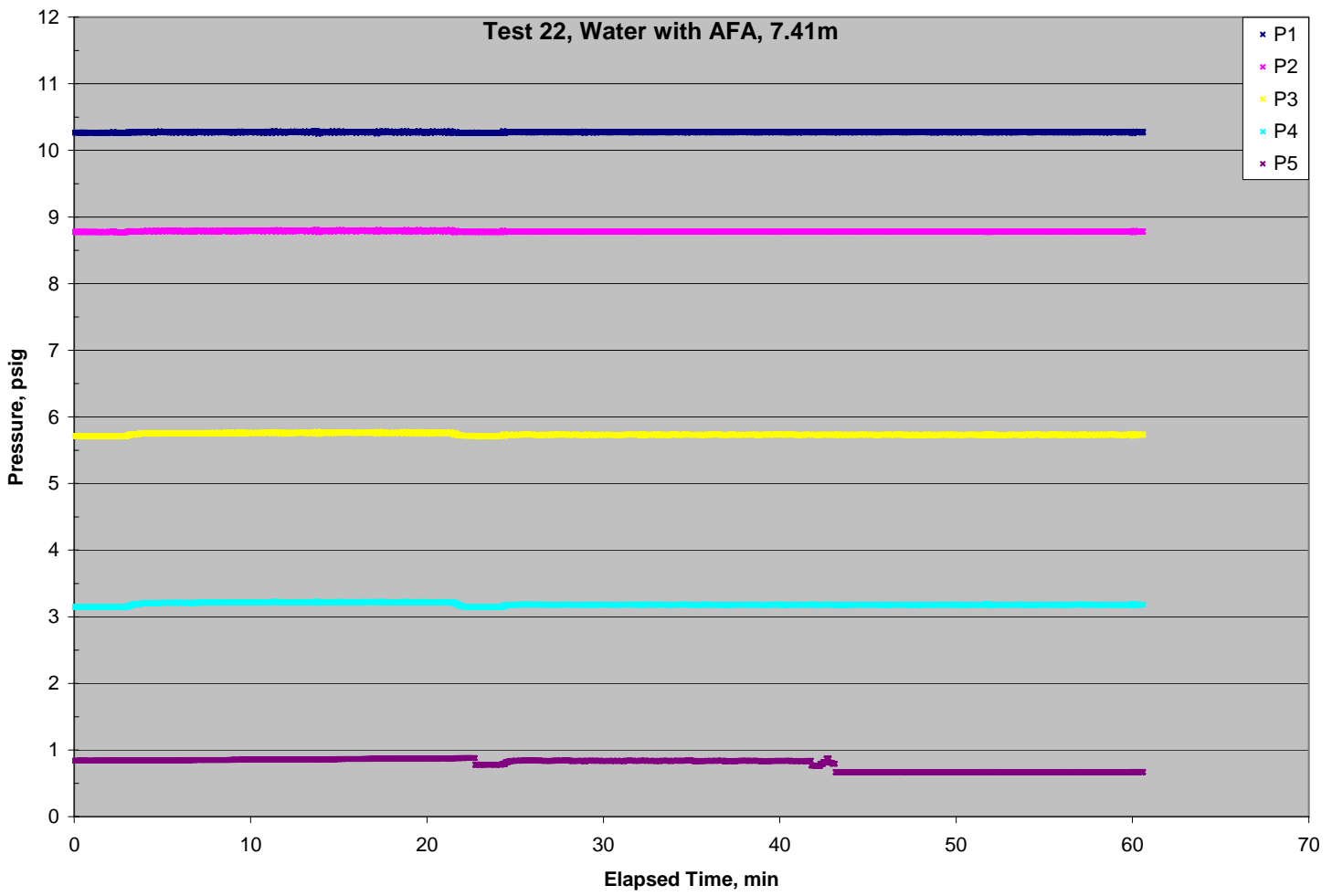

Figure -Test 22 Pressure Transducer Measurements 


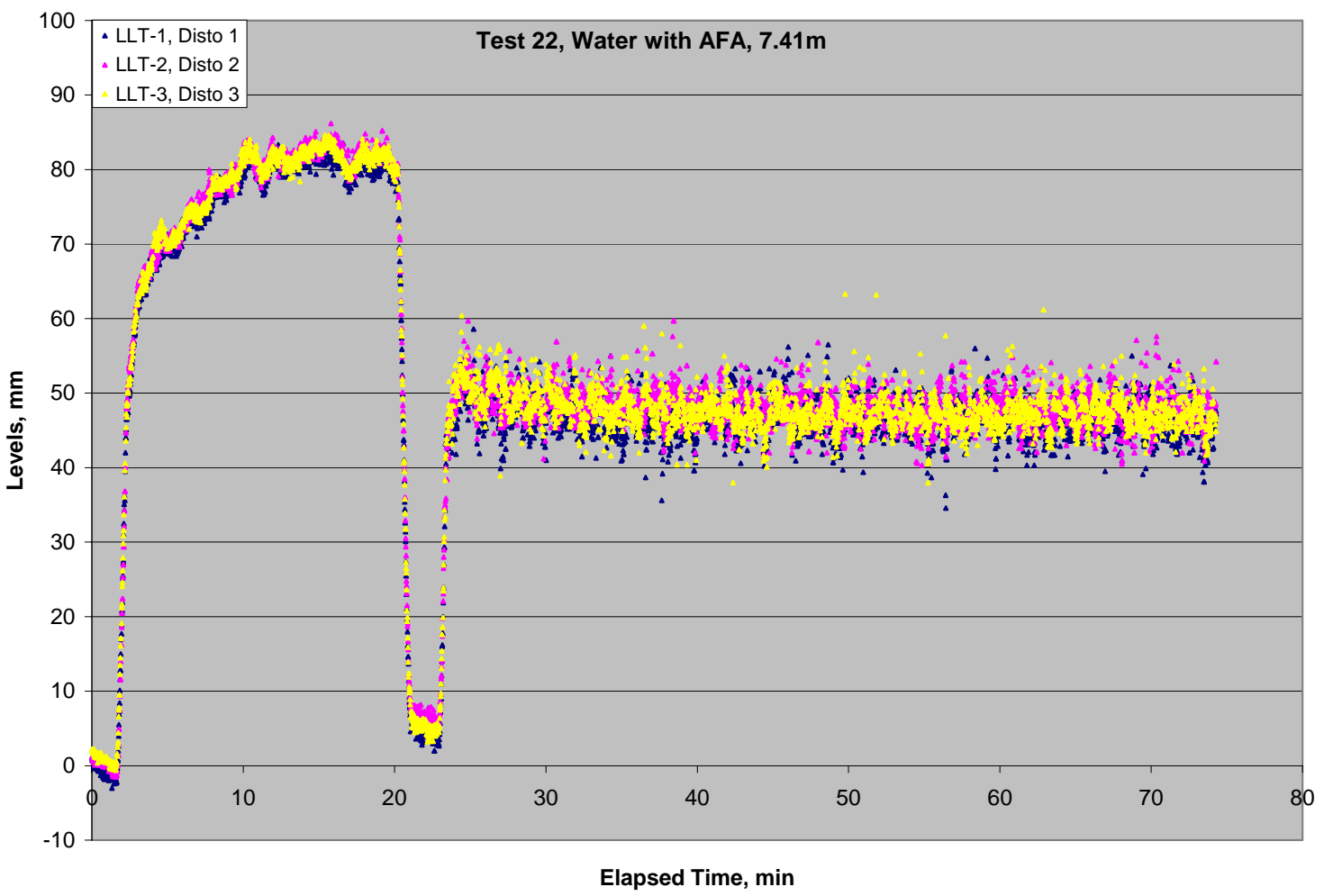

Figure Test 22 Differential Laser Measurements

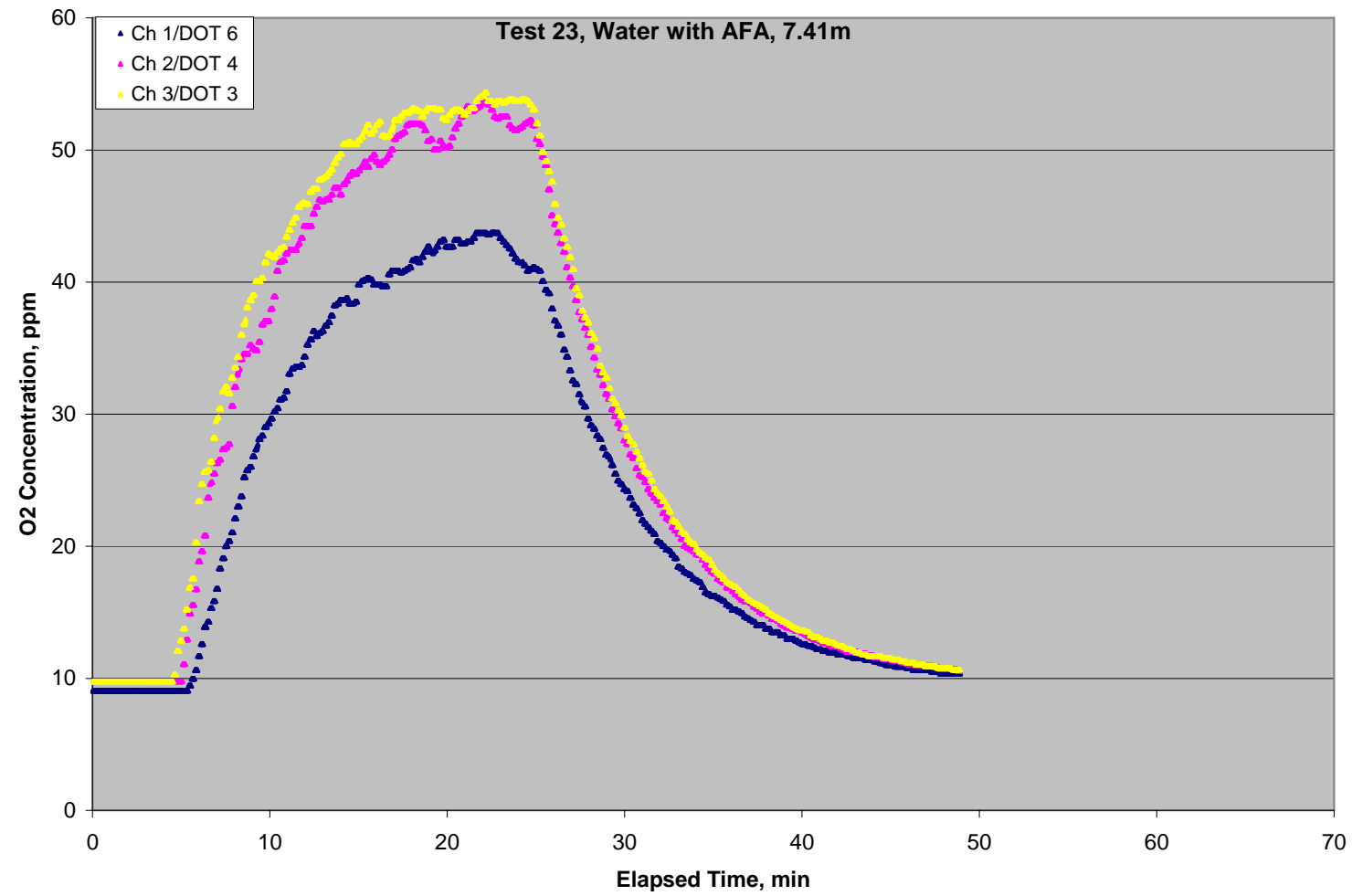

Figure Test 23 Dissolved Oxygen Concentrations 


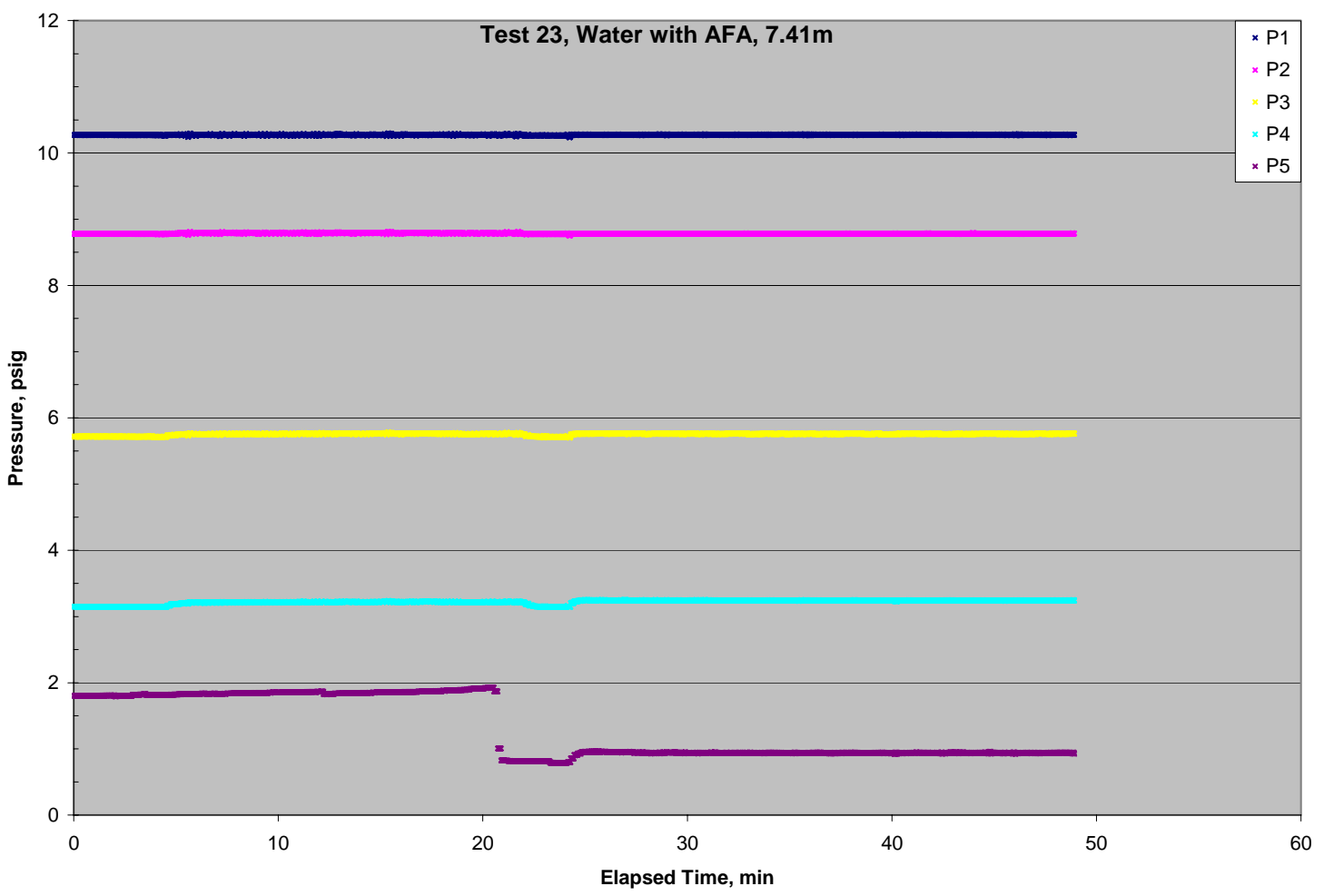

Figure Test 23 Pressure Transducer Measurements

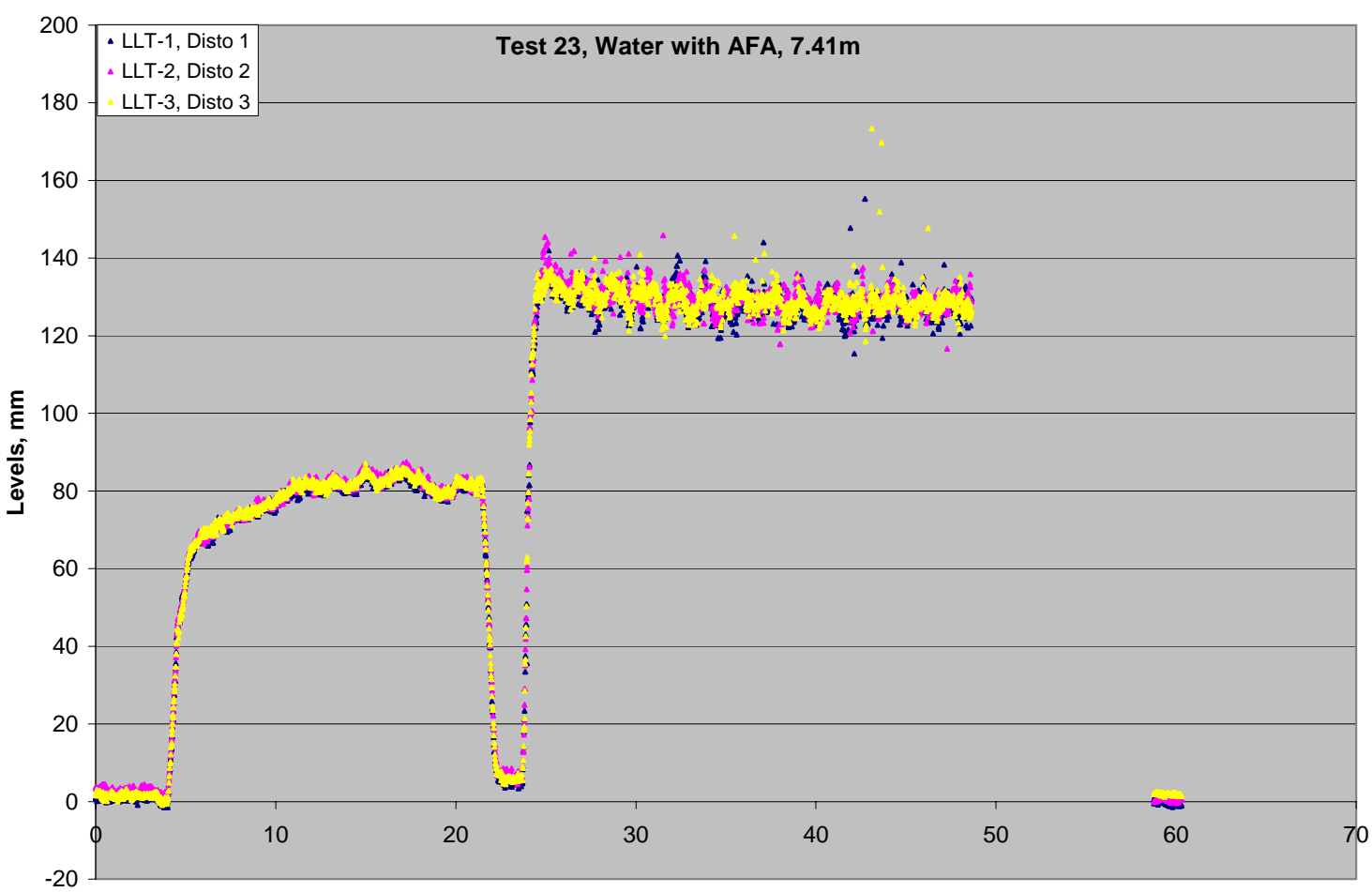

Elapsed Time, min

Figure Test 23 Differential Laser Measurements 


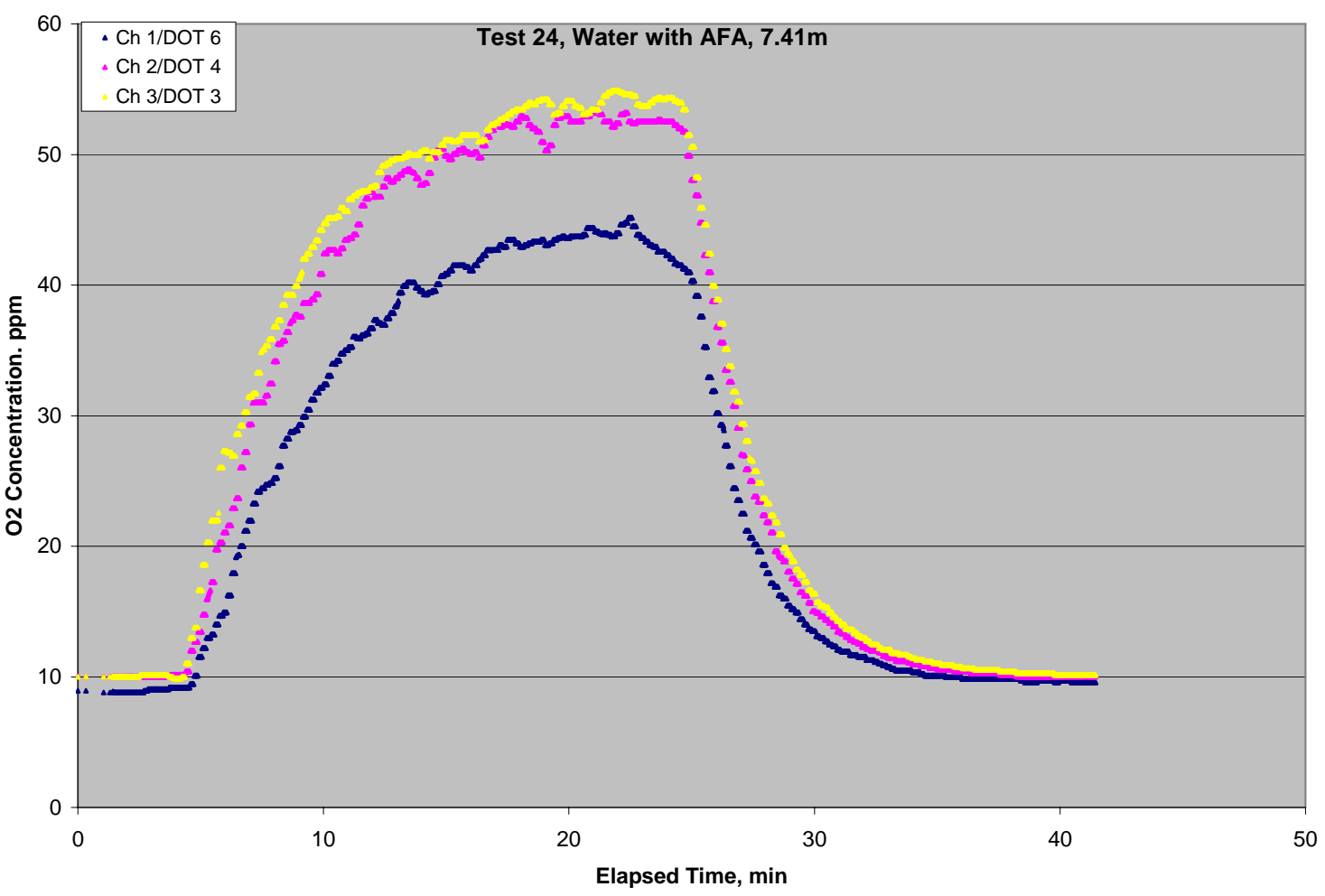

Figure Test 24 Dissolved Oxygen Concentrations

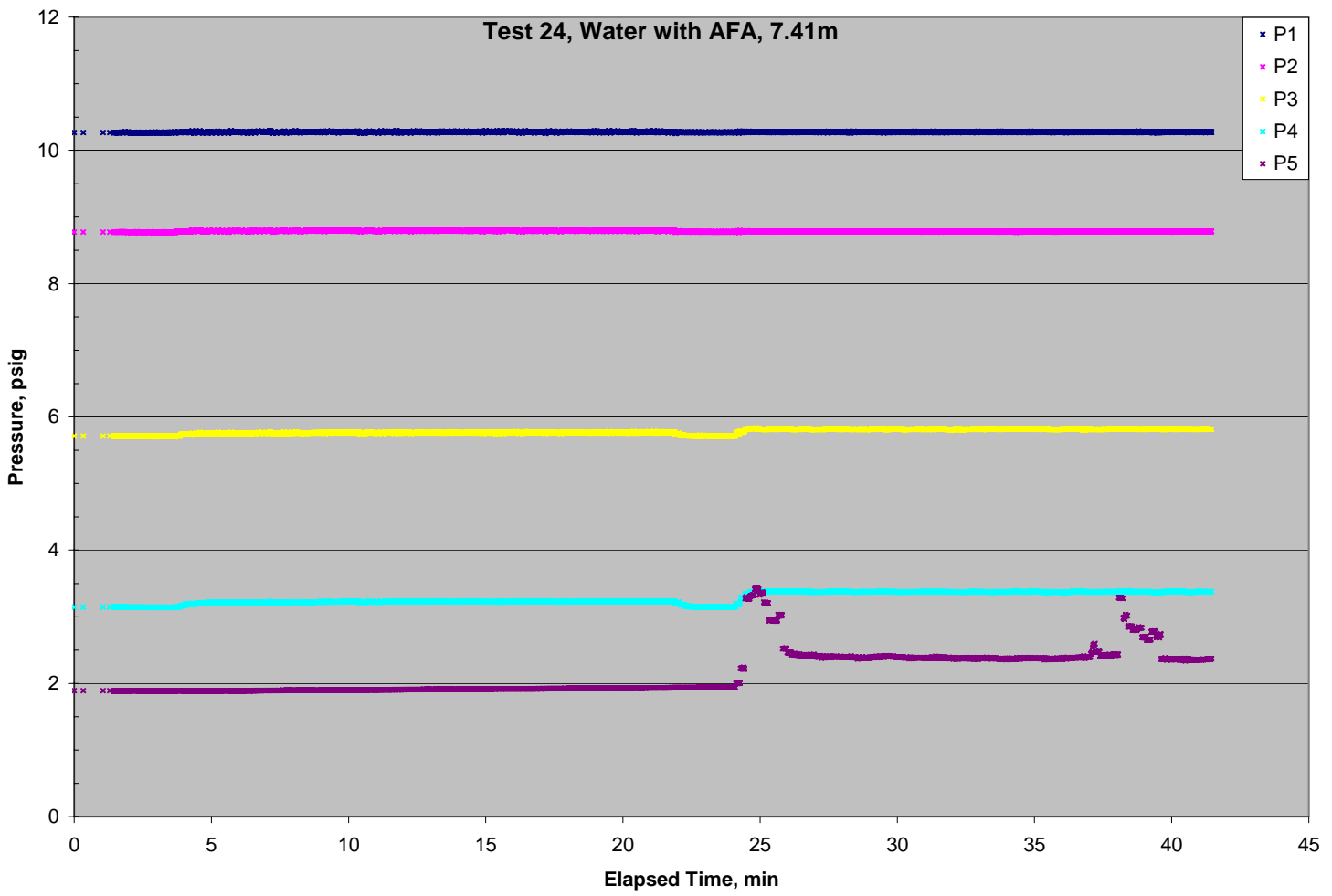

Figure Test 24 Pressure Transducer Measurements 


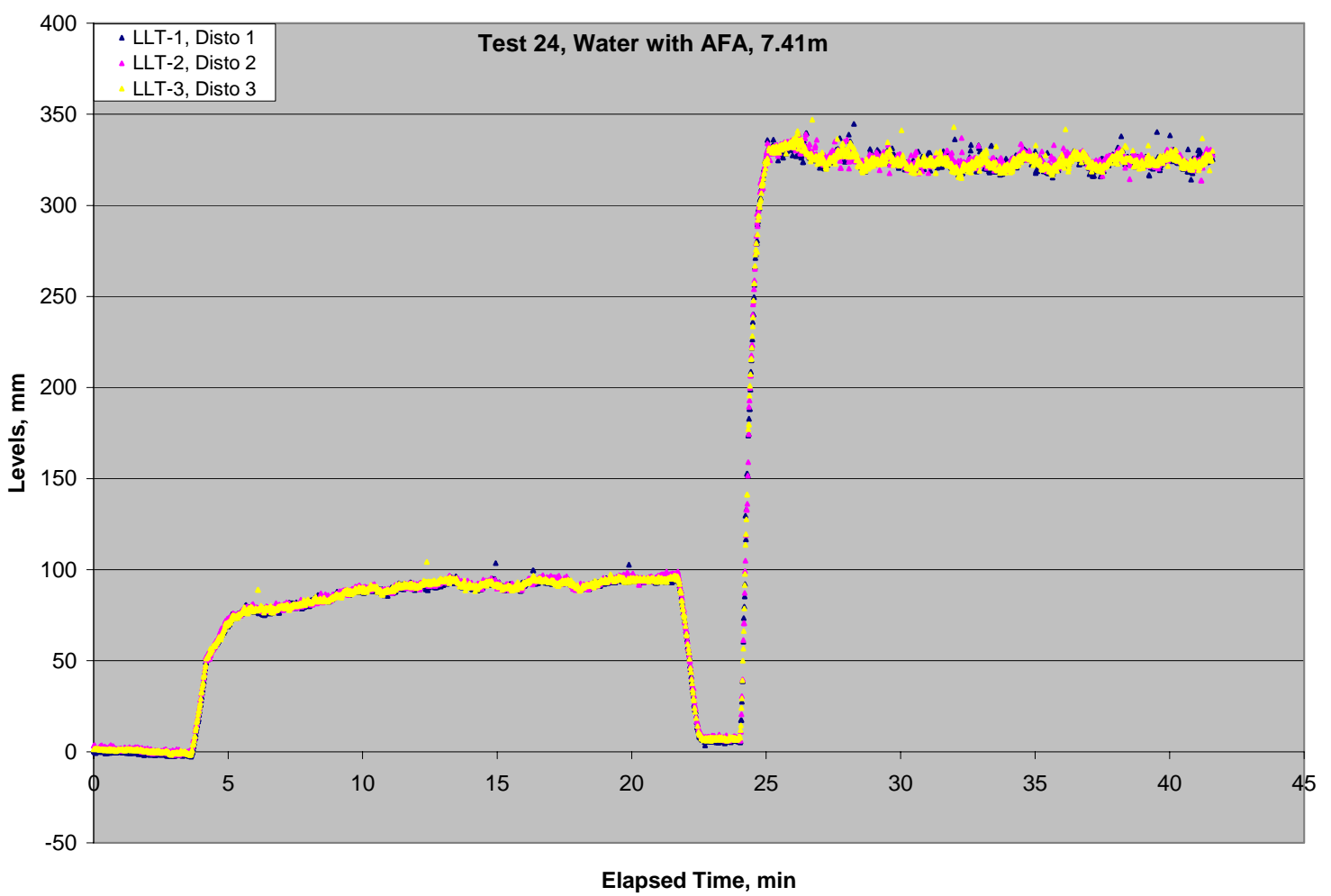

Figure Test 24 Differential Laser Measurements

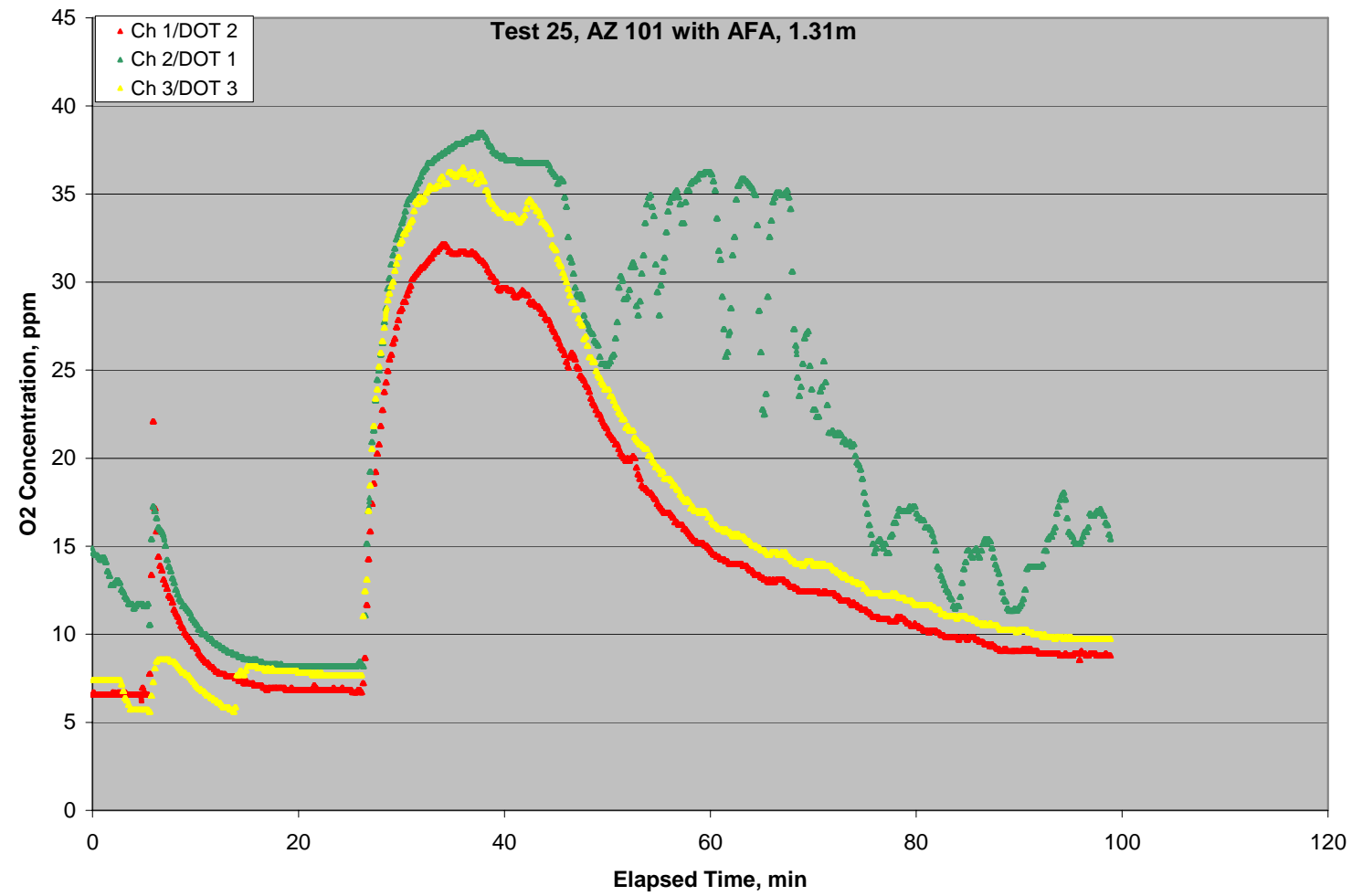

Figure Test 25 Dissolved Oxygen Concentrations 


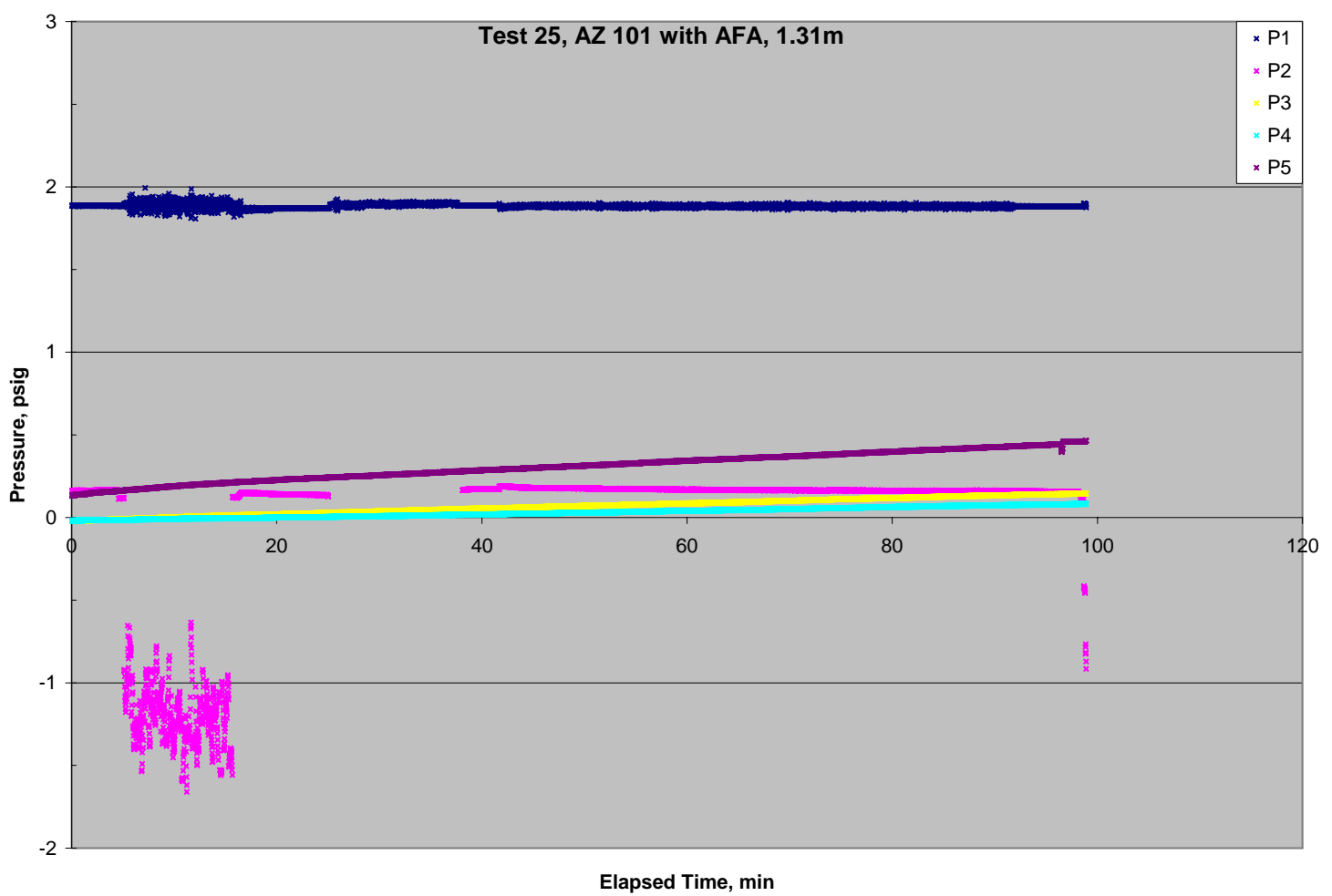

Figure -Test 25 Pressure Transducer Measurements

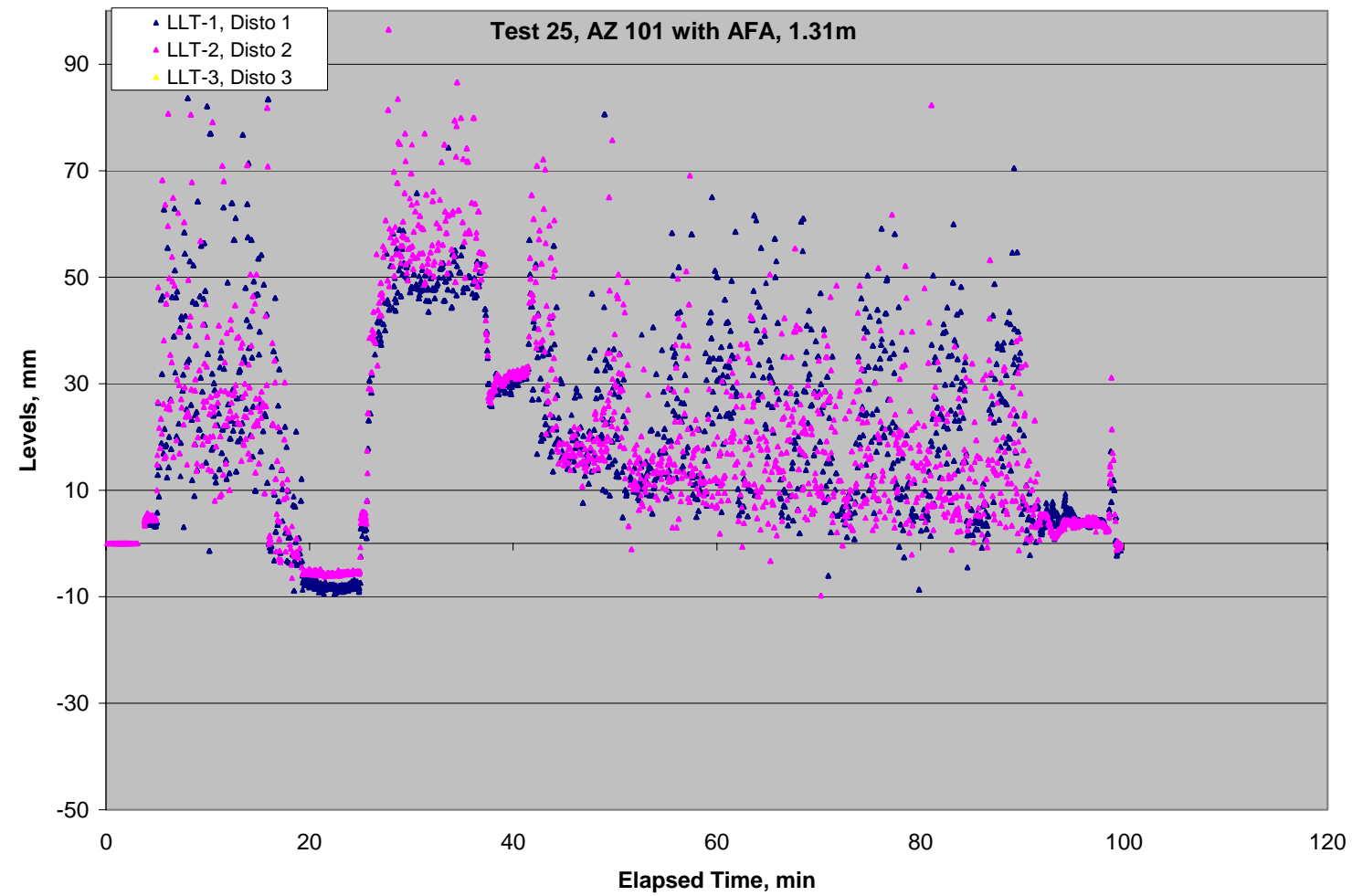

Figure -Test 25 Differential Laser Measurements 


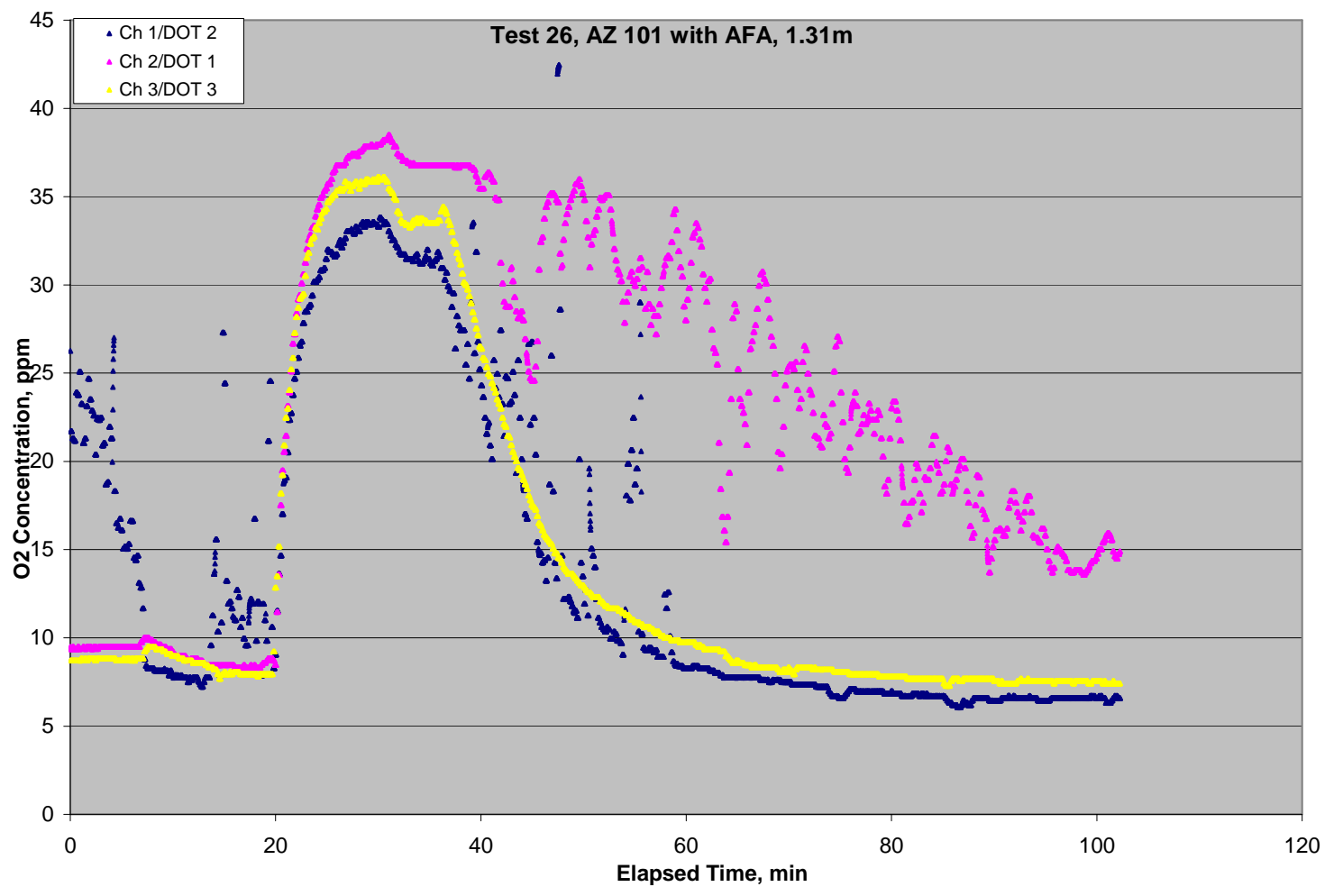

Figure Test 26 Dissolved Oxygen Concentrations

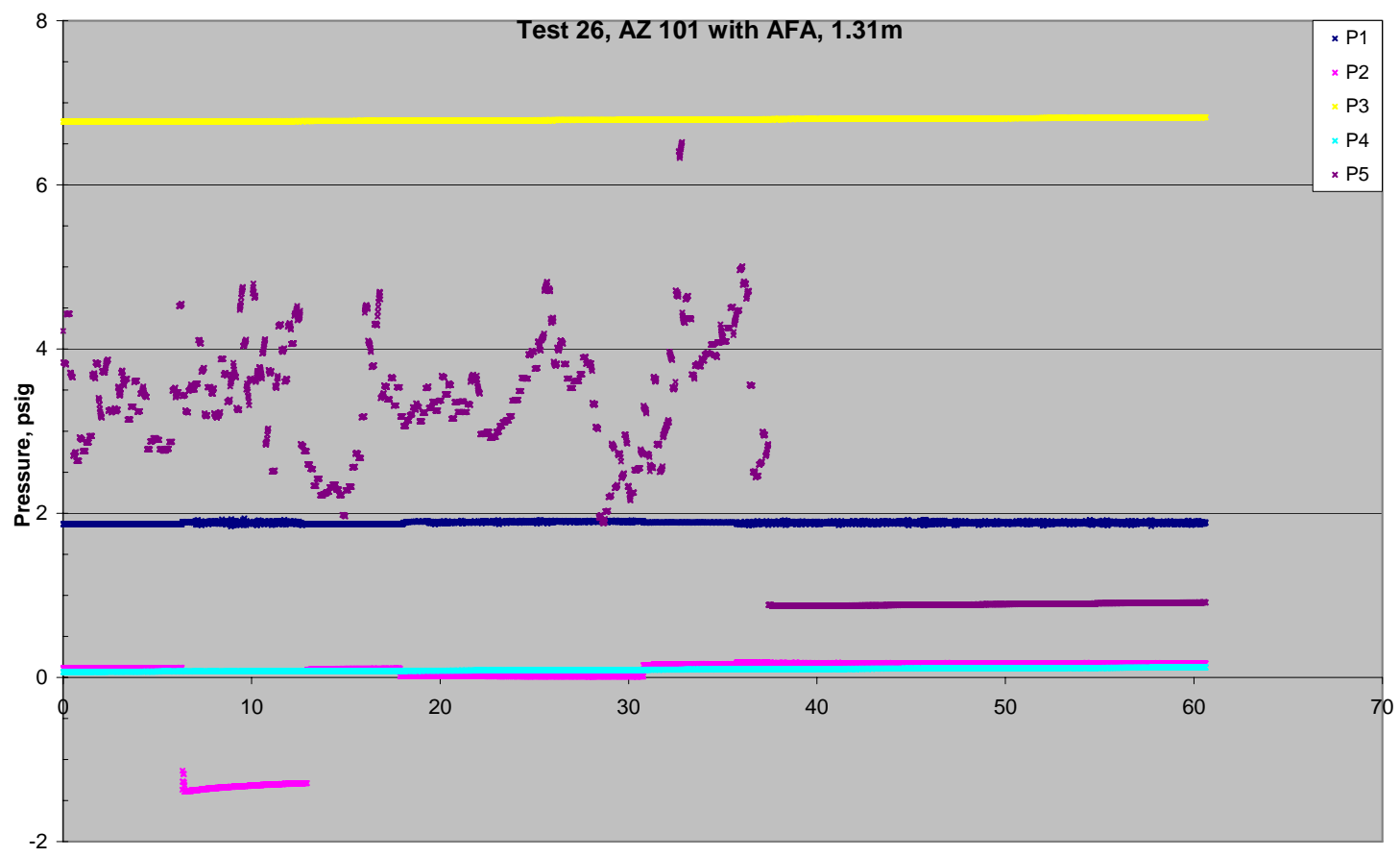

Elapsed Time, $\min$

Figure Test 26 Pressure Transducer Measurements 


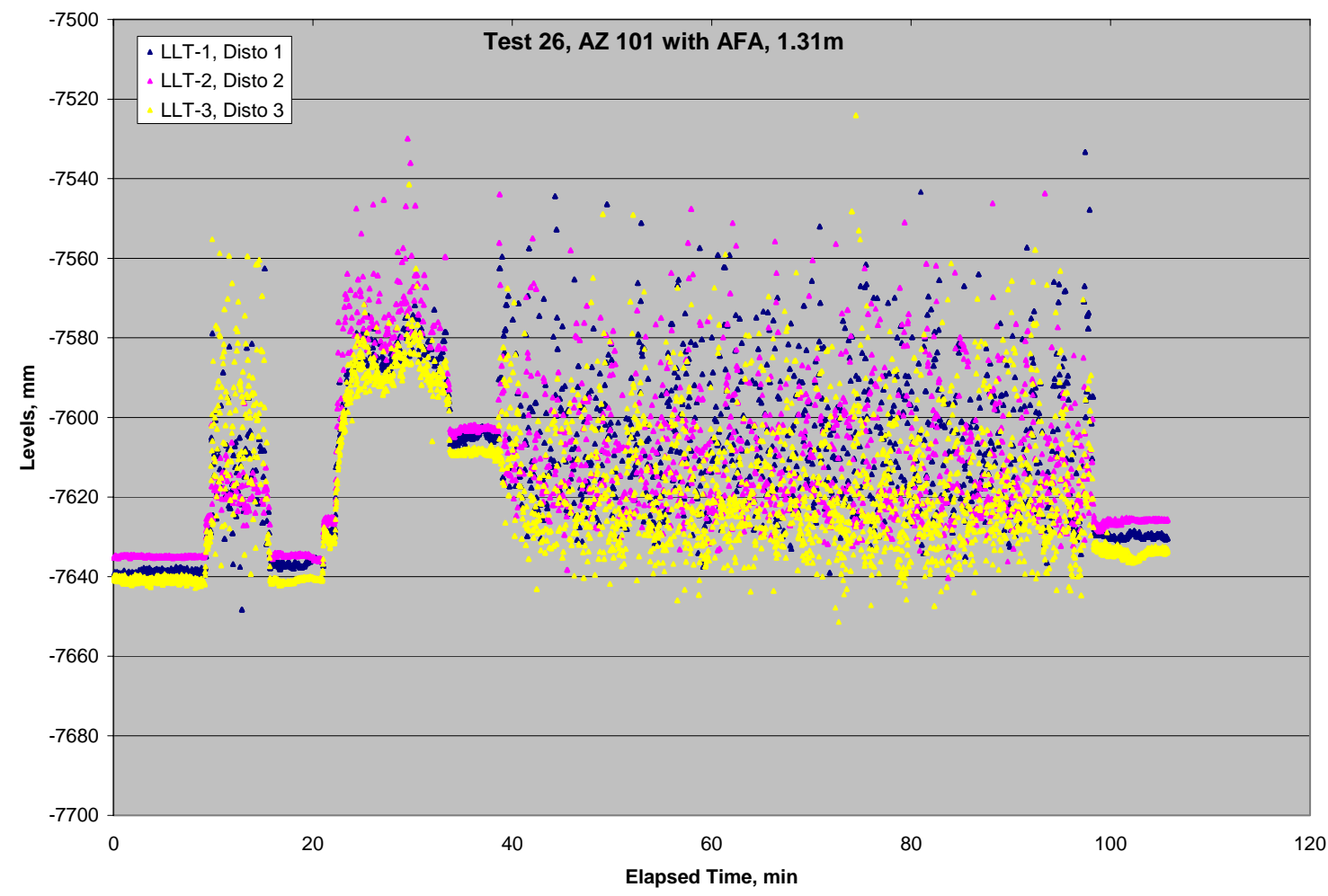

Figure Test 26 Differential Laser Measurements

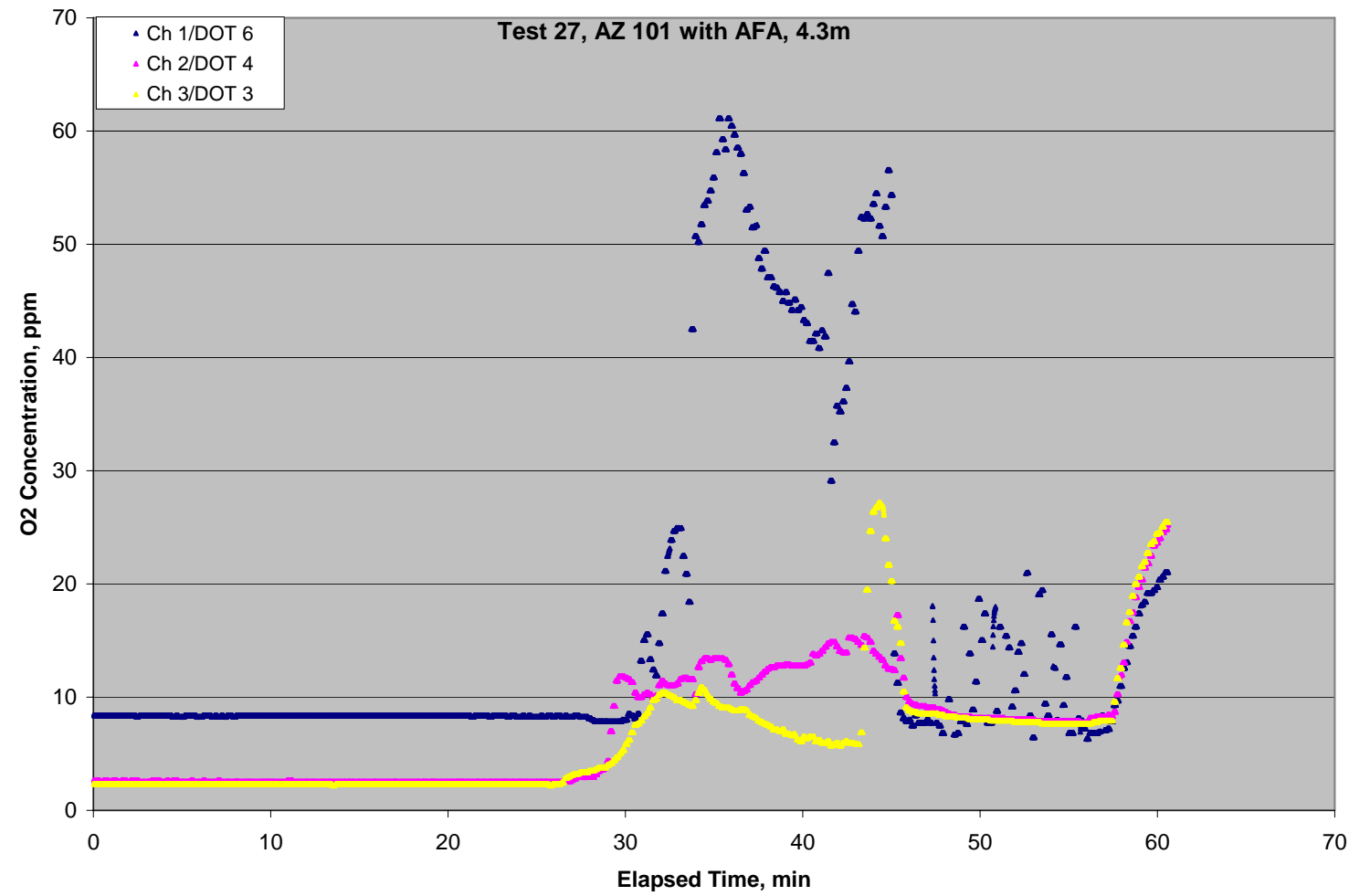

Figure -Test 27 Dissolved Oxygen Concentrations 


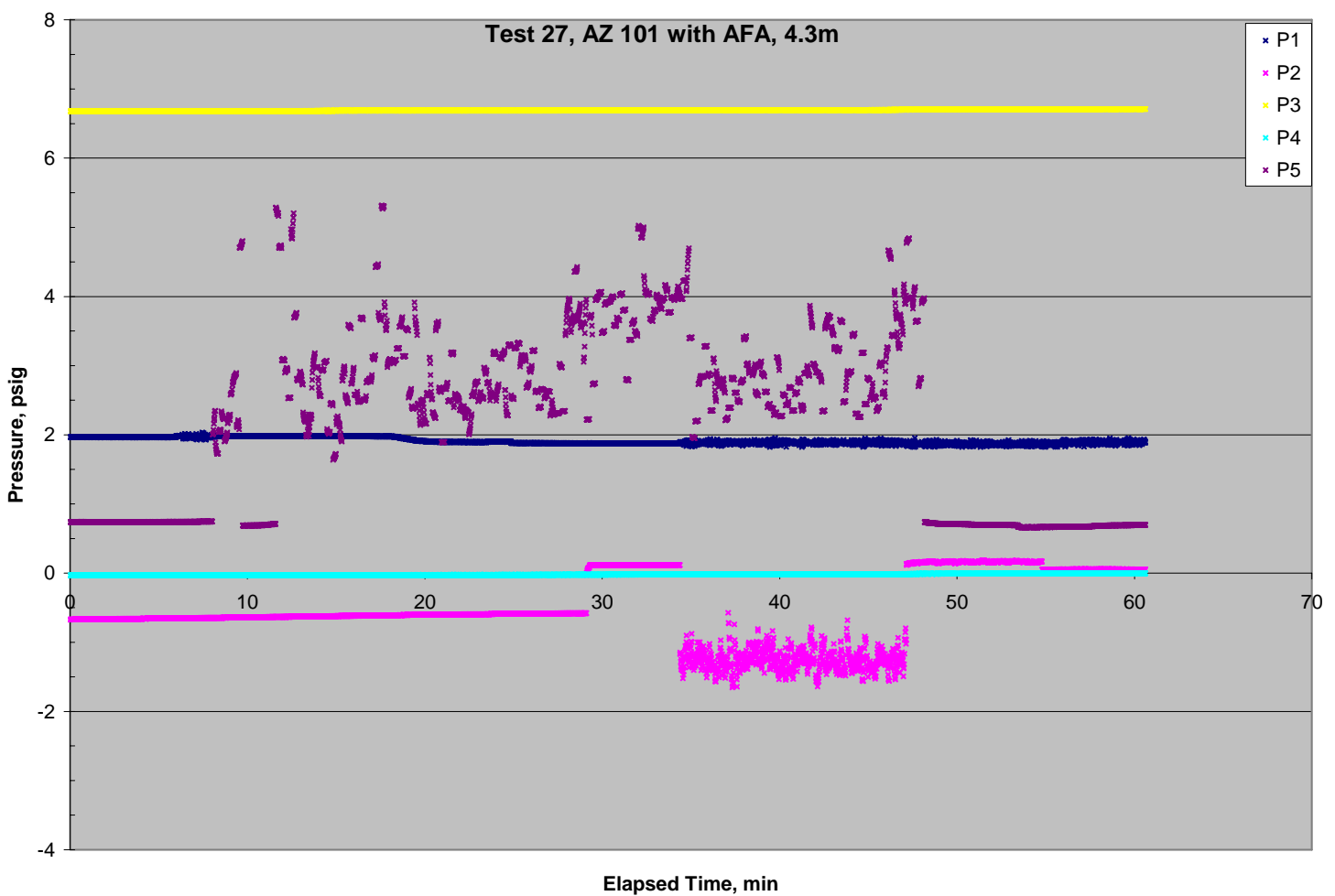

Figure Test 27 Pressure Transducer Measurements

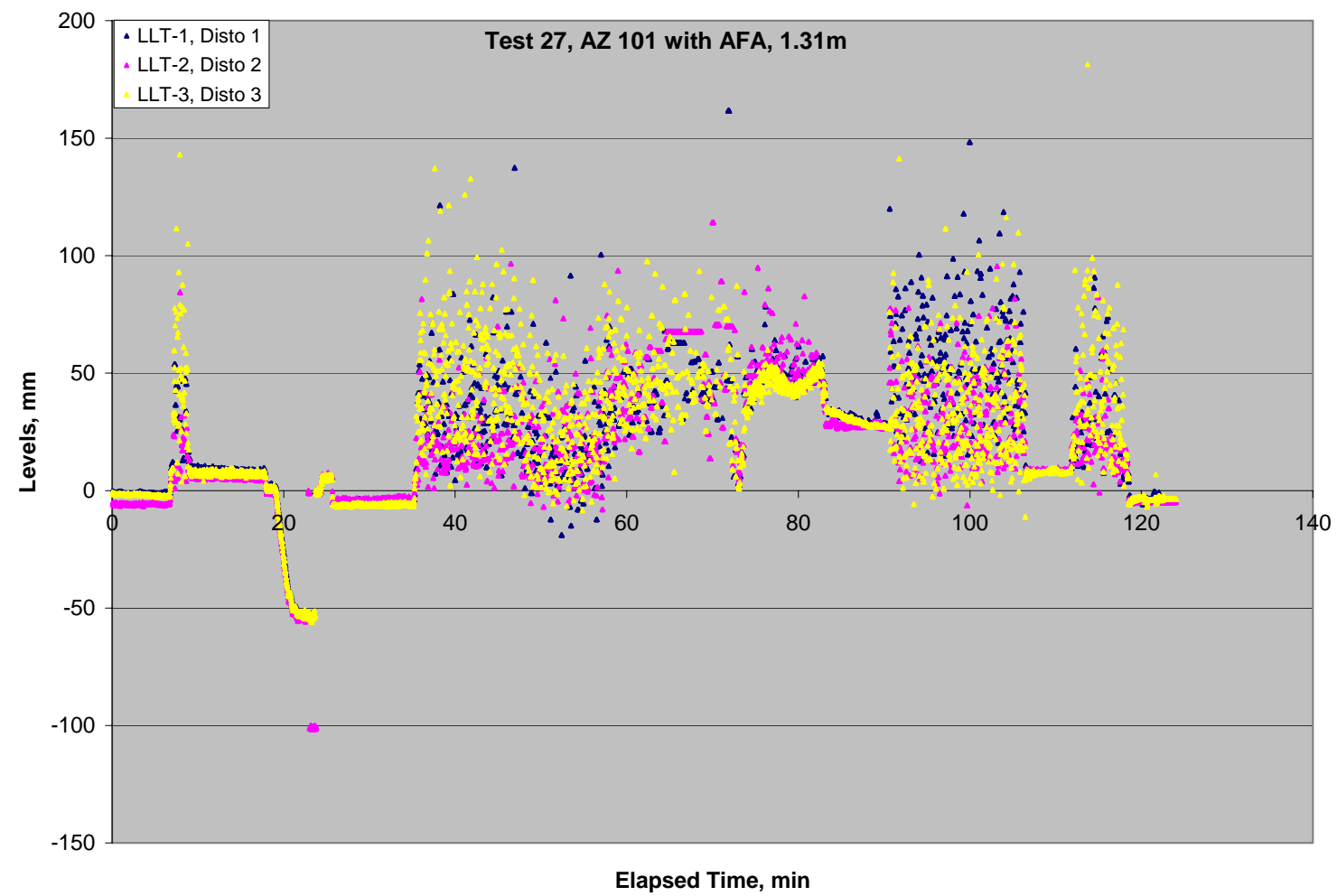

Figure Test 27 Differential Laser Measurements 


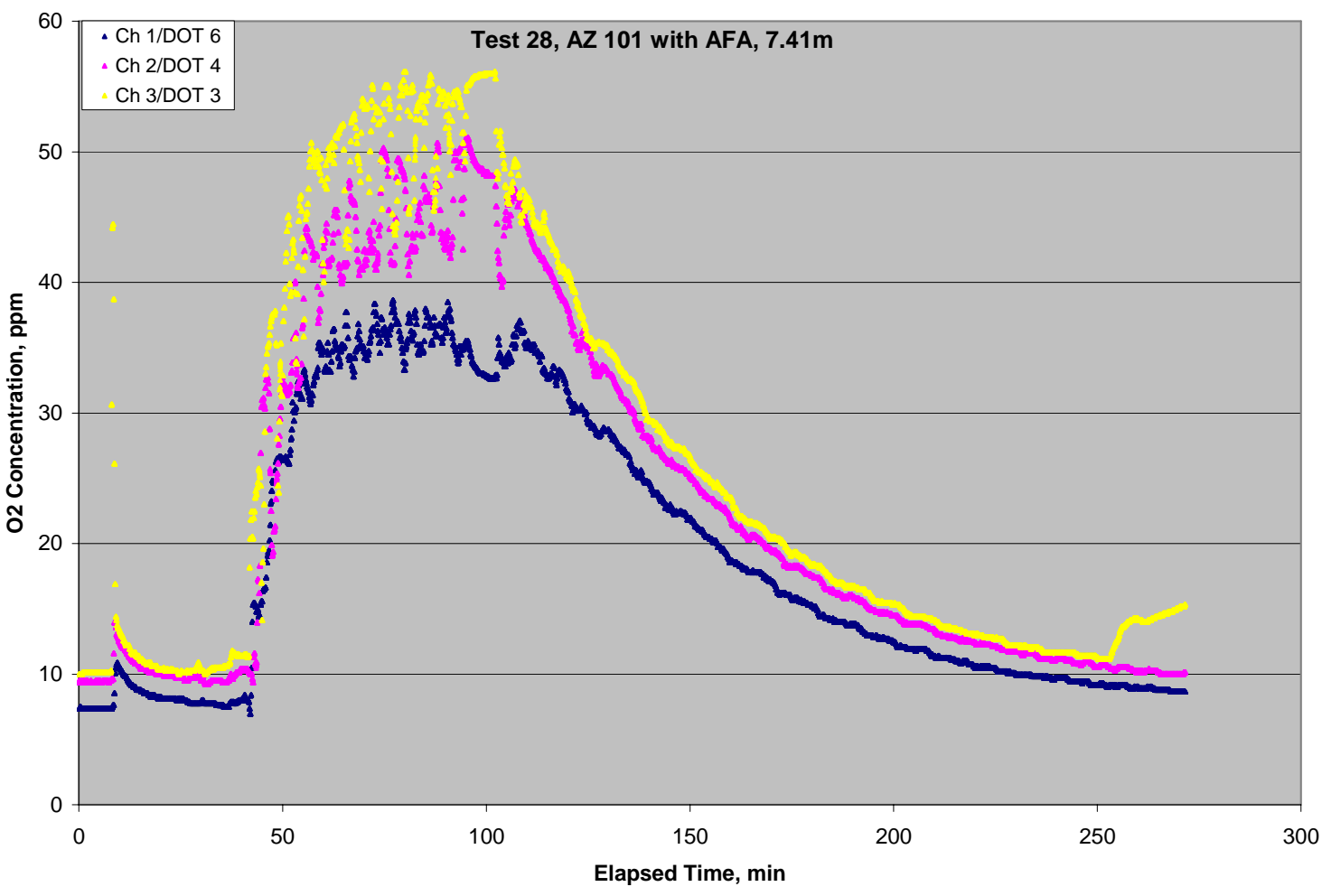

Figure Test 28 Dissolved Oxygen Concentrations

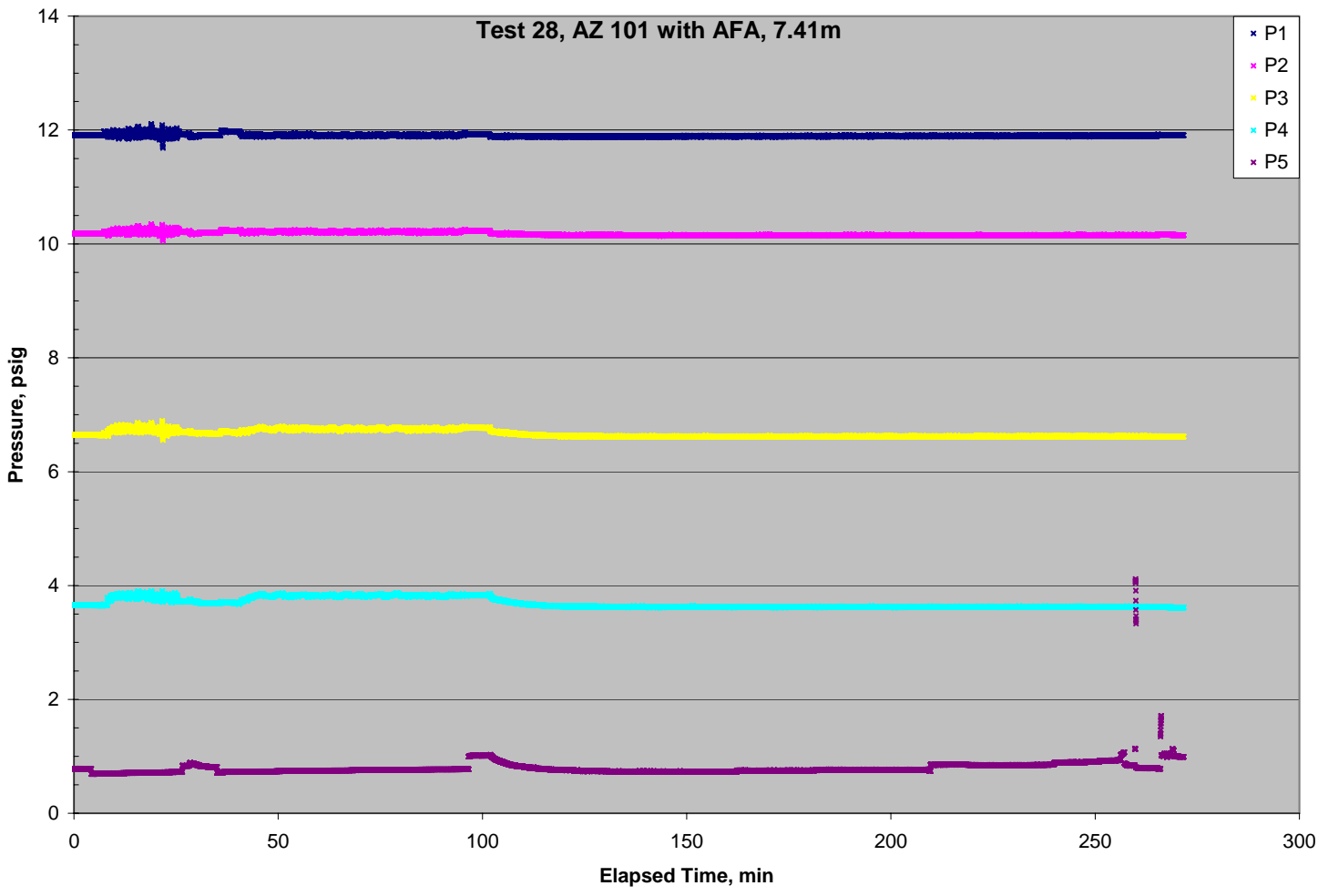

Figure Test 28 Pressure Transducer Measurements 


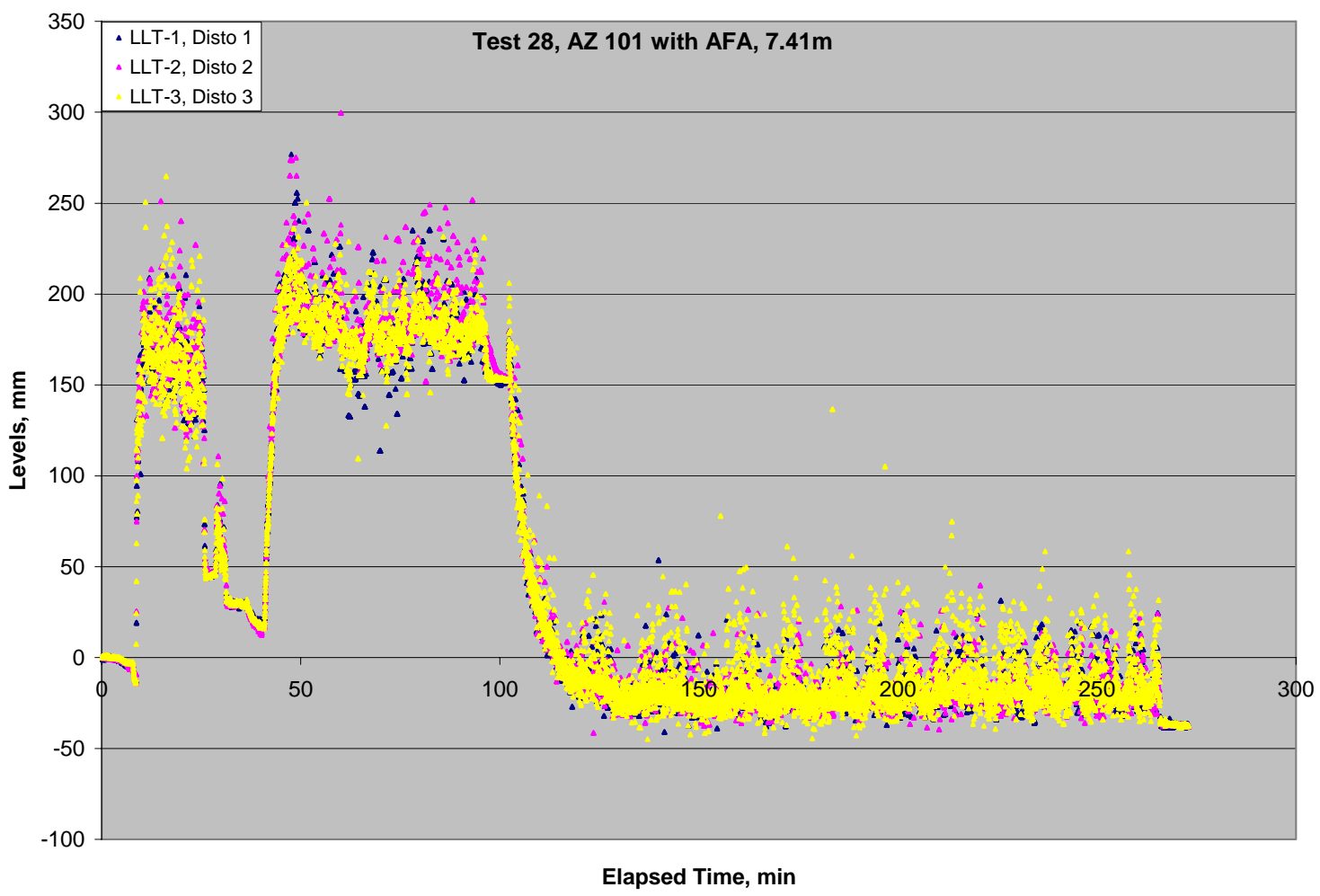

Figure Test 28 Differential Laser Measurements

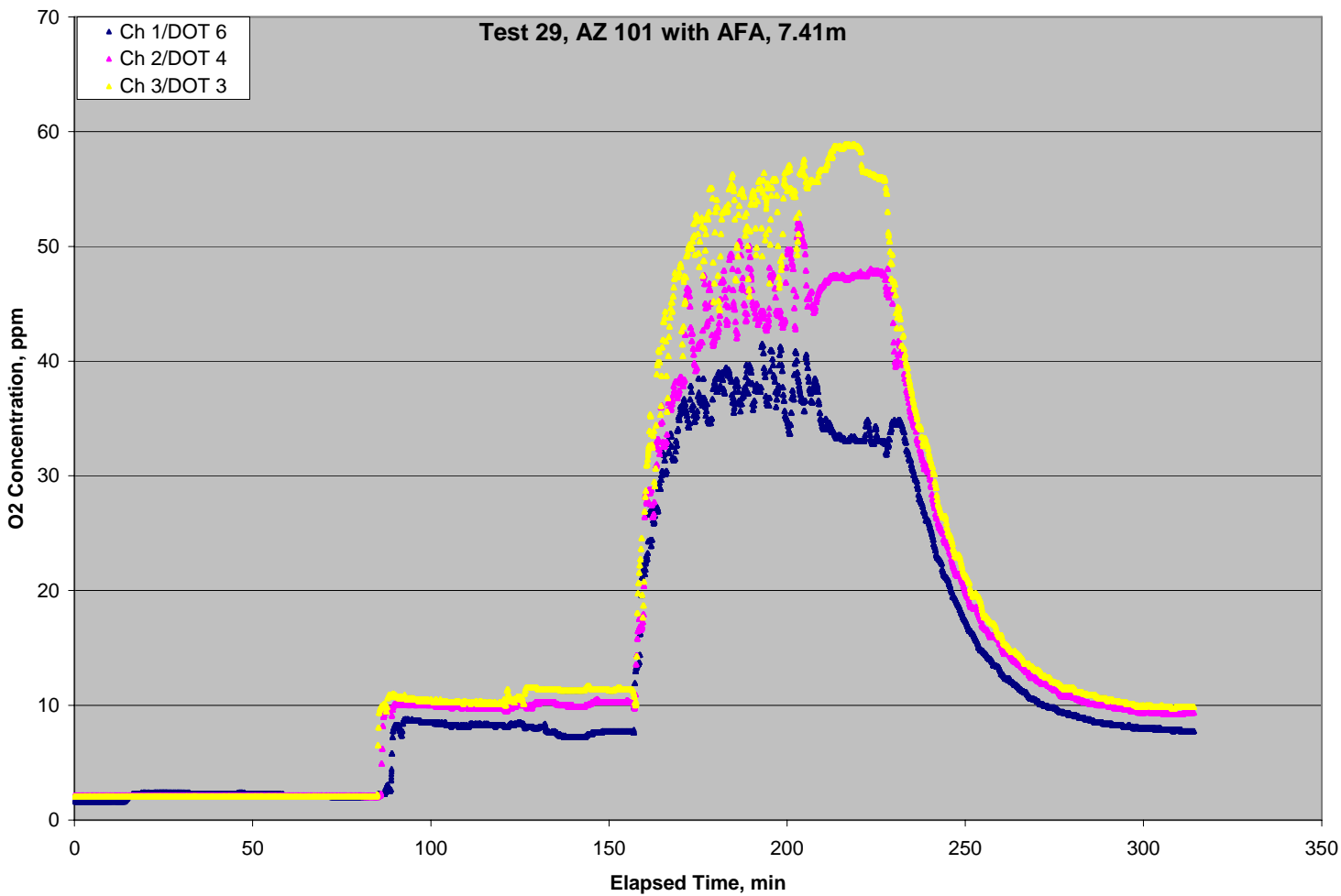

Figure Test 29 Dissolved Oxygen Concentrations 


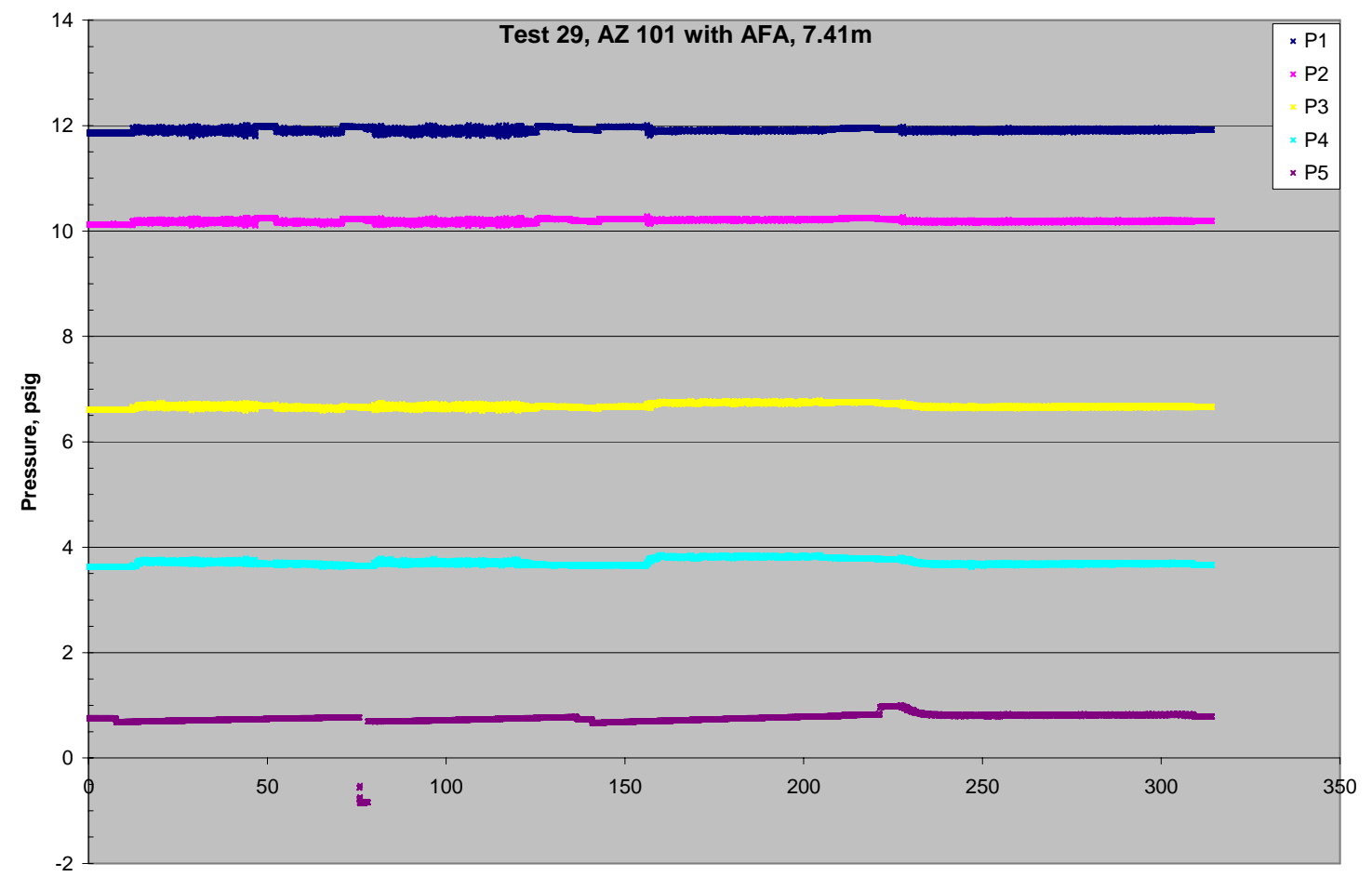

Elapsed Time, $\min$

Figure -Test 29 Pressure Transducer Measurements

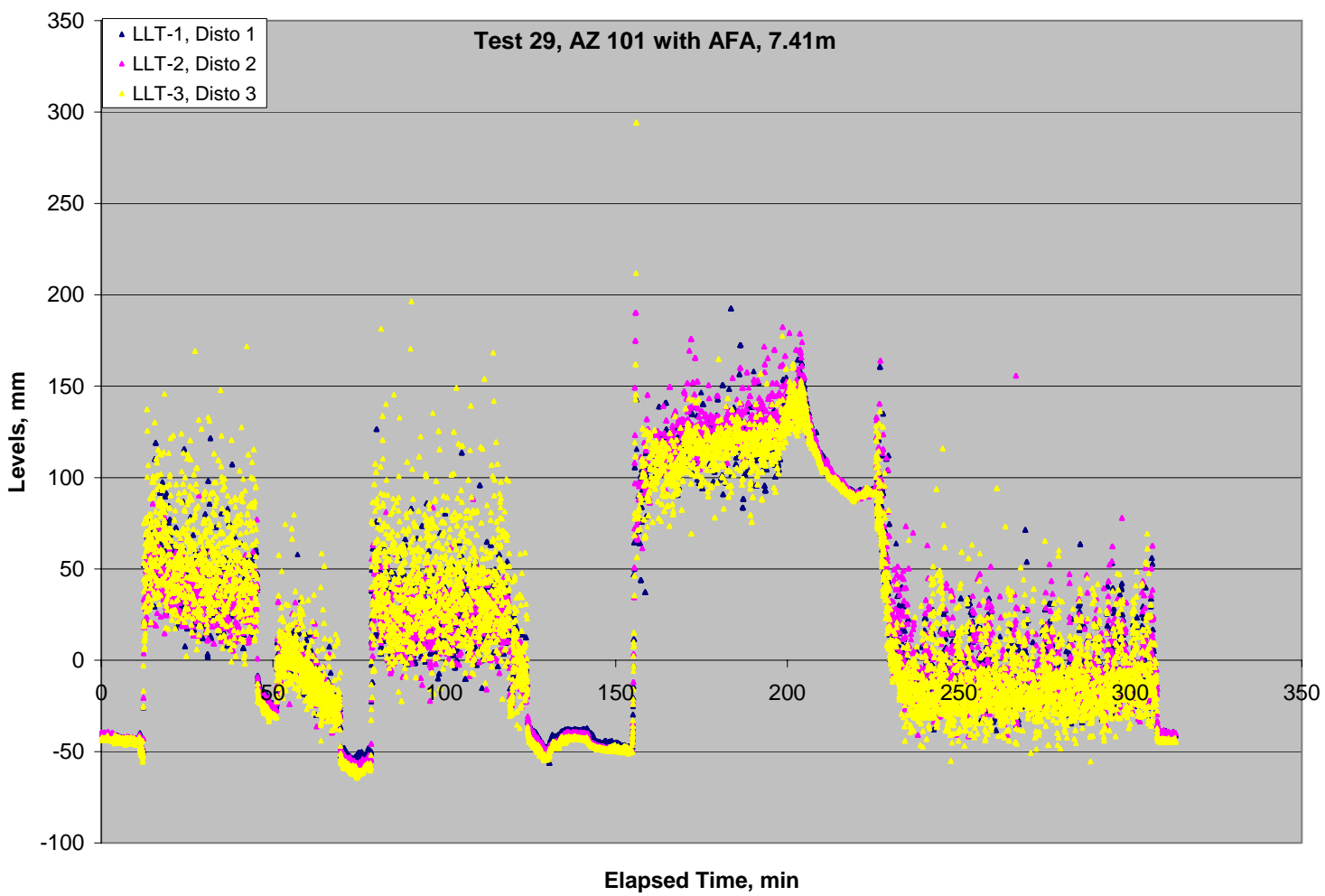

Figure Test 29 Differential Laser Measurements 


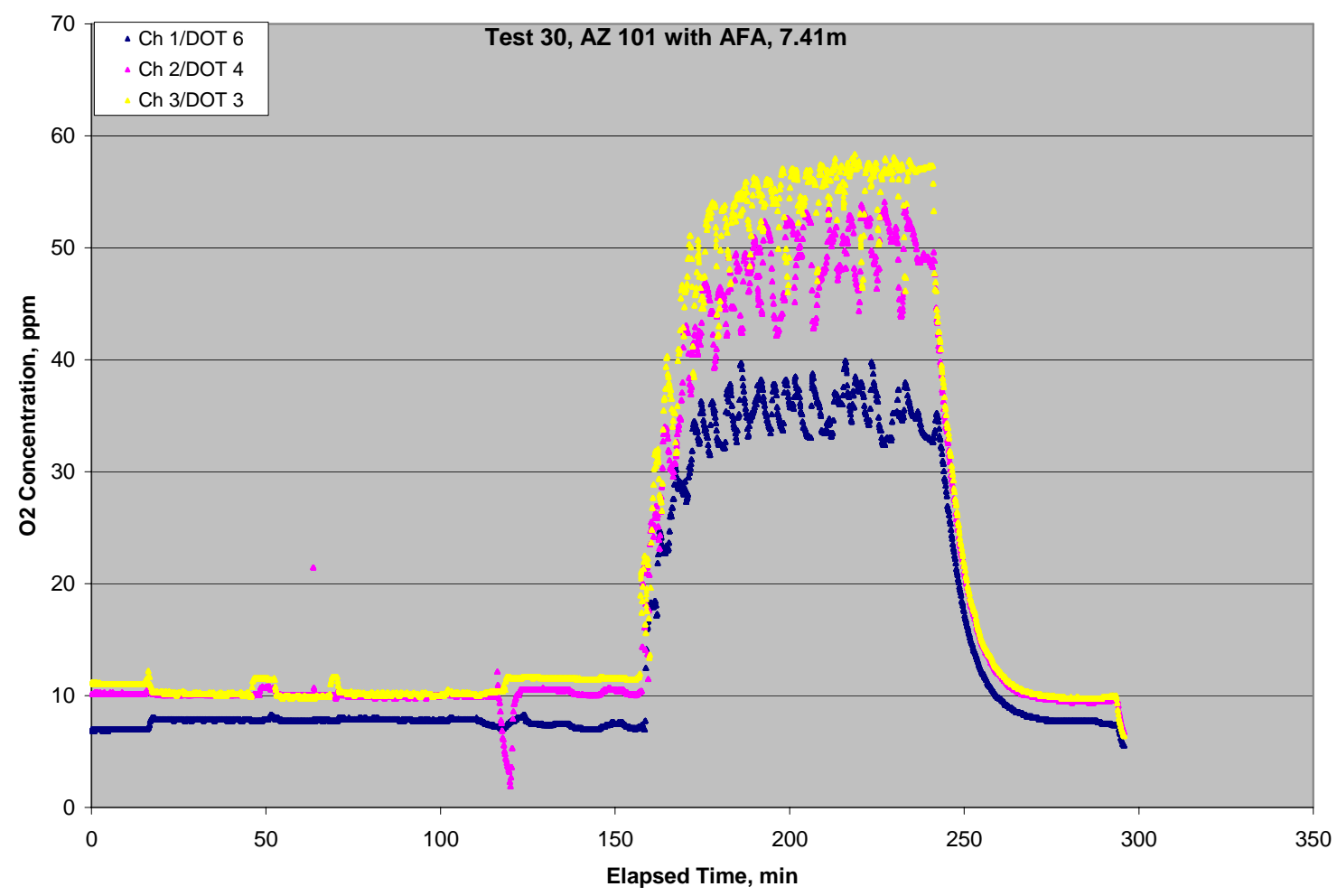

Figure -Test 30 Dissolved Oxygen Concentrations

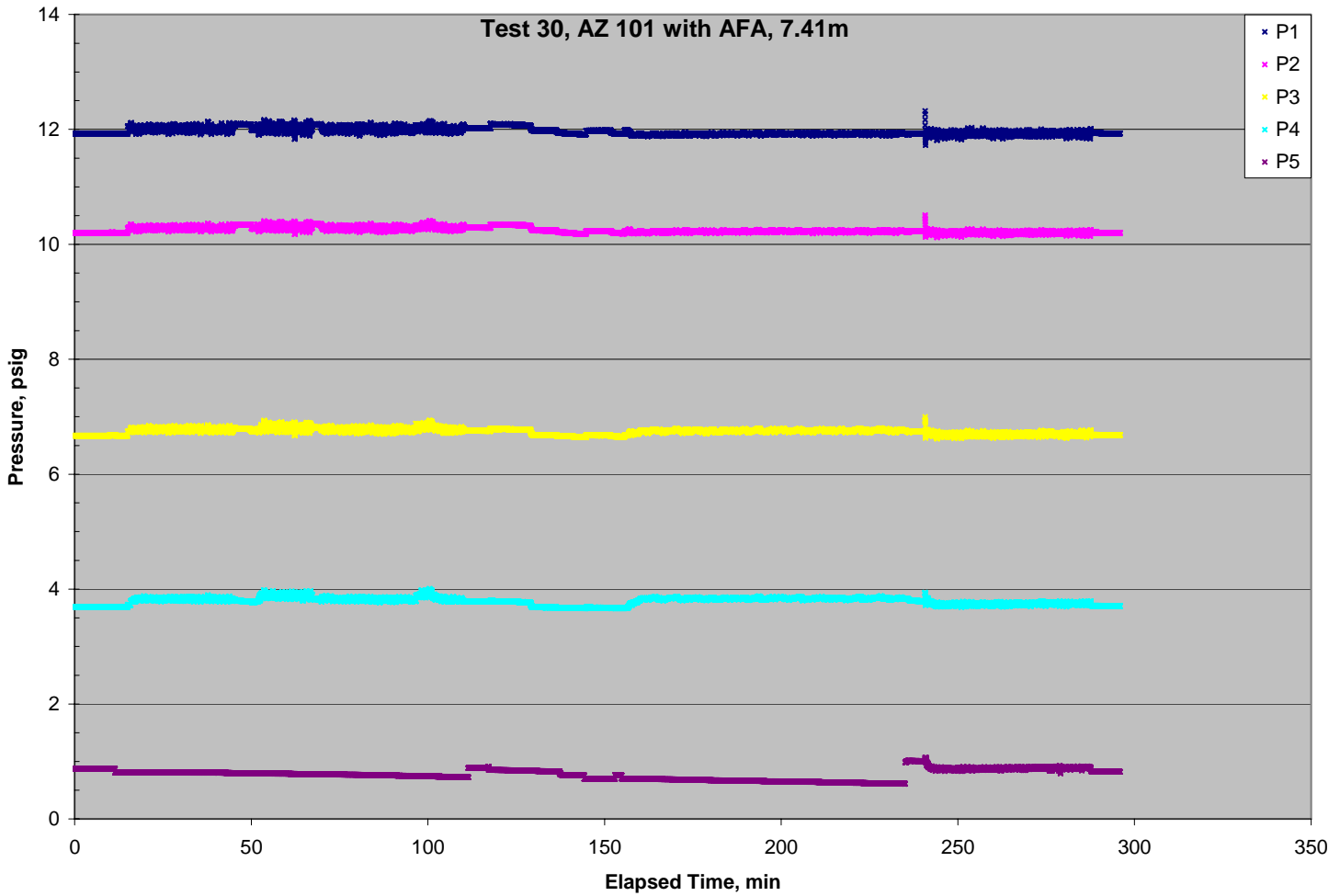

Figure Test 30 Pressure Transducer Measurements 


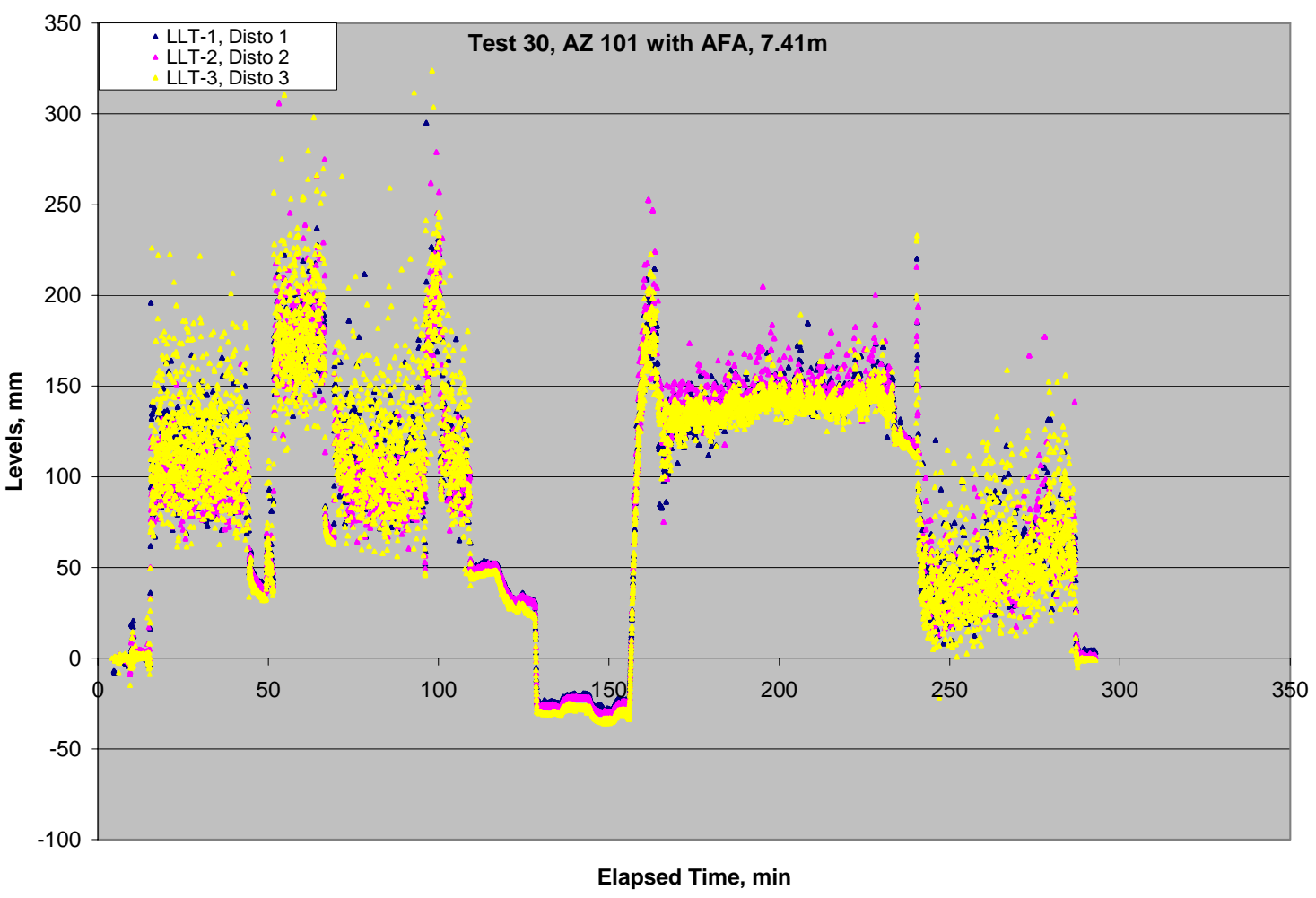

Figure Test 30 Differential Laser Measurements 
WSRC-STI-2007-00537, REVISION 0

SRNL-RPP-2007-00023, REVISION 0

\section{APPENDIX D. $K_{L}$ A CALCULATIONS}




\section{APPENDIX D: MASS TRANSFER CALCULATIONS}
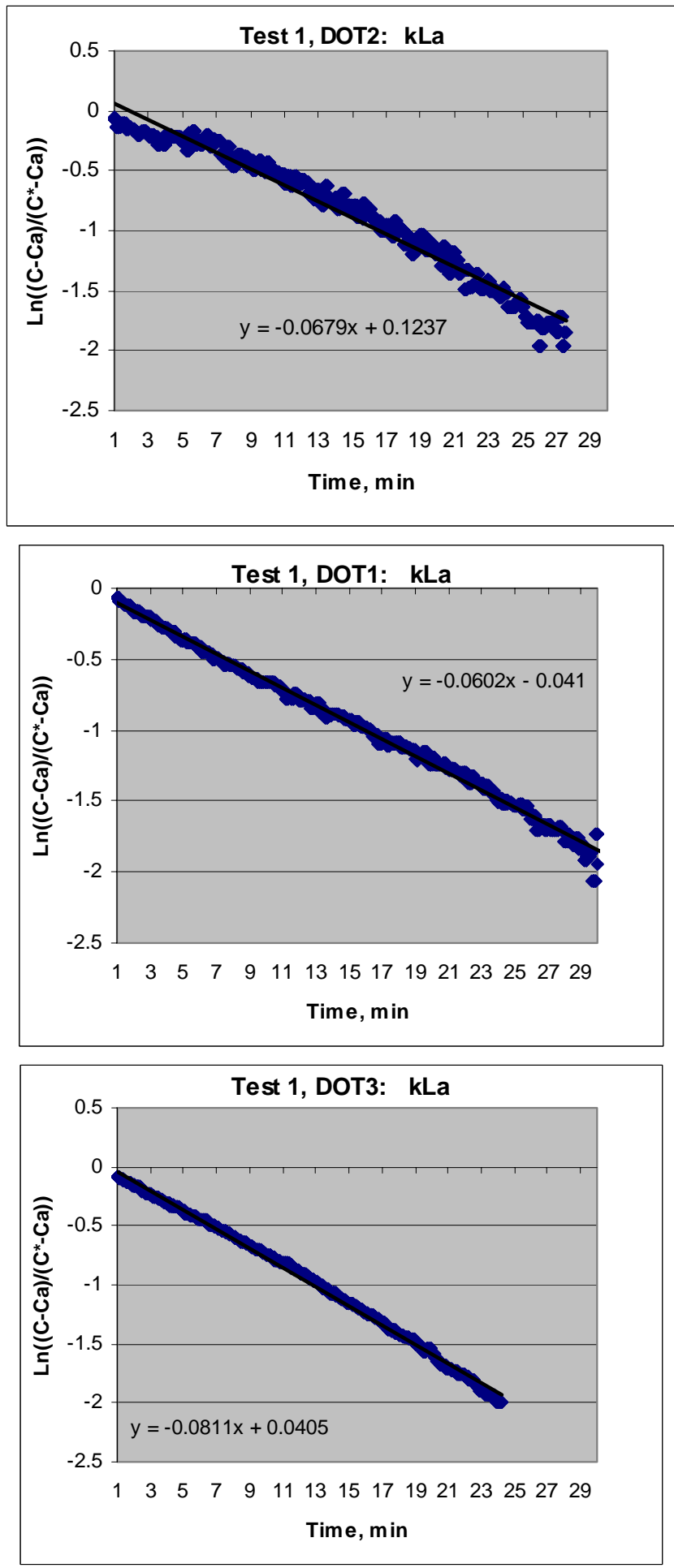

Figure Test 1 Mass Transfer Calculation 

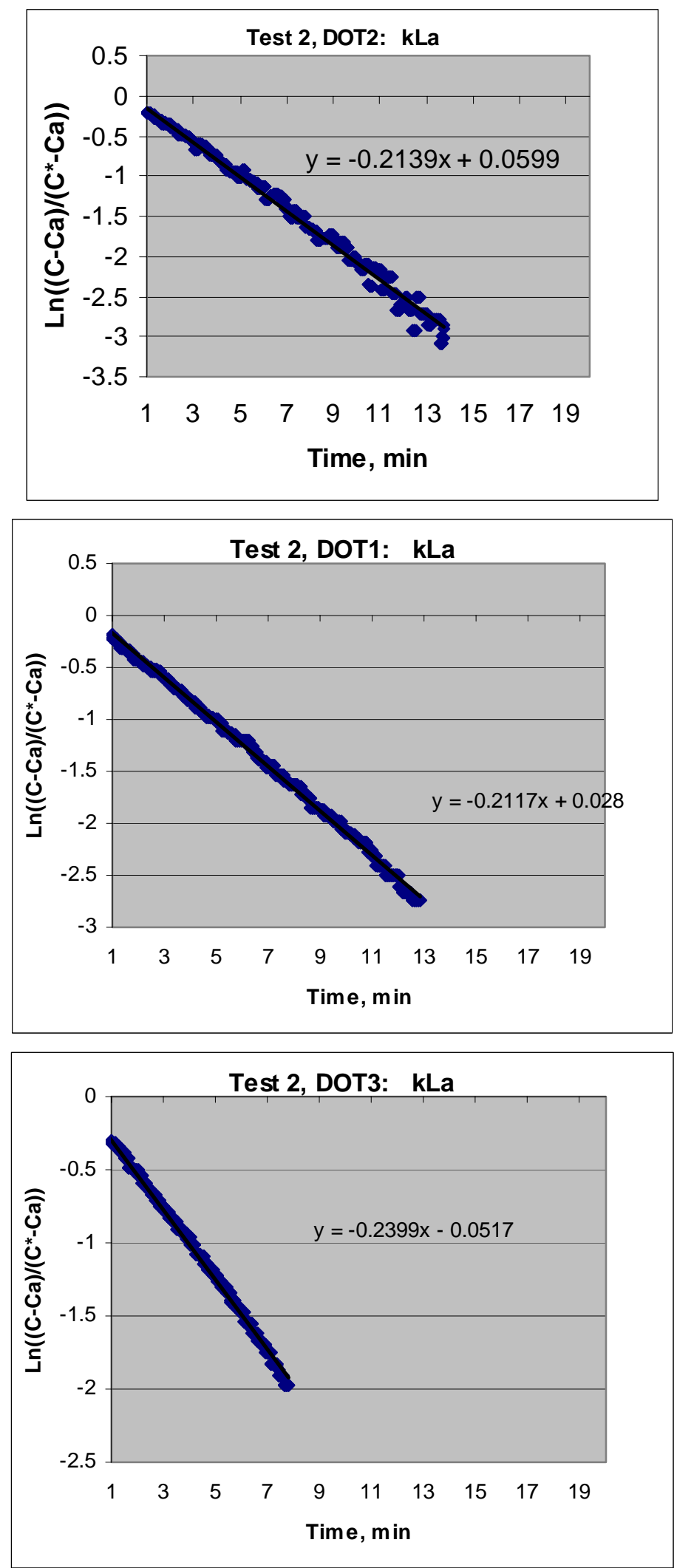

Figure Test 2 Mass Transfer Calculation 

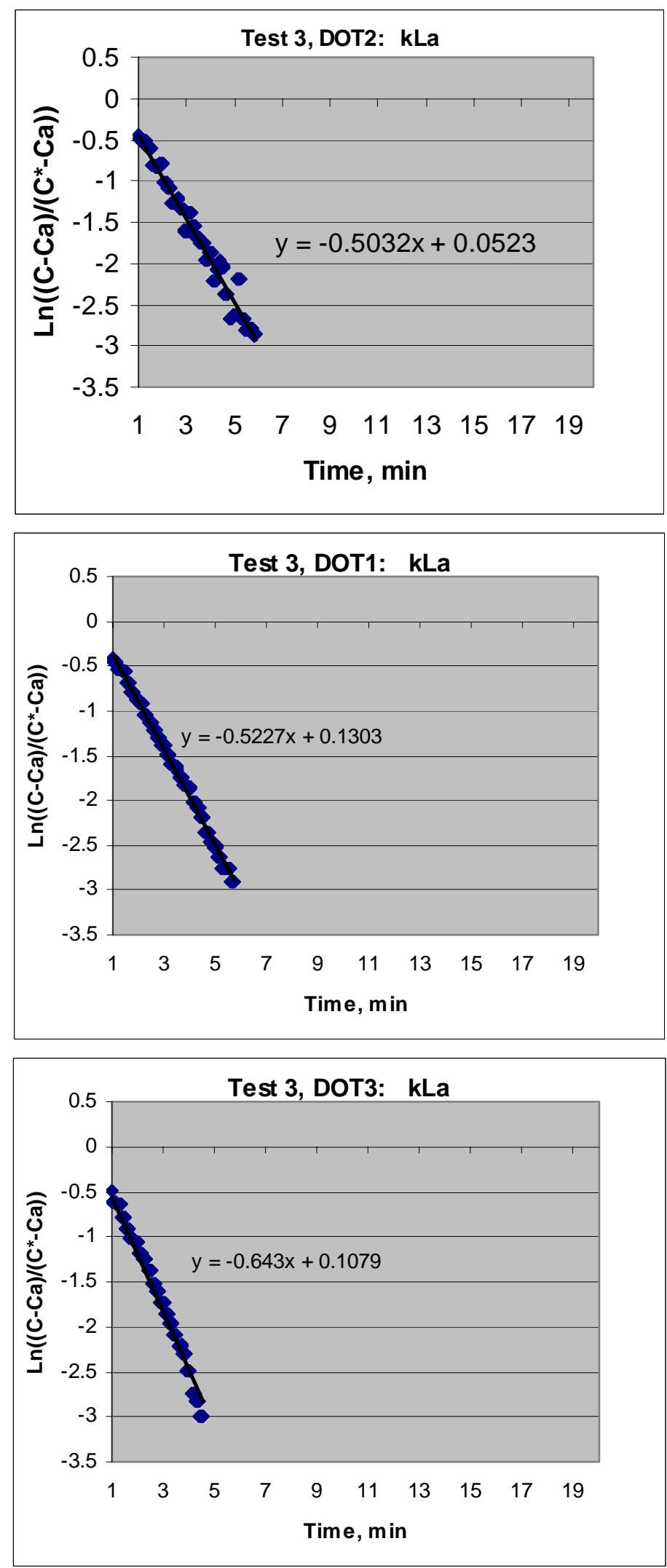

Figure Test 3 Mass Transfer Calculation 

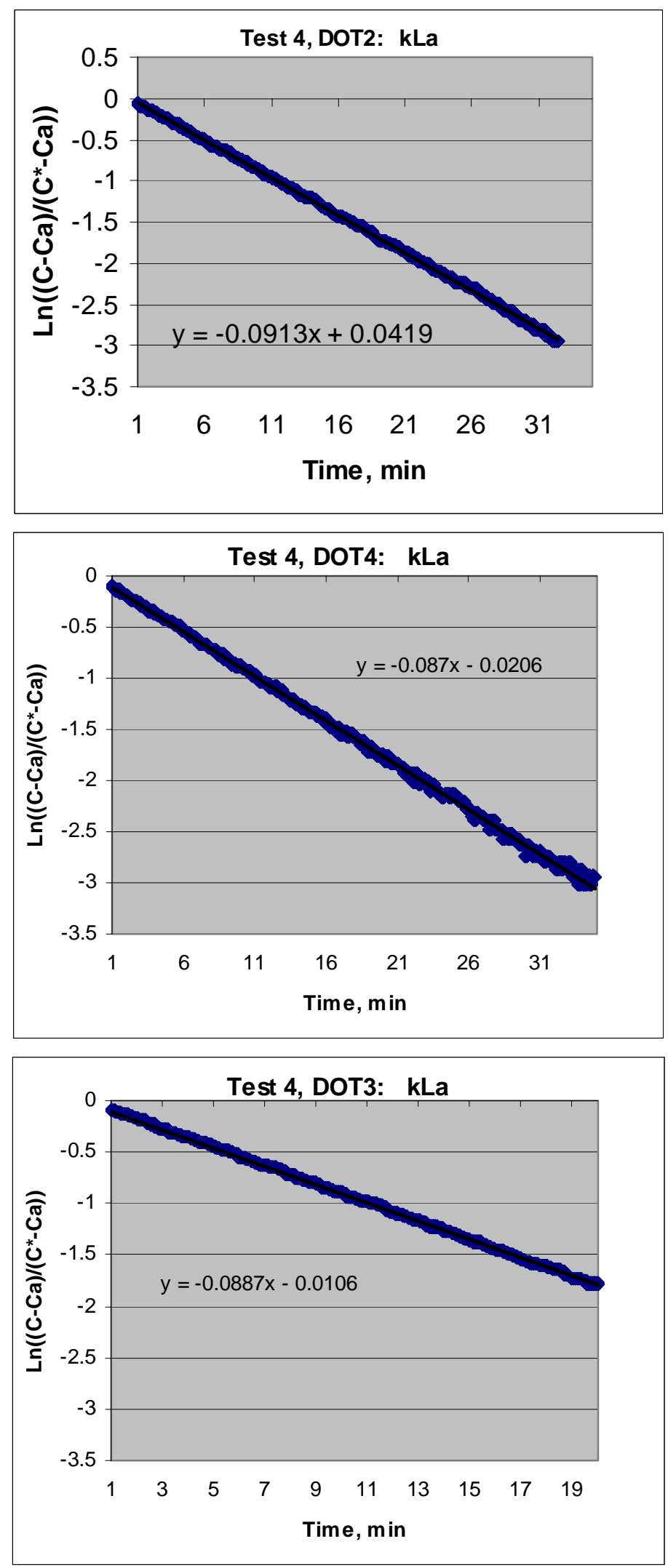

Figure Test 4 Mass Transfer Calculation 

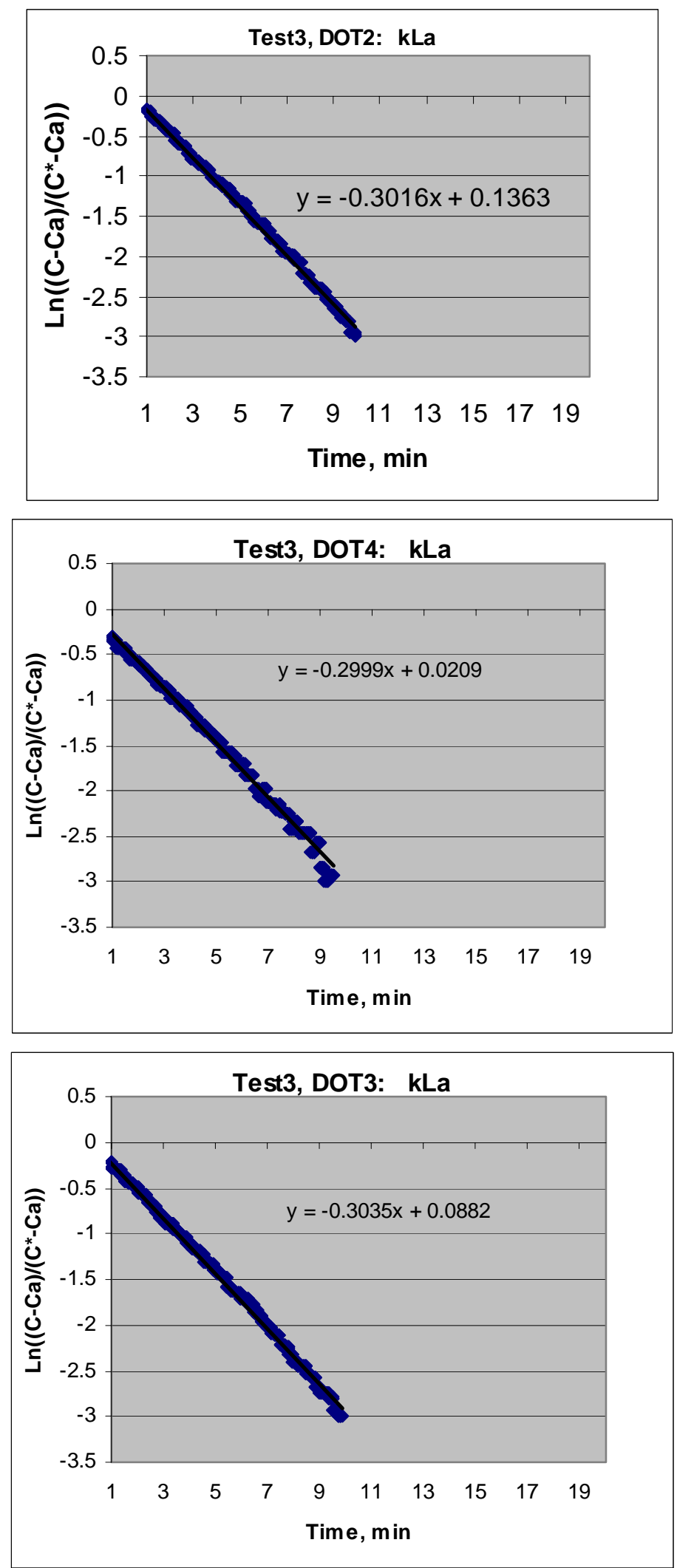

Figure Test 5 Mass Transfer Calculation 

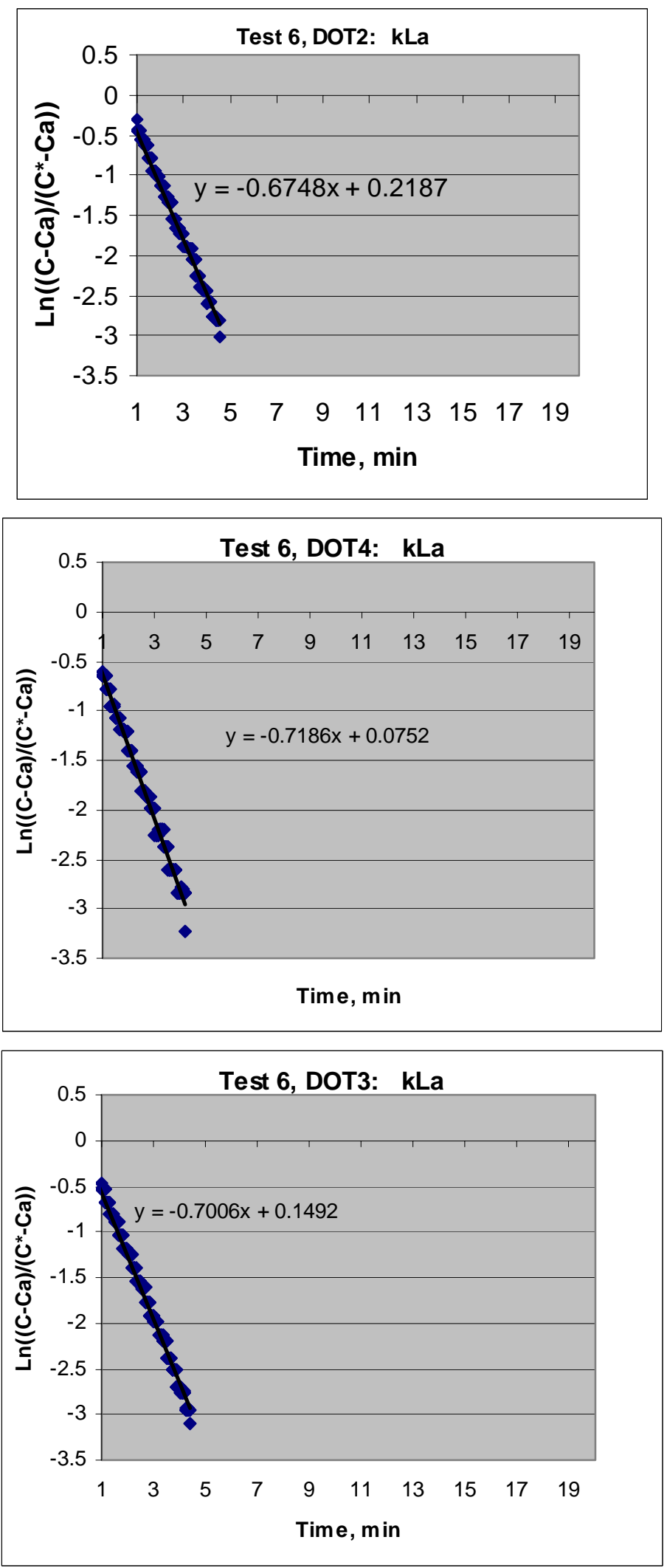

Figure Test 6 Mass Transfer Calculation 

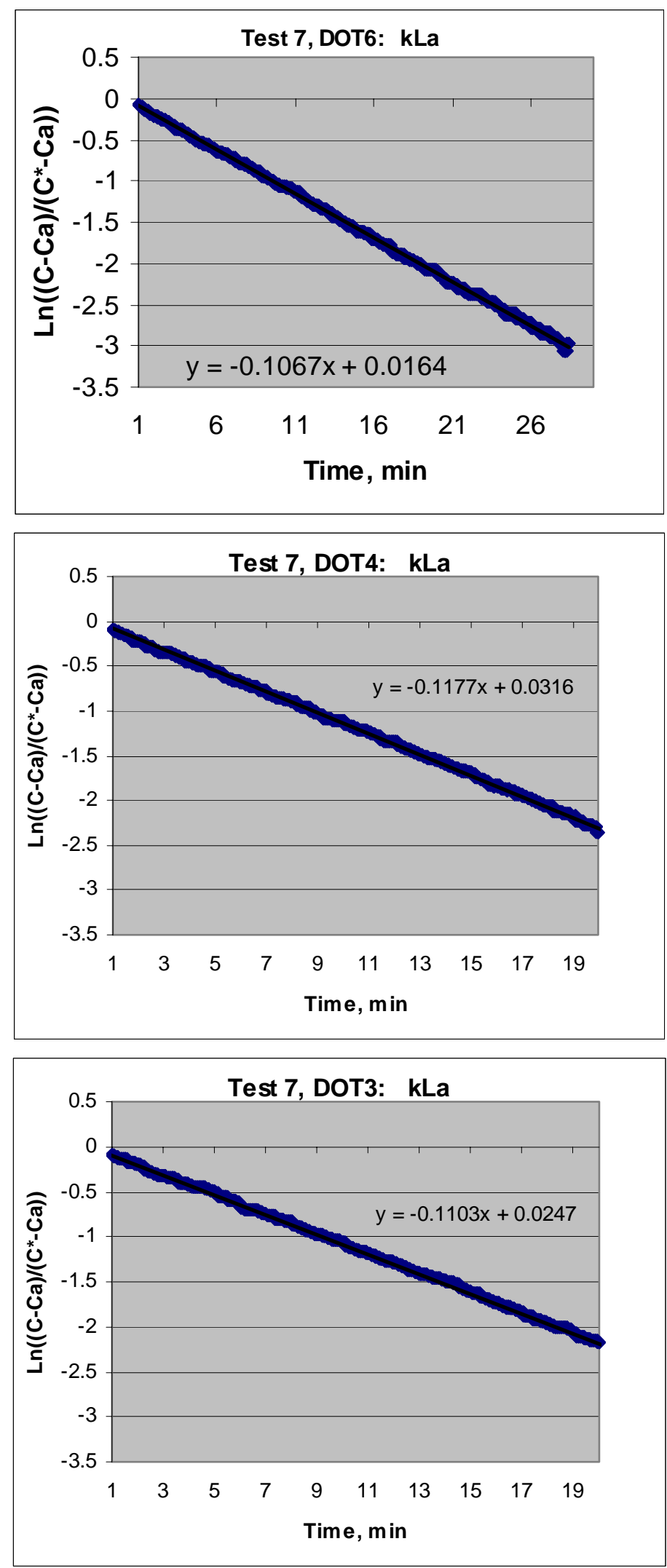

Figure Test 7 Mass Transfer Calculation 

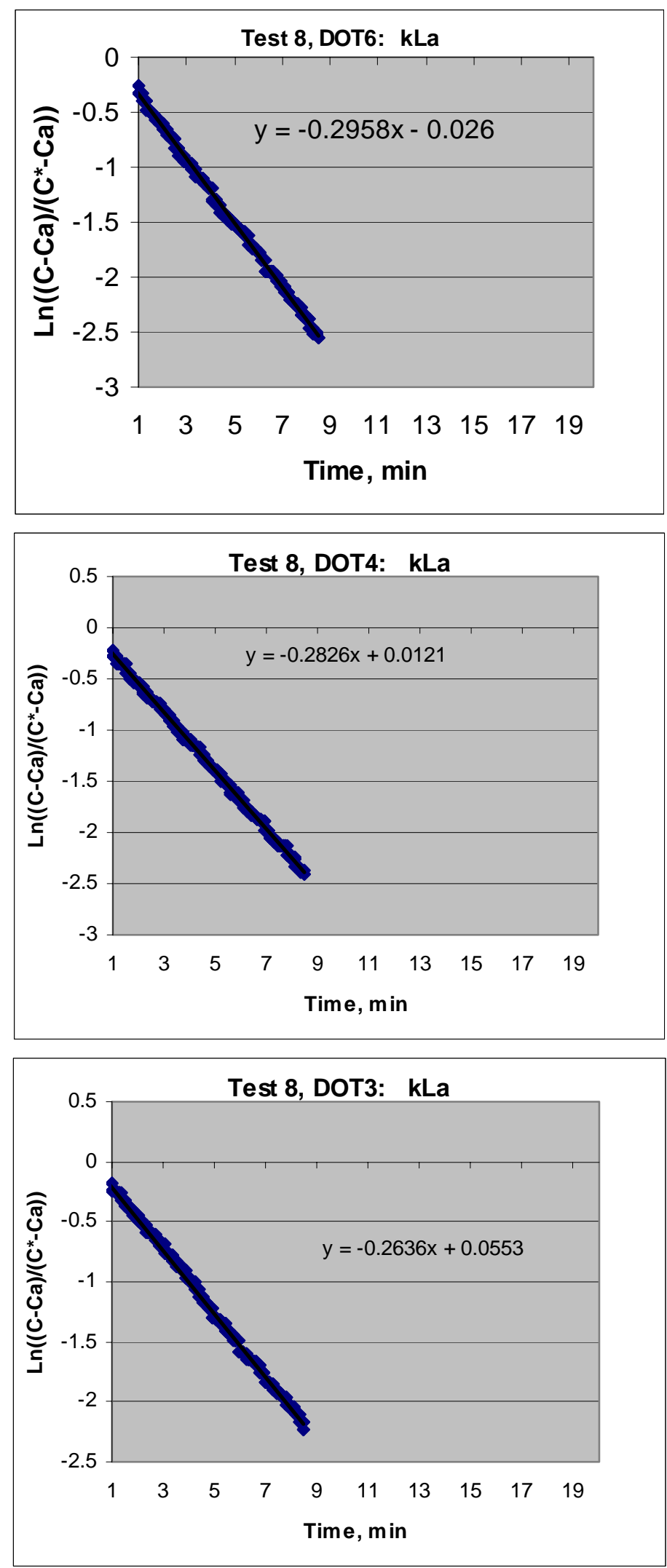

Figure Test 8 Mass Transfer Calculation 

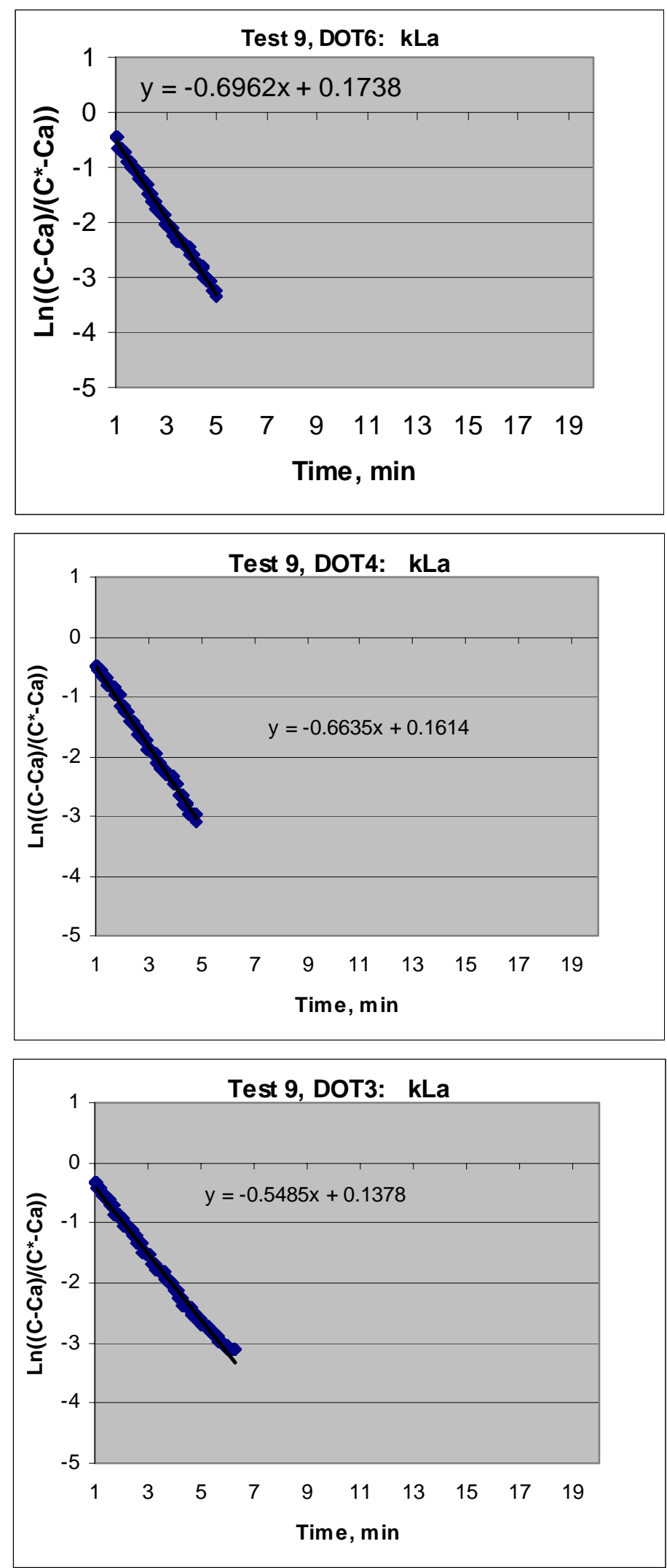

Figure Test 9 Mass Transfer Calculation 

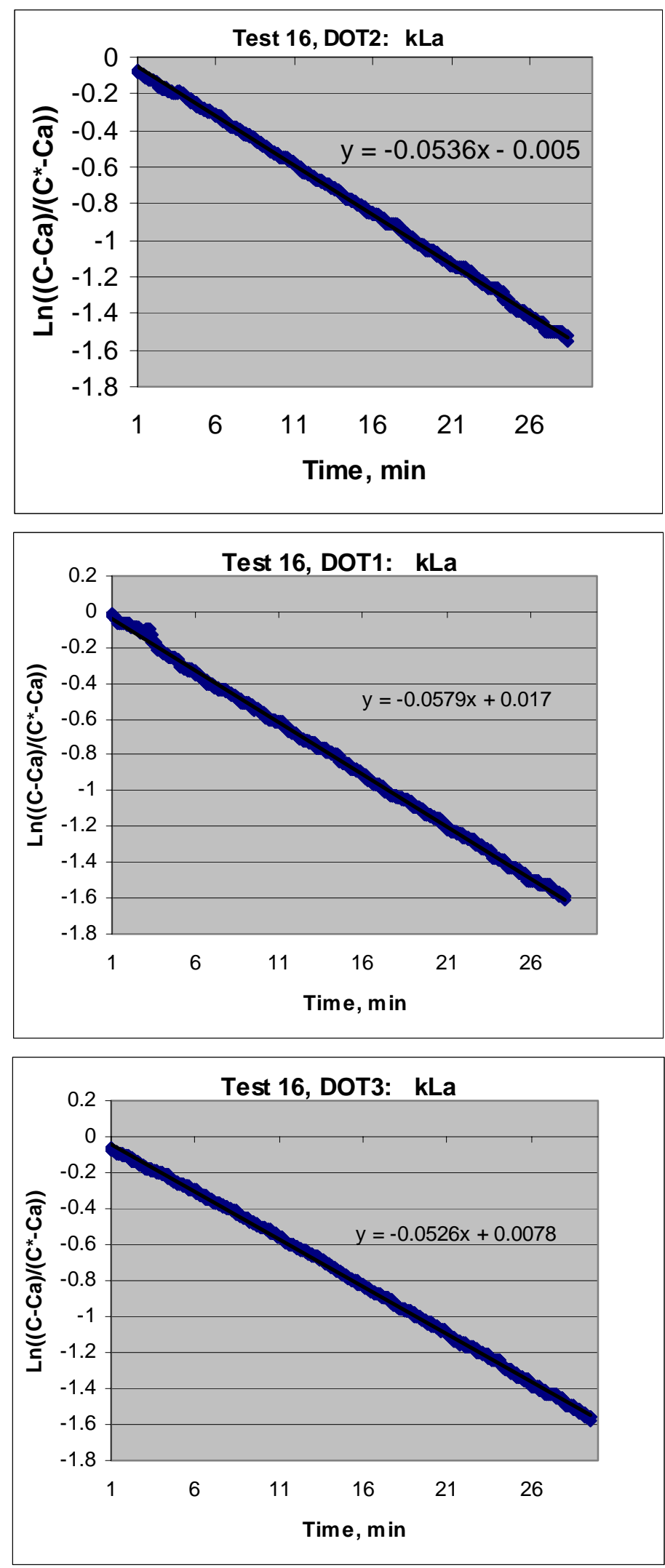

Figure Test 16 Mass Transfer Calculation 

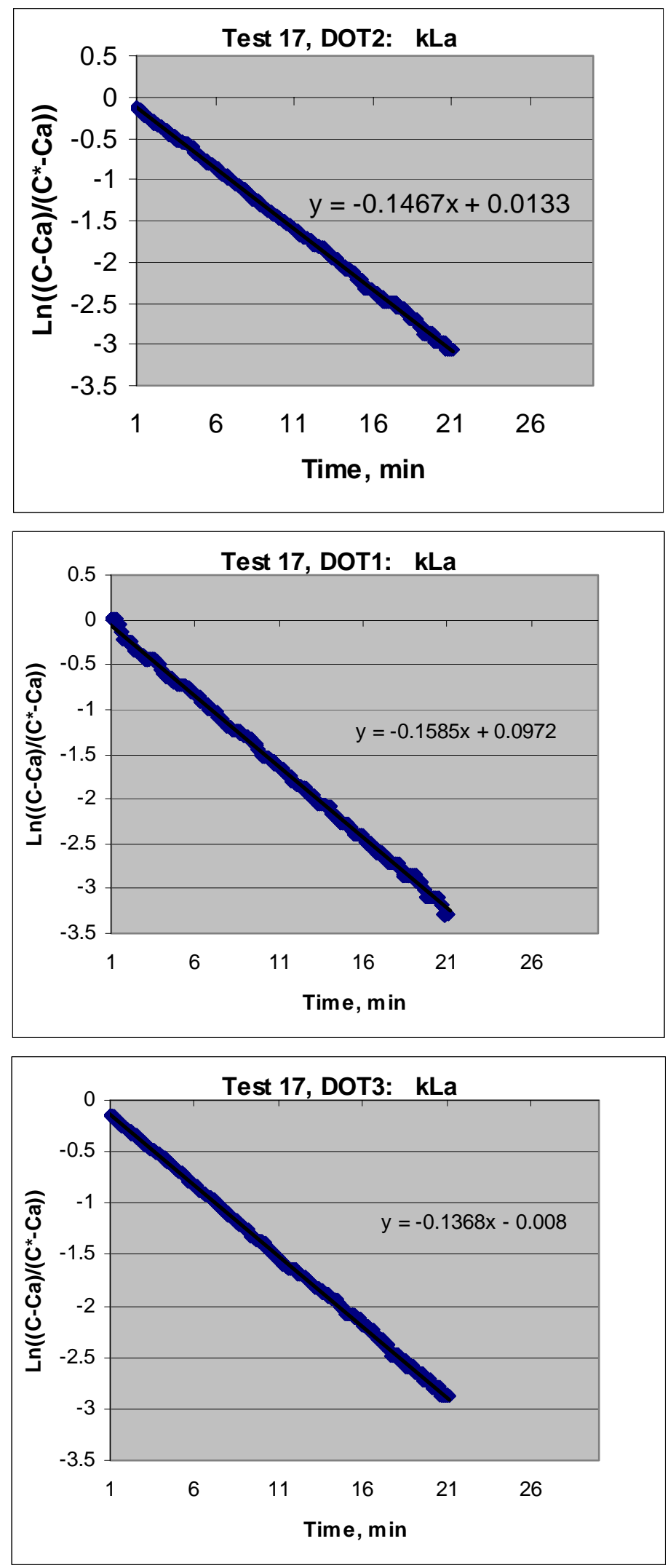

Figure Test 17 Mass Transfer Calculation 

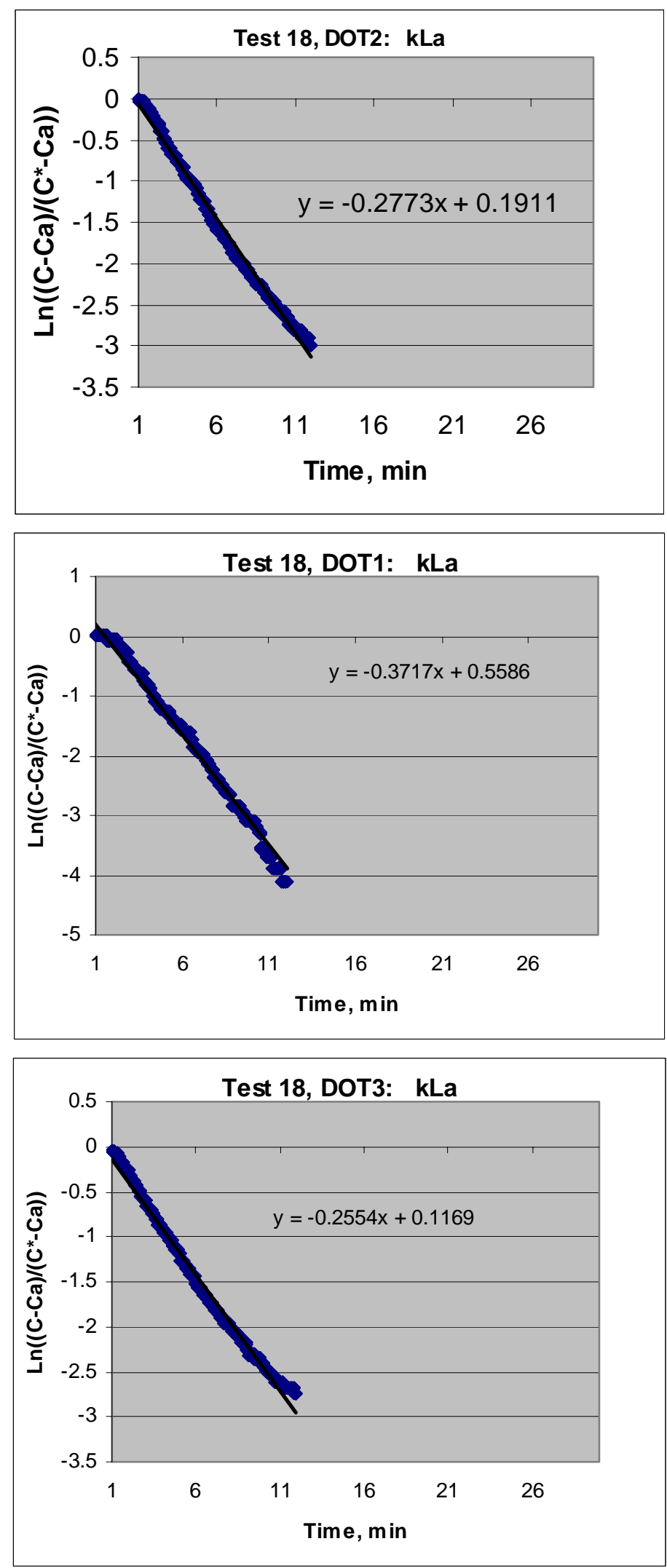

Figure Test 18 Mass Transfer Calculation 

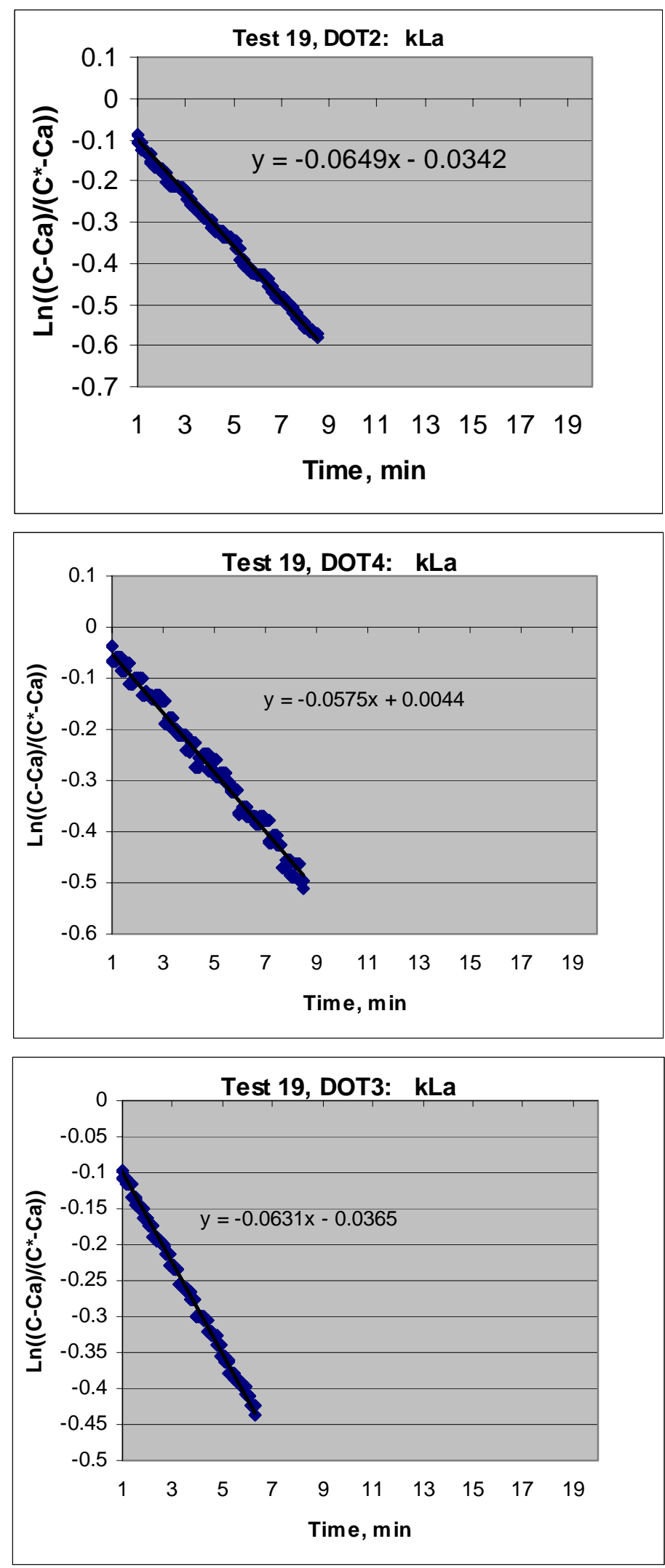

Figure Test 19 Mass Transfer Calculation 

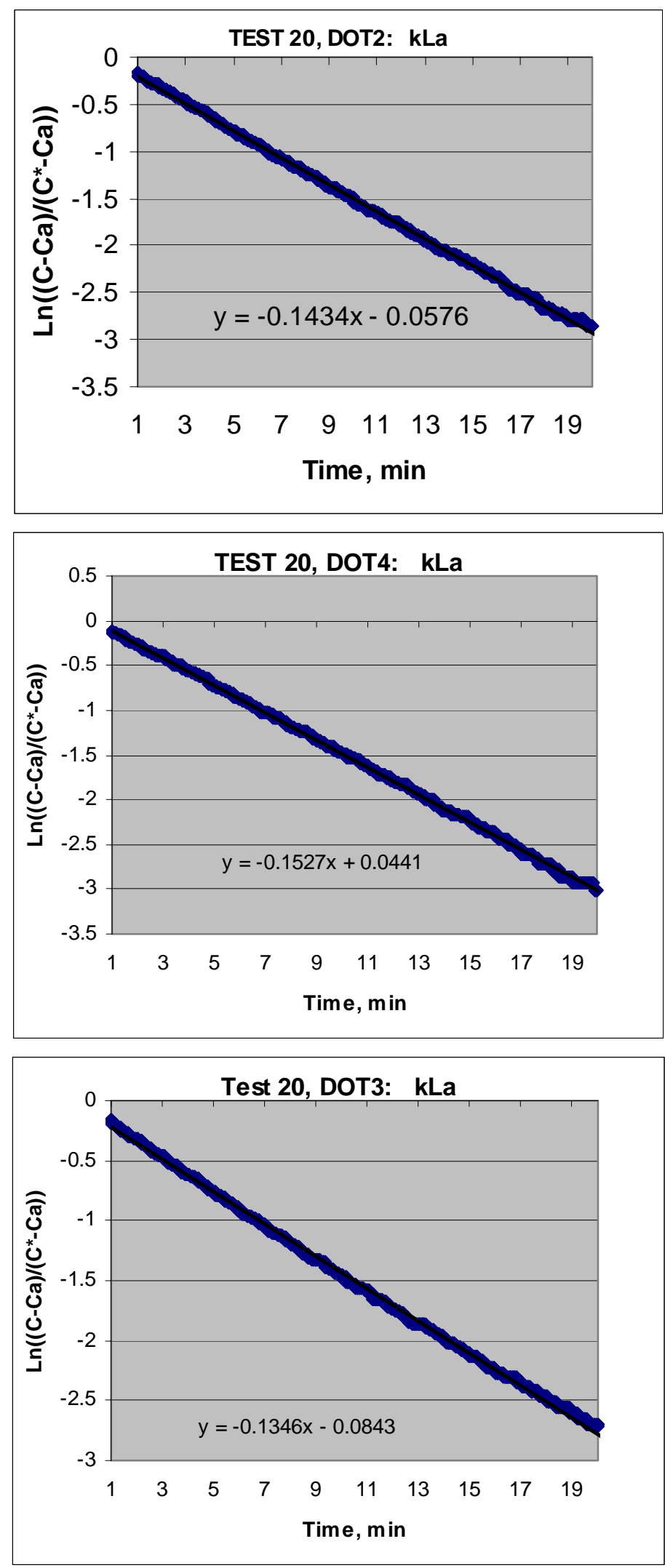

Figure Test 20 Mass Transfer Calculation 

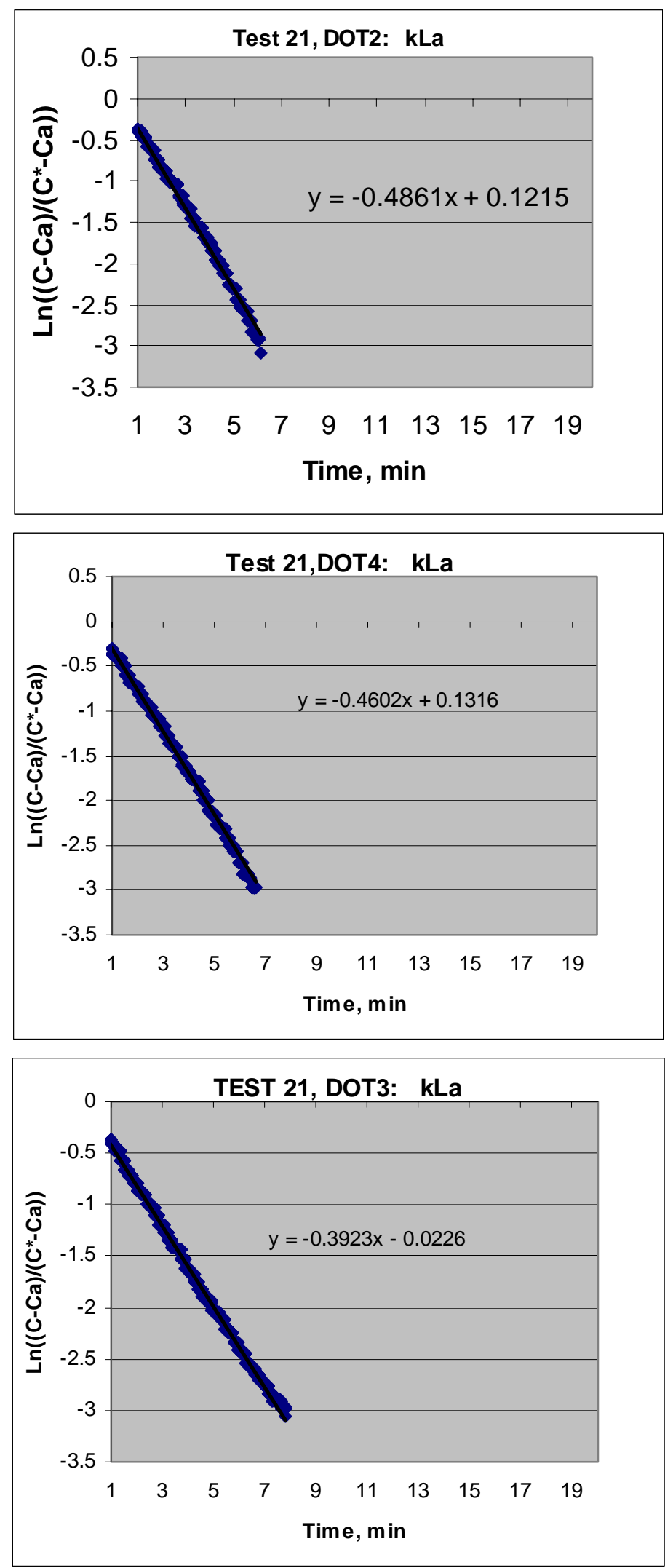

Figure Test 21 Mass Transfer Calculation 

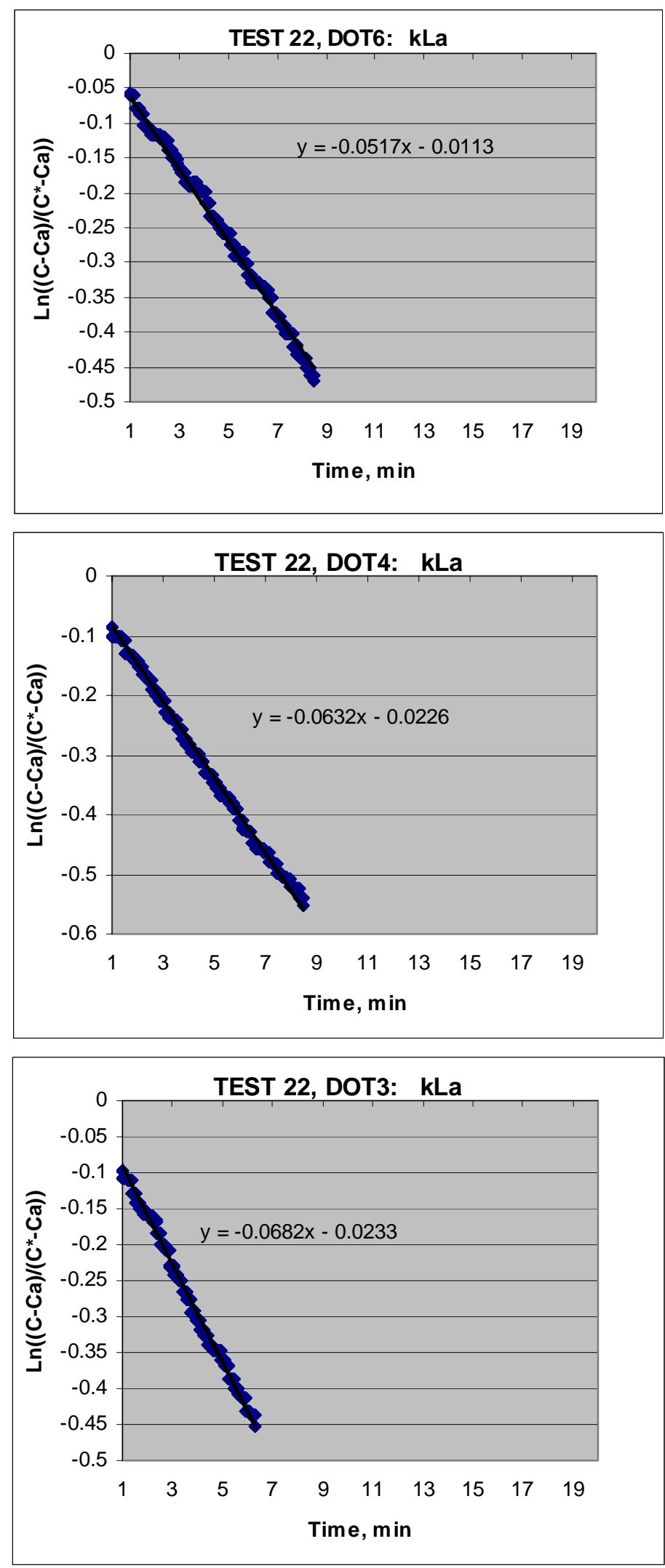

Figure Test 22 Mass Transfer Calculation 

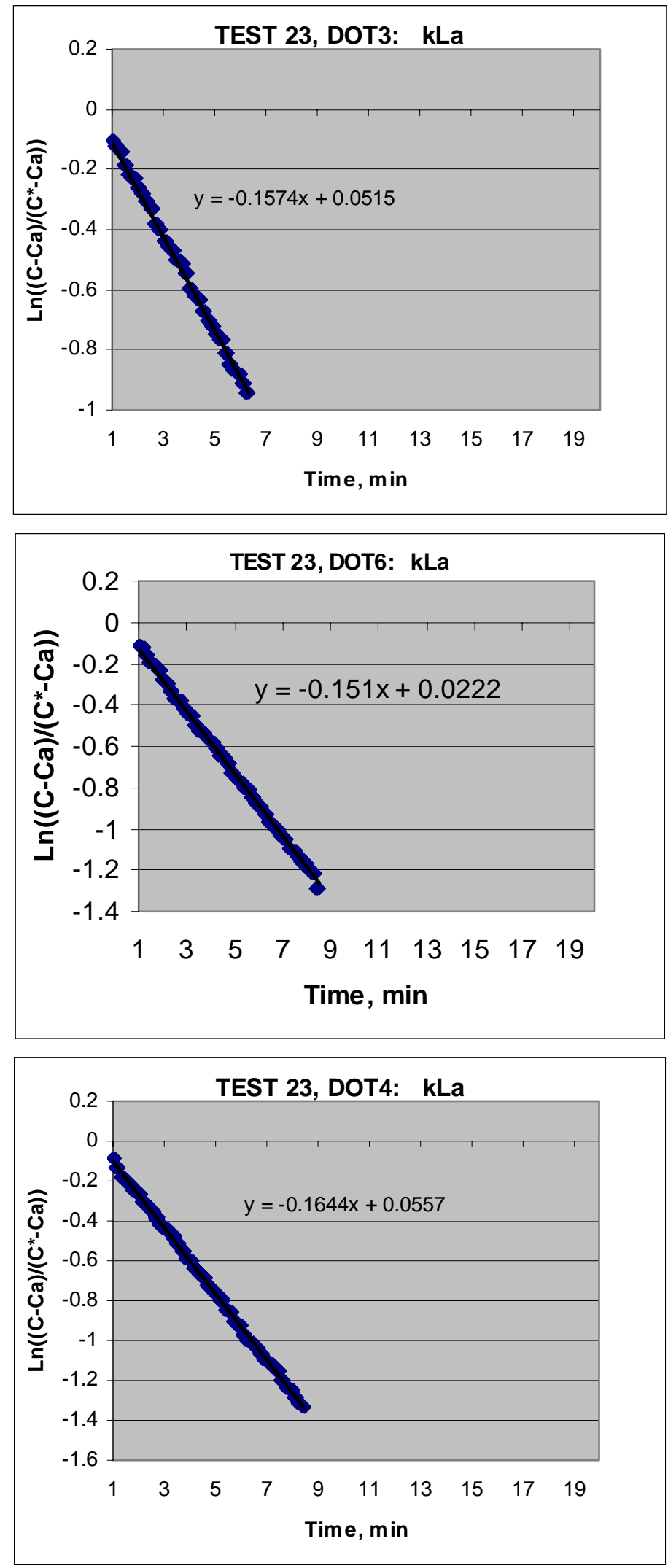

Figure Test 23 Mass Transfer Calculation 

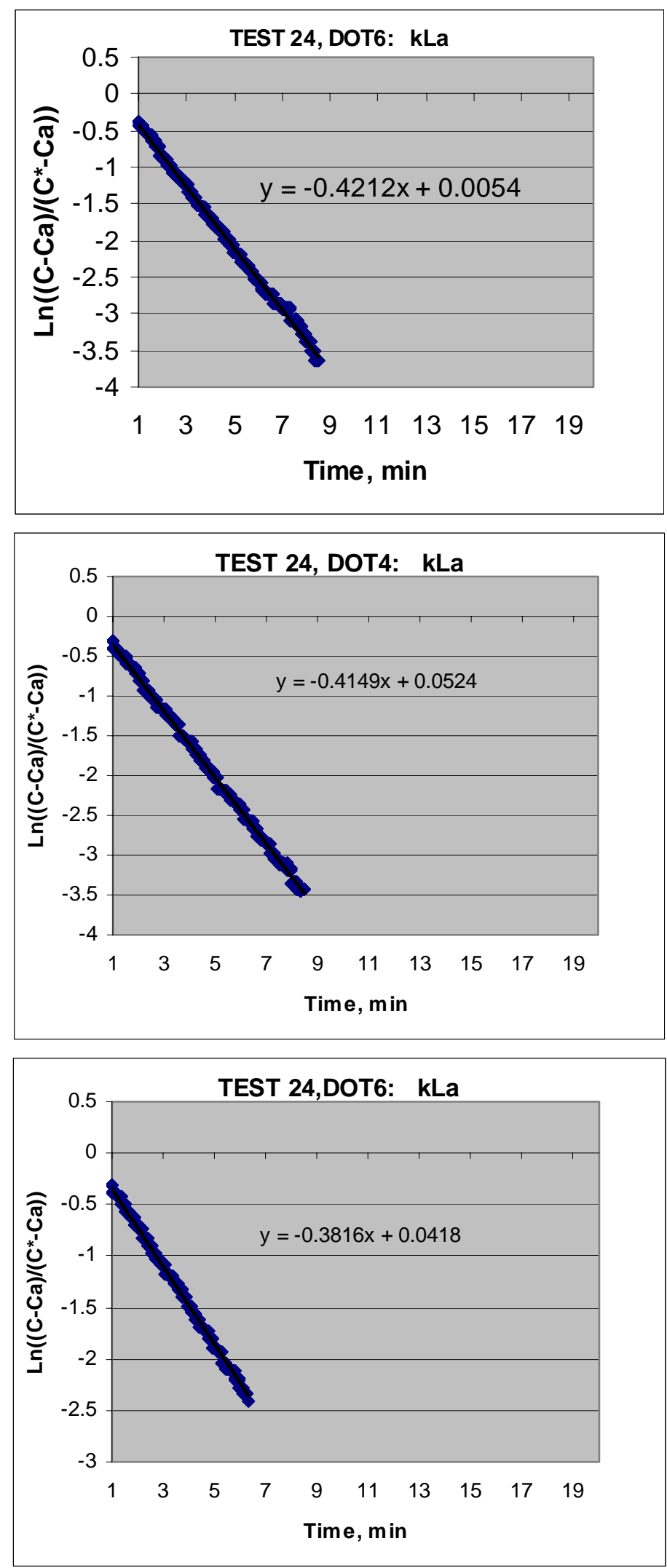

Figure Test 24 Mass Transfer Calculation 

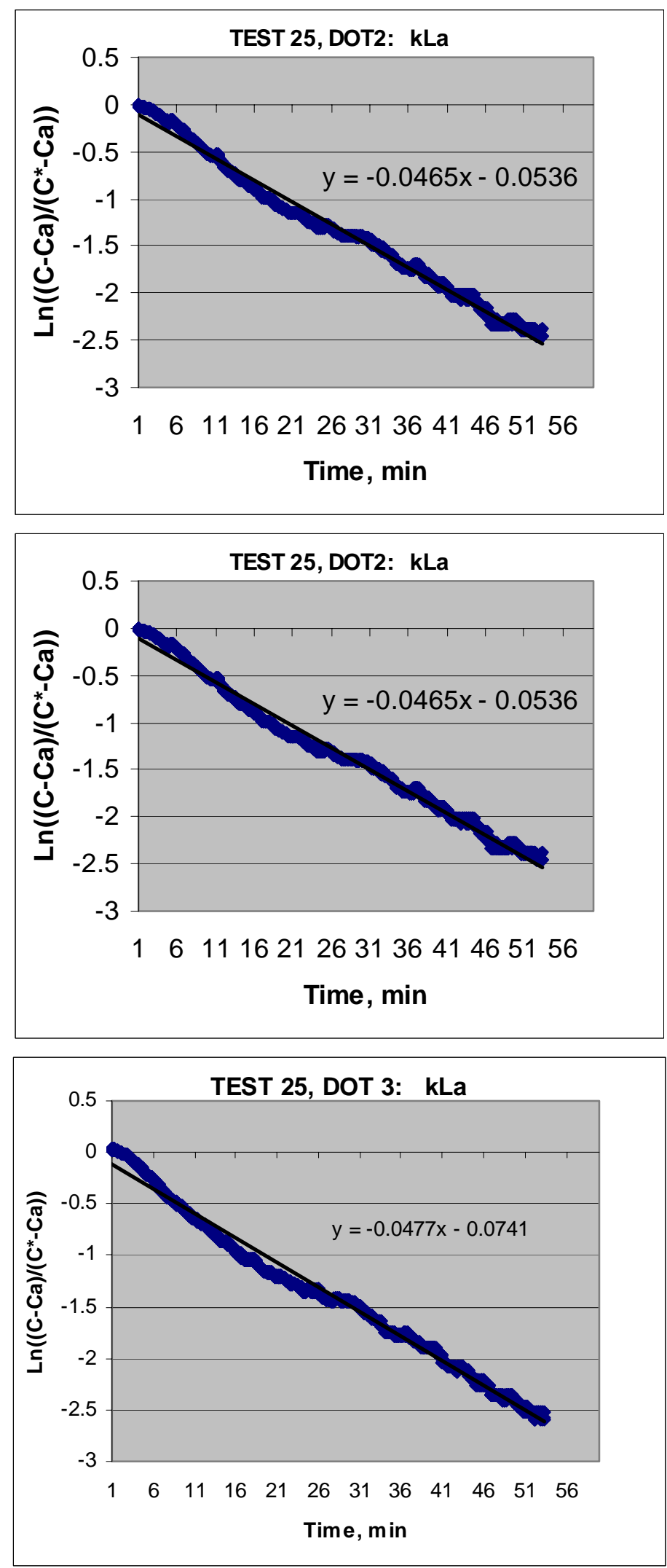

Figure Test 25 Mass Transfer Calculation 

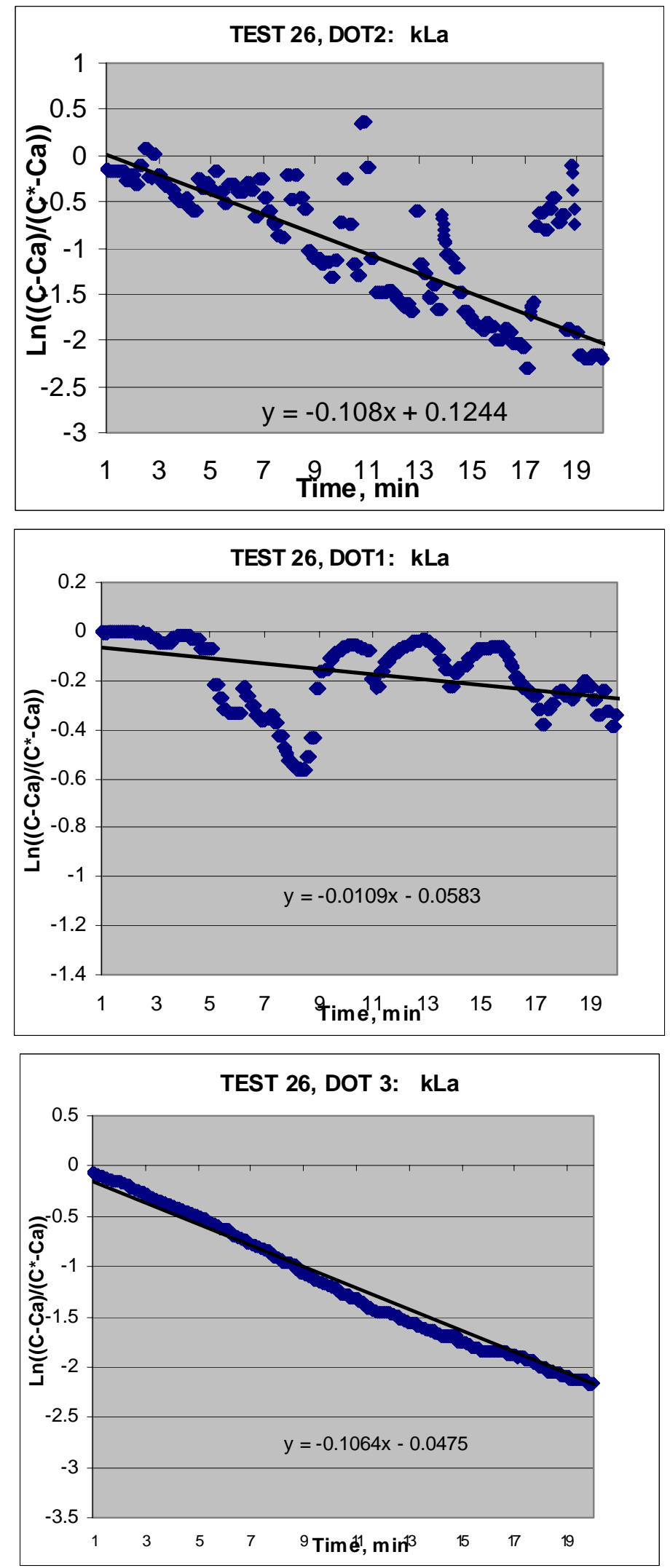

Figure Test 26 Mass Transfer Calculation 

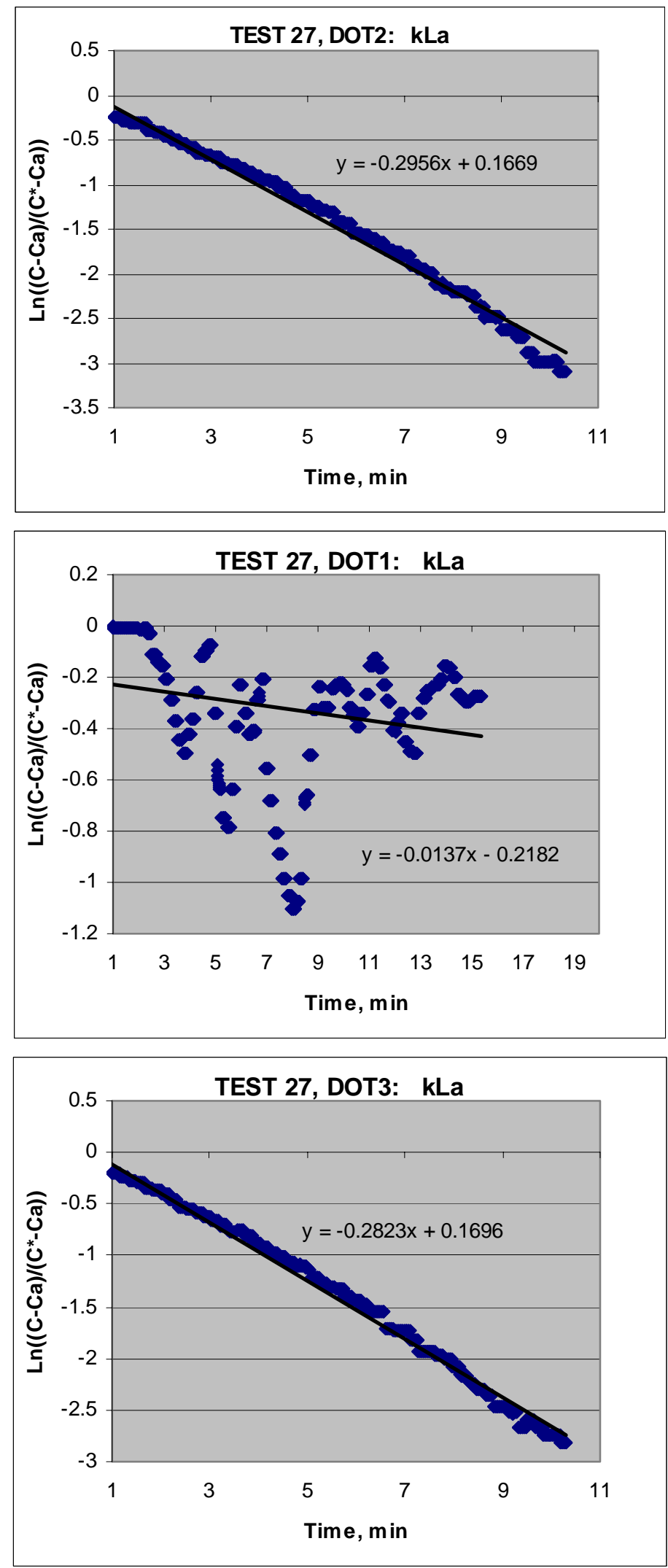

Figure Test 27 Mass Transfer Calculation 

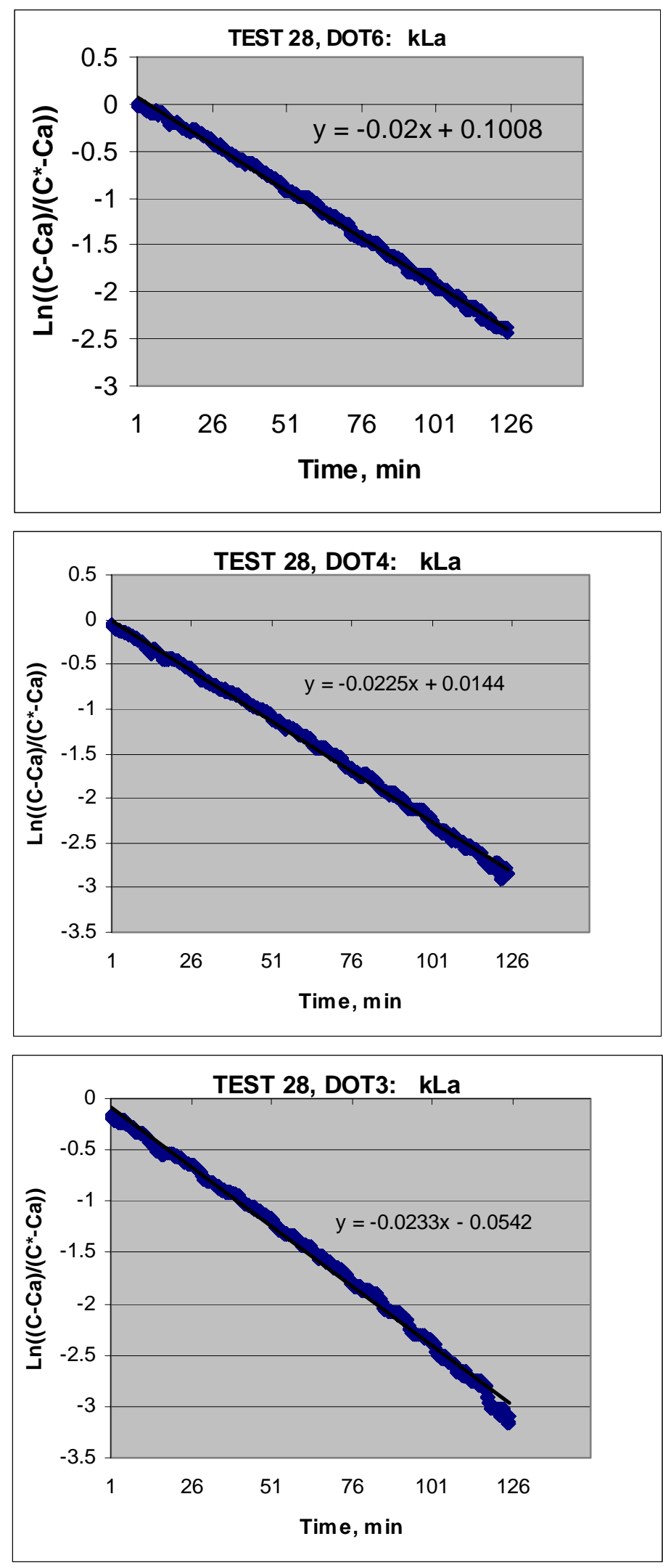

Figure Test 28 Mass Transfer Calculation 

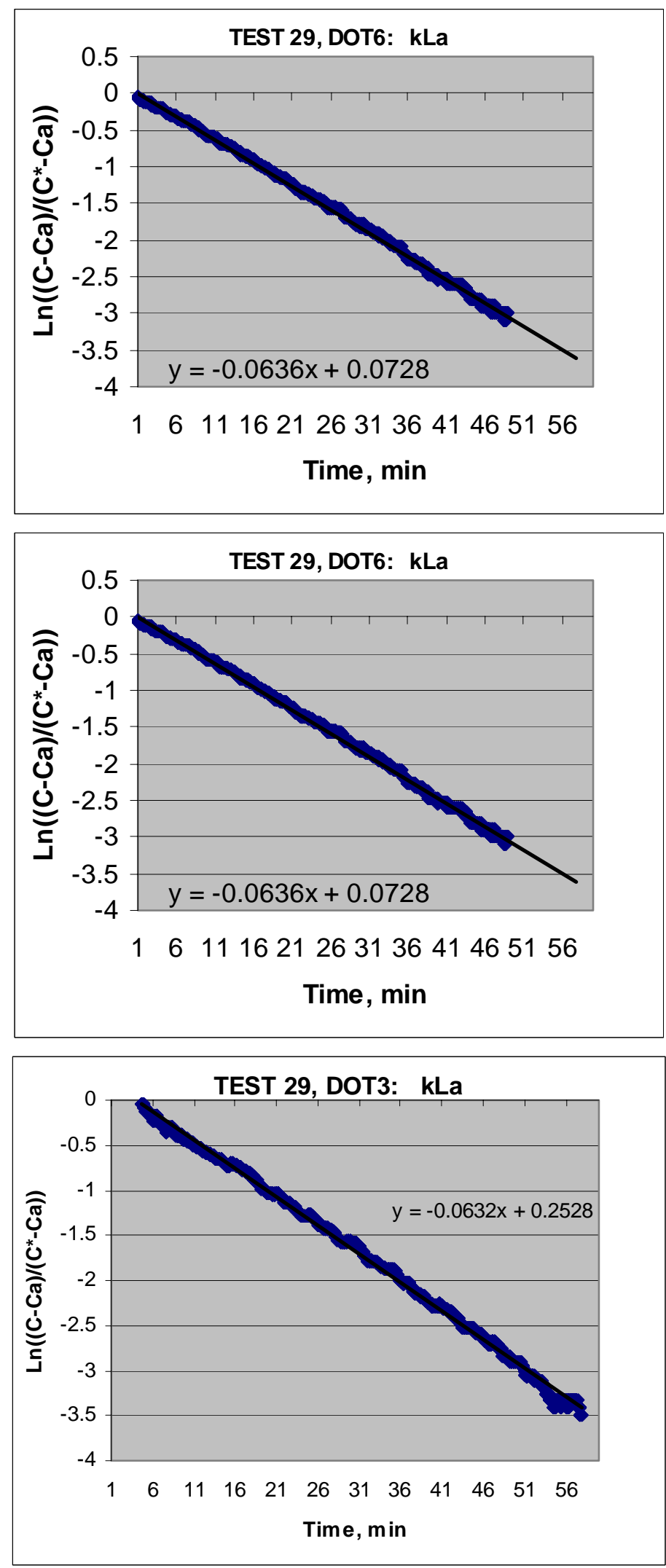

Figure Test 29 Mass Transfer Calculation 

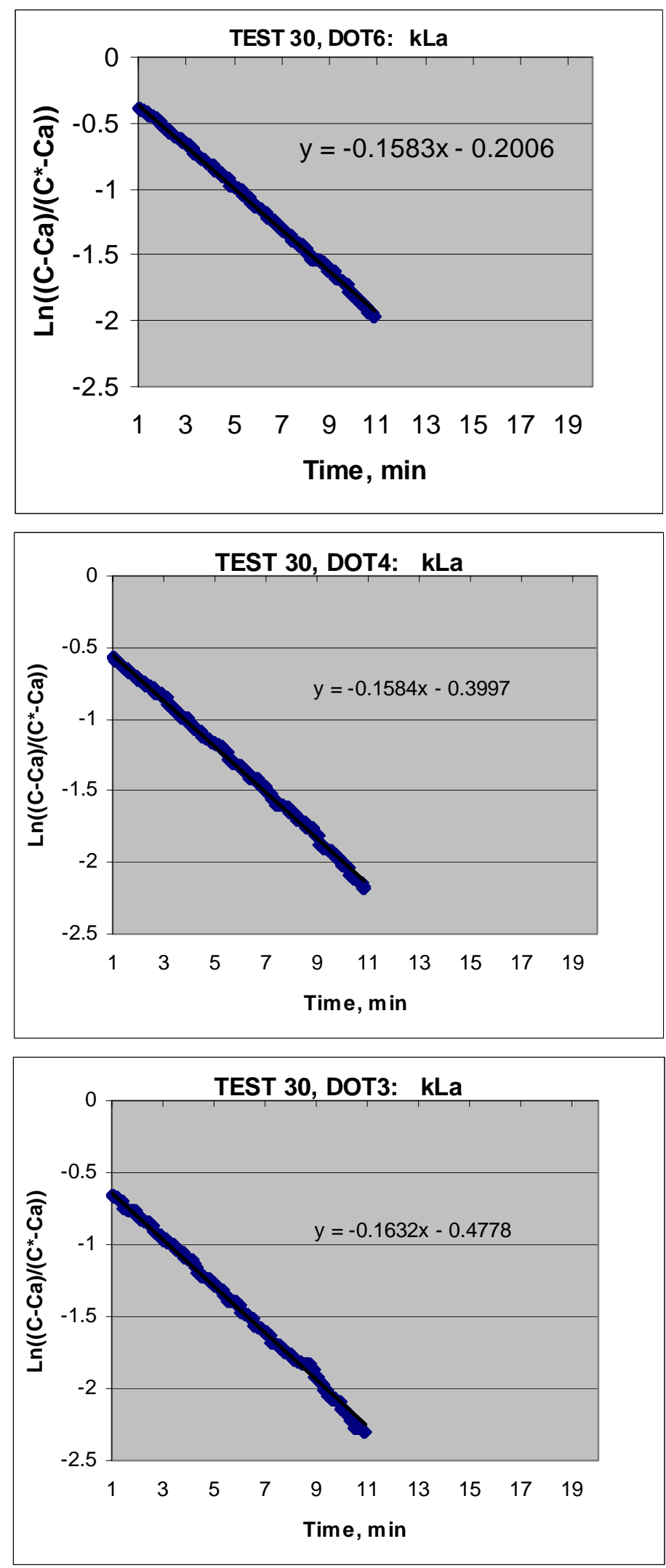

Figure Test 30 Mass Transfer Calculation 
This page intentionally left blank. 


\section{APPENDIX E: VOID FRACTION CALCULATIONS}

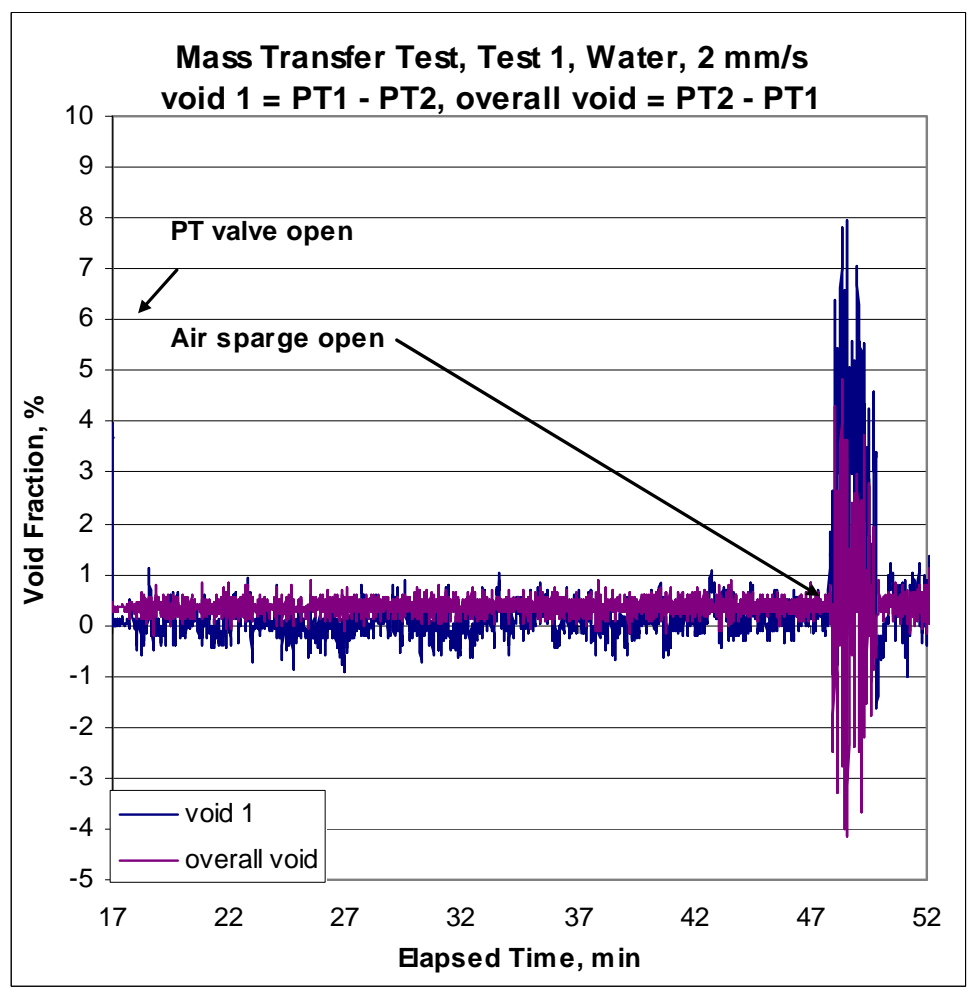

Figure Test 1 Void Fraction Calculation

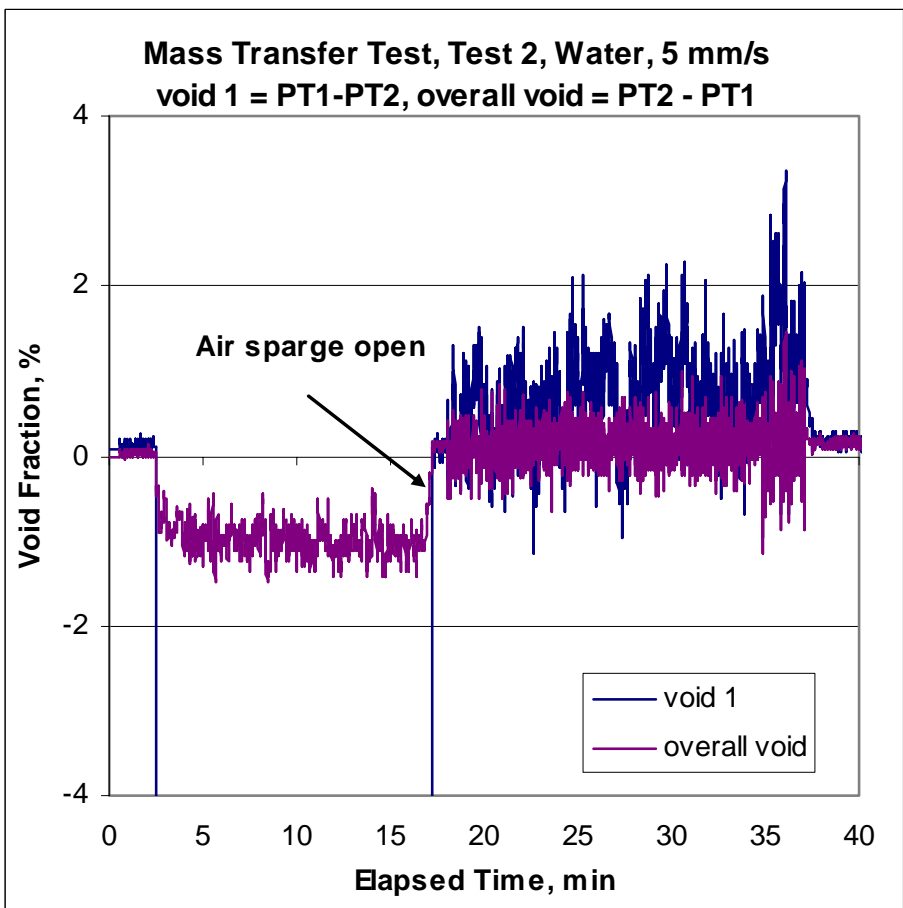

Figure Test 2 Void Fraction Calculation 


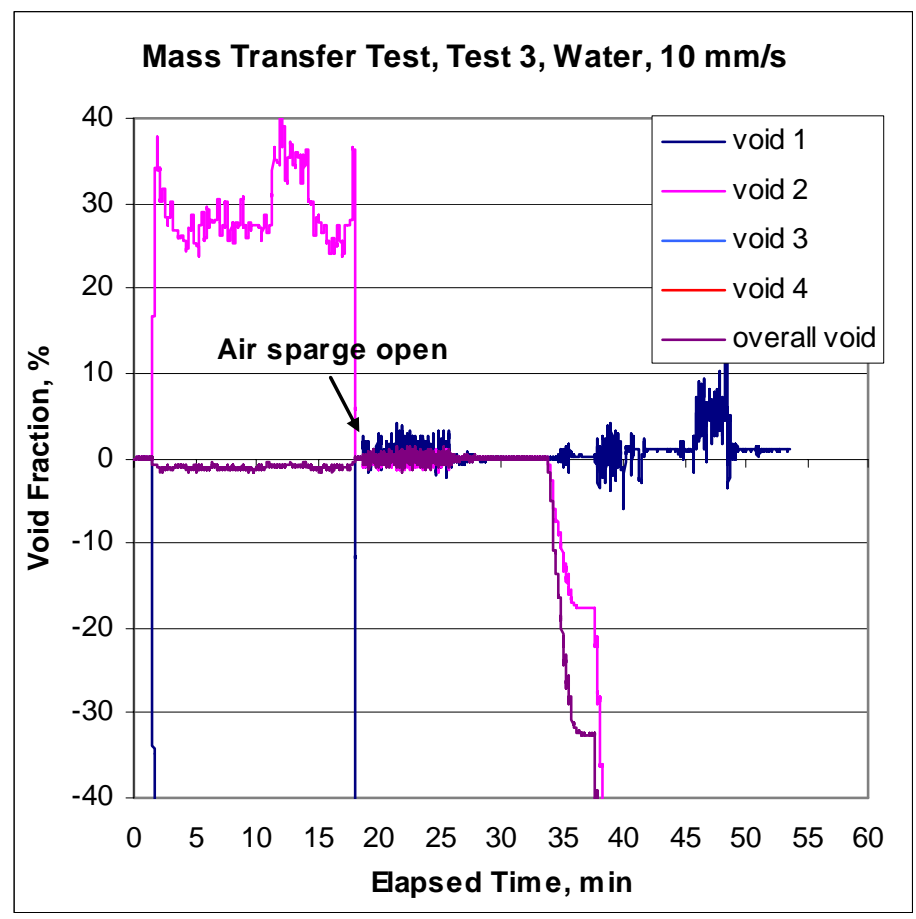

Figure Test 3 Void Fraction Calculation

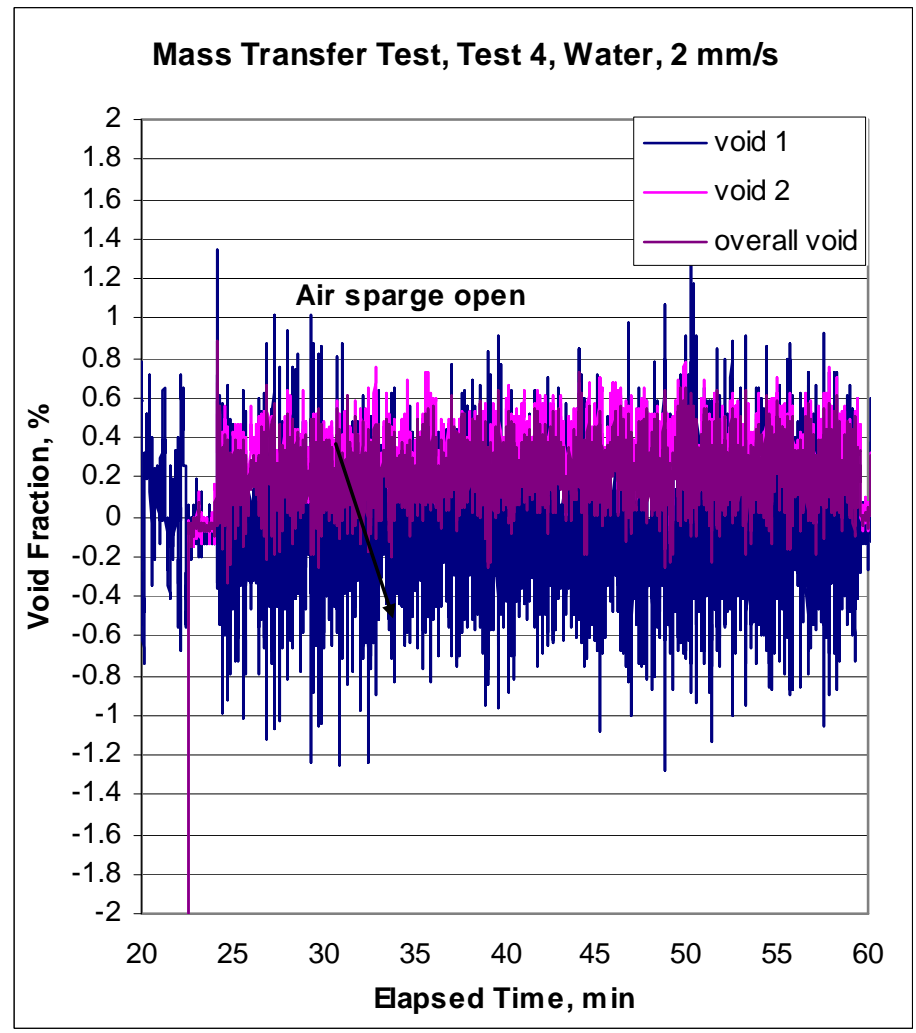

Figure Test 4 Void Fraction Calculation 


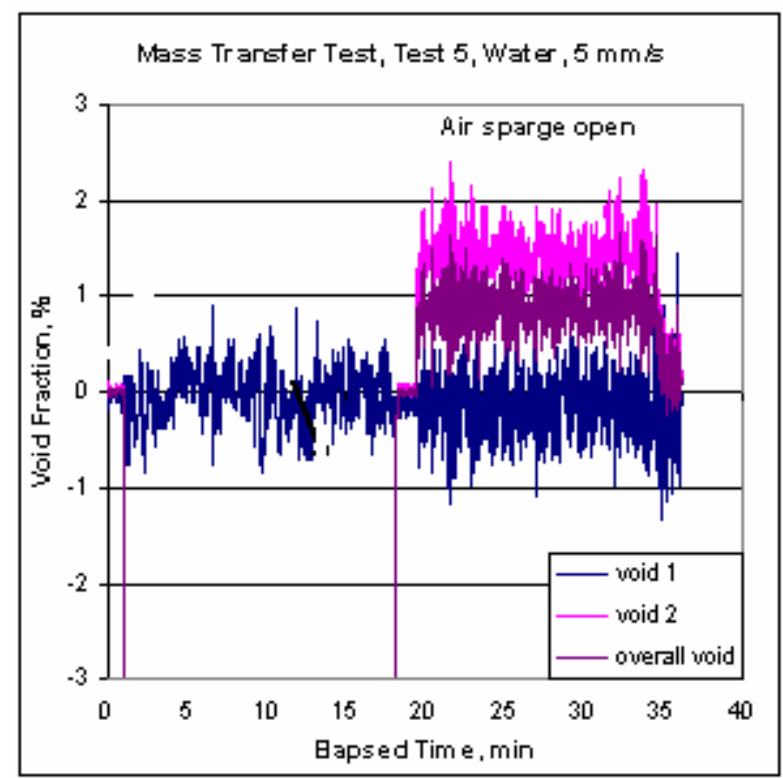

Figure Test 5 Void Fraction Calculation

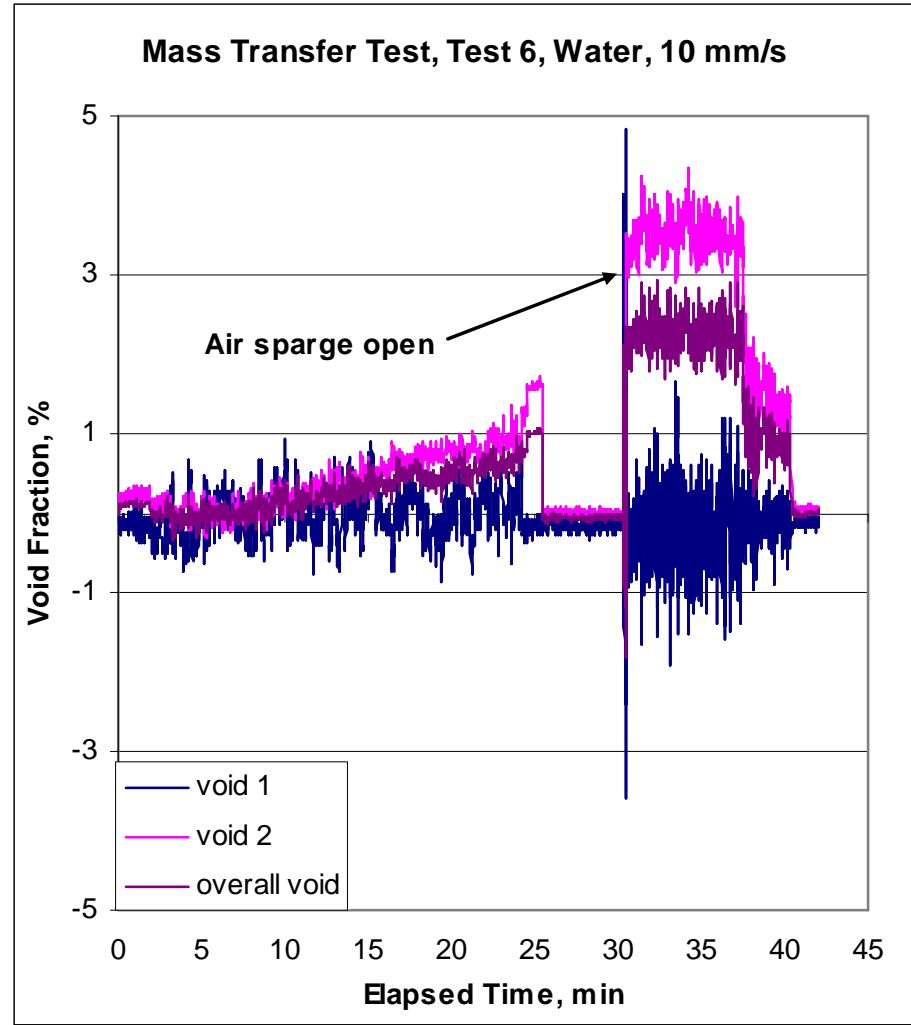

Figure Test 6 Void Fraction Calculation 


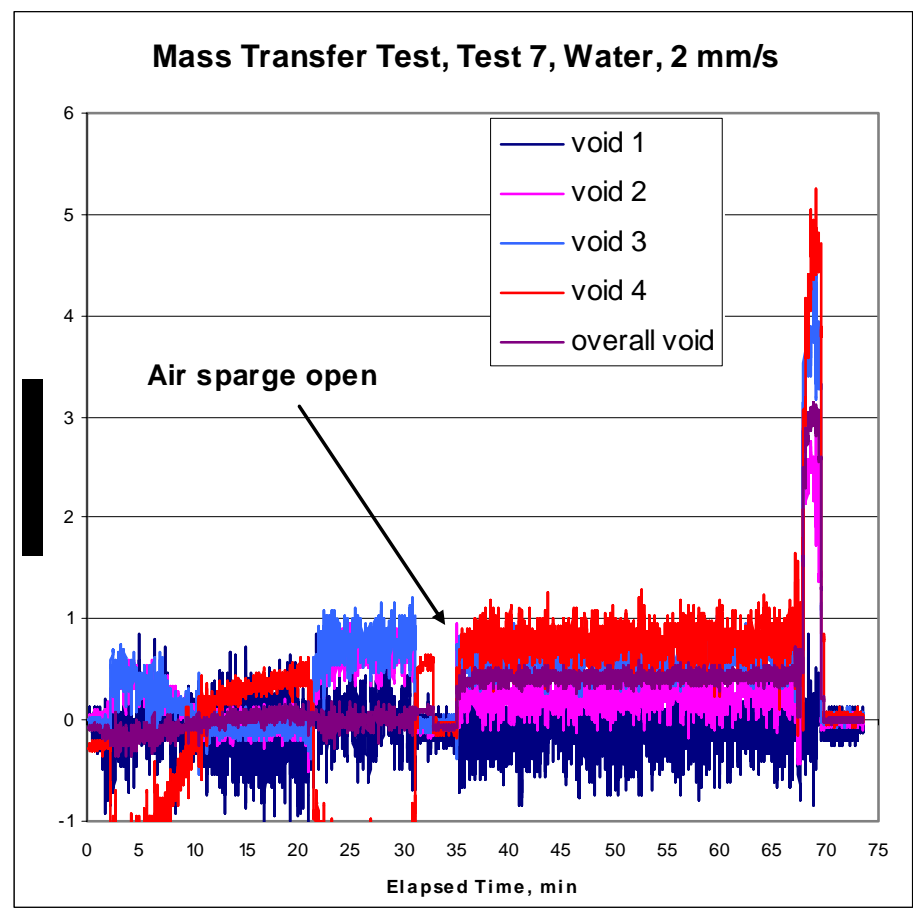

Figure Test 7 Void Fraction Calculation

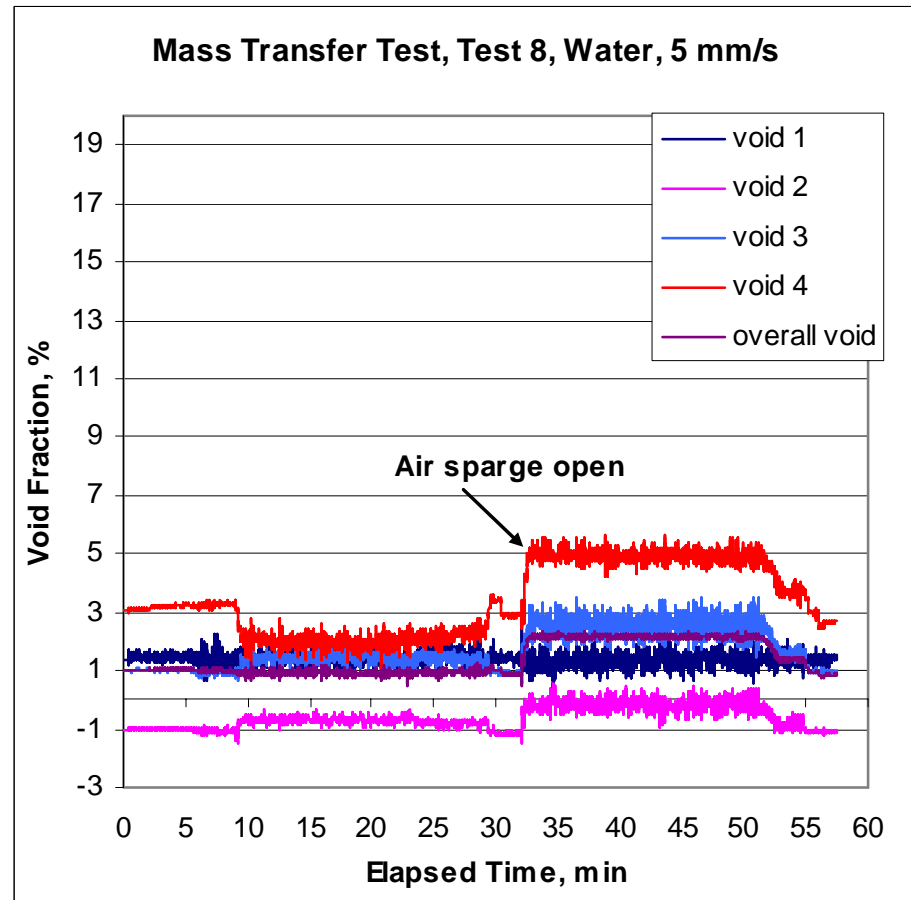

Figure Test 8 Void Fraction Calculation 


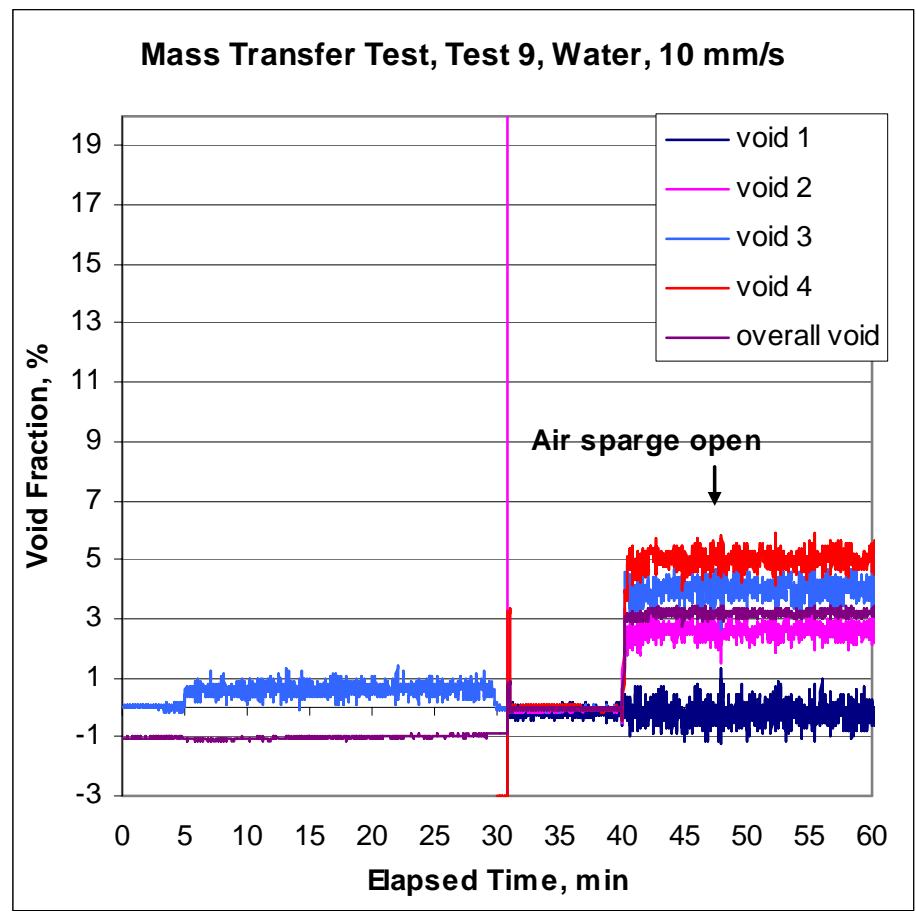

Figure Test 9 Void Fraction Calculation

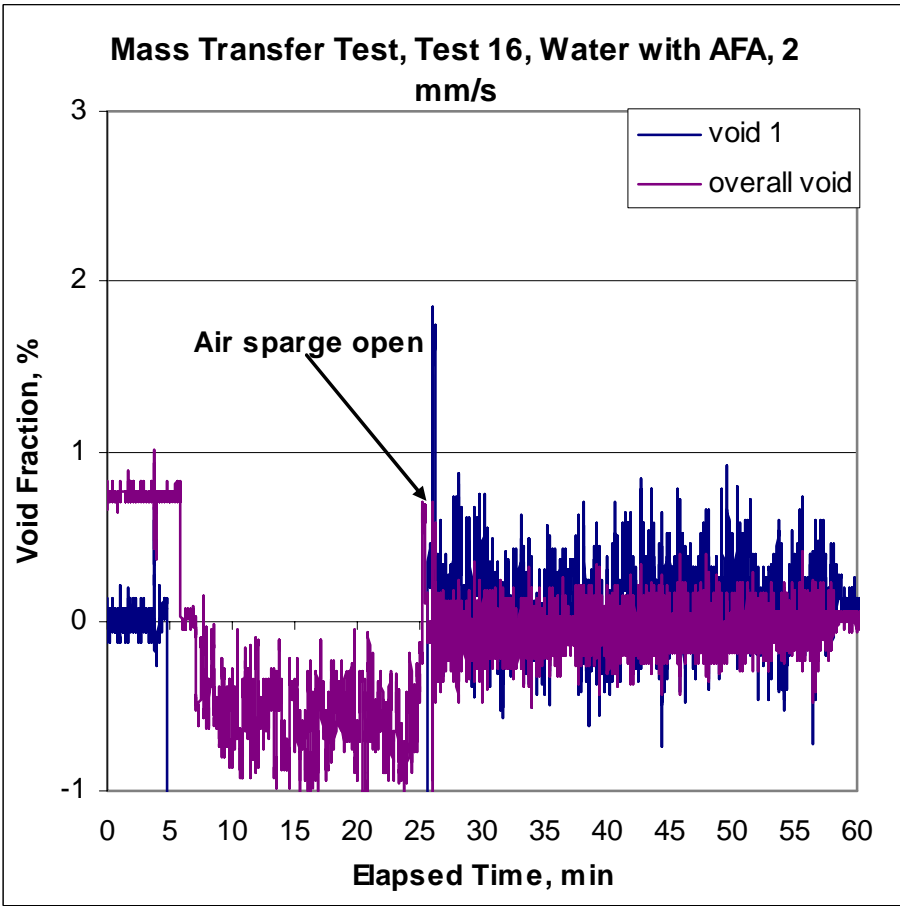

Figure Test 16 Void Fraction Calculation 


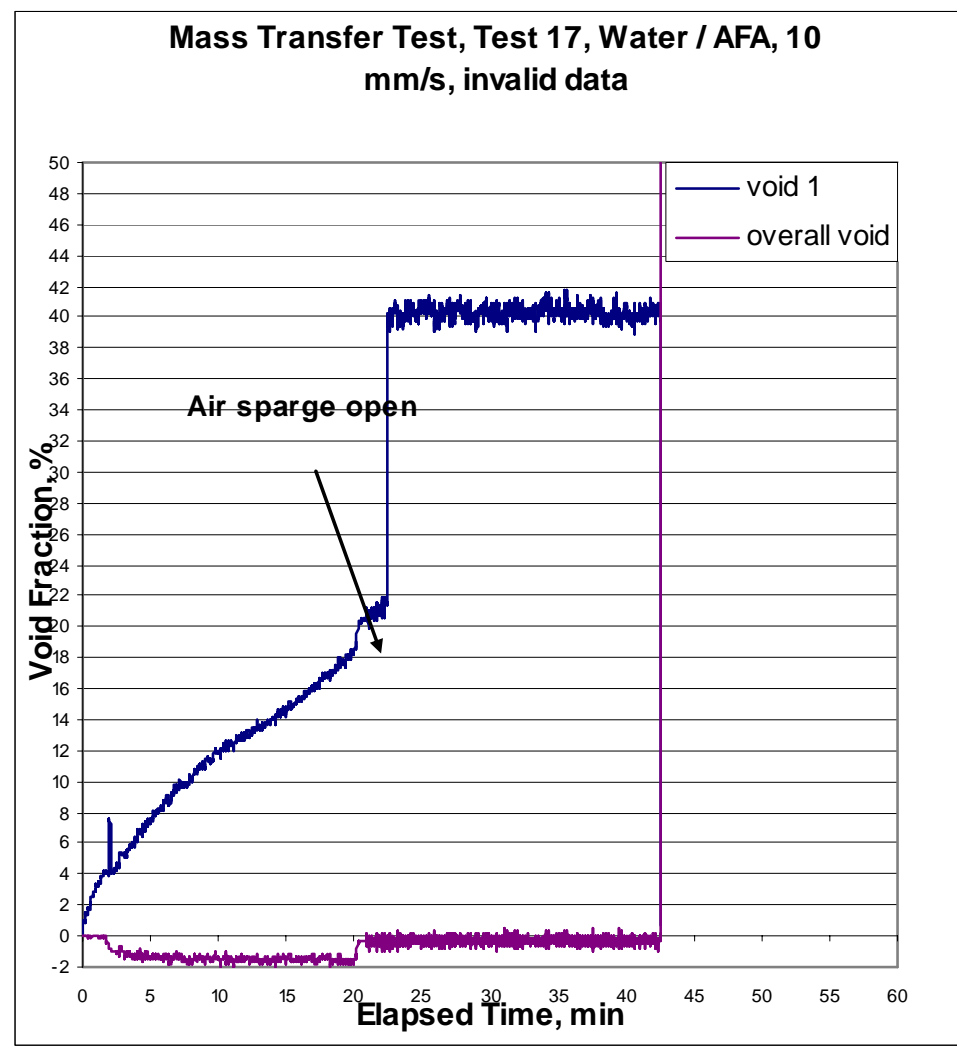

Figure Test 17 Void Fraction Calculation

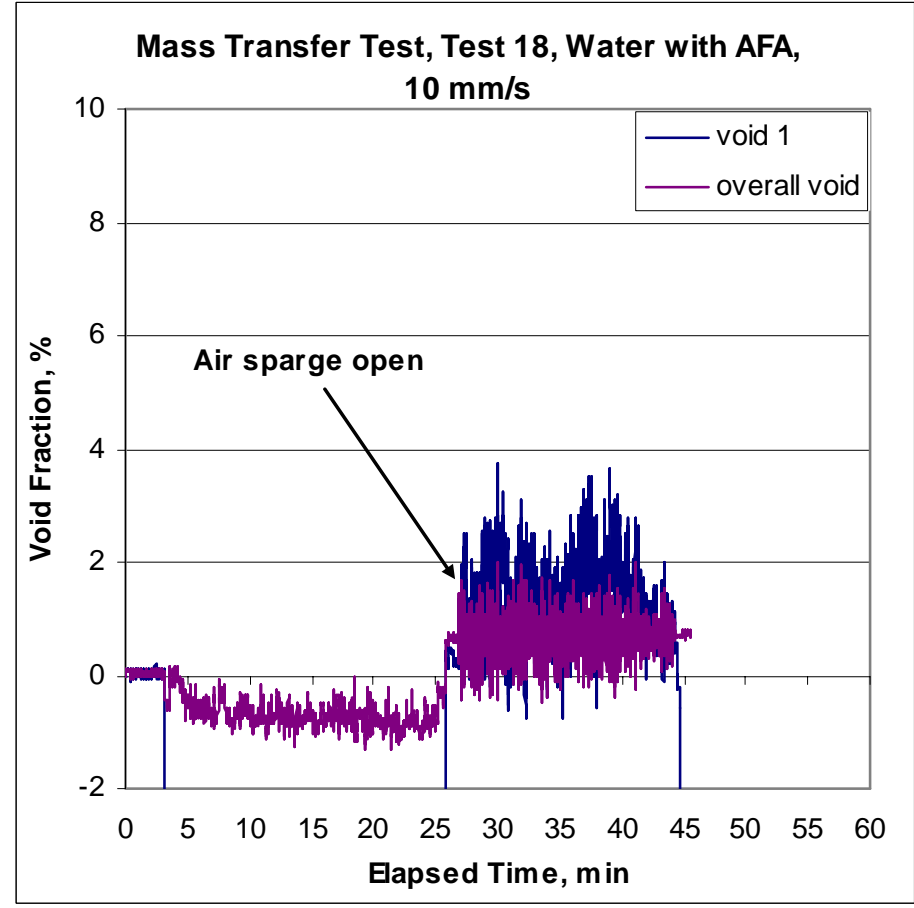

Figure Test 18 Void Fraction Calculation 


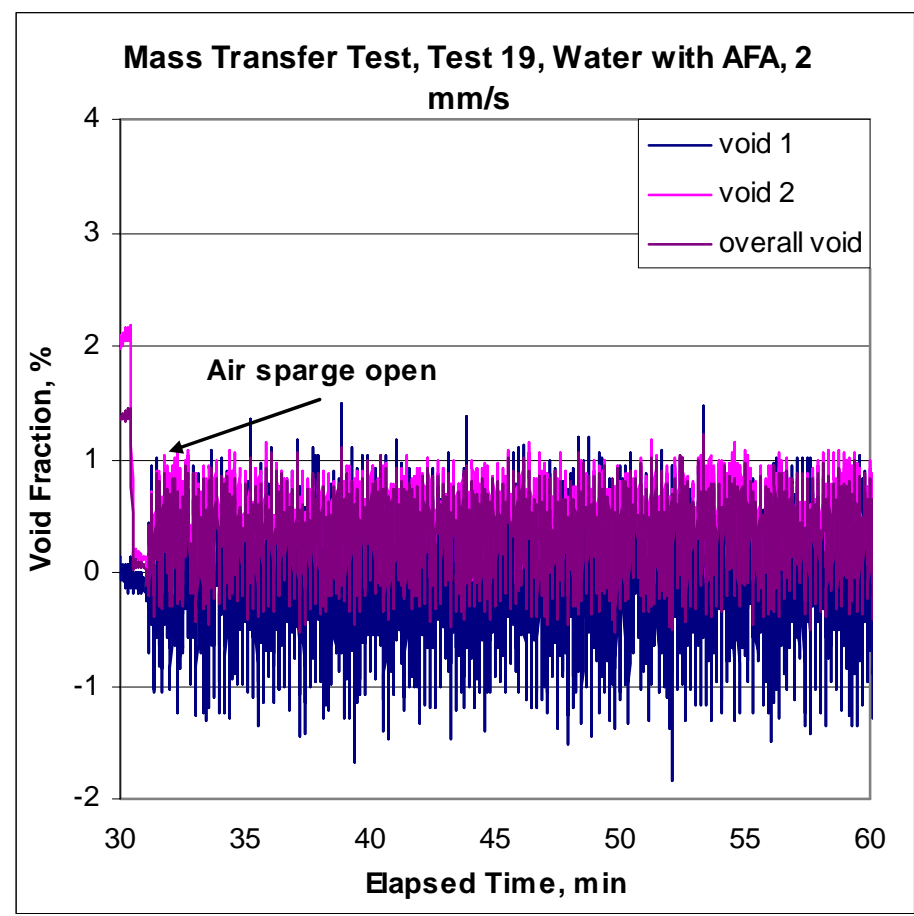

Figure Test 19 Void Fraction Calculation

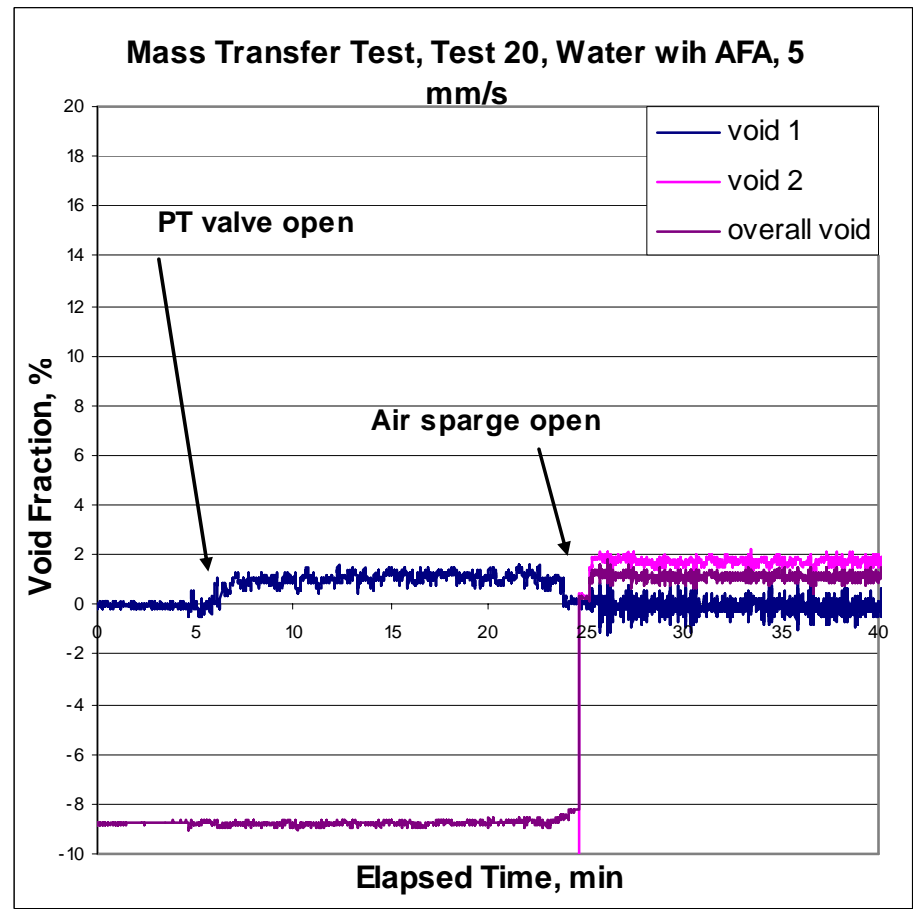

Figure Test 20 Void Fraction Calculation 


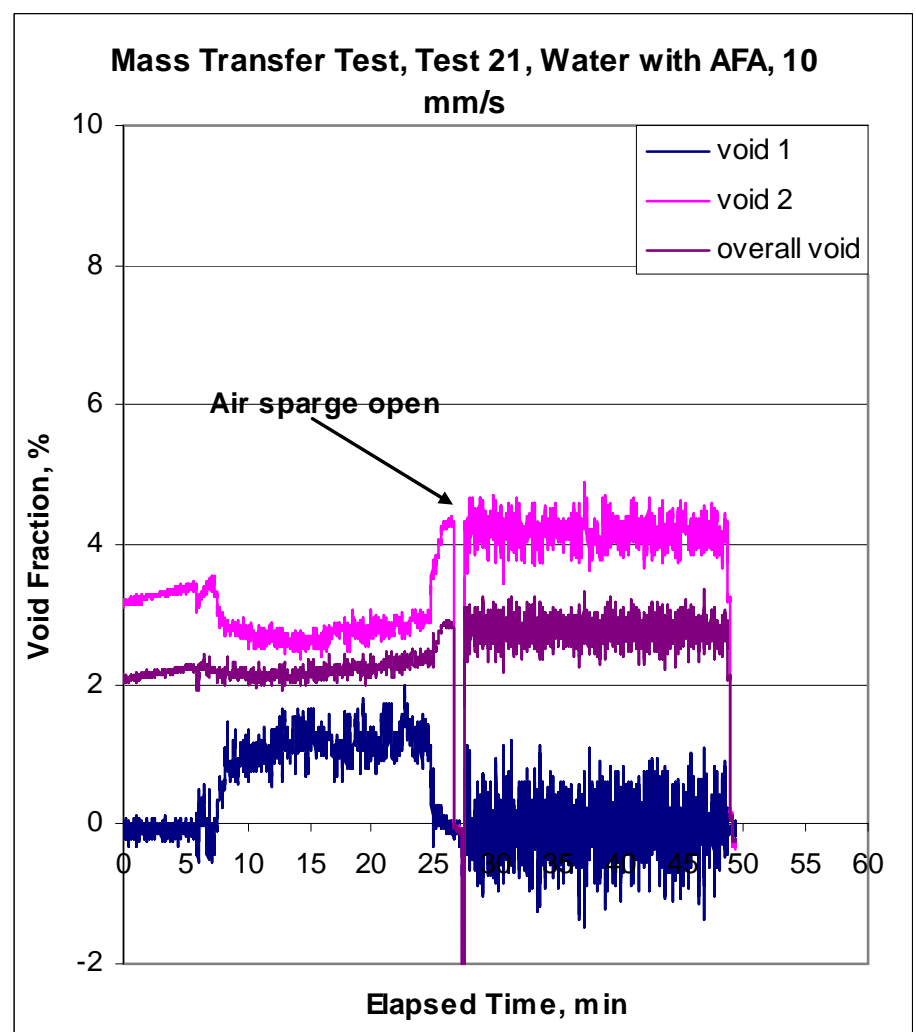

Figure Test 21 Void Fraction Calculation

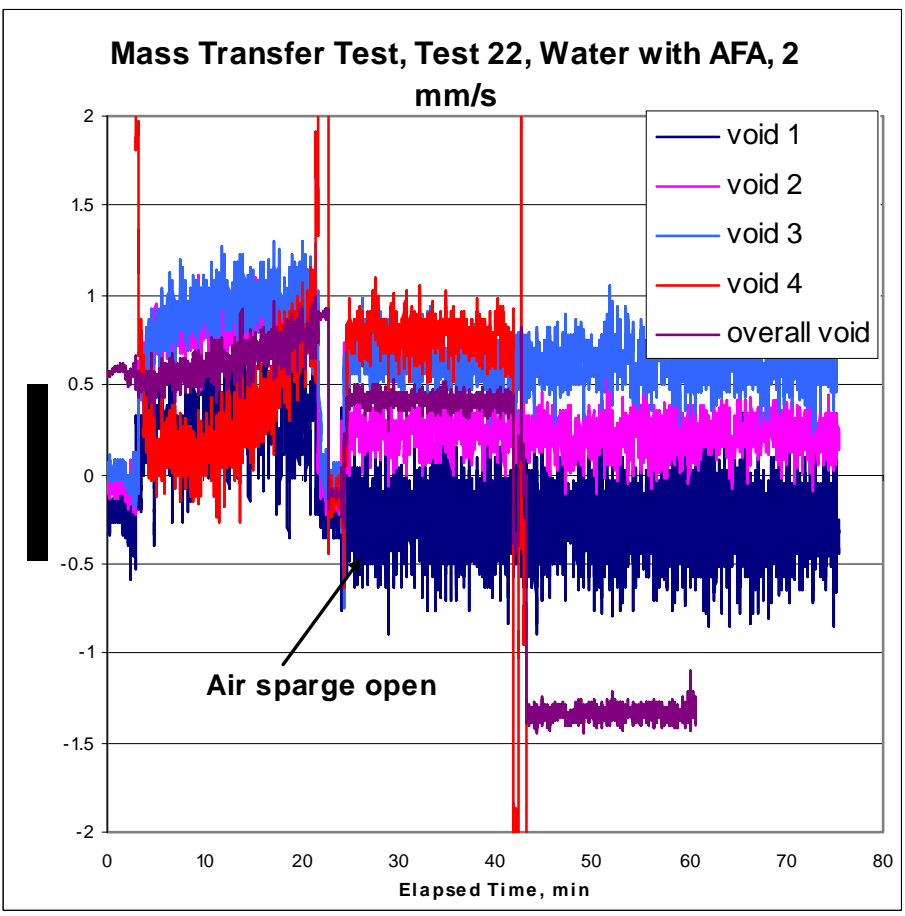

Figure Test 22 Void Fraction Calculation 


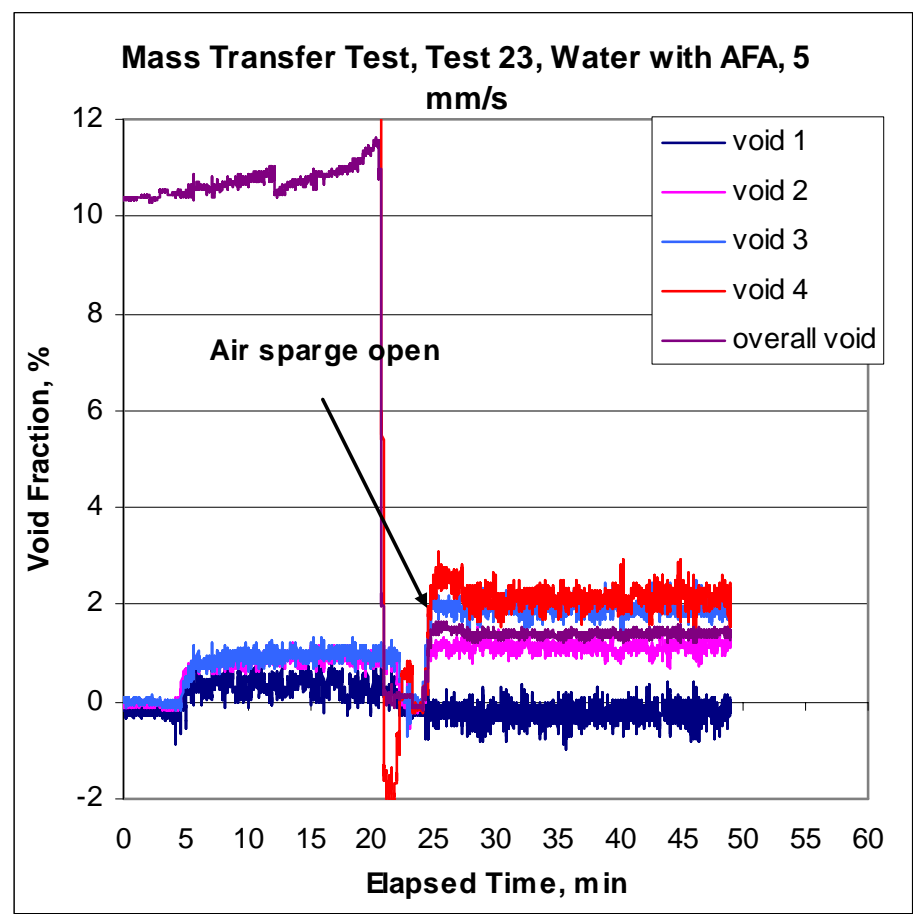

Figure Test 23 Void Fraction Calculation

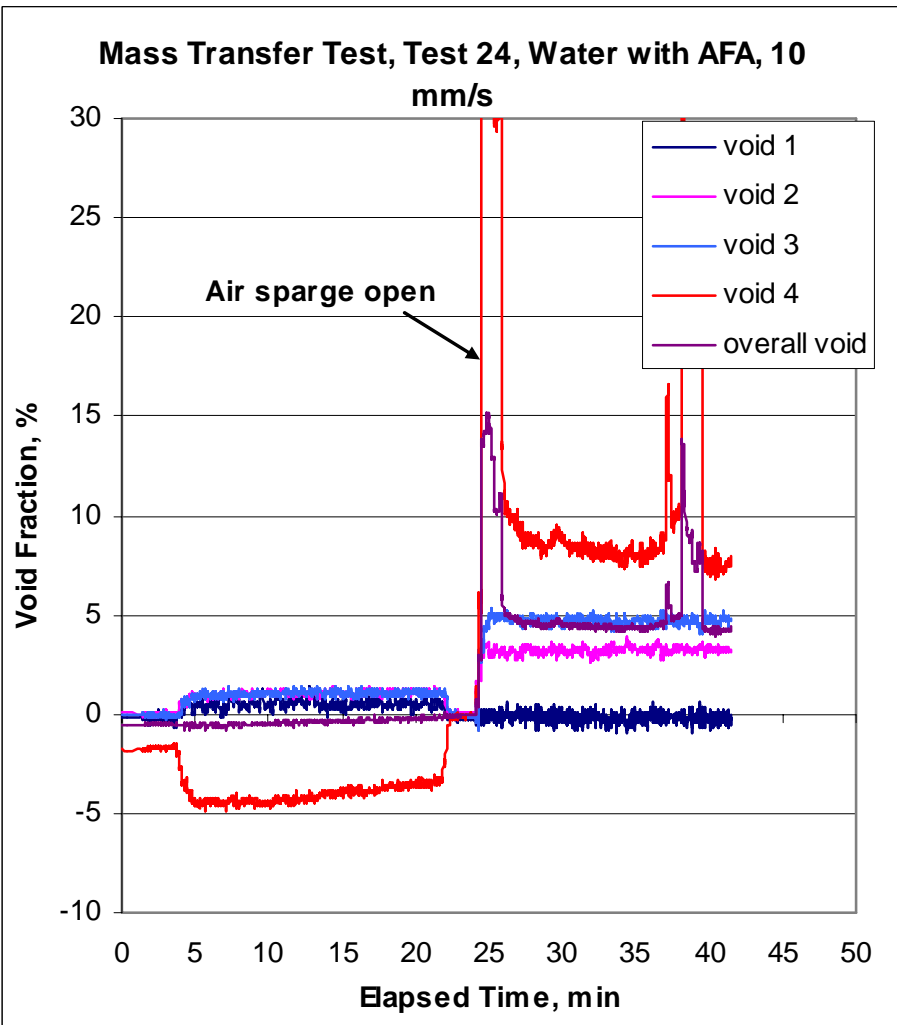

Figure Test 24 Void Fraction Calculation 


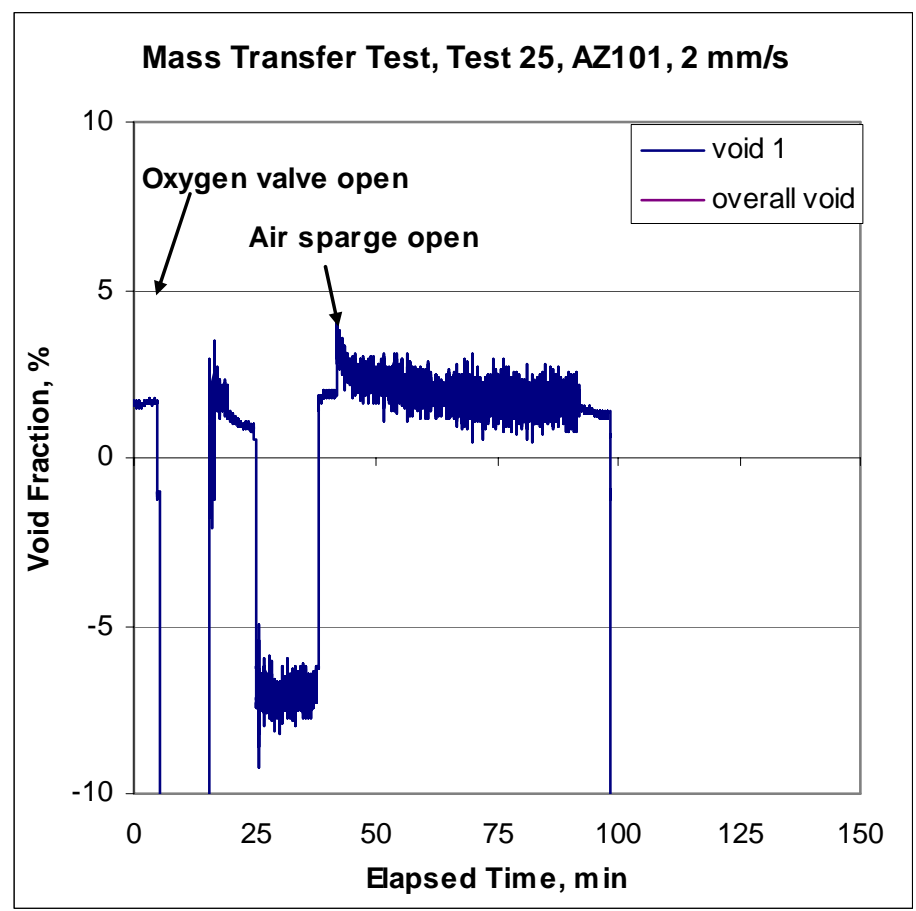

Figure Test 25 Void Fraction Calculation

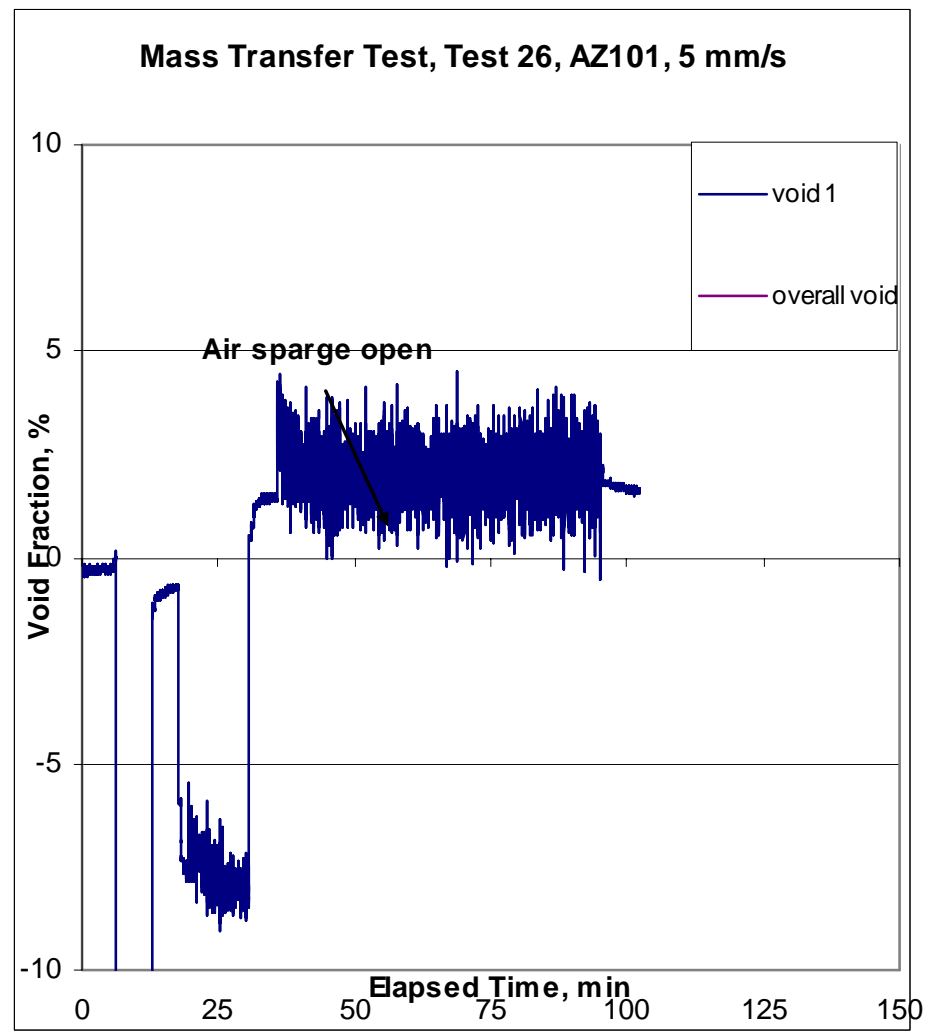

Figure Test 26 Void Fraction Calculation 


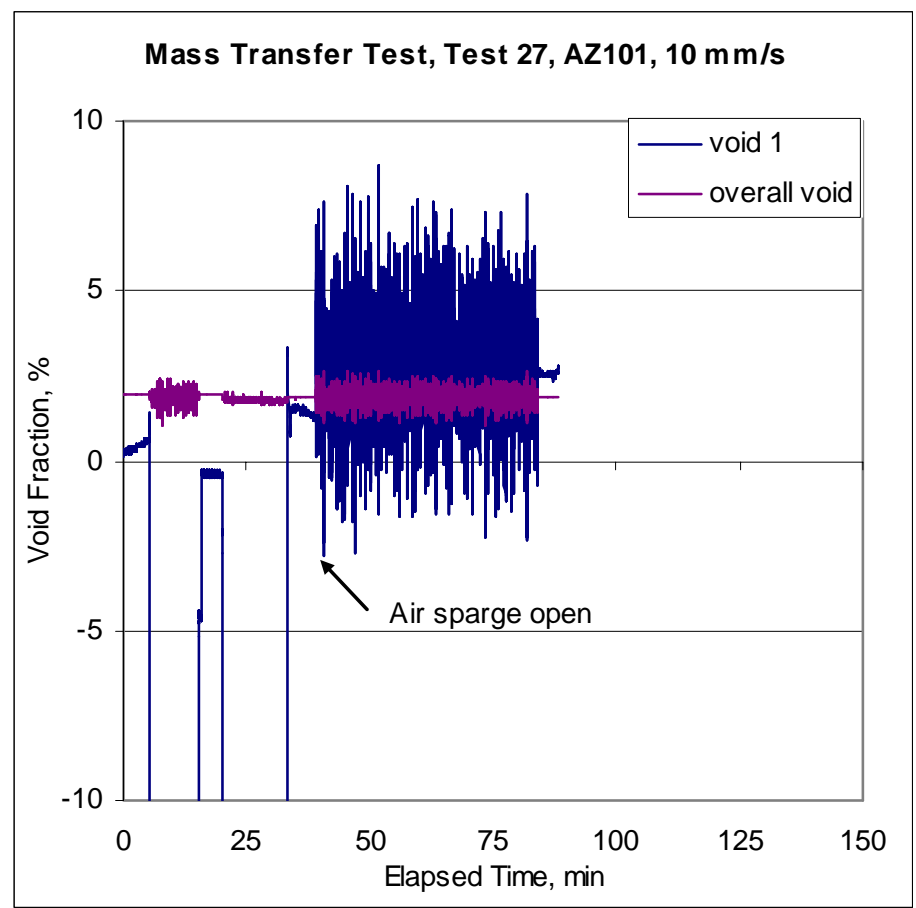

Figure Test 27 Void Fraction Calculation

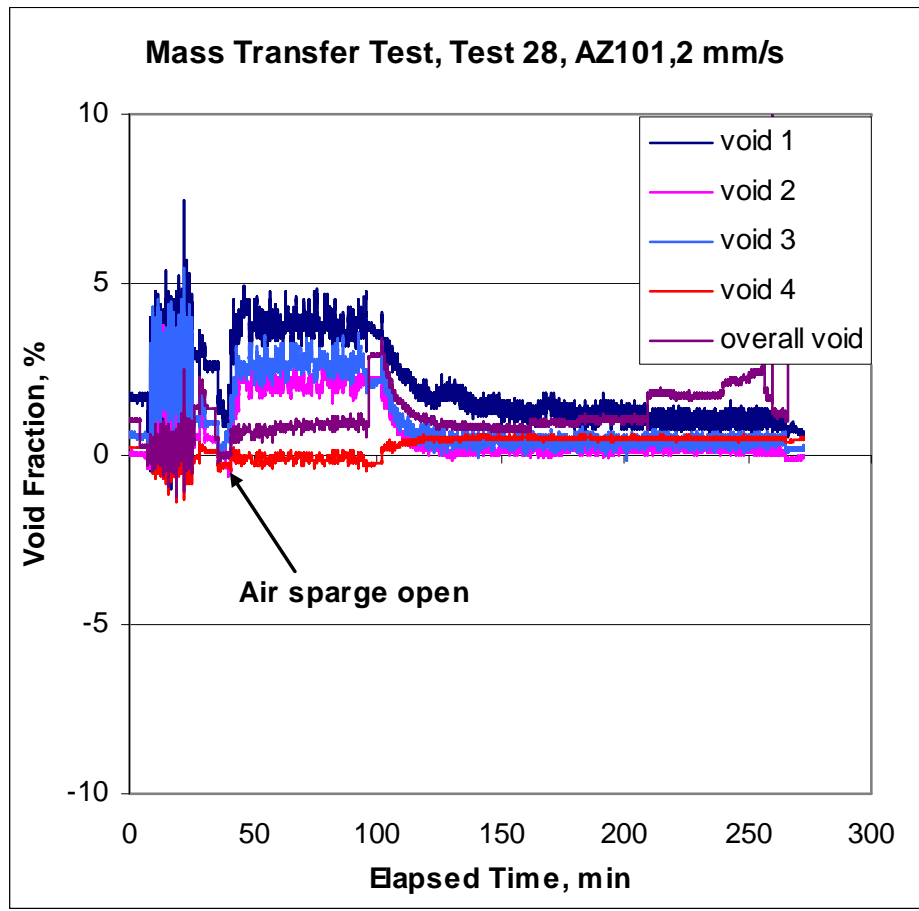

Figure Test 28 Void Fraction Calculation 


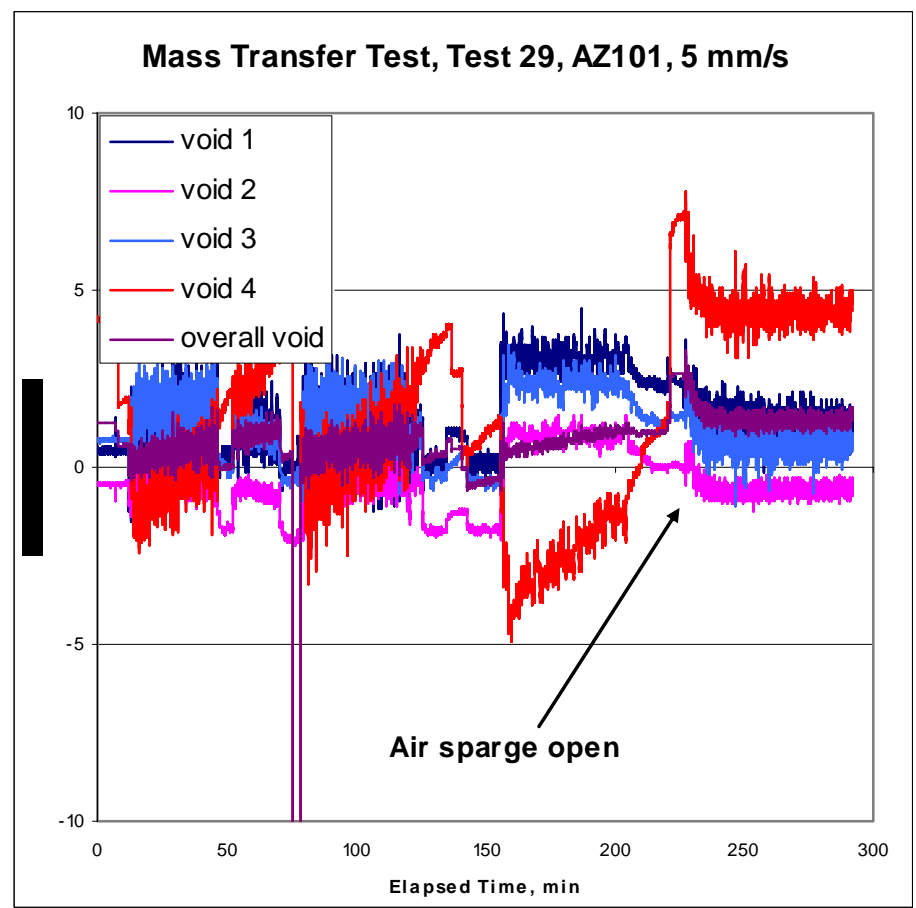

Figure Test 29 Void Fraction Calculation

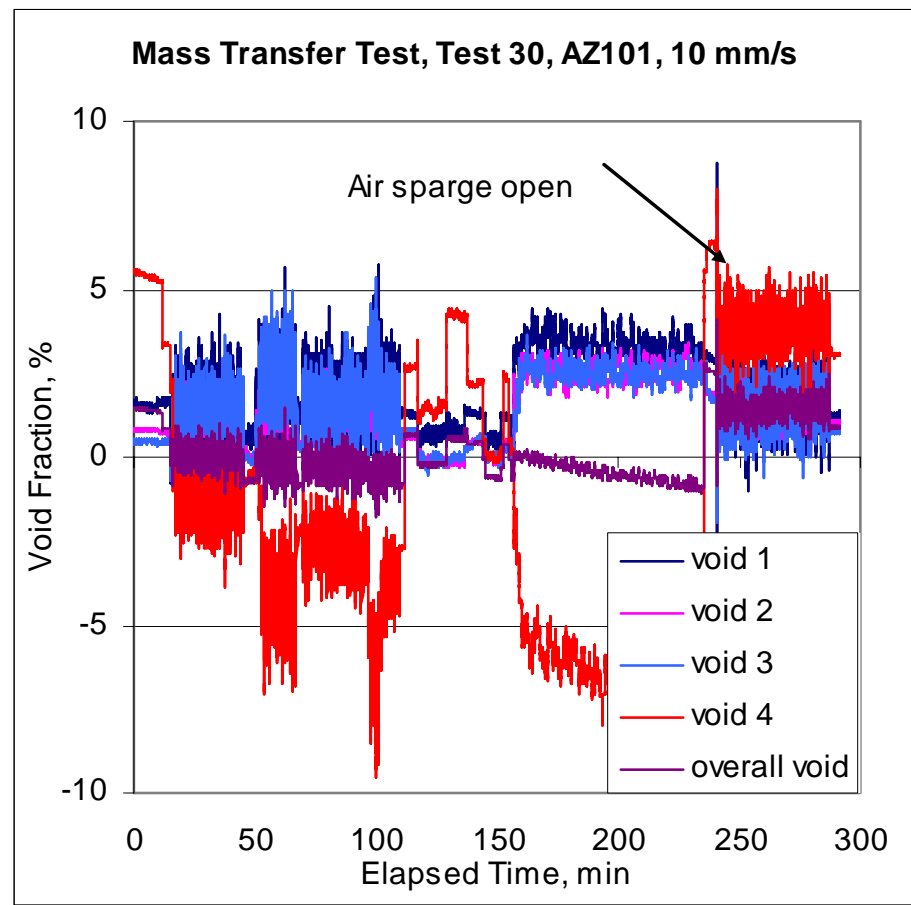

Figure Test 30 Void Fraction Calculation 